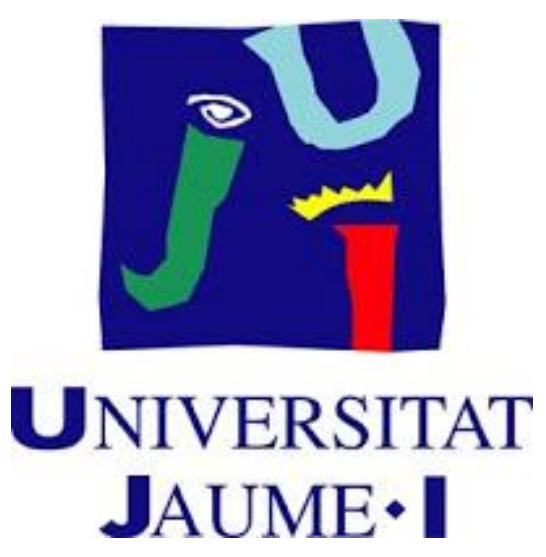

Departament d'Estudis Anglesos

\title{
Complaint Sequences across Proficiency Levels: The Contribution of Pragmatics and Multimodality
}

PhD Dissertation

Presented by:

Vicente Beltrán Palanques

Supervised by:

Dr. Mari Carmen Campoy Cubillo

Dr. Mercedes Querol Julián 

To Ariel 



\section{Acknowledgements}

First and foremost, I would like to express my sincere gratitude to my supervisors, Dr. Mari Carmen Campoy Cubillo and Dr. Mercedes Querol Julián, for their encouragement, guidance, and support during all the stages of this work, as well as their invaluable insights and suggestions. I have been extremely luckily to have two supervisors who cared so much not only about this manuscript but also about my academic life. Thank you so much for being by my side throughout the elaboration of the present work, showing me the value of multimodality and for encouraging me to explore interlanguage pragmatics from a multimodal perspective. After long and thought-provoking conversations with them, I understood the potential of multimodality and I started thinking about the possibility of talking about multimodal pragmatics.

I would also take the opportunity to thank Dr. Andrew Cohen who praised my approach for ILP in the infant stages of this work.

I would like to express my gratitude to my colleagues from the research group GRAPE for their support.

I am also grateful to all the participants of the present study. It would have not been possible to conduct the present study without them.

I am also indeed with Pilar Sebastián Veintimilla for her invaluable administrative and logistical support.

I would also like to thank Dr. Alicia Martínez Flor and Dr. Esther UsóJuan for their support during the elaboration of this study. I owe a great debt of gratitude to my colleague Dr. Noelia Ventura Campos, who showed me how to play with numbers. 
I am also indebted with my colleagues Dr. Nuria Edo Marzà and Dr. Antonio Silvestre for their valuable advice and support at all times. Thank you Nuria for the interesting conversations! Thank you, Toni for all the good moments and for being there to chat every now and then.

I would like to thank Vito Palanques for his technical support.

My deepest gratitude goes to my parents for their unwavering support, and encouragement. My father showed me how to be pragmatic and pursuit my dreams, while my mother encouraged me to break pragmatic rules when necessary. I would like to express my sincerest gratitude to Myriam for her support and patience throughout this long endeavour. Although the $\mathrm{PhD}$ was difficult and stressful I realised that nothing was more important than my nephew Ariel. Having him around kept me grounded and to him I dedicate this manuscript. 




\section{Objeto y objetivos de la investigación}

El interés por aprender una lengua extranjera y la necesidad de obtener su certificación ha aumentado considerablemente en los últimos años. Concretamente, una de las lenguas extranjeras que mayor atención he recibido y recibe es el inglés. Este interés ha crecido especialmente desde la aparición del Marco Común Europeo de Referencia (MCER) en 2001, cuyo objetivo es proporcionar una base común para poder elaborar programas de lenguas extranjeras, ofrecer orientación curricular y de diseño de materiales educativos, así como también evaluar lenguas extranjeras.

Cabe destacar también el trabajo laborioso de grupos independientes como la Association of Language Testers of Europe ${ }^{1}$ (ALTE) y la European Association for Language Testing and Assessment $^{2}$ (EALTA). Por una parte, ALTE se centra, entre otros, en difundir los criterios y especificaciones para la evaluación certificativa de una lengua extrajera y por otra parte, EALTA tiene como objetivo "promover la comprensión de los principios teóricos que rigen la evaluación de lenguas y la mejora y el intercambio de conocimientos y praxis entre profesionales en toda Europa"3 (Figueras, 2008, p, 30). Además, el conocido The DIALANG Project 4 , basado en las escalas del MCER, presenta descriptores para la autoevaluación de test de diagnóstico (Alderson, 2005). Con todo esto podemos ver que el interés por el aprendizaje de lenguas extrajeras, así como su evaluación y certificación que vienen respaldados por diversos grupos como el MCER, ALTE, EALTA, y The DIALANG Project.

\footnotetext{
${ }^{1}$ ALTE http://www.alte.org/

2 EALTA http://www.ealta.eu.org/

3 Traducción de Figueras (2008, p. 30). Original: "to promote the understanding of theoretical principles of language testing and assessment, and the improvement and sharing of testing and assessment practices throughout Europe.

4 http://www.celelc.org/projects/Past Projects/DIALANG/index.html
} 
Además de todo esto, es necesario tener en cuenta las distintas competencias que los aprendices de lengua extrajera deben desarrollar para ser competentes comunicativamente. Diversos son los modelos comunicativos que se han presentado para explicar los componentes del enfoque comunicativo (p. ej., Canale y Swain, 1980; Canale, 1983; Bachman, 1990; Celce-Murcia, Döryei y Thrurell, 1995, Celce-Murcia, 2007). Entre las diversas competencias cabe destacar la competencia pragmática, que es de especial interés para el presente estudio. Esta competencia se incluye por primera vez como un componente independiente dentro del modelo comunicativo por Bachman (1990). En términos generales, dicha competencia se refiere a la habilidad que el aprendiz de una lengua extranjera tiene para poder emplear los recursos lingüísticos y el conocimiento sociocultural para poder formular un acto comunicativo en un contexto en concreto. En este sentido, hablamos claramente del conocimiento del pragmalingüístico y sociopragmático (Leech, 1983; Thomas, 1983) que es necesario para poder expresarse de manera apropiada en un contexto determinado.

La presente tesis doctoral tiene como principal objetivo analizar la realización de actos de queja y de respuesta a quejas en inglés como lengua extranjera en una situación simulada entre dos amigos. El acto de habla de quejas se puede clasificar, según Brown y Levinson (1978, 1987), como un face threatening act, traducido por Garcés (1993) al español como un acto de habla contra la imagen. Este acto de habla se suele realizar cuando el hablante percibe que se ha cometido un acto ofensivo que puede dañarle. Según Olshtain y Weinbach (1987), el hablante expresa descontento o molestia por un acto concreto que se percibe como desfavorable. Al tratarse de un acto de habla contra la imagen, los hablantes deben tener especial cuidado con el tipo de expresiones que usan puesto que la elección de las funciones discursivas puede afectar a la relación entre los participantes. Es importante también señalar que el acto de habla de quejas, distinto a otros actos de habla como el de las peticiones, no tiene un prototipo de funciones 
discursivas (Laforest, 2002; Geluykens y Kraft, 2008). Se puede decir que la realización de quejas es compleja puesto que se trata de un acto de habla contra la imagen (Brown y Levinson, 1978, 1987) y no hay un prototipo de funciones discursivas para poder llevar a cabo este acto comunicativo. Para aprendices de inglés como lengua extrajera puede resultar complejo realizar una queja, así como también responder a una queja puesto que implica el uso de una gran diversidad de funciones discursivas que permitan comunicarse y proyectar el mensaje sin ofender al interlocutor. Por ello, se puede sugerir que los aprendices necesitan, no solo competencia lingüística sino también competencia pragmática para poder emitir la queja y responder a la misma.

Por lo tanto, las razones en las que se basa la elección del acto de habla de las quejas son: (1) la propia naturaleza de las quejas, que se definen como un acto de habla contra la imagen (Brown y Levinson, 1978, 1987); (2) la complejidad en su realización debido a la falta de funciones discursivas prototípicas; y (3) la exigencia lingüística y pragmática que implica para los aprendices de inglés como lengua extranjera.

Para este estudio se ha elegido la variable de nivel de lengua con el objetivo de analizar el efecto de dicha variable en la interacción simulada en inglés. El instrumento utilizado para la obtención de la muestra ha sido un role-play. El análisis del corpus se ha realizado desde la perspectiva del análisis de la conversación puesto que ofrece una visión más amplia del comportamiento de los participantes (Kasper, 2006a, 2006b, 2009a). Además, se ha realizado un análisis de la conversación desde un enfoque multimodal (Mondada, 2008, 2016; Streeck Goodwin y LeBaron 2011) para poder examinar los distintos modos que se integran para construir la conversación simulada. Por lo tanto, este estudio se enmarca dentro del campo de investigación de la pragmática del interlenguaje y de la multimodalidad. 
Esta tesis persigue el diseño de una nueva metodología para analizar la pragmática del interlenguaje desde el enfoque del análisis de la conversación y análisis multimodal de la conversación. Tradicionalmente, los estudios de pragmática del interlenguaje no han analizado la muestra desde un enfoque conversacional sino desde un modelo racionalista en el que la intención de los hablantes se acepta (Kasper, 2006a, 2006b, 2009a). Siguiendo un enfoque conversacional, se puede observar como la acción no depende solo de la intención del hablante, sino que también se construye a lo largo de la conversación (Kasper, 2006b). Dicho enfoque analítico permite identificar y analizar las distintas partes de la conversación, es decir, los moves (Swales, 1990), así como también las funciones discursivas que se utilizan para construir la conversación teniendo en cuenta la perspectiva de los dos participantes, es decir, el participante que se emite la queja y el que recibe y responde a dicha queja (Laforest, 2002). Además, siguiendo un enfoque multimodal del análisis de la conversación (Mondada, 2008, 2016; Streeck, y otros 2011), es posible explorar la conversación desde una perspectiva global. Concretamente, este enfoque permite explorar no sólo aspectos lingüísticos, sino también sistemas no lingüísticos como kinésicos y paralingüísticos. Teniendo en cuenta todo esto, tres aspectos subyacen en este estudio: (1) el análisis de la estructura de la conversación; (2) el análisis de las distintas secuencias de queja y de respuesta a queja; y (3) el análisis multimodal de la conversación.

Para llevar a cabo el presente estudio, se han realizado dos preguntas de investigación:

1. ¿̇Influye el nivel de lengua en la producción de interlenguaje de quejas?

2. ¿Cómo un enfoque multimodal enriquece el análisis del interlenguaje de quejas en distintos niveles de lengua? 


\section{Planteamiento y metodología utilizada}

Para poder lograr el objetivo de este estudio y contestar a las dos preguntas de investigación, en la primera parte de la tesis, es decir, en el marco teórico se realiza una revisión de la literatura que se centra en los siguientes aspectos: (1) pragmática en la conversación; (2) el acto de habla de queja y la variable de nivel de lengua; y (3) multimodalidad. Estos tres grandes bloques permitieron establecer la estructura del estudio y del análisis tanto pragmático como multimodal desde la perspectiva del análisis de la conversación.

Concretamente, dentro del bloque de la pragmática en la conversación se abordó la noción de pragmática (Crystal, 1985) y de sus componentes (Leech, 1983; Thomas, 1983) así como también de la competencia comunicativa (Hymes, 1972a). Se revisaron diversas teorías de cortesía haciendo hincapié particularmente en Brown y Levinson $(1978,1987)$ por su implicación en la realización de los actos de habla (Austin, 1962, Searle, 1969), que también se revisaron en el marco teórico desde una perspectiva general y centrándose en su contexto (Sbisà, 2002; Adolphs, 2008; Félix-Brasdefer, 2008a). Tras esto, se revisó la noción de pragmática del interlenguaje (Kasper y Blum-Kulka, 1993) así como también de los distintos instrumentos que se utilizan para obtener muestra dentro del campo de la pragmática del interlenguaje (Kasper y Roever, 2005), donde se ofreció de manera detallada una revisión de los instrumentos usados para obtener muestra oral y de los protocolos de verbalización. Además de esto, teniendo en cuenta el enfoque analítico de este estudio, se presentó una revisión sobre la disciplina del análisis de la conversación (Schegloff y Sacks, 1973), así como también del potencial de este enfoque analítico para el estudio de la pragmática del interlenguaje (Kasper, 2006a, 2006b, 2009a).

Después de esto centré mi atención en el acto de habla que se aborda en este estudio, así como también en la variable de nivel de 
lengua. Por una parte, presenté una revisión de la literatura sobre el acto de habla de la queja (Brown y Levinson, 1978, 1987; Olshtain y Weinbach, 1993; Trosborg, 1995) y de respuestas a quejas (Laforest, 2002), así como también de la estructura de la queja y de las distintas funciones discursivas que pueden emplearse para poder realizar tanto la queja como la respuesta a la queja (Laforest, 2002). Finalmente, se ofreció una revisión de la literatura de diversos estudios que se han llevado a cabo para analizar el acto de habla de la queja y de las respuestas a quejas (Olshtain y Weinbach, 1987; 1993; Piotrowska, 1987; DeCapua, 1989; Trenchs, 1994; Trosborg, 1995; Arent, 1996; Murphy y Neu, 1996; Laforest, 2002; Geluykens y Kraft, 2003; Tanck, 2004; Chen, Chen y Chang, 2011). En la segunda parte de este bloque se abordó la variable de nivel de lengua. Concretamente, el objetivo era ofrecer una revisión de manera general sobre estudios que han analizado el efecto de la lengua en el campo de la pragmática del interlenguaje. Tras esto, de manera más concreta, se realizó una revisión de la literatura de estudios del campo de la pragmática del interlenguaje donde se había analizado la variable de nivel de lengua en investigaciones de producción oral (Trosborg, 1995; Taguchi, 2006; 2013; Moskala-Gallaher, 2011; Al-Gahtani y Roever, 2012; 2013; Roever y Al-Gahtani, 2015).

El marco teórico se cerró con una revisión a la comunicación multimodal donde se introdujo el campo de la multimodalidad y sus enfoques analíticos. Además, esto se abordó también la naturaleza de los recursos kinésicos (Kendon, 1967, 2004; Bavelas, Hagen, Lane y Lawrie, 1989; McNeill, 1992) y paralingüísticos (Poyatos, 2002). Concretamente, en este bloque se ofreció una revisión de la gestualidad (Kendon, 2004), de su tipología (Efron, 1941, 1972; Ekman y Friesen, 1969; McNeill, 1992; Kendon, 2004), identificación (Kendon, 2004) e interpretación (Kendon, 2004). Además de esto, se prestó también atención a los movimientos de cabeza (Hadar, Steiner, Grand y Rose, 1983a, 1983b), expresiones faciales (Ekman y Friesen (1978) y la mirada 
(Argyle, Ingham, Alkema, y McCallin, 1981). Por otra parte, se realizó una revisión de la literatura para abordar la relación entre la kinésica y pragmática (Kendon, 1995; Gass y Houck, 1999; Kelly, Barr, Church, y Lynch, 1999; Chui, 2005; Streeck, 2009; Ladewig y Bressem, 2013; Rossi, 2014). Asimismo, la relación entre kinésica y la variable de nivel de lengua también se revisó (Gullberg, 1998; Gregersen, Olivares-Cuhat y Storm, 2009; Kim, 2012; So, Kita, y Goldin-Meadow, 2013). Después de esto, se presentó una revisión de la paralingüística, donde se introdujo dicho fenómeno (Poyatos, 2002), diferentes recursos paralingüísticos (Trager, 1958; Roach, Stibbard, Osborne, y Setter, 1998; Poyatos, 2002), así como también la relación entre la paralingüística y la pragmática (p. ej., Taguchi, 2002; Cheng, 2002, 2004; Pickering, Hu y Baker, 2012; Romero-Trillo, 2014).

Guiado por este marco teórico y por las preguntas de investigación del estudio, se planteó la metodología del estudio. En esta investigación 64 participantes universitarios que cursaban sus estudios en dos grados universitarios distintos se seleccionaron. Concretamente, los participantes pertenecían al Grado en Diseño y Desarrollo de Videojuegos y al Grado en Criminología y Seguridad. Los participantes se dividieron en dos niveles de lengua, concretamente en B1 y B2 según el MCER (2001). Cada grupo constó de un número equilibrado de participantes, tanto hombres como mujeres: 32 participantes en cada grupo de nivel de lengua siendo 16 hombres y 16 mujeres. En este estudio, el nivel de lengua se estableció mediante DIALANG. Además, se diseñó un cuestionario para poder obtener un perfil de los participantes. Diversos instrumentos se utilizaron este estudio. Por una parte, se usó una tarea oral simulada, un role-play, así como también un protocolo de verbalización que se implementó de manera retrospectiva. Además de esto, se diseñó una rúbrica basada en una escala de 1 a 4 para analizar la adecuación de la conversación.

El diseño de la tarea se realizó en base a los resultados de una tarea orientada a generar la tarea oral y un cuestionario de 
probabilidad. Esta metodología de generación de tarea se llevó a cabo con el fin de diseñar una tarea que estuviese basada en experiencias reales y que los participantes pudiesen representarla manteniendo, en la medida de lo posible, su identidad. Con esto se pretendía que los participantes simulasen una situación que fuera más próxima a su realidad. La muestra se recogió mediante grabación de audio y video con el objetivo de compilar un corpus de 32 videos. Es importante señalar que se administraron dos tareas. La primera tarea sirvió para romper el hielo y que los participantes se relajasen y evitar la posibilidad de variables que afectasen a la muestra negativamente, como por ejemplo estar nervioso por las cámaras. Para poder recoger la muestra se usaron tres cámaras, plano de cada participante y plano general, así como también una grabadora de voz. El escenario, dentro de las posibilidades, se intentó decorar para que simulase una conversación en un lugar de ocio como puede ser una cafetería. La grabación de la primera tarea no se incluyó en el corpus final. Los dos laboratorios de lengua inglesa del Departament d'Esdudis Anglesos de la Universitat Jaume I se usaron para poder llevar a cabo la grabación.

De manera simultánea se realizaron las grabaciones en las cuales participaron la Dr. Mari Carmen Campoy Cubillo, co-directora del presente estudio, y el doctorando. Inmediatamente después de realizar la tarea, se administró el protocolo de verbalización. Los participantes, por parejas, eran entrevistados por la Dr. Mercedes Querol Julián, codirectora de la presente tesis. Se tuvo especial esmero en evitar cualquier efecto de las tres personas involucradas en el estudio sobre los participantes.

El análisis de la muestra se realizó en diversas fases. Primero realicé la transcripción de las grabaciones de voz para poder analizar las quejas y las repuestas a las quejas según su move, función discursiva, así como también otros elementos conversacionales como backchannel, es decir, respuestas del interlocutor que no suponen un turno, y solapamiento u overlapping en inglés, así como también recursos 
paralingüísticos como pausas sonoras y risa. Además de esto, se llevó a cabo un análisis de la adecuación pragmática con una rúbrica que se diseñó concretamente para este estudio.

Con el fin de contestar a la primera pregunta de investigación, es decir, para ver el efecto de nivel de lengua sobre la producción pragmática desde un enfoque conversacional, la muestra se examinó desde una perspectiva cuantitativa y cualitativa con el objetivo de triangular los resultados. Por lo tanto, se hicieron diversos análisis estadísticos con el IMB Statistics SPSS 23 (Paquete Estadístico para Ciencias Sociales), concretamente, la prueba de $t$ para muestras independientes y estadísticos de fiabilidad con Alfa de Cronbach. Por otra parte, la muestra cualitativa se analizó con los datos obtenidos en los protocolos de verbalización.

Para contestar a la segunda pregunta, se realizó un análisis multimodal de la muestra seleccionada para ese fin desde una perspectiva conversacional. Para ello fue necesario utilizar una herramienta de anotación multimodal, concretamente el programa ELAN, que permitió introducir el video y la transcripción, tanto ortográfica como kinésica y paralingüística, y las anotaciones de los moves, funciones discursivas, backchannel, overlapping, y los recursos kinésicos y paralingüísticos, así como también sus funciones. Este análisis se enfocó principalmente desde una perspectiva cualitativa, aunque también fueron necesarios los datos cuantitativos.

\section{Aportaciones originales}

Las aportaciones más importantes del estudio se pueden resumir siguiendo las dos preguntas de investigación planteadas que ha guiado esta tesis.

La primera pregunta de investigación se centra en el efecto de la variable de nivel de lengua sobre la producción de quejas y de 
respuestas a quejas en aprendices de inglés como lengua extranjera desde una perspectiva del análisis de la conversación.

Este estudio parte de la necesidad de analizar la pragmática del interlenguaje desde la perspectiva de la conversación (Kasper, 2006a, 2006b, 2009). En respuesta a esta necesidad, recientemente se ha publicado una investigación realizada por Al-Gahtani y Roever (2012) que analiza el acto de habla de la petición en role-plays siguiendo la perspectiva del análisis de la conversación. Este estudio explora además la variable del efecto de la lengua, como en la presente tesis. La escasez de estudios que examinan los datos desde esta perspectiva $\mathrm{y}$ concretamente analizando el efecto de la variable de lengua, justifican la necesidad de abordar los estudios de la pragmática del interlenguaje desde este enfoque analítico.

Es importante señalar que el acto de habla de las quejas se ha examinado en menor medida que otros actos de habla como las peticiones. Cabe destacar también que, como se puede ver en la revisión de la literatura, a excepción de Laforest (2002), los estudios que se revisan en esta tesis sobre el acto de habla de la queja han analizado solo la perspectiva del hablante, mientras que la figura del interlocutor no se ha analizado. El trabajo realizado por Laforest en 2002 analiza quejas y respuestas a quejas en lenguaje natural. Por lo tanto, parece que hay una clara necesidad de investigar la perspectiva de ambos participantes para ver cómo se construye la conversación, especialmente siguiendo un análisis conversacional con aprendices de inglés como lengua extranjera.

Por lo tanto, este estudio se basa en la necesidad de analizar el acto de habla de la queja y de respuesta a queja desde un enfoque conversacional para poder examinar cómo se construye la conversación en grupos de diferentes niveles de lengua. Este análisis supuso la creación de una estructura de quejas y de respuestas a quejas basada en moves y funciones discursivas que permitiesen examinar las secuencias construidas en la conversación. 
Cabe destacar también que el análisis de la adecuación pragmática se ha examinado mayoritariamente por nativos de la lengua meta (p. ej., Taguchi, 2006, 2013) pero no por profesores de inglés como lengua extranjera como en este estudio. El análisis de la adecuación pragmática desde un enfoque de la conversación por parte de profesores de inglés como lengua extranjera es necesario para poder explorar como se construye la conversación en contextos de aprendizaje de lenguas y ver si este enfoque puede servir para mejorar el aprendizaje de lenguas extrajeras desde una perspectiva comunicativa. Este enfoque implicó el diseño de una rúbrica basada en una escala de 1 a 4 para analizar la adecuación de la conversación que abordase no sólo aspectos lingüísticos sino también multimodales. Para contestar a la primera pregunta de investigación sólo se tuvo en cuenta la parte lingüística de la rúbrica.

La segunda pregunta de investigación responde a la necesidad de analizar desde una perspectiva multimodal la pragmática del interlenguaje, y concretamente aplicarlo al estudio de quejas y de respuestas a quejas. La revisión de la literatura nos indica que hay una clara necesidad de investigar aspectos de la pragmática del interlenguaje para explorar como se construye la conversación no solo desde la perspectiva lingüística sino también teniendo en cuenta los distintos modos que se integran en una situación comunicativa simulada mediante un role-play.

La segunda parte del estudio requiere del análisis pragmático realizado en la primera parte puesto que el objetivo es enriquecer la parte lingüística desde un enfoque multimodal. Es decir, el objetivo es analizar cómo un enfoque multimodal puede contribuir al análisis pragmático desde una perspectiva conversacional. Por lo tanto, esta parte del estudio se basa en el análisis del acto de habla de la queja y de respuesta a queja desde un enfoque multimodal de la conversación (Mondada, 2008, 2016; Streeck y otros, 2011) para poder examinar 
cómo se construye la conversación simulada en grupos de diferentes niveles de lengua integrando distintos modos.

Además de esto, teniendo en cuenta el análisis de la adecuación pragmática a la conversación, en esta parte del estudio se analizó también la adecuación de los recursos kinésicos y paralingüísticos. Ese análisis se llevó a cabo el fin de cuantificar, mediante una rúbrica basada en una escala de 1 a 4, la adecuación de la conversación desde una perspectiva multimodal. Este análisis parte de la necesidad de observar como los aprendices de inglés como lengua extranjera emplean distintos modos para poder comunicarse y ver si los recursos kinésicos y paralingüísticos que se integran dentro de la conversación, es decir los distintos modos, contribuyen en la interacción.

Finalmente cabe destacar que, para poder llevar a cabo este estudio, se tomaron diversas decisiones metodológicas. Por una parte, se realizó un estudio para poder diseñar la tarea de los participantes (Ostrom y Gannon, 1996; Rose y Ng, 2001; Rose y Ono, 1995; Liu, 2006a) con el objetivo de administrar una situación que fuese más cercana a la realidad de los participantes. Por otra parte, junto a la tarea, es decir, el role-play, se administró un protocolo de verbalización para poder obtener más información sobre la realización de la tarea. Además, se usó el programa ELAN para explorar los aspectos multimodales de la conversación.

En este sentido, esta tesis desarrolla un tratamiento innovador para el análisis de datos de la pragmática del interlenguaje, concretamente del acto de habla de quejas y de respuestas a quejas, desde dos perspectivas: el análisis de la conversación y el análisis multimodal de la conversación que permitió la obtención de datos cuantitativos y cualitativos para poder ofrecer una visión más fructífera de los resultados. 


\section{Conclusiones obtenidas y futuras líneas de investigación}

El objetivo de la presente tesis doctoral fue analizar el acto de habla de las quejas y respuestas a quejas desde el punto de vista de la conversación. Con el fin de realizar este estudio se realizó un primer análisis de la conversación desde una perspectiva pragmática, y un segundo análisis desde un enfoque multimodal de dos parejas para explorar el potencial de un enfoque multimodal de la conversación. Para llevar a cabo el análisis de los datos, dos enfoques metodológicos fueron necesarios. Además, se analizó la adecuación pragmática de la conversación desde una perspectiva puramente lingüística y desde una perspectiva multimodal.

Los resultados de esta tesis han intentado dar respuesta a las dos preguntas de investigación que han guiado la investigación. Los resultados se deben considerar siempre dentro del marco del estudio y teniendo en cuenta el enfoque metodológico adoptado y el tratamiento de datos que se ha seguido.

En cuanto a la primera pregunta de investigación, los resultados han revelado que en algunos casos el efecto del nivel de lengua puede haber afectado a la producción pragmática. En cuanto a la estructura de la conversación vemos que los resultados tienden a indicar que el conocimiento de la lengua ha facilitado la producción de algunas funciones discursivas así como también la resolución de la queja. Los resultados de este estudio demuestran que los alumnos con mayor nivel de lengua resuelven más y de forma más eficiente mediante el uso de funciones discursivas específicas. Sin embargo, es necesario seguir investigando el efecto del nivel de lengua en la producción pragmática desde una perspectiva conversacional. Cabe destacar que el uso de un método conversacional ha favorecido al análisis de la muestra puesto que ha permitido explorar la construcción de los turnos, así como 
también el uso de otros elementos conversacionales y el papel que juega el oyente activo.

Los resultados de la segunda pregunta de investigación han indicado que el análisis pragmático se puede enriquecer desde una perspectiva multimodal puesto que es posible investigar cómo los aprendices de lengua construyen la conversación usando distintos modos y cómo éstos se integran para comunicar y mostrar señales de atención al hablante. Por lo tanto, se puede indicar que este tipo de análisis favorece la comprensión de la comunicación oral en tanto que es posible observar desde una perspectiva multimodal la construcción de la interacción. En cuanto a la variable de nivel lengua, cabe decir que es necesario seguir investigando la relación entre los recursos kinésicos y paralingüísticos para poder verter luz sobre este aspecto. 




\section{Table of contents}

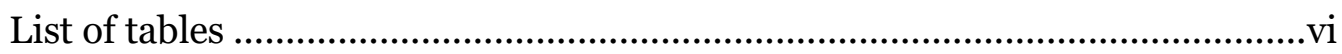

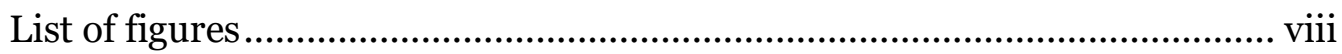

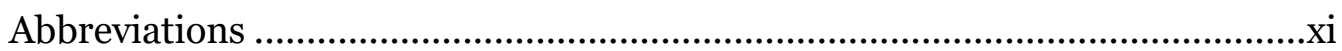

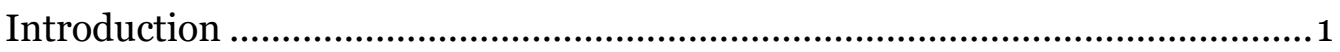

Chapter 1. Pragmatics in Conversation ...................................................... 9

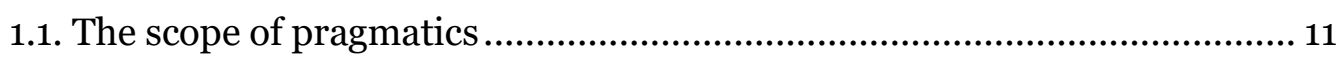

1.1.1. The discipline ..............................................................................12

1.1.2. Communicative and pragmatic competence: Towards a multimodal perspective........................................................................................... 15

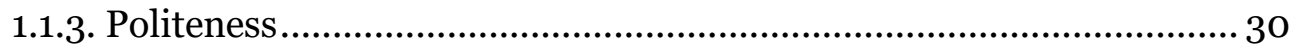

1.1.3.1. Different views on politeness …................................................ 31

1.1.3.2. Brown and Levinson's Politeness Theory ................................. 35

1.1.4. Speech acts: From philosophy to linguistics ....................................41

1.1.4.1. Speech Act Theory .................................................................... 42

1.1.4.2. Classifying speech acts......................................................... 44

1.1.4.3. Speech acts in context..................................................................47

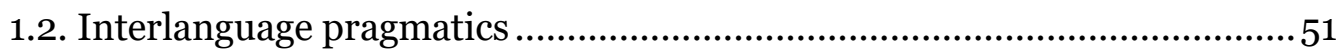

1.2.1. The field of interlanguage pragmatics .............................................. 51

1.2.2. Spoken data collection in interlanguage pragmatics ..........................55

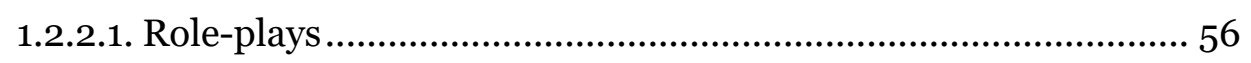

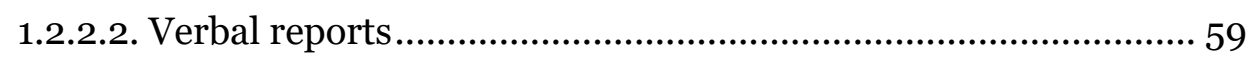

1.2.2.3. The contribution of verbal reports to role-play analysis............ 62

1.3. Conversation analysis ...........................................................................67

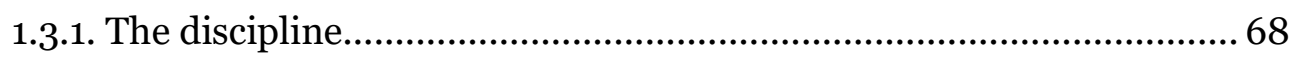

1.3.2. Simultaneous talk..........................................................................73

1.3.2.1. Overlapping and backchannel ...............................................74

1.3.2.2. Classification and functions of backchannel .............................77

1.3.3. Conversation analysis and speech act performance ......................... 84

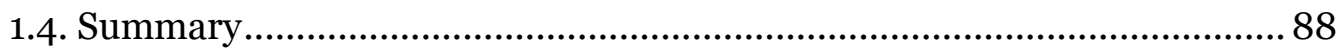


Chapter 2. The Speech Act of Complaints and Proficiency Effects ................. 96

2.1. The speech act of complaints ................................................................ 98

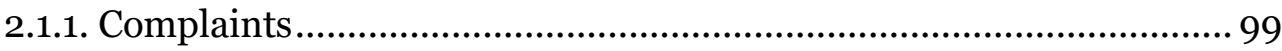

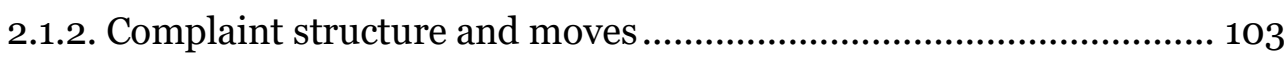

2.1.3. Research on complaints ............................................................129

2.2. Proficiency and interlanguage pragmatics ..............................................139

2.2.1. Overview of proficiency effects on ILP .............................................139

2.2.2. Proficiency effects on ILP: Spoken production ...............................142

2.3. Summary …........................................................................................ 157

Chapter 3. Spoken Conversation beyond Words: A Multimodal Perspective. 161 3.1. Multimodality ...........................................................................................16

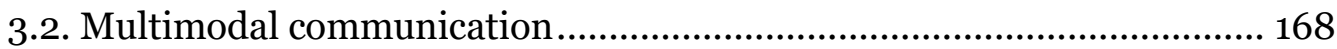

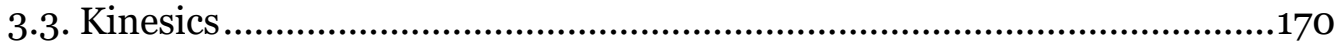

3.3.1. An overview of kinesic resources ..................................................... 171

3.3.1.1. Gestures ............................................................................... 172

3.3.1.1.1. Gesture type .................................................................174

3.3.1.1.2. Gesture identification...................................................... 177

3.3.1.1.3. Gesture interpretation..................................................... 180

3.3.1.2. Facial expression............................................................. 184

3.3.1.3. Gaze ...................................................................................187

3.3.1.4. Head movement.................................................................... 190

3.3.2. Kinesics and pragmatics .................................................................193

3.3.3. Proficiency and kinesic performance.......................................... 210

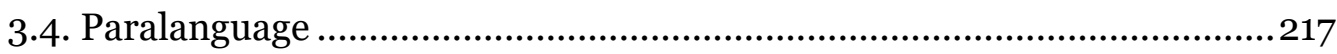

3.4.1. An overview of paralanguage ....................................................... 218

3.4.2. Paralanguage resources ...................................................................219

3.4.3. Paralanguage and pragmatics........................................................ 226

3.4.4. Kinesics and paralanguage ..........................................................231

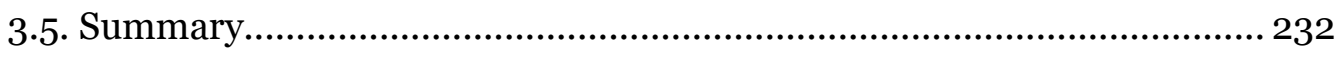

Chapter 4. Methodology and Experimental Design ...................................... 237

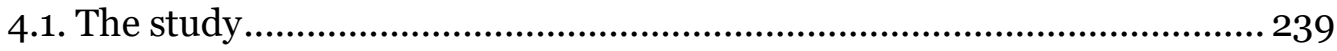




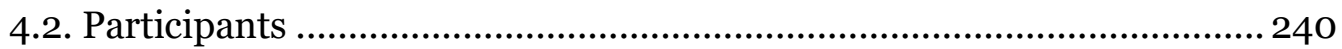

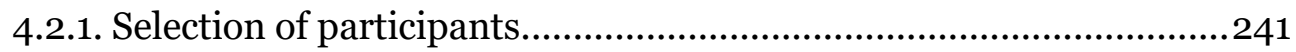

4.2.2. Participants of the study ................................................................ 245

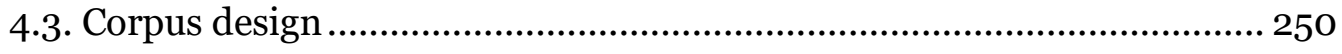

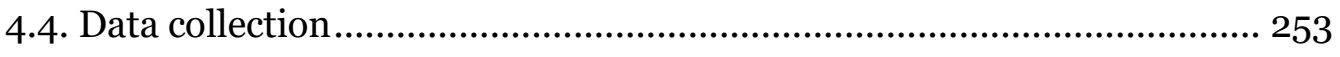

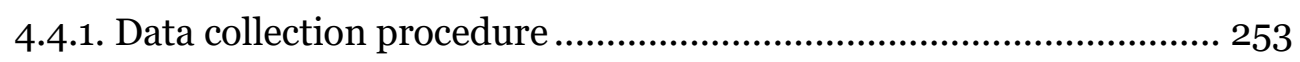

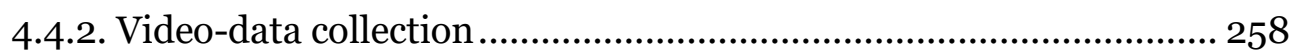

4.4.3. Data collection instruments ............................................................. 260

4.4.3.1. The design of the speaking task .............................................. 260

4.4.3.2. The role-play task ................................................................ 266

4.4.3.3. The retrospective verbal report ............................................. 270

4.5. Data preparation ............................................................................273

4.5.1. Verbatim transcription and annotation ..........................................273

4.5.2. Multimodal transcription and annotation.................................... 276

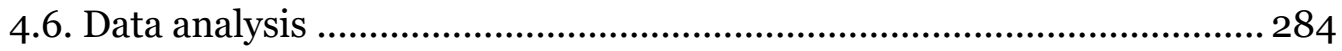

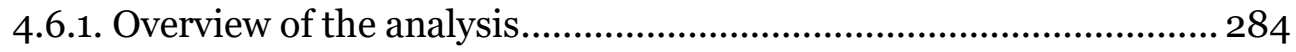

4.6.2. Appropriateness .......................................................................... 285

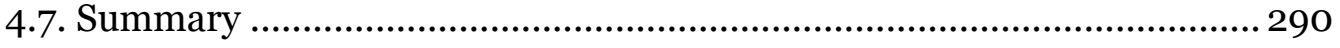

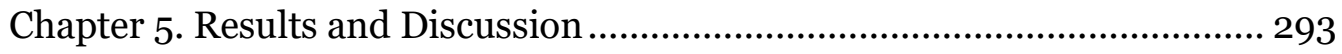

5.1. RQ1: Does language proficiency influence language learners' interlanguage complaints? ............................................................................................. 296

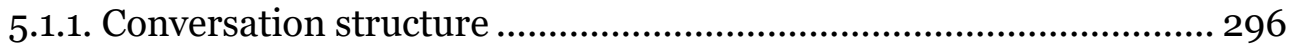

5.1.1.1. Moves, turns and repair ............................................................ 296

5.1.1.2. Time and words ........................................................................ 312

5.1.2. Sequence organisation ................................................................. 317

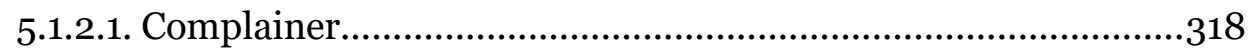

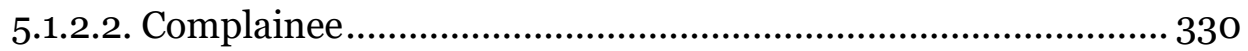

5.1.2.3. Structure of complaints ............................................................ 340

5.1.3. Specific conversational features....................................................... 344

5.1.3.1. Backchannels ............................................................................. 344

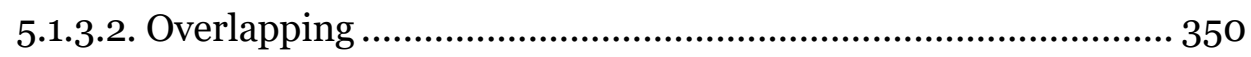

5.1.3.3. Paralanguage ...................................................................... 354

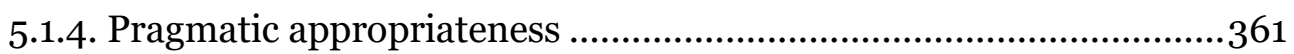


5.2. RQ2: How does a multimodal approach enrich the analysis of interlanguage complaints across proficiency levels? ..................................... 366

5.2.1. Multimodal pragmatics ..................................................................... 366

5.2.1.1. Opening move ............................................................................. 373

5.2.1.2 Pre-complaint move ............................................................... 376

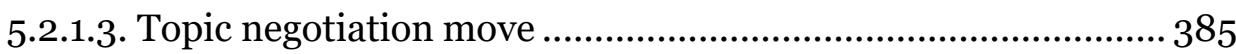

5.2.1.4. Post-complaint move...............................................................400

5.2.1.5. Closing move................................................................................414

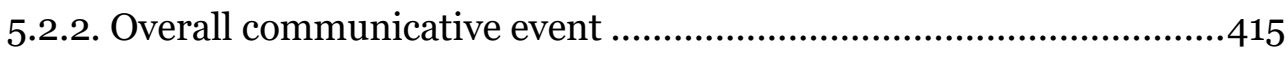

5.3. Summary ........................................................................................... 430

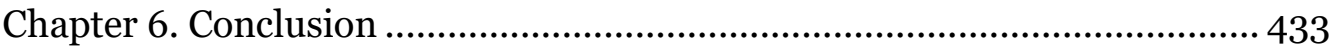

6.1. Summary of findings............................................................................. 435

6.1.1. RQ1: Does language proficiency influence language learners' interlanguage complaints?..................................................................... 436

6.1.2. RQ2: How does a multimodal approach enrich the analysis of interlanguage complaints across proficiency levels? ................................ 445

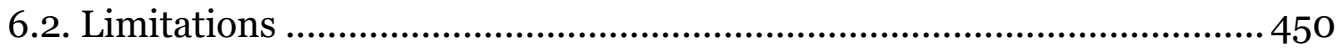

6.3. Directions for further research ........................................................... 452

6.4. Pedagogical implications ...................................................................... 454

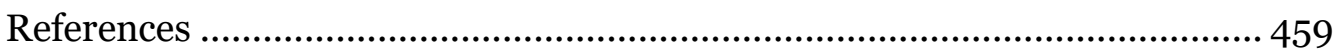

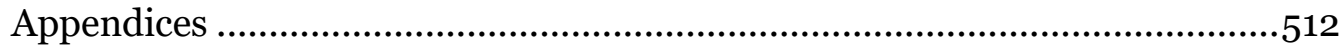

Appendix A. Consent form .....................................................................5 514

Appendix B. Background questionnaire .....................................................516

Appendix C. Retrospective verbal report .................................................. 527

Appendix D. Instruction for the role-play tasks ......................................... 528

Appendix E. Transcription conventions........................................................ 529 


\section{List of tables}

Table 1. Communicative competence components ......................................... 26

Table 2. Backchannel functions of Maynard (1986), Clancy et al. (1996) and

O’Keeffe and Adolphs (2008)........................................................... 83

Table 3. Complaint structure Complainer and complainee ...........................126

Table 4. Overview of research on the speech act of complaints .....................132

Table 5. Overview of studies examining the effect of proficiency in ILP ........ 151

Table 6. Overview of research on gesture, pragmatics and ILP .................... 207

Table 7. Overview of research on gesture and proficiency ............................215

Table 8. Discourse intonation choices............................................................ 223

Table 9. Overview of research on paralanguage and speech act performance 230

Table 10. Table of specifications of the background questionnaire .............. 243

Table 11. Initial distribution of participants according to gender and proficiency level ................................................................................ 246

Table 12. Participants' distribution of proficiency level and gender .............. 247

Table 13. Corpus of spoken interlanguage complaints and responses to complaints for RQ1 ........................................................................251

Table 14. Corpus of the multimodal analysis of spoken interlanguage complaints and responses to complaints for RQ2 ............................ 252

Table 15. Exemplar generation task ........................................................ 262

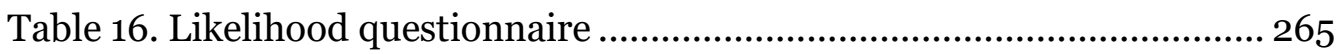

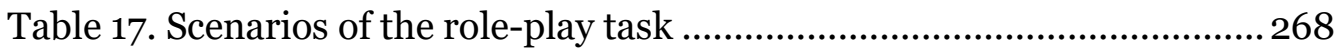

Table 18. Table of specifications for the retrospective verbal reports for the complainer and the complainee ...................................................... 272

Table 19. Rubric for multimodal pragmatic appropriateness in conversation 288

Table 20. Frequency of moves per proficiency level ...................................298

Table 21. Frequency of turns per move and participants' role...................... 299

Table 22. Frequency of turns per move and proficiency level........................ 301

Table 23. Frequency of repair per proficiency level ...................................... 307

Table 24. Distribution of time in moves and per proficiency levels.................313

Table 25. Distribution of frequency of words in moves per participants' role 314

Table 26. Distribution of frequency of words in moves per proficiency level.315 
Table 27 Frequency of words per moves by participants' role and proficiency level

Table 28. Frequency of complainer's discourse functions per moves and proficiency level

Table 29. Typology and frequency of complainer's discourse functions per moves and proficiency level. 322

Table 30. Frequency of complainee's discourse functions per moves and proficiency level. 331

Table 31. Typology and frequency of complainee's discourse functions per moves and proficiency level

Table 32. Structure of the complaints. 342

Table 33 Frequency of backchannel by participants' role 345

Table 34. Backchannel typology by participants' proficiency level. .346

Table 35. Backchannel typology by participants' proficiency level and role ..347

Table 36. Frequency of overlapping 351

Table 37. Frequency of filled pauses 354

Table 38. Frequency of laughter 358

Table 39. Inter-rate agreement .362

Table 40. Appropriateness according to proficiency level 362

Table 41. Appropriateness according to proficiency level and participants' role .363

Table 42. Multimodal conversation analysis results 368

Table 43 . Gesture type and gesture function results. 371

Table 44.Inter-rate agreement of multimodal pragmatic appropriateness .. 424 Table 45. Statistical results as regards the overall multimodal appropriateness

Table 46. Statistical results as regards multimodal appropriateness 425 


\section{List of figures}

Figure 1. Pragmatic components

Figure 2. Canale and Swain's (1980) and Canale's (1983) model of communicative competence .........................................................................17

Figure 3. Bachman's (1990) communicative competence model .19

Figure 4. Celce-Murcia et al.'s (1995, p. 10) communicative competence model

Figure 5. Celce-Murcia's (2007, p.45) revised communicative competence model

Figure 6. Possible strategies for doing FTAs (Brown and Levinson, 1987, p. 69)

Figure 7. Own representation of Kendon's continuum (McNeill, 1992, p. 37)176

Figure 8. Tiers employed for the multimodal analysis (example taken from a

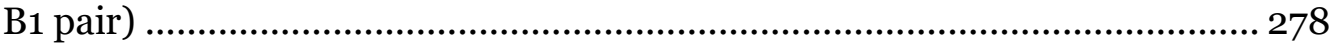

Figure 9. Multimodal analysis of a discourse function performed by a B1 pair 281

Figure 10. Multimodal density of the analysis of a move taken by a B1 pair . 283 




\section{Abbreviations}

\begin{tabular}{|c|c|}
\hline ACTR & American Council of Teachers of Russian \\
\hline $\mathrm{CA}$ & Conversation analysis \\
\hline CCSARP & Cross-Cultural Speech Act Realization Project \\
\hline CEFR & Common European Framework of Reference for Languages \\
\hline DCTs & Discourse completion tasks/tests \\
\hline EOI & Escuela Oficial de Idiomas \\
\hline ESL & English as a Second Language \\
\hline ESP & English for Specific Purposes \\
\hline$F$ & Frequency \\
\hline FACS & Facial Action Coding System \\
\hline FL & Foreign Language \\
\hline FLA & Foreign Language Acquisition \\
\hline FTA & Face Threating Act \\
\hline IELTS & International English Language Testing System \\
\hline IFID & Force Indicating Devices \\
\hline ILP & Interlanguage Pragmatics \\
\hline L1 & First Language/mother tongue \\
\hline L2 & Second Language \\
\hline LTM & Long Term Memory \\
\hline$M$ & Mean \\
\hline$m$ & Minutes \\
\hline MDA & Multimodal Discourse Analysis \\
\hline$N$ & Number of participants \\
\hline NNS & Non-Native Speaker \\
\hline NS & Native Speaker \\
\hline$p$ & p-value \\
\hline SD & Standard Deviation \\
\hline SFL & Systemic Functional Linguistics \\
\hline SF-MDA & Systemic Functional Multimodal Discourse Analysis \\
\hline SL & Second Language \\
\hline SLA & Second Language Acquisition \\
\hline STM & Short Term Memory \\
\hline
\end{tabular}


SUA

$t$

Social Unacceptable Act

t-value 



\section{Introduction}

In everyday conversation, people perform several speech acts to express their communicative purposes in different contexts and with different interlocutors. As speakers, we tend to adapt our language to the specific situation, taking into account various aspects, such as specific features of the context, interlocutors, politeness, and the actual communicative intent, among others (Brown and Levinson, 1978, 1987). While we, as speakers, might presumably be aware of the specific conditions that affect the performance of speech acts in our first language (L1) and/or second language (L2) in the case of bilingual speakers, this may not so evident for learners of a foreign/second language (FL/SL). In fact, language learners need to master pragmatic knowledge in order to express their communicative purposes properly in the target language (TL). While low proficiency level learners, due to their linguistic limitations, might be somehow open to potential difficulties that result, in some cases, in miscommunication problems, higher proficiency level learners, supposedly, may not face the same linguistic limitations. However, it seems that a high level of grammatical competence does not guarantee a high level of pragmatic competence (Bardovi-Harlig, 1999).

Pragmatic competence is one of the competences identified within the communicative competence model. Particularly, this specific competence is placed as an independent component of the communicative competence model by Bachman (1990). Broadly speaking, pragmatic competence involves two main components, pragmalinguistics and sociopragmatics (Leech, 1983, Thomas, 1983), which are tightly connected (Roever, 2011). SL/FL learners should master the pragmalinguistic knowledge and sociopragmatic knowledge of a given language in order to express utterances appropriately not only in terms of grammar but also from a pragmatic perspective. 
In addition to this, it is widely recognised that communication goes beyond words since several resources might be combined not only to express ourselves but also to provide signals of active listenership. This interplay of resources involves both verbal information and nonverbal information, which is, for example, conveyed by means of kinesics and paralanguage resources. When speaking in our L1/L2, we may or may not be aware of this interplay, but it is evident that several resources are present. The question, however, would be whether FL/SL learners are aware of the integration of different modes to communicate. This specific aspect requires an in-depth investigation so as to explore language learners' multimodal awareness. Albeit this could be a rather interesting contribution for the arena of FL/SL studies, my concern in this study is not to shed light into this specific issue, but rather examine interlanguage complaints as performed by the complainer and the responses elicited by the complainee at different proficiency levels from a conversational analytic perspective. Furthermore, I attempt to explore the potential of multimodality to enrich the interlanguage analysis.

For the purpose of this study, the speech act of complaints has been chosen. This particular speech act can be classified as a facethreatening act (FTA) (Brown and Levinson, 1978, 1987). Complaints are performed when the speaker perceives that a particular offence has been committed. Following Olshtain and Weinbach (1987), the complainer expresses displeasure or annoyance towards a particular action affects him/her unfavourably. Due to the face threating nature of complaints (Brown and Levinson, 1978, 1987), it is complex to utter them as their performance might affect negatively speakers' relationship. Speakers, and particularly complainers, should require specific pragmatic knowledge so as to approach the complainee and express complaints in a way that interlocutors are not damaged. By the same token, complainees' responses are also complex to construct. The responses to complaints are somehow connected to complainers' 
utterances as well as to complainees' assessment of the situation and the perceived offence.

It should be also noted that the speech act of complaints does not have a prototypical set of discourse functions (Laforest, 2002; Geluykens y Kraft, 2008). Therefore, the realisation of complaints and responses to complaints appears to become even more complex. Due to the complexities associated to the speech act of complaints and responses to complaints, it seems important to study them from the perspective of interlanguage pragmatics (ILP). In fact, the performance of complaints and responses to complaints becomes of special interest for FL/SL learners, who need to develop their communicative competence so as to become proficient speakers. Interestingly, all the interlanguage complaints studies that are reviewed in this study focus exclusively on the figure of the complainer, while no attention has been paid to the complainee, thereby revealing a scant of studies approaching interlanguage complaints from a conversationalist analytic perspective. Examining natural occurring data, Laforest (2002) present an investigation that focuses on the nature of the complainer and the complainee.

Therefore, the rationale behind the selection of the speech act of complaints and responses to complaints is based on: (1) the facethreating nature of the speech act of complaints (Brown and Levinson, 1978, 1987); (2) the complexity the complaints and responses to complaints presents due to the lack of prototypical discourse functions (Laforest, 2002; Geluykens and Kraft, 2008); and (3) the linguistic and pragmatic complexity that complaints and responses to complaints may represent for language learners.

In this study, the variable of proficiency has been chosen to explore how participants at different proficiency levels perform complaints and responses to complaints. The instrument employed in this study is a role-play task since it elicits spoken data that can be examined from the perspective of conversation, which may serve to 
provide a further detailed analysis of the complaint behaviour (Kasper, 2006a, 2006b, 2009a).

In addition, the present study also aims to contribute to the field of multimodality. Particularly, the performance of two pairs is examined from a multimodal perspective in order explore how complainers and complainees construct their communicative event not only verbally but also employing different extra-linguistic and paralinguistic elements at different proficiency levels.

Finally, another aspect that is examined in the present study is the appropriateness of participants' performance. This particular analysis examines data from a pragmatic and multimodal perspective in order to explore how appropriate the performance of the complainer and the complainee is during the simulated conversation. The distinguishing features of the appropriateness analysis of the present study are: (1) FL raters; and (2) the approach taken to explore pragmatic appropriateness, that is, from the perspective of pragmatics of conversation and multimodality, rather than exploring only pragmatic performance, thereby differently for example to Taguchi $(2006,2013)$.

Following a conversation analysis (CA) approach, I examine participants' data taking into account how participants construct the conversation. Concerning this, it is important to note that, traditionally, speech act data has not been explored from this perspective, thereby not showing how speech acts are constructed in social interaction. Kasper (2006a, 2006b, 2009a) emphasises the need to integrate a conversation analytic approach to explore ILP. This trend has been followed for example by Al-Gahtani and Roever (2012), who focused on learners' elicited requests by means of role-play tasks to explore sequential organisation of interactions across proficiency levels. Multimodal studies, however, have followed various approaches to examine data (see Jewitt, Bezemer and Halloran (2016) for a review). Norris (2004, 2011), for example, has approached the analysis of multimodality from the so-called multimodal interaction analysis that allows researchers to 
explore discourse-oriented communication, while other researchers have done it from the perspective of CA (e.g. Mondada, 2008, 2016; Streeck Goodwin and LeBaron 2011).

Taking into account these approaches, in this study I attempt to explore ILP data following a CA approach in order to examine how participants at different proficiency levels organise their talk through and in interaction (Kasper, 2006b). Moreover, following a multimodal CA approach (Mondada, 2008, 2016; Streeck, et al., 2011) I provide a detailed multimodal analysis of how participants interact and react in a simulated conversation.

Concerning this, I should highlight that it is important not to lose sight of the context of the study, which involves the analysis of language learners' interlanguage and therefore a different perspective should be taken to explore data. In line with this, this study, as any other study, has required the researcher to take specific methodological decisions as regards the research instruments and the sampling of the study. Particularly, this study involves the use of a role-play task in which participants, at two different proficiency levels, B1 and B2 according to the Common European Framework of Reference for Languages (CEFR) (2001), perform the speech act of complaints and responses to complaints.

Bearing in mind those aspects, the present study reports on an investigation that has been designed to examine how speakers at different proficiency levels of English perform complaints and responses to complaints. The research questions guiding the study are:

1. Does language proficiency influence language learners' interlanguage complaints?

2. How does a multimodal approach enrich the analysis of interlanguage complaints across proficiency levels? 
In an attempt to provide an answer to the first research question, participants' data is examined following a CA approach to explore how the conversation is organised and the different discourse functions that are performed in the communicative encounter. To do so, a structure of complaints and responses to complaints involving moves as well as different discourse functions is purposefully designed for the purpose of this study. Other conversational features such as backchannels, overlapping and paralanguage features are also analysed to respond this research question. Furthermore, participants' appropriateness across proficiency levels is also explored as regards their pragmatic performance in conversation.

In order to respond to the second research question, two different analyses are conducted. First, two selected pairs are examined from a multimodal CA approach to explore how participants at different proficiency levels employed different modes while taking part in a spoken simulated situation. The second analysis refers to appropriateness, which focuses on participants' performance of extralinguistic and paralinguistic elements in the context of the interaction.

It is important to note that the present study involves both a quantitative and qualitative analysis of the data. Particularly, data is collected by means of a role-play task and retrospective verbal reports in an attempt to triangulate the spoken data. These two instruments are purposefully constructed for the purpose of the study.

Having provided an overview of the study and the two research questions, I conclude the introductory chapter by presenting the structure of this study. The manuscript is divided into six chapters. Chapter 1 focuses on the nature of pragmatics in conversation by providing an overview of theories, concepts, research instruments, and approaches that are relevant for the present study. Subsequent to this, Chapter 2 focuses on the speech act of complaints and proficiency effects on ILP performance. Then, Chapter 3 introduces the multimodal approach for communication, in which I focus particularly on spoken 
data. Following this, in Chapter 4, I introduce the methodology followed in the present study to answer the two research questions, the participants, the instruments, the data set and the analysis of the data. In Chapter 5, I present the results and the discussion of the findings of the investigation concerning participants' complaints and responses to complaints from a pragmatic and multimodal perspective. The findings of the study and then summarised in Chapter 6, in which I also present the limitations of the study, directions for further research, as well as pedagogical implications. 

Chapter 1. Pragmatics in Conversation 



\section{Chapter 1. Pragmatics in Conversation}

In this Chapter, the different theories and concepts related to the realm of pragmatics, which are relevant to the study, are reviewed. Section 1.1 presents the scope of pragmatics by focusing on the discipline (Section 1.1.1), communicative competence (Section 1.1.2), politeness (Section 1.1.3) and speech acts (Section 1.1.4). In Section 1.2, I examine the concept of Interlanguage Pragmatics (ILP), which deals with how pragmatics is usually referred to within the field of Second Language Acquisition (SLA) (Section 2.1.1); and the different research instruments employed to gather data in ILP studies, paying special attention to the instruments used in the present work (Section 1.2.2). After this, in Section 1.3, I address the of conversation analysis approach by focusing on the discipline (Section 1.3.1), the nature simultaneous talk (Section 1.3.2), and the potential of the conversation analytic approach for examining speech acts (Section 1.3.3). This is followed by a summary of the chapter, which is intended to provide a general overview of aspects associated to the arena of pragmatics that are relevant to the study.

\subsection{The scope of pragmatics}

Pragmatics is a relatively young discipline that started to become an independent field of linguistics about 40 years ago. As I explain in this section, the modern concept of pragmatics is based on the work of Morris (1938), who introduced this term. Pragmatics has been defined by different authors (e.g. Crystal, 1985; Bublitz, 2001; Mey, 2001). In the area of language teaching, learning and assessment, pragmatics has become prominent. Specifically, various communicative competence models have included pragmatic knowledge within the competences described. It was, however, Bachman (1990) who first located pragmatic 
competence as an independent competence within the communicative construct. In this section, I first provide a review of the notion of pragmatics, in an attempt to show an overview of the discipline. Then, a review of the nature of the communicative competence model is given, paying special attention to the position given to pragmatic competence. Finally, pragmatic competence is revisit, addressing its definition as well as the possibility of viewing this competence from a multimodal perspective.

\subsubsection{The discipline}

The modern concept of pragmatics and its foundation might be traced back to the early 20th century when the American philosopher Charles Morris (1901-1979) first introduced the concept in 1938. Since he presented the modern concept of pragmatics, various definitions have been advanced, such as those by Crystal (1985), Bublitz (2001) or Mey (2001) (see Schauer (2009), for a review), which are typically employed to approach the concept of pragmatics. For the purpose of this study, I take the definition put forward by Crystal (1985), which is one of the most widely accepted. This author defines pragmatics as:

The study of language from the point of view of users, especially of the choices they make, the constraints they encounter in using language in social interaction, and the effects their use of language has on the other participants in an act of communication. (Crystal, 1985, p. 240)

Following this definition, pragmatics focuses both on language use in the context of interaction and on the role of speakers, the constraints they might face, as well as the effect speakers' can have on their interlocutors. In an interaction, speakers may not only provide linguistic 
utterances, which are performed taking into account different aspects such as the context of the situation and the communicative purposes or intentions, but also carry out non-linguistic or non-verbal acts. The performance of linguistic utterances and non-linguistic, or non-verbal, acts might affect the interlocutors' perception and understanding of the message conveyed in the interaction. In line with this, Thomas (1995) indicates that pragmatics involves speakers' negotiation of meaning, the specific context in which the utterances are performed, and the meaning of a particular utterance.

Moreover, as reviewed by Barron (2003), the choices and constraints that are identified in Crystal's (1985) definition are linked to the differentiation made by Leech (1983) and Thomas (1983) regarding general pragmatics. These two authors divided pragmatics into two main components, pragmalinguistics and sociopragmatics. Figure 1 provides an overview of the pragmatic components.

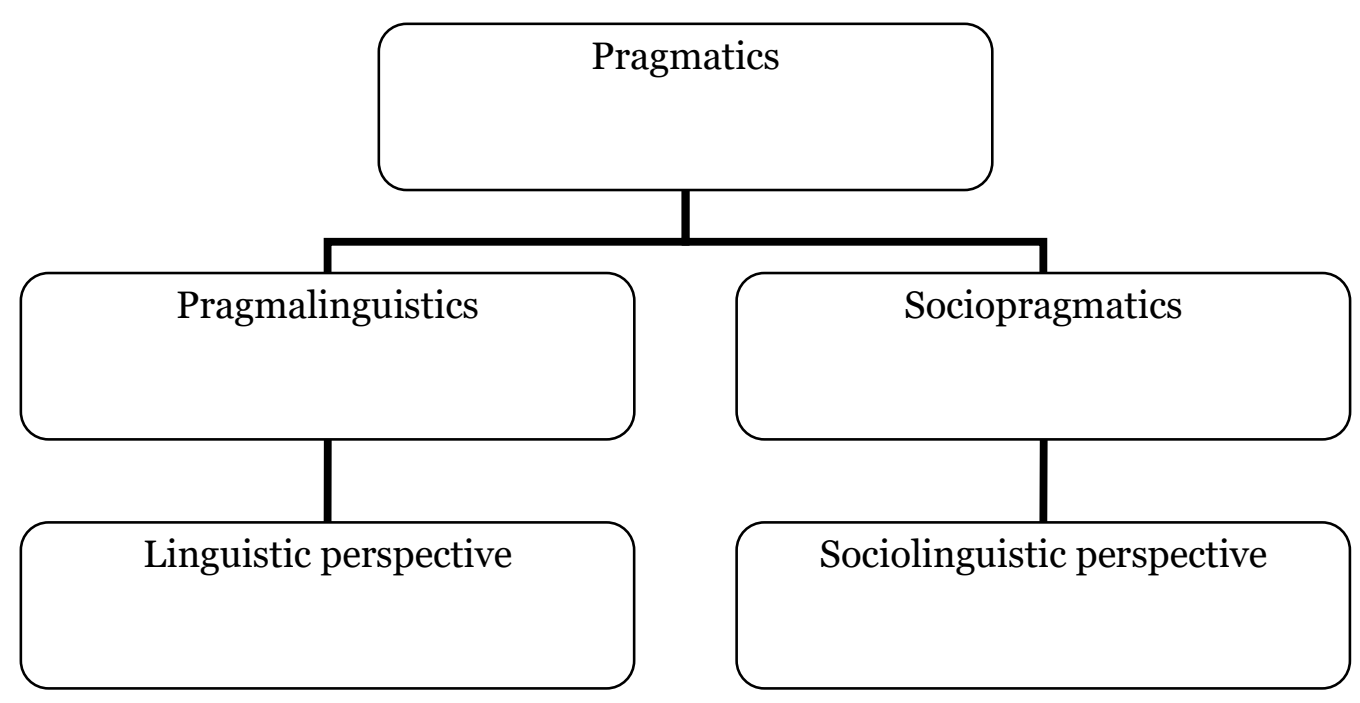

Figure 1. Pragmatic components

As shown above, pragmalinguistics refers to the study of "the particular resources which a given language provides for conveying particular illocutions" (Leech, 1983, p. 11). Therefore, it refers to the different linguistic resources speakers might select for a particular context such 
as pragmatic strategies, pragmatic routines and modification devices (Rose and Kasper, 2001; Barron, 2003). The term sociopragmatics involves the "sociological interface of pragmatics" (Leech, 1983, p. 10). Hence, sociopragmatics is concerned with the conditions that constrain and govern speakers' language use. Specifically, it focuses on how different social variables such as power or status, social distance and rank of imposition or severity of offence (Brown and Levinson, 1978, 1987) affect language use. Then, as indicated by Thomas (1983, p. 99), sociopragmatics involves "the social conditions placed on language in use".

Roever (2011, p. 2) points out that sociopragmatics and pragmalinguistics are "tightly connected, as a speaker's sociopragmatic analysis of a situation (in terms of politeness, possible meanings, and cultural norms and prohibitions) is linguistically encoded through pragmalinguistic choices". Furthermore, Thomas (1983) claims that in order to perform a pragmatically appropriate utterance, speakers should make two main adjustments, specifically: pragmalinguistic assessment of the pragmatic force of the linguistic features and the sociopragmatic judgement regarding the social factors involved in the social encounter. Hence, as pointed out by Roever (2009, p. 560), "it is essential that both aspects of pragmatic knowledge are developed and accurately mapped onto one another". In short, the areas of pragmalinguistics and sociopragmatics are crucial in language communication and are of special interest in SL/FL learning and teaching. Both components are then connected since the sociopragmatic features affect the pragmalinguistic realisation, and thus the first variable influences the linguistic choices the speaker might make.

As reviewed, since Morris (1938) described the notion of pragmatic competence, different definitions have been put forward (e.g. Crystal, 1985; Bublitz, 2001; Mey, 2001). Although there is no specific definition of this concept (Barron, 2003), for the purpose of this study, the definition presented by Crystal (1985) is also taken. Specifically, his 
approach reveals that speakers, context and the interaction between them are part of the notion of pragmatic competence as it focuses on speakers' intentions and the effects on the interlocutor. Moreover, as reported, pragmatics involves two components (Leech, 1983; Thomas, 1983): pragmalinguistics, i.e. linguistic resources; and sociopragmatics, i.e. sociological view of pragmatics (Leech, 1983). In the field of SL/FL teaching, pragmatic competence has been commonly associated as one of the components of communicative competence (Bachman, 1990). Therefore, in what follows, I address the concept of communicative competence, of which pragmatic competence is one of the components (Bachman, 1990).

1.1.2. Communicative and pragmatic competence: Towards a multimodal perspective

The anthropologist and sociolinguist Dell Hymes first introduced the term communicative competence in 1964, although it was not defined until 1972.

That year, Hymes defined the term communicative competence as a reaction against Noam Chomsky's (1965) notion of competence, which related to the rules of grammar in isolation without taking into account contextual appropriateness. Hence, Chomsky's (1965) competence was based on an ideal speaker-listener with perfect linguistic knowledge, who seems not to be affected by cognitive and situational factors during the linguistic performance. Chomsky's (1965) approach to performance, which might be classified as formalist, involved "the actual use of language in concrete situations" (p. 4). For Hymes (1972a), competence involved both tactic knowledge and ability to use, thereby including within the notion of competence non-cognitive factors, e.g. attitudes, values, motivation and the inseparability of cognitive from affective and volitive factors. 
Hymes (1972a), among others such as Habermas (1970), reacted against this vision and argued that Chomsky's view could not account for real-life communication. Hymes (1972a) argued that his view did not involve any reference to aspects related to language use in social contexts and the appropriateness of an utterance to a specific situation. Thus, Hymes (1972a) proposed the term communicative competence from a sociolinguistic perspective, which consisted of both grammatical competence, as in Chomsky (1965), and sociolinguistic competence. In so doing, Hymes (1972a) pointed out that communicative competence involves not only knowledge of grammatical aspects but also knowledge of the sociocultural rules of appropriate language use. In this sense, Hymes (1972a) understood the notion of communicative competence not only from a theoretical viewpoint, but also taking into account practical needs. Concerning this, the author pointed out that "[i]t is not that there exists a body of linguistic theory that practical research can turn to and has only to apply. It is rather that work motivated by practical needs may help build the theory that we need" (Hymes, 1972a, p. 269).

Hymes's (1972a) perspective influenced the field of SL/FL teaching, not only because his work was regarded as a theoretical background for developing a new language teaching approach and language teaching materials, but also because several researchers followed his tenet, presenting various communicative models and the different components that the construct might involve. Hence, drawing on Hymes's (1972a) notion of communicative competence several theoretical models emerged. However, I have decided to limit the present literature review to the models that, to the best of my knowledge, have been widely recognised by several authors due to their influence within the realm of SL/FL teaching and assessment.

The model proposed by Canale and Swain (1980) is considered the pioneering work which includes the basis of the communicative approach to language teaching. Their interest in communicative 
competence appeared to be related to their need to develop language tests to measure learners' knowledge of and proficiency in language use. This communicative competence model, clearly influenced by Hymes's (1972a) approach, consisted of three different competences, specifically those of: (1) grammatical competence, (2) sociolinguistic competence, and (3) strategic competence. This model was further developed by Canale (1983), who added (4) discourse competence. Figure 2 illustrates Canale and Swain's (1980) and Canale's (1983) model of communicative competence.

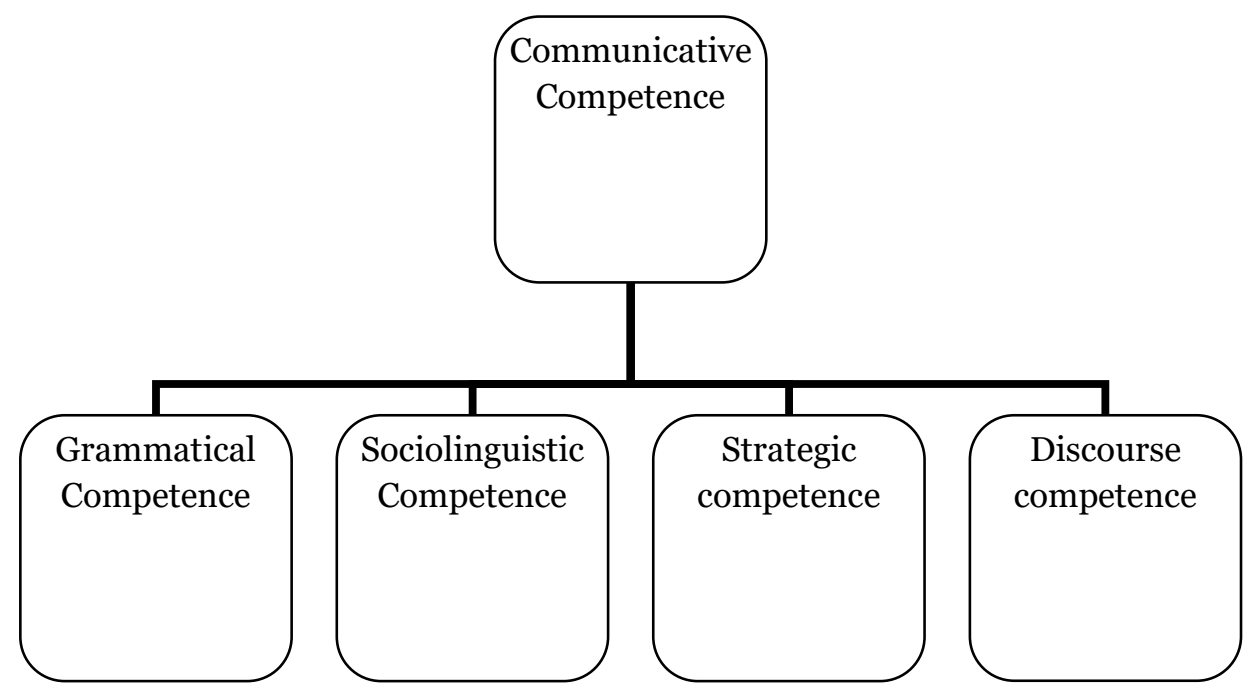

Figure 2. Canale and Swain's (1980) and Canale's (1983) model of communicative competence

Grammatical competence refers to the knowledge of the language system including knowledge of lexis, morphological rules, syntax, phonology and semantics. Sociolinguistic competence involves the knowledge of the sociocultural rules of use. Strategic competence relates to the knowledge of how to use verbal and non-verbal communication strategies to overcome communicative breakdowns or to reinforce speakers' communicative intention. The last competence included in this model is that of discourse competence, which involves learners' 
understanding and production of texts in different modes (i.e. listening, speaking, reading and writing) and it is related to coherence and cohesion in different text-types.

These two models described, albeit very influential, are not without criticism. For example, Bachman and Cohen (1998) indicated that these two models of communicative competence were to some extent static, with little discussion on how the different components interact with each other or how language users confront the characteristics of the context of situation in which a speech event took place. Moreover, Schachter (1990) also claimed that they did not provide an accurate description of pragmatic competence. In fact, Schachter (1990, p. 42) asked "[w]here does pragmatics fit into the Canale and Swain framework? Is it assumed not to exist? Or is it thought to be coextensive with discourse competence?" Pragmatic competence was, however, not included as an independent element within the communicative model until the late 1980s, when Bachman, in 1990, advanced a communicative language ability model that placed pragmatic competence in its own right.

Bachman (1990), drawing on the works of Hymes (1972a), and Canale and Swain (1980), provided a framework for communicative language ability that was described as "consisting of both knowledge, or competence, and the capacity for implementing, or executing that competence in appropriate, contextualised communicative language use" (Bachman, 1990, p. 84). This model maintained the components proposed by Canale and Swain (1980) and Canale (1983), but expanded the nature of strategic competence. Moreover, the author placed pragmatic competence as an independent component. Bachman's (1990) approach focused more on language assessment than on SL/FL teaching. In particular, the author presented a model of communicative language ability (see also Purpura (2004) for another theoretical model of language ability). This model includes three components: (1) language competence, "a set of specific knowledge components that are 
utilised in communication via language" (Bachman, 1990, p. 66); (2) strategic competence, "the mental capacity for implementing the components of language competence in contextualised communicative language use" (Bachman, 1990, p. 67); and (3) psychophysiological mechanisms, "the neurological and psychological processes involved in the actual execution of language as a physical phenomenon" (Bachman, 1990, p. 67). Figure 3 shows the components of language competence.

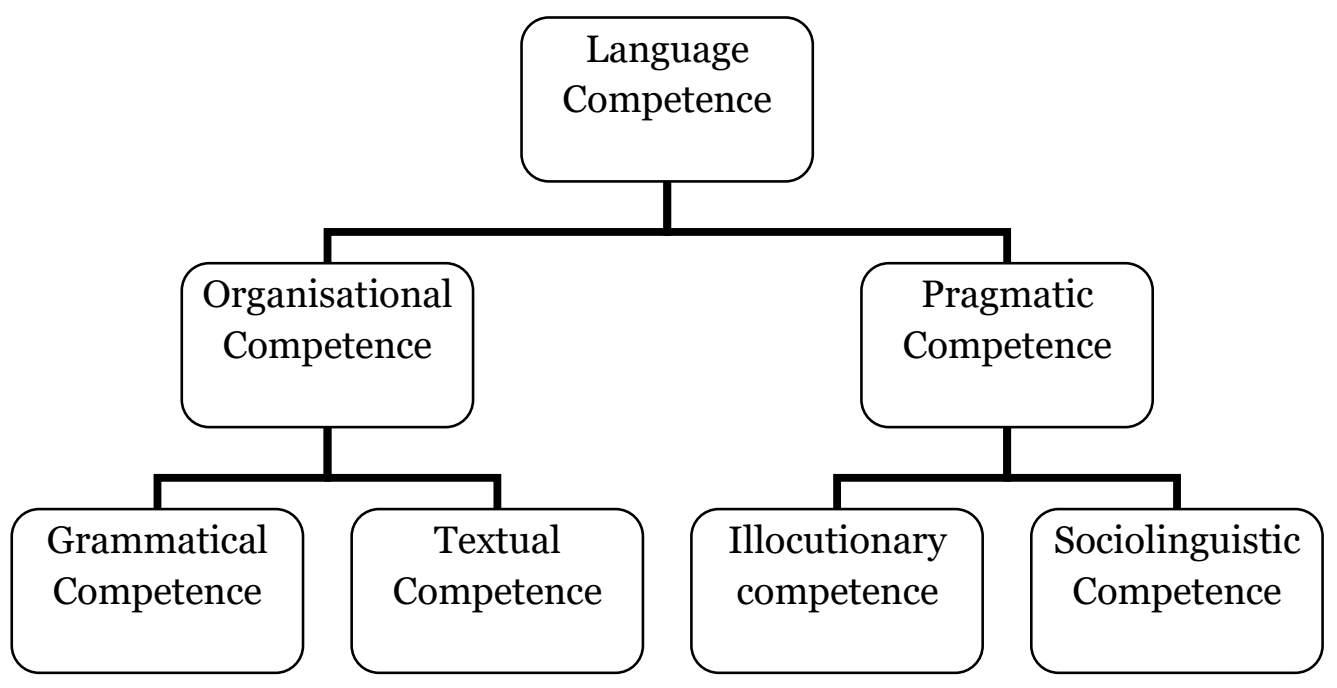

Figure 3. Bachman's (1990) communicative competence model

As shown, the language competence proposed by Bachman (1990) is therefore further divided into two main components, organisational competence and pragmatic competence. Organisational competence consists of grammatical competence (related, as we have said above, to the knowledge of lexis, phonology, morphology, and syntax) and textual competence, which involves the knowledge of the norms to join utterances to form a text, either spoken or written, that is coherent and cohesive. Pragmatic competence is further divided into illocutionary competence and sociolinguistic competence. This division seems to be associated to Leech's (1983) and Thomas's (1983) distinction between pragmalinguistics and sociopragmatics. Hence, illocutionary 
competence refers to the ability to perform and interpret utterances, and sociolinguistic competence is concerned with the knowledge of the conventions of language used for performing utterances appropriately in a given context. This competence appears to be similar to Canale and Swain's (1983) and Celce-Murcia, Dörnyei and Thurrell's (1995) and Celce-Murcia's (2007) sociocultural competence. In addition to this, the author also suggested strategic competence (see, for example, the works of Jordan (2004), Peterwagner (2005) and Phakiti (2008) for further information on strategic competence) which was first introduced by Canale and Swain (1980), involving three different components: (1) assessment component; (2) planning component; and (3) execution component. The concept of strategic competence appears to go beyond Canale and Swain's (1980) perspective in the sense that this term was used by Bachman (1990, p. 84) "to characterise the mental capacity for implementing the components of language competence in contextualised communicative language use".

Although the author provided an expanded version of that proposed by Canale and Swain (1980) and Canale (1983), several problems were identified. In Bachman's (1990) model, as in the models advanced by Canale and Swain (1980) and Canale (1983), the relationship among the different components is not explicitly described as, for example, in Celce-Murcia et al. (1995). In 1996 Bachman and Palmer revisited Bachman's (1990) model and showed how language knowledge, metacognitive strategies and affect interacted with each other during language use. This model also showed the interaction between the components of communicative language ability and the features of the language use context, the test task as well as mental schemata. The authors also replaced the name illocutionary competence with functional knowledge, and argued that functional knowledge "enables us to interpret relationships between utterances or sentences and texts and the intentions of language users" (p. 69). Similarly, they 
replaced the term competence with knowledge, including for example pragmatic knowledge instead of pragmatic competence.

In the mid 1990s, Celce-Murcia et al. (1995) proposed a communicative competence model that accounted for the existing relationship between the different components of the communicative model. This model included the following competences: (1) discourse competence; (2) sociocultural competence; (3) linguistic competence; (4) actional competence; and (5) strategic competence. Figure 4 shows an adapted representation of Celce-Murcia et al.'s (1995) model.

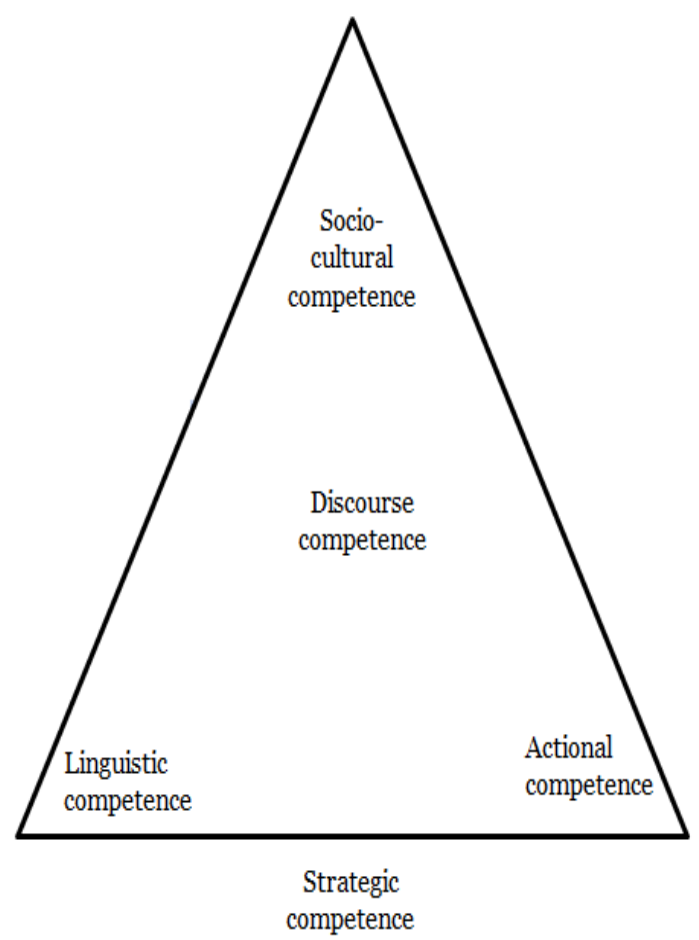

Figure 4. Celce-Murcia et al.'s (1995, p. 10) communicative competence model

As shown in Figure 4, discourse competence is located in the circle inside the pyramid as it represents the core competence. It refers to the selection, sequencing and arrangement of the sentences to obtain a unified spoken or written text. This competence might be associated to 
Bachman's (1990) textual competence. The three points of the triangle represent top-down sociocultural competence and bottom-up linguistic competence and actional competence. Sociocultural competence involves the speakers' knowledge of how to convey appropriate messages in a particular social and cultural context, as in the case of Canale and Swain's (1980) and Bachman's (1990) sociolinguistic competence. Linguistic competence might be similar to Canale and Swain's (1980) grammatical competence and Bachman's (1990) grammatical competence. In this case, however, this competence also relates to basic elements of communication, including sentence patterns and types, the structure, morphological inflections, phonological and orthographic systems and lexical resources. Actional competence, which might correspond to Canale and Swain's (1980) sociocultural competence and Bachman's (1990) pragmatic competence, involves performing and understanding communicative intent, thus relating actional intent with linguistic form that carries illocutionary force, i.e. speech act sets5. The arrows serve to illustrate that the different components are in constant interaction with each other and with discourse competence.

Finally, in the circle that surrounds the pyramid, the authors place strategic competence, which is also observed in Canale and Swain (1980) and Bachman (1990). It is important to note that all the different components of the model are influenced by strategic competence. This competence refers to the knowledge of communication strategies and how to employ them. The strategies identified involved three functions of strategy used from different perspectives, specifically, the psycholinguistic perspective, interactional perspective and communication continuity/maintenance perspective. Furthermore, strategic competence involves the following communicative strategies: avoidance or reduction strategies; achievement or compensatory

$5 \quad$ Speech act set involves the set of realisation patterns that are typically used by the NSs of a TL (Olshtain and Cohen, 1983). 
strategies; stalling, or time-gaining strategies such as fillers, hesitation devices, gambits, and repetitions; self-monitoring strategies; and interactional strategies. Although, as pointed out by Celce-Murcia (2007), this model implied "a step forward with respect to Canale and Swain (1980) and Canale (1983)" (p. 45), there were still some gaps that the author tried to solve (Celce-Murcia, 1995) by emphasising the role of formulaic language and the paralinguistic features of oral communication.

In 2007 Celce-Murcia presented a revised version of the models proposed in 1995 (Celce-Murcia et al., 1995; Celce-Murcia, 1995). This model involves six different competences, namely those of (1) discourse competence; (2) sociocultural competence; (3) linguistic competence; (4) interactional competence; (5) formulaic competence; and (6) strategic competence. Figure 5 illustrates an adapted representation of her model.

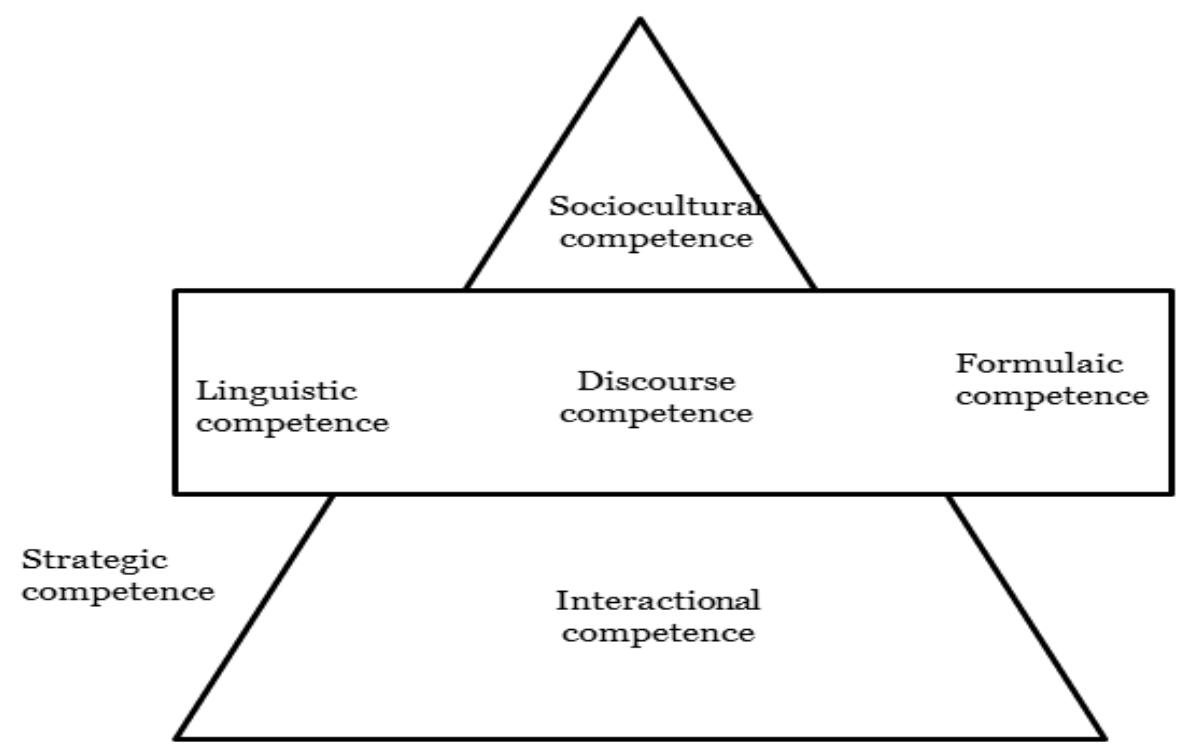

Figure 5. Celce-Murcia's (2007, p.45) revised communicative competence model 
The revised model also places discourse competence in the central position of the model and it involves, as in Celce-Murcia et al. (1995), the selection, sequencing and arrangement of the sentences to obtain a unified spoken or written text. The author further distinguishes various areas of discourse competence including cohesion, deixis, coherence and generic structure. The top-down includes sociocultural competence, as in the previous model, which has to do with the speakers' pragmatic knowledge and indicates that three crucial sociocultural variables for the current model are those of social contextual factors, such as age; gender; status; social distance; and power and effect; stylistic appropriateness, including politeness strategies, genres and registers; and cultural factors, such as background knowledge of the TL group, for example.

The bottom-up place is used to place interactional competence, which includes three different competences, namely those of actional competence, conversational competence and non-verbal/paralinguistic competence. Actional competence, as in Celce-Murcia et al. (1995), refers to how to perform speech acts and speech act sets. Conversational competence is related to the turn-taking system (Sacks, Schegloff and Jefferson, 1974) as well as to other dialogic genres such as how to open and close conversations; collaborate and backchannel; and get, hold and relinquish the floor, among others. The last competence included in interactional competence is that of non-verbal/paralinguistic competence, which relates to kinesics, proxemics, haptic behaviour and non-linguistic utterances, silence and pauses.

Linguistic competence and formulaic competence are placed on the left and right. The former, as in Celce-Murcia et al. (1995), includes phonological knowledge, lexical knowledge, morphological knowledge and syntactic knowledge; and the latter, i.e. formulaic language, refers to the chunks of language speakers use in everyday interactions such as routines, collocations, adjectives, idioms and lexical frames. 
Finally, strategic competence, similarly to Celce-Murcia et al. (1995), refers to the knowledge of communication strategies and how to employ them. In this regard, Celce-Murcia (2007), building on Oxford's (2001) strategies for language learning and language use, indicates that cognitive, metacognitive and memory-related strategies are important for this new model. Furthermore, the author also mentioned that other strategies crucial for this model were those included in Celce-Murcia et al. (1995), i.e. achievement, stalling or time gaining, self-monitoring, interacting and social strategies.

Table 1 shows a summary of the components of communicative competence models revisited. 
Chapter 1. Pragmatics in conversation

Table 1. Communicative competence components

\begin{tabular}{l|l}
\hline \multicolumn{1}{c|}{ Author } & \multicolumn{1}{c}{ Components } \\
\hline & Grammatical competence \\
& Sociolinguistic competence \\
\hline Canale and Swain (1980) & Grammatical competence \\
& Sociolinguistic competence \\
& Strategic competence \\
\hline Canale (1983) & Grammatical competence \\
& Sociolinguistic competence \\
& Strategic competence \\
& Discourse competence \\
\hline Bachman (1990) & Organisational competence: grammatical \\
& competence and textual competence \\
& Pragmatic competence: illocutionary \\
& competence and sociolinguistic competence \\
\hline Celce-Murcia et al. (1995) & Discourse competence \\
& Sociocultural competence \\
& Linguistic competence \\
& Actional competence \\
& Strategic competence \\
\hline Celce-Murcia (2007) & Discourse competence \\
& Sociocultural competence \\
& Linguistic competence \\
& Interactional competence \\
& Formulaic competence \\
& Strategic competence \\
\hline
\end{tabular}

As reported, various authors have provided different communicative competence models for language teaching (Canale and Swain, 1980; Canale, 1983; Celce-Murcia et al., 1995; Celce-Murcia, 2007) and communicative language ability models (Bachman, 1990). In this review, I have selected some of the most influential models for the field of SL/FL teaching and assessment. There are, however, other models that are also of paramount interest for researchers and language teachers in the aforementioned fields (e.g. Savignon, 1983; Bachman and Palmer, 1996, 2010; Purpura, 2004; Usó-Juan and Martínez-Flor, 2006).

In addition to this, considering that communication is multimodal by nature (Jewitt, 2013) and that language learners need to master some specific competences to develop their communicative competence, it 
would then be necessary to think of multimodal communicative competence. When using a given language, several paralinguistic and extra-linguistic sources are used together with linguistic sources to communicate either in the spoken or written mode. Speakers constantly produce multimodal output and receive multimodal input; therefore, from the perspective of SL/FL learning, it could be suggested that both the multimodality and communicative competence approaches should be integrated. In so doing, it becomes possible to recognise the importance of using various modes to communicate within the domain of language teaching, learning and assessment. In line with this, I also argue, as Royce (2007), for moving from the traditional perspective of communicative competence to a multimodal communicative competence. In this sense, I would suggest that multimodal communicative competence would go beyond the development of visual literacy, digital issues and the interrelation of different semiotic modes in spoken or written communication. Rather, multimodal communicative competence should be discussed drawing on previous research on communicative competence and taking into account the different competences that have already been described. Thus, in developing a multimodal communicative approach, it is necessary to take into account different competences, the way they are interrelated, how they are increased and how their development affects overall multimodal communicative competence. Otherwise, it might be complex to specify how this approach can be integrated in the language classroom and which the best route to assist language learners is. Royce (2007, p. 373) also posits that multimodal communicative competence "makes a number of importance assumptions that are derived from the SFL [systemic functional linguistics] model". Accordingly, it seems that multimodal communication is constructed having in mind the perspective of exchanging, projecting, or sending meanings in a particular social context. The channel employed for conveying meaning could involve various modes and each channel may communicate the 
meaning in a way that is appropriate for the medium. Royce (2007) also argues that it is assumed that the selections of social meaning might depend on the cultural context. Moreover, the author indicates that it is assumed that the way people communicate in different visual and verbal modes are the outcome of speakers' choice of particular semiotic systems. Concerning those aspects, the author pointed that " $[t]$ hese meanings and choices, realized in differing modes, will necessarily have a message and interactional-focus, and will draw on the textual or compositional conventions appropriate to the mode" (p. 374). In line with this, Stenglin and Iedema (2001) indicate that multimodal communicative competence also involves how learners may become competence in interpreting and constructing meaning from a multimodal perspective.

My intention here is not to provide a definition of the term multimodal communicative competence but to open a discussion on the vision of communicative competence from a multimodal perspective. This is only an approach based on previous research and, more especially, on the nature of communicative competence from the perspective of SL/FL learning. The phenomenon of multimodal communicative competence requires, as I see it, further investigation in order to examine which competences should be integrated, if any, and how it should be dealt with from both theoretical and practical perspectives.

As shown above, pragmatic competence is one of the components of the communicative competence model, and it was in 1990 when Bachman identified this specific competence as an independent one within the communicative competence model. Since then, pragmatic competence has become an object of inquiry in different disciplines such as linguistics, applied linguistics, anthropology, sociology, psychology, communication research, and cross-cultural studies (Taguchi, 2009). In the field of SL/FL research, pragmatic competence is commonly regarded as the ability to perform and understand 
utterances that are appropriate for a particular sociocultural context (Rose and Kasper, 2001; Thomas, 1983). In this respect, Thomas (1983, p. 92) defines pragmatic competence as "the ability to use language effectively in order to achieve a specific purpose and to understand language in context". Pragmatic competence can be viewed "as the knowledge of the linguistic resources available in a given language for realising particular illocutions, knowledge of sequential aspects of speech acts, and finally knowledge of the appropriate contextual use of the particular languages' linguistic resources" (Barron, 2003, p. 10). This is also supported by Taguchi (2009, p. 3), who argues that pragmatic competence is "broadly defined as the ability to use language appropriately in a social context". Thus, pragmatic competence might be seen as the knowledge of the linguistic sources that speakers of a given language have available in a language in order to perform specific utterances and the knowledge of the contextual factors affecting language use, i.e. knowledge of pragmalinguistic and sociopragmatic features. In line with this, it is important to note that several researchers have proposed different approaches for integrating pragmatic competence in the language classroom by focusing on specific pragmatic aspects (see, for example, the works of Olshtain and Cohen, 1991; Judd, 1999; Ishihara and Cohen, 2010; Martínez-Flor and Usó-Juan, 2010a; Tatsuki and Houck, 2010; Martínez-Flor and Beltrán-Palanques, 2013, 2014).

Pragmatic competence might also be viewed from a multimodal perspective (see Beltrán-Palanques (in press) for a pedagogical implementation of multimodal pragmatic competence in the FL classroom), thereby involving not only verbal performance but also other elements such as paralanguage and extra-linguistic features that are employed to communicate. In this sense, I would argue for the use of the term multimodal pragmatic competence, which could involve not only pragmalinguistic and sociopragmatic knowledge but also kinesics, paralanguage, proxemics, haptic behaviour, non-linguistic utterances 
such as silence and pauses (see Celce-Murcia's (2007) interactional competence), and other resources such as visuals, objects, etc. even visuals used when writing such as emoticons, capitalisation, etc. Pragmatics is present in interaction, whether spoken or written, and therefore all the different modes that operate at the level of pragmatic competence should be taken into account as they do convey meaning. This is why I suggest following a multimodal approach for pragmatics, so that the non-verbal and extra-linguistic components that are involved in a communicative encounter are not ignored (Beltrán-Palanques, in press).

In a communicative encounter, interactional conventions of language use play a paramount role. Concerning this, different politeness theories have been proposed within the arena of pragmatics. Bearing in mind this idea, in the following section, I focus on the phenomenon of politeness.

\subsubsection{Politeness}

The study of linguistic politeness has called the attention of researchers in the field of pragmatics over the years. Since the late 1970s, different politeness theories have been advanced within the field of pragmatics in an attempt to explain the conventions of language use (Barron, 2003). Providing an accurate definition of politeness, however, appears to be a rather complex issue, and most researchers tend to agree with the idea that politeness is part of the affective aspects of interaction and that it is related to the notion of face (Brown and Levinson, 1978, 1987; Kasper, 1990, 2009b; Watts, 2003; Geyer, 2008). Hence, in this section I provide an overview of various views on politeness and then I draw on Brown and Levinson's approach. 


\subsubsection{Different views on politeness}

Grice (1975, p. 45) suggests that conversations are governed by the Cooperative Principle, which comprises four different maxims: (1) Quality, i.e. speakers need to be as informative as required for the hearer to understand them; (2) Quantity, i.e. speakers must be truthful and not say anything they believe to be false and for which they cannot provide accurate evidence; (3) Relevance, i.e. speakers should say something which is relevant to the given topic; and (4) Manner, i.e. people should say things in a clear manner in order to avoid obscurity and ambiguity. The author, however, does not aim to present these maxims from a rigid perspective but, instead, he expects hearers to infer the meaning from the available contextual information, a practice that is termed by the author as conversational implicature. Nevertheless, his approach has been criticised by Leech (1983) and Brown and Levinson (1978, 1987) for not taking into account the different variables that can affect language use.

The phenomenon of politeness has been addressed by a number of researchers and a larger number of studies dealing with this issue have been published in the last two decades. However, there is still no single definition of the notion of politeness. In 1973, Lakoff published the article "[t]he logic of politeness; or minding your p's and q's" in which she provides an account of how she understands the nature of politeness. Lakoff's work is one of the first attempts to integrate the phenomenon of linguistic politeness into a theory of language use. The author adopts Grice's universal construct of conversational principles to expand the phenomenon of politeness. Specifically, Lakoff (1973) proposes establishing a set of pragmatic rules to complement the syntactic and semantic rules, and adding a set of rules of politeness. She argues that instead of focusing exclusively on the syntactic structure of a given utterance, the context in which such utterance is produced should be regarded as a criterion to decide whether the sentence is polite or 
impolite. According to this same author, semantics, syntax and pragmatic should be considered together rather than separately.

Lakoff (1973) proposes two universal rules of pragmatic competence: (1) Be clear (rule of conversation); and (2) Be polite (rule of politeness). The two rules might reinforce each other in some cases, but one of them usually supersedes the other. Hence, in cases of conflict between clarity and politeness, being polite supersedes clarity because the main purpose of an interaction seems to be to toughen the relationship of the different interlocutors. Rule 1 is based on Grice's Cooperative Principle Maxims, although she terms it as rules of conversation. Rule 2 refers to the rule of politeness, which is further divided into three different rules, (1) don't impose; (2) give options; and (3) make A (the receiver) feel good - be friendly (see Watts (2003) for a detailed review).

As reported by Félix-Brasdefer (2008a), Lakoff's (1973) model is concerned with showing respect to the interlocutor's territory, offering alternatives, and making the interlocutor feel good. The author further adds that it seems unclear whether polite behaviour is parallel to what is understood as appropriate behaviour, such as performing specific speech acts (e.g. greetings), leave-taking formulas, and other routine formulae, which might not necessarily be understood as polite behaviour.

Another approach taken to examine politeness is advanced by Leech (1983), who, also influenced by Grice's work, argues that the Cooperative Principle does not present an accurate explanation of how real language is employed and why people in some cases decide to use indirect language. The model presented by Leech (1983) is known as the Conversation-maxim view. Leech (1983) notes that Grice's model suggests that speakers communicate taking into account the assumption that the interlocutor is cooperative, yet this does not provide any account as to the degree of politeness that is at work during the interaction. Furthermore, the author also aims to explain why people 
often use indirect language. Hence, drawing on Grice's Cooperative Principle, Leech (1983) posits the Politeness Principle in an attempt to complement the Cooperative Principle. Leech (1983) uses the term rhetorical in his approach to pragmatics and focuses on a "goal-oriented speech situation, in which $s$ uses language in order to produce a particular effect in the mind of $h$ " (p. 15). An important contribution by Leech (1983) is the distinction between speaker's illocutionary purpose and speaker's social purpose, that is to say, the communicative act or acts that the speaker performs and the position that the speaker adopts. Leech (1983) proposes a pragmatic framework that involves (1) textual rhetoric; and (2) interpersonal rhetoric. The former, in turn, involves four different principles, p. (1) processibility; (2) clarity; (3) economy; and (4) expressivity. The latter consists of the (1) cooperative principle; (2) politeness principle; and (3) irony principle. Hence, in Leech's view, the cooperative principle and the politeness principle constitute the principles of interpersonal rhetoric. Concerning pragmatics, Watts (2003, p. 64) points out that "[i]f Leech were attempting to set up a model of pragmatic competence - which he is definitely not concerned to do - it would have to be augmented by the principles of textual rhetoric and related to the principles of pragmalinguistics and sociopragmatics".

Leech's model has made a great contribution to politeness theory, although the model itself and the claim for universality have been questioned. Although Leech's model has been tested by Gu (1990) in the Chinese context, further research is needed in order to examine its applicability to other cultures. Furthermore, the lack of an empirical description of politeness has also called Leech's approach into question (Brown and Levinson, 1978, 1987; Fraser, 1990; Eelen, 2001; Watts, 2003).

A different perspective is proposed by Fraser (1978) and Fraser and Nolen (1981), and later further developed by Fraser in 1990, who propose the Conversational Contract View, which is regarded as the 
most global perspective on politeness (Kasper, 2009b). Similarly to Brown and Levinson $(1978,1987)$, this view on politeness is also based on Grice's Cooperative Principle and values the importance of Goffman's (1967) notion of face, which is revised in Section 1.1.3.2. However, unlike other models, the conceptualisation of politeness in Fraser's model appears to be a discourse-based approach instead of a speech act-based approach.

In this model, it is assumed that when a speaker enters into a conversation he/she has an understanding of some initial rights and obligations, based on the social relationship, which will determine, at least in the beginning, the expectations of the participants. These rights and obligations might change over the course of the conversation, that is to say, they are not seen as a stable concept as it can change due to negotiation. In Kasper's (2009b, p. 161) words, "the terms of the conversational contract are determined by participants' rights and obligations; however these may change during and as a result of the interaction itself". The rights and obligations are somehow determined by the given situation or by the previous conversations as well as by an awareness of the situation (Fraser and Nolen, 1981). Drawing on such rights and obligations, speakers seem to be aware of how they should behave and what to expect during the conversations, e.g. they might know when to take turns, when and how much should be spoken, and when they should be silent. Furthermore, speakers should take into account different social variables, i.e. status, power, role of the participants, and the nature of the context, in order to know what they should say and how they should address the other speakers. This view of politeness seems to be rather dynamic because it locates politeness in the actual moment of talk and, therefore, the conversational contract view can be identified within a discursive approach to politeness (Geyer, 2008).

Summarising, different views on politeness can be found in the literature, although one of the most widely accepted politeness theories 
is that provided by Brown and Levinson $(1978,1987)$, which I review in the following section.

\subsubsection{Brown and Levinson's Politeness Theory}

Brown and Levinson's $(1978,1987)$ theory is nowadays still one the most influential theories within the field of politeness. Brown and Levinson (1987) provide a remarkable and comprehensive theory of politeness. This particular theory combines aspects of speech act theory, Grice's (1975) maxims and Goffman's (1967) notion of face. Brown and Levinson's $(1978,1987)$ present a theory of politeness in which the notion of face is central. The notion of face is first introduced by Goffman (1967, p. 5), who states that this particular term can be defined as "the positive social value a person effectively claims for himself by the line others assume he has taken during a particular contact", and, as reported by Hickey and Vázquez (1994, p.269), from the "English folk terms 'losing face' (i.e. being humiliated)" and 'saving face' (i.e. being saved from humiliation)". Since a central assumption within Brown and Levinson's $(1978,1987)$ theory relates to the work of Goffman, it is important to review the work of Goffman before going any deeper into their contribution.

The notion of face and facework appear to be rooted in a model of social interaction. The concept of social interaction that Goffman refers to involves peoples' behaviour in public places and social encounters. Goffman develops the notion of interpersonal rituals, defining a ritual as "a perfunctory, conventionalised act through which an individual portrays his respect and regard for some object of ultimate value or to its stand-in" (1971, p. 63). These rituals are related to the sacred property of individuals which he calls face. The author defines the notion of face as the "positive social value a person effectively claims for himself by the line others assume he has taken during a particular contact" (1967, p. 5). Face is therefore an individual possession, and 
individuals try to maintain their face and the interlocutor's face during a social interaction, which might change depending on the social interaction itself and the social expectations of a given culture. Goffman also suggests that "a person may be said to have, or be in, or maintain face when the line he effectively takes presents an image of him that is internally consistent" (1967, p. 6).

In addition to this, facework is needed to compensate for incidents that might occur over the flow of the interaction (Goffman, 1967). Specifically, Goffman defines facework as "the actions taken by a person to make whatever he is doing consistent with face" (1967, p. 12). For Goffman, facework consists of defensive, i.e. saving one's own face, and protective, i.e. saving others' face, practices that are performed simultaneously. As Goffman (1967, p. 14) argues, "[i]n trying to save the face of others, the person must choose a tactic that will not lead to a loss of his own; in trying to save his own face, he must consider the loss of face that his action may entail for others". Moreover, the author also points to other indications of social value that are associated to face, such as, avoidance rituals and corrective processes. The former involves a variety of manoeuvres that should avoid face threats, while the latter is operative when a face threat could not be avoided by the speakers and cannot be overlooked. Therefore, as indicated by Goffman (1967, p. 19), speakers "are likely to give it accredited status as an incident" and take some measure to rectify it since "one or more participants find themselves in an established state of ritual disequilibrium or disgrace, and an attempt must be made to re-establish a satisfactory ritual state for them".

In short, facework seems to be based on the social interaction in which (at least two) different interlocutors negotiate their interactions over the flow of the conversation. Then, the notion of face can be seen as a social entity that needs to be constructed in interaction.

The notion of face is also defined by Brown and Levinson (1987, p. 61), who state that face refers to "the public self-image that every 
member of society wants to claim for himself". For them, face involves two different but related aspects negative face and positive face. Their distinction between negative and positive face is based on Goffman's (1967) notion of avoidance rituals and presentational rituals. On the one hand, negative face refers to "the basic claim to territories, personal preserves, rights to non-distraction - i.e. to freedom of action and freedom from imposition" (Brown and Levinson, 1987, p. 61), thereby involving speakers' need to keep one's territory unimpeded so that independence and autonomy are emphasised. On the other hand, positive face is "the positive consistent self-image or 'personality' (crucially including the desire that this self-image be appreciated and approved of) claimed by interactants" (Brown and Levinson, 1987, p. 61), thus referring to the speakers' desire to be liked, valued, respected and appreciated by others. The authors further add that "face is something that is emotionally invested, and that can be lost, maintained, or enhanced, and must be constantly attended to in interaction" (Brown and Levinson, 1987, p. 61). Maintaining one's face depends on the cooperation of people, which is "based on the mutual vulnerability of face" (Brown and Levinson, 1987, p. 61).

It is assumed that the notion of face is universal and consequently people are concerned with their face, their self-image and what other people perceive, and they might also be aware that other people can also have face wants (Brown and Levinson, 1987). Brown and Levinson's $(1978,1987)$ politeness approach is based on speech act realisation, and they argue that some speech acts are categorised as FTAs, involving "those acts that by their nature run contrary to the face wants of the addressee and/or of the speaker" (Brown and Levinson, 1987, p. 65). Thus, taking into account the fact that humans are rational beings, they try to select the most appropriate act to reach their communicative move, avoiding FTAs, or using specific strategies to minimise the threat. Speakers may choose from a range of strategies in order to perform the FTAs, in which the speaker takes into account "the relative weightings 
of (at least) three wants: (a) the want to communicate the content of the FTA $x$, (b) the want to be efficient or urgent, and (c) the want to maintain H's face to any degree" (Brown and Levinson, 1987, p. 68). Figure 6 illustrates the possible strategies for doing FTAs.

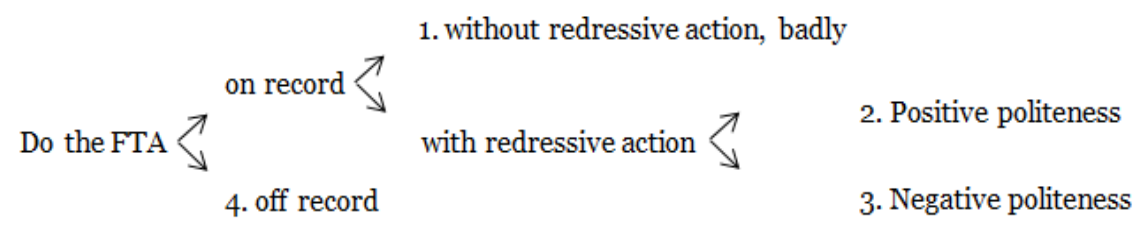

Don't do the FTA

Figure 6. Possible strategies for doing FTAs (Brown and Levinson, 1987, p. 69)

The five linguistic strategies are ordered according to the level of politeness involved. The risk of the loss of face might increase when one ascends the scale, which ranges from 1 to 5 . The strategy varies depending on the risk, i.e. the greater the risk; the more polite the strategy used. The speaker has to decide whether to elicit or not the FTA; if he/she decides to commit, then he/she may go on record, i.e. "in doing an act $\mathrm{A}$ if it is clear to participants what communicative intention led the actor to do A" (Brown and Levinson, 1987, p. 68-69) or off record, i.e. "in doing $\mathrm{A}$, then there is more than one unambiguously attributable intention so that the actor cannot be held to have committed himself to one particular intent" (Brown and Levinson, 1987, p. 69). If the speaker goes on record, he/she can perform the act with or without redressive action.

Redressive action involves the speaker attempting to mitigate the threat of the act, and it may take two different forms, negative and positive politeness. Positive politeness "is oriented toward the positive face of $\mathrm{H}$, the positive self-image that he claims for himself" (Brown and 
Levinson, 1987, p. 70), whereas negative politeness "is oriented mainly toward partially satisfying (redressing) H's [Hearer's] negative face, his basic want to maintain claims of territory and self-determination" (Brown and Levinson, 1987, p. 70). Moreover, Brown and Levinson (1987) also propose doing the act of bald on-record strategies, i.e. without face-redressing strategies, and doing the act off the record, i.e. inferencing is needed to understand the meaning.

In addition to this, when performing a speech act, the speaker is expected to assess the nature of the FTA depending on a set of factors (Brown and Levinson, 1987): (1) the social distance (D) between the speaker and the hearer, i.e. the degree of familiarity between the interlocutors; (2) the relative power (P) of the speaker as regards the hearer; and (3) the absolute ranking (R) or rank of imposition in the specific culture. The authors further argue that the seriousness of a given FTA is calculated as follows: $W_{x}=D(S, H)+P(H, S)+R_{x}$ (Brown and Levinson, 1987, p. 76). In this formula, $\mathrm{W}_{\mathrm{x}}$ represents the numerical value that measures the weightiness of an FTA; D $(\mathrm{S}, \mathrm{H})$ involves the value that measures the social distance between the speaker (S) and the hearer $(\mathrm{H}) ; \mathrm{P}(\mathrm{H}, \mathrm{S})$ refers to the measure of power that the hearer $(\mathrm{H})$ has over the speaker ( $S$ ); and finally, $\mathrm{R}_{\mathrm{x}}$ relates to the value that measures the degree to which a particular FTA $x$ is rated an imposition in a given culture. Thus, all these three dimensions, i.e. P, D and R, indicate the level of seriousness of a given FTA in a particular situation and, consequently, they involve the level of politeness of the FTA (Brown and Levinson, 1987).

Brown and Levinson's $(1978,1987)$ politeness theory is not without its critics. For example, Brown and Levinson's claim for universality has been called into question. The universality of the notion of face has been criticised because it assumes that the notion of self is valid across cultures (Kasper, 1994). In this regard, despite the fact that this particular politeness approach is widely accepted in the Western tradition, the Eastern perspective has challenged Brown and Levinson's 
politeness theory (see for example Okamoto (2010), or Mills and Kádár (2011)). Researchers working on non-Western cultures indicate that the face construct is applicable only to some Western cultures, but this is not so when dealing with other languages such as East Asian languages (e.g. Ide, 1989; Matsumoto, 1988; Gu, 1990; Mao, 1994; Fukada and Asato, 2004; Brown, 2011).

Further criticism is related to Brown and Levinson's nature of FTAs. Several researchers have argued that a sentence-level speech act might not be regarded as the basic unit of analysis (e.g. Coupland, Grainger and Coupland, 1988; Blum-Kulka, 1990). Coupland et al. (1988, p. 255) assert that "[a]ny empirical work on politeness needs to confront the sequential realisation of politeness phenomena in discourse". O'Driscoll (2007) also adds that Brown and Levinson's facework can only be explained in terms of single acts. Moreover, Johnson (1992) suggests that a whole production might become an FTA, that is, a global FTA, containing local and individual FTAs. In line with this, Calvo and Geluykens (1995) point out that, in conversation, FTAs should be examined in terms of the longer sequential organisation, thereby including turn-taking, and not just the sentence-level speech acts.

Another major concern focuses on the direct relationship between increasing indirectness and increasing politeness. Brown and Levinson's assumption seems to be incorrect, as some empirical studies show (Blum-Kulka, 1987; House-Edmondson, 1986). Similarly, it has also been suggested that it would not be consistent to conclude that negative politeness is used in situations in which the degree of face-threat is high, while positive politeness is used when the face-threat is perceived as low, regardless of whether positive or negative face is the one affected (Lim and Bowers, 1991; Turner, 1996). On the basis of Brown and Levinson's $(1978,1987)$ model of politeness, Rinnert and Kobayashi (1999) focus on the relationship between indirectness and politeness. Accordingly, when participants risk a loss of face while performing a 
particular speech act, they might opt for using an indirect strategy so as to be polite. Following Brown and Levinson $(1978,1987)$, when speakers employ a high level of indirectness in performing a given speech act, a higher degree of politeness is shown. In this regard, LoCastro (2003, p. 123) indicates that "the greater the face threat, the greater the need to use linguistic politeness, and the more indirectness is used". Hence, speakers' use of indirect speech acts might be somehow associated with speakers' attempts to be polite.

Different views of politeness might be found in the literature but for the sake of the present study, Brown and Levinson $(1978,1987)$ is considered one of the most influential politeness theories. In this study, as I report in Chapter 4 about the methodology of the study, their politeness approach, particularly concerning the social variables of social distance, power and severity of offence, is taken into account to design the role of the proposed spoken task.

Having reviewed the concept of politeness, as well as the nature of both the communicative competence model and pragmatic competence, in what follows, attention is paid the Speech Act Theory. Speech acts are introduced here since, as Barron (2003, p. 11) contends "[i]t was the dawn of speech act theory which triggered the development of the field of pragmatics". As a matter of fact, the study of speech act theory within the domain of pragmatics is necessary since language is performed by means of communicative acts, which might, of course, be enriched by multimodal elements.

\subsubsection{Speech acts: From philosophy to linguistics}

Speech Act Theory originated from the works of John Austin (19111960), who presented the main features of his theory in a series of lectures given in Oxford during the years 1952-1954 under the title of Words and Deeds, and later, in 1955, at Harvard University. The notes of his William James Lectures were published in 1962 under the title 
How to do Things with Words. Some years later, in 1969, the American philosopher John R. Searle, one of Austin's pupils, attempted to synthesise and formalise Austin's work and published his own version of the theory of speech acts in the work entitled Speech Acts - An Essay in the Philosophy of Language, as well as several works dealing with this particular issue. In the following section, I provide a review of the nature of the Speech Act Theory by pointing to the works of Austin and Searle, speech act classifications and, finally, I focus on the nature of speech acts in context.

\subsubsection{Speech Act Theory}

In his influential book, Austin (1962) suggested that in saying something that has a particular sense and reference, a speaker is also doing something other than just saying something. Austin held that in doing with words, a speaker might produce three different acts: (1) locutionary; (2) illocutionary; and (3) perlocutionary. The locutionary act refers to the act of saying something (phonemes, morphemes, sentences) and also referring to and talking about the world. The illocutionary act represents what is done in saying something, that is, the force or intention behind the words. The perlocutionary act refers to what is done by saying something, that is, the intended effect that the speaker's utterance has on the hearer. The perlocutionary act refers to what is done by saying something, that is, the effect that the speaker's utterance has on the hearer. Hence, as reported by Barron (2003), in producing an utterance, speakers are not exclusively saying something about the world, that is, the locution, but at the same time they perform an act, an illocution, by which speakers intend to have an effect on the hearers (i.e. perlocution).

Searle, Kiefer and Bierwish (1980, p. vii) point out that: "[t]he theory of speech acts starts with the assumption that the minimal unit of human communication is not a sentence or other expression, but 
rather the performance of certain kinds of acts, such as making statements, asking questions, giving orders, describing, explaining, apologising, thanking, congratulating, etc.”. The illocutionary act indicates how a given proposition should be interpreted, since one proposition may occur in different illocutionary acts. Barron (2003, p. 12), based on Searle et al. (1980, p. vii), illustrates this with the following examples, p. "Jane, go to bed", "Jane, will you go to bed?" and "Jane will go to bed". These three utterances might have the same proposition, but the illocutions are different since they represent the following, p. an order, then a question and finally a prediction.

Speakers use language so as to reach a given communicative purpose while producing communicative acts such as complaints, apologies and suggestions, among others. Austin (1962), in the analysis of ordinary language, identified some sentences and utterances as performative, which are used not only to say something but also to perform a particular action. For example, "I name this ship Queen Elizabeth" or "I promise that I'll come tomorrow" (examples taken from Sbisà, 2009, p. 230). Nevertheless, some circumstances need to be met in order for performatives to be realised appropriately, i.e. the so-called felicity conditions. Félix-Brasdefer (2008a, p. 37) reports that Searle (1969) proposed a set of felicity conditions including the following, p. (1) propositional content which concerns the reference and predication of an act of a certain type of condition (content condition); (2) conditions that must be attained prior to the performance of the act (preparatory conditions); (3) the speaker's true intention or belief in performing an illocutionary act (sincerity conditions); and (4) the conditions that indicate how an utterance is considered.

As I report in the following section, different classifications of speech acts can be found in the literature. 


\subsubsection{Classifying speech acts}

Austin (1962, p. 151) proposed a classification of utterances drawing on their illocutionary force, which included, p. (1) verdictives; (2) exercitives; (3) commissives; (4) behabitives; and (5) expositives. Verdictives refer to the fact of giving a verdict or judgement by a jury, arbitrator or umpire, e.g. assessing, reckoning and appraising. Exercitives involve the exercising of power, right or influence, e.g. appointing, ordering and warning. Commissives are illocutionary acts that entail committing the speaker to do something, but they also include declaration or announcement of intention, e.g. promising, agreeing and betting. Behabitives involve the adoption of an attitude, e.g. apologising, complimenting and thanking. Expositives are concerned with the speech acts that address the clarifying of reasons, arguments and expounding of views, e.g. denying, reporting and stating.

Searle (1976) identified some of the weaknesses of the taxonomy proposed by Austin (1962). Specifically, he reported that Austin's taxonomy involved six different difficulties. In Searle's words (1976, p. 9-10): "there is a persistent confusion between verbs and acts, not all the verbs are illocutionary verbs, there is too much overlap of the categories, too much heterogeneity within the categories, many of the verbs listed in the categories don't satisfy the definition given for the category and, most important, there is no consistent principle of classification". Then, considering these aspects, a different taxonomy was proposed by Searle (1976), which involves five categories: (1) representatives; (2) directives; (3) commissives; (4) expressives; and (5) declarations (Searle, 1976, p. 1-16). Representatives are linguistic acts in which the speaker commits himself/herself to the belief that the proportional content of the utterance is true. Directives refer to the acts in which the speaker's purpose is that of getting the hearer to do something. In line with this, Searle (1976) suggested that directives are attempts to make the world match the words. Commissives involve acts 
in which the speaker commits himself/herself to some future course of action. Expressives have the purpose of expressing the speaker's psychological state of mind about or attitude towards a certain prior action or state of affairs. Finally, declarations are acts that bring about a correspondence between the propositional content and the world, hence, they are institutionally-bound.

Searle's contribution, however, has also received some criticism. For example, Wunderlich (1980) argued that Seale's classification might not provide an accurate description of the speech acts. In this regard, the author suggested that, for example, commissives should be seen as reactions to directives instead of speech acts in themselves, and questions should be regarded as a speech act rather than as a type within the directives. Moreover, the author also criticised the fact that Searle's taxonomy did not account for some speech acts such as warnings, proposals, offers and advice. Considering these aspects, Wunderlich (1980) advanced a new taxonomy of speech acts that included: (1) the use of grammatical markers, including the interrogative mood, the declarative mood, the imperative type and specific performative formulas; (2) the type of propositional content and the illocutionary outcome; (3) their function, that is, whether the speech acts involve an initiating or a reacting move; and (4) their origin, whether they are natural or primary speech acts, or rather institutional or secondary speech acts. In this regard, Wunderlich (1980) suggested that speech acts might be defined according to the semantics of grammatical mood since some speech acts seem to be grammatically marked, as is the case of questions. In line with this, Yule (1996) argued that speech acts can be classified according to their structure. The author argued that there is a relationship between the three structural forms, i.e. declarative, interrogative and imperative, and the three communicative functions, i.e. statement, question, and command or request. The following example best illustrates his perspective (Yule, 1996, p. 56): "You wear a seat belt" (declarative); "Do you wear a seat 
belt?" (interrogative); and "Wear a seat belt!" (imperative). Following Yule (1996), this distribution involves a distinction between direct and indirect speech acts. The former refers to a declarative structure to a statement, whereas the latter relates to the use of the same declarative structure for example to perform a request.

In addition to this, speech acts can be further divided into direct and indirect speech acts. Austin and Searle acknowledged that most utterances are indirect bearing in mind that the illocutionary force of most utterances is not really shown in the form of the sentence. The distinction is based on whether there is a direct or indirect relationship between the structure and the function. In the area of pragmatics, the notion of indirectness is commonly associated to the syntax of a given sentence in the sense that the illocutionary force is related to the linguistic form of a particular utterance. Direct speech acts are acts in which "the speaker says what he means" while indirect speech acts refer to acts in which the speaker "means something more than what he says" (Searle et al. 1980, p. viii). Searle (1975) defined indirect speech acts as containing two acts, a non-literal, primary act, and a literal, secondary act. Therefore, indirect speech acts are those performed by a sentence that has a literal interpretation other than the illocutionary force that it conveys (Searle, 1975). Hence, "could you pass the salt?" would provide a primary act involving a request for you to do a particular action, and a secondary act involving a literal meaning which refers to the actual ability to do so. Indirect speech acts are widely employed and in some cases "little inferencing is required to establish the underlying intention" (Barron, 2003, p. 13).

In line with this, Nattinger and DeCarrico (1992) argued that indirect speech acts can be classified as non-conventional indirect speech acts, i.e. no correspondence between form and function, and conventional indirect speech acts, i.e. described in terms of the recurrent phases used to introduce them. The authors argued that this type of speech acts seems to contrast with the form that many indirect 
speech acts have, since most of Searle's examples are indirect requests and indirect offers, and the form they take is conventional. Nattinger and DeCarrico (1992) discussed examples of indirect speech act frames, such as "Can you...?" and indicated that they might involve formulaic chunks of language, which "exist somewhere between the traditional poles of lexicon and syntax, conventionalised form/function composites that occur more frequently and have more idiomatically determined meaning than language that is put together each time" (57). In line with this, research into routinised speech acts in corpus has revealed the widespread performance of formulaic language related to a particular speech act force (Adolphs, 2008).

Having provided a review of the classification of speech acts, in the following section I address the nature of speech acts in context.

\subsubsection{Speech acts in context}

Adolphs (2008) claims that interpreting a particular function of a given speech act expression may depend on the context in which it is performed, and therefore describing those contexts becomes "a vital part of its functional profile" (p. 31). Austin (1962) argues that the appropriate circumstances that involve the production of a communicative act involve the speaker, the hearer and the situation. Searle (1969) understands context in relation to the felicity conditions that are needed in order to perform a particular speech act. Therefore, Austin (1962) understands the notion of speech act context "as a cluster of states of affairs or events of various kinds" (Sbisà, 2002, p. 422), while Searle's (1969) position is based on a set of "propositional attitudes of the participants" (Sbisà, 2002, p. 422), specifically, the "beliefs or intentions of the participants" (Sbisà, 2002, p. 422). Thus, for Austin (1962), the context is seen as a set of conditions or events, whereas for Searle (1969) it involves speakers' beliefs or intentions. Concerning context, Lavandera (1988), drawing on Brown and 
Levinson's $(1978,1987)$ linguistic politeness, argues that the threat of a particular speech act and the redressive power of a strategy are determined by the context. Furthermore, Goffman (1967) adds that the notion of context for the negotiation of face is determined by the "rules of the group and the definition of the situation" (p. 6).

Searle (1969, p. 70) proposes the example of a wife reporting to her husband at a party "It's really quite late". According to Searle (1969) this utterance can be seen as "a statement of fact; to her interlocutor who has just remarked on how early it was, it may be (and be intended as) an objection; to her husband it may be (and be intended as) a suggestion or request" (70) made by the wife to leave the party. Thus, interpreting this particular speech act of Searle (1969) may depend "on its place in the ongoing discourse, as well as on situational factors, and speaker relationships" (Adolphs, 2008, p. 31). In line with this, Adolphs (2008) suggests that corpus data would allow an analysis of the different functions that this particular utterance could have by considering the preceding and the subsequent discourse, and taking into account the context of the situation. This particular approach, however, would involve an analysis that examines the overall discourse, which does not focus only on the utterance (Adolphs, 2008).

Sbisà (2002, p. 424-427) proposes three criteria that could be applied for the analysis of speech acts in context, p. (1) Given vs. constructed context; (2) Limited vs. unlimited context; and (3) Objective vs. cognitive context. Regarding "given vs. constructed context", the author contends the context of a speech act is constructed and renegotiated during social interaction, rather than being determined prior to the performance of the speech act itself (Searle, 1969). Sbisà (2002) further adds that participants determine the construction of the context during the realisation of speech acts over the course of interaction. With reference to "limited vs. unlimited context", the author argues that the context of a speech act is limited to a specific situation and it is evaluated by the participants of a given 
communicative event. Finally, in the case of "objective vs. cognitive context", the author suggests that the context of a speech act is objective if it is determined by various external social or material circumstances. More precisely, Sbisà (2002, p. 427-428) states that "[a] context has an objective nature in the sense relevant here if it is conceived as determined, not by the content of the participants' intentional states, but by relevant states of affairs occurring in the world, of which participants might not even be aware". Thus, the context of a speech act is dynamic and can change as the interaction proceeds. It also involves the speaker's intention, the hearer's evaluation of the communicative situation as well as the circumstances affecting the communicative situation. In line with this, Félix-Brasdefer (2008a) notes that context should be viewed "as a dynamic social entity which is constantly changing according to the speakers' intentions and the interactional needs of the situation" (p. 42). The author also highlights that the context should involve: details of the social distance and power between the participants, the sociocultural circumstances involved during the performance of the speech acts, the gender, the level of education and the social class, as well as the age of the participants.

It is also important to note that speech acts can be also viewed from a multimodal perspective. Specifically, when communicating, speakers might employ, if desired, all the different resources they have at their disposal to convey their communicative act. Then, when speakers perform a particular speech act, they could provide further information by other means that are not essentially verbal. Therefore, I consider further aspects such as the fact that the different modes employed to convey a particular communicative act should be taken into account, if possible, when examining speech act performance.

In addition to this, it is important to refer to Hymes's (1972b) distinction between speech situation, speech events and speech acts. Speech situation involves activities in a particular community that are socially recognised for their status, such as parties or ceremonies. 
Speech events take place within speech situations, for example, "the exchange of vows is a speech event occurring within a wedding" (Johnstone and Marcellino, 2011, p. 61). Adolphs (2008) and O'Keeffe, Clancy and Adolphs (2011) indicate that, for example, the speech event of a lecture would involve a specific structural organisation and distribution of speaker roles. Speech acts take place with speech events and speech situations, and involve social norms in the linguistic form (Hymes, 1972b). Then, a speech act is regarded as the minimal unit of speech from an anthropological perspective and it might be expressed by means of greetings, compliments, apologies, requests, or complaints, among many others. The interpretation of speech acts depends on the social status and the relationship of the participants, as well as on the context of the utterances. Concerning this, Hymes (1972b, p. 57) posits that " $[t]$ he level of speech acts mediates immediately between the usual levels of grammar and the rest of a speech event or speech situation in that it implicates both linguistic form and social norms". In line with this, Adolphs (2008) argues that the interpretation of speech acts involves the analysis of the sequential organisation in discourse and the analysis of the speakers' role in the context in a particular time.

As reviewed, speech acts are part of the communicative event and various classifications have been proposed to account for them (Austin, 1962), and indirect speech acts have also acknowledged. Furthermore, the notion of speech act in context has also been reviewed by pointing to the importance of the context in which speech acts are performed. The present study addresses the speech act of complaint, which is reviewed in Chapter 2.

Having reviewed the nature of the communicative competence model and pragmatic competence, as well as specific pragmatic related features such as politeness and speech acts, in what follows I focus on the field of ILP. 


\subsection{Interlanguage pragmatics}

Kasper and Blum-Kulka (1993), in their introduction to their edited work, Interlanguage Pragmatics, provide a definition of the notion of ILP. The authors indicate that ILP belongs to two different disciplines. Particularly, within the SLA arena, ILP relates to the field of interlanguage studies, for example, interlanguage grammar or interlanguage phonology; and as part of pragmatics, ILP refers to the study of non-native speakers' (NNSs) use and acquisition of the target patterns in a given language. In this section, I focus on the notion of ILP by briefly reviewing its focus of study. Following this, I present some of the research instruments that can be used in the specific area of ILP, by centring attention on the research instruments chosen for the current study. Finally, a reflection is provided on the understanding of ILP from a multimodal perspective.

\subsubsection{The field of interlanguage pragmatics}

The term interlanguage, as it is used in the arena of SLA, was coined by Selinker in 1972. Larsen-Freeman and Long (1991, p. 60) state that interlanguage might be seen as "a continuum between $\mathrm{L} 1$ and L2 along which all learners traverse. At any point along the continuum, the learners' language is systematic, i.e. rule-governed, and common to all learners". Therefore, as Barron (2003) posits, a learner's interlanguage might share features of the L1 and L2. In line with this, Littlewood (1984) argues that the term interlanguage "draws attention to the fact that the learner's language system is neither that of the mother tongue, nor that of the second language, but contains elements from both" (p. 33). Drawing on Ellis (1985), Trosborg (1995) adds that the basic assumptions underlying the concept of ILP involve learners' language being permeable, dynamic and systematic. The first feature 
suggests that the rules that constitute a learner's knowledge at any particular stage are not fixed, but, instead, open to amendment. The second feature relates to the fact that the continual revision of the internal system of rules and adoption of new hypotheses about the TL system mean that a learner's interlanguage is in constant change. The last feature implies that a learner's selection from his/her interlanguage rules is carried out in a systematic and predictable manner based on the existing rule system.

The study of pragmatics within the domain of SL/FL studies is usually referred to as ILP, following the analogy with, for example, interlanguage grammar or phonology (Kasper and Blum-Kulka, 1993). As already mentioned, the development of pragmatic competence involves the acquisition of pragmatic aspects, such as speech acts, among other aspects. Various definitions of the term ILP can be found in the literature. For example, Kasper and Dahl (1991, p. 215) defined it as "the investigation of non-native speakers' comprehension and production of speech acts, and the acquisition of L2-related speech act knowledge". Kasper (1998, p. 184) defines ILP as "the study of nonnative speakers' comprehension, production, and acquisition of linguistic action in L2, or, put briefly, ILP investigates how to do things with words in a second language”. And finally, Kasper and Rose (1999, p. 81) also indicate that ILP is "the study of non-native speakers' use and acquisition of L2 pragmatic knowledge". As reported by Barron (2003), these definitions appear to emphasise that ILP focuses on language in use, that is, language as action. The author further adds that the term ILP might suggest that research should focus on "learners' use and acquisition of pragmatic knowledge" (2003, p. 27). Thus, the field of ILP attempts to explore how NNSs acquire and use pragmatic knowledge. Then, the direction of research in this particular case should be that of examining how learners actually use and acquire pragmatic knowledge. For a recent review of the nature of ILP, refer to the volume edited by Han and Tarone (2014). 
Despite the fact that the area of ILP is a relatively young discipline that emerged in the 1970s based on pragmatic theories and SL pedagogy (Schauer, 2009), there is a growing body of literature devoted to exploring this specific phenomenon. In line with this, Taguchi (2010) suggests that ILP research has mainly explored pragmatic use rather than pragmatic development. Moreover, Bardovi-Harlig (1999) indicates that acquisitional ILP research involves two approaches, the study of the changes in the FL/SL pragmatics system and their influences on the systems. These types of studies have been carried out following three different methodological approaches: cross-sectional, longitudinal and instructional. Cross-sectional studies, been the most common, are carried out from two or more cross-sections of a sample, based on, for example, differences in level of language proficiency. Longitudinal studies, which involve observing the same participants over an extended period of time, have not been widely conducted and therefore this area of ILP research remains largely unexplored (e.g. Bardovi-Harling, 1999, 2000; Kasper and Rose, 1999, 2002; Taguchi, 2010). Longitudinal research involves the observation of the same participants over a period of time. Finally, instructional studies in ILP refer to interventional studies that tend to explore how teaching affects the acquisition of pragmatic aspects (e.g. Rose and Kasper, 2001; Rose and Ng Kwai-Fun, 2001; Takahashi, 2001; Alcón, 2005; Koike and Pearson, 2005; Rose, 2005; Martínez-Flor, 2012; Ifantidou, 2013; Eslami, Mirzaei and Dini, 2015).

In addition to this, it is also important to note that researchers usually differentiate between SL and FL, and the difference seems to be reasonable and logical. SL is seen as a language that plays an institutional and social role in a specific community, while FL refers to a language that is not part of the community itself but it is learnt in the educational context (Ellis, 1985). This is the case, for example, of the context in which this study was conducted, Spain, where English is not regarded as a SL but as an FL. Literature also discusses the notion of 
English as a lingua franca. Specifically, Thomason (2001, p. 269) defines lingua franca as a "language of wider communication - that is, a language that is used for communication between groups who do not speak each other's language, as well as between native speakers (if any) of the lingua franca and other groups". Hence, a lingua franca is seen as a common language of communication among speakers who do not share the same L1. Furthermore, regarding the term additional language, Bhatia (2009, p. 50) indicates that "[a]n additional language may be a language of the country or spoken outside the country (i.e. foreign language)". For the purpose of this study, I take the distinction between SL and FL, FL referring to a context in which English, in this particular case, is not the language of the community but a language that is studied either in formal or informal contexts.

Concerning ILP development, which is the inquiry of this investigation, research has shown the SL context to be superior to the FL context in the sense that language learners might have more opportunities to be exposed to authentic input and to use the language for communicative purposes in real interactions (Kasper, 2001). Bardovi-Harlig and Dörnyei (1998) also support the idea of the lack of pragmatic learning opportunities in the FL context. These authors further add that this could be related to the great emphasis that is given to grammar. Niezgoda and Roever (2001), however, contend that the context might not be the only factor affecting learners' pragmatic awareness development, pointing out that individual factors might also play an important role. It is true, however, that the context in which the TL is learnt can affect learners' opportunities for developing pragmatic competence, but I also support the idea that learners' individual differences and informal learning opportunities might influence their pragmatic development. Broadly speaking, the context in which the TL is learnt also affects learners' opportunities for input and output, and feedback, since in SL contexts learners can be exposed to the TL in informal settings, whereas in FL contexts, learners are normally limited 
to classroom opportunities for input, output and feedback. However, it is also true that FL contexts might present informal learning opportunities, although these might be more limited and the quality of these opportunities may be questionable. Nevertheless, this does not mean that these learning opportunities of the SL context might not be questioned, since it would depend on the quantity and quality of the input received and the opportunities for output. Thus, perhaps it is not only the context which affects language learning, but also other variables, such as motivation. Furthermore, it would be important to carefully examine each FL teaching context in particular, as there might be other aspects influencing learners' ILP development such as teaching practices, the status of the FL, language attitudes, as well as a variety of individual differences.

Another aspect that should be reviewed when dealing with the field of ILP refers to the research methods used to gather data. This issue, as it is relevant to this study, is explored in the next section. More specifically, I provide a review of the different data collection instruments that are typically employed in the field of ILP, paying special attention to role-plays and verbal reports as they are used in the current study.

\subsubsection{Spoken data collection in interlanguage pragmatics}

In conducting ILP research, researchers have at their disposal various research methods or techniques to choose from in order to gather data. A detailed description of the research instruments used in this study is presented in Chapter 4 Section 4.4.3.

In production studies, data collection methods might be distinguished according to how the data is collected, that is, naturally occurring or purposefully elicited for a specific investigation. In this regard, ILP spoken data might be collected by means of (1) naturally occurring data, (2) elicited conversation, (3) role-enactment and (4) 
role-plays. On the other hand, Kasper and Roever (2005) classify the different research methods into the following categories: (1) observational data of spoken interaction involving authentic discourse; elicited conversation and role-plays; (2) questionnaires including written discourse completion tasks/tests (DCTs) and multiple choice questionnaires; (3) rating scales; (4) oral and narrative forms of selfreport; (5) diaries; and (6) verbal protocols. Among all these different research methods, role-plays and DCTs seem to be the most widely employed in the field of ILP (Félix-Brasdefer, 2010; Roever, 2011). Verbal reports, although less frequently used, are also employed in the field of ILP, usually in combination with role-plays and DCTs.

Because in the present study role-play and verbal reports are used to gather speech act data, this review is limited to these two instruments. For further information about the nature of the research instruments, see Kasper and Roever (2005).

\subsubsection{Role-plays}

The role-play methodology may be defined as "a social or human activity in which participants 'take on' and 'act out' specified 'roles', often within a predefined social framework or situational blueprint (a 'scenario')" (Crookall and Saunders, 1989, p. 15-16). Specifically, participants are encouraged to take part in specific scenarios, perform them and say what they would say in such situations and circumstances (Crookall and Saunders 1989; Roever, 2010). Typically, role-plays contain contextual information about both the context in which the simulated situation might occur and the participants involved in the conversation. Role-plays represent simulations of communicative events purposefully designed to make participants elicit specific speech act data when performing various roles (Kasper, 2000). Two main types of role-plays can be distinguished according to the level of interaction, namely closed or monologic and open or interactive (Kasper and Dahl, 
1991; Kasper and Roever, 2005). In closed role-plays, participants are expected to provide an answer to a particular situation without having the response of another interlocutor. In this type of role-play, however, since participants only have a turn to respond, interaction is reduced and dissimilar to authentic discourse (Gass and Houck, 1999). Contrarily, in open role-play, also known as discourse role-play tasks, participants are presented with some background information about the different roles and the context of the situations, and they are provided with further opportunities for interacting. Unlike closed role-plays, open role-plays can involve as many turns and discourse phases as interlocutors need to reach the communicative goals. This fact may, in turn, benefit researchers as further information about the simulated discourse can be obtained (Márquez-Reiter, 2000). In line with this, Kasper and Dahl (1991, p. 228) point out that open role-plays "represent oral production, full operation of the turn-taking mechanism, impromptu planning decisions contingent on interlocutor input, and hence, negotiation of global and local goals, including negotiation of meaning, when required".

Researchers have valued the use of role-plays positively, since they allow them to control specific contextual variables (e.g. Kasper, 2000; Félix-Brasdefer, 2010). In designing role-play tasks, it is necessary to account for contextual variables involving, p. power, social distance, and rank of imposition or severity of offence (Brown and Levinson, 1987, 1987), which could have an effect on the performance (Kasper and Dahl, 1991; Kasper, 2000; Roever, 2011). The different contextual variables can be combined so that various roles can be elaborated. The combinations of the different variables could be done by assigning levels of power (i.e. high, equal and low), social distance (i.e. high, equal and low) and rank of imposition or severity of offence (i.e. high and low) (Roever, 2011). Therefore, it is important to arrange different roles so that researchers can observe how sociopragmatic features can have an influence on the pragmalinguistic realisations uttered in the interaction. 
Hence, researchers should elaborate the different scenarios carefully, select the different variables, and, of course, provide appropriate contextual information so that participants can accurately understand what they are expected to perform.

An important drawback may be related to participants' familiarity with the scenarios. For example, as argued by Golato (2003), in some cases, participants might not be necessarily familiar with the simulated situations because they have never performed similar spoken interactions in real-life conversations. Thus, in order to avoid that problem, researchers should elaborate situations and assign roles that participants can be familiar with (Trosborg, 1995). Other aspects to take into account when designing role-play tasks are the representativeness of the contexts (Hudson, Detmer and Brown, 1995), since participants should be presented with situations that show known contexts, and whether the situations designed are socio-culturally appropriate for the target group (Beltrán-Palanques, 2013).

For the purpose of this study, the production task chosen is that of role-play, and more specifically an open role-play. Yet, for the sake of simplicity the term role-play is used throughout the study. This technique has been selected for several reasons. To start with, in an FL context it is difficult to carry out an investigation relying on naturally occurring data due to the lack of participants. Moreover, I am interested in examining how language learners perform a specific pragmatic aspect, i.e. the speech act of complaint, in the spoken mode, and consequently the most suitable research instrument is that of role-play. Furthermore, role-plays provide researchers with data as regards spoken discourse features, including the structure of talk exchanges, turn-taking features, sequences of conversational contributions, the coordination between speaker and listener, and participants' achievement of transactional and interpersonal skills, production of communicative action, as well as the comprehension or miscomprehension of interlocutors' contributions (Kasper, 2000). In 
addition to this, data gathered by means of role-plays might also reveal evidence of participants' active listening, backchannel signals, and nonverbal language over the course of the interaction. Nevertheless, it is important to note that although role-plays provide simulated data that is elicited under specific circumstances, and therefore the data might vary from that gathered in natural contexts (Kasper, 2000; Golato, 2003), the data collected might, to some extent, provide features of spoken data that resemble authentic spoken discourse (Kasper and Dahl, 1991; Kasper, 2000; Roever and Kasper, 2005; Félix-Brasdefer, 2007, 2010; Roever, 2011). Furthermore, role-play tasks can be replicated (Kasper and Dahl, 1991), thereby allowing the collection of data from several participants. Not to mention that role-plays, when video recorded, can also serve to examine not only verbal production but also non-verbal behaviour, as in the present study. The task designed for the purpose of present study (see Chapter 4, Section 4.4.3.2), follows the above recommendations as regards the degree of familiarity of the situation (Trosborg, 1995), whether it provides participants with a known context (Hudson et al., 1995), as well as whether the situation presented is socio-culturally appropriate for the group (Beltrán-Palanques, 2013).

\subsubsection{Verbal reports}

Verbal reports have been widely used in the field of psychology since the early $20^{\text {th }}$ century. They are defined as a type of instrument that allows researchers to access participants' thoughts or psychological processes when completing a given task (Ericsson and Simon, 1984, 1993; Ericsson and Kintsch, 1995; Cohen, 1996, Kasper, 2000; Kasper and Roever, 2005; Mackey and Gass, 2005). Mackey and Gass state that (2005, p. 77) "verbal reporting is a special type of introspection and consists of gathering protocols, or reports, by asking individuals to say what is going through their minds as they are solving a problem or 
completing a task". However, as I review in this section, variations might be identified, since not all the verbal reporting may be necessarily conducted while completing a task, as data can also be gathered retrospectively.

This particular research method is based on the Processing Model, which reflects that human cognition as information processing has a limited capacity. Specifically, human cognition as information processing is stored in a set of memories, namely short-term, or primary, memory (STM) and long-term, or secondary, memory (LTM) (Eriscsson and Simon, 1993; Ericsson and Kintsch, 1995). As reported by Chiras (2012), in STM, new information can be held for a short period of time and this specific information is not necessarily transferred to LTM, and then it is not always retained and even falls into oblivion. Conversely, LTM retains information for a long period of time and its storage capacity is larger than that of STM. Ericsson and Simon (1993) see STM as a central process that regulates the cognitive processes, while LTM is conceived as a large collection of interrelated information that is stored for a long period of time. As pointed out by Ericsson and Simon (1993, p. 11) "it is assumed that information recently acquired (attended or heeded) by the central processor is kept in STM, and is directly accessible for further processing (e.g. for producing verbal reports), whereas information from LTM must be first transferred (transferred to STM) before it can be reported". Hence, participants' thoughts can be seen as a sequence of states of heeded information, part of which is stored in LTM, and it can be retrievable once the thought processes are completed after the task.

Verbal reports can be conducted concurrently (i.e. while doing a task) or retrospectively (i.e. after completing a task), and therefore two types of verbal reports can be distinguished, according to how they are generated, p. (1) concurrent verbal reports, and (2) retrospective verbal reports. The use of this type of research method has been evaluated in the field of language teaching and learning (see Bowles, 2010), as well 
as in the field of ILP (see Felix-Brasdefer (2010), Beltrán-Palanques (2014)), which is the area examined in this investigation. As a matter of fact, there has been an increasing interest in the use of both concurrent and retrospective verbal reports in the domain of ILP in order to assess learners' thoughts so as to explore pragmatic knowledge (e.g. Robinson, 1992; Cohen and Olshtain, 1993; Widjaja, 1997; Félix-Brasdefer, 2008a, 2008b; Hassall, 2008; Woodfield, 2008, 2010, 2012; BeltránPalanques, 2013, 2016a, 2016b; Beltrán-Palanques and Martínez-Flor, 2015). In line with this, Cohen (2004, p. 321) points out that by means of verbal protocols "one may learn what the responders actually perceived about each situation (e.g. what they perceived about the relative role status of the interlocutors) and how their perceptions influenced their responses". However, this research method might present some limitations. According to Kasper and Roever (2005, p. 329 ), the major disadvantage of concurrent verbal reports is that they "may produce reactivity, that is, they may interfere with doing the tasks". In the case of retrospective verbal reports, it has been suggested that it may be difficult for participants to reveal their experiences accurately due to memory limitation (Kasper, 2000; Kasper and Roever, 2005; Adolphs, 2008). As pointed out by Adolphs (2008, p. 4), "participants might not themselves be able to recollect their own interpretations at a later stage”. Furthermore, Bednarek (2011, p. 542) also argues that it is not easy to determine whether verbal reports can "be a 'reflection' of actual behaviour, cognitive processes and knowledge structures". Although some limitations can be identified, verbal reports offer researchers opportunities to obtain specific information that cannot be obtained by other means.

As aforementioned, verbal reports have also been used in the ILP field to gather further information as regards participants' production, for example to explore their pragmatic knowledge and issues related to the validity of the research instruments (e.g. role-play tasks and DCTs). Studies combining verbal reports with other research methods indicate 
that they can be instrumental in revealing information about different issues that may not otherwise be observed by other means, such as participants' pragmatic knowledge, perception of speech acts, sociocultural knowledge, politeness issues, attended aspects and language of thought.

In what follows, a review of the use of retrospective verbal reports in combination with role-play tasks is provided.

\subsubsection{The contribution of verbal reports to role-play analysis}

A pioneering study that combined retrospective verbal reports with role-play was that carried out by Cohen and Olshtain (1993). The authors attempted to investigate how 15 advanced learners of English plan and execute speech acts. Six video role-play tasks eliciting apologies, complaints and requests were employed. The situations were videotaped and after each set of two situations of the same type, the tape was played back and participants were asked about the factors that contribute to the production of their responses. The retrospective verbal reports revealed that participants engaged in very little conscious planning of vocabulary and grammatical structure for their utterance, that two or even three languages were used when planning and executing the utterances, that sometimes different languages were employed when planning and executing the speech acts, and that not much attention was paid to grammar and pronunciation in planning and executing utterances.

Using videotaped role-play tasks and retrospective verbal reports was carried out by Widjaja (1997), who investigated 10 female Taiwanese learners of English as a SL and 10 female American university students refusing dates. The author examined the pragmalinguistic choice and realisation of refusals and the factors affecting participants' responses. In this case, participants were instructed to use either English or their L1 (i.e. Mandarin) during the 
retrospective verbal reports. Results showed that participants' L1 pragmatic knowledge affected the responses provided and that participants did not have sufficient sociopragmatic knowledge as regards the level of directness in the L2. The retrospective verbal reports also indicated that participants' perception of social distance with the male interlocutors seemed to be influenced by their sociocultural considerations.

The speech act of refusals was also examined by Félix-Brasdefer (2008a, 2008b). Particularly, Félix-Brasdefer (2008a) examined the similarities and differences in the performance of discourse functions and the perceptions of refusals. Forty male participants took part in this study, 20 NSs of Mexican Spanish living in Mexico and 20 NSs of American English living in the United States. Retrospective verbal reports were administered immediately after completion of the role-play tasks and recordings were played back to the participants during the retrospective verbal reports. By means of retrospective verbal reports, the author examined participants' attended aspects and sociocultural knowledge. Participants were asked about their perception of directness or indirectness and their perception of the addressee's insistence in the act of refusing an invitation. Data revealed insights into participants' meta-pragmatic politeness concerning social perception of refusals. Results seemed to suggest that the notion of directness and indirectness could provide various cultural values. Moreover, the notions of insistence indicated that each group expressed relational work with different expectations. More specifically, Mexicans perceived insistence as a cultural expectation and socially appropriate behaviour, whereas for the North American group it was something unexpected and regarded as an imposition and violation of face.

In a similar vein, role-play tasks, eliciting refusals, in combination with retrospective verbal reports were also employed in the study conducted by Félix-Brasdefer (2008b). This study explored the cognitive processes and perceptions of 20 advanced learners of Spanish 
refusing invitations involving roles of equal and unequal status. Specifically, the participants took part in two refusal interactions with two NSs of Spanish. As in Brasdefer (2008a), retrospective verbal reports were conducted immediately after completion of the role-plays and recordings were played back for each participant during the retrospective verbal reports. Findings revealed that retrospective verbal reports were instrumental in accessing information about cognition; that is, attended aspects while planning and executing the speech act of refusal and attention to politeness, discourse, grammar and vocabulary; the selection of the language of thought (i.e. English and Spanish); and participants' perception of insistence after declining an invitation.

A similar study was conducted by Hassall (2008), who examined participants' pragmatic knowledge as regards requests and complaints elicited by means of role-play tasks in a group of undergraduate learners of Indonesian at two different proficiency levels, i.e. low intermediate and upper-intermediate. Retrospective verbal reports revealed thoughts concerning the planning and the execution of the speech acts including verbal planning, pragmalinguistic and sociopragmatic knowledge, and conversational management and emotion/affect, and participants' sociopragmatic knowledge. Low intermediate participants revealed thinking about pragmatics less often than they reported thinking about the linguistic planning of the speech act realisation. The upperintermediate group appeared to think about pragmatics more often than thinking about the linguistic planning of the speech act. The author indicated that low intermediate participants seemed to have acquired some pragmatic knowledge by means of formal instruction, while the upper-intermediate group appeared to show "subtle knowledge of sociopragmatics that the Low learners did not possess" (Hassall, 2008, p. 90), which indicated that learning those sociopragmatic norms appears to be easier when immersed in the target community.

The value of retrospective verbal reports in combination with roleplay tasks has been also acknowledged by Woodfield (2012). Her study 
investigated the role of retrospective verbal reports as a research methodology to examine learners' perceptions and cognitions on speech act performance in role-play tasks. Role-play data was collected at three different points at a university in the UK during a period of 8 month and retrospective verbal reports were only employed in the final phase. Findings from retrospective verbal reports revealed that participants focused mainly on grammar, vocabulary, sociopragmatics and politeness. In some participants' retrospective verbal reports, reasons for pragmalinguistic choice and the influence of formal learning experience on pragmatic choices were also evidenced. Furthermore, 2 of the 8 participants reported on the development of pragmatic knowledge during their stay abroad period in the UK. Finally, the retrospective verbal reports were also instrumental in revealing that participants, at times, seemed to have difficulties to select the appropriate forms to convey their pragmatic intent (Cohen and Olshtain, 1993; Hassall, 2008).

Finally, Beltrán-Palanques and Martínez-Flor (2015) conducted a study involving 26 students in a role-play task in which participants were asked to perform apologies in a given set of situations. Participants' proficiency level was classified as B1 according to the CEFR (2001) and all the participants were bilingual (i.e. Catalan and Spanish). Results from this study showed that participants' language of thought was influenced by the variable of bilingualism as they had a tendency to combine Catalan, Spanish and English. Regarding the attended aspects, results from the retrospective verbal reports revealed that participants seemed to focus on the process of explanation, concern for the hearer, but also on grammar and vocabulary. Participants' attended aspects were also related with the sociopragmatic features involved in the situations, more specifically, the severity of offence, which also affected participants' speech act performance. The retrospective verbal reports were conducted in learners' $L 1$. 
In the current study, retrospective verbal reports are used in combination with an open role-play task. The rationale behind the selection of the verbal reports, and in particular retrospective verbal reports, is based on the fact that this technique can be instrumental in obtaining specific information concerning participants' performance in the role-play task.

ILP data, however, might involve more than 'words', and more specifically when it comes to spoken data. Hence, one might argue for a multimodal approach for the analysis of ILP data since it might reveal further feature of authentic communication. Nevertheless, it is important to note the approach taken to analyse data and the choice as regards the instrument depends on the purpose of the study. Bearing in mind this idea, in the following I attempt to provide a vision of ILP from a multimodal perspective. I would suggest that if one's goal is to examine ILP data taking into account not only what is uttered verbally, it is necessary to look at all the different modes that interplay with the verbal component.

As reported, ILP focuses on NNSs' comprehension, production and acquisition of pragmatic knowledge in the TL (Kasper and Dahl, 1991; Kasper, 1998; Kasper and Rose, 1999; Barron, 2003) as well as on learners' use of pragmatic knowledge (Barron, 2003). This definition could be enriched by adding the multimodal component. In so doing, ILP would involve not only the pragmatic knowledge of the TL as regards verbal components, but also all the components of the pragmatic knowledge that are not purely verbal. In this sense, and in line with the idea of pragmatic competence, ILP could be extended to comprehend, produce, acquire and use the pragmatic knowledge in the TL considering not only the verbal, but also the non-verbal elements that construct meaning. Hence, I might argue for the multimodal approach for examining ILP.

This vision, however, does not involve a change in the approach taken to conduct research in the arena of ILP, but simply expands the 
researchers' vision to see which other elements interplay with verbal pragmatic production. In fact, the same research instruments employed to gather speech act data, either in the written or the spoken mode, might be employed to examine multimodal elements. In the present study, for example, a role-play task is used to collect data but instead of capturing data only verbally by means of voice-recording, audio-visual data is gathered. In so doing, the research obtains further information as regards participants' interaction that might not be gathered by traditional audio recorders. In the case of written production, DCTs embedded in digital platforms that, for example, allow computermediated communication might provide participants with opportunities to add further semiotic resources such as emoticons or various fonts. Thereby, revealing not only ILP data but also multimodal data.

After reviewing the nature of the field of ILP research, the various research instruments that are used in order to collect data, particularly role-plays and verbal reports, and noting the multimodal perspective that could be adopted to obtain further information as regards participants' performance, another important aspect to be discussed in this chapter is the so-called CA, which, as shown in the following section, can be employed to examine, among several aspects, pragmatic data (e.g. speech acts).

\subsection{Conversation analysis}

$\mathrm{CA}$ is an approach to language that emerged in the mid-to-late 1960s in California as a subfield of the discipline of sociology. Emanuel Schegloff develops a different approach to exploring sociological analysis which was based on observations on people in interaction. Harold Garfinkel developed a research policy known as ethnomethodology, which was one of the main influences for the CA paradigm. Garkinkel $(1967,2002)$ examines social order from an empirical perspective, demonstrating that social order is created among 
participants. That is, his work reveals that social action is achieved by means of participants' use of tactics, practical reasons, skills and competences (Wooffitt, 2005). In this section I address the discipline of CA from its origins and its contribution for the analysis of data. Finally, I focus on how the CA approach might contribute to the analysis of speech acts.

\subsubsection{The discipline}

CA has expanded over the years out of the field of sociology and it has been integrated within other disciplines such as communication, psychology, anthropology and applied linguistics. During the early stages of CA the focus was on describing the organisation of ordinary, mundane conversation, as well as the organisational structure by considering the turn-taking systems of the sequences and repairs (Schegloff, 1968; Jefferson, 1974, 1978; Sacks et al., 1974; Schegloff, Jefferson and Sacks, 1977). Sacks and Schegloff moved on to the analysis of non-institutionally-oriented data. In the late 1970 s there was an interest in gathering institutionally-oriented data, for example, meetings and interviews (Heritage, 1984, 1997). Concerning this, Heritage (1997, p. 223) indicates that there are two different types of approach to conversation analysis: "[ $t$ ]he first examines the institution of interaction as an entity in its own right; the second studies the management of social institutions in interaction".

As technology advanced, new means of capturing data, i.e. video recording, became available to researchers. Yet, although it did not become as popular as audio recording (ten Have, 2007), some CA researchers have used video recording to explore data from a multimodal perspective, focusing for example on visual aspects of interaction (e.g. Goodwin, 1981, 1996, 2000a, 200ob; Heath, 1986, 1989; Heath and Luff, 1996, 2000; Heath, Hindmarsh and Luff, 2010). Also, in the area of English for Academic Purposes, several researchers 
have used video data to study non-linguistic features and linguistic features in conference presentations and lectures (e.g. Querol-Julián, 2011; Querol-Julián and Fortanet-Gómez, 2012; Crawford, 2015; RuizMadrid and Fortanet-Gómez; 2015; Zhang, 2015). Indeed, studies considering communication from a multimodal perspective, that is, integrating different resources such as gestures, gaze or body postures, require the use of video technologies to capture social action (e.g. Mondada, 2016).

Sacks' pioneering work influenced a large body of literature that focused on the structural features of talk-in-interaction, including for example turn-taking, sequence organisation, and repair, which are the three main aspects that define CA. Turn-taking is one of the most salient features and contributions of CA (ten Have, 2007). In Sacks et al.'s words (1974):

\begin{abstract}
Turn-taking seems a basic form of organisation for conversation - 'basic', in that it would be invariant to parties, such that whatever variations the parties brought to bear in the conversation would be accommodated without change in the system, and such that it could be selectively and locally affected by social aspects of context. (Sacks et al., 1974, p. 700)
\end{abstract}

Speakers, in an interactive conversation, take different roles and turns within the communicative act. As Sacks et al. (1974) observed, a conversation involves that there is one person speaking at a time, and that change of speaker occurs with the minimal gap and minimal overlapping. The authors argue that the turn-taking system involves two components: the turn constructional component and the turn allocation component. The first involves a set of unit-types, e.g. lexical items, a phrase, a clause or a sentence, that are available for speakers to elaborate a turn, whereas the second specifies how speakers manage the opportunities for talking. In this sentence, turn-allocation techniques 
might include two types, those provided by how the speaker selects the next speakers, and those in which the next turn is allocated by selfselection to continue the conversation; if this does not occur, then the current speaker may continue. This process continues at each transition relevance place, which allows the flow of the conversation taking into account that only one speaker speaks at a time. However, overlapping and silence might happen over the course of the conversation and indeed these aspects should be taken into account as they can be significant for the interaction (González-Lloret, 2010).

Another feature of talk-in-interaction is sequence organisation. Following Schegloff (2007), the term refers to "any kind of organization which concerns the relative position of utterances or action" (p. 2). Therefore, it refers to any type of organisation which relates to how speakers organise turns in a set of interrelated communicative actions (Mazeland, 2006). A sequence may be understood as "an ordered series of turns through which participants accomplish and coordinate an interactional activity" (Mazeland, 2006, p, 156). The second part of a sequence may for example involve the so-called adjacency pairs (Schegloff and Sacks, 1973).Examples of adjacency pairs could be question-answer, offer acceptance/refusal, among others. Essentially, adjacency pairs are multi-turn units involving a first part and a second part and they are the main instruments for the analysis of sequential organisation (ten Have, 2007). As pointed out by Schegloff and Sacks (1973),

[w]hat two utterances, produced by different speakers, can do that one utterance cannot do is: by an adjacently positioned second, a speaker can show that he understood what a prior aimed at, and that he is willing to go along with that. Also, by virtue of the occurrence of an adjacently produced second, the doer of a first can see that what he intended was indeed understood, and that it was or was not accepted. Also, 
of course, a second can assert his failure to understand, or disagreement, and, inspection of a second by a first can allow the first speaker to see that while the second thought he understood, indeed he misunderstood. (Schegloff and Sacks, 1973, p. 296)

Speakers might use adjacency pairs in order to interact and in the way they construct their relationships and the conversation. A current speaker displays his/her understanding towards a prior turn and the prior speaker focuses on the current turn so as to see whether the turn is understood and whether the current speaker shows understanding, otherwise repair might be needed. The way a speaker understands a prior turn can reflect the "intrinsic motivation for listening" (Sacks et al., 1974, p. 727). In this sense, aspects such as interest or politeness alone might not be sufficient to show attention (Sacks et al., 1974). Understanding and displaying understanding are other features of the turn-taking model presented by Sacks et al. (1974). The former relates to the way utterances are understood, for example, "how are you?" would be commonly understood as a greeting. The latter refers to the appropriateness of the response, which reveals understanding on the part of the speaker, for example, an answer to a question or an apology to a complaint.

Regarding adjacency pairs, other scenarios might also be found, since in many cases a third part is added to the pair as an acknowledgement or evaluation by the first speaker of the second speaker's utterance (ten Have, 2007). Hence, a new sequence may be inserted in the one stated, for instance, a request for clarification or specification (Schegloff, 1972, 2007). As ten Have (2007) puts it:

So a first question (Q1) can be followed by another question (Q2) by the would-be answerer, which is then first answered by the speaker who produced Q1 (A2), before the questioned answers the first 
answer (A1); thus you get the order Q1, Q2, A2, A1.

(ten Have, 2007, p. 131)

Then, a sequence expansion could happen, i.e. a sequence format can be followed through, restricted, expanded or broken off, and the parties need to negotiate on a turn-by-turn basis (Jefferson and Schenkein, 1978). An adjacency pair involves a basic sequence that might be, albeit not necessarily, expanded in different ways. The sequence expansions can be described as pre-expansion, insert expansion and post-expansion (Schegloff, 2007). Pre-expansion refers to a sequence that "lays the groundwork for a base first-pair part in some way" (Stivers, 2013, p.193). Pre-sequences are regarded as adjacency pairs that serve as preparatory elements for a next pair (Schegloff, 2007), for example preinvitations, pre-requests, among others. A different type of expansion is insert sequences, which are placed between the first and second part of an adjacency pair, that is, between the initiation of a sequence and the response to it (Schegloff, 2007). Two different forms are identified, specifically, as addressing some issues of the initiating act, i.e. post-first, or as a preliminary to it, i.e. pre-second (Schegloff, 2007). Postexpansions can be regarded as thirds which are used to close a given sequence (Schegloff, 2007). Concerning this, two types are distinguished, minimal and non-minimal. The former involves a reaction to a second-position response, that is, it refers to "the addition of one additional turn to a sequence after its second pair part" (Schegloff, 2007, p. 118). This type of post-expansions involves one turn, for example, “oh”, which can be placed after a second part (Sidnell, 2009). Like minimal post-expansions, non-minimal post-expansions may also take several forms (e.g. really), serve as assessment and they project at least one more turn.

Finally, the third salient feature of CA is repair organisation, which focuses on how speakers deal with problems while interacting, for example (mis)hearing or misunderstanding (ten Have, 2007). Repair 
has been examined as sequentially structured phenomena (e.g. Schegloff et al., 1977; Schegloff, 1987, 2000; Jefferson, 1974, 1987; Macbeth, 2004). A repair sequence starts with a repairable, that is, an utterance that contains the trouble source. The repair is usually initiated by the speaker of the trouble source, that is, self-initiated repair. The speaker who self-initiates the repair tends to complete the repair by performing a repair solution (Kitzinger, 2013). Another type of repair is performed when the recipient shows some kind of misunderstanding and then the original speaker initiates repair (Schegloff, 1992). When another participant initiates repair, this is usually done in the next turn, i.e. a next turn repair initiation, which provides the original speaker with an opportunity to self-repair the problem (ten Have, 2007). Examples of this might be "huh?" or "what?". Also, another speaker can offer a speaker understanding of a given utterance, which might be accepted, rejected or rephrased by the original speaker (ten Have, 2007). An example could be "I mean".

Having provided an overview of the field of CA, its origins and an introduction the three main features (turn-taking organisation, sequence organisation and repair), the following section focuses on the nature of backchannel as a feature of the pragmatics of conversational interaction.

\subsubsection{Simultaneous talk}

Simultaneous talk is an important discourse organisational feature that shows the different ways in which speakers organise their talk (Cheng, 2003). According to Brown and Levinson (1978, 1987), simultaneous talk in conversation can threaten the face of the interlocutor. Particularly, the authors indicate that "[t]urn taking violations (interrupting, ignoring, selection of other speakers, not responding to prior turns) are all FTAs" (p. 232-233). Concerning this, Fernández-Amaya (2013) indicates that simultaneous talk may not be 
always regarded as negative as it can be interpreted as expressions of positive politeness in the sense that speakers attempt to talk simultaneously as they are interested in the conversation.

A pragmatic corpus-based study such as the current one might provide not only information as regards the speech act selected for the purpose of the study (the speech act of complaints is described in Chapter 2 Section 2.1.1), but also conversational features of how talk is constructed. In this sense, and taking a pragmatic approach to explore conversation, participants may reveal instances of simultaneous talk, and verbal and non-verbal signals to show for example that they are attending the other interlocutor. Bearing in mind this idea, in the following section I focus on two conversational features: overlapping and backchannel.

\subsubsection{Overlapping and backchannel}

Following Sacks (2004), simultaneous talk can be divided into two categories, overlaps and interruptions. For him, overlaps may occur when a new speaker starts talking at the possible completion point of the current turn of the speaker. On the other hand, interruption refers to a situation in which a new speaker starts to talk intentionally while the current speaker is constructing his/her turn.

There are, however, different types of overlapping talk. Schegloff (2000) divides overlapping talk into problematic or competitive as regards to the turn-taking and to those that are unproblematic or noncompetitive. Competitive overlaps are disruptive and they might be regarded as FTAs (Brown and Levinson, 1978, 1987) and they are typically performed in order to project the new speaker voice over the current one.

Overlapping can be either turn competitive or non-competitive (French and Local, 1983; Schegloff, 2000). Competitive overlapping can be defined as instances in which the new speaker aims to obtain the 
floor not when the current speaker has completed the turn but in the specific movement he/she performs the overlap (French and Local, 1983). This type of overlapping can be classified as problematic (Schegloff, 2000). Non-competitive overlaps may be the so-called backchannel. Particularly, backchannels can occur while the current speaker is speaking but they are not used to take the floor but to show the interlocutor signals of active listenership.

For the purpose of this study, I treat backchannels as a distinct category from overlapping. In so doing, I make a distinction between overlapping and backchannel. While, overlapping is considered as a turn that is performed while the current speaker is speaking in an attempt to project his/her voice and takes the floor, backchannels involve listeners' responses to the current speakers' talk.

Literature shows that the first researcher to examine listener response is Fries (1952), in a study that explores listener responses in telephone calls. However, the term backchannel was coined by Yngve (1970), who defines them as short and non-floor-grabbing messages that are performed over the course of a conversation; specifically the author states:

[w] hen two people are engaged in conversation, they generally take turns... In fact, both the person who has the turn and his partner are simultaneously engaged in both speaking and listening. This is because of the existence of what I call backchannel, over which the person who has the turn receives short messages such as yes and un-huh without relinquishing the turn. (Yngve, 1970, p. 568)

On the other hand, Peters and Wong (2014, p. 408) indicate that backchannels are commonly defined "as the intermittent vocal noises e.g. $\mathrm{mm}$, oh, right, yeah" that are performed by the listener in a conversation. Gass and Houck (1999, p. 82) argue that backchannels are 
"important for the establishment and maintenance of a harmonious interaction, for they can signal those aspects of a conversation that lead to harmony (e.g. agreement, understanding, attention)". Backchannels can therefore provide the current speaker's with signals of the listener's attention, for example by showing that the message is received or understood.

In line with Yngve (1970), Hayashi and Hayashi (1991) present a model of listener behaviour that involves the main channel, i.e. used by the speaker who holds the floor; and the back channel, i.e. the channel used by the listener to show attentiveness, agreement and disagreement. As described by Hayashi and Hayashi (1991), in a conversation, one person takes the role of the speaker which involves his/her taking a turn and his/her talking in the main channel of communication. The other speaker takes the role of the listener and his/her utterances are seen as backchannels.

It is important to note that one of the most salient features of backchannels is that they are not turns (Yngve, 1970; Duncan and Fiske, 1985). In line with this, Maynard (1986) argues that the most difficult issue in identifying a backchannel could be to ascertain whether a given behaviour is a backchannel or a turn. As reviewed above, for Sacks et al. (1974), a turn involves one or more turn-constructional units and each unit ends at a transition-relevance place. Their model is useful to understand the turn-taking system, but it is to some extent limited as a means to identify backchannels in context since it does not take into account the concept of having the floor (Hayashi, 1988; Maynard, 1986). The concept of having the floor is based on participants' perception of who has the floor, and the quantity and frequency of speech (Cutrone, 2013). Hayashi (1988, p. 273) defines the notion of floor "with respect to: (1) who is orienting his/her attention to the ongoing conversational content, (2) who the central figure(s) of the ongoing conversation is/are, and (3) to whom and where the communicative territory belongs". The author also adds that the floor 
should not be regarded as something static since it is constructed in mutual interaction by the speakers and therefore it is part of their communicative competence.

After defining the nature of backchannel, in the following section I focus on the classification and function of this particular phenomenon.

\subsubsection{Classification and functions of backchannel}

Different terms might be used to refer to backchannels, for example reactive tokens (Clancy, Thompson, Suzuki and Tao, 1996), response tokens (Gardner, 2001; McCarthy, 2002), accompaniment signals (Kendon, 1967), listener response (Rosenfeld, 1987) or aizuchi (Maynard, 1990; Hayashi, Mori, and Tagaki, 2002; Mori, 2002). In this study, however, I use the term backchannel. Backchannels, as I review in this section, include not only verbal responses but also non-linguistic responses such as nods, or silence.

Yngve's (1970) contribution is adopted by Duncan (1972, 1973, 1974) and Duncan and Fiske (1974), who advance a framework for studying interaction that includes both linguistic and non-linguistic features. Duncan (1972) formulates a system of signals and rules known as the turn-taking mechanism, later referred to as the turn system (Duncan and Fiske, 1977, 1985). In their research, Duncan (1972, 1973) and Duncan and Niederehe (1974) attempt to describe the turn-taking system in conversation by showing that it consists of three basic signals, one of them being backchannel. Duncan (1973, p. 38-39) provides a classification of backchannels that involve, p. (1) " $m-h m$ " described as a group of readily identified verbalisations; (2) sentence completions; (3) requests for clarification; (4) brief restatements; (5) head nods and head shakes; and smiles, which was added in 1985 by Duncan and Fiske.

However, researchers have expanded the description of backchannels, and therefore the literature contains a variety of 
classifications. For example, Edmondson (1981, p. 148-152) provides a set of listener behaviours that includes (1) go-ons, i.e. showing that the listener is attending and is in favour of the speaker's continuing; (2) accepts, i.e. showing that an act is heard and understood and that it is not unacceptable, e.g. yes, $\mathrm{mm}$; (3) exclaims, i.e. revealing an emotional reaction to the discourse or situation, e.g. surprise, interest; (4) okays, i.e. showing that the listener is satisfied with the outcome.

In line with Yngve (1970), Oreström (1983) divides utterances into speaking turns and backchannel items. According to Oreström (1983), backchannels involve lexical and non-lexical listener responses involving "rather special functions where the listener informs the speaker that his message has been received, understood, agreed to and/or has caused a certain effect" (p. 24). Drawing on Duncan's classification of backchannels, Oreström (1983, p. 106-107), proposes a different classification, including (1) supports (e.g. $m$-hm, yes), expressing acceptance, agreement, and/or that the listener has understood the message; (2) exclamations (e.g. oh, gosh), which are emotional expressions, e.g. surprise; (3) exclamatory questions (e.g. what, really); (4) sentence completions; and (5) restatements. Unlike Duncan's classification, requests for clarifications are considered a turn as they directly affect the course of the talk and they are similar to pair turns such as question-answer.

In a study that examines backchannel behaviour across cultures (i.e. American and Japanese) elicited in dyadic interactions, Maynard (1986) identifies six different types of backchannels (171-172). The author redefines Edmondson's (1981) classification, p. (1) continuer, i.e. shows that the listener is bypassing the change to initiate a repair, similar to Edmondson's (1981) go-ons; (2) display of content understanding, i.e. used when there is doubt on the part of the speaker as to the listener's understanding, equivalent to Edmondson's (1981) accepts; (3) supports towards the speaker's judgement, i.e. used as a response to a speaker's evaluative statement; (4) agreement, i.e. 
performed as a response to a question or question-like statement, however, this is not seen as an opportunity to take the floor but only to express agreement; (5) strong emotional response, i.e. including a laugh or exclamation, similar to Edmondson's (1981) exclaims; and (6) minor addition, correction or request for information.

Another cross-cultural study was conducted by Clancy et al. (1996). Data for this study include Mandarin Chinese, Japanese and English. The authors propose a different classification "based partly on their form and partly on their sequential function" (p. 356). In this case, the term used is reactive token. The authors indicate that reactive tokens do not usually "disrupt the primary speaker's speakership and do not claim the floor" (p. 354). Clancy et al. (1996, p. 359-364) distinguish five different types of reactive tokens, including (1) backchannels, i.e. a non-lexical vocalic form that serves as a continuer (Schegloff, 1982), shows interest or claims understanding; (2) reactive expressions, i.e. non-floor-taking lexical phrase or word, including assessments (Goodwin and Goodwin, 1987, 1992a, 1992b; Goodwin, 1996); (3) collaborative finishes (Lerner, 1987, 1989, 1991), i.e. when the nonprimary speaker, the listener, finishes the utterance of the current speaker; (4) repetitions, i.e. when part of the speech of the speaker is repeated; (5) resumptive openers, i.e. non-lexical element that is used at turn-initial points. As Clancy et al. (1996, p. 362) points out, "[t]hese forms would be coded as backchannels if they weren't followed by full turns". Four features distinguish this typology: they are typically monosyllabic non-lexical, vocalic forms; they usually appear as a separate intonation unit; normally only short pauses take place after this form; and they are performed at the beginning of a new turn.

More recently, O'Keeffe and Adolphs $(2008$, p. 84) provide a model of backchannels including the following: (1) continuer tokens, i.e. they maintain the flow of the discourse, e.g. yeah; (2) convergence tokens, i.e. markers of agreement/convergence which are linked to points of the discourse in which there is a topic boundary or closure and 
when there is a need to converge on an understanding of shared knowledge, including single-word items such as yeah, follow-up questions like did you?, and short statements such as agreeing statements, for example, yeah it's pretty sad; (3) engagement tokens, i.e. markers of high engagement in which the listener provides emotional responses, including single-word forms such as excellent, short statement, repetitions, oh wow, and follow-up questions like did you?; (4) information receipt tokens, i.e. markers that show that the information has been received, e.g. right.

It is worth recalling that the literature also acknowledges nonverbal backchannels (Duncan, 1973; Duncan and Fiske, 1985; Maynard, 1989; Gass and Houck, 1999; Carter and Adolphs, 2007). For example, as described above, Duncan (1973) and Duncan and Fiske (1985) include, among the classification of six types of backchannels, two that are non-verbal, namely (1) head nods and shakes; and (2) smiles. Maynard (1989) discusses the nature of head movements as non-verbal signs, specifically, nods and head shakes, pointing to their interactional functions. The author also argues that head movements can be performed accompanied by backchannel vocalisations. However, in her discussion of backchannels, Maynard (1989) separates head nods from verbal backchannels.

Gass and Houck (1999, p. 87-91), in their investigation of interlanguage refusals including Japanese and English data, point out that listener's nods and head shakes occur in the following contexts: (1) separately, with no vocalisation; (2) with minimal vocalisations, e.g. $\mathrm{mm}$; (3) with lexical items that express agreement, e.g. yes; with; and (4) brief statements, e.g. it's a problem. Gass and Houck (1999) link the listener's nods with the illocutionary and interaction functions of Maynard (1989) and Edmondson's (1981) discourse internal acts. Their data reveal the following categories: (1) agreement, i.e. brief confirmations and positive responses to yes-no information questions; (2) acceptance, i.e. a positive response to a speech act that requires an 
acceptance or a refusal; this category, however, is not regarded as backchannels in the works of Edmondson (1981), Maynard (1986), or Clancy et al. (1996); (3) common backchannel functions, i.e. minimal responses, nod or nod with verbalisations such as $\mathrm{mm}$, yeah, that are performed as a continuer (or transition filter), as a minimal signal of understanding, or as an indicator of support.

In the Japanese language, response tokens, which are referred to as aizuchi, have also been examined by other researchers and their results show that nods, gaze and silence can be employed more frequently than verbal backchannels in conversations (Maynard, 1990; Hayashi et al., 2002; Mori, 2002). For example, Maynard (1990) examines videotaped pair conversations in Japanese and American English and carried out a contrastive CA to explore the listener's backchannels in casual conversations. Non-verbal response tokens in this study involve both head movement and laughter.

Carter and Adolphs (2007) also argue for an integrated approach to the analysis of backchannels. These authors provided a multimodal approach to exploring active listening drawing on data derived from a spoken corpus, i.e. an academic supervision context. Specifically, Carter and Adolphs' (2007, p. 281) analysis of head nods includes, p. (1) Type $A$, i.e. small (low amplitude) nods with short duration; (2) Type B, i.e. small (low amplitude), multiple nods with a longer duration than type A; (3) Type C, i.e. intense (high amplitude) nods with a short duration; (4) Type $D$, i.e. intense and multiple nods with a longer duration than type C; (5) Type E, i.e. multiple nods, comprising a combination of types $\mathrm{A}$ and $\mathrm{C}$, but with a longer duration. Also exploring pragmatic functions in multimodal corpora and drawing on academic supervision sessions, Knight and Adolphs (2008) provide a similar classification to that of Carter and Adolphs (2007). Specifically, Knight and Adolphs (2008, p. 182) distinguish the following types: (1) Type 1, i.e. small (nonchalant) nods of short duration; (2) Type 2, i.e. small (nonchalant), multiple nods of longer duration than type 1; (3) Type 3, i.e. intense nods of short 
duration; (4) Type 4, i.e. intense and multiple nods of longer duration than type 3; (5) Type E, i.e. multiple nods, consisting of a combination of types 1 and 3 .

Furthermore, backchannels can show different lexical forms, and in this sense three different forms are identified: (1) simple (Oreström, 1983), e.g. mmm, yeah; (2) double (Tottie, 1991), e.g. $\mathrm{mmm} \mathrm{mmm}$, yeah yeah; (3) complex (Tottie, 1991), e.g. yeah...right, yeah I know. Oreström (1983), however, places double and complex forms together and they are referred to as series. According to Gardner (2001), simple forms are brief mono or bisyllabic utterances, involving single words, while double forms refer to a sequence of a specific lexical form that is repeated two or more times. Complex backchannels refer to "one of several items from different backchannel categories and/or one of several open-class lexical items" (Tottie, 1991, p. 263).

Regarding functions, backchannels are employed to "achieve a systematically differentiated range of objectives which, in turn, are specifically consequential for the onward development of the sequences in which they are employed" (Heritage, 1984, p. 335). However, it is complex to explain in detail the functions of each backchannel (Gardner, 1997). Regardless of this complexity, research has shown that some backchannel forms are widely used as regards their discursive function (Knight, 2011). Focusing particularly on the pragmatic function of backchannels, Peters and Wong (2014, p. 409) state that backchannels are, on some occasions, "discussed in terms of being used by listeners to support the speaker's turn as continuers (Schegloff, 1982) or having a 'carry on' function (Tottie, 1991, p. 256)". Following Peters and Wong (2014), the latter also involves other supportive functions such as understanding and agreement, thereby supporting "the speaker's topic of conversation and their stance" (p. 409). Support for the speaker and topic, are also noted by O'Keeffe and Adolphs (2008), specifically in two of the functions they describe, i.e. convergence token and engagement token. The illocutionary and interaction functions are 
also noted by Maynard's classification of backchannels, including for example agreements, corrections or requests for information. In the ILP arena, backchannels are also of paramount interest since backchannel signals elicited by the listener might have an effect on the other interlocutor, the current speaker. Concerning this, Yamashita (2008, p. 206) states that " $[k]$ nowing and being able to react properly to such expressions also depends on learners' pragmatic competence or ability". Moreover, speakers' overall proficiency level, as well as their interactive competence, could also affect the way they understand backchannel responses and how they react towards these responses.

In the present study, backchannels are also examined, since they are part of the communicative event. Table 2 displays the different backchannel functions considered for the purpose of the present study.

Table 2. Backchannel functions of Maynard (1986), Clancy et al. (1996) and O'Keeffe and Adolphs (2008).

\begin{tabular}{|ll|}
\hline \multicolumn{1}{|c|}{ Author } & \multicolumn{1}{c|}{ Function } \\
\hline Maynard (1986) & Continuer \\
& Display of content understanding \\
& Supports the speakers' judgement \\
& Agreement \\
& Strong emotional responses \\
& Minor addition, correction or request for \\
& information \\
& Backchannels \\
Clancy et al. (1996) & Reactive expressions \\
& Collaborative finishes \\
& Repetitions \\
& Resumptive openers \\
O'Keeffe and Adolphs (2008) & Continuer tokens \\
& Convergence tokens \\
& Engagement tokens \\
& Information receipt tokens \\
\hline
\end{tabular}

The work of Maynard (1986), Clancy et al. (1996) and O'Keeffe and Adolphs (2008) are taken as a starting point, and therefore those functions are employed as the basis to create the possible classification of backchannels in the data of the present study. 
This section has provided an overview of the backchannel phenomena by highlighting the definition of backchannels and focusing on their nature. As shown, backchannels are not regarded as turns, but as responses elicited by the listener while interacting that do not create a new turn. These responses do not attempt to claim the floor or take it; instead, they are used as a response to what is expressed by the current speaker.

In what follows I focus on the expansion of CA into the realm of SLA and foreign language acquisition (FLA), focusing particularly on speech act performance.

\subsubsection{Conversation analysis and speech act performance}

CA has expanded into other areas such as that of SLA and several researchers have explored the intersection between CA and SLA (e.g. Markee, 2000; Schegloff, 2002; He, 2004; Markee and Kasper, 2004; Seedhouse, 2004, 2005; Kasper, 2006a, 2006b; Richards and Seedhouse, 2005; Firth and Wagner, 2007; Kasper and Wagner, 2014). Regarding pragmatics, which is the area of interest for the current study, Schegloff, Koshik, Jacoby and Olsher (2002) argue that CA can contribute to the analysis of intercultural communication and ILP. In this regard, Seedhouse (2004, p. 234) states that "although CA's main interest has been in how social acts are performed through language, it has always been interested in the reflexive relationship between grammar and interaction and the domain of pragmatics". By the same token, Kasper (2006b, 2009a) values the potential of CA in analysing ILP; particularly, the author states:

Of the different proposals for the analysis of speech acts in interaction, conversation analysis (CA) has accrued by far the largest and most coherent cumulative body of research, lending high credibility to 
its theoretical foundations and methodology. CA therefore recommends itself not only as a lens for critical scrutiny of speech act research but provides a well documented perspective. (Kasper, 2006b, p. 285).

The literature shows that speech act sequences have been examined from the perspective of CA. For example, sequences of agreeing and disagreeing (Pomerantz, 1984; Mori, 1999); greetings and openings (Schegloff, 1968; Coronel-Molina, 1998; Baker, Emmison and Firth, 2001; Rintel, Mulholland and Pittam, 2001; Taleghani-Nikazm, 2002; Arminen and Leinonen, 2006); apologies (Robinson, 2004); blaming (Watson, 1978); rejections (Davidson, 1984); complaints (Drew and Holt, 1988; Darsley and Wootton, 2000; Schegloff, 2005; Monzoni, 2008); invitations (Drew, 1984); compliments and responses to compliments (Pomerantz, 1978; Golato, 2002, 2005; Huth, 2006); advice-giving (Heritage and Sefi, 1992; He, 1994; Hutchby, 1995; Leppanen, 1998), questions (Kasper, 2006c; Kasper and Ross, 2007; Egbert and Vöge, 2008) or requests (Wootton, 1981; Kasper, 2006c; Taleghani-Nikazm, 2005, 2006; Tateyama and Kasper, 2008; AlGahtani and Roever, 2012).

Some studies have examined speech act sequences in everyday conversation and in telephone conversations between friends and family (Taleghani-Nikazm, 2002, 2005, 2006). For example, TaleghaniNikazm examines (2006) the speech act of requests in everyday German discourse. Specifically, the author focused on how requests are placed within a conversation and indicates that "their sequential placement, content and grammatical structure are tightly connoted to preference organization and maintenance of social solidarity" (2006, p. 79). This study revealed three types of request placements: built into the request turns to pursue a preferred response, placed after dispreferred responses, and after preferred responses. Furthermore, the author argued that concerning the pre-sequences, "it is not only the linguistic 
composition of a turn but also its sequential placement that makes a turn recognisable as a pre-request" (2006, p. 18).

Taleghani-Nikazm (2002) focused on cross-cultural interactions and explored greetings and opening in telephone conversations in Iranian telephone calls, German telephone calls, and telephone calls between NSs of German and Iranian NNSs of German in Germany. The author centred on the interactional organisation of specific ritual routines across cultures. Results revealed features of pragmatic transfer; specifically, it was shown that the transfer of routinised ritual inquiries can hinder the conversation and lead to breakdowns. As argued by the author, this could be related to German NSs' expectations and understanding of the task, which may be different from that of the Iranian participants. Also, the study demonstrated how the ritual inquiries about the co-participants' and their families' status were treated by the German NSs as topical inquires. The author also pointed out that pragmatic transfer could be related to the fact that Iranian speakers of German might not be consciously aware of the conversational routines in their $\mathrm{L} 1$ and in the L2.

Further studies have investigated cross-cultural interactions (Coronel-Molina, 1998; Golato, 2002; Robinson, 2004; Egbert and Vöge, 2008). Golato (2002), drawing on Pomerantz's (1978) study, examined the preference organisation of compliment responses in German and compared German and American English compliment responses in conversations among families and friends. Results revealed that rejections and turns containing certain agreement and disagreement features were elaborated similarly in both languages. However, the difference was identified in agreement sequences. The author also pointed to the value of $\mathrm{CA}$ for the integration of pragmatics into SL and FL teaching. This is also supported, for example, by Ishihara and Cohen (2010). Additionally, Robinson (2004) examined, from a CA perspective, the sequential organisation of explicit apologies in naturally occurring interactions, i.e. American and British English 
conversations, including telephone calls, people talking during meal times and games, and doctor-patient consultations. In this study, results showed that apologies might be located in different sequential positions with different implications. Preferred and dispreferred responses can be identified as the first parts of adjacency pair sequences. The former involved responses that "mitigate or undermine an apology's claim to have caused offense" (2004, p. 319), and the latter "endorse an apology's claim to have caused offense" (2004, p. 319). Moreover, the author found that apologies can be used to display non-apology actions.

Using institutional data, some studies have focused on crossinstitutional comparison of speech acts by means of CA (Monzoni, 2008; Baker et al., 2001). Monzoni (2008) compared complaint sequences in two different interactional contexts, p. everyday conversations and institutional calls, i.e. ambulance calls. Results revealed that direct complaints might be performed in situations in which an event occurred and that event caused some problems for the complainer. In institutional interactions questions were used to establish the shared knowledge of the speakers as regards the event. Once both parties shared the same knowledge about a particular event, the callers performed turns in order to provide further information about the event.

Of particular interest for the present study is the investigation carried out by Al-Gahtani and Roever (2012), not only because they examined ILP data from a CA perspective, but also because proficiency was examined. The variable of proficiency, however, is not introduced here but in Chapter 2. As argued by Al-Gahtani and Roever (2012), CA contrasts with SLA studies, and particularly with ILP ones, in the sense that ILP research uses elicited data, manipulates tasks and participants' variables to examine speech act performance and proposes specific analytic frameworks, while CA typically addresses naturally occurring data. Concerning this, Al-Gahtani and Roever (2012, p. 46) state that " $[\mathrm{w}]$ hile $\mathrm{CA}$ and interlanguage pragmatics may appear fundamentally 
incompatible, compromise positions have started to emerge". In fact, as aforementioned, Kasper (2006b, 2009a) emphasises the need to integrate a CA approach to explore ILP. As in the present study, AlGahtani and Roever (2012) focused on elicited requests by means of role-play tasks. The authors, as I review in Chapter 2, examined the sequential organisation of the interactions and how this is affected by proficiency level. This study shows that the integration of $\mathrm{CA}$ is essential to understand the effects of proficiency on the sequential organisation of interaction. The CA approach, which is not typically employed in ILP, provides a broadened vision of how proficiency level affects the sequential organisation of requests.

In short, $\mathrm{CA}$, although it did not originally emerge within the realm of linguistics, can be applied to different fields such as applied linguistics, and particularly to the areas of SLA/ FLA and ILP (Kasper, 2006b, 2009a). Typically, CA examines natural conversations, as opposed to elicited data, for example by means of role-play tasks. The literature describes several studies examining speech acts from a $\mathrm{CA}$ approach. By applying a CA approach, Al-Gahtani and Roever (2012) examined elicited spoken data by means of role-play, thereby providing a different perspective of spoken data.

\subsection{Summary}

This chapter has provided an overview of the scope of pragmatics by addressing some of the essential issues related to this discipline. The first part of the chapter has focused on the discipline of pragmatics, the nature of communicative competence in which special attention has been paid to pragmatic competence and the multimodal view of pragmatic competence. As reported, the discipline of pragmatics is still rather new as it became independent from the field of linguistics about 40 years ago. The modern concept of pragmatics can be traced back to 
Morris (1938), and since then various definitions of this discipline have been put forward, for example, that proposed by Crystal (1985). Specifically, the author posits that pragmatics relates to the study of language from the perspective of the speakers, the choices they make, the constraints found when using language in social interactions, as well as the effects speakers' performance might have on the other participants. This view of pragmatics is in line with the work of Leech (1983) and Thomas (1983), who argued that pragmatics involves two main aspects, pragmalinguistics and sociopragmatics. The former refers to the linguistic resources available in a given language and the latter relates to the context and the participants of the communicative event, which might affect the paralinguistic realisation.

In addition to this, in this chapter I have also focused on the nature of communicative competence by focusing on Hymes's (1972a) contribution. This author, as a reaction against Chomsky's (1965) vision of language, suggested the term communicative competence and indicated that language takes place in social context and, therefore, two different competences were to be identified: linguistic competence and sociolinguistic competence. Hymes's remarkable contribution has been followed by several researchers who have attempted to provide a description of the communicative competence model and the competences that it might involve. Although open to criticism, I have provided a review of the most well-known and influential communicative models, by focusing on the contributions of Canale and Swain (1980), Canale (1983), Bachman (1990), Celce-Murcia et al. (1995) and Celce-Murcia (2007). Other communicative competence models have been mentioned throughout the chapter, but no explicit reference to their construct have been made (see for example the works of Savignon, 1983; Bachman and Palmer, 1996, 2010; Purpura, 2004; Usó-Juan and Martínez-Flor, 2006). As reported above, one of the major contributions is related to Bachman (1990), as pragmatic competence was, for the first time, seen as an independent competence 
and not included as part of other competences such as sociolinguistic competence (Canale and Swain, 1980) or actional competence (CelceMurcia et al., 1995). This competence is of paramount interest for the present study as I focus particularly on pragmatic competence, which, as indicated, might also be observed from a multimodal perspective taking into account that communication is multimodal by nature, and therefore speakers provide not only verbal information but also other types of information that derives for example from paralinguistic and extra-linguistic elements. In this sense, I have argued for the term multimodal pragmatic competence, although further research is needed in order to examine whether this term can be used to refer to the interplay between the verbal aspects of pragmatic competence and the non-verbal aspects that might characterise pragmatic competence.

The role of politeness within pragmatics has also been described in this chapter, specifically, by addressing the notion of face and facework, different views on politeness including those proposed by Grice (1975), Lakoff (1973), Leech (1983), Fraser (1978, 1990) and Fraser and Nolen (1981), and one of the most widely recognised politeness theories, that proposed by Brown and Levinson $(1978,1987)$. The notion of face and facework, which are rooted in a model of social interaction, are defined by Goffman (1967). Accordingly, face is regarded as an individual possession and speakers tend to maintain both their and their interlocutors' face during an interaction. Facework refers to the actions taken to compensate for incidents that might occur during the flow of the interaction between the speakers. Moving on, some perspectives of politeness reported in this chapter involve, for example, Grice's (1975) Cooperative Principle, which includes four different maxims, namely, (1) quality; (2) quantity; (3) relevance; and (4) manner. Another politeness approach is that proposed by Lakoff (1973), who focuses the politeness principle on a set of pragmatic rules. Thus, instead of focusing only on the syntactic structure, emphasis is also given to the context in which utterances are performed. Concerning this, the author 
proposes two universal rules of pragmatics: (1) Be clear (rule of conversation), similar to Grice's Cooperative Principle, and (2) Be polite (rule of politeness). In addition to this, Leech (1983) advances the Conversation-maxim view, and proposes a pragmatic framework that involves (1) textual rhetoric; and (2) interpersonal rhetoric. The former involves four different principles: (1) processibility; (2) clarity; (3) economy; and (4) expressivity. Finally, Fraser $(1978,1990)$ and Fraser and Nolen (1981) argue for a model known as the Conversational Contract View, which seems to take a discourse-based approach instead of a speech act-based approach.

One of the most widely recognised politeness theories is that advanced by Brown and Levinson $(1978,1987)$. Specifically, these authors provide a theory of politeness that combines aspects of previous approaches, such as Grice's maxims and Goffman's (1969) notion of face. For Brown and Levinson (1987) face relates to "the public selfimage that every member of society wants to claim for himself" (61) and they also distinguish between positive (speaker's desire to be liked, valued, respected and appreciated by others) and negative face (speakers' need to keep one's territory unimpeded). Furthermore, Brown and Levinson's $(1978,1987)$ politeness approach is speech actbased and they posit that some speech acts are FTAs, thereby including acts that might affect the face wants of the speaker or the interlocutor. Concerning this, the authors propose various strategies by which speakers can perform the FTAs. An important contribution of their theory, which in turn is important for the present study, is the different social factors that intervene in interaction, specifically those of social distance, relative power, and rank of imposition or severity of offence. Accordingly, speakers can perform speech acts taking into account the aforementioned aspects. In this sense, achieving pragmatic competence, involving pragmalinguistic and sociopragmatic features, is of paramount interest for SL/FL learners, since by mastering the social norms and the politeness conventions, learners' opportunities for 
successful communication, and hence not being rude or inappropriate, are increased.

This chapter has also provided a review of Speech Act Theory by presenting a general perspective of the theory since its origins. In this sense, I have focused on the influential works of Austin (1962) and Searle (1975), who provided fruitful insights into the area of speech acts. Their contributions are still relevant for the study of speech acts and ILP. Furthermore, I have reviewed the notion of indirect speech acts, which were also recognised by Austin (1962) and Searle (1975). Concerning this, Nattinger and DeCarrico (1992) suggested that indirect speech acts can be classified as non-conventional indirect speech acts and conventional indirect speech acts, and Adolphs (2008) also indicates that research into speech acts in corpora revealed the performance of formulaic language associated to a particular speech act force. Concerning speech acts in context, it seems that speech act expression might depend on the context in which they are performed and consequently the context should be taken into account as it reveals fruitful information (Adolphs, 2008). The context could also be regarded as the knowledge shared among the participants in a particular encounter and the social features in which speech acts are performed and interpreted (Félix-Brasdefer, 2008a).

Following this, I have focused on ILP. As reported, pragmatic competence is known as ILP in the field of SLA, as an analogy for example with interlanguage grammar. The phenomenon of ILP refers to NNS's comprehension, production and acquisition of pragmatic knowledge in the TL (Kasper and Dahl, 1991; Kasper, 1998; Kasper and Rose, 1999; Barron, 2003) as well as to learners' use of pragmatic knowledge (Barron, 2003). Concerning ILP research, Taguchi (2010) indicates that the vast majority of studies conducted within this field have explored pragmatic use rather than pragmatic development. Different methodological approaches have been followed in ILP research, namely cross-sectional, longitudinal and instructional, cross- 
sectional being the most common approach. In order to explore production data, either written or spoken, various research instruments can be used, namely those of DCTs for written data, and naturallyoccurring data, elicited conversation, role-plays and role-enactment for spoken data, role-plays being the most widely used research instrument for collecting spoken data. Despite the fact that a role-play is a simulated task, and therefore the data collected might not be authentic as naturally-occurring data, it has been widely employed in the field of ILP to gather spoken data since this type of task provides features of conversation such as turn-taking and negation of meaning (Kasper and Dahl, 1991).

Another type of research instrument that is used within the arena of ILP is the so-called verbal report, which can be conducted concurrently and retrospectively (Felix-Brasdefer, 2010). Although the amount of literature in the field of ILP that combined verbal reports with for example role-plays is somehow limited, there is an interest in conducting ILP research using verbal reports, as shown in this chapter (Section 1.2.2.3). The use of verbal reports has been praised by several authors as they are instrumental in obtaining specific information concerning participants' performance in the role-play task (Cohen and Olshtain, 1993; Widjaja, 1997; Félix-Brasdefer, 2008a, 2008b; Hassall, 2008; Woodfield, 2012; Beltrán-Palanques and Martínez-Flor, 2015).

In addition to this, ILP research can also be explored from a multimodal perspective, since when producing pragmatic forms, speakers can employ various resources other than spoken data such as paralanguage features and extra-linguistic elements. Similarly, in studies in which written data is elicited, participants, if arranged for example in a digital platform, may also combine different semiotic resources. In this sense, ILP could also move from what is exclusively performed by means of words and explore other elements that contribute to the meaning of the utterances elicited by means of a particular research instrument. 
Finally, this Chapter has focused on the discipline of CA, which is also important for the present study since spoken data is analysed drawing on this specific analytical approach. Although not originated to account for speech act performance and simulated data, this approach can provide researchers in the field of ILP research with further insights into participants' written or spoken production, by examining for example sequences, adjacency pairs, repairs and how turns are organised. Bearing in mind the potential of CA, Kasper (2006b, 2009a) argues for the application of CA to analyse speech act data. As reported, the amount of research that has examined speech act data from a CA perspective is rather limited, and it becomes even more reduced when dealing with elicited data. Regarding this, the work presented by AlGahtani and Roever (2012) appears to be significant for the present study as the authors examine spoken elicited data following a CA approach.

Furthermore, I have also reviewed the nature of simultaneous talk by focusing on overlapping and backchannel. Backchannels, as shown, are also known as reactive tokens (Clancy et al., 1996), response tokens (Gardner, 2001; McCarthy, 2002), accompaniment signals (Kendon, 1967), listener responses (Rosenfeld, 1987) or aizuchi (Maynard, 1990; Hayashi et al., 2002; Mori, 2002). Nevertheless, in this study I refer to this phenomenon as backchannel. As indicated, the literature shows different classifications of backchannels, including for example those advanced by Edmondson (1981), Oreström (1983), Maynard (1986), Clancy et al. (1996), and O'Keeffe and Adolphs (2008), which focus on the verbal component of the backchannel, as well as other classifications such as those by Maynard (1990), Gass and Houck (1999) and Carter and Adolphs (2007), which also account for extra-linguistic resources.

In short, Chapter 1 has focused on some of the most important aspects related to the pragmatics of interaction that are relevant for the present study. In Chapter 2 I provide a review of the speech act selected for the purpose of this study, specifically, that of complaints by focusing 
on its definition, a literature review of research on complaints as well as on a selection of relevant complaint structures. In addition to this, I provide a review of the effects of the variable of language proficiency on speech act production. 
Chapter 2. The Speech Act of Complaints and Proficiency Effects 



\section{Chapter 2. The Speech Act of Complaints and Proficiency Effects}

Chapter 2 attempts to provide a revision of two main aspects that are of paramount interest for the present study: the speech act of complaints (Section 2.1) and the variable of proficiency (Section 2.2). I first focus on the speech act of complaint by providing a general overview of the speech act (Section 2.1.1). Following this, the structure and moves of the speech act of complaints are advanced (Section 2.1.2), and then, I present a literature review of research on complaints (Section 2.1.3). The second part of the chapter covers the variable of proficiency, where I introduce a literature review divided into two sections: Section 2.2.1 focuses on proficiency effects on ILP research from different perspectives and using different research instruments (other than spoken elicitation instruments), and Section 2.2.2 presents a review of studies examining proficiency effects on studies examining interlanguage spoken data. Finally, I provide a summary of the chapter.

\subsection{The speech act of complaints}

The speech act of complaints, according to Austin's classification, falls into the category of performatives acts, and following Searle's taxonomy, it is placed within the category of expressives. This category relates to moral judgements that express the speaker's approval and disapproval of the behaviour referred to in the judgment. This speech act involves two different categories: direct complaints (D'AmicoReisner, 1985) and indirect complaints (Boxer, 1993, 1996). The two types of complaints represent two different behaviours, and they are rather different from each other. Indirect complaints refer to "the expression of dissatisfaction to an interlocutor about oneself or someone/something that is not present" (Boxer, 1996, p. 219). In direct 
complaints, the speaker expresses displeasure or annoyance as a consequence of a past or ongoing action that affects him/her unfavourably (Olshtain and Weinbach, 1987). This study focuses on direct complaints and therefore throughout the study, I use the term complaints to refer to these. For a review on indirect complaints, see for example Boxer (1993, 1996, 2010). In what follows, I address the notion of complaints, and then I focus on the nature of complaint move and its discourse functions, and finally, I provide an overview of research on complaints.

\subsubsection{Complaints}

Complaints usually involve a FTA in terms of Brown and Levinson (1987) "because it asks the addressee to remedy a complaint" (Boxer, 2010, p. 164). FTAs, as reviewed in Chapter 1, refer to acts that threaten face (Brown and Levinson, 1978, 1987). Complaints are typically performed when the speaker feels that an offence has been committed. Hence, in complaints, the target of the complaint is typically the recipient (Pomerantz, 1986; Edwards, 2005), who experiences the complaint as being related to him/her (Hakulinen, 2010). Olshtain and Weinbach (1993, p. 108) argue that "in the speech act of complaining, the speaker (S) expresses displeasure or annoyance - censure - as a reaction to a part or ongoing action, the consequences of which are perceived by $\mathrm{S}$ as affecting her unfavourably". Hence, the communicative act of complaining is uttered when the speaker needs to express his/her feelings towards a particular action that affects him/her unfavourably. In line with this, Trosborg (1995) defines this specific speech act as "an illocutionary act in which the speaker (the complainer) expresses his/her disapproval, negative feelings etc. towards the state of affairs described in the proposition (the complainable) and for which he/she holds the hearer (the complainee) responsible, either directly or indirectly" (p. 311-312). Trosborg (1995) suggests that this definition 
might explain why the speech act of complaints is seen as a FTA (Brown and Levinson, 1978, 1987). A similar approach is taken by Edmondson and House (1981, p. 145) who state that "in making a complaint, a speaker potentially disputes, challenges, or bluntly denies the social competence of the complainee".

Olshtain and Weinbach (1993) provide a set of preconditions in which the speech act of complaints takes place. Specifically, the authors propose:

1. H [Hearer] performs a socially unacceptable act (SUA) that is contrary to a social code of behavioral norms shared by $\mathrm{S}$ [Speaker] and $\mathrm{H}$.

2. $S$ perceives the SUA as having unfavorable consequences of herself, and/or for the general public.

3. The verbal expression of $\mathrm{S}$ relates post facto directly or indirectly to the SUA, thus having the illocutionary force of censure.

4. $\mathrm{S}$ perceives the SUA as: (a) freeing $\mathrm{S}$ (at least partially) from the implicit understanding of a social cooperative relationship with $\mathrm{H}$; $\mathrm{S}$ therefore chooses to express her frustration or annoyance, although the result will be a "conflictive" type of illocution in Leech's terms (Leech, 1983, 104); and (b) giving S the legitimate right to ask for repair in order to undo the SUA, either for her benefit or for the public benefit. It is the latter perception that leads to instrumental complaints aimed at "changing things" that do not meet with our standards or expectations. The main goal of such instrumental complaints is to ensure that $\mathrm{H}$ performs some action of repair as a result of the complaint.

(Olshtain and Weinbach, 1993, p. 108) 
Thus, the speaker, who expects a favourable event to occur, encounters himself/herself in a situation in which the hearer performs a SUA, whose consequences are perceived as offensive for him/her and even for the general public. Therefore, the speaker perceives that the hearer is responsible for the SUA and decides to express his/her displeasure. Hence, the authors perceive the speech act of complaints as a communicative act in which the speakers blame the hearers for a given offence, and they usually expect some kind of repair from the hearers. The speech act of complaints is therefore a FTA that threatens the hearer's positive face wants because the speaker maintains a negative attitude towards the hearer. It might also threaten the hearer's negative face wants since a complaint could be expressed with a request (Brown and Levinson, 1978, 1987). In line with this, Trosborg (1995, p. 312) points out that complaints are "by definition non-polite" and, despite the fact that Leech (1983, p. 105) contends that "politeness is out of question" and "to threaten or curse someone in a polite manner is virtually a contradiction", mitigation is required when uttering complaints in order to avoid conflicts (Trosborg, 1995).

The speech act of complaints, as all FTAs, is usually performed indirectly, and it does not account for prototypal discourse functions which serve to identify them in a less complex manner, as for example in the case of request or suggestions. Laforest (2002) points out that it may be difficult to differentiate complaints from communicative acts such as disapproval, criticism, accusations or insults, among others, which might be also uttered in context involving a complaint situation. Laforest (2002, p. 1597) further adds that from an interactive perspective, "if we take the complaint as the first part of an adjacency pair, there is no typical corresponding second part, p. the complaint can be followed by a denial, rejection, justification, making excuses, etc." As a matter of fact, in some contexts, it might be complex to ascertain whether the speech act of complaints is uttered as it can be overlapped with other speech acts such as disapprovals, criticism, reprimands, 
insults or accusations, to name a few (Brown and Levinson, 1978, 1987; Laforest, 2002; Edwards, 2005; Márquez-Reiter, 2005).

The above definitions provided indicate that the communicative act of complaining involves the speaker expressing negative feelings towards the hearer for a given action that is perceived by the speaker as offensive or unacceptable. In this study, the speech act of complaints is defined as a communicative act that is uttered to express negative feelings, displeasure, dissatisfaction or indignation towards a particular event or situation that affects the speaker, who considers someone else responsible for such uncomfortable situation. The present study also takes into account the responses to the complaints uttered by the speakers, that is to say, the interaction between the two participants involved in the complaint situation are taken into account, thereby focusing on the complaints elicited by the complainer and the responses to complaints elicited by the complainee (Laforest, 2002). This decision is taken on the basis that speech acts might not occur in isolation and therefore exploring only the initiating speech act would not provide a complete representation of communicative act. Hence, the position of the hearer is also relevant for the purposes of this study as responding to the complaint uttered would allow the researcher to explore how the complaint strategies are negotiated.

The speech act of complaints is a complex communicative act in which the complainer expresses negative feelings towards the complainee, as the speaker assumes that someone else, the hearer, has offended him/her in a particular manner. This speech act is also complex as there is no prototypal set of strategies, as in the case of requests where the different categories are clearly established (see for example Trosborg's (1995, p. 205) taxonomy of requests). The lack of a prototypical set of strategies would make it harder for the researcher to analyse possible complaint realisations, especially in authentic conversations. Furthermore, the position of the complainee is also relevant because his/her responses will affect the negotiation of the 
complaint situation. Another important factor to take into account when dealing with complaints is the personality traits of the complainer and the complainee since this would also affect its production and comprehension.

\subsubsection{Complaint structure and moves}

Geluykens and Kraft (2008) claim that the communicative act of complaining is regarded as a complex communicative act that typically occurs "as substrategies of conflict talk" (p. 102). The authors also contend that complaints are more complex than other speech acts such as apologies or requests in the sense that "they do not have clearcut components which are discernible as the complaint proper" (102). This view is also shared by Laforest (2002, p. 1597), who writes "[i]t is all the more difficult to capture theoretically, given that there is no prototype of it, as there is for request or the excuse". Thus, the speech act of complaints seems not to have a prototypical or recurrent set of semantic formulae as might happen in other speech act such as requests or refusals, where there is a clear classification to categorise each strategy.

I also support this view because a complaint can be performed in different ways and consequently it seems rather complex to establish the prototypical speech act behaviour of this specific pragmatic aspect. Furthermore, due to its complexity, it is challenging to ensure that a given taxonomy can capture all the different semantic formulae. Hence, this speech act appears to be more complex than other speech acts in which identifying a recurrent set of strategies, form example in the case of requests or refusals, is less demanding. As reported by MárquezReiter (2013), research devoted to examining talk-in-interaction shows that complaints do not usually contain an adjacency pair structure but extended sequences (Drew and Walker, 2009) that are constructed when participants assume the roles of story-tellers and story-recipients (Heinemann, 2009). Because of these aspects that make this speech act 
further complex, a discourse perspective should be adopted to explore the communicative act of complaints appropriately (Geluykens and Kraft, 2008).

As shown, it seems that there is no a consensus in the classification of the speech act of complaints as several speech acts can be combined to express this communicative act. In performing a complaint, the complainer, for example, would not employ a performative verb, i.e. "I hereby complain", and Illocutionary Force Indicating Devices ${ }^{6}$ (IFIDs) are not typically used as an initiation, e.g. I "would like to complain", (Geluykens and Kraft, 2008). Regardless the complexity of the realisation of this speech act, several researchers have proposed different discourse functions to describe this particular communicative act (Olshtain and Weinbach, 1987, 1993; Laforest, 2002). In this section I attempt to provide a review of various classifications that have been employed to examine the speech act of complaints. One of the first speech act sets is proposed by Schaefer (1982), Inoue (1982) and Giddens (1981) who conduct parallel studies on oral complaints produced by NSs of Japanese (Inoue, 1982), Mexican Spanish (Giddens, 1981) and American English (Schaefer, 1982). Specifically, the authors examine the syntactic and semantic formulae of spoken complaints produced by the NSs of the aforementioned languages. Schaefer (1982, p. 14-15) identifies nine different discourse functions, including:

1. Opener: referring to an utterance initiating the speech act set without giving information about the wrong, e.g. "Listen, Jimmy"

2. Orientation: relating to an utterance giving the speaker's intent in initiating the complaint, but with no detail, e.g. "I've been meaning to talk to you about the rubbish you've been leaving outside"

$6 \quad$ IFIDs was coined by Searle (1969) and it shows "how the proposition is to be taken, or to put it another way what illocutionary force the utterance is to have" (p. 16 
3. Act statement: involving an utterance which states the problem directly, e.g. "This is the fourth time this month you've been really late!"

4. Justification of the speaker: implying an utterance explaining why the speaker is making the complaint and the effects of the wrong on the speaker, e.g. "because I...you're making me miss the lectures by turning up late"

5. Justification of the addressee: referring to an utterance giving a reason or excuse for the addressee having committed the wrong or considering the effect on the addressee, e.g. "Is this time particularly difficult for you?"

6. Remedy: consisting of an utterance calling for some corrective action, e.g. "This is going to have to stop"

7. Threat: including an utterance stating an action the speaker might take, depending on the reaction of the addressee, "I, er... could take it higher than just talking to you"

8. Closing: relating to an utterance made by the speaker to conclude the complaint set, e.g. "OK, thanks"

9. Valuation: involving an utterance expressing the feelings of the speaker about either the addressee or the problem, e.g. "It's really disgusting"

This structure is adopted by Piotrowska (1987) in a study that examines the speech act of complaints, elicited by learners of English and NSs of English at Hong-Kong University by means of role-plays. Piotrowska (1987, p. 27-28) adds eight discourse functions:

1. Societal justification: referring to an appeal to socially accepted values and norms of behaviour, e.g. "because other people are not going to be pleased to have it smelling outside their houses" 
2. Request for explanation: involving an utterance calling for an explanation for the addressee's behaviour, e.g. "I mean, why do you do it?"

3. Blame: including an utterance finding fault with or holding the addressee responsible for the wrong, e.g. "You realise 'cause you're late again..."

4. Resignation: implying an utterance expressing a verb shrug of the shoulders, e.g. "Sorry about that, but that's just the way it is"

5. Conciliation: referring to an utterance attempting to restore harmony, e.g. "Well, it's not too bad, but..."

6. Persuasion: including an attempt to move the addressee, e.g. "Wouldn't take long"

7. Indirect disagreement: relating to an utterance expressing indirect disagreement, e.g. "Well, it might be public, but..."

8. Request for agreement: referring to an utterance seeking ground with the addressee, e.g. "Isn't it making your flat smell?"

Moreover, the study conducted by Piotrowska (1987) revealed more discourse functions, specifically:

1. An expression of gratitude, e.g. "Thank you for your co-operation"

2. An appeal for understanding, e.g. "I hope you appreciate and understand my situation"

3. An apology, e.g. "I'm sorry"

4. A counter to a denial, e.g. "I've evidence and other neighbours will..will, er..support me that his is you to done this..to do this"

5. Asking for an opinion, e.g. "What's your opinion?"

6. Plea, e.g. "so please do me a favour, as much as you can"

Another structure of complaints can be observed in the study conducted by Olshtain and Weinbach (1987) who carry out a study that explores the speech act of complaint as produced by NSs and NNSs of 
Hebrew by means of written DCTs. Specifically, the authors seek to provide a description of the main semantic formulas employed in the communicative act of complaining and compare those formulas used by NSs and NNSs of Hebrew. In this study, the authors distinguish different complaint discourse functions based on the severity of the complaint (1987, p. 202):

1. Below level reproach: when the speaker avoids an open confrontation with the hearer in order not to offend him/her; e.g. "No harm done, let's meet some other time"

2. Disapproval: when the speaker does not clearly express a complaint but shows that a kind of offence has been done without referring explicitly to the nature of offence and the person who did it; e.g. "It is a shame that we have to work faster now"

3. Complaint: when the speaker expresses a complaint and refers to the SUA, or hearer, or both, without mentioning any consequences; e.g. "You are always late for these meetings and now we have less time to do the job"

4. Accusation and warning: when the speaker decides to utter an open FTA and express the potential consequences of the offence that the hearer made, e.g. "Next time don't expect me to sit here waiting for you"

5. Threat: when the speaker attacks the hearer verbally, e.g. "If we don't finish the job today I'll have to discuss it with the boss"

As shown, this study proposes following a scale for the severity of complaint so as to account for the speech act set of complaints. The author states that further studies comparing various types of complaints in different contexts are needed so as to explore the validity of the suggested speech act sets. For example, this study reveals that both groups of participants seem to employ all the discourse functions available and that participants cluster around the centre of the scale, 
preferring disapproval, complaints and accusation to the softened and polite below the level of reproach and the extreme FTA threat.

Another influential classification is proposed by Trosborg (1995). The author investigates interlanguage complaints in Danish learners of English in comparison with NSs of English. Data for this is study is collected by means of role-plays. Trosborg (1995, p. 316-319) classifies complaints into eight subcategories, which are marked according to the level of directness and indirectness, which ranges from Category 1, the most indirect, to Category 4 , the most direct:

1. Category 1 No explicit reproach: The complainer might avoid conflict using hint strategies in which the complainable is not mentioned.

1.1. Strategy 1 Hints: The complainer does not directly state that something is bad and then the complainee does not know whether an offence is referred to or not. It might be used to prepare for more forceful strategies, e.g. "There was nothing wrong with my car yesterday".

2. Category 2 Expression of annoyance or disapproval: the complainer might express his/her annoyance, dislike, disapproval, etc. towards a particular complainee's act.

2.1. Strategy 2 Annoyance: the complainer by expressing his/her state of affairs, he/she holds the complainee responsible but avoids mentioning him/her as the guilty person, e.g. "Oh dear, I've just bought it"

2.2. Strategy 3 Ill consequences: the utterance might express some ill consequences that derive from an offence for which the complainee is implicitly responsible e.g. "Oh, damn it, I'll lose my insurance bonus now"

3. Category 3 Accusation: in this case the purpose is to establish the agent of a complainable. Two level of directness are identified: 
3.1. Strategy 4 Indirect: the complainer may ask the hearer questions about the situation or assert that he/she is somehow associated with the offence and then try to establish the hearer as the potential agent of the complainable (implicit accusation), e.g. "You borrowed my car last night, didn't you?"

3.2. Strategy 5 Direct: the complainer may directly accuse the complainee of having committed the offence (explicit accusation), e.g. "Did you happen to bump into my car".

4. Category 4 Blame: the act may presuppose that the accused is guilty of the offence. As shown below, three different levels of explicitness are identified and in all cases the complainer expresses judgement on the complainee:

4.1. Strategy 6 Modified blame: the complainer expresses modified disapproval of an action for which the accused is responsible e.g. "You should take more care with other people's car"

4.2. Strategy 7 Explicit blame (behaviour): the complainer explicitly states that an action for which the accused is held responsible is bad e.g. "It's really too bad, you know, going round wrecking other people's cars"

4.3. Strategy 8 Explicit blame (person): the complainer explicitly states what is implicit at all other levels, namely, he/she finds the accused a non-responsible social member, e.g. "Oh no, not again! You really are thoughtless"

In this study the author finds that in comparing the complaints performed by the NSs of English and NSs of Danish, the strategies used by the two groups are rather similar as regards annoyance, which occurs frequently, and hints, accusation and blame, which happen less frequently. Results also show that when speaking to an authority, English speakers tend to adjust their strategies more than Danish 
speaker do. Moreover, data also reveals that when addressing to a person of higher standing, Danish learners of English appear to vary their strategies frequently.

In 1996 Murphy and Neu conduct a study that examine complaints as performed by NSs of English and Korean learner of English by means of oral DCT. The authors, drawing on Cohen and Olshtain's (1981) speech act set of apology, attempt to identify the semantic formulas of the speech act of complaints. Data reveal the following speech act set of complaints (1996, p. 199-203):

1. Explanation of purpose used by the complainer to explain the purpose to his/her interlocutor, e.g. "Hello Professor Filano. Uh, I got my paper back here and after looking through it..." (NSs' example, 1996, p. 199).

2. Complaint: a complaint is initiated when the complainer perceives that he/she has been treated unfairly, e.g. "I think, uh, it's my opinion maybe the grade was a little low" (NS' example, 1996, p. 200). Some participants, i.e. 11 Korean NNSs of English, seem to have not produced complaints, but criticism, e.g. "But you just only look at your point of view and uh you just didn't recognize my point" (NNS' example, 1996, p. 200).

3. Justification of the complaint: a justification shows that the complainer can support his/her claims, that he/she can explain why he/she is complaining, e.g. "I put a lot of time and effort in this..." (NS' example, 1996, p. 201)

4. Candidate solution (request or demand): an utterance that is proposed by the complainer as a way to solve the problem, e.g. "I would appreciate it if you would consider my grade" (NS' example, 1996, p. 201)

The authors find a high correlation between NSs and NNSs when producing explanation of purpose, justification, and candidate solution. 
However, NSs and NNSs appear to differ in the performance of complaint.

In addition to this, more recently, further classifications for the speech act of complaints have been advanced. For example, Laforest (2002, p. 1600-1602) conduct a study based on spoken corpus of family conversations in Montréal. Specifically, the author proposes the following discourse functions:

1. Allusion to an offensive act or behaviour: the typical form is an assertive utterance with no evaluation or no second person markers. It involves an utterance without explicit mention of the act or behaviour and without calling into question the complainee, e.g. "My birthday's on the $30^{\text {th" }}$.

2. Justification of discontent: an utterance indented to show that the complainer is justified in protesting about the act or behaviour being criticised. The utterance tends to express the result or consequence of the offensive act so the performance of the complaint is focused on the speaker, i.e. the victim, rather than on the offensive act or behaviour. In this case, no typical form is identified, e.g. “Every time it's just like: Let's say it's just like you wanted to say Well get up lazy bones let's go see Sophie! Get up lazy bones let's go see Sophie!”. As the author explains, in this example the offensive act involves repeating the same request frequently. The speaker evokes the effect the repletion has on him, which may give him the impression that he is being treated as lazy.

3. Request that the complainee justify his/her offensive act or behaviour: the typical forms are: "why are you doing/di you X; What are you doing X for?", e.g. "What are you staring at me for Nathalie you're making me nervous".

4. Mentioning the offensive act or behaviour: it shows a statement of the offending act or behaviour addressed to the complainee. The typical forms are: “you're doing/you did X; you're not doing/you 
didn't do $\mathrm{X} ; \mathrm{X}$ is [negative evaluative adjective/too much/not enough]; $\mathrm{X}$ again", e.g. "You TALK, you spit on ME, you get it [food] all over your FACE!"

5. Requesting that the complainee change behaviour or make up for the offensive act or behaviour: in this case, the request might become an order. The typical forms are "You're not going to $\mathrm{X}$ anymore; I don't want [you to] X; are you through Xing?", e.g. "I don't EVER want, to see it AGAIN. [the speaker hits the table] I'm NOT putting the red place-mat out for you!"

6. Adverse criticism of the hearer an utterance without mentioning the offensive act or behaviour or anything else that could be associated with the preceding categories. Typical forms are "you are [negative evaluation]; you [disappointed me/made me mad, etc.]", e.g. Aaaaah! You stupid IDIOT!

The author argues that the discourse functions identified concur with previous research on complaints. However, they also show the special character of the data of the study. In this study, the author not only focused on the performance of the speaker but also on the hearer, thereby, different to the above describe classifications of the speech act of complaints, Laforest (2002) also account for the responses to complaints. Laforest (2002, p. 1597) points out that "[f]rom an interactional standpoint, if we take the complaint as the first part of an adjacency pair, there is no typical corresponding second part: the complaint can be followed by a denial, rejection, justification, making excuses, etc". Laforest (2002), pointing to the work of Newell and Stutman $(1989,1990)$ on verbal confrontation, indicates that few studies have focused on the response to complaints. Laforest (2002) argues that there are many ways of responding to a complaint, which can be included into two main categories: (1) acceptance of the fact that a supposedly shared rule has been broken; and (2) rejection of the fact. However, the author also admits that this dichotomy might not capture 
some responses that can be paraphrases, which involve conceding, typically implicitly, "that the complaint is well founded, but only in part" (2002, p. 1605). The other option is rejecting the complaint, in which the complainee ignores the complaint, either by remaining silent or by performing something that has nothing to do with the complaint. Concerning this, Laforest (2002, p. 1605) expands the responses to complaints to four discourse functions including:

1. Acceptance of the complaint responses should be equivalent to the remark "it's true". Two different discourse functions are identified 1.1. Admitting responsibility for the act/behaviour complained about, e.g. "Ah I was going to put it away"

1.2. Excusing oneself; "I am daydreaming I'm sorry".

2. Partial acceptance of the complaint as in the previous one, responses should be equivalent to the remark "it's true". Two different discourse functions are identified

2.1. Justifying oneself the complainee's strategy involves arguing that he/she has good reasons for behaving as he/she does, e.g. "[tone of protest] I took a PEE!"

2.2. Not taking the complaint seriously reacting by laughing or joking, e.g. "(laughs) Do you promise me not to tell your sister about it?[Nathalie is an only child]"

3. Rejection of the complaint responses to complaints must be equivalent to the remark "no, I didn't break the rule". Three different discourse functions are identified

3.1. Denying the complaint an utterance indicating that "I didn't do/I don't do what you criticized/criticize me for doing”, e.g. "No! I ate the big one. There's still some left".

3.2. Counterattacking complaining or accusing back, e.g. "YOU'RE THE ONES who interrupted me!". Denial is implied in these cases. 
3.3. Not acknowledging the act/behaviour complained about as a problem/challenging the speaker's assertion in these cases, there is a refusal to acknowledgement the complaint, insofar that the complainee does not agree to consider that the act or behaviour in question is blameworthy, e.g. "[tone of protest] What's wrong with it?"

4. Disregarding the complaint the complaint is manifestly ignored, as the complainee remains silent, continues with an intervention unrelated to the complaint or, if the complaint is very indirect, takes it literally and then ignores the function of the complaint, e.g. the complainer utters "Hey are you though spitting on me?" and the response of the complainee is " 3 -s pause)".

The data examined in this study, which, as aforementioned, is taken from a corpus of family conversations, shows the preferential discourse functions of the speech act of complaint taking into account not only the perspective of the complainer but also the responses uttered by the complainee. The author indicates that the preference organisation of the discourse functions might be associated in part to the intimacy of the relationship between the interactions.

More recently, Chen, Chen and Chang (2011, p. 260-261) carry out a study that examines, by means of DCTs, the speech act of complaint as elicited by NSs of English and NNSs of English (Chinese). Drawing on the data, the authors identify six types of discourse functions

1. Opting out: when the complainer does not say anything, usually involving situations in which issuing a complaint is socially acceptable.

2. Dissatisfaction: when the complainer asserts the complainable but does not explicitly mention the complainee. Typically, they are expressed in the form of simple statement beginning with "I", "My 
+ noun phrase", "We" or "Our + noun phrase", e.g. "My letter was opened".

3. Interrogation: when the complainer presupposes that the complainee is responsible for the offence and questions him/her. It is usually expressed by means of wh-questions and yes-no questions, e.g. "Why did you open my letter?"

4. Accusation: the complainer charges the complainee with having committed an offence. It is usually expressed in the form of a simple statement beginning with "You" or "Your + noun phrase", e.g. "You opened my letter".

5. Request for repair involves two functions, p. the first one is compensation where the complainer expects the complainee to compensate for the offence, and the second function refers to a change in behaviour where the complainer expects the complainee to stop the offence or prevent repetitions of the offence. Requests are analysed according to the Cross-Cultural Speech Act Realization Project7 (CCSARP) (Blum-Kulka, House and Kasper, 1989), then the realisations are categorised as hedged performative, i.e. an utterance whose illocutionary verb expressing the requestive intent is modified for examples by a model verb, e.g. "I would like to ask you to give me extra pay"; and as want statement, i.e. an utterance that expresses the speaker's desire for the hearer to perform the act, e.g. "I want to get off duty on time" (examples taken from Chen et al., 2011, p. 264).

6. Threat when the speaker attacks the hearer openly by pointing out the consequences caused by the offence, e.g. "If you open my letter again, I'll move out”.

7 CCSARP is one of the most influential ILP projects. The aim of this project was to provide speech act realization data from speakers of different L1 and L2, which was intended to be comparable for cross-cultural studies. 
The authors indicate that although interrogation and accusation incorporate both the complainable and the complainee, interrogation is less direct than accusation since in the case of the interrogation room for complainee's explanation is given. The data elicited by the NSs of English was examined by two North American teachers in Taiwan and the data elicited by the Chinese participants by the researchers of the study.

As shown in the above literature review, several authors have provided different structures of the speech act of complaint. Similarities and differences across the structures of complaint reviewed may be observed. For example, Olshtain and Weinbach (1987) and Chen et al. (2011) present a structure of complaints drawing on written data elicited by means of DCTs, while the remaining structures of complaints are based on or designed to account for spoken data. Interestingly, Laforest (2002) presents a structure of complaints drawing on authentic spoken data, rather than on simulated spoken data (e.g. Trosborg, 1995). This is important since, typically, in ILP studies, simulated data is gathered, rather than naturally occurring data (see Chapter 1). Nevertheless, Trosborg (1995) attempts to employ a spoken elicitation technique, i.e. enactment role-plays, which, as aforementioned, appears to capture the dynamics of spontaneous interactions in a different way role-plays do. Moreover, it is important to note that all the structure of complaints described (expect for Laforest, 2002) are employed to examine data elicited by NSs and NNSs of the TL to explore the speech act of complaints from a cross-cultural perspective.

Concerning the structure, it is worth mentioning that Schaefer (1982) is the only author that accounts for the opening and the closing of the conversation, specifically in the discourse functions of opener and closing. The remaining structures of complaints above reviewed focus directly on the complaint itself, and the opening and closing is not explicitly shown. This is reasonable for studies employing written DCTs (Olshtain and Weinbach, 1987; Chen et al., 2011), since interaction is 
rarely observed (but see for example Martínez-Flor and Usó-Juan, (2010b) and Beltrán-Palanques (2013, 2016a) who argue for the use of interactive written DCTs). This could be associated to the fact that the focus of those studies is to analyse speakers' complaint behaviour, rather than the overall conversation, which could include opening and closing. Concerning this, Trosborg's (1995), in her description of supportive moves ${ }^{8}$, account for example for preparators and disarmers. The former is part of the organisation of the conversation in which a complaint happens in the sense that they are used to prepare the complaint situation, e.g. "Listen, Lene, there is something I want to talk to you about, you remember our agreement, don't you" (1995, p. 330). The latter involves the avoidance of producing an act that is too FTA. Thus, the complainer needs to save complainee's face and consequently his/her own face, too, e.g. "Look, I don't want to be horrible about it" (1995, p. 330)

It is worth mentioning that if studies examining spoken data also account for opening and closing moves (Schaefer, 1982) or supportive moves (Trosborg, 1995), further aspects of the overall communicative event might be explored. Schaefer (1982) also includes orientation (an utterance giving the speakers' intent in initiating the complaint), Trosborg (1995) hints (the complainer does not directly state that something is bad) and Murphy and Neu (1996) explanation of the purpose (used by the complainer to explain the purpose to his/her interlocutor). These discourse functions might sever to initiate the complaint event without explicitly focusing issue and being too direct, instead they could be used to prepare the situation and utter further moves. From a different perspective, Olshtain and Weinbach (1987) include below the level of reproach, in the complainer when he/she avoids the complaint situation in order not to offend the other interlocutor or the opting out proposed by Chen et al. (2011). In

$8 \quad$ Trosborg (1995, p. 329) defines supportive moves as "supportive strategies used to justify the complainer's right to place the blame for something on the complainee". 
performing this type of utterances, the complaint situation might be avoided and therefore communicative event in which a complaint situation takes place might be seen as finished.

Regarding the discourse function of justification, several authors have included this specific move in their classifications, for example, justification of the speaker and justification of the addressee (Schaefer, 1982); societal justification (Piotrowska, 1987); justification of the complaint (Murphy and Neu, 1996); and justification of discontent (Laforest, 2002). Schafer (1982) provides two different discourse functions for justification: the first one seems to address why the complainer is complaining and the effect that the offence might have on the complainer; whereas in the second, the author refers to an utterance that is performed in order to give a reason or excuse for the complainee having committed the offence. Piotrowska (1987) discourse function of justification, however, attributes an appeal to social accepted values and norms of behaviour, rather than a support for the complainer to complaint; as in the case of Murphy and Neu (1996) and Laforest (2002). Laforest (2002), similar to Schaefer (1982), also argues that justification of discontent might reflect the consequence of the offensive act on the speaker, or the victim.

Some studies also account for the discourse function of threat (Schaefer, 1982; Olshtain and Weinbach, 1987; Piotrowska, 1987; Chen et al., 2011) and blame (Piotrowska, 1987; Trosborg, 1995). Regarding threat, Schaefer (1982) indicates that it refers to an action that the speaker might take, whereas Olshtain and Weinbach (1987) and Chen et al. (2011) indicate that threat involves attacking the complainee, and the latter also adds that threat is limited to uttering the consequences caused by the offence. In the case of blame, Trosborg (1995) presents three levels of explicitness: modified blame (expresses modified disapproval of an action), explicit blame behaviour (expresses explicitly that the action the complainee has committed is bad) and explicit blame person (expresses explicitly what is implicit at all level, for example, 
finding the complainee a non-responsible social member). In a different way, Piotrowska, (1987) also deals with blame pointing that it involves an utterance that expresses an action the complainee is responsible for.

Another discursive function that has been identified by researchers in the field is request, for example: request for explanation and request for agreement; candidate solution, which involves request or demands; request that the complainee justify his/her offensive act or behaviour, and request for change behaviour or make up for the offensive act or behaviour; and request for repair. Request for explanation (Piotrowska, 1987) and request that the complainee justify his/her offensive act or behaviour (Laforest, 2002) appear to be rather similar insofar both pursue an explanation or a justification for the offence. Request for agreement seems to focus on the seeking of ground with the complainee. Although not exactly the same, Murphy and Neu (1996) propose the use of candidate solution, which is uttered to solve the problem Chen's et al. (2011) request for repair, which can be used to obtain some kind of compensation on the part of the complainee or a change in behaviour and avid repetitive actions of the offence; thereby similar to Laforest's (2002) request for change behaviour or make up for the offensive act or behaviour, although in this case, the request might become an order. In line with this, although not considered as requests, the discourse function of conciliation proposed by Piotrowska (1987), whose purpose is to restore harmony, seems to concur with repair, or even remedy, proposed by Schaefer (1982), which refers to an utterance produced to claim for some corrective action. Other discourse functions that involve the complainee to do something could be could be for example an appeal for understanding, plea, ask for opinion (Piotrowska, 1987).

The discourse function of disapproval is also identified by Olshtain and Weinbach (1987) and Trosborg (1995). On the one hand, Olshtain and Weinbach (1987) argue that disapproval involves an utterance in which the complainer does not clearly express a complaint but indicates 
that a particular offence has been done. However, explicit reference to the nature of the offence and the complainee are not made. On the other hand, Trosborg (1995), in the structure of complaints, includes a discourse function known as expression of annoyance or disapproval, which is further divided into annoyance and ill consequences. Following Trosborg (1995), this specific discourse function, i.e. expression of annoyance or disapproval, is performed when the complainer expresses his/her annoyance, dislike, disapproval, etc. towards the complainee's act. Annoyance involves an utterance in which the complainer expresses his/her state of affair towards the particular situation but the complainee is not mentioned. Trosborg's (1995) approach to annoyance differs, to some extent, from Olshtain and Weinbach's (1987) disapproval in the sense that in this move, the complainer does not clearly express a complaint, whereas in Trosborg's (1995, p. 316), the complainer shows his/her annoyance, dislike, disapproval, etc. towards the complainee's act. This author further adds that "[b]y explicitly asserting a deplorable state of affair in the presence of the complainee, the complainer implies that he/she hold the complainee responsible but avoids mentioning him/her as the guilty person" (p. 316). In both structures, however, these discourse functions involve that the complainee is not explicitly referred to. Chen et al. (2011) also propose a similar move, dissatisfaction, in which the complainer indicates the offence but does not explicitly mention the complainee. Continuing with Trosborg (1995), the author also places under the umbrella of expression of annoyance or disapproval the move of ill consequences in which the complainer expresses some consequences that derive from the offence for which the complainee is implicitly responsible. Concerning this, the author argues that in performing an utterances involving annoyance, the complainer may also express ill consequences. This is, however, not observed in Olshtain and Weinbach's (1987) disapproval and Chen's et al. (2011) dissatisfaction. 
In Olshtain and Weinbach's (1987) accusation and warning, the complainer, who performs an open FTA, expresses also the consequences of the offence. In line with this, Chen et al. (2011) also advances the discourse functions of accusation, by which the complainer charges the complainee with having committed an offence. However, the authors do not include the consequences of the act in this discourse function. Trosborg (1995) also includes this specific discourse function, accusation, which is divided into indirect and direct. The former involves an implicit accusation in which the complainer may ask the complainee questions about the situation or assert that he/she is somehow associated with the offence, and the attempts to make the complainee responsible for the offence. The latter relates to an explicit accusation, in which the complainer directly accuses the complainee for having committed a particular offence. Similarly, Schaefer (1982) includes act of statement in which the complainer expresses the problem directly. Thereby, in line with Olshtain and Weinbach's (1987) complaint since the complainer expresses a complaint and refers to the SUA, the complainee, or both. Laforest (2002) includes in her structure of complaints mentioning the offensive act or behaviour in which the complainer expresses a statement as regards the offensive act that is addressed to the complainee. A similar discourse function is included in Murphy and Neu's (1996) structure of complaints, specifically, complaint, which is performed when the complainer perceives that he/she has been treated unfairly.

Other discourse functions involve for example persuasion (complainer attempts to move the complainee), indirect disagreement (expressing disagreement), resignation (shrug of the shoulders) (Piotrowska, 1987) or valuation (Schaefer, 1982), in which the complainer expresses feelings towards the complainee or the problem, thus the complainer provides evaluative comments on the either one or the other. Piotrowska (1987), in her study, also identifies other discourse functions such as counter to denial and apology. Chen et al. 
(2011) include interrogation, which relates to the use of both whquestion and yes-no questions. Laforest (2002) also includes allusion to the offensive act of behaviour in which the complainer performs an assertive utterance in which no explicit mention to the offence is made and the complainee is not called into question. Moreover, Laforest (2002) also proposes a discourse function involving an adverse criticism of the hearer, in which the complainer expresses an utterance without mentioning the offence.

Concerning responses to complaints, only one of the reviewed studies accounts for responses to complaints, the one proposed by Laforest (2002). The other works, however, only account for the perspective of the complainer. In order to examine the whole communicative act, it seems important to capture not only the utterances expressed by the complainer but also by the complainee. The responses elicited by the complainee might affect complainer's view of the situation, and consequently his/her utterances. As described above, Laforest (2002) proposes four different discourse functions: (1) acceptance of the complaint involving admitting responsibility for the act or behaviour and excusing oneself; (2) partial acceptance of the complaint that is divided into justifying oneself and not taking the complaint seriously; (3) rejection of the complaint including denying the complaint and counterattacking, and not acknowledging the speakers' assertion, and (4) disregarding the complaint.

As reviewed, some of the discourse functions seem to overlap or are similar, albeit singular nuances are identified. For example, some authors identify moves that are not common across the other structures, as in the case of Piotrowska, (1987), i.e. persuasion, indirect disagreement, resignation, counter to denial, apology; Schaefer (1982), i.e. opener, closing and valuation; Laforest (2002), i.e. allusion to the offensive act of behaviour and adverse criticism of the hearer or, Chen et al. (2011), i.e. interrogation. Discourse function which reflect an interest for not entering a complaint situation are also provided, for 
example, by Olshtain and Weinbach (1987) and Chen et al. (2011). Other discourse functions, albeit different, appear to express similar content, for example, orientation (Schaefer, 1982), hints (Trosborg, 1995), and explanation of the purpose (Murphy and Neu, 1996). Discourse functions concerning justification have been identified by various authors (Schaefer, 1982; Piotrowska, 1987; Murphy and Neu, 1996; Laforest, 2002), although, as reported, some differences among them are found. Some authors also account for threat (Schaefer, 1982; Olshtain and Weinbach, 1987; Piotrowska, 1987; Chen et al., 2011) and blame (Piotrowska, 1987; Trosborg, 1995), and as in the case of justification, variation across them can be found. This is also the case of requests, which have been also included in various structures of complaints (Piotrowska, 1987; Murphy and Neu, 1996; Laforest, 2002; Chen, et al., 2011). The approach taken to define disapproval moves (Olshtain and Weinbach, 1987; Trosborg, 1995), as above described, appears to differ, too, and to some extent, Chen et al.'s (2011) dissatisfaction seems to concur with disapproval. A move of accusation is also found in some classifications such as those proposed by Olshtain and Weinbach (1987), who also include warning, Trosborg (1995) and Chen et al. (2011). In line with this, moves in which the complaint itself is expressed are also found, such as in the structure of Schaefer (1982), Olshtain and Weinbach (1987), Murphy and Neu (1996) and Laforest (2002), which are to some extent similar to accusation.

In short, there are some commonalities among the structure, but it seems that some discourse functions are specific of the data examined. This might, to some extent, reflect the complex nature of this specific speech act in which there is not a set of recurrent strategies or at least not as clear as in the case of other speech acts. All of them might be valid to explore the speech act of complaints, and because of this, for the purpose of the present study, a structure for complaints moves, including the perspective of the complainer and complainee, is designed. 
What follows is a proposed structure of the speech act of complaints to examine the data of the present study, which is based on previous research. In fact, in order to study the speech act of complaints at the discourse level, it is necessary to account for the whole spectrum, thereby including complainer's and complainee's perspectives. This proposal attempts to describe the complaint behaviour of the spoken data of this investigation. What is shown here should be regarded as a starting point for classifying complaint moves. This structure is flexible and might be, if necessary, modified to account for participants' performance. Thus, further discourse functions might be considered when necessary to better describe the interaction between the participants, or contrarily, do not include them as they data do not reveal any instance. Regarding this, as it will be described in detail in Chapter 4, it is important to consider that data derives from a spoken corpus driven and a CA approach is followed to examine data. Consequently, a dynamic and open classification of complaint moves may be more appropriate for the purpose of the current study. In designing this structure, the following aspects have been also taken into account (1) the speech act of complaint is a complex communicative act that does not have a fixed classification; (2) different moves can be combined to utter the speech act of complaints; (3) moves of the complainer and the complainee are needed to account for an analysis of the whole conversation.

Drawing on Swales' (1981) seminal work, a text may be organised into different moves. According to Swales, moves signal specific sections in texts. These sections have their own communicative purpose which forms part of the overall communicative purpose of the text in question. The notion of move has been widely used both for written and academic text. This notion helps defining the different parts of a complaint.

This study presents a new approach to better define speech act taxonomies: to take the perspective of moves and their communicative purpose within an event. This allows us to observe the relationship 
between sequences and their discourse functions. From this point of view, any speech may or may not have an opening and a closing move. Then, a complaint event can be further divided into: pre-complaint, topic negotiation and post-complaint. In focusing on conversation, the structure of moves should account not only for the moves involving a complaint, but also those move that may be part of the whole conversation, thereby including also an opening and a closing. The opening move might serve to open the conversation. Following this, speakers might be involved in the complaint itself, which is divided into three different moves, the pre-complaint moves in which the complainer introduces the topic and the complainee responses to such a new input; the topic negotiation, where both participants develop various discourse functions as regards the complaint act; and postcomplaint moves in which both participants may attempt to repair the situation. Finally, the closing move is used to close the conversation. It is true, however, that the first and the last moves are not associated to the act of complaining, but as indicated, they might be part of the whole conversation and consequently it is believed that they should be part of the proposed structure of the complaint as it may have an influence on the interpersonal relation of the participants.

The present suggested structure of moves might serve to classify the different discourse functions elicited in the course of a conversation involving a complaint, which I present here. Hence, drawing on previous research on complaints (Schaefer, 1982; Piotrowska, 1987; Trosborg, 1995; Laforest, 2002; Chen et al., 2011) and responses to complaints (Newell and Stutman, 1989, 1990; Laforest, 2002), the following moves are suggested. Table 3 best illustrates the different discourse functions. 
Chapter 2. The speech act of complaints and proficiency effects

Table 3. Complaint structure Complainer and complainee

\begin{tabular}{|c|c|c|}
\hline \multirow{2}{*}{ Moves } & \multicolumn{2}{|c|}{ Discourse functions } \\
\hline & Complai & Complainee \\
\hline Opening & \multicolumn{2}{|c|}{ Greetings } \\
\hline \multirow{7}{*}{$\begin{array}{l}\text { Complaint } \\
\text { (pre-complaint, topic } \\
\text { negotiation and post- } \\
\text { complaint) }\end{array}$} & Preparation & Acceptance \\
\hline & Allusion to the & Apology \\
\hline & Dissatisfaction & Justification \\
\hline & Evaluation & Not taken it seriously \\
\hline & Accusation & Tonic_chanoe \\
\hline & Blame & \\
\hline & $\begin{array}{l}\text { Request } \\
\text { Gratitude }\end{array}$ & \\
\hline Closing & \multicolumn{2}{|c|}{ Terminal exchange } \\
\hline
\end{tabular}

Table 3 displays the structure of complaints used to classify the different discourse functions of the spoken data compiled for this study. The opening move accounts for the discourse function of greetings, which may be used to open the conversation. The opening move might be followed by the complaint move, where speakers might perform specific discourse functions.

Concerning the figure of the complainer, the following discourse functions are suggested (1) preparation; (2) allusion to the offensive act; (3) dissatisfaction, (4) evaluation; (5) accusation; (6) blame; (7) request; and (8) gratitude.

Preparation is included following Trosborg' (1995) supportive moves, specifically preparators. This particular discourse function can be used by the complainer to prepare the complainee for a forthcoming action that involves a complaint. Allusion to the offensive act involves an utterance in which the complainer refers to or alludes to the offensive act in an implicit manner and without directly pointing to the complainee (Laforest, 2002). The discourse function of dissatisfaction relates to an utterance in which the complainer shows that he/she is not pleased with a particular act or behaviour without explicitly mentioning the complainee (Chen et al., 2011). Evaluation refers to an utterance by 
which the complainer may show evaluative comments towards the act or the behaviour, the complainee, or both. Thus, the complainer analyses the situation and performs an evaluative comment. This discourse function is based on Schaefer's (1982) valuation, in which the complainer expresses feelings towards the complainee or the problem. Accusation is based on Trosborg (1995) and Chen et al. (2011) and it serves to charge the complainee with the offence. Blame, drawing on Piotrowska (1987) Trosborg (1995), involves an utterance by which the complainer directly expresses that the complainee is responsible for a given offence, either an act or behaviour. Request relates to an utterance performed in order to make the complainee do some, for example, change behaviour (Laforest, 2002), provide an explanation (Piotrowska, 1987), etc. A division of different types of requests is not done and in the study they are accounted as requests and then the specific typology is not described (but see for example Chen et al., 2011). Finally, gratitude is also included, as in Piotrowska (1987), involving an utterance performed to express gratitude towards a particular act or behaviour. However, this particular move might be also performed form an ironic perspective.

As regards the complainee, the following discourse functions have been suggested (1) acceptance; (2) apology; (3) justification; (4) not taken it seriously; and (5) topic-change. These discourse functions might be employed by the complainee to response to the complainer's utterances. Acceptance involves an utterance in which the complainee accepts the responsibility for the act or behaviour, thereby similarly to Laforest's (2002) acceptance of the complaint and admitting the responsibility for the act or behaviour complained about. The discourse function of apology might be performed to show that an error has been committed. In performing an apology, the complainee may reveal his/her assumption of the offence (Ohbuchi, Kameda and Agerie, 1989). Justification relates to an utterance that provides a reason for which something that has been done by including arguments that show why 
the offence has been committed. Not taken it seriously relates to an action in which the complainee elicits utterances that reveal that he/she does not take into account what is previously said by the complainer. Finally, topic-change refers to an utterance that the complainee performs to change the topic as he/she is not interested in talking about the offensive act or behaviour.

Other discourse functions that involve denying or ignoring the complaint (see Laforest, 2002) could have been included in this classification of responses to complaints. However, differently to Laforest (2002), data for the present study is not made up of naturally occurring data where real instances of responses to complaints are observed. Rather, data of this study is gathered by means of a simulated task, specifically a role-play, and participants are language learners who do not have any real implication with the offence presented in the task and their utterance do not have any impact in real life (see Roever, 2010). Therefore, due to the lack of real-life consequences, it is difficult to ascertain whether responses such as denying the complaint or ignoring it might occur. By the same token, in the case of the complainer, the discourse function of opting out (Chen et al., 2011) could be also included. Nevertheless, this is only a prediction and then if these moves occur, they can be included. Some of the discourse functions above described as regards the complainer and the complainee could have been divided into subcategories, as for example Trosborg (1995) does. However, this option, albeit initially considered, was not finally taken.

Having described the possible discourse functions for the complaint move, attention is now paid to the last part, i.e. closing move. In this case, the same discourse function is proposed for the complainer and the complainee, specially a terminal exchange which is used to finish the conversation.

Speakers, however, might not necessarily perform the three moves, as this would depend on the type of discourse function that they 
elicit. As observed in the above table, the discourse functions are not explicitly classified as part of a particular move since it is complex to predict the moves that may be used to accomplish each part and as indicated, speakers might not necessarily go through the different moves to develop their conversation. It is, however, true that for example a preparation discourse function, in the case of the complainer, is typically used in the pre-complaint move, but probably it is the only one that is clearly used for such purpose and therefore not included in either the topic negotiation move or the post-complaint. This classification of complaints and responses to complaint should be regarded as open in the sense that further discourse functions might be included if necessary to account for a better representation of the complaint behaviour.

In the following section I provide a literature review of the speech act of complaints.

\subsubsection{Research on complaints}

Several studies have been conducted in order to examine the communicative act of complaints; however, the body of literature, in comparison to other speech acts such as requests, is somehow reduced. In this section, I provide a literature review of influential studies that have carried out to examine the speech act of complaints. The literature review serves to provide an overview of research findings as regards the speech act of complaints and therefore assess what has been done so far, determine whether there is a research gap, and see which contribution the present study can make to the analysis of the speech act of complaints. Table 4 presents an overview of these studies, introducing the objective of the research and the type of instrument used to carry it out, a description of the participants, and the most outstanding results.

It is important to note thought some studies relied on written data by means of DCT, while other on spoken data that was gathered by 
means of oral DCTs, role-plays (either closed or open), enactment method, or natural data compiled in a spoken corpus. However, as these studies have shown, it is worth mentioning that typically DCT only allow participants to elicit one turn, whereas other instruments such as open role-plays provide researchers with opportunities for exploring data, in this case complaints, from an interactive perspective (see for example Laforest, 2002). The study conducted by Laforest might not be framed within the field of ILP since its purpose differs from the definition of ILP. However, this work was included in this literature review since the author focused on complaints and responses to complaints, which is the perspective taken for the current study. Consequently, although it might not follow the same procedure as the other studies and its objectives could be different to some extent; it was decided to incorporate it due to its relevance for the study of complaint sequences. 


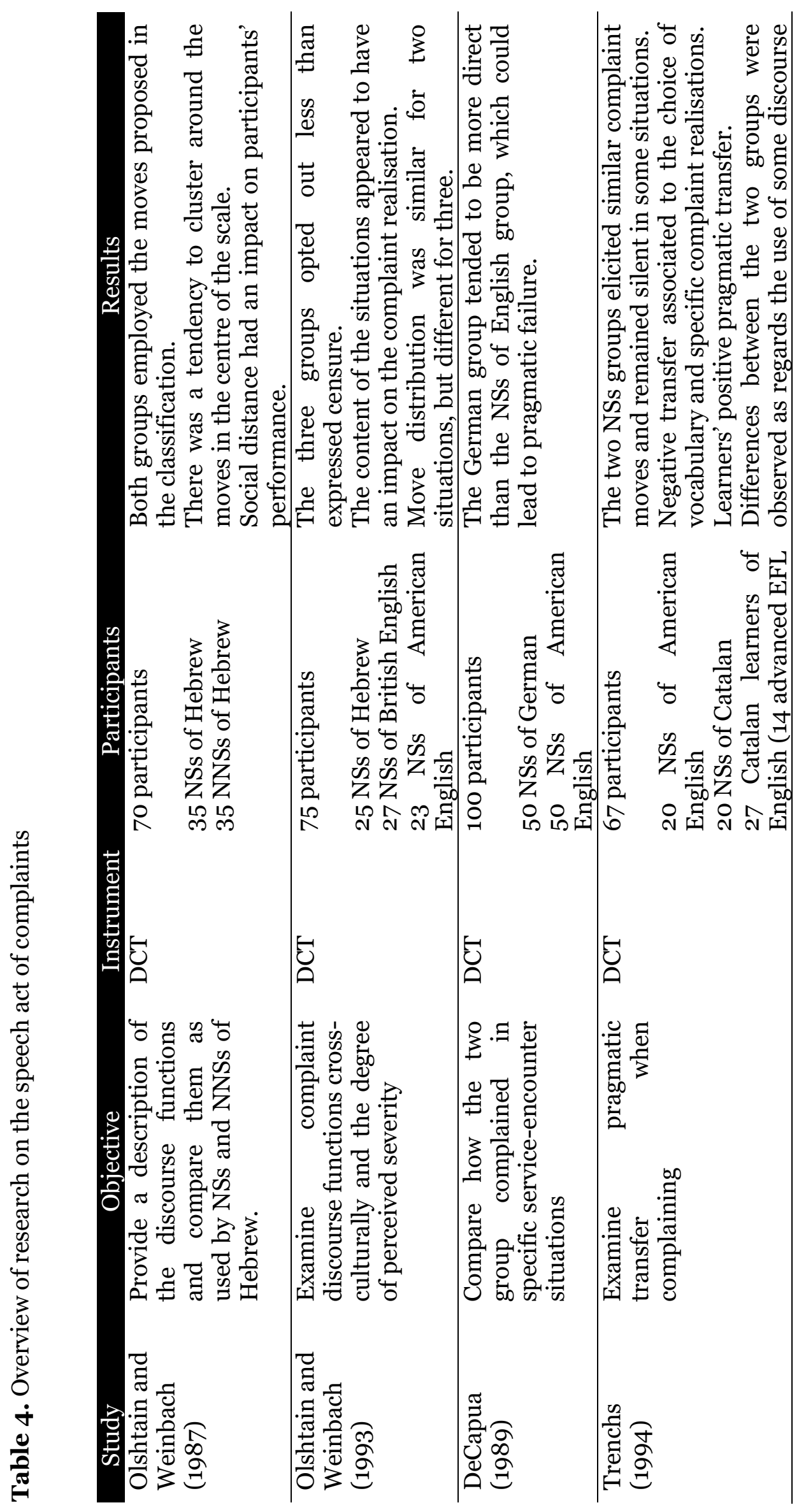




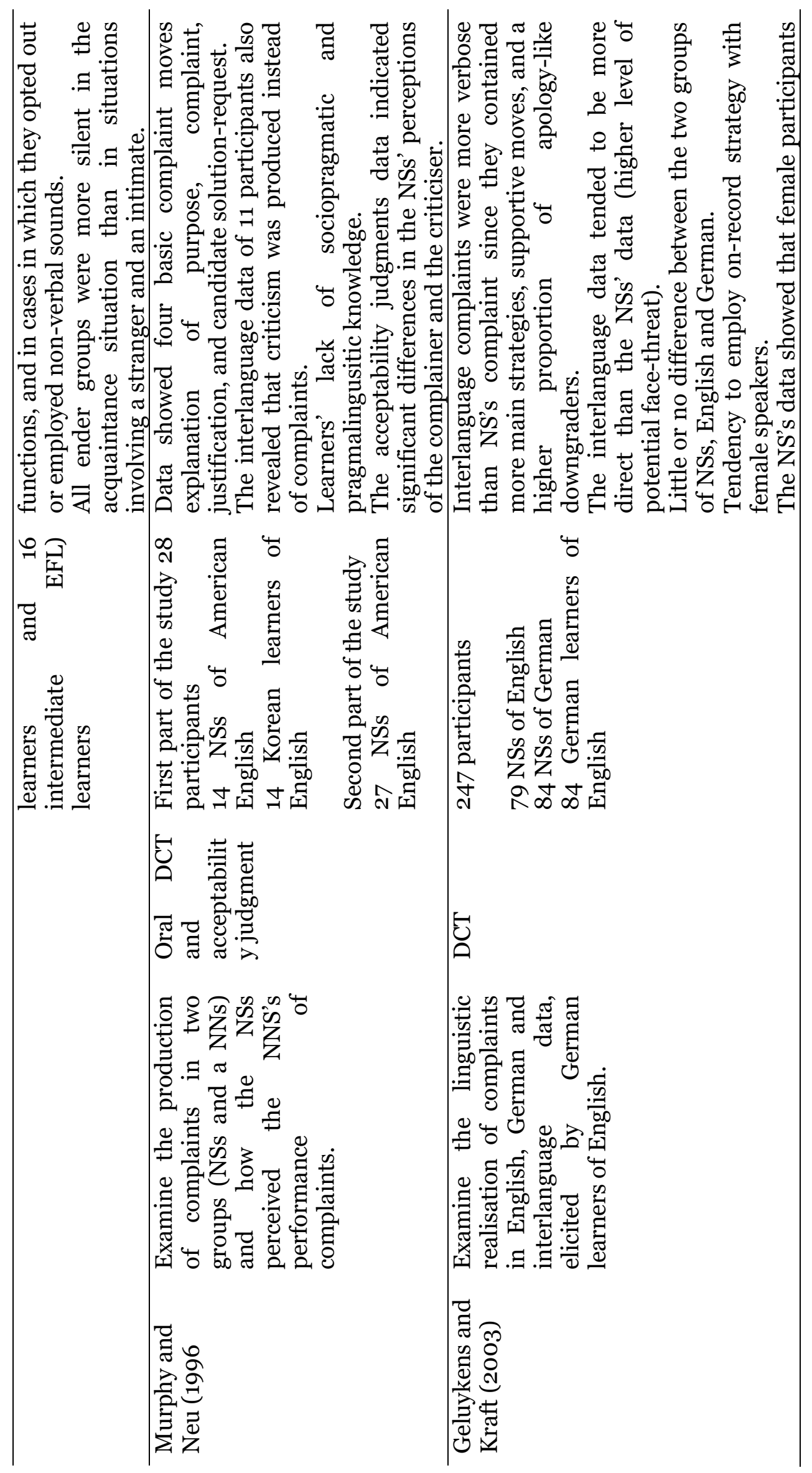




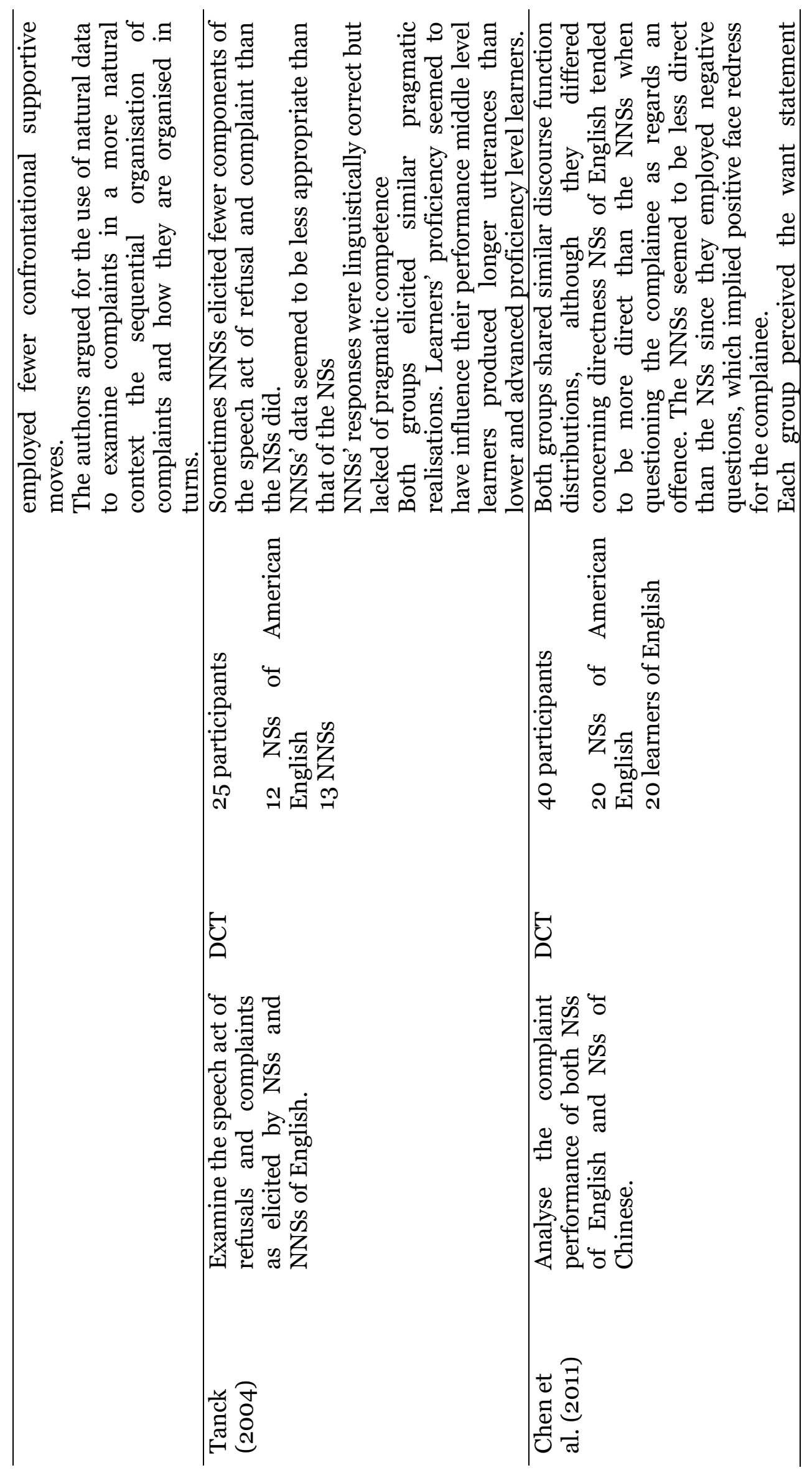



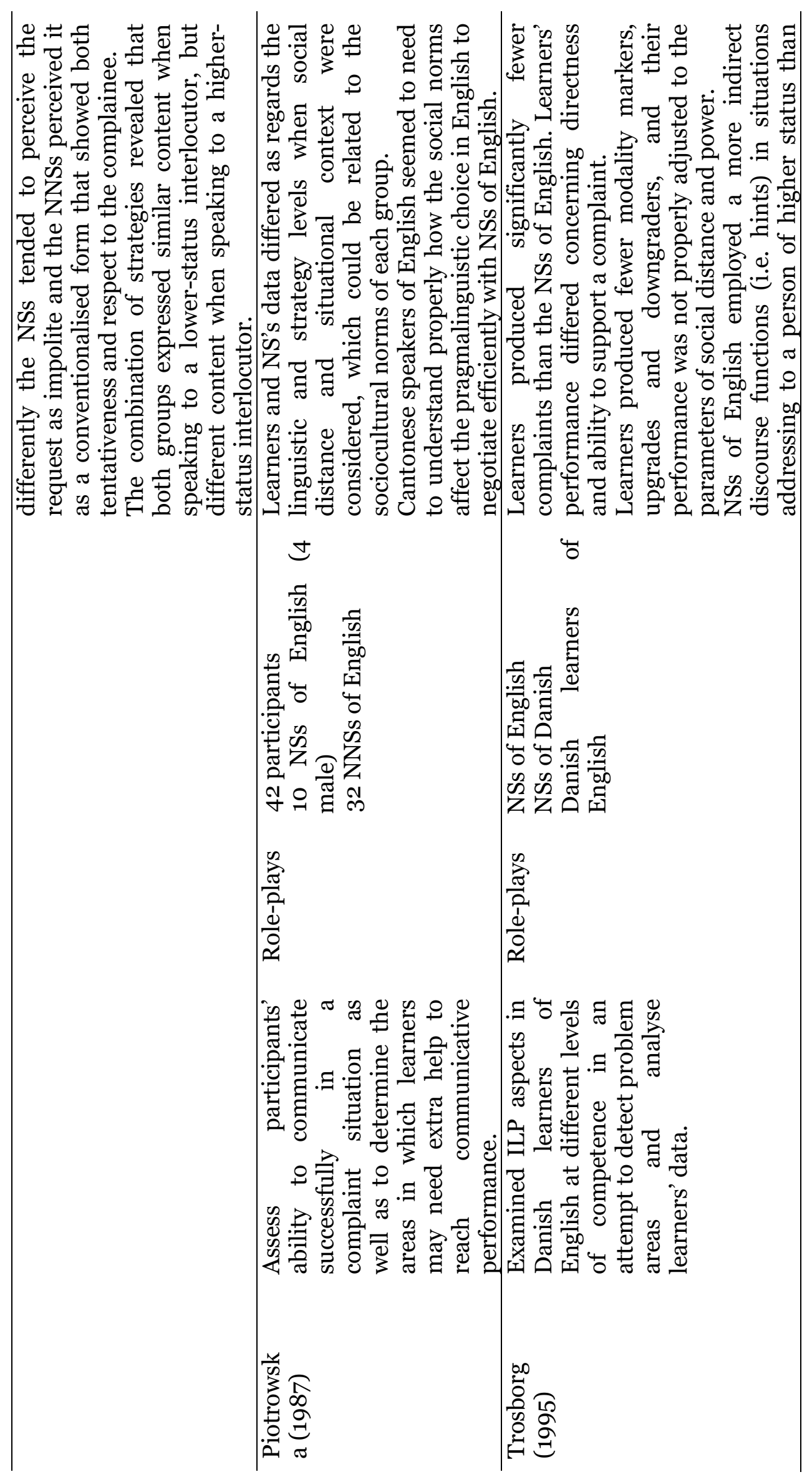


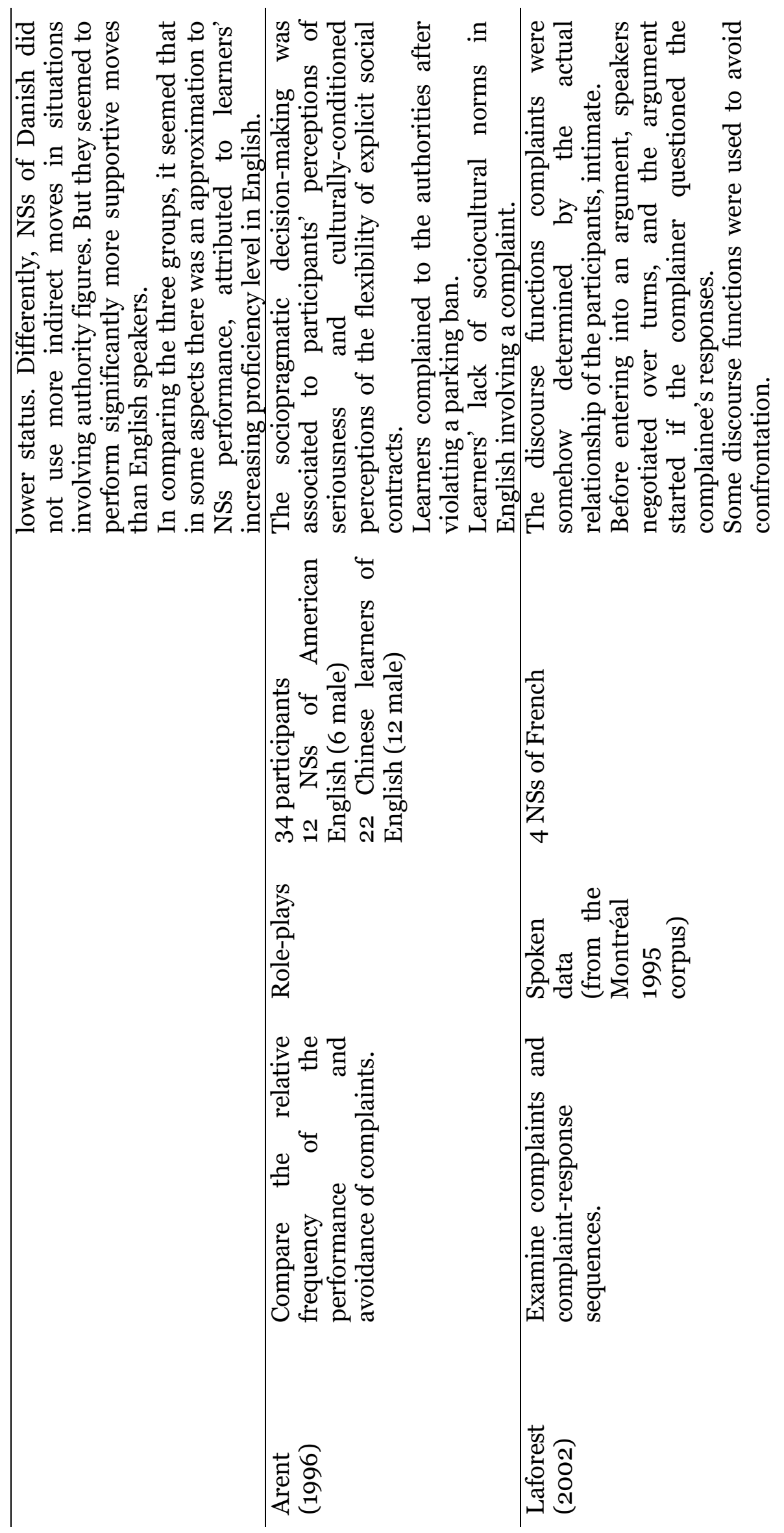


The studies above reviewed attempted to examine the pragmatic behaviour of the speech act of complaints, and also responses to complaints in one of the studies described. Most studies explored the speech act of complaints from a by examining data elicited by NSs of the TL and interlanguage learners' data (Olshtain and Weinbach, 1987; 1993; Piotrowska, 1987; DeCapua, 1989; Arent, 1996; Murphy and Neu, 1996; Tanck, 2004; Chen, et al., 2011), while a reduced number did by means of NSs of the TL, interlanguage learners data, and learners L1 (Trenchs, 1994; Trosborg, 1995; Geluykens and Kraft, 2003), and only one by means of natural data (Laforest, 2002). As seen, the TL that was commonly examined in the studies described was English.

Despite the fact that the studies reviewed might have different specific objectives, the major goal is to explore the pragmatic realisation of the speech act of complaints. Olshtain and Weinbach (1987), for example, attempted to examine the different sources employed to elicit complaint so as to provide a description of the complaint behavior. Other studies such as those conducted by Murphy and Neu (1996) or Laforest (2002) also revealed different discourse functions, who, differently for example to Olshtain and Weinbach (1987), explored complaints and responses to complaints in authentic spoken data, rather than in written simulated data. Olshtain and Weinbach (1987, 1993) and Laforest (2002) consider that there is a speech act set ${ }^{9}$ of complaints that is made up of various discourse functions that can be combined so as to create the complaint move.

The majority of the studies above described attempted to examine the realisation of complaint discourse functions as performed by NSs of the TL and learners of the TL (e.g. Olshtain and Weinbach, 1987; Piotrowska, 1987; Trosborg, 1995; Arent, 1996; Murphy and Neu, 1996; Geluykens and Kraft, 2003; Tanck, 2004; Chen, et al., 2011), while other also addressed for example learners' pragmatic competence by

9 Speech act set is defined as an internal composition of semantic formulas, which might be universal for some speech acts although their realisation could be language-specific (Olshtain and Cohen, 1983). 
focusing on problem areas (Piotrowska, 1987; Trosborg, 1995), and one examined the organisation of complaints and responses to complaints in natural data (Laforest, 2002).

The study conducted by Olshtain and Weinbach (1993) intended to examine the degree of perceived severity of the SUA found in the situations employed. Perceptions, although differently, were also examined by Murphy and Neu (1996) who employed a questionnaire to examine acceptability judgments. This questionnaire was intended to gather information as regards NS's perceptions of NNSs performance. In line with this, Arent (1996) also explored participants' perceptions of situational seriousness. Some authors have focused on pragmatic transfer, for example DeCapua (1989), who found that the NNSs tended to be more direct than the NSs leading to a pragmatic transfer from learners' L1, and Trenchs (1994), whose study revealed that transfer was observed in learners' data, for instance in the choice of both vocabulary and specific complaint realisations, while the two groups of NSs (i.e. American English and Catalan) exhibited similar complaint discourse functions.

Concerning discourse functions, the study conducted by Olshtain and Weinbach (1987) showed for example that there was a tendency to cluster around the centre of their classification of complaints, avoiding the two extremes of the scale, and in the study carried out in 1993, data revealed that similar moves were identified in some of the situations, but different in others. Trenchs (1994) found different as regards the performance of some discourse functions, specifically joking, preaching and cursing, as well as in cases in which participants opted out or used non-verbal sounds. Murphy and Neu (1996) found that the four complaint moves they suggested were elicited by the participants of the study. This study also showed that criticism was employed instead of complaints, which could be associated to participants' lack of pragmatic competence. Similarly, the lack of pragmatic competence was also pointed by Tanck (2002) in a study involving the speech acts of refusals 
and complaint. The author found that, although in general learners' performance was appropriate and that they have acquired a high level of pragmatic competence in the ESL context, in some cases, results also showed that learners' pragmatic elements were not properly received by the interlocutors. Trosborg (1995) found that learners produced fewer modality markers, upgrades and downgraders, and their performance was not properly adjusted to the parameters of social distance and power. Geluykens and Kraft's (2003) study demonstrated that interlanguage complaints were more verbose as they employed more main strategies, supportive moves, and a higher proportion of apologylike downgraders. Moreover, the author also found that the interlanguage data tended to be more direct than the NSs data, revealing higher level of potential face-threat.

The level of directness was also identified by the study conducted by Chen et al. (2011) who pointed out that when questioning the complainee about the offence, the NSs of American English appeared to be more direct than the Chinese participants. The latter group seemed to be less direct than the former group in that they employed negative questions, thereby showing positive face readdress for the complainee. Trosborg (1995) also pointed that learners elicited fewer complaints than the NSs of English and that their performance differed for example in terms of directness and ability to support a complaint. The NSs of English group seemed to be more indirect in situation involving higher status than lower status. Differently, the NSs of Danish were not more indirect in higher status situations, but they employed more supportive discourse functions than the NSs of English. Moreover, data revealed that, in comparing the three groups, there was an approximation to NSs performance, which could be associated to learners' proficiency level. The variable of proficiency level was pointed by Tanck (2004), too, suggesting that it had an effect on participants' performance in the sense that middle level learners produced longer utterances than lower and advanced level learners. 
The impact of sociocultural norms was also observed in Piotrowska's (1987) study, who found that learners and NS's data differed in terms of linguistic and strategy levels when social distance and situational context were considered, revealing learners' need to acquire the target social norms that involved in English to negotiate a complaint successfully. Arent (1996) found that the sociopragmatic realisation was associated to participants' perceptions of seriousness and to culturally-conditioned perceptions. The study conducted by Chen et al. (2011) indicated that participants for example perceived the want statement differently since the NSs tended to perceive the request as impolite, while the NNSs perceived it as a conventionalised form, showing both tentativeness and respect to the complainee.

Finally, Laforest (2002), in her study on complaints and responses to complaints found that participants' relationship might have also affected participants' performance since they were intimate. Moreover, the study showed that speakers tended to negotiate before entering into an argument and the same moves were used to avoid such confrontation. Data for this study, as indicated, was not collected by means of any elicitation instrument. Rather, it belonged to a spoken corpus of natural occurring data. The importance of examining complaints from an interactive perspective has been also claimed by Geluykens and Kraft (2003) could reveal the sequential organisation of complaints and how conversation is organised in turns.

This section has focused on the speech act of complaint by addressing its definition, some influential structures of complaints, which are of paramount interest for the present study as they have been used to propose the structure of complaint sequences, including complaint and responses to complaints, some of the most influential studies conducted to explore the communicative act of complaints Having reviewed those aspects, in what follows I focus on the variable chosen for the present study, specifically, proficiency. 


\subsection{Proficiency and interlanguage pragmatics}

The effect of language proficiency has been widely examined in the field of ILP. Findings seem to suggest that there is an advantage of proficiency on pragmatic performance (Kasper and Rose, 2002). However, a high level of grammatical competence does not guarantee a high level of pragmatic competence (Bardovi-Harling, 1999, 2000). Bardovi-Harlig (1999) indicates that grammatical competence and pragmatic competence are independent, although a lack of grammatical competence might cause an utterance to be less effective. Additionally, Barron (2003) indicates that grammatical competence is a prerequisite of pragmatic competence, and the way they correlate with each other is not a linear way. In this section, I first provide an overview of ILP studies exploring proficiency effects from different perspectives and using different data collection instruments, other than spoken elicitation instruments. In what follows, I focus on studies in which proficiency effects has been examined as regards spoken data.

\subsubsection{Overview of proficiency effects on ILP}

Literature on ILP research, however, shows that the effect of the variable of proficiency has been tackled from various perspectives, with different focus and using different research instruments. For example, some studies have examined the role of proficiency in participants' pragmatic and grammatical awareness (Harling and Dörnyei, 1998; Niezgoda and Roever, 2001). Bardovi-Harlig and Dörnyei (1998) analysed the extent to which instructed L2 learners of English were aware of differences in learners' and TL production in grammar (addressing the accuracy of utterances) and pragmatics (addressing the appropriateness of utterances). Results revealed that FL learners and their teachers appeared to consistently identify and rank grammatical 
errors as more serious than the pragmatic errors. Contrarily, the ESL group seemed to recognise a greater number of pragmatic errors than grammatical ones, and rank pragmatic error as more serious than grammatical errors. Following Bardovi-Harlig and Dörnyei (1998), Niezgoda and Roever (2001) examined whether the context of learning could influence learners' awareness of pragmatic and grammatical errors, as well as whether learners' proficiency level could influence their degree of awareness of pragmatic and grammatical errors. This study also showed that learners in the FL context recognised statistically more pragmatic and grammatical errors than the learners in the SL context did.

Pragmatic transfer has been also addressed (Koike, 1996; Maeshiba, Yoshinaga, Kasper and Ross, 1996; Wannaruk, 2008). For instance, Maeshilba, et al. (1996) focused on pragmatic transfer from L1 Japanese to L2 English in a study involving NSs of English and Japanese learners of English. Results revealed that in situations in which Japanese and American elicited apologies were the same, and learners showed positive transfer from Japanese apologies. However, significant differences between the two proficiency levels were not observed. In situation in which Japanese and American apologies were different, advanced learners showed transfer as regards their apology behaviour from L1 to L2. Hence, it seems that more advanced learners appeared to minimise negative L1 transfer. Also, some studies have shown that proficiency effects on pragmatic competence seemed to have been mediated by other variables (e.g. Shardakova, 2005; Xu, Case and Wang, 2009; Bardovi-Harlig and Bastos, 2011).

Using different research instruments, self-reported recognition task, a context identification task, a DCT and a modified Vocabulary Knowledge Scale (developed by Wesche and Paribakht (1996)), BardoviHarlig (2008) investigated the relationship between recognition and production of formulaic expressions. ESL learners ranging from intermediate to advanced proficiency level participated. Results 
indicated that all participants reported high recognition scores, although production scores were lower production scores. Proficiency seemed to have a positive effect on the self-reported recognition task since higher proficiency level learners showed higher recognition scores than lower ones. There was, however, no significant increase in production scores in the two proficiency level groups.

Other studies have examined written data elicited by means of DCTs (e.g. Pérez-i-Parent, 2002, Tank, 2004; Sabaté-Dalmau and Curell-Gotor, 2007). Sabaté-Dalmau and Curell-Gotor (2007), focusing on apologies, showed positive effects of proficiency on interlanguage production. The study involved NSs of English and Catalan EFL at three different proficiency levels, i.e. intermediate, advanced and proficient. Findings revealed that higher proficiency level learners exhibited a greater range of apology strategies and they were less likely to employ non-target-like apology expressions. Also, more proficient learners performed more lexical intensifiers but their overall token frequency of intensifier appeared to be significantly lower than that of NSs and they showed problems producing accurate pragmalinguistic forms. Tanck's (2004) study (already reviewed in Section 2.1.3), focused on refusals and complaints as elicited by NSs and NNSs of English. Results concerning proficiency revealed that middle level learners produced longer utterances than NSs, lower proficiency level than advanced proficiency levels. This result could be related to the fact that middle level learners could be uncomfortable with their attempts to produce appropriate utterances and therefore they keep talking. The author also indicated that high proficiency level learners might not be pragmatically successful by default, but they seemed to show pragmatic success.

The above reported studies have focused on different pragmatic aspects and have examined the relationship between pragmatic competence and proficiency from different perspectives employing diverse research instruments. In the following section I focus on studies that have addressed proficiency in interlanguage spoken production. 


\subsubsection{Proficiency effects on ILP: Spoken production}

The present literature review is structured as follows; it first focuses on studies that have explored the variable of proficiency as regards different speech acts (Taguchi, 2006; 2013; Al-Gahtani and Roever, 2012; 2013; Roever and Al-Gahtani, 2015), and then, it centres on studies examining this variable as regards the speech act of complaints (Trosborg, 1995; Moskala-Gallaher, 2011).

Taguchi $(2006,2013)$ has conducted different studies examining the appropriateness of speech act production in different studies. In 2006, the author analysed the appropriateness of oral requests as produced by FL learners at different proficiency levels. Participants' proficiency level was measured by means of TOEFL scores and teachers' ratings of oral proficiency. Participants were 20 NSs of English (10 male) who were college students in the US, and 59 Japanese college students in Japan who were divided into two different groups according to their proficiency level: 29 higher proficiency level (15 male) and 30 lower proficiency level (15 male). A role-play task was employed to gather data. The task included two types of situations that differed on three factors: interlocutors' power difference (P), social distance (D), and the rank of imposition (R). Furthermore, two more methods were used to examine participants' speech act production, more specifically, a six-point rating scale to measure appropriateness, and a coding framework for requests. Then, this study examined the production of requests in PDR-high and PDR-low situations from the perspective of appropriateness and the linguistic expression. Also, the study explored whether higher and lower proficient participants differed in their oral production and which features differed across them. Findings revealed that there was a significant difference in appropriateness scores between the two groups, thereby supporting previous research that found that as learners' proficiency increases, they produce speech acts more appropriately (e.g. Roever, 2005; Trosborg, 1995). However, it 
was found only a marginal difference in the types of linguistic expression used between the two groups. Concerning the quality of speech acts, which was exemplified in the higher proficiency group, results suggested that it was associated to a combination of factors, such as overall appropriateness of linguistic expressions, grammatical expressions, and comprehension of expressions. Then, grammatical and discourse control coded in the rating scale seemed to have affected the quantity of speech acts. Broadly speaking, results appeared to support Bardovi-Harlig's (1999, p. 686) claim, "high levels of grammatical competence does not guarantee concomitant high levels of pragmatic competence". Moreover, the author argued that a complete representation of the interaction among participants' overall linguistic competence, discourse management skill, and pragmatic competence would be needed so as to better understand the nature of pragmatic competence.

Similarly, Taguchi (2013) conducted another study examining the effects of proficiency on the production of the speech act of refusals. Participants were 59 Japanese learners of English enrolled in a branch American university in Japan, where English was the medium of instruction and then participants were exposed to spoken English in their classes. However, since $90 \%$ of the students were Japanese, no extensive exposure to English outside the class was received. Explicit teaching of the speech act investigated was not provided in class. Participants were divided into two different groups according to the proficiency scored obtained in the TOEFL, which resulted in 29 higherproficiency level students (14 male), and 30 lower-proficiency students (15 male). Furthermore, 20 NSs of English, who were studying at an American university, participated in the study as baseline data (10 male). Learners' speech act production was analysed in terms of appropriateness on a six-point scale and identifying the levels of directness of the refusal strategies, and fluency, which was examined for speech rates, that is, considering the average number of words per 
minute. Results showed a significant influence of proficiency on appropriateness and fluency, and a marginal difference between the typology of refusal strategies used across the two proficiency levels. The author further added that there was an interaction between proficiency and item type, indicating that proficiency effect was larger for formal situations than for informal situation on appropriateness and fluency. Finally, the author claimed that results seemed to suggest that more target-like refusals were found in the higher-proficiency levels as a result of different factors. Specifically, the author argued that differences between the two groups might not be only related to participants' choice of target-like linguistic strategies employed to elicit refusals, but also to other factors such as grammatical and discourse competences and oral fluency.

Additionally, Al-Gahtani and Roever (2012) investigated the effect of proficiency as regards the speech act of requests by means of roleplay tasks. The authors examined learners at four different proficiency levels and centred their analysis on the sequential organisation of the interaction and the impact of participants' proficiency level. Participants were 26 male Saudi learners of Australian English, which were further divided into four different groups beginner $(\mathrm{N}=5)$, lower intermediate $(\mathrm{N}=5)$, upper intermediate $(\mathrm{N}=8)$ and advanced $(\mathrm{N}=8)$. The first three groups were ESL students in Melbourne, while the remaining group consisted of 5 master degree students at two universities in Melbourne, $1 \mathrm{PhD}$ student, and 2 physicians working at Melbourne hospitals. Participants who were taking the language course took a placement test in the language programme. The author took participants' level in the language program, and in order to confirm the upper-intermediate group and the advanced group were different, a C-test with three different texts was administered and self-reported information about their IELTS (International English Language Testing System) scores were also collected. Data was gather by means of a role-play task that included three different request situations in which the variable of 
power vary, the variables of imposition and social distance were designed as low, and the scenarios were set in an Australian English speaking environment. This study revealed that the effects of proficiency were attributed to pre-expansions and the suppliance of first-pair parts. The effects of the social variable of power were less evident. Results showed that lower level learners were less likely to perform supportive moves as pre-expansions, instead, they rely on early production of the request. Moreover, the occasional occurrence of preliminary moves in request sequences, even in the beginner group, showed that these competencies could be available to learners regardless of their proficiency levels, although proficiency might affect whether learners could use them in a real-time discourse. The sequential organisation of learners' request seemed to have a strong effect on the interlocutor. The interlocutor was less likely to introduce complexity with lower learners, and even ignored his role-play instructions by providing formulations of requests. Learners' development of interactional abilities appeared to progress from a more passive role relying on the interlocutor to a more active role introducing background information by means of preliminary moves. Also, the early provision of request and lack of pre-expansion seemed to indicate the interlocutor a lower degree of interactional ability and the need to take control of the conversation and keep complication to a minimum. Furthermore, the authors also reported that only some learners of the advanced group showed any appreciable effect of sociopragmatic ability on the structure of the interaction. Regarding this, the authors suggested that the reason why lower proficiency groups did not reveal a similar effect could be associated with the lack of socialising opportunities due to their actual context, a language school. However, it could be also that only the advanced learners had sufficient linguistic ability to notice, in the input, how sociopragmatic rules of power affected pragmalinguistics (Roever, 2009). 
In a similar vein, Al-Gahtani and Roever (2013) conducted another study exploring the variable of proficiency in interlanguage requests. This study sought to investigate how learners at different levels differed in their use of preliminary moves, how low proficiency level learners organised their requests and managed to complete their requests. Participants were made up of 26 male learners of Australian English, whose L1 was Saudi Arabic. Participants were divided into three different proficiency levels, including low $(\mathrm{N}=10)$, intermediate $(\mathrm{N}=8)$ and advanced $(\mathrm{N}=8)$. Participants from the first two groups were enrolled in an ESL programme at an Australian university, and the advanced level group were either graduate students working in Australia or postgraduate students when the study was conducted. In the case of low and intermediate participants, proficiency level was based on the placement test they took in the ESL programme that were enrolled. Regarding the advanced group, researched took into account the results they obtained in the IELTS. The interlocutor in the role-play tasks was one of the researchers, a NS of Saudi Arabic with near-native proficiency level in English. Results showed that low proficiency level learners seemed to produce shorter and less typical requests in which few or no preliminary moves were included. This result, as the authors indicated, might be associated to learners' processing of the TL, which is less automatized and more effortful at beginning level, as well as to their lexical and grammatical resources since they are more limited. The authors reported that an early placement of the request was sequentially atypical, although breakdowns in communication were not observed. The role of the interlocutor was also relevant since it seemed that the interlocutor took a more passive role with higher proficiency level learners, but a more active role when interacting with low proficiency level learners, and complications were reduced, as in Al-Gahtani and Roever (2012). Concerning the use of preliminary moves, results revealed that low proficiency learners were least probable to employ preliminary moves, while intermediate proficiency learners elicited 
preliminary moves in each role-play, and advanced level learners nearly always employed them. An analysis of the variance showed that proficiency appeared to have an effect on the occurrence of preliminary moves, and a Tamhane T2 post-hoc ${ }^{10}$ comparison revealed that there were significant differences between the low proficiency group and the intermediate and advanced proficiency levels, but not between the intermediate proficiency group and advanced proficiency group. As regards low proficiency level learners' organisation of requests, results seemed to suggest that in over half of their productions, they uttered the request directly after an opening sequence and did not perform preliminary moves. In the remaining scenarios, this group appeared to follow the typical request structure using one or more preliminary moves preceding the preliminary moves, or in one case, a combination of these two types.

More recently, Roever and Al-Gahtani (2015) conducted another study to examine the role of proficiency in learners' pragmatic performance. The authors investigated how learners at different levels differed in the linguistic tools they use for uttering requests, and whether the social situation affected the performance of requests at different proficiency levels. Participants were 26 ESL learners from Saudi Arabia who were living in Australia, and they were divided into four groups, i.e. 5 participants in the beginner group, 5 participants in the lower-intermediate group, 8 participants in the upper-intermediate group, and 8 participants in the advanced group. The first three groups were made up of learners enrolled in a university preparatory ESL programme, whereas the advanced group involved learners who had already accomplished the English requirements and were either taking tertiary studies or working. All the different proficiency groups, but the beginner group, were established according to the results obtained in the IELTS. The instrument used was a role-play task, which involved 3 different scenarios and the interlocutor was one of the researchers. The

${ }^{10}$ Post Hoc Tests algorithms 
role-plays were designed to make learners elicit requests and the only aspect that varied across the instruments was the power relationship between interlocutors. Results showed that proficiency had an effect on the different linguistic tools learners have at different proficiency levels. This study revealed that increased general proficiency level seemed to benefit pragmatic performance. Higher proficiency level learners might have more linguistic tools available for pragmatic production than lower proficiency learners, whose repertoire was more limited and their production was more message oriented. Hence, as the level increased, participants were better able to use a wider variety of linguistic tools. The beginner level learners appeared to rely on imperatives and wantstatements, while the lower-intermediate learners were able to employ some modal such as 'can'. The upper-intermediate added 'could' and the advanced group were able to use some complex expressions. Then, beginner level learners used mostly imperatives and want-statements, lower-intermediate learners could also use model 'can' in interrogatives, upper-intermediate learners included 'could', and advanced learners incorporated formulaic expression such as 'would you mind'. The authors also added that learners seemed not to show great sensitivity to the social status of the interlocutor, except for the beginner group which tended to use imperatives when the learners had higher social status and want-statements in situations involving equal or lower status. Higher-level groups, however, did not modify their request performance in order to accommodate interlocutors' social status. This led the author suggest that learners seemed to perceive requests involving modals or formulaic expressions as universal regardless of interlocutor' role, which could be therefore related to the lack of knowledge about the social norms in the TL.

Focusing on the speech act of complaints, in an early study, Trosborg (1995) employed a role-play method to elicit three different speech acts, requests, apologies and complaints. Participants were NSs of English, NSs of Danish and Danish learners of English. The author 
compared the performance of three different proficiency groups of EFL learners, involving secondary school, high school, and university. Results showed that the use of internal and external modifications seemed to improve with increasing proficiency, thereby approximating to NS's discourse functions. Moreover, advanced learners appeared to provide more explanations for requests and downgraders for complaints so as to reduce the potential threat of the act.

Finally, Moskala-Gallaher's (2011) study compared the performance and perception of this speech act, complaints, by NSs of American English, NSs of Russian, and American learners of Russian as a FL. This study attempted to establish a baseline of complaint realisations by NSs of American English and Russian in order to examine interlanguage learners' perception and performance. Participants for the study were 30 NSs of American English (15 male), 30 NSs of Russian (15 male), and 37 learners of Russian (14 male). The proficiency level was established by means of oral proficiency interview in accordance to the ACTR (American Council of Teachers of Russian), which resulted in two groups: intermediate with 25 participants (8 male) and advanced with 12 participants (6 male). Data was elicited by means of oral open-ended oral discourse completion questionnaire and an assessment questionnaire. Results of the effect of proficiency on complaints revealed that both groups seemed to have some difficulty in adjusting the complaint strategies and the level of directness. The advanced group, however, appeared to be less direct when uttering their complaints and when proposing a solution than the intermediate group. Hence, this group showed greater control of linguistic strategies that served to mitigate the offence. Nevertheless, results also showed that there were no statistically significant differences between the intermediate group and advanced group as regards the level of directness in the strategies used. Concerning this, the author suggested that this result could be related to the small sample of the study. Differences between the two proficiency groups were encountered as 
regards the number of words, the number of moves, and the frequency of downgraders and upgraders. More specifically, it was found that the advanced group performed slightly more words and moves than the intermediate group, but statistical differences were not identified. The difference as regards the number of words and moves was related to the involvement of the advanced group in the face-saving strategies. It was also found that the advanced group performed more downgraders and upgraders than the intermediate group; however, statistical differences were not observed. The author concluded that further interlanguage pragmatic studies including more participants at both proficiency levels would be needed to further examine linguistic politeness, the frequency of words and moves, and the use of mitigating and intensifying strategies.

Table 5 provides a summary of the literature review above presented. 


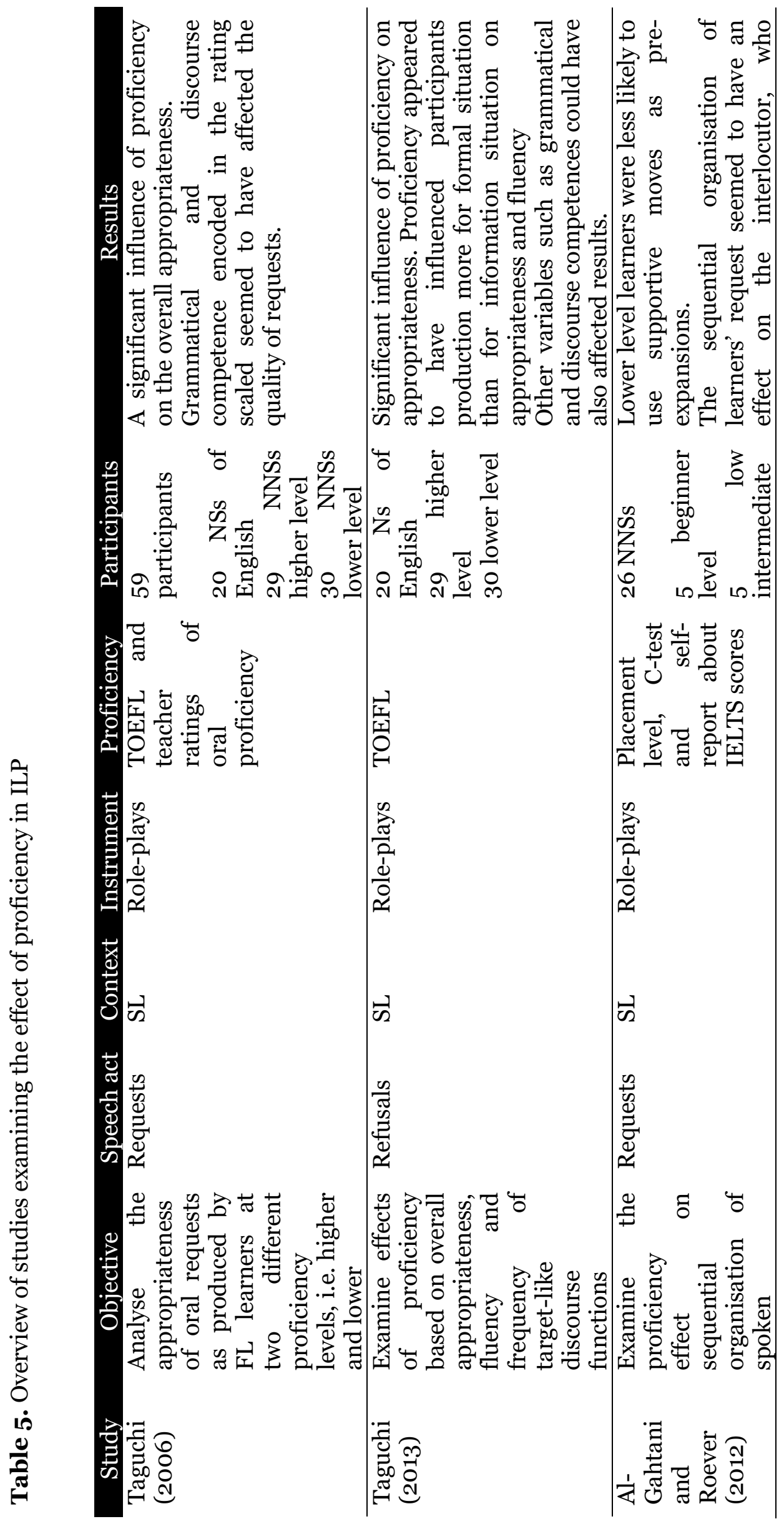




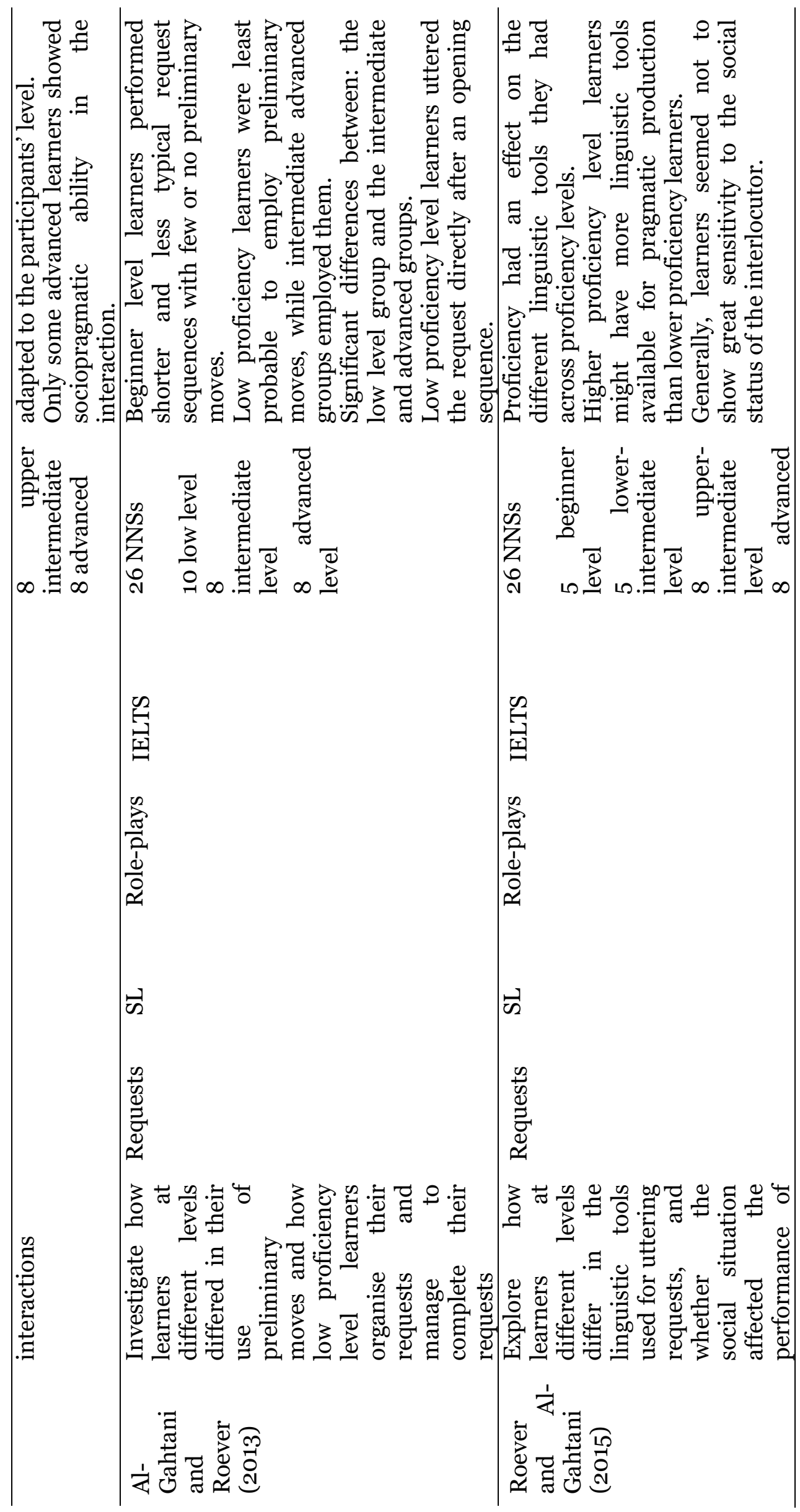




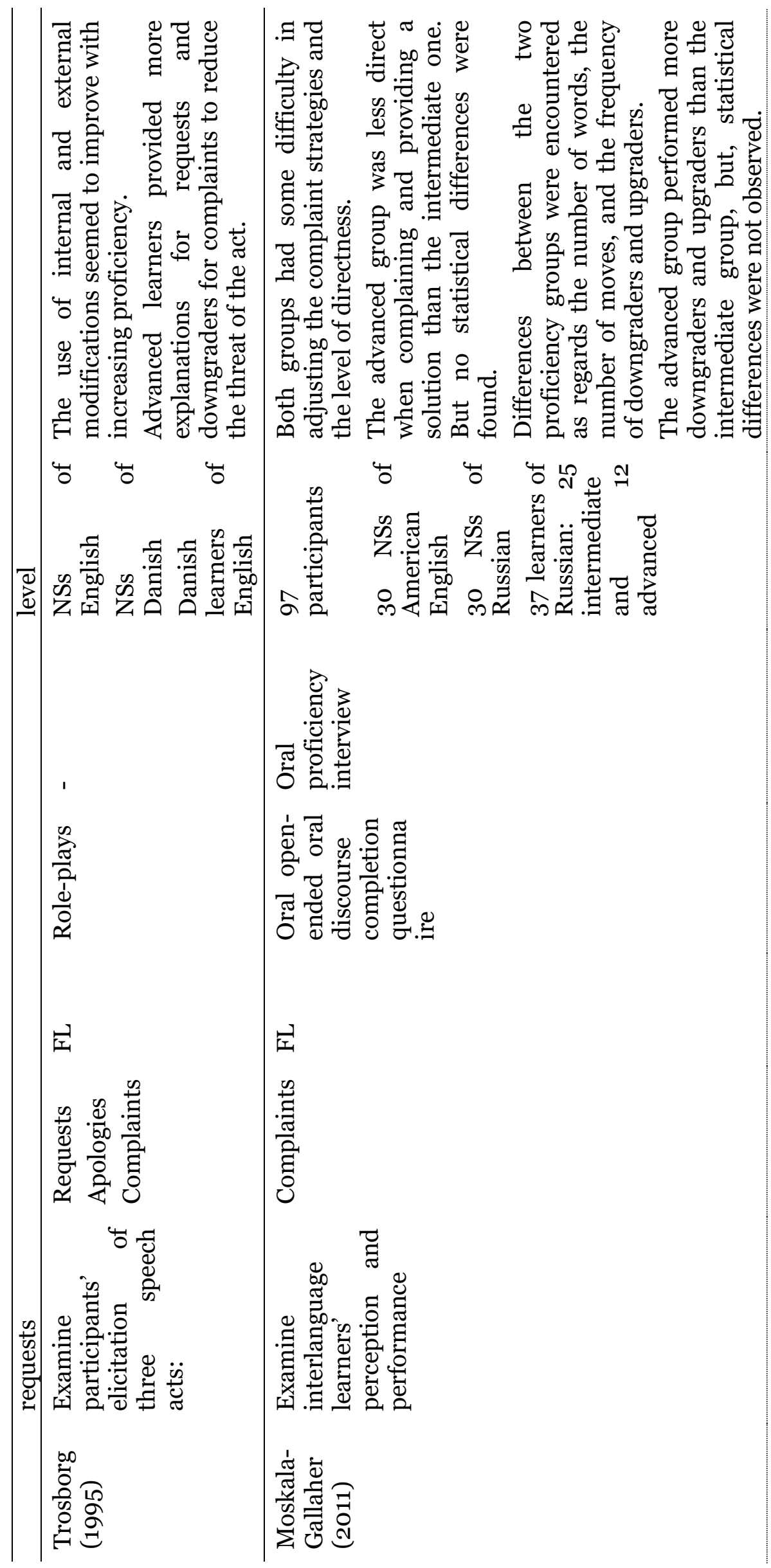


Although I have limited this literature review section to studies involving spoken data, it seems that there is a growing body of research that focuses on the effects of the variable of proficiency on speech act performance. As shown, much research has explored the speech act of requests (Taguchi, 2006; Al-Gahtani and Roever, 2012, 2013; Roever and Al-Gahtani, 2015), while a reduced number of studies have been carried out to investigate other speech acts such as refusals (Taguchi, 2013) or complaints (Trosborg, 1995; Moskala-Gallaher, 2011). A wide range of purposes are mentioned in the studies above reviewed. For example, examining appropriateness of request production at different proficiency levels (Taguchi, 2006); appropriateness, fluency and frequency of the target-like discourse functions (Taguchi, 2013); proficiency effects on sequential organisation (Al-Gahtani and Roever, 2012); effect of proficiency on leaners' use of preliminary moves and request performance organisation (Al-Gahtani and Roever, 2013); availability of linguistic resources to perform requests (Roever and AlGahtani, 2015); performance across levels (Trosborg, 1995) and perception and performance (Moskala-Gallaher, 2011).

Despite the fact that the studies reviewed might have different specific purposes, it could be argued that they are in a similar vein because they all explored the effect of proficiency in ILP performance. For example, Taguchi (2006) examined the appropriateness of oral requests at two different proficiency levels. Results seemed to suggest that proficiency had an effect on the overall appropriateness, although further issues such as grammatical and discourse competencies could have also influenced speech act performance. Focusing not only on appropriateness, but also fluency and frequency as regards refusals, Taguchi (2013) found that proficiency influenced appropriateness and fluency, although there was a marginal difference between the typology of refusal strategies uttered across proficiency levels. Interestingly, Taguchi $(2006,2013)$ pointed out other factors such as grammatical 
and discourse competencies as well as oral fluency could affect interlanguage performance.

The studies conducted by Al-Gahtani and Roever (2012, 2013) and Roever and Al-Gahtani (2015) focused on the speech act of requests. AlGahtani and Roever (2012) examined proficiency effects on sequential organisation of requests and found that lower level learners were less likely to utter supportive moves and used fewer first-pair parts, and performed the requests early replying on the interlocutor to elicit more information. Moreover, the interlocutor adjusted to learners' proficiency level in order to avoid complications. Later, in 2013, AlGahtani and Roever focused on how learners at different levels differed in their use of preliminary moves and how low proficiency level learners organised and produced requests. Results revealed that the low proficiency group produced requests by foregoing preliminary moves and uttering the requests at the beginning of the interaction. This organisation showed the interlocutor the need for assistance and collaboration over the course of the interaction. More recently, Roever and Al-Gahtani (2015), explored the influence of proficiency on learners' disposal of linguistic tools to perform requests and whether the social situation affected the performance. Findings suggested that proficiency affected pragmatic competence as regards the linguistic resources available for learners to perform requests but little sensibility towards the social situation was shown.

Concerning the speech act of complaints, Trosborg (1995), who examined the performance of requests, apologies and complaints at different proficiency levels, found that proficiency level influenced the use of internal and external modifications and that advanced learners showed more explanations for requests and downgraders for complaints. Moskala-Gallaher (2011) compared the performance and perception of complaints and found that both proficiency groups had difficulties to adjust their complaint strategies as well as the level of directness. The advanced group appeared to be less direct than the 
intermediate group, but statistical differences were not found. The same occurred as regards the numbers of words and moves, and frequency of downgraders and upgraders, where no statistical differences were found, albeit advanced learners seemed to performed more words and moves than the intermediate group, and this same group also employed more downgraders and upgraders.

The majority of the studies reviewed were both conducted in a SL context and involved participants who were NSs of the TL, as in several studies in the field of ILP. The participation of NSs would depend on the objectives of the study. While I am aware of this, in the present study NSs of English are not involved, since my purpose is not to compare NNSs of English data with NSs of English data, but to explore their interlanguage complaint behaviour across proficiency levels. The context in which the study is set might be also significant (see Wyner and Cohen (2015) for a review on individual differences according to the context). Literature has indicated that learners in a SL context could have further opportunities to employ the language for different purposes out of the formal language setting, whereas in FL context, these opportunities are mainly limited to the instructed setting. The superiority of the SL context over an FL context in pragmatic development has been demonstrated (e.g. Kitao, 1990; Bardovi-Harlig and Dörnyei, 1998; Schauer, 2006, 2009). Kasper (2001) provides an overview of studies focusing on the differences between the two contexts and concludes that SL teaching seems to have a greater potential for developing pragmatic competence. Nevertheless, Niezgoda and Roever (2001), replicating Bardovi-Harlig and Dörnyei (1998), found that the context may not be the only factor that affects the development of pragmatic awareness since individual factors could play a role. Most of the studies above reviewed are conducted in SL contexts where ESL learners might have, as indicated by literature, different opportunities for pragmatic development. This issue has been for example explored by researchers combining different variables such as proficiency and length 
of stay in the target community (see for example Bardovi-Harlig and Bastos, 2011; Shardakova, 2005; Taguchi, 2011; Xu et al., 2009).

\subsection{Summary}

Since this study examines the speech act of complaints and the effects of proficiency, a chapter has been devoted to review these two aspects. Therefore, Chapter 2, as shown, has been divided into two parts, the first one has been devoted to cover the speech act of complaints (Section 2.1) and the second one the variable of language proficiency (Section 2.2). In the first part I have focused on the definition of the speech act of complaints, indicating first that there are two different types of complaints, direct (D’Amico-Reisner, 1985) and indirect complaints (Boxer, 1993, 1996). On the one hand, direct complaint refers to a situation in which the speaker shows displeasure or annoyance for a particular action (Olshtain and Weinbach, 1987; Trosborg, 1995). On the other hand, indirect complaint involves speaker's expression of dissatisfaction to an interlocutor about oneself or someone of something that is not present in the interaction (Boxer, 1996). As indicated in this chapter, direct complaint has been chosen for the purpose of the study. Complaints, as shown, are seen as a FTA (Brown and Levinson, 1978, 1987) in which the speaker expresses the interlocutor that an offence has been done. Hence, this communicative act is used when a specific offence is committed and the speaker expresses his/her feelings towards it, and as indicated by Trosborg (1995), the complainer might hold the complainee responsible for that offence either directly or indirectly. Following Trosborg (1995), I have also indicted that in a complaint situation, at least two interlocutors are identified, a complainer, uttering the complaint, and a complainee, responding to a complaint.

Concerning the structure of the speech act of complaints, it is important to note that the act of complaints does not have a 
prototypical set of discourse functions, as the speech act of requests does, which may be confused in some cases by other speech acts such as disapproval, criticism, accusations or insults, among others (Laforest, 2002). The lack of specific structures of complaints makes the study of complaint complex since different acts can be involved in a complaint situation. In this chapter I have presented some of the influential structures of complaint discourse functions (Schaefer, 1982; Piotrowska, 1987; Olshtain and Weinbach, 1987; Newell and Stutman, 1989, 1990; Trosborg, 1995; Murphy and Neu, 1996; Laforest, 2002; Chen et al., 2011) as well as those that have served to design the classification for the present study (Schaefer, 1982; Piotrowska, 1987; Trosborg, 1995; Laforest, 2002; Chen et al., 2011). The structures of complaint presented in this chapter should be seen as a starting point to examine learners' complaint discourse functions, and therefore, it might be expanded if required to capture the nature of the complaints. This classification takes into account the perspective of the complainer and the complainee, and it is divided into different sequences: (1) opening; (2) pre-complaint moves: introducing the issue; (3) topic negotiation; (4) post-complaint: repair the situation; and (5) closing. Note that the structure proposed represents a prototypical and hypothetical view of conversation, and therefore all the different discourse functions might not be necessarily performed. Regardless of this, this sequence structure may serve to organise participants' spoken data according to the discourse functions they perform. For example, a speaker might decide to elaborate the complaint first by pointing to the situation (i.e. precomplaint), then expressing his/her feelings towards a particular action (i.e. complaint), and finally, negotiating some repair (i.e. postcomplaint). Alternatively, a speaker could opt for directly addressing the offence without taking into account the pre-complaint and the postcomplaint sequences.

I have provided a literature review of complaints including some of the most influential studies conducted as well as those which are of 
special interest for the present study. I have divided the literature review according to the research instruments employed, specifically, whether written (Olshtain and Weinbach, 1987, 1993; DeCapua; 1989, Trenchs, 1994; Murphy and Neu, 1996; Geluykens and Kraft, 2003, 2007; Tanck, 2004; Chen et al., 2011) or spoken data (Piotrowska, 1987; Arent, 1996; Laforest, 2002) were examined. This has been done purposefully since in the present study I explore spoken data. While I am aware of the differences between written and spoken data, one might not ignore the research conducted employing for example DCT eliciting written data as they are part of the body of literature of complaints. As reported in the literature review on research on complaints, most studies have only focused on the perspective of the complainer. As shown, all the studies but Laforest (2002) focused mainly on the perspective of the complainer, while in this study both perspective are taken into account.

The second part of this chapter has focused on the variable of proficiency and ILP. In this section, I have provided an overview of ILP studies examining the effects of proficiency from various perspectives, addressing for example pragmatic transfer (e.g. Maeshilba et al., 1996) or pragmatic awareness (e.g. Bardovi-Harlig and Dörnyei, 1998; Niezgoda and Roever, 2001), using different research instruments (Tanck, 2004; Bardovi-Harlig, 2008;), other than spoken elicitation instruments, and exploring the effects of various variables (e.g. BardoviHarlig and Bastos, 2011). Following this, I have presented a literature review of studies in which the variable of proficiency has been addressed in interlanguage spoken production. In so doing, I have reviewed studies involving different speech acts, such as requests (Taguchi, 2006; Al-Gahtani and Roever, 2012; 2013; Roever and AlGahtani, 2015), refusals (Taguchi, 2013), and complaints (Trosborg, 1995; Moskala-Gallaher, 2011). Results seem to suggest that the variable of proficiency may affect speech act production since learners at higher levels might have at their disposal more resources to convey the 
communicative act (e.g. Roever and Al-Gahtani, 2015). Therefore, as learners' proficiency increases, they seemed to produce speech act more appropriately (Trosborg, 1995; Taguchi, 2006). Nevertheless, in some cases statistical differences between groups have not been observed. For instance, in the study conducted by Moskala-Gallaher (2011) on complaints, who found that regardless the advanced group produced more downgraders and upgraders than the intermediate group, no statistical differences were identified. As shown, not many studies have been devoted to examine the variable of proficiency as regards the speech act of complaints and therefore there is a need to explore the effect of this variable on interlanguage complaints.

In short, in Chapter 2 I have attempted to provide a review of the pragmatic aspect examined in the present study as well as the variable chosen, i.e. proficiency. Chapter 3 centres on a different topic, particularly multimodality, where I address two elements that are part of communication, kinesics and paralanguage. 

Chapter 3. Spoken Conversation beyond Words: A Multimodal Perspective 



\section{Chapter 3. Spoken Conversation beyond Words: A Multimodal Perspective}

In this chapter spoken discourse is addressed from a multimodal perspective. I start by providing a general overview of the nature of multimodality (Section 3.1) and multimodal communication (Section 3.2), where I centre my attention to kinesic resources (Section 3.3) and provide a review of gestures (Section 3.3.1.1), facial expression (Section 3.3.1.2), gaze (Section 3.3.1.3), and head movement (Section 3.3.1.4). Following this, I address kinesics and pragmatics (Section 3.3.2) and the role of language proficiency in kinesic performance (Section 3.3.3). This is then followed by Section 3.4, where I focus on paralanguage. Particularly, I first provide an overview of the nature of paralanguage (Section 3.4.1), then attention is paid to the different paralanguage resources (Section 3.4.2), the nature of paralanguage and pragmatics (Section 3.4.3) as well as the relation between kinesics and paralanguage (Section 3.4.4). Finally, I provide a summary of the chapter. The aim of this chapter is therefore to present an overview of spoken conversation from a multimodal perspective in which special emphasis given to pragmatics.

\subsection{Multimodality}

Multimodality refers to the coexistence of more than one semiotic mode within a particular context. Kress and Van Leeuwen (2001) approach multimodality as "the use of several semiotic modes in the design of a semiotic product or event, together with the particular way in which these modes are combined" (p. 20). The idea of different modes working together seems not to be new for Kress and Van Leeuwen (2001), rather, the authors regard multimodality as a principle of text design where individual modes work in a simultaneous manner. 
Therefore, it seems that multimodality may attempt "to extend the social interpretation of language and its meanings to the whole range of representational and communicational modes or semiotic resources for making meaning with employed in a culture" (Jewitt, 2014a, p. 1).

For Jewitt (2014b) multimodality describes approaches that regard communication and representation to be beyond language itself and focuses on a variety of communicative forms (e.g. gesture, gaze) as well as on their relationship. Then, it seems that multimodality involves that modes consist of different semiotic resources that are chosen by people to shape communication and meaning (Jewitt, 2014b). The author indicates that language is part of a multimodal ensemble and suggests that language is typically associated as the most significant mode of communication, and more precisely in some contexts such as in education. Interestingly, Jewitt (2014b) posits that multimodality relies on the multiplicity of modes, assuming that all the modes may contribute to construct meanings, which are "made, distributed, received, interpreted and remade in interpretation through many representational and communicative modes - just through language" (Kress and Jewitt, 2003, p. 1). In a similar vein, Norris (2004, p. 2) also argues that all interactions are multimodal and claims that multimodality "steps away from the notion that language always plays the central role in interaction, without denying that if often does". Hence, it may be stated that a multimodal approach treats all the different communicative modes equally.

A definition of the term mode is required so as to better understand multimodality. Kress (2009, p.54) approaches the term as "a socially shaped and culturally given resource for making meaning" and it involves a range of "forms of communication" (Bezemer and Jewitt, 2010, p. 183) such as [i]mage, writing, layout, music, gesture, speech, moving image, soundtrack are examples of modes used in representation and communication" (Kress, 2009, p. 54). Within social semiotics, Jewitt (2014b) argues that a mode may be regarded as "an 
outcome of the cultural shaping of a material. The resources come to display regularities through the ways in which people use them. In other words, in a specific context (time and place) modes are shaped by the daily social interaction of people" (p. 23).

In addition to this, another key concept within multimodality is modal affordances, which refer to what is possible to express and represent with the resources of a mode (Jewitt, 2008a). Hence, it seems that each move might therefore carry specific affordances. This particular term has its origins in the work of Gibson (1977) on cognitive perspective and action. Drawing on Gibson (1977), Norman (1988, 1990) approaches modal affordances in relation to the material and social aspects of the design. Kress (1993) posits that modal affordances involve what is possible to express and represent with a given mode. The author argues that affordance is a complex concept connected to the material and the cultural as well as to the social historical us of a mode. In line with this, Jewitt (2008b) claims that Gibson and Norman approach of affordance can serve to show how tools are shaped by people's use in specific situations.

Having described briefly described multimodality, mode and modal affordances, I focus now on different approaches to multimodality.

SFL is associated to Halliday's $(1978,1985)$ work, which is based on the idea that language is a social semiotic system. Halliday's' approach of social semiotics and SFL were the starting point for social semiotic multimodal analysis (Kress and Van Leeuwen, 2001). From a multimodal perspective, SFL seems to connect a functional model of language to verbal communication as well as to other semiotic resources. Following Jewitt (2014b), social semiotic approach focuses on the sign-maker and the use of modal resources. The author further adds that the context appears to be of paramount interest as it shapes the different resources that are available for making meaning and how these are chosen and designed. 
Drawing on Halliday's (1985) social system functional grammar, O'Halloran (2005) establishes the framework for the so-called multimodal discourse analysis (MDA) and systemic functional multimodal discourse analysis (SF-MDA), which attempts to analyse how people produce meaning in social contexts not only verbally but also by means of various semiotic resources (Knox, 2012). As reported by Jewitt (2014b), the MDA focused on the developed of systemic grammars where semiotic resources are regarded as systems of meaning that change over time. SF-MDA approach is based on Halliday's premise that the organisation of semiotic resources reveals the social functions that the resources play (O'Halloran and Fei, 2014). The SFMDA approach involves systematic descriptions of semiotic resources that are organised according to metafunctions, analyses of text according to the system choices as well as interpretations of combinations of choices according to register and genre (Jewitt, et al., 2016).

In addition, multimodality can be also approached from the perspective of multimodal interactional analysis (Norris, 2004, 2011, Norris and Jones, 2005). This approach is based on interactional sociolinguistics (Scollon and Scollon, 2003), intercultural communication and multimodal semiotics so as to explore how the physical and material features of language provide meaning to people's actions (Jewitt, 2014b). This particular perspective moves from a focus on representation and communication (Kress, Van Leeuwen, and O'Halloran) to interaction, which involves that multimodal interactional analysis attempts to examine the situated interplay between modes at a particular moment in the interaction. In this sense, multimodality seems to expand the focus of interaction as linguistics to examine how people use gesture, gaze, posture, movement, space and objects to mediate interaction in a particular context (Jewitt, 2014b).

In addition to this, other research approaches are for example geosemiotics, multimodal ethnography, multimodal corpus analysis, and 
multimodal reception analysis (see Jewitt, et al., 2016 for a review). For example, the geo-semiotics attempts to explore the semiotic landscape by revealing the power of discourses in place. Multimodal ethnography focuses on specific cultural and social practices of a particular community. The multimodal corpus analysis tries to evaluate critique and validate multimodal hypotheses and theories. This particular perspective follows a SF-MDA approach and social semiotic theories. Finally, the multimodal reception analysis explores how multimodal messages are perceived and comprehend. As in the case of the multimodal corpus analysis, it follows a SF-MDA approach, together with cognitive theories of perception and attention and social theories of textual meaning making.

Finally, another approach for multimodal analysis is CA (e.g. Mondada, 2008, 2016, Streeck et al., 2011). The origins and contribution of $\mathrm{CA}$ to the area of language are not revisited here as they are reviewed in Chapter 1, Section 1.3.1. The multimodal approach of CA appears to be based on the idea that people construct action by means of different semiotic resources (Jewitt, et al., 2016). Accordingly, an action may be performed by means of an utterance while another action by means of a gesture, or simultaneously. It seems that semiotic resources individually may be partial and incomplete (Agha, 2007; Goodwin, 2007), but when they are united, different semiotic resources mutually elaborate each other to create a whole (Goodwin, 2000c). This mutual elaboration appears to relate to the social semiotic notion of affordance (Jewitt, et al., 2016).

The traditional approach of CA relies on the analysis of interaction involving for example two participants interacting, as in the present study. Newer approaches of multimodal CA include for instance the nature of mobile face-to-face interaction, as in the study conducted by Broth and Mondada (2013). More precisely, the authors examine situated organisation of talk-in-interaction by exploring the sequential environments in which activity closings are projected and achieved by 
participants. Jewitt et al. (2016) also indicate that, in terms of modes that go beyond language, research following a multimodal CA appears to have limited the analysis to gesture and speech while other modes such as facial expression has not received much attention. Moreover, the authors also suggest that the major focus has been NSs, whereas NNSs' performance has not been the major concern of CA. Finally, the authors also posit that a possible route to take would be the applied CA (Antaki, 2011), which explores not only interaction but also how it may be changed.

Taking into account those aspects, it is worth mentioning that in the present study my concern is to explore from a multimodal CA approach not only speech but also the different modes that emerged from the data, such as gestures, face, gaze and head movement as performed by FL leaners of English since I attempt to provide an account on how the interaction is constructed over the course of the conversation. Therefore, it may be indicated that in this study some of the new directions as regards multimodal CA are taken.

Having reported on the nature of multimodality and the different components as well as the various approaches to examine multimodal data, in what follows I focus particularly on the nature of multimodal communication.

\subsection{Multimodal communication}

Verbal and non-verbal domains are regarded as part of communication, and therefore, in doing things with/without words we are communicating. Traditionally, the realm of non-verbal language has been said to involve "facial actions, vocal cues, proxemics (use and perception of space), gaze, and kinesics (head, body, arm, and leg movement)" (Harrigan, 2013, p. 36). Non-verbal communication began to be established as a research area in the 1970s by Poyatos (1972). Since the earlier works, several authors have contributed to the body of 
literature of non-verbal communication. Following Poyatos (1983), verbal language is the basic system by which speakers communicate; there are other resources that contribute to meaning, such as kinesics (Birdwhistell, 1952, 1970) and paralanguage (Trager, 1958). The author proposed the so-called basic triple structure of discourse that involves language-paralanguage-kinesics (Poyatos, 2002), which consists of three different levels, (1) linguistic, i.e. grammatical rules, verbal elements and prosodic features; (2) paralanguage or vocal (non-verbal) communication; and (3) kinesic, human movements or manual gesture, facial expression, gaze, touch, and posture (Poyatos, 2002). Thus, for Poyatos (1983, 2002), communication consists of verbal language, speech, paralanguage, non-verbal voice qualities, modifiers and sounds employed to support meaning, and kinesics. Therefore, all these elements might be part of human communication and they could be performed to convey meaning.

In the previous section I have provided an overview of different approaches to analyse multimodal data, pointing for example to the multimodal interaction analysis (Norris, 2004). Particularly, this approach is taken in order to explore social action, interaction and identity. Interestingly, the actor of the action is central in this particular approach since it is through interaction that action is constructed from the environment or other social actors (Norris, 2004). The author uses the terms (1) higher level action to refer to large-scale actions, which involves different lower-level actions, e.g. a meeting; (2) lower-level action that related to smaller-scale actions, e.g. gestures that turn into "chains of lower-level interactions" (p. 13); and (3) frozen action that involves the material artefacts. It focuses on how a range of "modes are brought into and are constitutive of social interaction, identities and social relations" (Jewitt, et al., 2016, p. 114).

It should be noted that Norris (2004) makes a distinction between two sets of interactional modes. More precisely, the author distinguishes between embodied modes (e.g. gestures, gaze) and 
disembodies modes (layout, spatial modes). Following this perspective, the author examines the hierarchical and non-hierarchical structures among the modes that are employed in a specific interaction. Particularly, by means of modal density the author maps the modal shifts that foreground or background higher-level actions (Jewitt, et al., 2016). Modal density can be achieved by means of modal intensity or modal complexity. Norris (2004, p. 79) defines modal density as "the modal intensity and/or the modal complexity a higher level action is constructed". The intensity of the modes in interaction appears to be determined by the situation, the social actors, as well as other social and environmental factors. Therefore, the weight of a given mode may change from one interaction to another. Multimodal complexity refers to "the interplay of numerous communicative modes that make the construction of a higher-level action possible" (Norris, 2004, p. 87). That is, it centres on how modes interrelate.

Considering those aspects, in what follows, I provide a review of two different aspects, kinesics, with a special focus on gestures, head, face, gaze, and paralanguage resources.

\subsection{Kinesics}

The term kinesics was coined by Birdwhistell (1952, 1970), suggesting a discipline parallel to linguistics that would explore the visible bodily motion. He developed a system that was based on kines, that is, the smallest unit of "abstractable body motion" (Birdwhistell, 1952, p. 3). His work, however, did not focus explicitly on gestures, but on the overall body movement. A definition of kinesics is advanced by Poyatos (2002), who suggests that it involves:

[c]onscious and unconscious psychomuscularly-based body movements and intervening or resulting still positions, either learned or somatogenic, of visual, 
visual-acoustic and tactile and kinaesthetic perception, which, whether isolated or combined with the linguistic and paralinguistic structures and with other somatic and object-manipulating behavioural systems, possess intended or unintended communicative value (Poyatos, 2002, p. 185)

Then, kinesics involves three different categories, (1) gestures, "both conscious and unconscious, mainly of the head, the face alone, including gaze, and the extremities" (Poyatos, 2013, p. 289); (2) manners, "how we perform a gesture or adopt a posture, but also 'social manners" (Poyatos, 2013, p. 289); and (3) postures, "since they delimit, and are precisely the production of, movements, which they articulate in a communicative continuum, as silences do with respect to sounds" (Poyatos, 2002, p. 185). In addition to this, the author also included within kinesics gaze movements and direction; the hand moving inside a pocket; the heaving chest; the stride of a person or the unseen footsteps, as well as other subtle movements or still positions that carry meaning (Poyatos, 2013).

This is only a brief overview of the term kinesics in order to contextualise the area of gesture studies, which is one the aspects considered in the present study. Considering this, in what follows I present an overview kinesic resources, paying special attention to gestures, but also introducing facial expression, gaze and head movement.

\subsubsection{An overview of kinesic resources}

In communication in general and in face-to-face in particular, different we use several resources in combination with speech to deliver our talk but also to show active listenership. In this section, I focus 
particularly on some of the resources we employ in communication, more specifically, gestures, head movement, face expression and gaze.

\subsubsection{Gestures}

The role of gestures within the realm of linguistics has called the attention of several researchers from different perspectives and fields of work such as applied linguistic and cognitive linguistics. According to the Longman Dictionary of Language Teaching and Applied Linguistics (Richards and Schmidt, 2013, p. 246) gesture is defined as: "a movement of the face or body which communicates meaning, such as nodding the head to mean agreement. Many spoken utterances are accompanied by gestures which support or add to their meaning. [...] The study of the role of gestures in communication is part of the study of non-verbal communication". Following this definition, it seems that gestures involve a body-movement as a source of communication and that they, along with words, may convey meaning. Gestures are an integral part of communication and they can perform various functions (Calbris, 2011). Language and gestures, although seen as two different phenomena, are interrelated, their relationship has been recognised (Kendon, 2000), and the occurrence of co-speech gestures is regarded as universal, although the way they are produced could vary across cultures (Senft, 2014) for those gestures that are culturally bound.

However, one might wonder what gestures are and which their role in communication is. Starting with the earlier works of Adam Kendon in 1972 and continuing up to present, "gestures are regarded as parts of language itself - not as embellishments or elaborations, but as integral parts of the processes of language and its use" (McNeill, 2000, p. 9, his emphasis). In a recent publication entitled Understanding Pragmatics, Senft (2014), when dealing with the issue of gestures, provides a quotation that reflects the complexity of this phenomenon. 
The author quotes Kendon and Müller (2001), who in the first edition of the journal Gesture outline the scope of this research inquiry

GESTURE is a new journal for the emerging field of "gestures studies". The phenomena that this encompasses cannot easily be defined ("gesture" is a concept with fuzzy boundaries), but they include the wide variety of ways in which humans give what is usually regarded as wilful expression to their thoughts and feelings through visible bodily action. Thus, the movement of the body, especially the hands and arms, that are so often integrated with spoken expression, the use of manual action to convey something without speech, or the manual and facial actions of sing languages, are all recognized as a part of "gesture", broadly conceived, whereas expressions such as laughing and crying, blushing and the like are less likely to be so considered unless they are feigned or enacted. Kendon and Müller (2001, p. 1, their emphasis)

This quotation seems to offer the reader a perspective of what gestures are, although the nature of gestures is sometimes difficult to understand and apprehend due to its complexity and diverse interpretations. The authors also point to paralanguage features such as laughing or crying. (Paralanguage features are referred in Section 3.4). For Kendon (2004, p. 7) gesture "is a name for visible action when it is used as an utterance or as a part of an utterance". The author further adds that the word utterance involves here a given action or complex of actions that is treated by the participants within the interaction occasion. Thus, an utterance refers to any unit of activity that is treated as a communitive move, turn, or contribution. Finally, the author indicates that gestures involve "a movement of the body, or any part of it, that is expressive of 
thought or feeling” (p. 7-8). Hence, gestures involve a given visible action that is performed when speaking and they convey meaning since they are part of the communicative event.

Gestures play a role in communication and it is a basic part of speech since gestures may support speakers' verbal production. Speakers may execute gestures in different moments and contexts while speaking, and these gestures may have a communicative role in the process of communication; for example, when gestures support what speakers attempt to express (Kita, 2000). In observing people, for example in a face-to-face conversation, one might identify how people use their body, hands, arms, among others, while interacting. The execution of gestures should not be ignored as they may contain meaning, and this should be then regarded as being significant for the understanding of what is expressed verbally. Regarding this, interestingly, gestures, as reported by Goldin-Meadow and Wagner (2005), appear to rely on "visual and mimetic imagery to convey an idea holistically, whereas speech conveys meaning discretely, relying on codified words and grammatical devices" (p. 234). The authors further argue that the information that is conveyed by means of gestures and speech "can overlap a great deal" (p. 234).

Having briefly revisited this specific area, in the following, I provide a review of types of gestures, by paying special attention to the works of McNeill and Kendon.

\subsection{Gesture type}

Several researchers have drawn their attention to the study of gestures, and therefore, various taxonomies of gestures have emerged over the years (Efron, 1941, 1972; Ekman and Friesen, 1969; McNeill, 1992; Kendon, 2004). Research has evidenced, however, that the two classifications that remain the most widely recognised and accepted by 
the majority of researchers are those proposed by David McNeill and Adam Kendon.

Efron (1941) proposes one of the earliest classifications of gestures. The author distinguishes two main categories of gestures depending on whether they are "meaning independent of or only in conjunction with speech" (p. 1454). On the one hand, logical-discursive gesture that includes baton-like (i.e. rhythmic gestures used to emphasise specific words or phrases in a given utterance) and ideographic gesture (i.e. gestures used to show the path of a thought pattern) and objective gestures, on the other hand. Ekman and Friesen (1969), influenced by the work of Efron (1941), propose a classification of gestures that involved the following five categories: (1) emblems, are symbolic actions that have "specific verbal translation known to most members of a subculture, and is typically intended to send a message" (Ekman and Friesen, 1977, p. 38); (2) illustrators, involving "movements which are directly tied to speech, serving to illustrate what is being said verbally" (p. 68); these are considered conversational gestures; (3) affect displays that involve mainly facial expressions of emotions, considering here gesture from a broader perspective that includes not only hand gestures but also facial gestures; (4) regulators, referring to "acts which maintain and regulate the back-and-forth nature of speaking and listening between two or more interactants" (p. 82); and finally (5) adaptors that are "movements were first learnt as part of adaptive efforts to satisfy self or bodily needs or to perform bodily actions or to manage emotions or to develop or maintain prototypic interpersonal contacts or to learn instrumental activities" (p. 84), these gestures are neither communicatively intended, nor meaningfully related to the speech.

Although the two described classifications are of interest for the study of gestures, McNeill's (1992) proposal focuses on the description of the so called conversational gestures (or illustrators), identifying four different categories: (1) iconic; (2) metaphoric; (3) deictic; and (4) 
beats. Iconic gesture, which represents specific concepts and/or objects, seems to bear a formal relationship to the semantic content of speech. In this regard, Goldin-Meadow (2003, p. 7) outlines that "most of the time, iconics represent body movements, movements of objects or people in space, and shapes of objects or people". The second typology refers to metaphoric gestures, which are apparently similar to iconic gestures, expect for the fact that they describe abstract concepts rather than concrete objects. The third type identified by McNeill is that of deictic gestures, the pointing gestures, which are used to indicate objects that are referred to. This can be done using for example the hand, the finger, etc. Deictic gestures can be also used to point something or someone, or an abstract concept represented in front of the speaker in that specific moment (McNeill, 1992). Finally, the last type refers to beats that might emphasise concrete elements of the discourse such as specific words or phrases. Differently to iconic and metaphoric gestures, beats usually have the same form regardless of the content (McNeill and Levy, 1982). Furthermore, Morris (1977) also indicates that the beat tends to index the discourse elements that it accompanies.

Kendon's classification of gestures was first described in 1983 although it was not until 1988 when it was published, and it was named by McNeill $(1992,2000)$ as Kendon's continuum. McNeill posited the abstract idea of a continuum in which he identified different gestures. Figure 7 shows the classification.

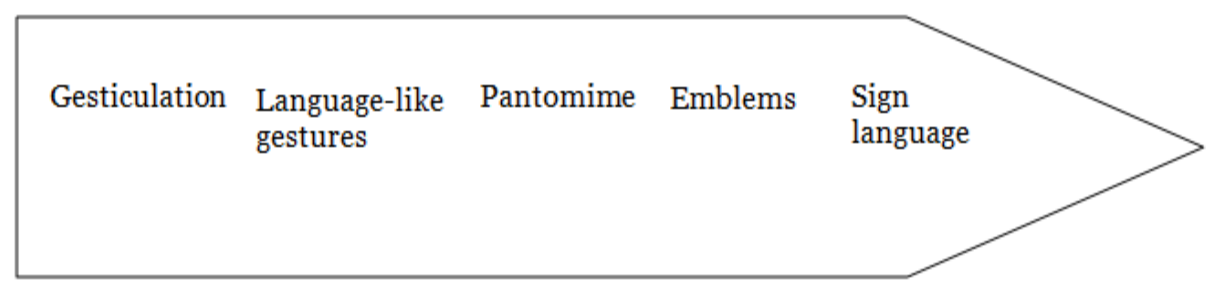

Figure 7. Own representation of Kendon's continuum (McNeill, 1992, p. 37) 
Gesticulations, or spontaneous or speech-associated gestures (Kendon, 1988; McNeill, 1992), are "idiosyncratic spontaneous movements of the hands and arms accompanying speech" (McNeill, 1992, p. 37). Language-like gestures are similar to gesticulation but they are grammatically integrated into the utterance, for example, "the parents were all right, but the kids [gesture]" (McNeill, 1992, p. 37), where the gesture replaces the grammatical category of a given adjective. Pantomime involves hands' description of objects or actions, although speech is not required, and "there may be either silence or just inarticulate onomatopoeic sound effect”, (McNeill, 1992, p. 37), as in the examples proposed by McNeill (1992, p. 37) “whoops!” or “click". Emblems "are the familiar "Italianate" gestures, mostly insults but some of them praise, and virtually all attempts to control other people's behaviour (Kendon, 1981)" (McNeill, 1992, p. 38); and finally, sing language involve "full-fledged linguistic systems with segmentation, compositionality, a lexicon, a syntax, distinctiveness, arbitrariness, standards of well-formedness, and a community of users" (McNeill, 1992, p. 38).

As reported, literature shows that different types of gestures might be identified, being the classifications advanced by McNeill (1992) and Kendon (2004) widely accepted. For the purpose of this study, I follow McNeill's (1992) proposal of gesture types, which, as indicated, involves iconic, metaphoric, deictics and beats, as well as Ekman and Friesen's (1969) adaptors. Having described the different gesture types, it is important to pay attention on the identification of gestures.

\subsection{Gesture identification}

According to Kendon (2004), the units of gestural action can be classified into two main categories, namely gesture unit and gesture phrase, which "are defined in terms of changes in how the body parts involved in gesturing are posed and moved" (Kendon, 2004, p. 108). 
Following Crystal and Davy (1969), speech is examined according to tone units, which, in Kendon's (2004, p. 108) words, involve "packages of speech production identified by prosodic features which correspond to units of discourse meaning". By the same token, gesture phrases are defined as "units of visible bodily action identified by kinesic features which correspond to meaningful units of action such as a pointing, a depiction, a pantomime or the enactment of a conventionalized gesture" (Kendon, 2004, p. 108). The author also indicates that in looking at the temporal coordination of gesture phases and the tone units in a given discourse, "we also look at the meaning relationships between these two aspects of utterance action" (2004, p. 108). In this respect, the author argues that speakers create ensembles of gesture and speech in order to attain the semantic coherence between them. This, however, does not involve that gesture and speech may express the same meaning, since they are typically different. In fact, the meanings provided by these two components appear to interact in the utterance, resulting therefore in a more complex unit of meaning. Gesture unit, as defined by Kendon (2004, p. 111), refers to the "excursion from the moment the articulators begin to depart from a position of relaxation until the moment when they finally return to one" and it might involve one or more gesture phases such as different strokes. In such excursion one or more phases might be distinguished, where articulators, i.e. hands and forearms, seem to reach points of furthest remove from the position of relaxation, also known as home position (Sacks and Schegloff, 2002). Thus, a gesture unit begins when for example hands depart from what is known as home position (Sacks and Schegloff, 2002) and it ends when hands go back to its rest position. The act gesticulation, from its initiation to its end, typically encompasses three different phases: preparation (in which for example the hand moves and performs the stroke), stroke (what is perceived as a gesture by people), and recovery or retraction (a movement that follows the stroke). Then, the phase of the movement that is closer to the apex, the main part of the gesture, is known as 
stroke. The phase of movement that leads to the stroke refers to the preparation. And finally, the phase of movement following the stroke is named as the recovery or retraction. In some cases, a post-stroke hold is also identified (Kita, 1993). Kendon (2004) argues that a post-stroke hold refers to a situation in which a speaker maintains the articulator in the stroke position after executing the actual stroke in an attempt to extend the meaning conveyed by the stroke. For Kendon (2004), as previously mentioned, gesture units include at least one gesture phrase, although further gestures phases may be added. Typically, people might identify the strokes of such gesture phases, which are perceived as gestures. In line with this, the author suggests that in trying to understand how speakers organise gestures and speech in the utterance, the different phases of gesture units and gesture phases should be taken into.

In addition to this, McNeill (1992) proposes a set of rules that govern how speech and gesture synchronise. The author argues that gestures both "anticipate and synchronize with speech" (p. 26). More specifically, the rules referring to synchrony deal with the stroke phase and the anticipatory ones to the preparation phase, thereby only the stroke phase of the gesture is integrated within the speech. The author suggests viewing synchrony as co-temporal performance in which the speech reflects the speech and gesture interaction according to three different levels: (1) the phonological synchrony; (2) the semantic synchrony; (3) pragmatic synchrony. The phonological synchrony rule means that "the stroke of the gesture precedes or ends at, but does not follow, the phonological peak syllable speech (Kendon, 1980)" (McNeill, 1992, p. 26). Hence, the stroke phase of the gesture is to be found within the phonology of the utterance. Accordingly, the expressive part of the gesture (i.e. the stroke) occurs at the same time as the prominent syllable of the speech and it could precede it, but it does not follow it. The semantic synchrony rule involves that "the two channels, speech and gesture, present the same meaning at the same time" (McNeill, 
1992, p. 27). Hence, if the speech and gesture occur at the same time, they can provide the same idea unit. Within this rule, three different complications can be identified: (1) pauses; (2) multiple gestures; and (3) gestures that correspond to more than one clause (see McNeill, 1992). The last synchrony rule is the pragmatic synchrony, which indicates that "if gestures and speech co-occur they perform the same pragmatic function. Pragmatic synchrony implies that speakers are limited to one pragmatic reference at a time (McNeill, 1992, p. 29).

After providing a review of the identification of gestures, I present a review that focuses on the interpretation of gestures.

\subsection{Gesture interpretation}

Several researchers divide gestures in two different groups (Efron, 1941; Ekman and Friesen, 1969; Kendon, 1987; McNeill, 1985), specifically, stereotyped gestures that might be employed with the absence of speech, and conversational gestures that are deployed with speech, do not have stereotypic forms and they are further divided into topic gestures and non-topic gestures (see Kendon, 1985). The form refers to the majority of conversational gestures that depict events, objects, actions, or ideas that are directly associated to the topic of conversation. The latter involves gestures that have been described as strokes of hand that apparently do not depict anything specific, rather they have an abstract relationship with the topic, such as emphasis or syntactic contrast. Efron (1941) and Ekman and Friesen (1969) refer to them as batons, Freedman (1972) terms them as speech primacy movements, and finally McNeill and Levy (1982) as beats. In line with this, Bavelas, Hagen, Lane and Lawrie (1989) and Bavelas, Chovil, Lawrie and Wade (1992) argue that most of these non-topic gestures involve direct references to other person in conversation, maintaining therefore the interaction required by the dialogue instead of providing meaning within the dialogue, as other gesture may do. Bavelas et al. 
(1989, 1992) and Bavelas, Chovil, Coates and Roe (1995) call them interactive gestures, which serve to maintain the conversation as a social system as well as to make reference to the interlocutor. Following these authors, interactive gestures might share two key characteristics of form and meaning, "[a]t some point the finger(s) and open palm(s) are oriented directly at the other person; [a]nd the paraphrased meaning of gesture in the context in which it occurs includes a reference to 'you', the person in the dialogue" (Bavelas et al., 1995, p. 395). Moreover, four basic functions are identified: (1) marking the delivery of the information (the delivery of new versus shared information); (2) citing the other's contribution (e.g. acknowledgment of the addressee's contribution); (3) seeking a response (e.g. agreement); and (4) turn coordination (e.g. taking the turn) (see Bavelas, et al., 1995, p. 397). The authors also report that this type of gestures might have similar functions as discourse markers, the rising intonation on declarative sentences, and framing statements. Furthermore, interactive gestures also include the role of the listener, in which an active role is given to this figure by means of backchannels, his/her responses as well as interactive facial manifestations. Interactive gestures might be found in spoken interaction, either natural or elicited as in the present study. In the case of complaints, for example, a speaker may mark the delivery of the information by providing information as regards the situation and the offence. Then, concerning citing the other's contribution, the person complaining may refer to what has been previously uttered by the complainee. Seeking a response in a complaint situation would involve as in the example above shown, seeking for agreement when taking part in the repair of the offence. Finally, as regards turn exchange, speakers might take the turn, give the turn or mark the turn is open to either person.

In addition to this, Kendon (2004) also proposes that gestures can accomplish three functions, namely (1) referential; (2) interpersonal; and (3) pragmatic. The first function, referential, provides a 
representation of any aspect of the content of an utterance. The second function, interpersonal, involves those gestures that may show how the interaction is organised, for example, they may regulate turn-taking. As indicated by the author, interaction functions have been often recognised (Kaulfers, 1931; Goodwin, 1981; Streek and Hartege, 1992), but there is not a systematic discussion on this particular issue. These types of gestures could be identified in Bavelas' et al. (1995) interactive gestures, above described. The third function, pragmatic, is furthered divided into three different categories: (1) performative function; (2) modal function; and (3) parsing function. The performative function refers to the speech act that is uttered by the speaker, for example, a refusal, an apology or a complaint. The modal function indicates speakers' attitude towards his/her discourse. The parsing function helps to make visible the process of organisation and the structure of the discourse. In Kendon's (2004, p. 225) words:

[t]he functions of gestures have as they contribute to or constitute the acts or moves accomplished by utterances are referred to as pragmatic functions. In the terminology proposed, gestures which show what sort of a move or speech act a speaker is engaging in are said to have performative functions. Gestures are said to have modal functions if they seem to operate on a given unit of verbal discourse and show how it is to be interpreted. Gestures may serve parsing functions when they contribute to the marking of various aspects of the structure of spoken discourse. (Kendon, 2004, p. 225)

Regarding this, the author further adds that "this is a typology of functions, not of gestures" (2004, p. 225) and the functions of gestures might vary depending on the situation. 
Kendon's (1995, 2004) research on pragmatic gestures has contributed to establish different gesture families, which are viewed as a group of gestures that have specific kinesic or formational features in common, that is, gestures that share one or more form features. Specifically, the author states:

[w]hen we refer to families of gestures we refer to groupings of gestural expression that have in common one or more kinesic or formation characteristics. [E]ach family not only shares in a distinct set of kinesic features but each is also distinct in its semantic themes. The forms within these families, distinguished as they are kinesically, also tend to differ semantically although, within a given family, all forms share in common semantic theme. Kendon (2004, p. 227)

Kendon's (2004) examples derive from Neapolitan gesture culture. Kendon (2004) focuses on the study of the kinesic features of hand shape and hand orientation, and distinguishes two main types of families according to the movement pattern used when performing gestures. The author distinguishes the following groups: (1) gestures with "precision grip" including G-family (grappolo) and the $R$-family (ring gestures) and (2) Palm Open Hand.

The first group involves two families, the G-family and the Rfamily. Specifically, the G-family or "Finger Bunch", also termed grappolo, implies that fingers are brought together and then tips "are in contact with one another at their tips" (Kendon, 2004, p. 229), and the R-family or ring gestures refer to "gestures that use the "ring" hand shape" (Kendon, 2004, p. 238) involving a shape hand in which "the tip of the index finger and thumb are brought into contact so that the two digits together outline a more or less circular space” (Kendon, 2004, p. 238). The G-family gestures seem mark the topic of the speaker's discourse, although it can be also used when the speaker is asking 
specific kinds of questions or demanding an explanation or justification for something. The R-family represents gestures that are executed in situations in which the speaker is indicating that they mean to be very precise about something, that what they are saying is actually exact somehow, and that it requires attention for this reason.

In the second group of gestures the author identifies the gestures family of Open Hand Prone or "palm down" family, and the Open Hand Supine or "palm up" family. Following Kendon (2004), the terms of context of use of the two familiar ones appear to be rather different. On the one hand, Open Hand Supine family gestures are used in contexts where the speaker is offering, giving or showing something. On the other hand, Open Hand Prone family gestures are employed in contexts where something is being "denied, negated, interrupted, or stopped, whether explicitly or by implication" (Kendon, 2004, p. 248), and which "share the semantic theme of stopping or interrupting a line of action that is in progress" (Kendon, 2004, p. 249).

I have provided here a revision of literature devoted to the interpretation of gestures by pointing to the different functions gestures might accomplish, as well as by focusing of family gestures. In the following, I focus on another kinesic resource, particularly facial expression.

\subsubsection{Facial expression}

Face expression may be regarded as the most important source for conveying emotion. The traditional approach was that face expressions were socially learnt and they varied among cultures (e.g. LaBarre, 1947; Birdwhistell, 1970). However, this particular perspective was challenged by the results of cross-cultural research, which shows the facial expressions of at least seven emotions: anger, fear, surprise, happiness, disgust, sadness, and contempt (Ekman, 1972; Ekman and Friesen, 1969; 1986). Recent research has also shown that pride and shame are 
also universal facial expressions (Tracy and Matsumoto, 2008). Ekman's (1972) work has contributed to show that emotional expressions are universal. In fact, evidences for universality have also served to hypothesise that the facial expressions of emotions are innate (e.g. Matsumoto and Willingham, 2009).

Ekman (1972) proposes a neuro-cultural model that focuses on the facial expressions of emotion. This model recognises not only the innateness of emotional facial expressions, but also that individuals can modify expressions according to the norms of the culture or community they belong to. Following Ekman (1972), there are four rules: (1) amplification (exaggerating the intensity of the expression); (2) attenuation (weakening the intensity of the expression); (3) concealment (hiding an expression by adopting a neutral face); and (4) substitution (showing an expression incongruent with the emotion experienced). Furthermore, facial expressions may evoke responses in the listener (Dimberg and Öhman, 1996; Keltner and Kring, 1998). For example, face expressions of anger might evoke specific responses in the listener that differ from those that could be evoked from smiles (Esteves, Dimberg, Öhman, 1994).

Ekman and Friesen (1978) develop a way of locating and evaluating individuals' facial expressions. Specifically, the authors employed the so-called the Facial Action Coding System (FACS), which is now being used extensively to measure facial movements. FACS involves an anatomically based system that serves to measure visually distinguishable facial movement (Rosenberg, 2005). FACS separates the face into three areas, the lower face including cheeks, nose, and mouth; the eyes and eyelids area; and the brows and forehead area. The FACS technique identifies which emotions are expressed in the three different areas. For example, by means of FACS, Ekman (1985) has identified the facial signs that betray a lie in the interpretation of what Ekman and Friesen (1969) have called micro expressions, which may convey 
emotional information (see Valstar (2015) for a review on microexpression and on automatic facial expression analysis).

A great body of research on face has considered it solely from the point of view of its role in emotional expression. While these studies have examined facial patterns as symptoms of affective state, they have lacked a systematic knowledge of how the face functions in social interaction. Kendon (1981) demonstrates, in his analysis of some functions of the face in kissing round, how the behaviour of the face can be studied within social interaction as well as how this behaviour integrates with other aspects of behaviour.

It is interesting to note that some facial expressions may have some grammatical function (e.g. Klima and Bellugi, 1979; Pfau and Quer, 2010). Hence, facial expressions may result in grammatical markers, which are also known as grammaticalised facial expressions (Reilly, McIntire and Bellugi, 1990). Among the different facial expression recognised by Ekman (1972), anger, disgust or contempt are typically used to express moral judgement as a result of violations of one's rights, societal norms or beliefs (e.g. Ekman, Sorenson and Friesen, 1969; Oatley, Keltner and Jenkins, 2006). Recently, BenitezQuiroz, Wilbur and Martínez (2016) have examined facial expressions of emotion involved in negative moral judgement. The study revealed that people from different cultures expressing negation appear to employ the same facial muscles as those used to express negative moral judgement. Facial expressions are of paramount interest for the present study as it explores simulated conversation involving a complaint, which could reveal speakers' changes in emotions expressed by means of face expression due to the face threating nature of the situation (Brown and Levinson, 1978, 1987).

In the following section I present another kinesic feature, more precisely, gaze. 


\subsubsection{Gaze}

Gaze has drawn the attention of many researchers (e.g. Argyle and Kendon, 1967; Duncan and Niederehe, 1974; Field 1981; Kimble and Olszewski, 1980; Nichols and Champness, 1971; Strongmana and Champnessa, 1968). Researchers seem to agree on the fact that gaze serves many functions in our communicative exchanges. It has been also suggested that eyes are central to communication since they are "particularly useful in ascertaining mental and emotional states of others" (Adams, Nelson and Purring, 2013, p. 229).

Gaze appears to be essential in face-to-face interaction. Kendon (1967) provides a comprehensive description of patterning of gaze in conversation, which is describes the patterning of gaze with respect to phrases and phrase boundary pauses. Due to the dynamic nature of conversations, behaviour is constantly modified in response to conversational and interpersonal factors (Kendon, 1967). The author, in observing the functions of gaze direction in dyadic conversations, examined as well as the direction in relation to the occurrence of short utterances. The author identified two types of signals, more precisely, attention signals and point grating or assenting signal. On the one hand, the former involves that the listener shows that he/she is attending and produces a short utterance such as "I see". On the other hand, in the latter, the speaker structures his/her argument in a way that his/her "continuing is dependent upon his interlocutor consenting to, or specifically grating him, the points that he is making" (Kendon, 1967, p. 73).

Kendon (1967) provides insights into the main functions of gaze in social interaction. He for example notes eye-contact is sought for in interaction since "we can only be sure we are being effective in what we do if we know that the other is taking account of it" (Kendon, $1967 \mathrm{p}$. 59). The author argues that the two types of signals are distinguished in terms of gaze direction since when the listener produces an attention 
signal, no change in gaze direction is observed as he/she looks steadily at the speaker, whereas in the point-granting or assenting signal, the listener seems to modify his/her gaze direction in order to look away. This particular result is associated to listener response as it shows how speakers in a face-to-face conversation orient and modify gaze direction when constructing the conversation.

Other studies have also revealed insights into the potential of gaze in interaction. For example, Goodwin's (1979) study on interactive sentences revealed that speakers seemed to use gaze to select a listener in a multiparty conversation and that gaze was also used by the listener to show that they attend to the talk. A coordination of gaze and gesture is identified by Streeck (1993), who found that there is a pattern in since speakers, when initiating a gesture, tend to bring their gaze to their hands at the beginning of the performance, pointing to the recipient and inviting them to consider that the hand movement is part of the action. Additionally, Hayashi (2005) showed how different modes such as talk, gaze, and gesture as well as body posture were coordinated to construct turns. It should be, however, noted that one may move head so as to change gaze direction (Kendon, 1967). Then, a head movement may be also observed when changing or reorienting gaze direction.

Ekman and Friesen (1975) suggest that many characteristics of the eye region are closely related to the communication of facial affect. Examples of this could be eyebrow position, upper and lower eyelid position, as well as other changes around the musculature of the eye. Emotions can be decoded from the eyes. Ekman and Friesen (1969) suggest that eye contact is one of the primary regulators of human social interaction. It seems that by means of changes in gaze direction, speakers can give expression of their feelings and attitudes. Kendon (1967) observed how a speaker tended to look away at points of high emotion. This aversion of eyes might function as a 'cut-off' act, but also as an indication to the hearer that the speaker is embarrassed or overaroused. He also observed the aversion of the eyes was often 
accomplished by dropping the lids loosely, that occured in association with point-granting signal, indicating the speaker was not going to challenge further what the other had just said. Argyle et al. (1981) suggest that one function of gaze is the communication of interpersonal attitudes. The authors indicate that the signal that is sent also depends on the facial expression that accompanies gaze. Argyle et al. (1981, p. 20) write that "the intensity of the attitude communicated is a joint product of the length of gaze and the intensity of the expression." In addition, the authors also contend that negative attitudes may be also portrayed for example by looking away.

Adams and Kleck (2003) also revealed that gaze direction influenced the perception of emotional expression. Particularly, direct gaze seemed to enhance the perception of approach emotions such as anger and joy, whereas averted gaze enhanced the perception of avoidance emotions such as sadness or fear. The study showed that when labelling fear and sad faces, the responses were shorter when the gaze was averted than when the gaze was oriented towards the participant. In a different study, Adams and Kleck (2005) identified that avert gaze was likely to be attributed to fear and sadness. The authors suggested that gaze direction and facial expression appeared to interact in a meaningful manner in the perceptual processing. Similar results were found by Benton (2010) for fear and sadness, and by Sander, Grandjean, Kaiser, Wehrle, and Scherer (2007) by means of dynamic threat displays.

The nature of gaze and particularly changes in gaze direction appears to be of paramount interest for the present study in which participants at different proficiency levels were engaged in a face-to-face interaction involving a FTA (Brown and Levinson, 1978, 1987), particularly a complaint situation. Concerning this, it might be suggested that in face-to-face interaction, gaze may not always be continuous but the way speakers address each other by means of gaze may play a paramount role in the communicative event, especially in a 
threatening situation. Interestingly, Kendon (1990a) notes that in conversation there is a big difference in the time the speakers gaze at the hearers, and eye contact is very brief at times. The author found that speakers tended to look away from the hearers at the beginning of an utterance, but gazed steadily at them towards its termination. Hearers, on the other hand, looked at the speaker more than the speakers looked at them, because of the interactional constraint that requires a speaker to look at a hearer who is looking at them (Goodwin 1981).

Having described gaze, in what follows, I focus on the nature of head movement as a kinesic resource.

\subsubsection{Head movement}

Another important kinesic resource is head movement. The study of this particular kinesic recourse involves examining the way individuals position heads. Following Calbris (2011, p. 94-96), the head can make different types of movements, such as in the sagittal plane, in the horizontal plane, and in the frontal plane. The first type involves for example (1) gazing downwards, (2) gazing into the distance, (3) gazing upwards, and (4) gazing skywards. The second one refers to the movement in the horizontal plane. The author indicates that a turn of the head shows the direction right or left by displaying the most prominent facial elements such as the nose and the chin, provided that the gaze moves in the same direction as the head or at least stays on the interlocutor. However, when the eyes close, the interpretation of the head movement varies, and it should be then understood in this case in relation to gaze, as it depends on the kinesic context. The meaning of repeating head rotation may change according to the plane in which a rotation is performed. The third is the movement in the frontal plane, which can (1) localise, designate right and left; (2) represent a particular point of view; (3) represent the slanted, imbalanced position of an object with regards to the vertical axis; or (4) represent a posture of 
tenderness. Concerning head movements, Norris (2004) posits that "head movement may be simple, meaning a clear lateral, sagittal or rotational movement, or it may be a complex movement, in which two or all three movement patterns overlap" (p. 33).

In addition to this, it should be also noted that research has explored the relationship of movements of the head to the speech production process. For example, Hadar, Steiner, Grand and Rose (1983a, 1983b) and Hadar. Hadar, Steiner, Grand and Rose (1984a) demonstrated that head movements appeared to co-occur most significantly between sentences or clauses, and were associated with taking or bidding a turn. Hadar, Steiner, Grand and Rose (1984b) also observed head movements following speech dysfluencies ${ }^{11}$, which they found to be of greater amplitude and velocity. In contrast, short pauses were more frequently accompanied by slower movements, postural shifts, or stillness.

In face-to-face interaction in general and particularly in multiparty interaction, head movements may be said to be intrinsically part of the conversation. They may be for example attributed to the functions of regulating the turn-taking system (e.g. Duncan, 1972), listener comprehension (e.g. Battersby and Healey, 2010; Knight, 2011), participants role (Salamin and Vinciarelli, 2012), marking semantic and syntactic boundaries of concurrent speech (Kendon, 1972), as well as indicating encoding difficulties (Dittmann, 1972). Kendon (1990b) also acknowledged the power of head movements so as to control interpersonal interaction, even in the absence of speech.

Concerning discourse functions, Kendon (1972) notes that particular patterns of movements appeared to vary according to the discourse function of the utterance. For instance, he found that the speakers' head position during a parenthetical remark appeared to contrast with that during statements that "move the substance of the discourse forwards" (Kendon, 1972, p. 193). The author also identified a

$11 \quad$ They define a dysfluency as a pause in speech longer than 0.2 second. 
temporal alignment of manual gestures and head movement, which seemed to vary "at times the onset of manual gestures precedes the head movement and at other times the reverse" (Kendon, 1972, p. 195). In line with this, McClave (2000) describes the functions of head movements as narrative. The first function refers to marking switches from indirect to direct discourse, which is marked by a new orientation of the head. Then second function relates to the expression of mental images of characters. The third function is deictic and it involves the referential use of space. The author also recognises head shakes that correspond to expression of inclusivity, intensification, and uncertainty. Additionally, the author also points to the functions of head nods, including interactive function such as backchannel signals and lexical repairs.

Moreover, in the speaking process, listeners have also been observed to synchronise their head movements with the speech of the speakers. Concerning this, Kendon (1970) found in his research one listener who raised and lowered his head to match the rise and fall of the speaker's pitch. The nature of listener nods has called the attention of several researchers (e.g. Dittmann and Llewellyn, 1968; Houck and Gass, 1999). For example, Dittmann and Llewellyn (1968) observed that listeners tend to nod and vocalise at boundaries of the speaker's phonemic clauses. The authors indicated that the temporal alignment (nods precede vocalisation) allowed the listener to signal the start of a response without interrupting the speaker.

Although the nature of backchannels has been acknowledged in Chapter 1, Section 1.3.2.2, this particular issue should be addressed here as well as backchannel may be also performed by means of head movements. For example, Duncan (1972), following Yngve, considers listener head nods as backchannels. In line with this, Erickson (1979) has discussed head nods as forms of listening response-behaviour that occurs at points in conversation where the speaker signals the relevance of some action by the recipient. Moreover, Goodwin (1980, p. 304) sees 
these head nods would seem similar to verbalisations such as yeah, $\mathrm{mm}$ $\mathrm{hm}$, and uh huh and might, like them, be considered signals of acknowledgment. Another contribution was made by Maynard (1987), who studied head nods that occurred during conversations among Japanese speakers. Although the most frequent head nod was that used by listeners as backchannels, speakers' nod also functioned to mark a clause boundary or end of turn, to fill a turn-transition phase, and to signal emphasis or affirmation. Maynard also observed that, in general, Americans nodded much less frequently in conversation than Japanese. The nature of non-verbal backchannel has been also addressed by Maynard (1990), who examined videotaped pair conversations in Japanese and American English and carried out a contrastive CA to explore the listener's backchannels in casual conversations. Non-verbal response tokens in this study involved both head movement and laughter. Also, Gass and Houck (1999), in their study of interlanguage refusals, focused, among other aspects, on non-verbal backchannel performed by means of head movements. Recent research on this particular issue involves for example the works of Carter and Adolphs (2007), who took a multimodal approach for the analysis of backchannel, as well as the study carried out by Knight and Adolphs (2008).

Having provided a description of different kinesic resources, in the following section I focus particularly on the nature of kinesics and pragmatics.

\subsubsection{Kinesics and pragmatics}

The act of gesturing, which may be regarded to some extent as a universal feature of communication, is employed by speakers across cultures, although as pointed out by Gullberg (2006, p. 107) "[g]estures are [...] subject to individual variation but also to noteworthy uniformity within groups". The type of gesture performed is typically, as previously 
reported, associated with the production of speech, as described in McNeill's typology. Gestures and speech tend to be two associated domains, which can be viewed in fact as only one system (McNeill, 1992) or at least, it can be assumed that they "can overlap a great deal" (Goldin-Meadow and Wagner, 2005, p. 234). This would be the reason why many researchers attempt to explore language not only from the verbal perspective but also from the non-verbal perspective (Tellier, 2009). This view, however, may not be always shared as the approach taken and the data selected in a specific study would rely on the researchers' interests and the purpose of the study. Nevertheless, it is true that examining both kinesics and language can provide researchers with further insights into language performance, as in the case of this study in which attention is not only paid to the verbal performance of complaint sequences, but also to other kinesic resources accompanying speech. In line with this, and focusing more specifically on the realm of gestures and pragmatics, Wharton (2011, p. 384) states that "[r]esearchers into gesture should no more ignore pragmatics than those working in pragmatics should ignore the study of gesture". It is also important to note that there is not a "clear notion of pragmatic gesture [...] neither in the area of (linguistic) pragmatics nor in gesture studies" (Payrató and Teßendorf, 2014, p. 1536).

It is well-known that communication is a social act in which various communicative acts or events of different types occur among speakers. The use of gestures while speaking has been widely recognised, although, as pointed out by Kendon (1997, p.113) "[s]peakers do not gesture every time they speak", and further adds that "the kinds of gesturing employed and the role gesture plays in relation to what is being said or in relation to the interaction situation varies". Hence, despite the fact that gestures may play an important role in interaction, although not being always executed, their role might vary according to the situation being faced. It is, however, necessary to note that gestures can provide information of how a given utterance should 
be understood (Kita, 2009). Speakers produce several gestures when speaking and sometimes they even produce gestures instead of uttering words. As Senft (2014) points out, some gestures may therefore replace somehow verbal language, for example when refusing or accepting for example an offer, a suggestion or a request, since a gesture might be sufficient to show a refusal or acceptance.

In a complaint sequence, gestures may also provide information that is not necessarily performed verbally. For example, while negotiating the complaint, speakers could perform gestures that involve specific actions that may affect the other speaker. Gestures can be also performed without the presence of the interlocutor, for instance, when having a phone conversation (Senft, 2014). Further examples can be identified, especially nowadays with the use of new technologies, for example, when taking part in mobile- and/or computer-mediated communication; of course, in situations that do not involve video imagine as in this case speakers see each other. In a situation involving video conferencing, speakers may perform different gestures while being in presence of the other speaker. Furthermore, in this situation, one could observe not only how speakers interact verbally and nonverbally but also how the different modes involved in mobile- and/or computer-mediated communication interplay. This could be also applied to a situation in which video is not employed. Albeit very interesting, this specific aspect goes beyond the scope of the current study.

My intention in presenting this is only to provide some examples on how gestures can be part of communication. It seems that, in speaking, different modes, such as kinesic and paralanguage resources, are performed along with language, and this combination might have an effect on what is uttered, whether the different speakers are present or not. Hence, it is important to take into account that kinesics, and particularly gestures, might have a given pragmatic effect, for example, when interacting, performing speech acts, or assisting and attending the 
other interlocutor, thereby showing for example signals of active listenership.

Kendon (2007, p. 3) describes different scenarios in which gestures are used. For instance, the author argues that gestures may be employed to point at things we are referring to when speaking as well as when describing objects or actions in an attempt to "enrich, clarify or elaborate our descriptions". Moreover, when speakers express abstract ideas, gestures can be also used "as visual aids to these expressions, showing abstract processes as diagrams or movement patterns or logical relations as if they can be laid out in space" (Kendon, 2007, p. 3). Gestures are also employed to show the action that is involved in what speakers utter, for example, when performing speech acts such as agreement and/or disagreement. By means of gestures, speakers can also show that "we are asking a question or begging another's indulgence, that we are doubtful [...] or that what we are saying is hypothetical" (Kendon, 2007, p. 3). Gestures are also important when we are in situations in which speaking is not possible because the interlocutor is too far so that he/she cannot properly hear us or in situations where there is too much noise, as well as in specific situations where speech cannot be used, such as in some tribal societies.

Furthermore, it should be noted that in reviewing the nature of pragmatic gesturing, it is necessary to refer to Kendon's research. Kendon (1995, p. 247) states that we might talk about pragmatic gesturing, which, as he posits, "expresses aspects of utterance structure, including the status of discourse segments with respect to one another, and the character of the "speech act" or interactional move of the utterance". In a recent review on gesture and speech, Kita (2009, p. 157) states that "[j] ust as usage of language for communication is systematic (e.g. Levinson, 1983), usage of gesture for communication is systematic". In this sense, the author refers to "this systematicity as 'gestural pragmatics' in analogy to linguistic pragmatics" (Kita, 2009, p. 
157). By gestural pragmatics one might understand the principles governing gestures in communication.

Providing an accurate and extensive literature review on the role of gestures and language from a general perspective is not indeed the purpose of this section, but to limit it to the studies dealing with gestures and pragmatics. Unfortunately, there is not, to my knowledge, a large body of literature that focuses on this specific field of research (Kendon, 1995; Kelly, Barr, Church, and Lynch, 1999; Chui, 2005; Streeck, 2009; Ladewig and Bressem, 2013; Rossi, 2014), and only one piece of research has been found examining ILP and gesture (Gass and Houck, 1999).

A pioneering study dealing with pragmatic and gestures was conducted by Kendon in southern Italy, near Salerno, in 1995. Kendon (1995) made an important contribution to the study of gestures as illocutionary and discourse markers in spoken data. The author, by means of natural conversations, explored the different pragmatic gestures (i.e. Mano a borsa or purse hand, Mani giunte or praying hands, the Finger Bunch and the Ring) in natural conversations. In the study, the author described how gestures accompany speech containing pragmatic, rather than substantive function. Kendon (1995), drawing on the data of this study, found four conventional pragmatic gestures. The first two referred to the Mano a borsa or Purse Hand and the Mani giunte or Praying Hands, which are quotable gestures or emblems. These two might function as if they categorised the illocutionary force of the utterance they belonged to, which were labelled as illocutionary marker gestures, and they can express the illocutionary intent of the utterances. The remaining two types of gestures described in this study served to show the status of units within the discourse, that is to say, the discourse structure, and they were termed as discourse unit markers gestures. In this case, the author identified the Finger Bunch, which is similar to the purse hand in form, and it indicates the topic as being distinct from the comment. The other category identified was the Ring, 
in which the tips of the index finger and thumb were in contact creating then a circle. This type appeared to mark the locally of a unit in relation to a particular theme. The latter were not considered as emblems.

A different type of study was conducted by Kelly et al. (1999). More specifically, the authors, in 4 different experiments, investigated the pragmatic role that hand gestures play in language comprehension and memory. The first experiment examined the role of manual pointing gestures in understanding indirect requests. This specific speech act might be somehow confusing because it is not always easy to determine whether an indirect request or a declarative statement is uttered, for example in a situation in which a speaker says "it is hot in here" (example adapted from Kelly et al., 1999). In this case, the understanding on the part of the interlocutor is crucial as it might be interpreted that the speaker wants you to open the door, or maybe it is just a remark. In this first experiment, 16 (8 males) undergraduate students of the University of Chicago took part. The materials for this experiment consisted of a videotape of 12 scenarios, which served as stimulus. The scenarios involved a representation of two actors who acted out a scripted interaction between two roommates. The experiment involved two conditions, the Speech Only condition and the Speech + Gesture condition. Results of the experiment revealed that the deictic gestures performed seemed to facilitate understanding.

The second experiment introduced a new condition to the aforementioned ones, more specifically, Gesture Only. The participants of this experiment were 18 (9 males) undergraduate students of the same university. The materials for this experiment were the same employed in the first one. Results showed that participants in the Speech + Gesture condition were more likely to understand the indirect requests than those in the Gesture Only condition. Broadly speaking, results from both experiments indicated that speech and gesture combined to convey meaning appropriately, although "the question of how they combine remains unresolved" (Kelly et al., 1999, p. 583). 
A third experiment was carried out to explore how spoken information affects the interpretation of pointing gestures. The purpose of this experiment was to compare people's ability to identify referents of manual pointing gestures executed in combination with speech when the speech is muted. Participants of this experiment were made up of a 15 (7 males) university students (University of Chicago). The materials for this experiment were the same videotapes used in the two previous experiments. In this case, the conditions were: Speech + Gesture and Gesture Only. This experiment showed that the referent of the pointing gestures in the scenarios was to some extent determined by the speech act. The results obtained appeared to reject the idea that speech and gesture contributed to meaning in additive fashion. Finally, in experiment four, the authors introduced the iconic gesture and examined the role that this specific gesture played in concrete communicative acts, i.e. description of activities and events. In this experiment, a memory paradigm was also used to explore whether people had difficulty in monitoring the source of information provided by means of speech and gestures. In this experiment, 15 (8 males) North-eastern Illinois University undergraduate took part. The material consisted of a video stimulus of a woman (an actress) who made 10 isolated statements about everyday situations. The findings seemed to indicate that information provided by means of iconic gesture was "incorporated in what participants considered an utterance's intended meaning" (Kelly et al., 1999, p. 587).

In short, the study investigated the pragmatic role that hand gesture played in language comprehension and memory in three different experiments. The experiments showed that specific non-verbal behaviours such as deictic and iconic gestures might have an impact on how people comprehend and remember pragmatic communication. Experiment 1 revealed that pointing gestures seemed to make respondents more likely to interpret utterances as direct requests when hearing only speech. Experiment 2 replicated Experiment 1 and 
provided control for the possibility that the difference in the first experiment was associated to gesture alone. Experiment 3 appeared to reject the additive contribution hypotheses of speech and gesture processing in favour of the interactive contribution hypotheses, revealing that speech often seemed to constrain the meaning of the gesture. Experiment 4 served to generalise the results of the different types of speech acts with a different gesture type, i.e. iconic gesture.

The relationship between topicality of utterances and gestural use in Chinese conversation was investigated by Chui (2005). The study focused on the semantic and pragmatic aspects of information of the speakers' verbalisation, rather than on the interaction between participants, i.e. speaker and addressee. Data for this study was "five casual, unpremeditated, multiparty conversations" (Chui, 2005, p. 636) that took place in the years 1994 and 1995 between university students who knew each other. Participants were not given specific topics, but instead, they were free to choose the topics of common interest. Conversations were video-recorded for about an hour, although only tone section of each conversation was extracted, specifically, that "in which students were more comfortable in front of the camera" (Chui, 2005, p. 637). The typology of gestures in this study was categorised following McNeill (1992). This paper examined the relationship between topicality of utterances and gestural use in Chinese conversation. Results showed that gestural types did not distinguish between topical and non-topical information as their occurrences in topical and nontopical contexts were similar. Nevertheless, it was found that iconic gestures could be associated to topicality since Chinese speakers tended to perform them mainly for new information in topical clauses. Moreover, the patterning of given and new information accompanying metaphoric, deictic, spatial, and beat gesture was similar in the two types of clauses. Finally, it was found that speakers rarely performed manual movement while conveying given information. 
Hand-gesture as incipient and premonitory components of communicative actions and components of action were described in Streeck's (2009) study. The author examined gestures and their projective achievements in the context of turns and sequences of talk. The analysis of gestures was made on the basis of video recordings of leisure and workplace conversations in English. Streeck and Hartge (1992) described that a function that could be achieved by hand gestures before the beginning of the talk was the projection of the type of communicative act the speaker was preparing to perform. Moreover, action projectors and stance markers such as shrugs were regarded as pragmatic gestures (Streeck, 2006), and pragmatic gestures could be seen as operators (Kendon, 2004) in the sense that they may display what a bit of talk does in a specific situation, speaker's stance towards utterance content or action, and how the forthcoming utterances would be designed or how this will be taken by the recipient. Concerning turn beginning, and differently to the gesture identified in the beginning of a turn or before the re-beginning of an abandoned turn that focused on speaker's floor, they announced the pragmatic status or illocutionary role of the utterance. Regarding gestures in multi-unit turns, the author reported that shrugs might show the speaker's stance towards an event that he was about to report and it also outlined the open-ended outcome. Hence, speaker's shrug showed a propositional attitude and anticipated the general idea of the forthcoming story (i.e. uncertain outcome), and then the recipient knew in advance that the subsequent was not a success story. The gesture also enabled anticipatory alignment by the recipient, who knew how to hear what was about to be told. In the case of mid-turn, the author indicated that hand gestures combined with utterances heterogeneously and that the projections made by them were diverse. Streek (2009) further added that pragmatic gestures of different types were frequent in the mid-course of the turnconstructional units and therefore it was often complex to establish what they involved for recipient since recipients usually provided a 
response to the turn-constructional units as a whole. Pragmatic markers could be used to avoid for example interruption by others; indicate and explicate trouble in the process of speaking; show speaker's stance towards it; or situate what was said in the context between speakers, addresses, and third parties. Finally, in case of the turn-completion, the author reported on a specific gesture, that of sagittal downward movement of the open hand, usually pivoting at the elbow, and the palm facing up. This specific gesture can involve the act of giving, presenting, offering, and handling over or, beckoning or solicitation. The author also posited that the meaning of open hand gestures could change over the course of conversation, accordingly, the more time passed after a turn-completion, the more pressing was the constrain on the recipient to produce a turn in response.

Ladewig and Bressem (2013) study on recurrent structures in gestures, analysed gestures based on four parameters, hand shape, orientation, movement, and position in gesture space. The authors argued for a specific procedure and methodological approach which enable them to uncover clusters of recurrent forms and a systematic variation of form and meaning in a recurrent gesture, and conducted two studies to prove it. The first study attempted to provide a description of the use, distribution and clusters of gestural form features in German speakers. Data for this study was gathered by means of dyadic naturally occurring conversations where 4 participants (1 male) talked about a subject of their choice and did not know that gestures were under investigation. Results revealed that 30 different hand shapes were performed by the speakers including ones used by all the participants and by those used by a single speaker, too. Out of the total number of hand shapes, the four participants only used 6 hand shapes recurrently, suggesting that these 6 could be characteristic hand shapes of German speakers. Similar results were found as regards orientation, movement, and position. Specifically, the authors found: 5 recurrent types of orientation (i.e. Palm Lateral towards Center; Palm 
up, Palm Down; Palm Vertical away Body; and Palm Vertical towards Body); regarding movement, all the participants employed the same movements: straight, arced, circle, wrist, and wrist orientation; 16 for the direction of movement of which 14 were recurrent among participants suggesting that speaker had a vast range of types of direction hand; for manner of movement, the following types were identified across participants: reduced, enlarged, accelerated, decelerated, and accentuated; as regards position, 5 were identified, including periphery upper, center upper, center center, center lower, and periphery lower. Concerning clusters, the authors found that the most widely used was that of flat hand, occurring with Palm Lateral towards Center, a straight movement downwards in which hands were located in the gesture space ranging from periphery upper to periphery lower.

The second study focused on a recurrent gesture. Data for this study was made up of 10 hours of naturally occurring conversations in which 12 German participants (5 male) took part. The corpus included 56 cyclic gestures, which were distributed following the context of use: 37 during a word or concept search; 12 in the context of descriptions; 6 in the context of a request; and 1 in the context of an enumeration, although the last one was not included in the systematic description as it was too low. The first item was classified as fulfilling a performative function, more precisely, meta-communicative function, indicating the process of searching for a word/concept, and it also functioned as a turn-holding device. The item of descriptions was used as referential function, as it showed semantic aspects of the actions or events. This variant was typically performed with an open hand oriented towards the speaker's body. Regarding the context of requests, a performative function was fulfilled and the typical variant was the right periphery of the speaker's body.

Drew and Couper-Kuhlen (2014) have recently edited a volume that focuses on the speech act of request in interaction in which aspects 
of verbal and non-verbal elements are acknowledged. In this section, I review some of the contributions. For example, Mondada (2014) examined requests that required immediate attention which were performed by means of language, gestures and the embodied engagement in the ongoing activity. Data for the study consisted of surgical procedures, the operating room. A study involving the analysis of facial expression, gestures, gaze and intonation involved in the directive trajectories in communicative project in family interaction was carried out by Goodwin and Cekaite (2014). Data for the study derived from video recordings of naturally occurring data involving interaction in families. These two studies are not reviewed in detail as the first one, Mondada (2014), focuses on the specific context of the operating room, thereby beyond the scope of the present study; and the second one, that of Goodwin and Cekaite (2014), is not either thoroughly reviewed as it explores the interaction between families involving for examples adults and children, which again seems not be directly related to the present study. Further studies can be found in the abovementioned edited volume, as well as in other volumes such as the recent edition by Crawford and Fortanet-Gómez (2015), which focuses on multimodality in the academic context. Nevertheless, these contributions are, to the best of my knowledge, beyond the scope of the present study and therefore this is the reason why I have decided not to provide a revision of these works.

Of interest for the present study, however, would be the investigation carried out by Rossi (2014), who examined the speech act of request and multimodality by means of a video corpus of naturally occurring data containing interaction among speakers of Italian. In this case, differently to Mondada (2014), everyday conversations among family members and friends were analysed. Although, Goodwin and Cekaite (2014) also examined data from family conversations, the data base differs from that presented by Rossi (2014), which seems to be more suitable for the present literature review due to the focus of the 
study. Data derived from informal encounters and activities among family members and friends.

Following Rossi (2014), in everyday interaction, participants often request others to pass, move, or deploy objects, and to get these objects to or from the requestee, requesters need to manipulate them. When performing manual actions such as holding something out, researching for it or placing it somewhere, requesters may or may not accompany them with verbal support. Therefore, this study attempted to show whether language was or not employed while requesting. When the action involved a projectable form of the advancement of an activity, presenting a relevant object was sufficient, whereas when the action requested was occasioned by a development of the activity requesters used language to indicate the other person what to do. Moreover, the study also revealed that when the action requested was projectable but the requestee was not visualising the requester's non-verbal behaviour, the requester employed language so as to attract the attention of the requestee.

The above reviewed studies focused on the specific nature of gestures and pragmatics in contexts in which participants were not learners of the TL, NSs of de language, and therefore interlanguage aspects of language and gestures were not observed. These studies, albeit influential, might not be considered as part of the body of literature devoted to examine learners' performance due to its purpose, methodology, and participants. It is therefore important to claim that there seems to be a research gap concerning the study of gestures in the domain of ILP, and more specifically, employing the elicitation techniques such as role-play tasks (described in Chapter 1 Section 1.2.2.1).

There is, however, to the best of my knowledge, only one study addressing the issue of non-verbal behaviour, and particularly gestures, in ILP research. The study conducted by Gass and Houck (1999) who set out to investigate the possible negotiation of outcomes in refusal 
responses in simulated spoken interactions, between NSs and NNSs of English, by means of role-plays. The analysis of non-verbal aspects centred direction of gaze and expression of affect by means of posture, facial expressions, and gestures. Among different aspects, the authors examined gestures of three different participants. Results showed that speakers did rely on gestures that reinforce their linguistic message on posture, as well as on head movements showing involvement in the NS's message, and on facial expression that revealed feelings about the interaction. Table 6 provides a summary of the studies above reviewed. 


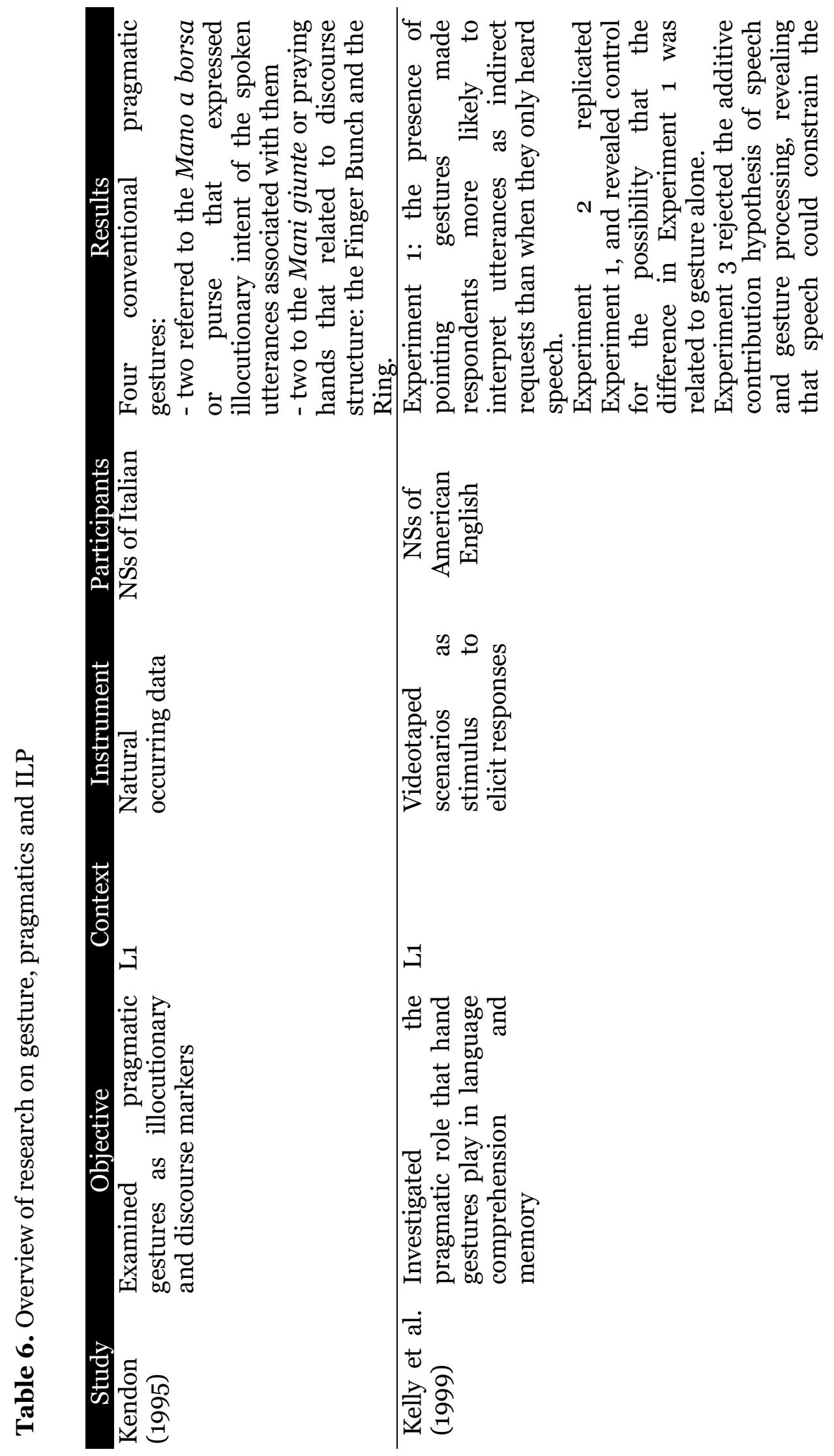




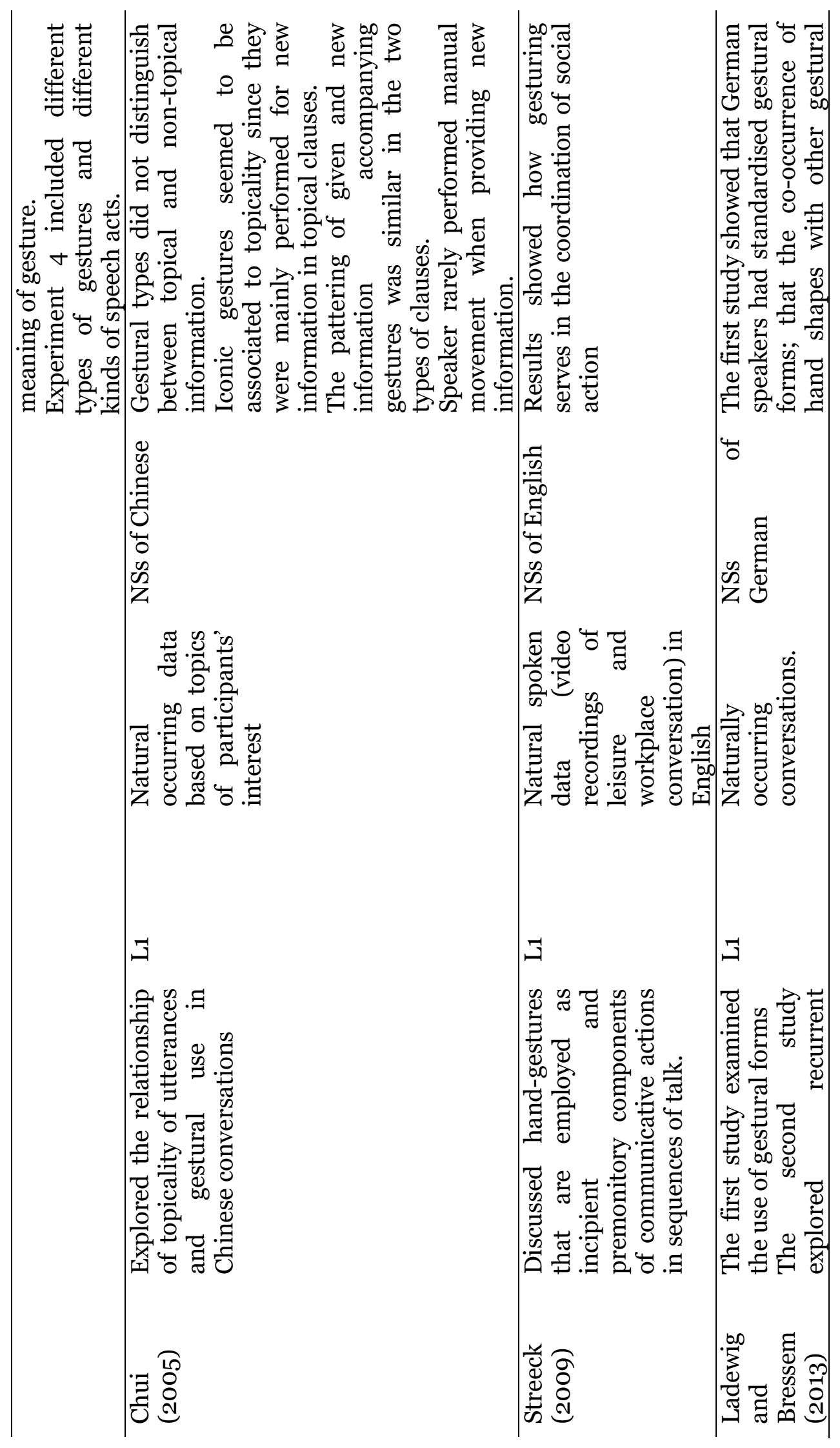




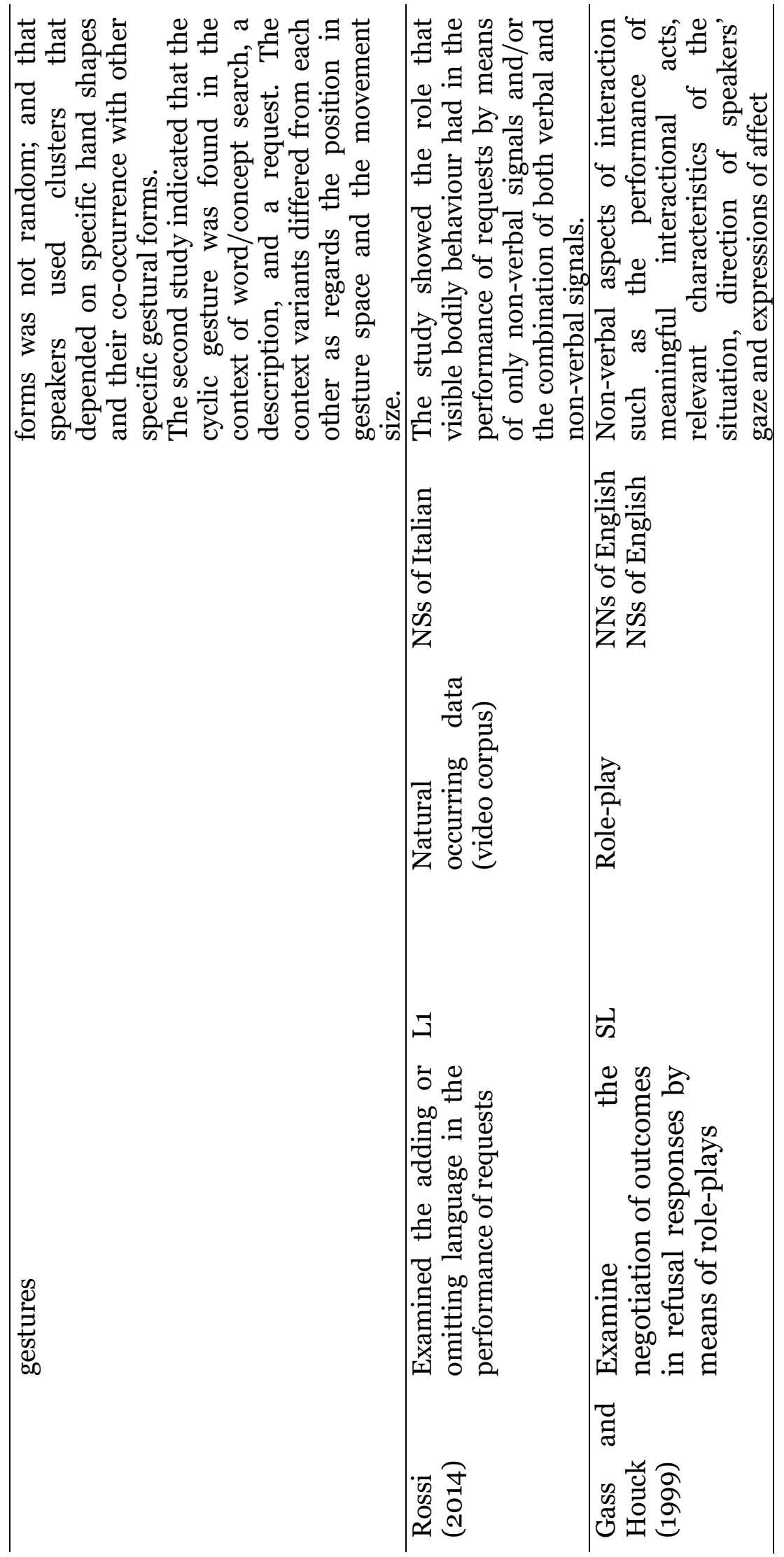


Gass and Houck's (1999) study appears to be of paramount interest since it has addressed the role of different multimodal resources in ILP research. The lack of studies on non-verbal aspects within the area of ILP could somehow imply that attention is mainly paid what is verbally expressed. However, I consider that there are other aspects to take into account apart from verbal utterances since communication is multimodal by nature (Jewitt, 2013) and therefore this should not be ignored, but observed and examined since the combination of different modes may serve to research communicative purposes, and these aspects becomes particularly interesting for language learners.

After revising the relation between kinesics and pragmatics, and providing a literature review of proficiency and kinesics performance, in the following section I address proficiency and kinesis performance.

\subsubsection{Proficiency and kinesic performance}

The purpose of this section is to provide a literature review of studies which have examined the variable of proficiency and its effects on kinesics performance. However, despite the fact that there is a growing interest in the relationship between SLA and gestures (see for example Gullberg, 2010, 2014), there are a scant number of studies that centre exclusively on the specific area of the effect of proficiency on gestures development and performance from the perspective of SL/FL learners. Nevertheless, albeit the amount of research conducted is rather limited, in this section I try to introduce those empirical studies that have explored the role of proficiency on gestures.

Gullberg's (1998) study on communication strategies and gestures explored issues related to communication strategy theories and gesture theory, as well as theoretical issues related to compensatory/strategic gestures. Data for this study was collected by means of retelling a story, which was presented as a cartoon. Participants were two groups of NSs, 
involving NSs of Swedish and NSs of French, who at the same time were students of other languages at the intermediate level. Thus, two different sets of language learners participated in this study which involved 5 NSs of Swedish learning French as a FL and 5 NSs of French learning Swedish as a FL. Participants in this study were required to perform the task in their L1 and in their L2. The experimental section involved two different studies. The first study, that is, the production study, analysed the gestures performed by Swedish learners of French and French learners of Swedish. Results showed that participants' proficiency level appeared to influence some of the gestures executed. This variable seemed to interact with other aspects such as the individual realisation of communicative competence, and more specifically, with the strategic competence. Furthermore, proficiency appeared to affect the use of some specific gestural communication strategies. The author also reported that the specific preferences for a particular strategy type could interact with individual and/or language tendencies towards a particular typology of gestures. Low proficiency was associated with the use of Code strategies, while participants with an advanced level of grammar showed lexical problems which were solved by means of Conceptual strategies.

Gregersen, Olivares-Cuhat and Storm (2009) explored the role of proficiency in a study that focused on the possible connections between SL competence and frequency and type of gestures used. This study involved 75 students enrolled in an American university who took Spanish as a FL. Participants were distributed into three different proficiency levels, i.e. 24 beginners, 37 intermediate and 14 advanced learners, according to the results obtained in the placements tests and previous course performance. Gestures were coded following the taxonomy proposed by Ekman and Friesen (1969), including illustrators, compensatory illustrators, adaptors, emblems, regulators and affect displays. Participants were videotaped performing in dyads a role-play, first in Spanish and then in English. Participants were 
videotaped acting out in pairs first in Spanish and then in English. The task involved a situation in which participants had to simulate the events of a crime and then one of the participants was assigned the role of the witness to a robbery and the other was the police officer. Results suggested that learners at higher levels seemed to be more likely to use gestures that enhance the meaning of the verbal message and contribute to greater communicative competence than less proficient learners. Advanced learners, using more illustrator gestures, appeared to reinforce grammatically, use visual discourse markers, reinforced meaning through the visual channel, and moreover, and responded with sociolinguistic gestural ability. Less proficiency participants tended to use adaptive behaviours that could reveal higher levels of FL anxiety. The authors also reported that these nervous gestures could have affected the execution of gestures that could enhance communication. Emblems, albeit not often performed, were more frequently used by beginning than by intermediate or advanced level participants. Regulatory, compensatory and effect displays gestures were not used with significant differences as regards the frequency across the three proficiency levels.

Kim (2012) investigated why speakers of English as a SL gestured and how proficiency was related to gesture performance. Specifically, 32 Korean-English bilingual participants who were undergraduate and graduate students at Midwestern University in the US took part in this study. Participants were divided into two different groups according to their age of arrival in the English-speaking county, length of stay, and a speaking test, thereby including the intermediate (16 undergraduate) and advanced (16 graduate) groups. For the purposes of this study, the author counted the representational gestures (i.e. pictorial meaning of a word) and compared the gesture rate per 100 words of 16 intermediate and 16 advanced speakers of English as a SL. This study was conducted in a room with a video camera that was set up at the corner to capture hand/arm movements and head movements. Participants were required 
to retell a listener a cartoon, the "Tweety and Sylvester" cartoon. The author, performing a micro-analysis of representational gestures found that due to their linguistic limitations, intermediate participants appeared to rely more on gestures channels (Kita, 1993; Gullberg, 1998). Results showed that higher rates of representational gestures performed by the intermediate group tended to be performed with their expressive difficulties at non-narrative levels, and higher rates of abstract deictics were employed to perform gestural spaces metaphorically in order to activate their lexical search and selforganisation process. The author reported that these results seemed to "suggest that gesture play a role as a window on L2 proficiency; that is, gestures show different L2 thinking process of L2 speakers at different proficiency levels" (p. 61). Thus, it was found that intermediate participants used more gestures than advanced speakers, and that they used them more for lexical search, orchestrate and formulate their discourse.

The role of proficiency and gesture types in narrative was examined by So, Kita, and Goldin-Meadow (2013). In this study, the authors explored whether specific deictic gestures, that is, those pointing to physical entities, could bear a different relation to speech, as well as whether that relation could be affected by the variable of language proficiency. Participants were 5o English-Mandarin bilingual undergraduate students who were born and grew up in Singapore and used both languages at home and in school, but for of them, English was a SL. Gestures that co-occurred with spoken reference were coded, specifically when the stroke phase or the post-stroke hold of the gesture was produced along with speaking. In the task, participants were asked to retell a story that involved two male characters. Results showed that specific deictic and iconic gestures appeared to bear a different semantic relation to the speech they accompanied, particularly in the case of proficient participants. Proficient participants seemed to produce iconic gestures to specify referents that had been already indicated in speech, 
and concrete deictic gestures to specify references that had not been indicated in the speech. These patterns were attenuated in less proficient speakers. In fact, they were as likely to produce concrete deictic and iconic gestures for references that had been already specified in speech as for references that had not been specified in speech. Finally, the authors reported that results seemed to indicate that gestures and proficiency need to be examined in order to explain how speakers perform gestures and speech in narrative discourse.

Table 7 displays a summary of the above reviewed studies. 


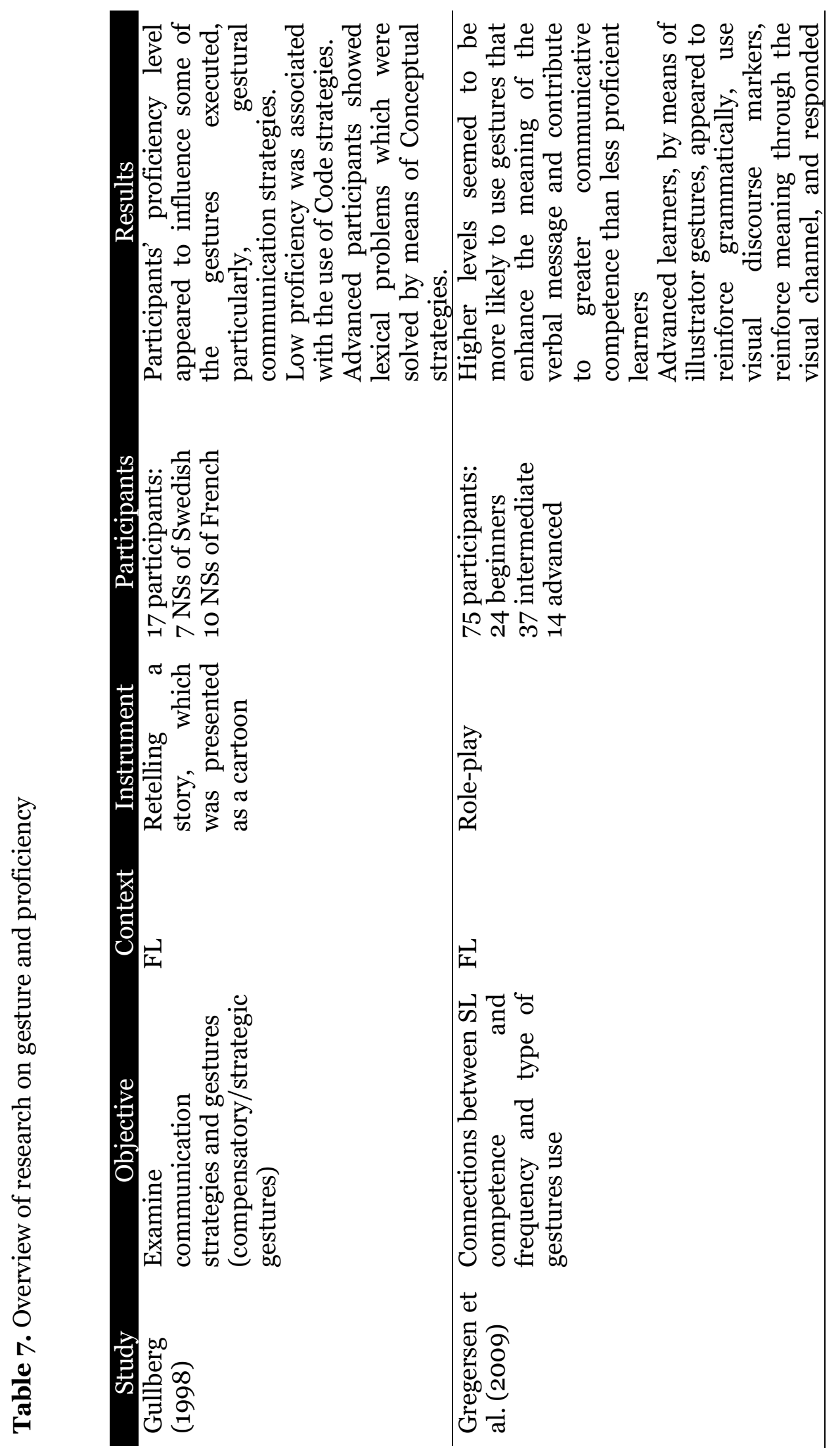




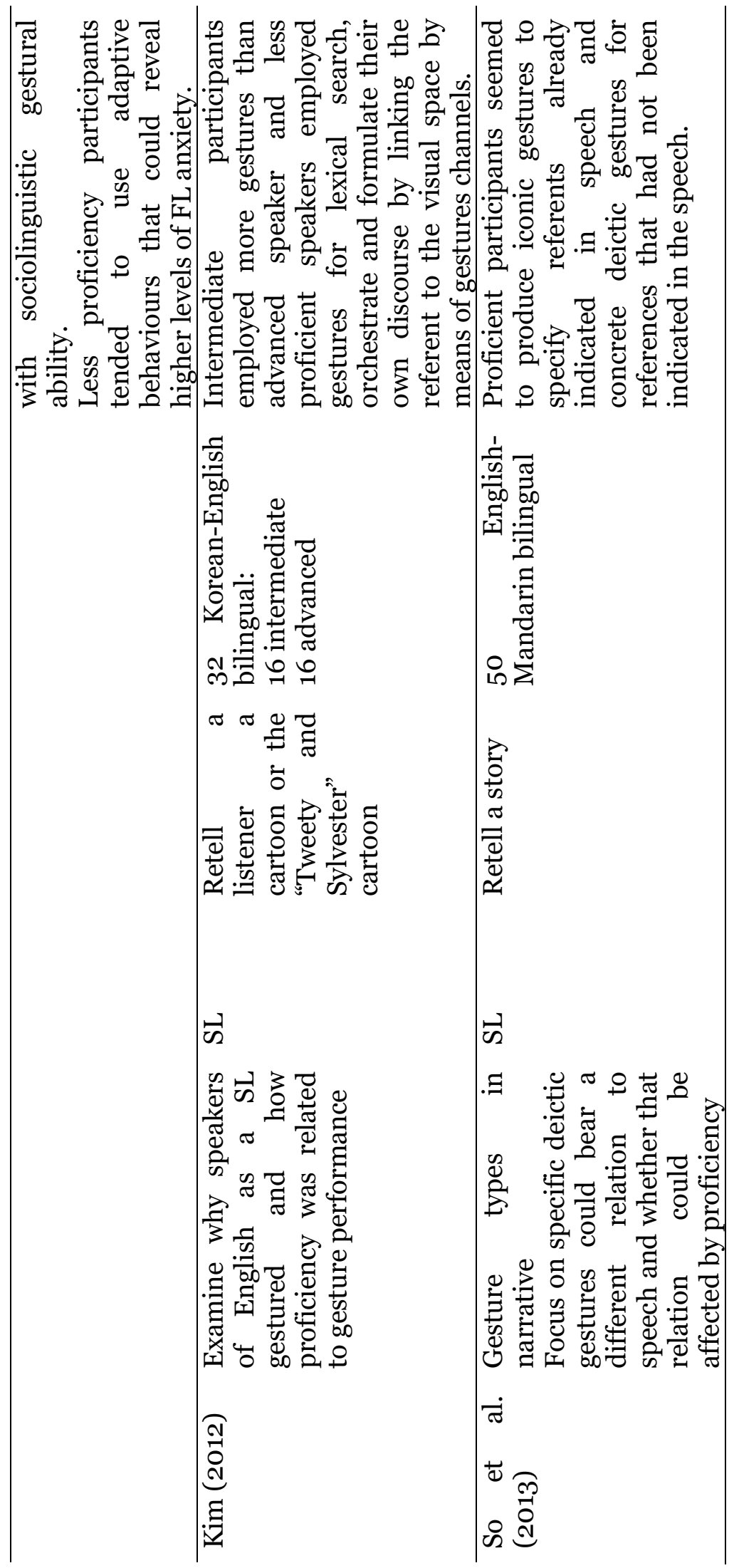


As reported, the number of studies conducted in the field of gestures that have examined the effect of proficiency on gesture performance in the SL/FL context is rather limited. The scant number of studies reveals therefore that there is a need to conduct research to investigate the effect of FL/SL proficiency and gesture performance. Broadly speaking, results derived from the studies above reported tend to indicate that proficiency had an effect on the performance of specific gestures, as can be noted in the studies conducted by Gregersen et al. (2009), Kim (2012) and So et al. (2013). It remains unclear whether FL/SL proficiency has an effect on gestures performance, and how this issue is, at least, as complex as the possible existing correlation between proficiency and pragmatics, where higher levels of proficiency does not necessarily involve higher pragmatic competence. Similarly, it would be tentative to assert that higher proficiency levels do correlate with gesture performance because one might also wonder whether learners at lower levels might use gestures to better convey the intended meaning.

This section has provided a review of kinesics by focusing particularly on gestures, head movement, face expressions and gaze. Moreover, I have addressed the nature of kinesics and pragmatics as well as the variable of language proficiency in gesture performance. Another aspect that should be revised when dealing with multimodal communication is that of paralanguage. Therefore, in the following, I focus on the nature of paralanguage, its classification and on research that examines this particular issue.

\subsection{Paralanguage}

Lyons (1977, p. 64) notes that "the most typical form of languagebehaviour is that which occurs in face-to-face conversation between members of the same culture; and this is what will be meant by the term 'normal language behaviour"'. The author also adds that all other uses 
and manifestations of language derived somehow from this normal language behaviour, which involves verbal and non-verbal components, consisting the latter of prosodic and paralinguistic parts. Paralinguistics is typically associated to non-verbal communication since it refers to the study of vocal signals beyond the verbal message (Nörth, 1990). Archibald Hill coined the term paralanguage in 1958 proposed a first approximation of the nature of paralanguage, and Trager (1958) provided a first approximation to paralanguage, and in turn, exerted influence over the field of non-verbal studies. Following this brief introduction, I provide a further extended review of the nature of paralanguage and its classifications.

\subsubsection{An overview of paralanguage}

The scope of paralanguage might involve a field of communicative phenomena that goes beyond language. Crystal (1975, p. 164) points out that "observations of people's everyday reactions to language suggest that paralanguage or paralinguistic phenomena, far from being marginal, are frequently the primary determinants of behaviour in an interaction" and that "paralanguage cannot be given anything other than a central role". Archer and Akert (1977), among other researchers, indicate that it is often the way something is said that sends the real meaning, rather than the words employed to convey the message itself. Crystal (1975, p. 47-64), in his survey of trends in paralinguistics, shows the scope of this field could be defined in different ways, p. (1) nonhuman as well as human vocalisations; (2) non-vocal as well as vocal features of human communication; (3) all non-segmental ("suprasegmental") features and some segmental ones"; (4) voice quality as well as (all or most) non-segmental features; (5) only nonsegmental features; (6) only a sub-set of non-segmental features other than prosodic phonemes and voice quality; and (7) functional definitions. The first and the second views are broad approaches to the 
notion of paralanguage. On the one hand, the first one involves acoustic modes of zoo-semiotic communication, and the second one focuses on the whole field of non-verbal communication, on the other hand. This view of paralanguage, in the broad sense, is shared also by linguistics such as Abercrombie (1968), Laver (1976), and Lyons (1977).

What seems to be clear is that the verbal message would imply very little without the vocal cues that accompany it, and in many occasions, the whole meaning is determined by the way something is said (Richmond and McCroskey, 2000). In line with this, Abercrombie (1968, p. 55) "we speak with our vocal organs, but we converse with our whole body". Obviously, in the spoken mode this might be observed, whereas in the written one, this would be different. It seems therefore that paralanguage would involve how something is expressed rather than simply what is actually said. Paralanguage is therefore part of communication, and it makes language communication be more accurate, vivid and forceful. It is, however, important to note that Shözt (2002) points that a terminology problem appears to distinguish in the speech between linguistic information, and all other type of information. Speech signal contains other information apart from linguistic, which is referred to as paralinguistic, extra-linguistic, and non-linguistic. In the current study, paralanguage and paralinguistic activities are employed without such distinctions. In what follows, I present some of the most influential classifications of paralanguage (Trager, 1958; Roach, Stibbard, Osborne, and Setter, 1998; Poyatos, 2002).

\subsubsection{Paralanguage resources}

Trager (1958) is the first author that classifies paralinguistic activity into different categories, involving: (1) voice set, psychological or physical peculiarities; (2) voice qualities; and (3) vocalisation that constitute specific noises such as qualifications and what Trager (1958) 
termed as "segragates" involving grunts and sneezes, i.e. vocal reflexes. The first category, voice set, is described as the background of speech. The contextual background involves speaker's characteristics, e.g. age, gender, present condition of health, state of enthusiasm, fatigue, and sadness and other emotions, as well as other aspects such as social status or education level. Voice set is closely therefore related to who the speaker is, and it helps to interpret the speaker's words more accurately (Trager, 1958). The second and the third category are those of voice qualities and vocalisations. On the one hand, voice qualities refer to tempo, resonance, rhythm control, articulation control, pitch control, glottis control, vocal lip control, and pitch range. On the other hand, vocalisations, which are closely related to voice qualities, involve audible vocal cues, which are linguistic, and may or may not be accompanied by words. Three different types of vocalisation might be distinguished. The first one is the vocal characteriser, which refers to non-articulated sounds such as laughing, crying, whimpering, giggling, snickering, and sobbing. Moreover, many audible chants are also seen as characterises, including for example groaning, moaning, yawning, growling, muttering, whining, and sighing. The second type identified is the vocal qualifier, which are similar to vocal qualities but while vocal qualities typically modify an entire utterance, vocal qualifiers regulate specific parts of the utterance. Vocal qualifier includes intensity, pitch height, and extent. Additionally, the vocal cues that vary the speed, loudness, or softness during the utterance are also qualifiers. The last type identified is that of vocal segregate. Accordingly, some of these non-articulated sounds have been described as non-words that are used as words. These cues include vocalisations such as shhh, uh-huh, and uh-uh, as well as many common filler sounds such as uh-uh-uh, er, ah; and even seeming words as for example and-ah and you know.

Other classifications can be found in the literature, for example, that provided by Poyatos (1993, 2002), who distinguishes three different categories: (1) qualities; (2) qualifiers; and (3) differentiators. 
Paralinguistic primary qualities include timbre, resonance, loudness, tempo, pitch (i.e. level, range, registers, and intervals), intonation range, syllabic duration, and rhythm. These voice qualities are always present in the human voice, and they are the basic components of voice and their communicative and grammatical functions. The second category is paralinguistic qualifiers or voice types, which modify syllables, longer speech segments, and a whole deliverance. Concerning qualifiers, the author differentiates ten types, which involve breathing control, laryngeal control, esophageal control, pharyngeal control, velopharyngeal control, lingual control, labial control, mandibular control, articulatory control, and articulatory-tension control. Qualifiers operate due to cultural, circumstantial, and personal reasons. Poyatos (2002) also acknowledges the communicative relevance of many physiological and emotional reactions, thereby describing the third category, i.e. paralinguistic differentiators. Specifically, differentiators include laughter, crying, shouting, sighing and gasping, panting, yawning, coughing and throat-clearing, spitting, belching, hiccupping, and sneezing.

In addition to this, Roach et al. (1998) also propose another classification of paralanguage resources. The authors refer to the work of Crystal (1969) when considering that prosodic features are characterised by variations in pitch, loudness, duration, and silence; whereas paralinguistic features are vocal but independent of those four variations for their identification. Roach et al. (1998) advance a gradient based on the categories proposed by Crystal and Quirk (1964) and Laver (1980), with prosodic features signalling linguistic information at one end, and features such as voice quality and non-linguistic noises on the other paralinguistic end. Moreover, paralinguistic features are further divided into (1) voice qualities, due to different modes of phonation, such as modal voice, falsetto, whisper, creak, harshness and breathiness; and (2) voice qualifications, which are non-linguistic vocal effects such as laughing, giggling, tremulousness, sobbing and crying. 
Prosodic features are further divided into tempo, prominence, pitch range, rhythm, tension, pause, and intonation.

A crucial concept in the study of paralanguage is indeed intonation, which can be defined as the systemic use of pitch in a language, that is, it is the term that is "commonly used about variation in the pitch of a speaker's voice" (Malmkjær, 2004, p. 276). According to Crystal (1975) intonation is used to segment and structure stretches of language, showing contrasts of meaning which are sometimes as clearcut as the contrasts signalled by phonemes or word-order. Speed, rhythm, and other tone-of-voice variations are not employed as systematically to indicate that a restructuring of the utterance has been done, as are contrasts of pitch (and also those contrasts in loudness generally referred to as 'stress'). This is therefore why sometimes intonation and stress systems are viewed separately from other paralinguistic characteristics, thereby considering them more central features of language.

Intonation has been typically described as involving two main functions, grammatical (Halliday, 1985) and emotional or attitudinal (O’Connor and Arnold, 1973). Discourse intonation involves an approach for the analysis and teaching (see for example Chun, 2002) of everyday speech. Discourse intonation was pioneered by David Brazil who co-worked with Malcolm Coulthard and Catherine Johns (1980) to publish one of the most influential works in English Language Teaching, and also in academic research, Discourse Intonation and Language Teaching. Then, the descriptive framework of discourse intonation was developed by Brazil (1984, 1995, 1997) and followed by other researchers such as Coulthard and Brazil (1981), Coulthard and Montgomery (1981), Sinclair and Brazil (1982), Hewings (1990) and Cauldwell (2002). His approach sees intonation as discoursal and pragmatic in function rather than as grammatical or attitudinal (Brazil, 1997). As pointed by the author, "[t]he significance of intonation is related to the function of the utterance as an existentially appropriate 
contribution to an interactive discourse" (Brazil 1994, p. 46). Speakers make intonation choice depending on their perception of the understandings they share with their hearers (Brazil 1997), such as their biographies and the purpose of their talk. Therefore, the communicative potential of intonation is focused on the choices speakers made as well as on their reaction to the task of making sense to their interlocutors in real-time (Caudwell, 2002). Discourse intonation systems, as indicated by Cheng, Greaves and Warren (2008, p. 11) "are motivated by realtime, situation-specific decisions by the speakers to add extra layers of interpersonal meaning to words as they are spoken".

Following Brazil $(1984,1997)$, discourse intonation provides a tool for analysing and interpreting speakers' significant intonation contextreferred that compromises four system of speaker choices, p. (1) prominence; (2) tone; (3) key; and (4) termination. Table 8 provides a summary of the descriptive categories of the discourse intonation.

Table 8. Discourse intonation choices

\begin{tabular}{ll}
\multicolumn{1}{c}{ System } & \multicolumn{1}{c}{ Choice } \\
Prominence & Prominent/non-prominent \\
& syllables \\
Tone & Rise-fall, fall, rise, fall-rise, level \\
Key & High, mid, low \\
Termination & High, mid, low
\end{tabular}

(Adapted from Hewings and Caudwell, 1997, p. vii, in Brazil, 1997)

The first prominence is the non-tonic, i.e. the onset, and the second is tonic, i.e. the location of tone. Differently to other description, discourse intonation does not relate any significant to the location of boundaries. The second intonation system is the tone, which involves rise-fall, fall, level, rise, and fall-rise choices, and the third, i.e. key, and the fourth, i.e. termination, involve that speakers can place prominent syllables (i.e. low, mid, or high) in relation to the previous prominence. 
These choices on the onset prominence might make up the key system while on the tonic prominence they involve the termination system. Cauldwell (2002) indicates that the interpretation of the choice of these two systems could be summarised as follows. On the one hand, low key adds meaning that could be paraphrased as "this tone unit has an equitable relationship with what has gone before", and high key adds "this tone unit has a denial of expectation relationship to what has preceded' or 'this is discourse-initial", and low termination also adds meaning such as "this is discourse-final", and high termination adds "this is something I want you to give judgment on". Though discourse intonation seems to disregard the attitudinal aspect of intonation, one can see the attitudinal function in it, since the key system enables the speaker to project a valid contrast to bring into opposition a pair of possibilities and simultaneously exclude one of them. In doing so, on a particular occasion, speakers may show feelings or anticipate feelings in their hearers.

Another important aspect to consider is hesitation forms, which might be classified into filled pauses (vocalised pauses) and empty pauses (silence) (see Ephratt (2008) for an extended discussion of the functions of silence). A common feature of speech, particular spontaneous speech, is the use of pauses. Vocalisations involve pauses, which are also known as filled pauses and verbal fillers. Both filled pauses and pauses might have a communicative function (e.g. SavilleTroike, 1985; Local and Kelly, 1986). From a functional perspective, filled and silent pauses might reflect different internal processes, specifically, filled pauses might show affective states such as anxiety, and silent pauses would be related to the cognitive difficulty of the task (Goldman-Eisler, 1968). Maclay and Osgood (1959) suggest that filled pauses may show a floor-holding function since they might inform the interlocutor that speaker's speech has not been finalised as he/she has more to say. Nevertheless, as indicated by Cenoz (1998), this view is not always supported since this approach could be declined considering for 
example the case of lectures, where filled pauses might be very common but there is no possibility of interruption. In addition, silence has been classified within the field of paralinguistics, together with qualities and vocalisations. Crystal and Quirk (1964) make reference to silence by differentiating the term silent from voiced pauses, thereby distinguishing between paralanguage and prosody. For them, prosody "can fairly easily be integrated with other aspects of linguistic structure" whereas paralanguage "seems remote from the possibility of such integration" (1964, p. 12). The authors list nine features that start from the most prosodic to the most paralinguistic, being the first tone and the last pauses. Vargas (1986) provides a list of non-verbal systems that "contribute significantly to all human communication, regardless of the spoken language they accompany kinesics; the eyes; paralanguage; silence; tacesics and stroking; proxemics; chronemics and color" (1011). In this case, silence seems to be located apart from paralanguage. Nevertheless, Vargas (1986) also focuses on silence as part of paralanguage, along with voice qualities. Specifically, pauses to punctuate or accent words, and hesitations might be part of paralanguage. For Vargas, the other silences refer to "interpersonal silences that are independent of verbal communication defy classification" (1986, p. 77), including for instance institutional silences and internally oriented silences, which might be employed to think or plan. Poyatos (2002) also focuses on pauses, which are placed in the alternant class within paralanguage. The author presents various examples in which pauses might serve to delimit speech segments as speech markers, turn opening and for psycholinguistic internal needs, e.g. lexical search, hesitation, self-correction. Silent alternants could be also regarded as a result of an emotional state, including for example grief or happiness, thereby, differently to Vargas (1986), who lists these silences as defy classification instead of paralinguistic alternants.

After providing a review of different classifications of paralanguage, and focusing in specific aspects such as intonation, 
pauses and silence, in what follows I focus on paralanguage and pragmatics, since this is of special interest for the present study.

\subsubsection{Paralanguage and pragmatics}

Paralanguage has drawn the attention of several researchers. Nevertheless, from the perspective of ILP research, no articles have been found, with the exception of Taguchi's (2002) study. Chomsky and Halle (1968) view intonation as sentence-based grammatical devices, as for example when rising tone in yes/no questions. Differently to Chomsky and Halle (1968), O’Connor and Arnold (1973) do not understand intonation mainly as a grammatical pattern, but as part of speaker's attitude. Thus, rising tone would be attributed to a particular attitude. These two views see intonation as secondary to the literal meaning of content words. A different approach, as review in the previous section is related to the works of Brazil (1997). The nature of pitch and intonation has been also tacked with from the perspective of impoliteness. Specifically, Culpeper, Bousfield and Wichmann (2003) and Culpeper (2011) argued that impolite aggression could be conveyed by means of paralinguistic elements such as pitch of voice.

Other studies of discourse intonation included for example those involving the Hong Kong Corpus of Spoken English, which as the "first large-scale attempt to use the categories and conventions of discourse intonation in its transcription" (Cheng et al., 2008, p. 3). Concerning this, different studies have been carried out by Cheng and her colleagues, for example examining intonation of indirectness in intercultural communication (Cheng, 2002); the intonation of yes/no questions and declarative questions in hotel (Cheng, 2004); disagreement in business discourse (Cheng and Warren, 2005).

Another important contribution to the study of pragmatics and prosody is done by Romero-Trillo (2014), who compared the prosodic patterns of pragmatic markers in the London-Lund Corpus and in the 
LINDSEI corpus (the Spanish section) to describe the prototypical performance of pragmatic punting ${ }^{12}$ in NSs and NNSs of English conversations. Also, in 2015, Romero-Trillo investigated the prosodic features of general extenders in English conversation. In 2012, the author co-edited a book entitled Pragmatics and Prosody in English Language Teaching, which focuses on pragmatics and the study of prosody features in real interaction. In this edited book, Pickering, $\mathrm{Hu}$ and Baker (2012) examined the pragmatic function of intonation in cueing agreement and disagreement in naturally occurring data of American English speakers and Chinese learners of English. Participants were 12 (6 male) NSs of English and 12 (6 male) NSSs of English who were undergraduate and graduate students in a tertiary institution in the US. Pairs of speakers were seated next to each other in front of a laptop computer, which participants controlled. The task, adapted from Koester (1990), involved a series of pictures of ten concept cars and they were asked to agree on their favourite car. Results showed that, in the majority of cases, both NSs and NNSs showed pitch concord in agreement sequences. Examples that did not reveal pitch concord, often showed other types of prosodic matching, e.g. matching pitch contours. In any case, data revealed uniform use of pitch matching in agreement sequences. NS data showed that the use of discordant pitch choices in disagreement sequences, suggesting that discordant pitch could be a robust discourse cue in NS interaction. The author concluded that the study raised several methodological questions, for example, how pitch concord should be operationalised.

A different type of study was carried out by Taguchi (2002) who applied the relevance theory ${ }^{13}$ (Sperber and Wilson, 1995) to SL research in order to analyse leaners' inferential ability in

12 Trillo-Romero (2014, p. 209) defines it as "the cognitive process that certifies that the communicative transfer from the speaker to the listener in a conversation has achieved its goal”.

${ }_{13} \quad$ Relevance theory is a framework for the study of cognition that assumes that a key element in human communication is the recognition of speakers' intentions. 
comprehending conversational implicature. This study attempts to provide some insights into the ways language learners process nonliteral, indirect messages. More specifically, the study focused on the comprehension strategies employed by learners at two different proficiency levels in order to provide a description of interaction between linguistic and non-linguistic knowledge during comprehension. Therefore, the study examined whether and how learners sought the relevance of implicit input in context as well as whether proficiency played a role in comprehension. Data was made up of 8 Japanese female students whose proficiency levels were lower $(\mathrm{N}=4)$ and higher $(\mathrm{N}=4)$ who were enrolled at an American college. The instrument chosen was a listening task which consisted of 24 dialogues performed by NSs, 2 practise dialogues, 15 experimental dialogues, and 7 control dialogues. Each dialogue contained a description in Japanese of each interaction. Results showed that learners were able to understand the intended meaning of implicatures, although higher proficiency learners were significantly better in their comprehension. The analyses of verbal report data showed that lower proficiency learners had similar access to inferential processes, but they seemed to be less confident or hesitant when making a definite answer choice. The author indicated that regardless proficiency effects, learners sought relevance of the speaker's implied meaning. Moreover, concerning learners' strategies when making inferences of implicatures, the study showed that different strategies identified in the verbal protocols support the relevance theory's claim, that is, the interpretation of an utterance does not only include decoding linguistic input nor the retrieval of logic. Indeed, both linguistic and non-linguistic information were placed at the same level. Learners seemed to gather information with the least processing effort and with the greatest relevance for interpretation. It was found that learners' use of paralinguistic elements and adjacency pair rules were the most common strategies, thereby revealing that these two were the cues that learners most immediately accessed in context. Paralinguistic 
features served to understand attitudinal/emotional aspects of a message and help learners to inference about speaker's intended meaning, especially when they did not understand the language. The use of background knowledge and experience and key word inferences appeared to be more reported by lower proficiency level learners. Higher proficiency level learners revealed that they recognised speakers' intention of implicatures more frequently. These results could support relevance theory in the sense that cognitive context is an individual affair and then learners' different experiences and ability with language could shape their context and provide different access to specific information. Table 9 displays a summary of the above reviewed literature. 


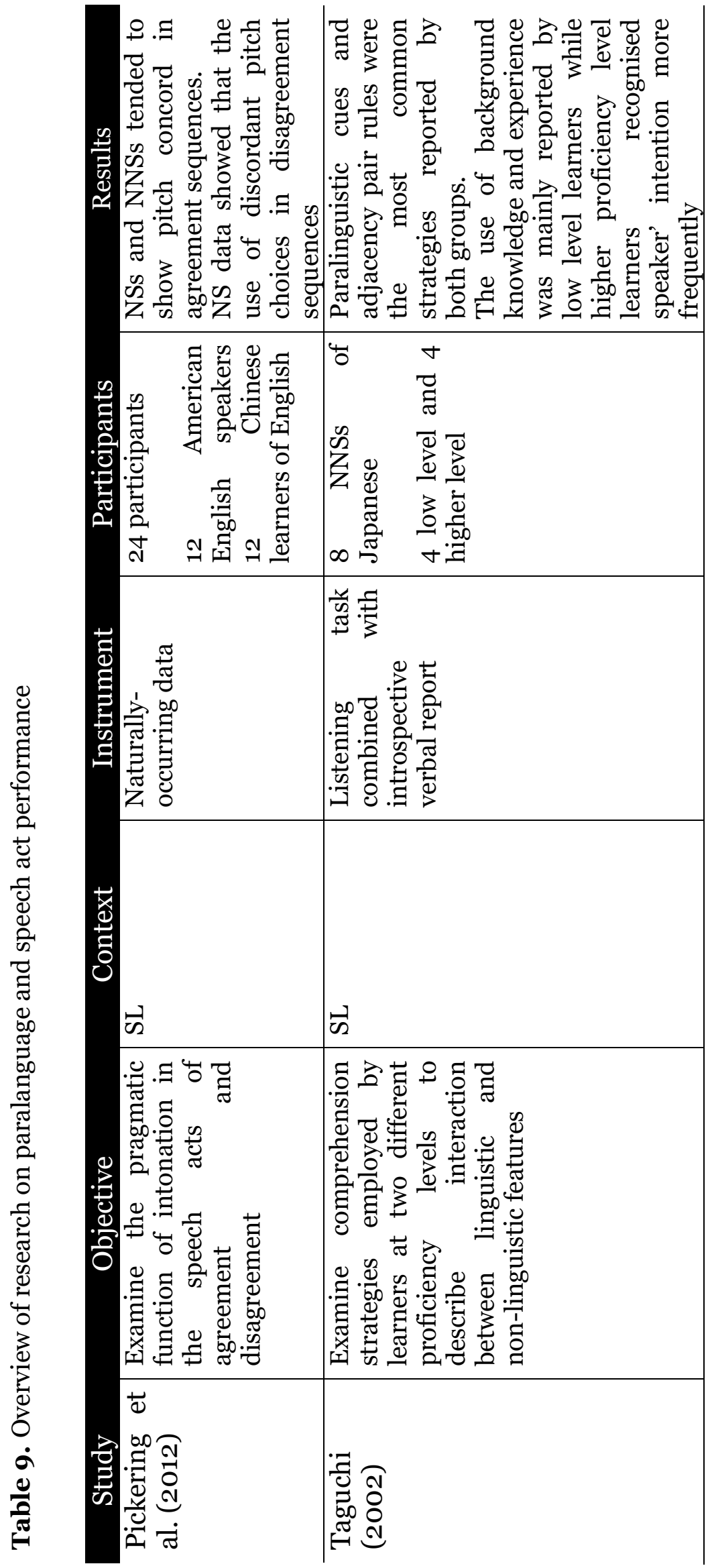


As shown in this literature review, the body of literature that examines paralanguage features in the field of ILP is rather limited. Of special interest for the purpose of the current study is the study conducted by Taguchi (2002), who examine the variable of proficiency. Pickering et al. (2012) also carried out a study exploring the pragmatic function of intonation in conversation containing the speech act of agreement and disagreement. This literature review shows that there is a need to further investigate paralanguage and pragmatics, and more precisely, from the perspective of language learners.

Having revised the area of paralanguage and pragmatics, in the following section I provide a final overview of paralanguage and kinesics.

\subsubsection{Kinesics and paralanguage}

The construction of multimodal communication involves the integration of several modes such as speech, kinesic and paralanguage resources. Multimodality is in fact an inherent property of human cognition and communication (Johar, 2015).

There are many different resources available to speakers in order to make meanings, especially in oral communication. As noted by Norris (2004, p. x), "people in interaction seldom communicate only through language. A person takes up a certain kind of distance to others, takes up a particular posture, gesture while speaking, and at times gazes at the interlocutor". All the different moves used in face-to-face interaction are embodied, which relates to how people use their bodies to communicate. Another important aspect of communication is the paralanguage resources, which are also part of the interaction and they can be exploited in spoken communication. Therefore, it might be suggested that face-to-face interaction may be characterised by kinesic and paralinguistic resources. 
Risager (2006) argues that individuals develop their linguistic resources in their L1 and in other languages. The linguistic resources are both productive and receptive or interpretive, and "[t]hey include social, private and inner speech as well as paralanguage and kinesics" (Risager, 2006, p. 79). The author further adds that each individual's repertoire encapsulates both notion and expectations about people's use. Nevertheless, it should be indicated that the repertoires appear not to coincide completely but partially. Moreover, as indicated by Patterson (2013), in an interaction each individual brings some set of perceptual and cognitive predispositions such as attitudes, expectations, among others, which provide a sort of filter for the incoming information. The author also posits that what happens in interaction seems to operate automatically. The predispositions of people in a common stetting appear to be more similar to one another than those that involve different settings. In fact, the settings may have specific characteristics that may shape the behavioural performance. Furthermore, Patterson (2013) suggests that automaticity in interactive behaviour is possible since a perception of the speakers' behaviour may evoke a response in the listener.

Concerning this, it might be suggested that when different modes are merged, including for example speech kinesics and paralanguage resources, the speaker sends out signals that can be decoded by the listener and vice-versa in face-to-face interaction. Nevertheless, personality as well as attention to non-verbal signals may play an essential role in the construction of meanings.

\subsection{Summary}

In Chapter 3, I have attempted to provide a review of spoken discourse from a multimodal perspective. As the title of the chapter anticipates, communication involves more than words since various elements can be combined in order to communicate. In this chapter, I 
have reviewed the nature of multimodality by addressing its scope (e.g. Jewitt, 2014a, 2014b). Furthermore, I have provided a revision of different perspectives to approach multimodality by focusing particularly on Halliday's (1985) SFL, MDA and SF-MDA (O'Halloran, 2005), multimodal interactional analysis (Norris, 2004, 2011, Norris and Jones, 2005), and multimodal conversation analysis (e.g. Mondada, 2008, 2016, Streeck et al., 2011). After this review, I have focused on the nature of multimodal communication by pointing to embodied modes and modal density. Following this, I have centred on spoken discourse by pointing to two different aspects that are usually combined with spoken discourse, kinesics and paralanguage. My intention here was not to provide an account of all the kinesic and paralanguage resources involved for example in a conversation, but to comment on them as part a communicative event that is conveyed in the spoken mode. Kinesics, as reported, was first coined by Birdwhistell $(1952,1970)$, who argued that it involved a discipline parallel to linguistics that examines the visible bodily motion. This was a first approach to kinesics, and this trend has been followed by other researchers, such as Poyatos (2002).

In this chapter, I have approached the nature of gesture (Efron, 1941, 1972; Ekman and Friesen, 1969; McNeill, 1992; Kendon, 2004). As reported, the works of McNeill and Kendon have been widely recognised in the literature devoted to explore gestures. Kendon, for example, presents a continuum that shows an abstract representation of gestures which ranges from gesticulation at one extreme of the continuum to sing language, at the other extreme of the continuum, including along it language-like gestures, pantomime and emblems. The classification of gestures provided by McNeill (1992) consists of four different categories: (1) iconic; (2) metaphoric; (3) deictic; and (4) beats. Regarding identification of gestures, I have reviewed the notions of gesture unit and gesture phrase (Kendon, 2004), which focus on the actual movements of the body. A gesture unit consists of the whole excursion from the articulators until the moment when it returns to its 
position (Kendon, 2004). A gesture unit might involve one or more gesture phrases, which are constituted by a gesture's stroke. That section has also focused on the set of rules proposed by McNeill (1992) that may govern how speech and gesture synchronise, specifically, three different levels: (1) the phonological synchrony; (2) the semantic synchrony; (3) pragmatic synchrony are characterised. This has been followed by a section devoted to gesture interpretation. As indicated, two types of gestures might be distinguished, stereotyped (employed with the absence of speech) and conversational (used with speech). The latter is further divided into topic and non-topic gestures (Kendon, 1985). Concerning the interpretation, I have for example reported on Bavelas' et al. $(1989,1992,1995)$ contribution, by pointing to the interactive gestures, which involve four basic functions: (1) marking the delivery of the information; (2) citing the other's contribution; (3) seeking a response; and (4) turn coordination (e.g. taking the turn) (Bavelas, et al., 1995, p. 397). Kendon (2004) also argues that gestures might accomplish three different functions, including referential; (2) interpersonal; and (3) pragmatic (further divided into three different functions, i.e. performative, modal and parsing). In addition, I have reported on Kendon's (2004) gesture's families by pointing to the $G$ family and R-family.

Moreover, other kinesic features have been reported in the present chapter, particularly facial expressions, gaze, and head movement. In so doing, I have attempted to highlight their role in communication. The nature of facial expressions has been acknowledged in this chapter by focusing particularly on the role they play in emotions. Concerning this, the work of Ekman (2007) and Ekman and Friesen (1978) have been addressed, who have identified six basic types of face expressions. The kinesic resource of gaze has been also reviewed as it seems to be of paramount interest in face-to-face interaction. This section has concluded with a revision of head movement, which has been associated to functions of regulating turn-taking (Duncan, 1972) as well as to 
backchannel behaviour (e.g. Duncan, 1972, Erickson, 1979, Goodwin, 1980, Maynard, 1987, 1990; Gass and Houck, 1999; Carter and Adolphs, 2007; Knight and Adolphs, 2008). This particular issue has been also addressed in Chapter 1 Section 1.3.2.2, when reporting on the classification and functions of backchannels. Nevertheless, due to the importance of backchannels for the present study, and the different modes that can be employed to perform them, they have been reported also in the present chapter.

Following this, I have presented a section that focuses particularly on pragmatics and kinesic features. I have included this section since the present study is framed within the area of ILP and therefore my purpose was to provide a literature review of studies exploring gestures in ILP. However, as shown, only one study that examines ILP and nonverbal behaviour has been identified, specifically, that of Gass and Houck (1999). The remaining studies reported (Kendon, 1995; Kelly et al., 1999; Chui, 2005; Streeck, 2009; Ladewig and Bressem, 2013; Rossi, 2014), albeit exploring pragmatic aspects and gestures, seem to centre on different issues rather than on NNSs' performance of speech acts. Furthermore, since in the present study I explore the variable of proficiency, I have provided a review of the role of proficiency on kinesic performance. These sections have revealed that there is a research gap in the area of ILP studies since there is a scant of studies that examine the role of ILP and kinesics, and particularly gestures.

In the last part of this chapter I have covered paralanguage, which, as reviewed, is associated to non-verbal language. I have introduced the notion of paralanguage by indicating that when speaking further elements are integrated and paralanguage involves how something is expressed. Different classifications of paralanguage have also been acknowledged in this chapter, for example by referring to the work of Trager (1958), i.e. voice set, voice qualities, and vocalisations; and Poyatos (1993, 2002), i.e. qualities, qualifiers, and differentiators. I have also indicated that one of the major concerns in the study of 
paralanguage is intonation. In so doing, I have reviewed the contribution of Brazil $(1984,1995,1997)$, who advanced a framework of discourse intonation. Another important aspect highlighted in this chapter is hesitation forms, which might be classified into filled pauses (vocalised pauses) and empty pauses (silence). This has been followed by an overview of paralanguage and pragmatics by focusing specifically on research conducted in this area. To name a few works reviewed, the recent contributions of Romero-Trillo (2012, 2014, 2015) reveal that there is a growing body of literature that focuses on prosody and pragmatics. Concerning ILP research, literature shows that very little has been done with the exception for example of the study conducted by Taguchi (2002). Therefore, it seems that there is another research gap, as in the case of kinesic studies, indicating that there might be a need to include paralanguage aspects in studies framed within ILP research.

The present study attempts to contribute to the field of ILP and multimodality by examining how participants at different proficiency levels employed extra-linguistic and paralinguistic elements when performing a particular spoken task. This particular issue, as shown in the present chapter, has not received much attention from the perspective of ILP research (see Chapter 1 and Chapter 2 on the nature of ILP and interlanguage complaints) and from the perspective of multimodality.

Briefly, Chapter 3 has focused on multimodal communication by pointing particular on gestures and paralanguage as part of the spoken discourse. In Chapter 4, I address the methodology employed for the present study. 
Chapter 4. Methodology and Experimental Design 



\section{Chapter 4. Methodology and Experimental Design}

Any piece of research requires the researcher to take specific methodological decisions in order to carry out the investigation. This section is crucial as it provides a description of the participants, the instruments and procedure followed to collect the data as well as of data analysis. Hence, in this chapter I attempt to provide an overview of the methodological decisions taken, the experimental design, the research instruments employed to gather the data for the present study, the participants of the study, the procedure followed in the data collection phase and the compilation of the spoken corpus, as well as on the approach followed to examine the data. This chapter presents the methodology followed in this study to answer the research questions posed in the introductory chapter. In the following pages, in Section 4.1, I first provide an overview of the study. This is then followed by Section 4.2 where I characterise the participants involved in the study. Then, in Section 4.3 the corpus of the study is presented. This is then followed by Section 4.4, which focuses on the data collection and the instruments used in the study. After this, Section 4.5 reports on the data preparation. Following this, the data analysis of the study is presented in Section 4.6. This chapter ends with an overview of the methodology of the study.

\subsection{The study}

This cross-sectional study was established in an attempt to explore how FL learners at different proficiency levels interact in a role-play involving a complaint situation. This particular study follows a mixed method approach as it takes both a quantitative 
and a qualitative perspective for the analysis of the data, which serve to triangulate the data.

The present study was carried out at Universitat Jaume I (Castelló, Spain), where I teach English for Specific Purposes (ESP) in different university degrees. The study was conducted during the 2014-2015 academic year. Participants of the study were learners majoring two different university degrees and who were taking an ESP course in two different disciplines, as I explain in detail in Section 4.2.2. University students were selected following language proficiency level criteria.

Data was collected at university taking into account the following aspects: (1) access to participants who were studying English as FL, ESP in this case and (2) legal age of participants ( $<18$ onwards) in order to obtain their permission and consent to take part in the study.

Having provided an overview of the study, in the following section, I provide a description of the participants involved in the current study.

\subsection{Participants}

Selecting the sampling of the study is crucial in any research, and in this particular case, my concern was to have a homogeneous group in terms of English language proficiency level and gender. In this section, I focus particularly on the selection of the participants involved in the study, which was made considering the results obtained in a proficiency level test and a background questionnaire (both will be detailed in the forthcoming section). Following this, I present the selection of the participants of the study. 


\subsubsection{Selection of participants}

The recruitment of the participants for the study was established by means of a proficiency level test and a background questionnaire, which were administered during the first part of the study together with the consent form to take part in the study (see Appendix A). In order to classify participants in different proficiency levels, A Proficiency test was employed to specify learners' abilities in a given SL/FL. One of the most influential classifications of proficiency levels, at least in Europe, is advanced by CEFR (2001: 6), which "provides a common basis for the elaboration of language syllabuses, curriculum guidelines, examinations, textbooks, etc. across Europe”. This framework presents what language learners need to learn in order to use language successfully in communicative events and what knowledge and skills need to be mastered to do so appropriately. Furthermore, The CEFR provides a six-level-classification consisting of basic user $\mathrm{A} 1$ and $\mathrm{A} 2$, independent user $\mathrm{B} 1$ and $\mathrm{B} 2$, and proficient user $\mathrm{C}_{1}$ and $\mathrm{C}_{2}$. This classification and the descriptors of the different levels as well as how they are constructed and articulated are of paramount interest especially for language teaching practitioners and language assessment practitioners, although also for SL/FL learners. As a matter of fact, language learners are usually familiar with the classification of levels and many learners, at higher education, take certification exams from different institutions as they are aware of the importance of obtaining certificates in FL.

In this study, the DIALANG test was employed to examine participants' proficiency level. The DIALANG Project is an assessment system that is used by language learners to gather diagnosis information as regards their proficiency level (CEFR, 2001; Alderson, 2005). The DIALANG is an on-line diagnosis test 
that consists of five aspects of language knowledge, namely reading, listening, writing, vocabulary and grammar in 14 different European languages. The descriptive scales of the DIALANG are based on the CEFR and then the results are reported according the six levels aforementioned. The test can be either completed online ${ }^{14}$, or downloaded ${ }^{15}$ and installed.

Furthermore, a background questionnaire was designed to select the sample of the study (Appendix B). The questionnaire was constructed and administered using Google Forms, which allows researchers to administer the questionnaire and store data in a relatively quick and easy manner. Drawing on Dörnyei (2003), the background questionnaire was constructed taking into account: (1) the objectives of the questionnaire itself and how it was related to the purposes of the current study, (2) the potential sample, (3) the typology of questions, (4) the administration of the questionnaire, (5) the layout of the questionnaire and the easiness to complete it, (6) the instructions given, (7) the time devoted to complete it, and (8) the analysis of the data. Then, the construction of the background questionnaire involved the following phases: (1) establish the objectives of the questionnaire; generate draft questions and revise and edit of the first draft questions; (2) experts' judgments; and (3) pilot the questionnaire.

In the first phase, the objectives of background questionnaire were established. The background questionnaire was designed to gather information about potential participants and to identify their profile and their appropriateness to participate in the study. The specific objectives were to obtain information as regards potential participants' socio-demographic information, sociolinguistic characteristics, language learning experience, English language qualifications, experience abroad, and language

$14 \quad$ http://dialangweb.lancaster.ac.uk/

15 http://www.lancaster.ac.uk/researchenterprise/dialang/about.htm 
use. Then, the draft questions were generated. The dimensions of the questionnaire were established considering research on SLA. Initially, the background questionnaire involved a total of five dimensions, five sub-dimensions and 20 draft questions. Then, the supervisors of the current study revised the first draft of table of specification and the background questionnaire, and provided feedback on the different items included and the draft questions. The background questionnaire was written in English since the study involved learners of English as a FL. However, it could have been done in learners' L1 and/or L2, in order to avoid possible proficiency effects, but it was considered more convenient to write it in English because the potential participants of the study were all learners taking an ESP course at university at the time the study was carried out. Nevertheless, in order to avoid problems with language, the items were purposefully designed using plain language. Then, the first version of the questionnaire was edited, and a total of twenty-three questions were finally included. Table 10 displays the table of specifications of the background questionnaire.

Table 10. Table of specifications of the background questionnaire

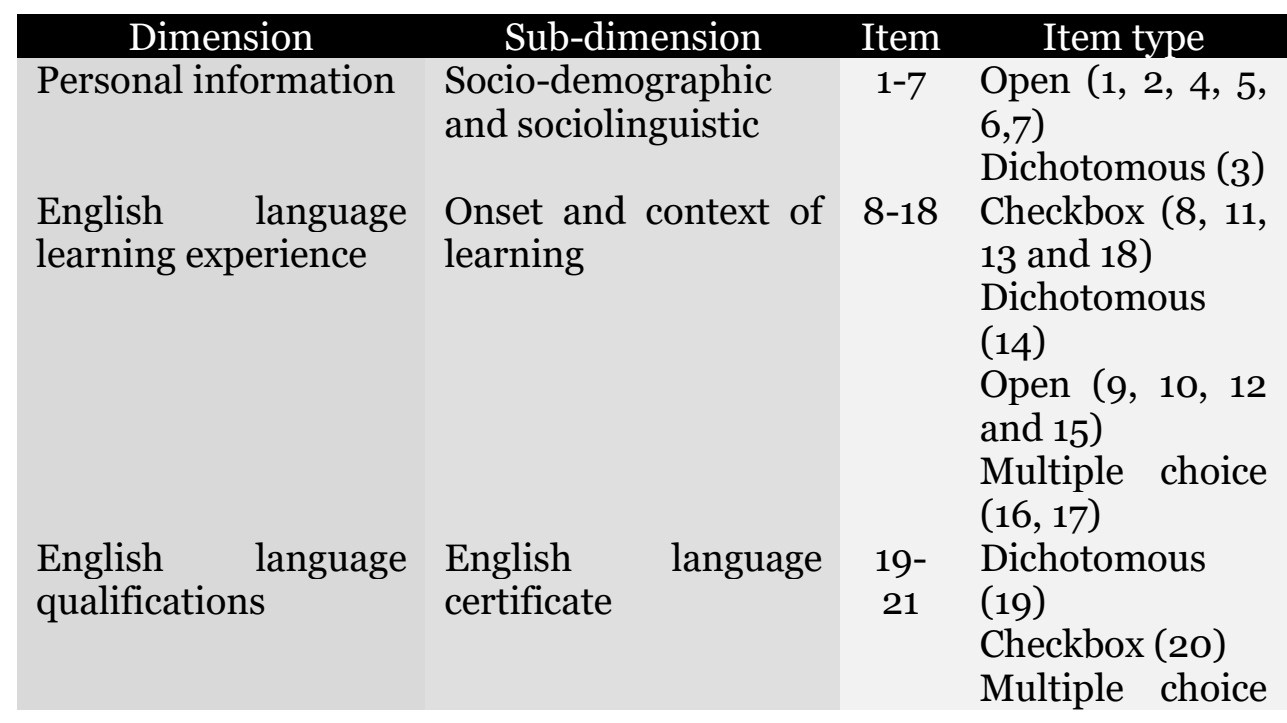




\begin{tabular}{ll|ll}
$\begin{array}{l}\text { Experience abroad in } \\
\text { an English speaking } \\
\text { country }\end{array}$ & $\begin{array}{l}\text { Place, purpose and } \\
\text { time }\end{array}$ & $\begin{array}{l}\text { (21) } \\
\text { Dichotomous } \\
\text { (first part) } \\
\text { Open (second } \\
\text { and third part) }\end{array}$ \\
English language use & $\begin{array}{l}\text { Multiple choice } \\
\text { (fourth part) } \\
\text { Language use in non- } \\
\text { formal contexts for } \\
\text { pleasure }\end{array}$ & & Multiple choice
\end{tabular}

As shown in the table of specifications, the background questionnaire consisted of five dimensions and five sub-dimension with a total of 23 items. The variables included in the background questionnaire covered personal information (socio-demographic features and sociolinguistic features); English language learning experience (onset and context of learning); English language qualifications (English language certificate); experience abroad in an English speaking country; and English language use (language use in non-formal contexts for pleasure). While controlling all participants' variables may not be possible, the questionnaire was designed taking into account the aforementioned dimensions in order to gather information as regards the profile of the sample.

The second phase involved the judgment validation, in which five experts, all researchers at different Spanish universities, participated, more specifically: two applied linguistics, a mathematician, a psychologist and a sociologist. This phase was conducted online, using Google Forms. The five experts had access to the background questionnaire and information as regards the purpose of the questionnaire was provided. Moreover, a quality assessment grid was provided in order to explore the validity, clarity and relevance of the background questionnaire. Particularly, the experts were asked to rank each item in terms of validity, clarity and relevance, from 1 to 4 , being 1 none and 4 completely; space was also given for any comment about each item, as well as general comments on the questionnaire. 
Furthermore, an interview with a psychologist was arranged in order to ensure that the background questionnaire was successfully designed. Some comments concerning the layout were provided and therefore minor modifications were made as regards content. Finally, the background questionnaire was piloted with the group of 20 participants The data gathered in the pilot study were analysed in order to verify whether participants understood the questions and provided the information that was required in each item. Some aspects as regards the language were modified in order to simplify the questions as it was detected that some participants, especially those with lower level of English had difficulties understanding them. The background questionnaire was finally designed drawing on the experts' judgments and the results obtained in the pilot study.

In short, participants' selection involved the administration of a proficiency level test and a background questionnaire. In the following section, I focus on the participants of the study.

\subsubsection{Participants of the study}

Initially, participants were 77 (38 male) undergraduate students majoring two different disciplines, Bachelor's Degree in Video Game Design and Development $(\mathrm{N}=30)$ and Bachelor's Degree in Criminology and Security $(\mathrm{N}=47)$. As I report in this section, in light of the results obtained in the proficiency level test, the sampling of the study finally involved 64 participants (mean age was 19.7.).

All the participants were taking an ESP course in their university degrees. The two ESP courses are taught in the first term and in the first university year. Both courses involve 60 hours classroom and 90 non-classroom hours (6o hours of personal work and 30 hours of exam preparation work). The ESP course for 
the Bachelor's Degree in Video Game Design and Development consists of two sessions per week, i.e. theory-based sessions (120 minutes) and practical sessions (120 minutes). The ESP course for Bachelor's Degree in Criminology and Security is divided into three sessions per week, i.e. theory-based sessions (6o minutes), practical sessions (120 minutes), and seminars (6o minutes). The study was conducted with students who were taking the practical sessions of each discipline.

As indicated, a proficiency level test and a background questionnaire were administered. The proficiency level test revealed the proficiency level of the 77 participants at the moment the study was conducted. The participants were distributed into different proficiency levels. Table 11 illustrates the total sampling of the study distributed according to gender and proficiency.

Table 11. Initial distribution of participants according to gender and proficiency level

\begin{tabular}{llllllll} 
Participants & \multicolumn{8}{c}{ Proficiency level distribution } & Total \\
& A1 & A2 & B1 & B2 & C1 & C2 & \\
Male & 1 & 3 & 16 & 17 & 1 & O & 38 \\
Female & 2 & 4 & 17 & 16 & O & O & 39 \\
Total & 3 & 7 & 33 & 33 & 1 & O & 77
\end{tabular}

As shown in Table 11, 66 participants (33 male) were distributed into the $\mathrm{B} 1$ and $\mathrm{B} 2$ proficiency levels according to the CEFR (2001), while 11 (5 male) scored different proficiency levels, and consequently they were discarded. Also, as I explain later, two more participants were also discarded in light of the results obtained in the background questionnaire. However, they took part in the whole process of the study as this investigation was carried out from a pedagogical perspective in their ESP courses. The final sampling consisted of 32 B1 participants (16 male and 16 female) and 32 B2 participants (16 male and 16 female), then an 
equal distribution of participants in each proficiency level was encountered. Table 12 shows the distribution of participants according to proficiency level and gender.

Table 12. Participants' distribution of proficiency level and gender

\begin{tabular}{cccc}
\hline Proficiency level & Male & Female & Total \\
B1 & 16 & 16 & 32 \\
B2 & 16 & 16 & 32 \\
Total & 32 & 32 & 64
\end{tabular}

Unfortunately, it was not possible to maintain the same number of participants of the same discipline, which perhaps would have provided a further homogenous sampling.

The results obtained in the background questionnaire provided information as regards participants' profile and determined participants' appropriateness to take part in the study. In reporting the results of the background questionnaire, I will refer to participants as B1 proficiency level and B2 proficiency level considering the results obtained in the proficiency level test administered in the study. My intention here is to show participants' profile. Further discussion on the results gathered and the possible research implications are not presented in this study.

Results of the background questionnaire of the 64 participants showed that all the male participants were Spanish except for 4 participants, who were born in Romania. They were included in the sample as they moved to Spain when they were very little. Participants' mother tongue was Spanish $(\mathrm{N}=23)$, Catalan ( $\mathrm{N}=37)$, and Rumanian $(\mathrm{N}=4)$. As regards English language learning experience, all the participants indicated that they had studied English at primary and secondary schools, and 5 did it at preschool level, as well. As regards the onset of learning, results revealed that the 5 participants who started English at 
preschool level started when they were 5 years old, whereas the remaining participants did it either at $7(\mathrm{~N}=30=$ or at $8(\mathrm{~N}=29)$.

A total of 38 participants, 23 B2 and 15 B1 level, had studied English in non-formal contexts. Results showed the following distribution: English lessons in language academies $(\mathrm{N}=25)$, private tuition classes $(\mathrm{N}=14)$, in language academies and by means of private tuition $(\mathrm{N}=25)$, and in language academies and language courses abroad $(\mathrm{N}=7) .3$ participants showed that they were taking private tuition sessions at the moment the study was conducted and 8 that were still studying English at language academies. The mean starting age of learning English in the aforementioned contexts was 11.50 years, and the mean duration was 4.3 years. The remaining 26 participants reported not having studied English in non-formal contexts. Concerning formal contexts, 7 participants indicated that they had studied English at the Escuela Oficial de Idiomas (EOI) (Spanish Official Language School), and 5 were studying at the EOI when the study was conducted. The mean age of starting for the former group was 16.5 years and the maximum level achieved $\mathrm{B}_{1}(\mathrm{~N}=5)$ and $\mathrm{B} 2(\mathrm{~N}=2)$. The 5 participants enrolled at EOI were completing B1 proficiency level $(\mathrm{N}=4)$ and $\mathrm{B} 2$ level $(\mathrm{N}=1)$. Therefore, 38 participants studied English in non-formal contexts and other different 7 participants in formal contexts.

Also, 11 participants were studying English either non-formal $(\mathrm{N}=11)$ or formal $(\mathrm{N}=5)$ contexts when the study was carried out. Out of 64, 50 participants were interested in studying English in different contexts in the close future, such as: language academies $(\mathrm{N}=11)$, private tuition $(\mathrm{N}=5)$, language course abroad $(\mathrm{N}=7)$, EOI $(\mathrm{N}=10)$, language academy and language course abroad $(\mathrm{N}=9)$ and EOI and language course abroad $(\mathrm{N}=8)$; but none in open/electronic education. 
Regarding participants' English language qualifications, results showed that 17 participants had completed the proficiency levels of $\mathrm{B} 1(\mathrm{~N}=11)$ and $\mathrm{B} 2(\mathrm{~N}=6)$ in an official institution: EOI (5 B1 level and 2 B2 level) and UCLES University of Cambridge Local Examinations Syndicate (6 B1 proficiency level and 4 B2 proficiency level). The remaining 47 participants indicated not having obtained any English language qualification at the moment the study was carried out.

Results also revealed 18 participants had been to an English speaking country. Specifically, 5 B1 level participants and 6 B2 level participants had been once for pleasure and the mean length for both groups was 4 days. 7 participants (3 B1 level and 4 B2 level) had been to study English once with a mean length was 3 weeks.

Finally, participants were also required to provide information as regards English language use. All the participants indicated that they listened to music in English 3-4 days a week. However, no participant indicated listening to the radio in English. As regards listening to podcasts in English, results showed that 15 participants (6 B1 level and $9 \mathrm{~B} 2$ level) listened to podcasts in English 1-2 days a week, whereas the remaining participants $(\mathrm{N}=49)$ of the different proficiency levels never did it. Moreover, 9 participants (2 B1 level and 7 B2 level) revealed that they watched TV, videos, sitcoms, films, in English 3-4 days a week, while 35 (9 B1 level and 26 B2 level) did it 1-2 days a week. The 29 remaining participants indicated that they never did it.

Concerning speaking English for pleasure, results revealed that only 3 B2 level participants did 1-2 days a week. The remaining participants indicated that they never spoke in English for pleasure. Results as regards reading and writing were different since more participants seemed to perform those activities, but with the same frequency. 8 participants (6 B2 level and 2 B1 level) 
wrote for pleasure 1-2 days a week, and 9 participants (6 B2 level and $3 \mathrm{~B} 1$ level) revealed that they read for pleasure a few days (i.e. 1-2 days). The remaining participants seemed not to ever write $(\mathrm{N}=56)$ and read $(\mathrm{N}=55)$ for pleasure.

Some of the dimensions included in the background questionnaire, such as English language learning experience and study abroad experience could represent variables to be explored in this study. However, they were not considered. The background questionnaire was constructed to elaborate participants' profile. Two participants, one female B1 level and one male B2 level were discarded in light of the results of the questionnaire. The female B1 level was not included as she had only lived in Spain for 3 years when the background questionnaire was administered. The male B2 level was discarded as his results in the proficiency level test and the maximum level he indicated in the background questionnaire did not match. Particularly, he had obtained a C1 level certificate but the proficiency level test revealed that he was B2. The results of these two participants have not been reported in this section as they did not take part in the study.

After describing the participants of the study, in what follows I provide an overview of the corpus compiled for the purpose of the study.

\subsection{Corpus design}

The design of the corpus of present study was guided by a number of considerations. The corpus of the study involved spoken data gathered by means of audio recorder and video cameras. Audio-visual data was collected in order to create a spoken video corpus that allowed the analysis of the different modes speakers used. The corpus involves elicited speech act data in interaction as performed by FL learners of English. The 
speakers were divided into two proficiency levels, more precisely B1 proficiency level and B2 proficiency level. Then, the corpus is further divided into two sub-corpora, one corresponding to each proficiency level. The speech act data chosen for the purpose of the study was complaints and an interactive perspective was taken to explore participants' complaints and responses to complaints. Therefore, each sub-corpus was also divided according to participants' role, that is, the complainer and the complainee.

Then, the present study is based on the analysis of a small corpus particularly, an interlanguage complaint corpus. The corpus consists of 32 videos, involving data of 64 learners of English at two different proficiency levels, 32 B1 proficiency level (16 male) and 32 B2 proficiency level (16 male). This small corpus represents conversations of 64 participants, half of them performing the role of complainers and half the role of complainees. Table 13 presents the corpus of the study.

Table 13. Corpus of spoken interlanguage complaints and responses to complaints for RQ1

$\begin{array}{llccc} & & \text { B1 } & \text { B2 } & \\ & & & \text { Minutes } & \text { Total } \\ & & 52.09 & 40.79 & 92.88 \\ \text { Complainer } & 1728 & \text { Words } & \\ \text { Complainee } & 1675 & 2255 & 3983 \\ & \text { Total } & 3403 & 3755 & 5430 \\ & & & 6010 & 9413\end{array}$

The criteria followed in the design of the spoken corpus were based on the objectives of the study, which aimed to analyse interlanguage complaints and responses to complaints as elicited by learners at different proficiency levels. The corpus generated for the purpose of this study does not contain natural occurring data, but simulated spoken data elicited by means of a role-play task. It should be noted that length has been described according to the 
number of words elicited, including repetitions, and filled pauses, since all of them are part of the communicative event. This particular corpus was employed to examine participants' pragmatic behaviour and to answer the first research question: Does language proficiency influence language learners' interlanguage complaints? More specifically, my concern is to analyse from a quantitative perspective the structure of the conversation, the sequence organisation, conversational features such as backchannels, overlapping and paralanguage resources, and the appropriateness of interaction.

A sample of this corpus was also used to perform a multimodal qualitative analysis. The second research question is: How does a multimodal approach enrich the analysis of interlanguage complaints across proficiency levels? Then, in order to answer this question, a multimodal analysis of two video, one of the B1 proficiency group and one of the B2 group were used. Table 14 displays the small corpus for the multimodal analysis.

Table 14. Corpus of the multimodal analysis of spoken interlanguage complaints and responses to complaints for RQ2

$\begin{array}{lcccc} & & \text { B1 } & \text { B2 } & \\ & & \text { Minutes } & \text { Total } \\ & 4.45 & 4.10 & 8.55 \\ \text { Complainer } & & \text { Words } & \\ \text { Complainee } & 276 & 312 & 588 \\ & 235 & 424 & 659 \\ & \text { Total } & 511 & 736 & 1247\end{array}$

The participants selected for this part of the study were four male learners of English as FL. The rationale behind the selection of these two pairs was based on the following: (1) the four participants belonged to the same university degree; (2) same gender and similar ages; (3) their real relationship was the same, more specifically, the four participants had met at university at the 
beginning of the course; (4) they knew their respective proficiency levels as they were together in class. The two first items were selected taking into account the results obtained in the background questionnaire, while the remaining two draw on the results of the retrospective verbal reports.

In this section I have attempted to provide an overview of the corpus design of the study, which involved, as reported, a corpus interlanguage complaints and responses to complaints of 64 participants across two proficiency levels, B1 and B2. In the following section I present the data collection of the data.

\subsection{Data collection}

The data collection procedure of the present study involved different phases, as I explain in this section. More precisely, I provide a description of the data collection procedure, the videodata collection procedures and the instruments employed in the study to collect the data.

\subsubsection{Data collection procedure}

As already mentioned, this study took place during the first term of the 2014-2015 academic year when the participants involved in this investigation were taking their ESP courses in the two disciplines selected, i.e. Bachelor's Degree in Video Game Design and Development, and Bachelor's Degree in Criminology and Security. Before implementing the study, potential participants were informed of the investigation and they were kindly asked to take part in it. They were also offered the option to not participate in the investigation, albeit they were informed that 
the tasks should be completed as they were implemented as part of the course syllabus. After the researcher explained the study none of the potential participants took this option, and they volunteered to participate in the study. Specific information about the objectives of the study was not provided in order to avoid any influence on participants' behaviour, which could in turn negatively affect the results of the study. All the participants, including those who took part in the study itself and the pilot study were provided with a consent form that was signed and returned to the researcher in charge of the investigation. All participants involved in the study gave their signed consent to be recorded as part of the study and data collection procedures

It should be noted that in some stages of the data collection, the two supervisors of the study participated actively in the process of collecting the data. Data was collected over a period of two months. The role-play recordings and the retrospective verbal reports were completed in non-class hours.

During the first weeks of the semester, the proficiency level test and the background questionnaire were administered. Explanations about the use of Google Forms were provided in order to avoid learners' difficulties in completing the background questionnaire and the proficiency level tests. Participants first completed a proficiency level test, and once all the participants had completed it, they proceeded with the background questionnaire. Time restrictions were given to complete the proficiency test but not for the background questionnaire in order to provide them with sufficient time to complete it. Then, the data obtained in the proficiency level test and the background questionnaire was carefully examined.

Following this, the exemplar generation task was implemented by means of Google Forms during class sessions in the language laboratory as computer and internet connection were 
needed. Time restrictions were not given to complete this task. Each group of learners were provided with the same training as regards how to complete the exemplar generation task. The data resulting from the exemplar generation task was then analysed in order to create the likelihood questionnaire, which was also embedded in Google Forms and completed in the language laboratory. Drawing on the results of the likelihood questionnaire, two different scenarios were finally designed.

Following this, the pairs and the schedule for performing the role-play tasks and the retrospective verbal reports was established. The pairs were organised according to proficiency level (B1 and B2) and gender (male-male and female-female). The slot time provided included 20 minutes per pair and they were required to be 10 minutes ahead of their actual timing. Before taking part in the role-play tasks, the researcher met the participants in order to remind them of the tasks, provide the schedule of the role-play tasks and the organisation of the pairs. Doubts about the procedure were solved in that session. The schedule for the role-play tasks was also posted in the corresponding virtual platforms of each subject. Moreover, it should be mentioned that that those students who were discarded in light of the results of the background questionnaire and the proficiency test were also included in the final task. They were grouped according to their proficiency level and gender, when possible. Despite the fact that their data was not to be examined for the purpose of the study, they took part in the all the phases of the study.

Then, an experimental task was carried out in which participants completed the role-play tasks and the retrospective verbal reports. Due to the nature of this phase of the study, parallel sessions were required. Hence, the researcher of this study and the two supervisors of the study worked collaboratively to gather the 
data. The researcher of the study and one supervisor were in charge of the role-play tasks, while the other supervisor conducted the retrospective verbal reports. Otherwise, it would have not been possible to conduct the study in the aforementioned sessions.

Then, two language laboratories were booked to perform the role-play task and the retrospective verbal reports were conducted in an office located close to the language laboratories. Each pair was assigned to a specific room at a specific time in order to act out the role-play tasks. It should be indicated that in order to avoid any extraneous variable effect on the experiment, some aspects were taken into account. The experiment was first conducted with the B1 group and then with the B2 group. Students of each discipline were assigned to a particular room in which the researcher in charge of administrating the task was an unknown person for them. The retrospective verbal reports were conducted by the other supervisor of the study, who was also unknown for them. This specific distribution was done purposefully in order to avoid any investigator effect on participants since two of the researchers involved in the data collection procedure were teaching their corresponding ESP courses.

Once each pair entered the room, they were welcome by one of the teachers and they were given time to become familiar with the setting. After that, they were asked to locate themselves in the right place of the room to proceed with the role-play tasks. Then, participants were provided with the instructions for the task (see appendix D) and the task itself, the first scenario (warm-up roleplay) and the second (the role-play task). Participants were given ample time to read the instructions and doubts were solved if needed. Then, participants were encouraged to negotiate the role they wanted to act out. The negotiation was done in English, Spanish and/or Catalan. The use of English was not required at this stage since this was not part of the task itself. Then, 
participants were allowed to read the first situation and when they were ready, they started the conversation. The same procedure was followed for the second situation.

The performance of the participants was not only audio recorded, but also video recorded. Then, the spoken data including the role-play tasks and retrospective verbal reports were stored digitally in MP3 and MP4 formats. Immediately after acting the role-play scenarios, the teacher in each room guided the pairs to the office where the retrospective verbal reports were conducted. During the retrospective verbal reports session participants were interviewed in Spanish. The researcher carried out this task in a systematic manner and participants provided their responses and added comments when necessary. Due to time constraints, participants were not provided with the video and/or audio recording of the role-play in this session, so they could not listen and watch back their performance.

It is important to note that in implementing the retrospective verbal reports, the following aspects were considered: (1) retrospective verbal reports were conducted immediately after the completion of the task (e.g. Gass and Mackey 2000; FélixBrasdefer, 2008a; 2008b; Beltrán-Palanques 2013, 2016a; Ren 2014), and (2) participants use their L1/L2 in an attempt to avoid the influence of the FL proficiency (Gass and Mackey, 2000). Using English would be seen as a drawback in this particular case due to participants' proficiency level limitations to express themselves in a satisfactory manner. Furthermore, in allowing participants to use their L1/L2, any problem associated with the use of a FL such as anxiety might be reduced, and then Spanish was chosen to conduct the retrospective verbal reports.

After describing the data collection procedure, in what follows I present the video-data collection phase of the role-play scenario and retrospective verbal reports. 


\subsubsection{Video-data collection}

The present study involved the compilation of a spoken corpus of interlanguage complaints performed by learners of English as a FL in a particular situation. Decisions as regards the procedure and compilation of the data elicited by means of roleplay tasks and retrospective verbal reports were taken. In both cases, the data was audio and video recorded.

The use of cameras in spoken discourse research appears to be rather popular, especially in studies that explore non-verbal aspects. In the field of ILP, audio recorders are typically used in studies examining spoken data, while video cameras are rarely utilised. By means of video cameras one can record specific aspects of the performance and the context of the situation which cannot be captured using an audio recorder. The use of cameras, however, depends on the purpose of the study. In the present study cameras were essential to compile audio-visual data, which serve to obtain a wider representation of the interaction as it provided visual information about the setting and the construction of

As reported by Querol-Julián (2011), the physical context and speakers' performance are of special interest when video recording. When selecting an appropriate place to carry out the study and taking into account the facilities at the university, it was considered that these two twin language laboratories could be used for the following reasons: (1) enough room for furniture and cameras management; (2) possibility of using two rooms with similar characteristics which were located in the same corridor. Furthermore, the retrospective verbal reports sessions were conducted in an office which is located in the same area, thereby facilitating participants' data collection. The two language laboratories were medium size university rooms with computers, 
and an open space at the back with no desks and computers. The study was carried out in that particular space.

In order simulate an authentic-like setting some adjustments in the two language laboratories were made. In particular, a table simulating a table that might be encountered in a café was placed in each room. Decisions as regards the position of the cameras in order to capture the visual data appropriately were also taken. To do so, and in order to avoid quality problems, a cameraman provided his support. Three cameras and an audio recorder located in each language laboratory were used to collect participants' data. In so doing, a wide shot of both participants and a medium shot of each participant were obtained. The audio recorder was employed exclusively to store the spoken data in case the cameras did not record the voice successfully.

Three cameras were used in order to capture different angles of vision, as well as to have an extra copy of the videos in case a quality problem might arise. The audio recorder was placed on the table to ensure the quality of the voice. The cameras and the audio recorder started to work when participants were located in exact positions. Participants were standing up during the performance of the task as if they were talking together in a natural setting such as at a café. A researcher was present in each laboratory in order to control the cameras and audio recorder. Participants were located in frontal position and the table was used not only as decoration for the setting, but also to place the audio recorder. In this study, however, field notes were not taken while participants were performing the spoken task.

Although the researcher and the supervisors tried to set up the recording equipment in a non-intrusive manner, it should be noted that the use of recording equipment, and more specifically cameras, may have an impact on participants due to the observer's paradox (Labov, 1972). The author questioned whether it was 
possible to observe authentic interactions since the presence of the researcher or the recording equipment might have an effect on participants' data. Hence, in an attempt to minimise the effect of the observer's paradox as well as to ensure participants' comfort with the spoken task and the cameras, a first role-play scenario was exclusively used to break the ice, as it will be explained in Section 4.4.3.2.

Finally, in the case of the retrospective verbal reports session, it should be mentioned that participants were audio and video recorded. This session was conducted in a regular office. Instead of using a video camera, a computer was used to record the session together with an audio recorder, both placed on the desk.

After reporting on the use of the audio and video data collection procedure and the decisions taken as regards their use, in the following section I present the data collection instruments.

\subsubsection{Data collection instruments}

To collect the data for the present study, two different instruments were arranged. I use mixed methods with the purpose of enriching the quantitative data with the incorporation of qualitative data (see Creswell, 2003), thus interrelating both types of data and triangulating the data sources. In what follows, I report on the design of the role-play task and the retrospective verbal reports.

\subsubsection{The design of the speaking task}

In this study a role-play scenario was designed to gather spoken data. Role-play format was chosen as it was deemed suitable for an FL context. An exemplar generation task and a 
likelihood questionnaire were employed as part of the procedures followed to design the task.

The technique of the exemplar generation task (Rose and Ono, 1995; Groves, 1996; Ostrom and Gannon, 1996; Rose and Ng, 2001; Liu, 2006a, 2006b) was followed in order to generate the scenario for the role-play. This technique was used as it was believed that designing role-play tasks drawing on learners' real views on complaint situations would facilitate their comprehension as they would provide examples of situations in which they could be involved taking into account their personality, personal experience, age and gender. That is, the exemplar generation task was used in order to obtain examples of complaint that could represent authentic situations that they could experience. Alternatively, the situation could have been generated drawing on the researcher's experience or on intuition, but since I aimed to provide a task that could represent a situation that potential participants may encounter in their everyday life, this option was discarded. Moreover, in so doing, potential participants are actively engaged in the design of scenario of the role-play task. The pedagogical value of this technique, however, is not discussed in this study, but it is worth mentioning that it can be used to design a task that represents learners' needs and interests.

The exemplar generation task was designed as an activity class, therefore written in English, and developed by means of Google Forms in order to facilitate the administration, the collection and the analysis of the data. In this task, learners were required to remember three different situations in which they made a complaint. The document included instructions and an example to facilitate learners' comprehension and completion of the questionnaire. Training as regards the completion of the task was provided. Table 15 illustrates the exemplar generation task. 
Table 15. Exemplar generation task

\section{Exemplar generation task: Instructions}

As you know, we usually make complaints to express that a particular situation annoys us.

In this activity we would like you to think about 3 situations in which you made a complaint or saw someone making a complaint.

Please, consider the following aspects:

- you and the other person should be of similar ages

- you and the other person should be equal (if / when two students have the same status, then, they are equal)

- how familiar are you with him/her? (is the other person is a stranger, someone you know, someone you know well, a close friend, or someone you have an intimate relationship with?)

- how offensive the situation was?

(1) very offensive

(2) not very offensive

- how did you feel?

(1) a little bit angry

(2) angry

(3) very angry

(4) extremely angry

Please, have a look at the following example:

Place: At the university

Participants: a new classmate and I

Degree of familiarity: someone I know

Describe the situation: I had to do a project work with one of my new classmates but he was so late that I had to start writing it on my own.

How offensive was the situation? very offensive

How did you feel? extremely angry

As shown above, the activity required participants to (1) indicate the place where the situation took place, (2) specify the participants involved in the situation, (3) indicate the degree of familiarity, from stranger to someone you have an intimate relationship with, (4) provide a description of the situation, (5) 
indicate how offensive it was, and (6) rank by means of a scale from 1 (a little bit) to 4 (extremely) how angry they were.

The activity was designed taking into account the variables of power or status, social distance and severity of offence (Brown and Levinson, 1987). It was decided that all the situations should involve participants of equal power although the social distance of the participants could vary. The social distance of the participants was done on the basis of the distinction among the following three parameters: stranger, acquaintance; and intimate (Brown and Levinson, 1987). However, this was adapted to a 1-5 scale in order to provide a wider range of possibilities, which consisted of the following items: (1) a stranger; (2) someone you know; (3) someone you know well; (4) a close friend; and (5) someone you have an intimate relationship with.

This technique was applied in an attempt to generate a scenario that could represent potential participants' real experience or at least a situation in which they could be engaged in a real context. Therefore, it was considered that participants should be provided with situations representing known contexts (Hudson, et al., 1995), assigned to both roles that they could be familiar (Trosborg, 1995) and situations that may be socioculturally appropriate for the target group (Beltrán-Palanques, 2013). Hence, the aim was to create a role-play situation that was within their realm, thereby a simulated situation representing known contexts, familiar roles, and culturally appropriate contexts.

I am aware that most scenarios employed in the field of ILP involved different roles of social distance, power and rank of imposition or severity of offence. However, I opted for focusing on a relation of power that implied equal status and on situations and roles that they could have experienced or at least could perform in their everyday life at the time the study was conducted. However, 
this should not be seen as a criticism towards studies including different power relationships. It is important to note that the design of the scenarios and roles depends on the research purposes.

As in the case of the background questionnaire, Google Forms was used to administer the exemplar generation task. Before administering the exemplar generation task to the participants of the study, it was piloted with a group of 20 participants. Participants of the pilot study and the study itself did not receive instruction as regards the speech act of complaints before administering the generation questionnaire, but both groups received some training on the functioning of the task. The pilot study showed that the exemplar generation was a bit complex for some participants and therefore it was decided to simplify the information provided in an attempt to facilitate potential participants' comprehension and completion of the task.

After the pilot study, the exemplar generation task was administered to the participants of the study. A total of $192\left(3^{*} 64\right)$ situations were generated, but some examples were discarded due to repetition, incompleteness, not appropriately completed as the examples did not follow the instructions of the activity, and because they include comments on sex, politics, and alcohol. Then, a total of 20 situations were selected. The data obtained in the exemplar generation task was used to construct the likelihood questionnaire, which was used to measure the likelihood of occurrence, in their everyday life, of the situations elicited in the exemplar generation task (Liu, 2006a, 2006b). The likelihood questionnaire consisted of a 1 to 4 Likert Scale: 1 extremely unlikely; 2 unlikely; 3 likely; and 4 extremely likely (adapted from Vagias, 2006). Table 16 shows the instructions of the task. 
Table 16. Likelihood questionnaire

\section{Likelihood questionnaire: Instructions}

In this questionnaire, you should rank from 1 to 4 the likelihood of the situation presented below. Please, take into account the following scale:

1 extremely unlikely

2 unlikely

3 likely

4 extremely likely

Example of Situation 1

Situation 1: I was waiting for my friend in the park because he had to be there at seven o' clock but at $8 o^{\prime}$ clock he wasn't there yet. $1-2-3-4$

The likelihood questionnaire included the instruction for the completion of the questionnaire and the 20 different situations selected that participants had to rank from 1 to 4 according to the likelihood of occurrence.

As in the case of the exemplar generation task, the questionnaire was carefully revised by the two supervisors. The questionnaire was embedded in Google Forms and then administrated to the pilot group ( $\mathrm{N}=20)$. During the pilot study, participants were provided with opportunities for asking questions and commenting on the questionnaire. The pilot study revealed that participants were able to understand and complete it successfully. Differently to the exemplar generation task, the pilot study of the likelihood questionnaire appeared not to reveal any type of complexity or difficulty as regards comprehension and completion. Hence, no modifications were made and the initial version of the likelihood questionnaire was administered to the potential group of participants.

After reporting on the design of the task, in the following section I present the role-play task that was finally used in the current study. 


\subsubsection{The role-play task}

The simulated spoken task was designed taking into account the results derived from the exemplar generation task and the likelihood questionnaire. Specifically, a total of 20 situations elicited in the exemplar generation task were embedded in the likelihood questionnaire which provided information as regards participants' views on the likelihood of the situations. In light of the results obtained and considering that only two situations were aimed to be used in this study, the two most voted situations representing the same social distance and the two extremes of severity of offence, i.e. low and high, were used to create two scenarios for the role-play task. This was done purposefully in order to have two different situations involving a complaint that represented two participants who had both the same relationship and two different levels of offence.

It was decided beforehand that one of the scenarios resulting from the likelihood questionnaire would be used as warm-up and the other one as the task itself to gather data. Hence, taking into account the results obtained in the likelihood questionnaire, the situation involving a low level of offence served as a warm-up scenario (first scenario in the task administration of the study) and the one representing a high level offence (second scenario in the task administration of the study) was employed to gather the data for the study. The rationale behind this choice was based on the fact that the scenario involving a high level of offence was regarded as a more difficult scenario, compared to the first situation, as it involved a face threatening situation.

In order to avoid the effect of any extraneous variable, such as demand characteristics, situational variables or investigator effects, some methodological issues were taken into account. As regards the effects of the demand characteristics, it should be 
indicated that the data was collected following the same procedure for all the participants involved in the study, in similar rooms (two language laboratories) containing the same elements, and the three researchers involved in the data collection procedure were trained to followed the same or at least a similar procedure. To avoid situational variables, standardised procedures were followed so the same conditions were provided for all the participants. In an attempt to avoid participants' variables that could affect the elicitation of data, a warm-up scenario was administered. This was done to avoid any uncomfortable situation and provide participants with opportunities to become familiar with the task, the setting and the audio recorder and the video cameras. Furthermore, the warm-up scenario served also to calm participants if necessary, due to task complexity and or any uncomfortable feeling, if perceived. Importantly, participants were not informed of the purpose of each scenario to avoid any effect on the outcomes. Regardless the artificiality of the context, the audio recorder and the video cameras, the researcher and the two supervisors did the best to create a natural and comfortable atmosphere in which participants could feel relaxed and pleased in order to perform the task in a relatively natural manner. The warm-up scenario appeared to function as a training and icebreaker for participants to become familiar with the task, the context and the different devices used to collect the data, which allowed minimising the observer paradox (Labov, 1972). After this training, the second situation was performed.

It is worth mentioning that data collected by means of retrospective verbal reports revealed that participants found the first scenario rather easy compare to the second one, and it did not represent any conflicting situation. Most participants also reported that performing first a scenario involving a situation that was not seen as offensive as the second one helped them to relax, become 
familiar with the setting and the cameras, as well as with the roleplay task. In light of these qualitative results, it might be suggested that using a situation as a warm-up scenario was instrumental in order to avoid any uncomfortable situation that could affect participants' performance, thereby ensuring that data was elicited and collected in a satisfactory manner avoiding any extraneous variables (i.e. participants' variables). In trying to avoid the investigator effects on participants, three different researchers were involved in the study. Table 17 displays the two situations.

Table 17. Scenarios of the role-play task

\section{Situation 1}

Having a drink with a friend

It is a sunny day and you are having a drink with a friend. Then, tell your friend that you're going to the toilet.

Go to the toilet.

When you come back your friend has drunk all your coke. You think that this is unfair. He is so cheeky! How could he?

You complain.

It is a sunny day and you are having a drink with a friend. While your friend is in the toilet, you drink all his/her coke because you are very thirsty.

You should respond to any comment your friend makes. Situation 2

I was not invited to the party

You discover that your friend has organised this great party and you have not been invited. Your favourite music group will be playing there. Your best friends are all going to the party. But you're not invited. You think that this is so unfair and you feel really angry.

You complain.

You have organised an incredible party with all your best friends and with your favourite music group. You just can't believe they are coming! You should respond to any comment your friend makes.

As observed above, the first scenario involves two friends having a drink in a bar. The role represents a relationship of two equals who are two close friends. As seen, the participant complaining decides to go to the toilet and when he/she is back, the other participant, who is his/her friend, has drunk his/her drink. The situation 
involves a low level of offence, as this could not be regarded as something very offensive. The participant complaining could utter a complaint, if necessary, and the other participant could provide a response to such communicative act.

Likewise, the second scenario involves two close friends, but the severity of offence differs. One of the participants has organised a party but he/she has not invited his/her friend despite the fact that all their friends will go to the party and that his/her favourite music group will be playing at that event. This situation was classified as high level of offence due to the participants' relationship and the damage caused.

In both situations, participants were asked to act in a natural manner and employed as many turns as necessary to reach their communicative purposes. Moreover, they decided the role they wanted to perform and they could choose which participant should start the conversation. It was decided not to impose the roles and the person who started the conversation in order to allow them to take such decisions. Data of this prior negotiation was also gathered, but it is not used in this study. Importantly, time was not a restriction. It was considered that each pair might have ample time to interact and reach their communicative purposes with no time pressures. Furthermore, time restrictions could pressure them in the sense that they would be focusing on completing the task in the exact time, and possibly, their performance could have been affected by such condition. Moreover, with no time restrictions participants have opportunities to use as many turns as needed in an attempt to reach their communicative purposes.

The role-play situations were piloted by 8 volunteers ( 4 male), whose proficiency levels were $\mathrm{B} 1(\mathrm{~N}=4)$ and $\mathrm{B} 2(\mathrm{~N}=4)$. They were all first year university students. Participants were informed of their task and they received some training in order to be aware of the aspects that they should focus on. Specifically, the purpose 
of the pilot study of the role-play task was to analyse whether the situations were clearly understood and elicited complaints and responses to complaints.

Having provided a detailed review of the generation of the role-play scenario, which involved an exemplar generation and a likelihood questionnaire, in what follows, I focus on the retrospective verbal report used in this study to collect qualitative data.

\subsubsection{The retrospective verbal report}

Qualitative data concerning participants' performance was also collected. Specifically, retrospective verbal reports (see Appendix C), administered immediately after the completion of the role-play task, were employed. As reported in Chapter 1, Section 1.2.2.2, this technique can be used to obtain information about learners' cognitive processes when performing a given task (Ericsson and Simon, 1993). In this study, retrospective verbal reports were used in order to obtain further insights into learners' performance.

The retrospective verbal reports constructed for the purposes of this study were based on previous study in ILP using verbal reports (Félix-Brasdefer, 2008a, 2008b; Beltrán-Palanques, 2013, 2016a), which served as a starting point to create the basic questions of the retrospective verbal reports of the current study. However, further questions were included so as to gather more information. The construction of the retrospective verbal report involved the following: (1) deciding on the length, the format and the main parts; (2) the items; (3) selecting items and their sequencing; (4) providing instructions when needed; and (5) piloting and validating the retrospective verbal reports. Hence, the 
approach taken was similar to that followed in the construction of the background questionnaire of the present study.

In the elaboration, the following aspects were considered: (1) the objectives of the retrospective verbal report and how it was related to the purposes of the current study, (2) the potential sample, (3) the typology of questions, (4) the administration of the retrospective verbal report, (5) the easiness to verbally complete the retrospective verbal report and the language used, (6) the instructions given, (7) thanking for participating, (8) the time devoted to respond to the retrospective verbal report, and (9) the analysis of the data. The construction of the retrospective verbal report involved the following phases: (1) establish the objectives of the questionnaire, generate draft questions and revision and edition of the first draft questions; (2) experts' judgments; and (3) piloting the questionnaire.

The construction of the retrospective verbal reports involved different phases. First, the objectives of the retrospective verbal reports were established, which were to gather information about participants' performance as regards the different dimensions included in the table of specifications designed: (1) real relationship between participants, (2) fictitious relationship, (3) pragmatic knowledge, (4) perception of production, (5) real context, and (6) perception of task. The table of specifications and the nine draft questions of the retrospective verbal reports were generated. Then, the table of specifications and the questions were revised by the supervisors of the current study. The feedback as regards the content of the questions and the way of formulating them was applied. The dimensions and sub-dimensions were not modified after the revision. The final version of the retrospective verbal reports involved nine questions. Table 18 illustrates the table of specifications. 
As displayed, the retrospective verbal reports aimed to elicit spoken data as regards learners' relationship (real and fictitious), pragmatic knowledge, perception of the spoken production, actual behaviour in a real situation, and perception and assessment of task.

Table 18. Table of specifications for the retrospective verbal reports for the complainer and the complainee

\begin{tabular}{llcc}
\multicolumn{2}{c}{ Dimension } & Item & Question type \\
\cline { 2 - 3 } Real relationship & $\begin{array}{l}\text { Actual relationship } \\
\text { between } \\
\text { participants }\end{array}$ & 1 & Open question \\
\hline $\begin{array}{l}\text { Fictitious } \\
\text { relationship }\end{array}$ & $\begin{array}{l}\text { Fictitious } \\
\text { relationship between } \\
\text { the participants }\end{array}$ & $2-3$ \\
\hline $\begin{array}{l}\text { Pragmatic } \\
\text { knowledge }\end{array}$ & Pragmalinguistics & 4 \\
\hline $\begin{array}{l}\text { Perception } \\
\text { production }\end{array}$ & of & $\begin{array}{l}\text { Perception of spoken } \\
\text { production }\end{array}$ & 6 \\
\hline Real context & $\begin{array}{l}\text { Production in a real } \\
\text { context }\end{array}$ & 7 \\
\hline $\begin{array}{l}\text { Perception } \\
\text { task }\end{array}$ & of & $\begin{array}{l}\text { Perception and } \\
\text { assessment of task }\end{array}$ & 8 \\
\hline & &
\end{tabular}

Then, the retrospective verbal reports were validated by a group of five experts, which involved the same researchers who participated in the validation of the background questionnaire. Using also Google Forms, researchers explored validity, clarity and relevance, and ranked each item from 1 to 4 , being 1 none and 4 completely. Also, an interview with a psychologist was arranged in order to ensure that the retrospective verbal report was successfully designed. The experts commented on the way of addressing some questions. The feedback provided by the experts was taken into in order to improve the quality of the retrospective verbal reports. Finally, the retrospective verbal reports were piloted with the group of participants $(\mathrm{N}=8)$ who took part in the pilot study of the role-play tasks. The data gathered in the pilot 
study was analysed in order to verify whether participants understood the questions and provided the information that was required for the purpose of the study.

This section has provided an overview of the different instruments designed for the purpose of the present study, which involved the role-play task and the retrospective verbal report. In the following section, I report on the preparation of the data for the analysis.

\subsection{Data preparation}

The present study involves the analysis of a small corpus of 64 participants eliciting spoken complaints and responses to complaints at two different proficiency levels. In this section I attempt to characterise the verbatim transcription and annotation as well as the multimodal transcription and annotation.

\subsubsection{Verbatim transcription and annotation}

To systematically analyse the spoken data of the corpus, the data was transcribed. The conventions followed for the transcriptions of the present study were adapted from the established Jefferson (2004) and MICASE conventions, albeit some modifications were done (see Appendix E). Before transcribing the spoken data, the audio and video recordings were organised and classified according to participants' proficiency levels, the pair number they were assigned to, which ranged from Pair 1 to Pair 32, and each participants in a pair was labelled as complainer (A + pair number) and complainee (B + pair number). Consider the following example: Pair 1 consists of participant A1 and participant B1. 
After this, a verbatim transcription was done. The audio files were used to perform the verbatim transcription of the data that was employed to response to the first research question of the study. Hence, I adopted the procedure that is usually followed in the area of ILP since audio data is typically gathered. This procedure was also followed in order to avoid the influence of the video data on the verbatim transcription, which in turn could influence the approach taken to answer the first research question. Note that the speech data was not monologic, but dialogic, so two speakers were taking turns and talking simultaneously in some specific parts, which made the task of transcribing more complex.

In the first approach, the transcription involved gathering information as regards the participants, turns, overlapping, backchannels, fillers, and paralanguage features. Prosody features, however, were not transcribed since they were not examined in this study and then it was believed to be beyond the scope of the present investigation. Following this, I proceeded with the annotation of the data, which involved annotating the turns, the moves and the discourse functions and backchannels. It is important to note that this study involves a corpus-driven approach in the sense that my purpose was to integrate all the different elements that emerged from the data (see Nesi, 2013 for further information as regards the corpus-based and corpusdriven). This particular approach was taken in order to prepare the data for the analyses required to answer the first research question in which data was treated from a more traditional manner, that is, by means of transcriptions.

Spoken data was annotated according to the structure of the moves, the turns, the discourse functions involved in each move, backchannelling, overlapping, paralanguage elements and gestures. First, the structure and the turns were annotated in order to properly establish the layout of the data. The organisation of the 
turn served to clarify the participants' interventions, and this was done numerically. Overlapping and backchannels were not seen as turn. Concerning the structure of the moves, I followed the preestablished moves advanced for the purpose of the study (see Chapter 2, Section 2.1.2), which involved (1) opening sequences; (2) complaint sequences, further divided into pre-complaint, complaint and post-complaint moves; and (3) closing sequences. By the same token, the discourse functions of complaints and responses to complaints described in Chapter 2 Section 2.1.2, was used to annotate the emerging discourse functions in each move. As indicated, the proposed structure and discourse functions were used as a starting point to complete the annotation of the complaints and responses to complaints elicited by the participants. Nevertheless, due to the $\mathrm{CA}$ approach taken to examine the spoken data, the proposed discourse functions were expanded in order to account for a full representation of the different discourse functions that emerged from the data. In addition to this, other elements were annotated, such as backchannels and overlaps. In the case of backchannels, previous research on this phenomenon was followed (Maynard, 1986; Clancy et al., 1996; O'Keeffe and Adolphs, 2008) (see Chapter 1, Section 1.3.2.2) in order to annotate the deriving data. Overlapping speech during the conversation was also annotated pointing to the turn overlapped. Finally, paralanguage (e.g. Trager, 1958, Poyatos, 2002) (see Chapter 3, Section 3.4.2) was also annotated.

For the retrospective verbal reports, a verbatim transcription was done based on the video files. The video data of the retrospective verbal reports involved 119.84 minutes and 21711 words for the B1 group, and 133.58 minutes and 22.505 words for the B2 group, resulting in a total of 253.42 minutes (2 hours, 13 minutes and 42 seconds) and 44.216 words. 
The purpose of this section was to present the verbatim transcription and annotation of the data. In what follows, I focus particularly on the multimodal transcription and annotation.

\subsubsection{Multimodal transcription and annotation}

The analysis of multimodal data is a difficult task since it involves many different elements that go beyond voice, and it seems that the level of difficulty is increased when multimodal interaction is investigated. As pointed out by Norris (2011, p. 79), the transcription of multimodal interactions is a rather complex task that involves "translating the visual audio aspects into some printable format”. Furthermore, as Goodwin (200ob) suggests, we are still at the beginning of visual transcription. Due to the nature of the data collected in the current study, methodological decisions as regards the treatment of the data were taken.

To do so, the different verbal features were identified following the structure of complaints proposed for the present study (Chapter 2, Section 2.1.2), which was also used to conducted the interlanguage pragmatic analysis. Once the verbal data was identified, I proceeded with the identification of the non-verbal resources, particularly gestures, head, gaze, face expressions and paralanguage that accompanied the face-to-face interaction. To do so, the software program ELAN (EUDICO, European Distributed Corpora, Linguistic Annotator) was employed, which is a multimodal annotation software (Wittenburg, Brugman, Russel, Klassmann, Sloetjes, 2006). This particular software was chosen as it allows users to create transcriptions and annotations for the analysis of the multimodal data and create as many tiers as required to perform the analysis.

In this study, 36 tiers were created. 2 for the verbatim transcription of each participant, the complainer and the 
complainee; 1 for moves; 2 for discourse functions (complainer and complainee); 2 for overlapping (complainer and complainee); 2 for backchannel (complainer and complainee); 2 for paralanguage (complainer and complainee); 2 for paralanguage functions (complainer and complainee); 2 for gesture (complainer and complainee); 2 for gesture type (complainer and complainee); 2 for gesture functions (complainer and complainee); 2 for face expressions (complainer and complainee); 2 for face functions (complainer and complainee); 2 for head movement (complainer and complainee); 2 for head movement functions (complainer and complainee); 2 for gaze (complainer and complainee); and 2 for gaze function (complainer and complainee). Additionally, extra tiers were created for gesture and face in case these kinesic resources were performed simultaneously.

Hence, with this particular tool I could create as many layers or tiers as required for the different types of transcription and annotation. In this particular case, 36 tiers were created taking into account the structure of complaints proposed for the interlanguage analysis of the spoken data (see Chapter 2, Section 2.1.2) as well as the different kinesic and paralanguage aspects that emerged from the multimodal data. Figure 8 shows the different tiers used in the multimodal analysis. 
Figure 8. Tiers employed for the multimodal analysis (example taken from a B1 pair)

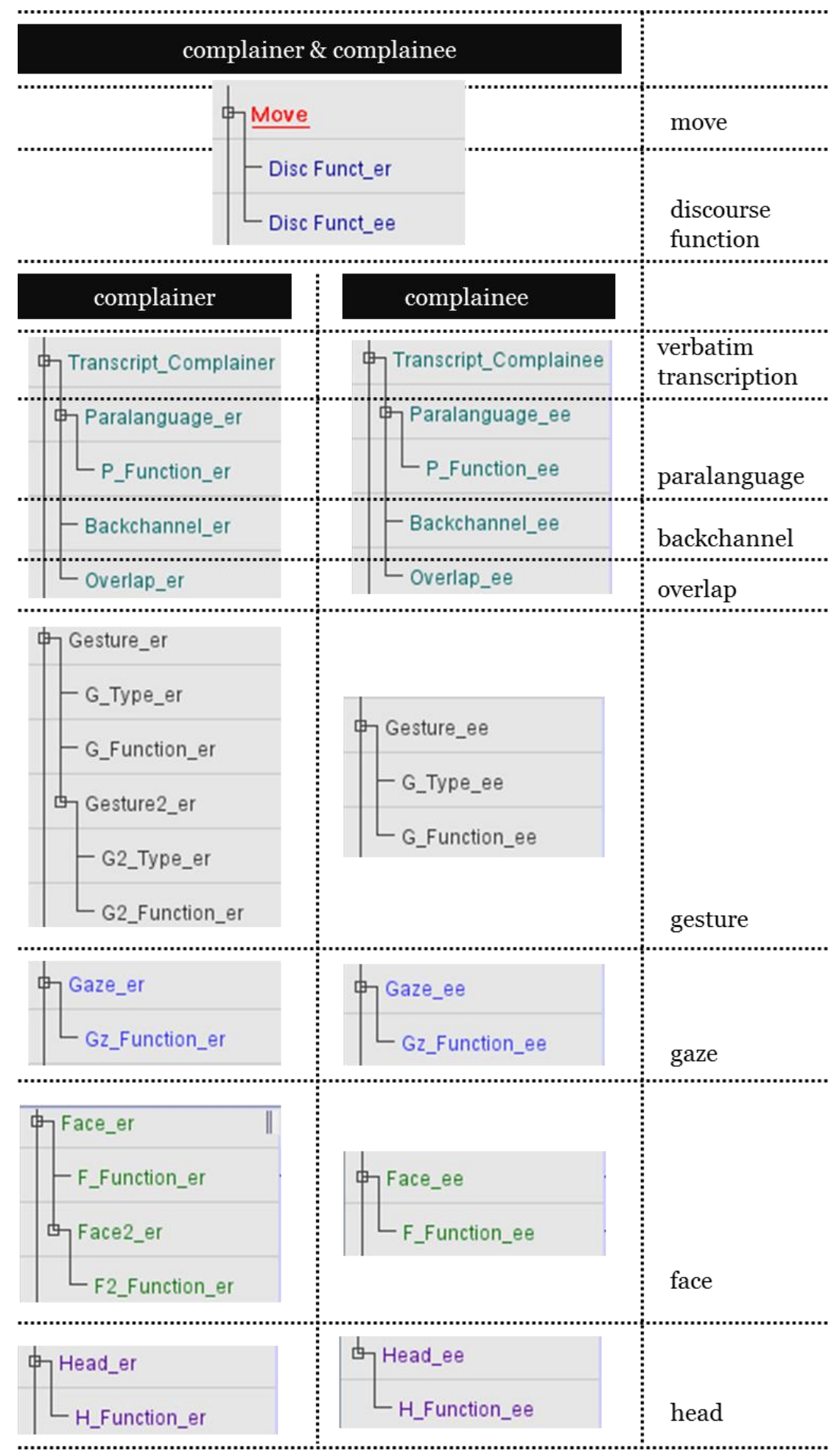


In order to examine face-to-face multimodal interaction data, different tiers for each participant were needed. Following QuerolJulián's (2011) multimodal annotation in ELAN, various tiers were created for the present study.

A parent tier for move was created for both speakers. In this case, the move was annotated following the pre-established moves of complaint presented in this study (Chapter 2, Section 2.1.2). Furthermore, linked to the parent tier, a tier was created (one for each participant's role) in order to annotate the discourse functions performed during the conversation: Disc Funct_er (complainer) and Disc Funct_ee (complainee).

Two parent tiers were created to insert the verbatim transcription, one for the complainer (Transcript Complainer) and one for the complainee (Transcript Complainee). Linked to these parent tiers, four paralanguage tiers were created to: two to transcribe the type of paralanguage resource (Paralanguage_er and Paralanguage_ee) and two to annotate the specific paralanguage function (Paralanguage Function_er and Paralanguage Function_ee). Drawing on Querol-Julián (2011), different tags based on abbreviations were created to annotate paralanguage and paralanguage functions. The paralanguage resources identified involved, filled pauses (vocalised pauses), pauses, snorts, (Poyatos, 2002; Trager, 1958), laughter (differentiators), loudness (qualities), and syllable duration (qualities), following Poyatos (2002). Paralanguage functions were also identified according to the function they accomplished, more precisely, attitude, content, involvement, internal process (e.g. lexical search, thinking processes) and nervousness.

Moreover, also linked to the parent tier of the verbal transcript of each participant, the tiers of backchannel (Backchannel_er and Backchannel_er) and overlap (Overlap_er and Overlap_ee) were created. These four tiers served to indicate 
occurrence of these two conversational features in the spoken data perfomed by the two participants.

Regarding kinesic resources, four different parent tiers were created, particularly for gestures, gaze, face, and head; and one for each participant. For the analysis of these resources, it was important to provide not only the transcription, that is a physical description of the resource, but also to annotate the function they accomplished. In the case of gestures, three different types of tiers were used: Gesture_er and Gesture_ee to transcribe the gesture, G_Type_er and G_Type_ee to annotate the type of gesture (McNeill, 1992; Ekman and Friesen (1969), and G_Function_er and G_Function_ee to annotate the function (Kendon, 2004). Gesture types were classified following (McNeill, 1992) for iconic, metaphoric, deictic and beats; and Ekman and Friesen's (1969) classification and definitions were used for adaptors and emblems Moreover, gesture functions were also identified, specially, referential, interpersonal, and pragmatic (performative, modal and parsing) (Kendon, 2004).

Figure 9 displays a sample of the multimodal annotation view in ELAN of a B1 pair. Two videos were used in order to obtain an appropriate vision of both participants. The example shows the transcriptions and annotations involved in the analysis of a specific discourse function, a request $(R Q)$. All the different discourse functions were organised in a system of abbreviations in order to annotate the verbal data. 
Figure 9. Multimodal analysis of a discourse function performed by a B1 pair

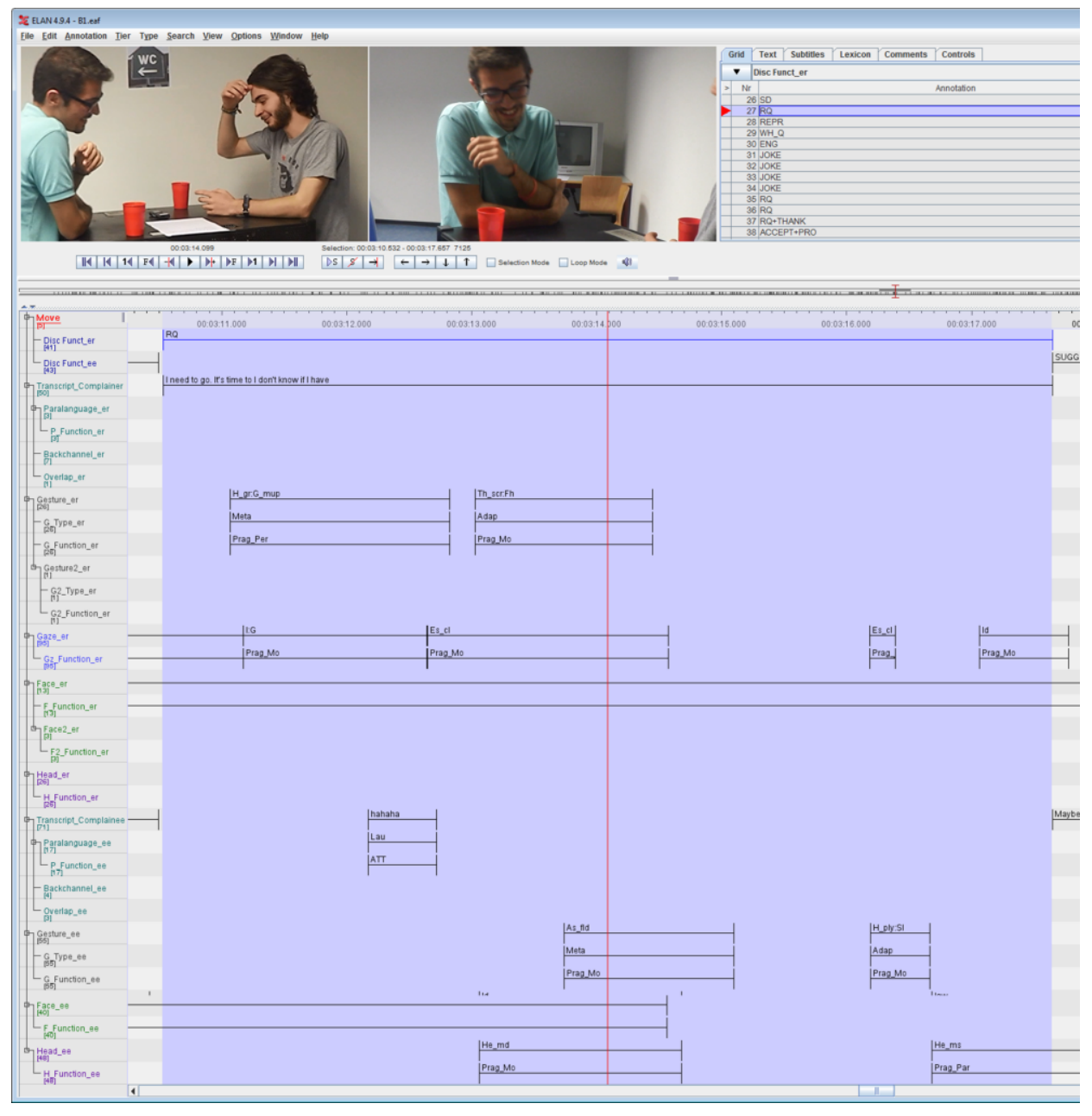

Tags for the annotation of gesture type and functions involved also abbreviations (Querol-Julián, 2011). Examples of these that appear in the analysis of this request are: Meta: metaphoric gesture and Adap: adaptor gesture for gesture types; and Prag_Per: pragmatic function of the performative type, Prag_Mo: pragmatic function of the modal type, and Prag_Mo: pragmatic function of the parsing type for gesture functions. Moreover, head movements, face expressions (Ekman and Friesen, 1969) and gaze (Bavelas, Coates and Johnson, 2002), also included in the analysis, followed the same tagging system. 
Following Querol-Julián (2011), the transcription of the kinesic resources was created based on a series of abbreviated information that described:

what makes the action__action: the recipient/ object of the action $\sim$ description of the action

Depending on the action all this information can be given or only part of it. An example of the above systematic tagging could hand_grapping: glass moving upwards. In line with this, examples of gestures are: hand grapping glass and moving upwards (H_gr:G mup), thump scratching forehead (Th_scr:Fh), folding arms (As_fld), and hand playing with sleeve (H_ply:Sl). Examples of gaze involve: looking at the glass (l:G), closing eyes (Es_cl), looking down (ld), and looking away (law). Examples of head could be: moving down (md) and moving to one side (ms). And an example of face would be smiling ( $\mathrm{sm})$.

Moreover, it should be noted that in order to analyse the conversation from a multimodal perspective, all the information that was integrated in the communicative event was considered. Figure 10 shows the multimodal density of the analysis of a move taken by a B1 pair; in particular, a topic negotiation move. This figure also aims at visually evidence the amount of new information, from the two participants, that is considered in the analysis of interlanguage complaints when a multimodal approach is adopted in the study. 


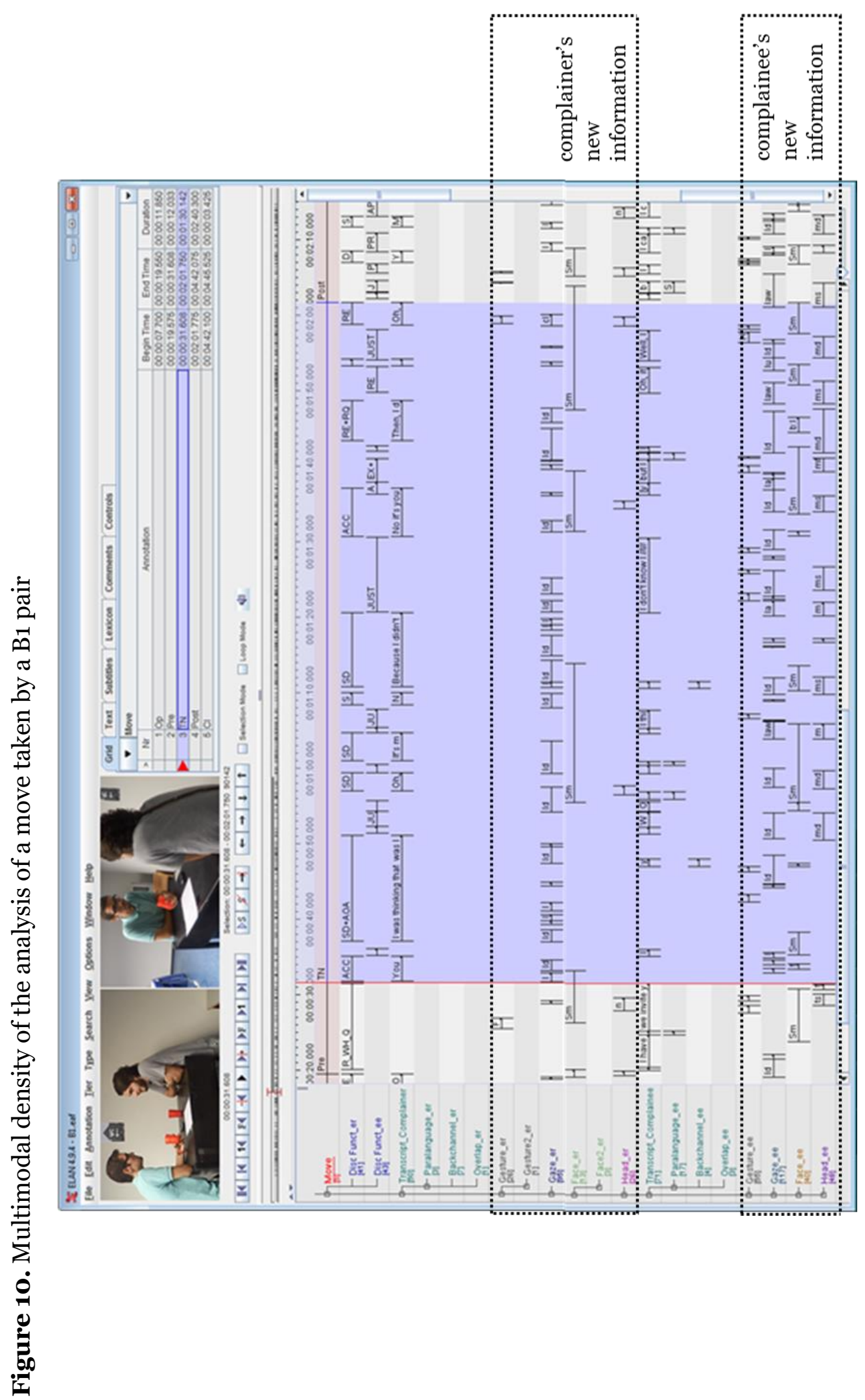


The information that emerged from the multimodal data was rich in terms of multimodal density (Norris, 2004). Modal density refers to the levels of attention and there is no hierarchy among them, but they depend on the context of the situation (Norris, 2004). Particularly, Norris (2004) indicates that modal density can be achieved either by intensity, indicating that one mode is more appropriate to deliver a message under specific circumstances, or by complexity, in which several modes are employed simultaneously to convey the message and all the different modes are important to research that end. Following this trend, it was possible to focus on the multimodal ensemble as a whole so as to examine how the different modes participants employed to construct the conversation interacted to encode their message. Then, to carry out the multimodal analysis, the different modes were identified and classified following the approach described above.

This section has focused on the data preparation by pointing to the verbatim transcription and the annotation followed in the present study. In what follows, I present the data analysis

\subsection{Data analysis}

Data analysis is essential for understanding the results of the data gathered in a given study. In this particular case, spoken data elicited by means of a role-play task and retrospective verbal reports were employed to gather both quantitative and qualitative data types.

\subsubsection{Overview of the analysis}

The quantitative analysis of the verbatim transcription and annotation of the performance of the 64 participants during the role-play 
was conducted using the IBM Statistics SPSS 23 (Statistical Package for the Social Science) by means of independent-samples t-test.

The qualitative data gathered by means of the retrospective verbal reports of those participants was analysed with respect to the table of specifications presented in this chapter (Section 4.4.3.3).

The multimodal performance of four participants was analysed following a CA approach. This particular approach was applied in order to provide a qualitative analysis of the organisation of talk-in-interaction by exploring the sequences in terms of language, extra-linguistic resources and paralanguage. However, the frequency and percentages of the resources have been also calculated.

Finally, the appropriateness of participants' performance was also examined from a quantitative and qualitative perspective. This analysis approach deserves further explanation and is presented in more detailed in the next section.

\subsubsection{Appropriateness}

The notion of pragmatic appropriateness is described by Mey (2001) as the existing relationship between a particular expression and a context of use, which might be both culture-specific and language-specific. Lenvinson (1983) and Mey (2001) indicate that the use of a particular sentence or expression is related to a context, which determines the appropriateness of such sentence or expression. Concerning this, Fetzer (2004: 20) indicates that appropriateness involves "the connectedness between a communicative action, its linguistic realization and its embeddedness in linguistic and social contexts". Focusing particularly on the context of interaction, Sivenkova (2010) identifies four different functions of appropriateness: interpersonal relationships between participants, appropriate roles of interactants, appropriate time and 
appropriate space of the conversational contribution. Of interest for the present study are the notions of interpersonal relationships between participants and appropriate roles of interactants since they point to the appropriateness of an utterance according to participants. Interpersonal appropriateness involves the correspondence between the relationship shared by the participants on a given interaction and the speech act elicited. Regarding the role of appropriateness, Sivenkova (2010: 243) indicates that "to be felicitous a speech act needs to be compliant with speaker's and addressee's various roles".

In the arena of ILP, various studies have been conducted to explore pragmatic appropriateness (see for example Taguchi, 2006, 2013). Cohen (2010) suggests that in order to avoid pragmatic failure, several aspects of appropriateness should be taken into account: (1) the appropriateness of the level of directness or indirectness; (2) the appropriateness in the selected term of address; (3) the appropriateness of the timing for a speech act in the given situation; (4) the acceptability of how the discourse is organised; and (6) the cultural appropriateness of the selected patterns and the appropriateness of the language structures used to represent them. Hence, a speaker should take some decisions as regards the way of addressing their interlocutors which might determine whether pragmatic purposes are reached successfully. To produce pragmatically appropriate moves, speakers need to undertake two different processes. They need to resort to their linguistic knowledge of how grammar is used pragmatically to produce pragmatically correct the different discourse functions and they need to understand the situation and assess the context of the situation in order to produce moves that are sociopragmatically acceptable.

In an attempt to examine pragmatic appropriateness in conversation, a rubric based on a 1 to 4 scale drawing on previous research (Mey, 2001; Cohen, 2010; Sivenkova, 2010) is advanced. The appropriateness rubric involves six different descriptors that are based on the analysis performed 
in the study, that is, pragmatics in conversation from a multimodal perspective. Specifically, the descriptors of the rubric are communication, expression, turn-taking, backchannel, kinesics and paralanguage. It is important to indicate that the appropriateness was first revised by the supervisors and then, using Google Forms, it was judged by the group of experts. The purpose of this judgement was to explore the validity, clarity and relevance of the rubric. To do so, the five experts were asked to rank each item from 1 to 4 , being 1 none and 4 completely.

Table 19 displays the rubric designed to explore the phenomenon of appropriateness. 


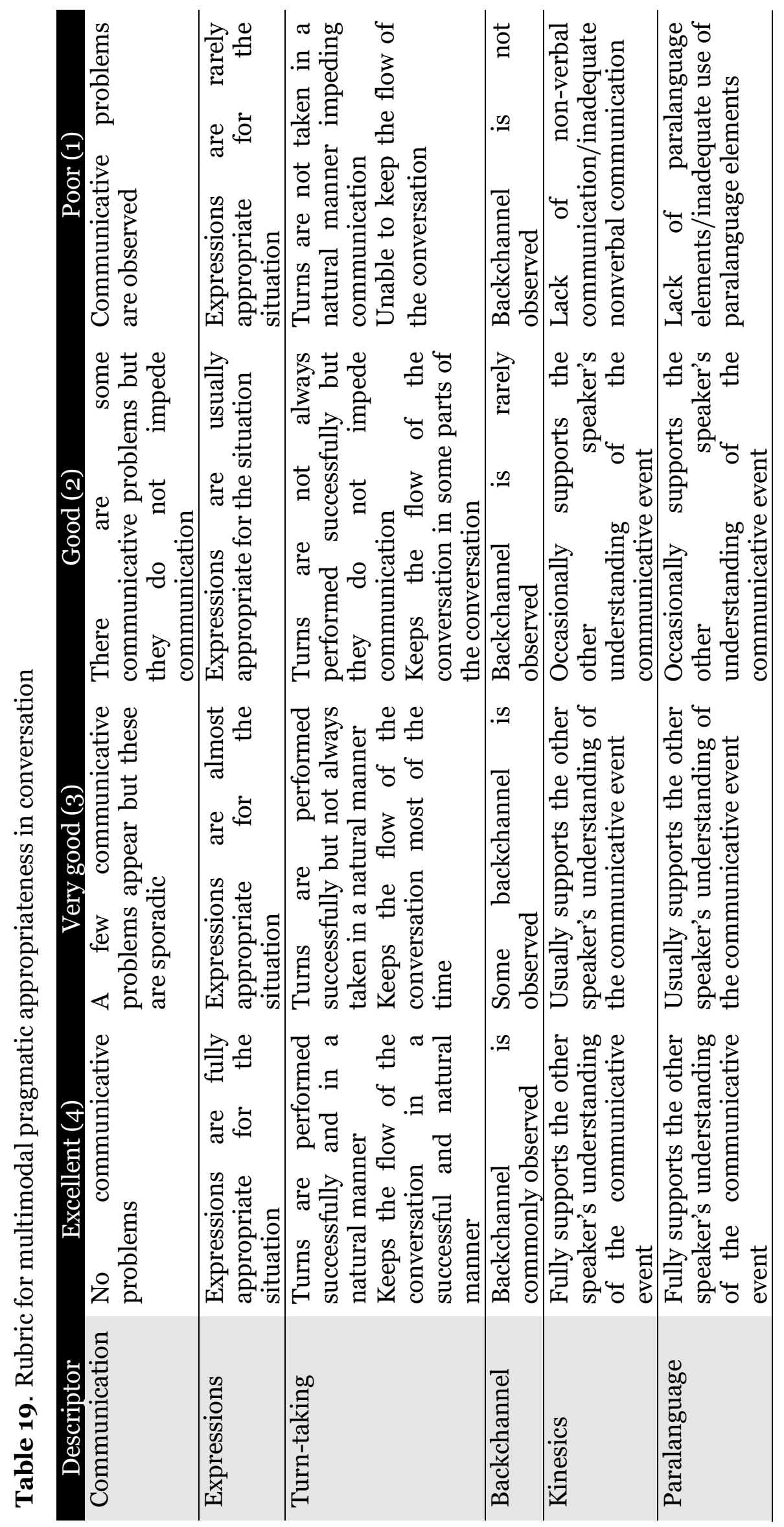


This rubric attempts to explore both pragmatics and the different multimodal resources that are used in the conversation. The descriptors included in this particular rubric attempt to examine participants' performance in a conversation involving in this particular case a complaint situation. Nevertheless, it might be applied to the analysis of appropriateness of other types of communicative events. The six descriptors are (1) communication; (2) expressions; (3) turn-taking; (4) backchannel; (5) kinesics; and (6) paralanguage. Although the first four descriptors might be seen as purely linguistic while the last two related to non-verbal and para-verbal communication, they are all integrated in the same rubric. However, for the purposes of the present study, the analysis of appropriateness was conducted in two different phases, as I explain in Chapter 5 (Section 5.1.4 and Section 5.2.2).

Considering the pragmatic perspective of conversation, it is important to examine aspects as regards communication by focusing on whether participants communicate successfully, negotiate the given situation, and create the interaction. The descriptor of expressions refers to participants' pragmalinguistic choice, which is affected by the sociopragmatic conditions of the situation. The descriptor of turn-taking involves the management of turn and interaction over the course of the conversation. Finally, the descriptor of backchannel refers to participants' active listenership in the conversation. From a multimodal perspective, the appropriateness of kinesics and paralanguage elements is also important. In fact, the multimodal perspective is also crucial, considering that communication is multimodal by nature (Jewitt, 2013). These two elements contribute to the speakers' spoken discourse by adding, in most cases, (a subtle) meaning, which may not be necessarily understood by addresses. In this study, attention has been also paid to the appropriateness of kinesics and paralanguage in order to examine whether these two resources are 
used to construct and support the interaction and show signals of active listening.

Related to overall appropriateness is the fact that speakers of an SL/FL, and particularly language learners in their communicative competence development, need to pay attention not only the linguistic aspects of a SL/FL, or to be more precise in the context of this study, the "language of pragmatics", but also to kinesics and paralanguage elements (Beltrán-Palanques, in press).

The analysis of appropriateness involved two different phases. First, an analysis of the spoken data was done so as to rank the descriptors of communication, expressions, turn-taking and backchannel. Second, an analysis of the video data was conducted to examine the descriptors of kinesics and paralanguage. In both cases, two raters were involved in the analysis. In attempt to ensure concordance between the two raters, an analysis of interrater reliability was estimated for each descriptor. The quantitative analysis of the appropriateness was conducted using the IBM Statistics SPSS 23 by means of reliability analysis and independent-samples t-test.

\subsection{Summary}

In Chapter 4 I have presented the methodology followed in the present study. In so doing, I have first provided an overview of the context of the study in an attempt to introduce the current study. Then, I have focused specifically on the selection on participants, pointing to the criteria followed to select the sample. The proficiency level test and the background questionnaire served to provide participants' profile and select the sample. As reported in Section 4.2.2, participants of the present study belonged to two different proficiency levels, more specifically, B1 and B2 levels according to the CEFR. Proficiency' groups involved a balanced 
number of male and female participants. The small corpus of the study was also presented in this chapter.

The other important aspect presented in this chapter was the instruments used to collect data. Considering that the aim was to gather spoken data, a role-play task was purposefully designed. As reported in this chapter, the simulated spoken task was constructed taking into account participants' results in the generation task (Ostrom and Gannon, 1996; Rose and Ng, 2001; Rose and Ono, 1995; Liu, 2006a, 2006b) as well as in the likelihood questionnaire, which was used to measure the likelihood of occurrence of the situations elicited in the exemplar generation task (Liu, 2006a, 2006b). This study also included a retrospective verbal report, which was constructed so as to gather further information as regards participants' performance. In addition to this, an appropriateness scale was also created in order to examine participants' appropriateness as regards pragmatic competence, interaction and multimodality, thereby focusing on pragmatics from a multimodal perspective. The combination of these instruments served to triangulate the data.

This chapter has also focused on the preparation of the data for the analysis. More precisely, I have reported on the verbatim transcription and the annotation of the data. The data gathered by means of audio recorder was used to respond to the first research question, while the video data was employed to respond to the second research question. In the first approach, I focused on the participants' moves, turns, discourse functions, overlapping, backchannels, and paralanguage resources, while in the second approach, attention was also paid to gestures, facial expressions, gaze, head movement, and paralanguage resources.

The data analysis of the present study was also presented in this chapter. Since the study takes a mixed method approach, quantitative and qualitative analyses were performed. First, 
statistical analyses were performed using SPSS in order to quantify the data examined as regards complaints and responses to complaints and appropriateness. The data of the retrospective verbal reports was analysed from a qualitative perspective. Following quantitative and qualitative approaches, the multimodal data was examined.

Hence, this particular chapter has reported on the methodology and the experimental design of the study, which, broadly speaking, has involved the selection of participants, the instruments used in the study, the data preparation as well as the analysis of the data. In the following chapter, Chapter 5 , I present the results and discussion of the study. 
Chapter 5. Results and Discussion 



\section{Chapter 5. Results and Discussion}

This chapter reports on the results obtained in the study, from both a quantitative and qualitative perspective, following the mixed analysis approach of the study. In order to design a mixed method for the research of multimodal interaction, we need to decide (1) the implementation sequence by which we are going to collect our data, (2) which method takes priority in the analysis, (3) what we get from integrating methods and how we do so, and (4) the theoretical perspectives involved. In this study we follow a concurrent transformative mixed method in which the research questions determine the theoretical and guide methodological choices. This perspective makes it possible to evaluate the theory behind the study at different levels of analysis. The quantitative results, as indicated in Chapter 4 (Section 4.6), are presented following the results obtained in the statistical analysis. The qualitative data that I present in this chapter is based on the transcript of the conversations as well as on the retrospective verbal reports. Examples are shown to better illustrate the results. In this section, I focus first on the structure of the conversation (Section 5.1.1). Then, I present the results of the sequence organisation of the complaints and the responses to complaints (Section 5.1.2). This is followed by the results obtained as regards the specific conversational features examined in the study (Section 5.1.3) and the pragmatic appropriateness (Section 5.1.4). Finally, a multimodal approach for the analysis of interlanguage complaints is presented (Section 5.2.1 and Section 5.2.2). 


\subsection{RQ1: Does language proficiency influence language learners' interlanguage complaints?}

The first research question is concerned with the effect of proficiency on the performance of learners' interlanguage complaints. To answer this question, different analyses were carried out to examine the structure of the conversation, the sequence organisation, conversational features such as backchannels, overlapping and paralanguage resources, and finally pragmatic appropriateness.

\subsubsection{Conversation structure}

In order to examine the structure of the conversation, I focus on the participants' behaviour in the conversation as regards the organisation of moves, turns and whether participants repaired or not the situation as well as the time devoted to complete the conversation and amount of words elicited.

\subsubsection{Moves, turns and repair}

I report here on the results of participants' organisation of moves, the amount of turns and whether participant repaired or not the grievance. Specifically, I examined participants' behaviour as regards these three aspects to see if proficiency had an effect.

As indicated in Chapter 2 Section 2.1.2, the suggested structure for a complaint situation in a spoken conversation involves opening, complaint that involves pre-complaint, topic negotiation and postcomplaint, and finally closing. The opening and closing moves involve the different exchanges participants may use to open and close the conversation. The complaint is divided into three different moves: the pre-complaint move, where the complainer introduces the 
topic of the complaint; the topic negotiation move in which participants negotiate the complaint; and the post-complaint move, in which participants may attempt to repair the situation.

To carry out this analysis, all the different turns were first identified, and then, they were classified according to the move they belonged to. It should be noted that in some cases it was difficult to divide turns into moves, especially in the case of opening and precomplaint since examples in which an utterance contained values of both were identified. In order to decide which move that particular conflicting utterance belonged to, the implicature of the content was carefully examined. Therefore, utterances containing the initial part of a pre-complaint in which the offence was neither explicitly nor implicitly mentioned and the speaker's utterance still offered an opening value were classified as opening. Although this might be a point of criticism, it should be argued that in spoken data sometimes it is difficult to draw the line between the utterances, and if the aim is to classify them into moves some decisions should be taken. This conflicting issue was for example observed in the transition from the opening to the pre-complaint move. It also affected the transition from the pre-complaint to the topic negotiation when the complainers' turn revealed content values of core complaint, for example by addressing the grievance. In those cases, the utterance was carefully examined in order see in which move it could be included. In the case of topic negotiation and post-complaint, both speakers tended to show the transition by means of turns that revealed for instance repair values. Finally, in the case of closing, utterances were clearly identified since they were not usually embedded in the post-complaint.

Taking into account the pre-established structure of the moves, conversations were analysed from a quantitative perspective to examine whether these pre-established moves were identified in the data. The total number of moves performed by the 64 participants in the study was 112, with the following distribution: opening $15.18 \%$, 
complaint $74.11 \%$, and closing $10.71 \%$. Regarding the three moves that conform the complaint move, they appeared to have a similar distribution: pre-complaint $23.21 \%$, topic negotiation $28.58 \%$, and post-complaint $22.32 \%$.

Once moves were identified, data was analysed in order to compare proficiency levels as regards the moves employed. Table 20 shows a summary of the statistical results.

Table 2o. Frequency of moves per proficiency level

\begin{tabular}{lccccccc}
\multicolumn{1}{c}{ Move } & Group & $N$ & $f$ & $M$ & $S D$ & $t$ & $p$ \\
Opening & B1 & 16 & 9 & .56 & .51 & .344 & .733 \\
& B2 & 16 & 8 & .50 & .16 & & \\
\hline Pre- & B1 & 16 & 14 & .87 & .34 & .889 & .381 \\
complaint & B2 & 16 & 12 & .75 & .45 & & \\
\hline Topic & B1 & 16 & 16 & 1.00 & .00 & & \\
negotiation & B2 & 16 & 16 & 1.00 & .00 & & \\
\hline Post- & B1 & 16 & 11 & .69 & .48 & 1.275 & .212 \\
complaint & B2 & 16 & 14 & .87 & .34 & & \\
\hline Closing & B1 & 16 & 7 & .44 & .51 & .713 & .481 \\
& B2 & 16 & 5 & .31 & .48 & & \\
\hline Total & B1 & 16 & 57 & 3.50 & 1.03 & .171 & .865 \\
& B2 & 16 & 55 & 3.43 & 1.03 & .171 & .865 \\
\hline p $<.05^{*}$ & & & & & & &
\end{tabular}

Results showed that there were no statistical differences between them. Nevertheless, it should be noted that examples in which the topic negotiation move was directly elicited were found, especially in the B1 group. Data also revealed that some pairs did not perform the post-complaint move. It should be noted that in the case of the topic negotiation move both groups performed the same amount of moves and therefore the t-value and $p$-value could not be analysed. Therefore, the B2 group did not outperform the B1 group as regards the structure of moves employed to organise the conversation. That is, from a quantitative perspective, the variable of proficiency did not affect participants' constructions of turns. These results are in contrast to Moskala-Gallaher (2011) who found that advanced participants performed more moves than the intermediate group. This finding could be attributed to participant's prior 
knowledge of how a conversation should be structured in terms of opening and closing and how a complaint might be performed.

Another important aspect to take into account in the structure of the conversation was the turns performed by the participants. Turns were analysed from both a qualitative and quantitative perspective. Focusing on the quantitative perspective, I first compared the total turns used by each participant's role without distinguishing the proficiency level; and then, the total amount of turns splitting data into participants' proficiency level.

Participants performed 769 turns in the data sample $(50.20 \%$ the complainer and $49.80 \%$ the complainee). In comparing the frequency of turns performed by the complainer and the complainee in each move, without distinguishing the proficiency level (see Table 21 for a summary of the statistical results), no statistical differences were observed.

Table 21. Frequency of turns per move and participants' role

\begin{tabular}{llllllll}
\multicolumn{1}{c}{ Move } & Role & $N$ & $f$ & $M$ & $S D$ & $t$ & $p$ \\
Opening & Complainer & 32 & 21 & .65 & .55 & .201 & .842 \\
& Complainee & 32 & 22 & 1.14 & .69 & & \\
\hline Pre- & Complainer & 32 & 46 & 1.43 & .91 & .000 & 1.000 \\
complaint & Complainee & 32 & 46 & 1.43 & .80 & & \\
\hline Topic & Complainer & 32 & 175 & 5.47 & .98 & .000 & 1.000 \\
negotiation & Complainee & 32 & 175 & 5.47 & 1.41 & & \\
\hline Post- & Complainer & 32 & 126 & 3.93 & 2.35 & .0 .54 & .957 \\
complaint & Complainee & 32 & 127 & 3.97 & 2.25 & & \\
\hline Closing & Complainer & 32 & 18 & .56 & .76 & .937 & .352 \\
& Complainee & 32 & 13 & .40 & .56 & & \\
\hline Total & Complainer & 32 & 386 & 12.06 & 2.82 & .134 & .894 \\
& Complainee & 32 & 383 & 11.97 & 2.80 & & \\
\hline p $<.05^{*}$ & & & & & & &
\end{tabular}

The lack of statistical difference between the two roles without distinguishing proficiency level groups, as regards the amount of turns, might indicate that both participants organised the conversation in a similar manner in terms of quantity of turns. It is important to note that in both roles, the largest amount of turns was found in the topic negotiation move, more precisely data revealed an amount of $45.34 \%$ in the complainer and a total of $45.70 \%$ in the case 
of the complainee. This result could lead to suggest that both participants employ this specific move in a balanced manner to project their complaint turns in the case of the complainer, and to elicit responses to the complaints in the case of the complainee.

By the same token, the result as regards the remaining moves that conform the complaint move indicated that both roles appeared to produce a similar quantity of turns within the complaint. More specifically, in the pre-complaint the complainer exhibited an amount of $11.92 \%$ and the complainee of $12.01 \%$, and in the case of the post-complaint, the complainer revealed a total of $32.64 \%$ and the complainee $33.15 \%$. These results seemed to suggest that participants tended to elicit more turns in the topic negotiation move followed by the post-complaint move, and finally, in the precomplaint, which contained fewer turns. Hence, results indicated that participants employed more turns to negotiate the grievance as well as to repair the situation.

On the other hand, the number of turns elicited in the precomplaint was, compared to the other moves that conform the complaint move, shorter. This result may be related to the nature of this move. Particularly, the pre-complaint is intended to serve as anticipatory for the immediate complaint, and it is the complainer who may decide whether or not use it. In using it, the complainer seems to soften to some extent the impact of the complaint as he/she might introduce the topic in a more indirect manner. Indeed, in performing it, participants may show sociopragmatic sensibility towards the complainee. Finally, results seemed to reveal a similar distribution in the opening (complainer 5.44\% and complainee $5.74 \%$ ) and in the closing (complainer $4.66 \%$ and complainee $3.39 \%$ ).

In addition to this, the amount of turns dividing the sample into participants' proficiency level was examined (see Table 22 for a summary of the statistical results). 
Table 22. Frequency of turns per move and proficiency level

\begin{tabular}{lccccccc}
\multicolumn{1}{c}{ Move } & Group & $N$ & $f$ & $M$ & $S D$ & $t$ & $p$ \\
Opening & B1 & 32 & 24 & .75 & .67 & 1.010 & .316 \\
& B2 & 32 & 19 & .59 & .56 & & \\
\hline Pre- & B1 & 32 & 47 & 1.47 & .84 & .291 & .772 \\
complaint & B2 & 32 & 45 & 1.40 & .87 & & \\
\hline Topic & B1 & 32 & 176 & 5.50 & 1.22 & .205 & .838 \\
negotiation & B2 & 32 & 174 & 5.44 & 1.22 & & \\
\hline Post- & B1 & 32 & 84 & 2.62 & 1.45 & 5.693 & $.000^{* *}$ \\
complaint & B2 & 32 & 169 & 5.28 & 2.20 & & \\
\hline Closing & B1 & 32 & 16 & .50 & .72 & .186 & .853 \\
& B2 & 32 & 15 & .46 & .62 & & \\
\hline Total & B1 & 32 & 347 & 10.84 & 2.48 & 3.689 & $.000^{* *}$ \\
& B2 & 32 & 422 & 13.19 & 2.60 & & \\
\hline p<.001** & & & & & & &
\end{tabular}

Results showed that a significant difference $\mathrm{p}<.001^{*}$ was found in the case of the post-complaint, revealing that the B2 group produced slightly more turns than the B1 group. However, in the remaining moves no significant differences were found. In comparing the total amount of turns elicited by each proficiency group, results showed a significant difference $\mathrm{p}<.001^{* *}$ showing that the $\mathrm{B} 2$ group elicited slightly more turns than the B1 group.

In light of these results, it might be indicated that the variable of proficiency did affect the overall amount of turns, as well as the amount of turns elicited in the post-complaint move. This particular result could be associated to participants' linguistic disposal as well as their ability to employ the linguistic resources to elicit slightly more turns in general and in particular in the post-complaint move. The post-complaint move may involve a rather complex move in the sense that participants may try to repair the situation. Repairing the situation would be linguistically and psychologically more demanding than complaining. In this sense, research has shown effects of language proficiency in less demanding speech acts than in more demanding speech acts, showing that less complex situations are easier and faster to perform than complex ones (Taguchi, 2007). The use of more turns in the post-complaint move could be also attributed to participants' assessment of the situation which led them to employed more turns to repair the situation, thereby showing 
sociopragmatic sensibility towards the situation. Nevertheless, it should be noted that in the present analysis attention is only paid to the amount of turns rather than to the pragmatic behaviour participants' exhibited in those turns. This particular analysis is presented in Section 5.1.2.1 and Section 5.1.2.2.

In order to exemplify how participants organised their conversation in various moves and turns, two examples are presented here.

Example 1 shows how the conversation of a pair in the B1 level was organised in moves and turns.

Example 1. B1 level participants: Moves organisation and turn-taking

\begin{tabular}{|c|c|c|c|}
\hline Line & Turn & Participant & \\
\hline \multicolumn{4}{|c|}{ A: Complainer and B: Complainee } \\
\hline \multicolumn{4}{|c|}{ Pre-complaint } \\
\hline 1 & 1 & A_\#9 & $\begin{array}{l}\text { (name of the participant) I want to } \\
\text { talk with you because I'm very } \\
\text { angry umm <A9:F_PAUSE } \\
\text { < umm >//F_PAUSE > } \\
\text { because I don't understand the } \\
\text { reason why you didn't invite me to } \\
\text { the party }\end{array}$ \\
\hline \multicolumn{4}{|c|}{ Topic negotiation } \\
\hline 2 & 2 & B_\#9 & $\begin{array}{l}\text { umm }<\text { A9:F_PAUSE } \\
<\text { umm }>/ / \text { F_PAUSE }>\text { sorry Africa } \\
\text { (o.2) but umm < <9:F_PAUSE } \\
<\text { umm }>/ / \text { F_PAUSE }>\text { we're a lot of } \\
\text { people in my house and = }\end{array}$ \\
\hline 3 & 3 & A_\#9 & $\begin{array}{l}\text { =yes but you umm you know that } \\
\text { (o.1) this group is my favourite } \\
\text { group and I always tell you that I'm } \\
\text { I'll be very happy if I come came to } \\
\text { a concert of this group }\end{array}$ \\
\hline 4 & 4 & B_\#9 & $\begin{array}{l}\text { umm ok (o.1)but I don't want that } \\
\text { you (o.1) er <A9:F_PAUSE } \\
<\text { er }>/ / \text { F_PAUSE }>\text { (o.1) go to my } \\
\text { party because umm <A9:F_PAUSE } \\
<\text { umm }>/ / \text { F_PAUSE }>\text { (o.1) because } \\
\text { (o.3) I (o.1) //I// angry (o.1) you }\end{array}$ \\
\hline 5 & 5 & A_\#9 & why are you angry (o.1) with me? \\
\hline 6 & 6 & B_\#9 & $\begin{array}{l}\text { because the other day (o,1)you } \\
\text { went to the cinema with the girls } \\
\text { (o.1) and (o.1)no (o.1) and (o.1) } \\
\text { don't (o.1) and don't (o.1) call me }\end{array}$ \\
\hline 7 & 7 & A_\#9 & yes \\
\hline
\end{tabular}




\begin{tabular}{|c|c|c|c|}
\hline 8 & 8 & B_\#9 & aha \\
\hline 9 & 9 & A_\#9 & $\begin{array}{l}\text { but (o.1) er }<\text { A9:F_PAUSE } \\
<\text { er }>/ / \text { F_PAUSE }>\text { (o.1) umm } \\
\text { A9:F_PAUSE } \\
<\text { umm }>/ / F \_P A U S E>\text { (o.1) that } \\
\text { (o.1) was (o.1) because the film we } \\
\text { were going to (o.1)to watch (o.1) } \\
\text { you don't like it (o.1) I know that } \\
\text { (o.1) film (o.1) don't like you }\end{array}$ \\
\hline \multicolumn{4}{|c|}{ Post-complaint } \\
\hline 10 & 10 & B_\#9 & $\begin{array}{l}\text { ok well (o.1) this is your invitation } \\
\text { for the party }\end{array}$ \\
\hline 11 & 11 & A_\#9 & oh thank you \\
\hline
\end{tabular}

As observed in this example, three moves were employed, rather than five, as it was pre-established in the structure of complaint proposed for the present study (see Chapter 2 Section 2.1.2). Data revealed that a pre-complaint, a complaint and a post-complaint were employed by these participants to complete the spoken task. As observed in line 1 , the complainer addressed directly to the complainee without using an opening move, but a pre-complaint move instead that contained one turn. Although this realisation discourse function was classified as pre-complaint, the utterance also contained a complaint value, especially when the complainer uttered "I don't understand the reason why you didn't invite me to the party". Nevertheless, it was classified as pre-complaint. It is worth mentioning that participants appeared to address each other in a rather direct manner, instead of using an indirect discourse function that could mitigate the force of the utterance (Brown and Levinson, 1978, 1987). However, since participants acted out a situation involving two close friends, they seemed to act in a more direct manner.

The retrospective verbal reports were instrumental in obtaining information as regards participants' performance. In the retrospective verbal reports participants were asked about their actual and fictitious relationship. These two female participants indicated that they met in class some time before the task was carried out and that they had a good relationship. They revealed that the fact 
that they knew each other and that they had a good relationship appeared to influence the way they completed the task since they felt more comfortable with a known interlocutor. Concerning this, it could be also argued that the fact that they knew each other and that they were performing the role of two close friends, could have affected the elaboration of the turns and the way they approached to each other. Furthermore, the complainer indicated that she would have reacted in a similar manner in real situation, showing her feelings towards the complainee. The participant performing the role of the complainee, however, indicated that she would have expressed herself in a different way in her L1 due to her ability to elaborate more on her responses. Concerning this, it might be suggested that this participant was somehow limited when trying to express her ideas due to her FL linguistic limitations. Moreover, it might be argued that the fact that they knew each other allowed them to feel more comfortable to complete the task, and although their reaction in a real situation would differ mainly in terms of language performance, they would react in a similar way.

Example 2 presents a situation involving two participants of the B2 level group so as to observe how participants organised their conversation into different moves and turns.

Example 2. B2 level participants: Moves organisation and turn-taking

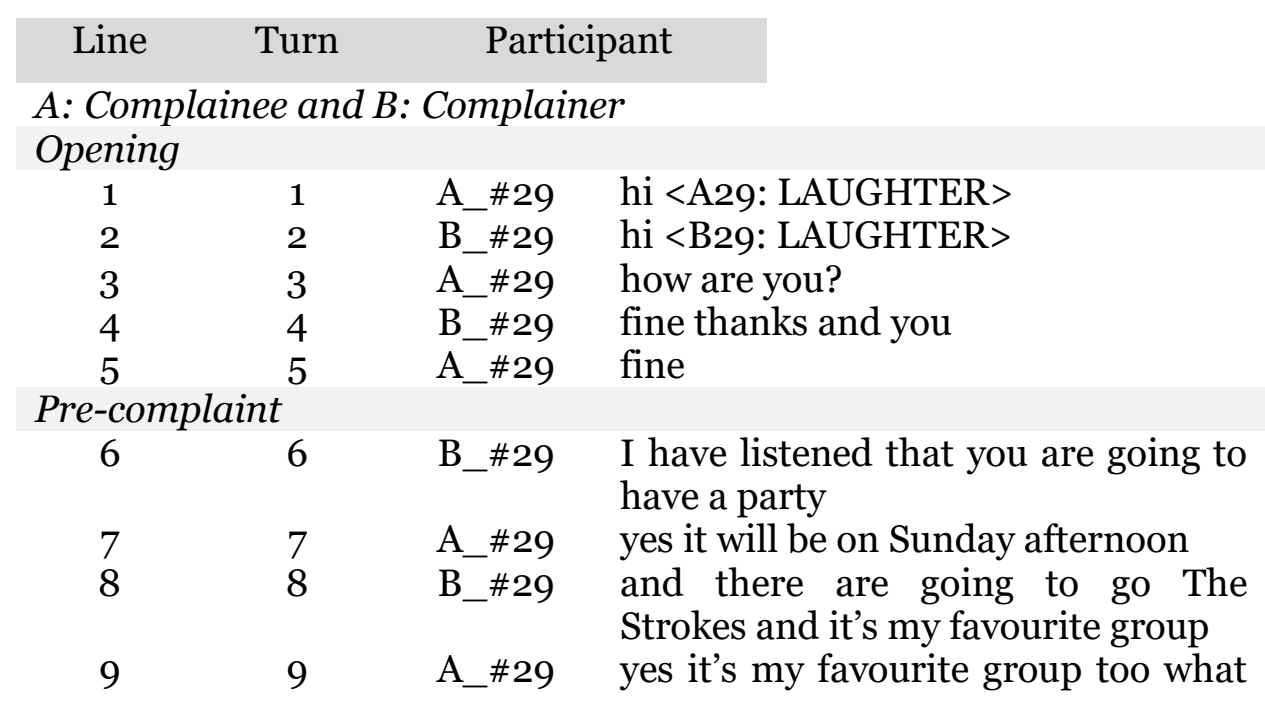




\begin{tabular}{|c|c|c|c|}
\hline \multirow{2}{*}{\multicolumn{4}{|c|}{ Topic negotiation }} \\
\hline & & & \\
\hline 10 & 10 & B \#29 & that I'm not invited to the party \\
\hline 11 & 11 & A_\#29 & $\begin{array}{l}\text { oh I'm sorry but I didn't have your } \\
\text { address so I can't er <A29:F_PAUSE } \\
<\text { er }>/ / \text { F_PAUSE }>\text { send you the } \\
\text { invitation }\end{array}$ \\
\hline 12 & 12 & B_\#29 & but you have my mobile phone \\
\hline 13 & 13 & A_\#29 & $\begin{array}{l}\text { but my mobile phone is broken. I'm } \\
<\text { A29:LAUGHTER > sorry, I can't get } \\
\text { through with you }\end{array}$ \\
\hline 14 & 14 & B_\#29 & $\begin{array}{l}\text { You see my every day at class <B29: } \\
\text { LAUGHTER }>\end{array}$ \\
\hline \multicolumn{4}{|c|}{ Post-complaint } \\
\hline 15 & 15 & A_\#29 & $\begin{array}{l}<\text { A29:LAUGHTER }>\text { okay maybe I } \\
\text { have forgotten to tell you anything er } \\
<\text { A29:F_PAUSE <er }>/ / \text { F_PAUSE }> \\
\text { (o.1) but if you want, you can come } \\
\text { maybe you can go before the party } \\
\text { and if you forgive me, I will present } \\
\text { you The Strokes }\end{array}$ \\
\hline 16 & 16 & $\begin{array}{l}\text { B_\#29 } \\
\text { A_\#29 }\end{array}$ & $\begin{array}{l}\text { it's a really good idea } \\
\text { really and you forgive me? }\end{array}$ \\
\hline 17 & 17 & B_\#29 & yes \\
\hline 18 & 18 & A_\#29 & $\begin{array}{l}\text { Okay, perfect. So see you on Sunday } \\
\text { at 7:00 PM? }\end{array}$ \\
\hline 19 & 19 & B_\#29 & yes \\
\hline 20 & 20 & A_\#29 & okay, perfect \\
\hline 21 & 21 & B_\#29 & at your home? \\
\hline 22 & 22 & A_\#29 & at my home \\
\hline 23 & 23 & A_\#29 & okay \\
\hline 24 & 24 & B_\#29 & perfect \\
\hline 25 & 25 & A_\#29 & okay \\
\hline \multicolumn{4}{|c|}{ Closing move } \\
\hline 26 & 26 & B_\#29 & bye <B29: LAUGHTER $>$ \\
\hline 37 & 27 & A_\#29 & bye \\
\hline
\end{tabular}

This example shows how participants organised their conversation over the different moves (including opening, precomplaint, complaint, post-complaint, and closing) and turns. The opening involved four different turns in which participants greeted each other and after that the complainer initiated the pre-complaint move by uttering a preparation utterance. This was then followed by the topic negotiation move in which both participants negotiated the grievance. The problem was further discussed in the post-complaint in an attempt to repair the situation, which resulted in a repair. 
Finally, after repairing the situation, they were engaged in the closing move where only two turns were elicited.

This is a clear example of how participants organised the conversation into various moves and turns in order to reach communicative purposes. In this case, as in Example 1, the situation involved two close friends so they were in the same status, albeit it could be argued that the complainer is in a higher position of power since the complainee has committed an action that has damaged and affected negatively the complainer. As shown in line 6, the complainer approached the complainee in a rather indirect manner, thereby without directly accusing the complainee for not having invited her to the party, and the idea was then reinforced in line 8. It is in line 10 , in the topic negotiation move, when the complainer directly addressed the issue, as a response to the complainee's utterance performed in line 9. It should be noted that in examining data, it seemed that the B2 group tended to be less direct, and thereby prepare the complainee for the forthcoming situation, than the B1 group was.

In this particular case, the retrospective verbal report also provided evidences of how participants organised their conversation. Participants indicated that they would have organised the complaint in a similar manner in an authentic although they would modify to some extent their behaviour. The complainer revealed that she would act similarly although she would not become angry as she did in the situation in order to show her feelings towards the complainee. The complainee indicated she would be more direct than she was in the role-play as she would try to solve the problem immediately without focusing so much on the topic negotiation, as she did in the role-play task. These results seemed to indicate that although some modifications would be done in order to perform the same situation in their L1, a similar structure would be employed, albeit probably using less turns in the case of the complainee. Moreover, participants 
reported that some modifications as regards the complaint behaviour would be made in real life.

The last aspect presented in this section is repair. Particularly I focused on whether participants repaired or not the situation, thereby showing whether harmony between speakers was restored. The two proficiency level groups were compared to explore whether there was a statistical difference as regards the repair (see Table 23 for a summary of the statistical results).

Table 23. Frequency of repair per proficiency level

\begin{tabular}{cccccccc} 
& Group & $N$ & $f$ & $M$ & $S D$ & $t$ & $p$ \\
Repair & B1 & 16 & 8 & .50 & .52 & 2.423 & $.022^{*}$ \\
& B2 & 16 & 14 & .87 & .34 & & \\
\hline p $<.05^{*}$ & & & & & & &
\end{tabular}

Results showed that from the 26 instances of repair found in the data set, in the B2 group almost every pair repaired the situation, 14 pairs out of 16 , while in the B1 group, 8 out of 16 . A statistical difference between the two groups was found $\mathrm{p}<.05^{*}$ since the B2 group repaired the situation in more occasions than the $\mathrm{B} 1 \mathrm{did}$. It should be noted that performing a post-complaint move does not necessarily involve repairing the situation. Similar results were found by Moskala-Gallaher (2011), who found that more advanced learners seemed to attempt to provide solutions more frequently than the lower group. Therefore, it could be suggested that less proficient participants, due to linguistic limitations, found more challenging repairing than more proficient participants (Taguchi, 2007). In order to repair a complaint situation, the complainee should perform some specific action so that the situation can be solved (Olshtain and Weinbach, 1993). Furthermore, repairing the situation involves sociopragmatic knowledge of the situation (Olshtain and Weinbach, 1993). The statistical difference as regards repair might be related to participants' sociopragmatic sensibility towards the complainee and the situation. Although not examined in this section but in Section 
5.1.2, the choice of complainers' and complainee's realisation of discourse functions would be also associated to repair. Example 3 and Example 4 might serve to illustrate how participants opened and closed the conversation as well as how the situation was either repaired or not.

Example 3 provides the extract of two participants who were classified in the B1 group.

Example 3. B1 level participants: Lack of repair

\begin{tabular}{|c|c|c|c|}
\hline Line & Turn & articipant & \\
\hline \multicolumn{4}{|c|}{ A: Complainer and B: Complainee } \\
\hline \multicolumn{4}{|c|}{ Opening move } \\
\hline 1 & 1 & A_\#3 & hi (name of the participant) \\
\hline 2 & 2 & B_\#3 & hi (name of the participant) \\
\hline \multicolumn{4}{|c|}{ Pre-complaint move } \\
\hline 3 & 3 & A_\#3 & hey I heard there's a party tonight \\
\hline 4 & 4 & B_\#3 & yes it's true \\
\hline \multicolumn{4}{|c|}{ Topic negotiation move } \\
\hline 5 & 5 & A_\#3 & but I wasn't invited \\
\hline 6 & 6 & B_\#3 & $\begin{array}{l}\text { oh yes because my house is big but I } \\
\text { have a limit of guests and you are not } \\
\text { on the list, sorry }\end{array}$ \\
\hline 7 & 7 & A_\#3 & $\begin{array}{l}\text { but I wanted to go (o.1) I always } \\
\text { wanted to go there }\end{array}$ \\
\hline 8 & 8 & B_\#3 & $\begin{array}{l}\text { yes of course I absolutely understand } \\
\text { you but }\end{array}$ \\
\hline 9 & 9 & A_\#3 & $\begin{array}{l}\text { when you started to planned it I said I } \\
\text { (o.1) I wanted to go there }\end{array}$ \\
\hline 10 & 10 & B_\#3 & $\begin{array}{l}\text { oh yes but there are much people who } \\
\text { many people who want to go to the } \\
\text { party and there was a limit of guests } \\
\text { and you are not on the list }\end{array}$ \\
\hline 11 & 11 & A_\#3 & but //but// I am your friend \\
\hline 12 & 12 & B_\#3 & yes \\
\hline 13 & 13 & & $\begin{array}{l}\text { you should and all the guys that are } \\
\text { coming to my party //party// I } \\
\text { should go there because my er } \\
<\text { B3:F_PAUSE }<\text { er }>/ / \text { F_PAUSE }>\end{array}$ \\
\hline 14 & 14 & A_\#3 & $\begin{array}{l}\text { I know it's your favourite group but } \\
\text { it's also of the other guests who is are } \\
\text { coming to the party }\end{array}$ \\
\hline 15 & 15 & B_\#3 & $\begin{array}{l}\text { I'm the best fan of Death Row, I } \\
\text { should go }\end{array}$ \\
\hline 16 & 16 & A_\#3 & I really don't think so because \\
\hline 17 & 17 & B_\#3 & yes \\
\hline 18 & 18 & A_\#3 & no you don't have all his discs and \\
\hline
\end{tabular}




\begin{tabular}{|c|c|c|c|}
\hline 19 & 19 & B_\#3 & I don't know if I have them all \\
\hline 20 & 20 & A_\#3 & $\begin{array}{l}\text { only people who have bought all his } \\
\text { discography could come to the party }\end{array}$ \\
\hline 21 & 21 & B_\#3 & $\begin{array}{l}\text { you didn't achieve the requirements } \\
\text { to come to the party. You don't have } \\
\text { the discography of his group }\end{array}$ \\
\hline 22 & 22 & A_\#3 & but I thought you would say that \\
\hline 23 & 23 & B_\#3 & what? can you repeat, please? \\
\hline 24 & 24 & A_\#3 & no \\
\hline 25 & 25 & B_\#3 & so \\
\hline 26 & 26 & A_\#3 & $\begin{array}{l}\text { it's better than nothing to do to do } \\
\text { with it }\end{array}$ \\
\hline 27 & 27 & B_\#3 & we have a guest limit \\
\hline 28 & 28 & A_\#3 & oh one more \\
\hline 29 & 29 & B_\#3 & $\begin{array}{l}\text { I have invited more guests than I } \\
\text { could but }\end{array}$ \\
\hline 30 & 30 & A_\#3 & you should not do that \\
\hline 31 & 31 & B_\#3 & yeah I know but \\
\hline 32 & 32 & A_\#3 & because then I can go there \\
\hline 33 & 33 & B_\#3 & $\begin{array}{l}\text { yes, but if I invite you, other guys can } \\
\text { come to the party also //also// can } \\
\text { come }\end{array}$ \\
\hline 34 & 34 & A_\#3 & $\begin{array}{ll}\text { umm } & <\text { A3:F_PAUSE } \\
<\text { umm }>/ / \text { F_PAUSE }>\text { I want to go }\end{array}$ \\
\hline 35 & 35 & B_\#3 & $\begin{array}{l}\text { I know you wanted to go - to come to } \\
\text { the party but there was a guest limit }\end{array}$ \\
\hline 36 & 36 & A_\#3 & okay I chamber all of your house \\
\hline \multicolumn{4}{|c|}{ Closing move } \\
\hline 37 & 37 & B_\#3 & okay bye \\
\hline 38 & 38 & A_\#3 & bye \\
\hline
\end{tabular}

As seen in line 1, the complainer first addressed the complainee in order to open the conversation. Each participant took turns to greet each other, and then they moved to the turns that were classified as part of the pre-complaint move, lines 3 and 4. The topic negotiation move was then developed over several turns until they were engaged in the post-complaint move. As shown in the turns elicited by the complainer during the topic negotiation, the complainer urged the complainee to make him change his point of view. Nevertheless, as observed for example in line 8, the complainee understood the situation but still he did not modify his point of view, which led them to close the event without a post-complaint move and the situation was not repaired. This example is interesting as it shows 
that although the complainer attempted to modify the grievance that the complainee had done, by insisting and providing arguments that support his view, the complainee did not modify his behaviour and then the situation was not repaired. The retrospective verbal reports of these two participants revealed that they would not behave in such way in a real conversation as they would try to solve the problem. This fact leads to suggest that because they were aware of the nonreal-life consequences (Roever, 2010), they seemed not to reveal authentic-like pragmatic performance. The fact that no real consequences were conveyed in the interaction was also noted by various participants performing the role of the complainer, particularly a total of 9 participants (B1 $f=4$ and B2 $f=5$ ) explicitly indicated that they were aware of this issue.

Example 4 involves the extract of two participants who were classified in the B2 group.

Example 4. B2 level participants: Repair the situation

\begin{tabular}{|c|c|c|c|}
\hline Line & Turn & \multicolumn{2}{|c|}{ Participant } \\
\hline \multicolumn{4}{|c|}{ A: Complainer and B: Complainee } \\
\hline \multicolumn{4}{|c|}{ Pre-complaint } \\
\hline 1 & 1 & A_\#23 & $\begin{array}{l}\text { so I heard you're going to make a } \\
\text { party }\end{array}$ \\
\hline 2 & 2 & B_\#23 & yes it's going to be all right \\
\hline \multicolumn{4}{|c|}{ Topic negotiation } \\
\hline 3 & 3 & A_\#23 & I'm not invited? \\
\hline 4 & 4 & B_\#23 & I don't know (0.2) what? \\
\hline 5 & 5 & A_\#23 & you don’t know? \\
\hline 6 & 6 & B_\#23 & $\mathrm{no}=$ \\
\hline 7 & 7 & A_\#23 & =you're organizing it \\
\hline 8 & 8 & B_\#23 & $\begin{array}{l}\text { yes but }(0,3) \text { Can you repeat what } \\
\text { you said? I was not listening to you } \\
\text { very well }\end{array}$ \\
\hline 9 & 9 & A_\#23 & $\begin{array}{l}\text { so you're making a party er } \\
<\text { A23:F_PAUSE } \\
<\text { er }>/ / \text { F_PAUSE }>\end{array}$ \\
\hline 10 & 10 & B_\#23 & a big party. \\
\hline 11 & 11 & A_\#23 & you didn't invite me in \\
\hline 12 & 12 & B_\#23 & $\begin{array}{l}\text { I know (o.1) er <A23:F_PAUSE } \\
<\mathrm{er}>/ / \mathrm{F} \text { _PAUSE }>\end{array}$ \\
\hline
\end{tabular}




\begin{tabular}{|c|c|c|c|}
\hline 13 & 13 & A_\#23 & why? \\
\hline 14 & 14 & B_\#23 & $\begin{array}{l}\text { you know Maria, right? she's } \\
\text { going to be there and you hate her } \\
\text { she hates you. }\end{array}$ \\
\hline 15 & 15 & A_\#23 & she's a bitch man \\
\hline 16 & 16 & B_\#23 & I know that's right but \\
\hline 17 & 17 & A_\#23 & so you prefer her before me? \\
\hline 18 & 18 & B_\#23 & $\begin{array}{l}\text { she's a girl, she's going to be it'll } \\
\text { be a big, amazing show and all } \\
\text { that }\end{array}$ \\
\hline 19 & 19 & A_\#23 & $\begin{array}{l}\text { she ain't going to do nothing, } \\
\text { man. she got a boyfriend }\end{array}$ \\
\hline 20 & 20 & B_\#23 & $\begin{array}{l}\text { I know, but not for me, but I can } \\
\text { watch }\end{array}$ \\
\hline 21 & 21 & A_\#23 & $\begin{array}{l}\text { so you prefer this girl before me } \\
\text { (o.1) your old-time friend }\end{array}$ \\
\hline 22 & 22 & B_\#23 & $\begin{array}{l}\text { I know man but (o.1) I don't know } \\
\text { the list was short it was like so } \\
\text { many important people here }\end{array}$ \\
\hline 23 & 23 & A_\#23 & $\begin{array}{l}\text { yes [but } \quad<\text { B23:OVERLAP } \\
<\text { but }>/ / \text { OVERLAP }>\end{array}$ \\
\hline 24 & & B_\#23 & [you said] \\
\hline 25 & & A_\#23 & not this one \\
\hline 26 & & B_\#23 & $\begin{array}{l}\text { you } \quad \text { said XXX] <A23: } \\
\text { OVERLAP_<said } \\
\text { XXX }>/ / \text { OVERLAP> }\end{array}$ \\
\hline 27 & & A_\#23 & $\begin{array}{l}\text { [it's my] favourite group touching } \\
\text { it }\end{array}$ \\
\hline 28 & 24 & B_\#23 & $\begin{array}{l}\text { I know, but you'll have another } \\
\text { one }\end{array}$ \\
\hline 29 & 25 & A_\#23 & what? \\
\hline 30 & 26 & B_\#23 & $\begin{array}{l}\text { we will have another one right? or } \\
\text { this is the only one you like? }\end{array}$ \\
\hline 31 & 27 & A_\#23 & $\begin{array}{l}\text { I don't like this but I don't know if } \\
\text { you can afford (o.1) to take } \\
\text { another group }\end{array}$ \\
\hline \multicolumn{4}{|c|}{ Post-complaint } \\
\hline 32 & 30 & B_\#23 & $\begin{array}{l}\text { you said it right we are friends we } \\
\text { are neighbours I'm going to do it } \\
\text { for you now that you said it that } \\
\text { you're complaining to me I feel } \\
\text { you all right }\end{array}$ \\
\hline 33 & 31 & A_\#23 & you're my folk \\
\hline 34 & 32 & B_\#23 & all right \\
\hline
\end{tabular}

Example 4 shows an extract in which two participants developed over several turns and in different moves, particular precomplaint, topic negotiation, and post-complaint. Most of the turns were elicited in the topic negotiation move where the complainee tried to provide some explanations why he was not invited to the 
party, which was mainly because of a girl. However, they finally solved the problem as they understood that they were friends and therefore they should not have an argument about that issue. In the retrospective verbal report, the complainer indicated that he felt bad when he realised that he was not invited, as the complainee wanted to meet a girl at the party. In real life, the complainer indicated that he would not have provided so many explanations, but he would act instead to solve the problem. The complainee indicated that in real life he would show his feelings in a more natural way as he revealed he was nervous and therefore he was not able to show his feelings properly.

These two examples serve to show how participants organised the talk in different moves and turns and whether they repaired or not the situation. I would suggest that repairing the situation would be tightly related to the relationship of the participants and the grievance, which would then affect, for example, the effort taken by speakers to solve the problem if they really want to do so. Ideally, in a complaint situation, speakers should repair or try to repair the situation to restore harmony between them. Nevertheless, this may not be always the case since speakers' personality traits, the perception of and the assessment of the situation could also affect participants' behaviour. Concerning this, the retrospective verbal reports seemed to show that all the participants would have tried to repair the situation in a real context albeit not of them did in the roleplay tasks.

\subsubsection{Time and words}

The time and the number of words devoted to complete that task were examined in order to see whether the variable of proficiency level could have affected these two items.

Results seemed to suggest that there was no statistical difference as regards the total amount of time pairs devoted to 
complete the task when comparing the B1 group and the B2 group. Table 24 shows a summary of the statistical results.

Table 24. Distribution of time in moves and per proficiency levels

\begin{tabular}{lcccccccc}
\multicolumn{1}{c}{ Move } & Group & $N$ & $m^{16}$ & $M$ & $S D$ & $t$ & $p$ \\
Opening & B1 & 16 & 0.32 & .02 & .026 & 1.569 & .127 \\
& B2 & 16 & 0.88 & .05 & .085 & & \\
\hline Pre-complaint & B1 & 16 & 2.27 & .14 & .20 & .912 & .369 \\
& B2 & 16 & 4.14 & .25 & .41 & & \\
\hline Topic & B1 & 16 & 40.29 & 10.22 & 30.80 & 1.166 & .253 \\
negotiation & B2 & 16 & 20 & 1.25 & .67 & & \\
\hline Post-complaint & B1 & 16 & 9.11 & .57 & .84 & 1.309 & .200 \\
& B2 & 16 & 15.57 & .97 & .90 & & \\
\hline Closing & B1 & 16 & 0.1 & .015 & .02 & .085 & .933 \\
& B2 & 16 & 0.2 & .016 & .02 & & \\
\hline Total & B1 & 16 & 52.09 & 2.40 & 1.14 & 3.14 & .755 \\
& B2 & 16 & 40.79 & 2.27 & 1.14 & & \\
\hline p<.05* & & & & & & &
\end{tabular}

As shown, no significant differences were found as regards the overall amount of time each proficiency group devoted to complete the task. In examining the time devoted by pairs to complete each move of the conversation, thereby focusing on opening, precomplaint, complaint, post-complaint and closing, results revealed that no significant differences were found in each move across the two proficiency levels. Therefore, these results appeared to indicate that the time that participants devoted to complete the task and each specific move did not reveal any significant difference.

Participants' utterances was also examined by exploring first the amount of words that each role elicited without distinguishing proficiency level, then the number of words according to participants' pair and proficiency level, and finally, data was analysed focusing on participants' proficiency level and role.

The first aspect examined was whether participants' role, the complainer and the complainee, exhibited any statistical difference as regards the number of word produced. In this case, the variable of proficiency was not taken into account as the purpose was to see first participants' production according to their role. Results as regards

$16 \quad \mathrm{~m}$ (minutes) 
the total amount of words indicated that no statistical difference between the complainer and the complainee. See Table 25 for a summary of the statistical results.

Table 25. Distribution of frequency of words in moves per participants' role

\begin{tabular}{|c|c|c|c|c|c|c|c|}
\hline Move & Group & $N$ & $w$ & Group & $S D$ & $t$ & $p$ \\
\hline \multirow[t]{2}{*}{ Opening } & Complainer & 32 & 90 & 2.81 & 4.07 & \multirow{2}{*}{.490} & \multirow{2}{*}{.626} \\
\hline & Complainee & 32 & 76 & 2.37 & 2.98 & & \\
\hline \multirow{2}{*}{$\begin{array}{l}\text { Pre- } \\
\text { complaint }\end{array}$} & Complainer & 32 & 449 & 14.03 & 13.55 & \multirow[b]{2}{*}{2.359} & \multirow{2}{*}{$.021^{*}$} \\
\hline & Complainee & 32 & 232 & 7.25 & 8.98 & & \\
\hline \multirow{2}{*}{$\begin{array}{l}\text { Topic } \\
\text { negotiation }\end{array}$} & Complainer & 32 & 2371 & 74.09 & 58.43 & \multirow[b]{2}{*}{1.003} & \multirow[b]{2}{*}{.320} \\
\hline & Complainee & 32 & 3609 & 112.78 & 210.27 & & \\
\hline \multirow{2}{*}{$\begin{array}{l}\text { Post- } \\
\text { complaint }\end{array}$} & Complainer & 32 & 1021 & 31.90 & 44.39 & \multirow{2}{*}{.959} & \multirow{2}{*}{.341} \\
\hline & Complainee & 32 & 1475 & 46.09 & 70.97 & & \\
\hline \multirow[t]{2}{*}{ Closing } & Complainer & 32 & 52 & 1.62 & 2.66 & \multirow{2}{*}{.730} & \multirow{2}{*}{.468} \\
\hline & Complainee & 32 & 38 & 1.19 & 2.10 & & \\
\hline \multirow[t]{2}{*}{ Total } & Complainer & 32 & 3983 & 124.47 & 91.16 & \multirow[b]{2}{*}{1.052} & \multirow{2}{*}{.297} \\
\hline & Complainee & 32 & 5430 & 169.69 & 225.29 & & \\
\hline
\end{tabular}

Concerning each move, a statistical difference was found in the case of the pre-complaint move, $\mathrm{p}<.05^{*}$ between the complainer and the complainee, thereby revealing that the complainer employed slightly more words than the complainee. This might be attributed to the fact that the complainer was the participant who approached the complainee to prepare him/her for the forthcoming move involving a complaint. While the complainer might have provided information in the pre-complaint move to contextualise the situation, the complainee did not need to provide much information in such move. In the remaining moves, no statistical differences were found. These results could be related to the fact that the two participants, regardless the role they performed, were engaged in a conflicting situation involving FTAs and both parts were expected to express themselves to restore the situation.

This was then followed by an analysis of data according to participants' proficiency level considering the words elicited by each pair in each proficiency group. In Table 26 a summary of the statistical results is presented. 
Table 26. Distribution of frequency of words in moves per proficiency level

\begin{tabular}{lccccccc}
\multicolumn{1}{c}{ Move } & Group & $N$ & $w$ & $M$ & $S D$ & $t$ & $p$ \\
Opening & B1 & 32 & 91 & 2.84 & 4.20 & .560 & .577 \\
& B2 & 32 & 75 & 2.34 & 2.79 & & \\
\hline Pre- & B1 & 32 & 331 & 10.34 & 11.23 & .198 & .844 \\
complaint & B2 & 32 & 350 & 10.94 & 12.718 & & \\
\hline Topic & B1 & 32 & 2357 & 73.66 & 60.50 & 1.026 & .309 \\
negotiation & B2 & 32 & 3623 & 113.22 & 209.61 & & \\
\hline Post- & B1 & 32 & 577 & 18.03 & 37.62 & 3.012 & $.004^{*}$ \\
complaint & B2 & 32 & 1919 & 59.97 & 69.21 & & \\
\hline Closing & B1 & 32 & 47 & 1.47 & 2.61 & .208 & .386 \\
& B2 & 32 & 43 & 1.35 & 2.18 & & \\
\hline Total & B1 & 32 & 3403 & 106.34 & 73.96 & 1.935 & .057 \\
& B2 & 32 & 6010 & 187.81 & 226.33 & & \\
\hline p<.05 & & & & & & &
\end{tabular}

Concerning the total amount of words, results revealed no statistical difference between the B1 group and the B2 group. Therefore, differently to Moskala-Gallaher (2011), who found differences as regards the number of words in complaints across proficiency levels. However, in observing each particular move, results showed that a statistical difference was found in the case of the post-complaint $\mathrm{p}<.05^{*}$, where the amount of words in the B2 group was greater than that of the B1 group. This result could be associated to participants' interest in repairing the situation that could have made them utter more words and turns, thereby revealing sociopragmatic sensitivity towards the complainee.

In the remaining moves no statistical differences were found. The lack of statistical differences in the moves of opening, precomplaint, topic negotiation, and closing indicates that both groups performed a similar amount of words in these moves. By contrast, in the case of the post-complaint move, results revealed that participants in the $\mathrm{B} 2$ level employed more words than the $\mathrm{B} 1$, which might be associated to participants' attempt to repair the situation.

After this general analysis, a statistical analysis focusing on participants' role and proficiency level groups was also conducted. Table 27 presents a summary of the statistical results. 
Table 27 Frequency of words per moves by participants' role and proficiency level

\begin{tabular}{|c|c|c|c|c|c|c|c|}
\hline Move & Group & $N$ & $w$ & $M$ & $S D$ & $t$ & $p$ \\
\hline \multicolumn{8}{|c|}{ Complainer } \\
\hline \multirow[t]{2}{*}{ Opening } & B1 & 16 & 53 & $3 \cdot 31$ & 5.22 & .688 & .497 \\
\hline & B2 & 16 & 37 & 2.31 & 2.55 & & \\
\hline \multirow{2}{*}{$\begin{array}{l}\text { Pre- } \\
\text { complaint }\end{array}$} & $\mathrm{B} 1$ & 16 & 210 & 13.12 & 12.42 & .373 & .712 \\
\hline & B2 & 16 & 239 & 14.94 & 14.95 & & \\
\hline \multirow{2}{*}{$\begin{array}{l}\text { Topic } \\
\text { negotiation }\end{array}$} & B1 & 16 & 1150 & 71.87 & 64.66 & .439 & .834 \\
\hline & $\mathrm{B} 2$ & 16 & 1221 & 76.31 & 53.52 & & \\
\hline \multirow{2}{*}{$\begin{array}{l}\text { Post- } \\
\text { complaint }\end{array}$} & B1 & 16 & 288 & 18.00 & 39.04 & .056 & .076 \\
\hline & $\mathrm{B} 2$ & 16 & 733 & 45.81 & 46.22 & & \\
\hline \multirow[t]{2}{*}{ Closing } & $\mathrm{B} 1$ & 16 & 27 & 1.69 & 2.87 & .621 & .897 \\
\hline & $\mathrm{B} 2$ & 16 & 25 & 1.56 & 2.53 & & \\
\hline \multirow[t]{2}{*}{ Total } & B1 & 16 & 1728 & 108.00 & 82.99 & 1.02 & .315 \\
\hline & $\mathrm{B} 2$ & 16 & 2255 & 140.94 & 98.53 & & \\
\hline \multicolumn{8}{|c|}{ Complainee } \\
\hline \multirow[t]{2}{*}{ Opening } & B1 & 16 & 38 & 2.37 & 2.96 & .000 & 1.000 \\
\hline & $\mathrm{B} 2$ & 16 & 38 & 2.37 & 3.09 & & \\
\hline \multirow{2}{*}{$\begin{array}{l}\text { Pre- } \\
\text { complaint }\end{array}$} & $\mathrm{B} 1$ & 16 & 121 & 7.56 & 9.47 & .194 & .848 \\
\hline & $\mathrm{B} 2$ & 16 & 111 & 6.93 & 8.74 & & \\
\hline \multirow{2}{*}{$\begin{array}{l}\text { Topic } \\
\text { negotiation }\end{array}$} & B1 & 16 & 1207 & 75.44 & 58.09 & 1.00 & .323 \\
\hline & B2 & 16 & 2402 & 150.12 & 291.60 & & \\
\hline \multirow{2}{*}{$\begin{array}{l}\text { Post- } \\
\text { complaint }\end{array}$} & B1 & 16 & 289 & 18.06 & 37.41 & 2.40 & $.023^{*}$ \\
\hline & $\mathrm{B} 2$ & 16 & 1186 & 74.12 & 85.64 & & \\
\hline \multirow[t]{2}{*}{ Closing } & B1 & 16 & 20 & 1.25 & 2.40 & .166 & .870 \\
\hline & $\mathrm{B} 2$ & 16 & 18 & 1.12 & 1.82 & & \\
\hline \multirow[t]{2}{*}{ Total } & B1 & 16 & 1675 & 104.69 & 66.41 & 1.679 & .103 \\
\hline & $\mathrm{B} 2$ & 16 & 3755 & 234.69 & 302.44 & & \\
\hline
\end{tabular}

Concerning the complainer, results did not reveal a statistical difference as regards the total amount of words in the two proficiency levels, thereby not indicating a statistical difference across the two proficiency levels. In examining each particular move, no statistical differences were either found. In the case of the complainee, similar results were found when comparing the total amount of words across the two proficiency levels since a statistical difference was not found. Likewise, similar results were encountered in the opening, precomplaint, and closing since any significant difference was observed. Conversely, in the case of post-complaint, a significant difference was found $\mathrm{p}<.05^{*}$, showing that the complainee of B2 group elicited more words than the B1 group in that particular move. This result could be attributed to participants' attempt to repair the situation, as well as participants' linguistic disposal of resources to elicit more words in 
the post-complaint move, which is an essential part of the complaint move.

Hence, as shown, in this particular case, results seemed to suggest that when comparing the two proficiency groups, the B2 group elicited more words than the B1 group in the post-complaint. In examining each particular move according to participants' proficiency level and role, results appeared to indicate that a statistical difference was also observed in the case of the postcomplaint, indicating that the $\mathrm{B} 2$ complainee performed more words than the B1 complainee. This result might be related to the fact that the complainee seemed to have elicited more words to solve the problem as well as to the linguistic resources that the B2 group had at their disposal.

In this section I have presented the results as regards the structure of the conversation by analysing the moves, turns, whether participants repaired or not the situation, and the time devoted to complete the task and the total words uttered. In what follows, I address the results of the sequence organisation.

\subsubsection{Sequence organisation}

This section focuses on the discourse functions performed by the complainer and the responses to complaints elicited by the complainee to complete the spoken task. The scenario chosen for this study involved two speakers of equal status, who were close friends (social distance) and a severity of offence classified as high. It is important to note that any situation in which the complainer and the complainee did not elicit utterances involving a complaint sequence or a response to a complaint sequence was found in the data. In a real context, however, participants could decide whether to opt out and therefore not perform a complaint or express his/her feelings. Both situations would involve different consequences. Non-performing a 
complaint could be seen as polite, but at the same time it might indicate that the complainer is not relief from such problem and that he/she is affected by the grievance (Olshtain and Weinbach, 1993). Performing the complaint would serve to express displeasure towards a particular situation, but special care should be taken to perform a complaint as doing it without using appropriate mitigators could damage speakers' relationship. When uttering a complaint, the complainer might employ less direct discourse functions and use mitigators inasmuch as possible in order to be able to express his/her feelings and restore harmony. By the same token, when receiving a complaint the complainee could accept, decline it or disregard it (Laforest, 2002) and this choice may affect speakers' interaction and repair. In the following section, I focus on the results of the complainer and the complainee.

\subsubsection{Complainer}

The complaint discourse functions elicited by the complainer were analysed following the structure of complaint sequences presented in Chapter 2 Section 2.1.2. As indicated, the proposed structure should be regarded as a starting point to analyse complaint sequences and it should be modified if necessary to account for a whole representation of the complaint discourse functions elicited. As reported, a complaint may be divided into different moves (opening, pre-complaint, topic negotiation, post-complaint, and closing) as well as into different possible discourse functions. In this section, I first present the results as regards the overall use of discourse functions in each move, and then I focus on the specific discourse functions performed. Notice that each turn in the conversation may express more than one discourse function, thus the analysis was done on the 446 discourse functions performed by the complainers.

The statistical analysis of the total amount of discourse functions that conform the five moves (see Table 28 for a summary of 
the statistical results) revealed that a statistical difference was found in the case of post-complaint, $\mathrm{p}<.05^{*}$, indicating that the $\mathrm{B} 2$ group showed more discourse functions than the B1 group in that particular move. Nevertheless, no statistical results were found in the case of opening, pre-complaint, topic negotiation, and closing. These results seemed to suggest that the variable of proficiency only affected the post-complaint move, where the repair might take place.

Table 28. Frequency of complainer's discourse functions per moves and proficiency level

\begin{tabular}{|c|c|c|c|c|c|c|c|}
\hline Move & Group & $N$ & $f$ & $M$ & $S D$ & $t$ & $p$ \\
\hline \multirow[t]{2}{*}{ Opening } & B1 & 16 & 12 & .75 & .58 & \multirow[t]{2}{*}{.878} & \multirow[t]{2}{*}{.387} \\
\hline & B2 & 16 & 9 & .56 & .63 & & \\
\hline \multirow{2}{*}{$\begin{array}{l}\text { Pre- } \\
\text { complaint }\end{array}$} & B1 & 16 & 27 & 1.68 & 1.30 & \multirow[t]{2}{*}{.136} & \multirow[t]{2}{*}{.892} \\
\hline & B2 & 16 & 28 & 1.75 & 1.30 & & \\
\hline \multirow{2}{*}{$\begin{array}{l}\text { Topic } \\
\text { negotiation }\end{array}$} & B1 & 16 & 106 & 6.62 & 5.43 & \multirow[t]{2}{*}{.158} & \multirow[t]{2}{*}{.875} \\
\hline & B2 & 16 & 102 & 6.37 & 3.24 & & \\
\hline \multirow{2}{*}{$\begin{array}{l}\text { Post- } \\
\text { complaint }\end{array}$} & B1 & 16 & 50 & 3.12 & 2.68 & \multirow{2}{*}{2.436} & \multirow[t]{2}{*}{$.023^{*}$} \\
\hline & B2 & 16 & 95 & 5.94 & 3.85 & & \\
\hline \multirow[t]{2}{*}{ Closing } & B1 & 16 & 9 & .56 & .73 & \multirow[t]{2}{*}{.280} & \multirow[t]{2}{*}{.781} \\
\hline & B2 & 16 & 8 & .50 & .52 & & \\
\hline \multirow[t]{2}{*}{ Total } & B1 & 16 & 204 & 12.75 & \multirow[t]{2}{*}{7.15} & \multirow[t]{2}{*}{.983} & \multirow[t]{2}{*}{.333} \\
\hline & B2 & 16 & 242 & 14.93 & & & \\
\hline
\end{tabular}

Finding that both groups seemed to exhibit a similar amount of discourse function in the opening, pre-complaint, topic negation and closing may reveal that participants showed a similar pragmatic ability in the structure of the interaction except for the postcomplaint move. These results are to some extent in contrast with AlGahtani and Roever's (2012) finding, which suggested that only some advanced learners showed pragmatic ability in the structure of the interaction.

Concerning the post-complaint move, as revealed in the retrospective verbal reports, it might be suggested that repairing the grievance could be more challenging for lower proficiency groups due to linguistic limitations and the complexity that repairing the situation would involve (Taguchi, 2007). In line with this, it is important to note that it was found a significant difference in the case 
of repair (see Section 5.1.1.1), revealing that the B2 group repaired more than the B1 group. This specific result might be associated to participants' disposal of linguistic resources since repairing would, for example, require participants' use of more discourse functions; even though participants at the B1 level may also have linguistic resources to repair the situation. Nevertheless, it should be noted that the B1 group was aware of the importance of repairing the damaged caused, but, as shown in the retrospective verbal reports, some participants (7/16) indicated having linguistic problems that prevent them from conveying the desired message.

An important aspect to take into account is participants' perception of offence as this would also affect the choice of the pragmalinguistic realisations in the conversation. The influence of social distance between participants was also noted by Olshtain and Weinbach (1987) who indicated that variables such as the level of frustration and the potential repair could affect participants' selection of discourse functions. In this study, the complainer, although in a position of power due to the grievance caused by the complainee, was not expected to address the complainee in a nonpolite manner. Rather, in order to repair the situation and avoid having problems with the interlocutor (Olshtain and Weinbach, 1993), the complainer had to employ specific discourse functions to show that he/she was not comfortable with the situation, and if possible, they should solve the problem. It might be suggested that the level of offence and the social distance between the complainer and the complainee could have affected participants' interaction and the communicative purpose since the B2 level appeared to employed more discourse functions in the post-complaint and tended to repair the offence more frequently than the B1 group. In line with this, it could be suggested that the $\mathrm{B} 2$ group had more linguistic resources to elaborate more discourse functions in the post-complaint move.

Focusing particularly on the post-complaint move, the retrospective verbal reports indicated that all the participants found 
that a damaged had been committed since it involved a situation in which a close friend was not invited to a party. This result showed that they perceived the situation as a high offence. Moreover, the retrospective verbal reports revealed that all the participants indicated that if the situation was real, they would feel disappointed and even hurt. In this sense, a B1 female participant uttered "if you are not invited to the party, you feel bad, and if she does so there must be a reason ${ }^{17}$ ", showing that the situation would hurt her not only because you are not invited but also because there must a kind of problem between them and their relationship could be at risk. Nevertheless, the B2 group repaired and employed more discourse functions in the post-complaint than the B1. An explanation for this would be participants' disposal of linguistic resources to complete the task and repair the situation. Hence, more advanced participants appeared to have more linguistic resources to express themselves.

The second statistical analysis conducted as regards complainer's performance focused on the typology of discourse functions employed in each move. The results (see Table 29 for a summary of the statistical results) showed that statistical differences were found in the case of the performance of: allusion to the offensive act $\left(\mathrm{p}<.001^{* *}\right)$, in the topic negotiation move, and in dissatisfaction $\left(\mathrm{p}<.05^{*}\right)$ and acceptance $\left(\mathrm{p}<.05^{*}\right)$ in the post-complaint move. These results seemed to indicate that the $\mathrm{B} 2$ group produced more discourse functions of these types than the B1 group.

${ }_{17} \quad$ Free translation from: "si no te invita te sientes mal y si no te invita es por algo". 
Chapter 5: Results and discussion

Table 29. Typology and frequency of complainer's discourse functions per moves and proficiency level

\begin{tabular}{|c|c|c|c|c|c|c|c|}
\hline $\begin{array}{l}\text { Discourse } \\
\text { function }\end{array}$ & Group & $N$ & $f$ & $M$ & $S D$ & $t$ & $p$ \\
\hline \multicolumn{8}{|c|}{ Opening } \\
\hline \multirow[t]{2}{*}{ Greeting } & B1 & 16 & 12 & .75 & .57 & \multirow[t]{2}{*}{.878} & \multirow[t]{2}{*}{.387} \\
\hline & $\mathrm{B} 2$ & 16 & 9 & .56 & .62 & & \\
\hline \multicolumn{8}{|c|}{ Pre-complaint } \\
\hline \multirow[t]{2}{*}{ Preparation } & B1 & 16 & 7 & .44 & .51 & \multirow[t]{2}{*}{1.265} & \multirow[t]{2}{*}{.216} \\
\hline & $\mathrm{B} 2$ & 16 & 11 & .69 & .60 & & \\
\hline \multirow[t]{2}{*}{ Acceptance } & B1 & 16 & 1 & .06 & .25 & \multirow[t]{2}{*}{1.000} & \multirow[t]{2}{*}{.325} \\
\hline & $\mathrm{B} 2$ & 16 & $\mathrm{O}$ & .00 & .00 & & \\
\hline \multirow[t]{2}{*}{ Request } & B1 & 16 & 5 & .31 & .48 & \multirow[t]{2}{*}{.361} & \multirow[t]{2}{*}{.721} \\
\hline & $\mathrm{B} 2$ & 16 & 6 & .38 & .50 & & \\
\hline \multirow[t]{2}{*}{ Evaluation } & B1 & 16 & 1 & .06 & .25 & \multirow[t]{2}{*}{1.000} & \multirow[t]{2}{*}{.325} \\
\hline & $\mathrm{B} 2$ & 16 & $\mathrm{O}$ & .00 & .00 & & \\
\hline \multirow{2}{*}{$\begin{array}{l}\text { Allusion to the } \\
\text { offensive act }\end{array}$} & B1 & 16 & 9 & .56 & .51 & \multirow[t]{2}{*}{.616} & .542 \\
\hline & $\mathrm{B} 2$ & 16 & 7 & .44 & .63 & & \\
\hline Dissatisfaction & $\mathrm{B} 1$ & 16 & 4 & .25 & .45 & .000 & 1.000 \\
\hline & $\mathrm{B} 2$ & 16 & 4 & .25 & .45 & & \\
\hline & & & op & otiati & & & \\
\hline Allusion to the & B1 & 16 & 6 & .37 & .72 & 3.935 & $.000^{* *}$ \\
\hline offensive act & $\mathrm{B} 2$ & 16 & 22 & 1.37 & .72 & & \\
\hline Dissatisfaction & B1 & 16 & 20 & 1.25 & .93 & 1.431 & .163 \\
\hline & $\mathrm{B} 2$ & 16 & 27 & 1.69 & .79 & & \\
\hline Blame & $\mathrm{B} 1$ & 16 & 7 & .44 & .73 & .808 & .426 \\
\hline & $\mathrm{B} 2$ & 16 & 4 & .37 & .88 & & \\
\hline Justification & $\mathrm{B} 1$ & 16 & 3 & .19 & .54 & .957 & .346 \\
\hline & $\mathrm{B} 2$ & 16 & 7 & .44 & .89 & & \\
\hline Disagreement & B1 & 16 & 3 & .19 & .75 & .832 & 412 \\
\hline & $\mathrm{B} 2$ & 16 & 6 & .37 & .50 & & \\
\hline Evaluation & B1 & 16 & 4 & .25 & .58 & .355 & .725 \\
\hline & B2 & 16 & 3 & .19 & .40 & & \\
\hline Accusation & $\mathrm{B} 1$ & 16 & 11 & .69 & .70 & .696 & .492 \\
\hline & $\mathrm{B} 2$ & 16 & 8 & .50 & .82 & & \\
\hline Request & $\mathrm{B} 1$ & 16 & 18 & 1.12 & 1.20 & 2.024 & .052 \\
\hline & $\mathrm{B} 2$ & 16 & 7 & .44 & .63 & & \\
\hline Gratitude & B1 & 16 & 3 & .19 & .40 & 1.861 & .073 \\
\hline & $\mathrm{B} 2$ & 16 & $\mathrm{O}$ & .00 & .00 & & \\
\hline Acceptance & B1 & 16 & 7 & .43 & .63 & .635 & .530 \\
\hline & $\mathrm{B} 2$ & 16 & 4 & .25 & 1.00 & & \\
\hline Joke & B1 & 16 & 3 & .19 & .75 & 1.000 & .325 \\
\hline & $\mathrm{B} 2$ & 16 & $\mathrm{O}$ & .00 & .00 & & \\
\hline Empathy & B1 & 16 & 1 & .06 & .25 & 1.000 & .325 \\
\hline & $\mathrm{B} 2$ & 16 & $\mathrm{O}$ & .00 & .00 & & \\
\hline Refusal & B1 & 16 & 7 & .44 & 1.26 & .357 & .723 \\
\hline & $\mathrm{B} 2$ & 16 & 5 & .31 & .60 & & \\
\hline Suggestion & $\mathrm{B} 1$ & 16 & 3 & .19 & .54 & 1.379 & .178 \\
\hline & B2 & 16 & $\mathrm{O}$ & .00 & .00 & & \\
\hline Interrogation & B1 & 16 & 9 & .56 & .72 & .785 & .439 \\
\hline & $\mathrm{B} 2$ & 16 & 6 & .37 & .62 & & \\
\hline Not taken it & B1 & 16 & 1 & .06 & .25 & .000 & 1.000 \\
\hline seriously & $\mathrm{B} 2$ & 16 & 1 & .06 & .25 & & \\
\hline Warn & $\mathrm{B} 1$ & 16 & $\mathrm{O}$ & .00 & .00 & 1.464 & .154 \\
\hline & $\mathrm{B} 2$ & 16 & 2 & .12 & .34 & & \\
\hline
\end{tabular}




\begin{tabular}{|c|c|c|c|c|c|c|c|}
\hline \multicolumn{8}{|c|}{ Post-complaint } \\
\hline \multirow[t]{2}{*}{ Dissatisfaction } & B1 & 16 & 4 & .25 & .44 & 2.300 & $.029 *$ \\
\hline & B2 & 16 & 17 & 1.06 & 1.34 & & \\
\hline \multirow[t]{2}{*}{ Disagreement } & B1 & 16 & 3 & .18 & .75 & .415 & .681 \\
\hline & B2 & 16 & 4 & .06 & .25 & & \\
\hline \multirow[t]{2}{*}{ Evaluation } & B1 & 16 & 1 & .06 & .25 & 1.643 & .111 \\
\hline & B2 & 16 & 6 & .37 & .72 & & \\
\hline \multirow{2}{*}{ Request } & B1 & 16 & 15 & .94 & 1.06 & .202 & .841 \\
\hline & B2 & 16 & 16 & 1.00 & .63 & & \\
\hline \multirow{2}{*}{ Acceptance } & B1 & 16 & 7 & .44 & .51 & 3.652 & $.001^{*}$ \\
\hline & B2 & 16 & 32 & 2.00 & 1.63 & & \\
\hline \multirow[t]{2}{*}{ Gratitude } & B1 & 16 & 5 & .31 & .49 & .799 & .431 \\
\hline & B2 & 16 & 3 & .18 & .40 & & \\
\hline \multirow[t]{2}{*}{ Joke } & B1 & 16 & 3 & .19 & .75 & .632 & .532 \\
\hline & B2 & 16 & 1 & .06 & .25 & & \\
\hline \multirow[t]{2}{*}{ Empathy } & B1 & 16 & 4 & .25 & .44 & .000 & 1.000 \\
\hline & B2 & 16 & 4 & .25 & .44 & & \\
\hline \multirow[t]{2}{*}{ Refusal } & B1 & 16 & 3 & .19 & .40 & .681 & .501 \\
\hline & B2 & 16 & 6 & .37 & 1.02 & & \\
\hline \multirow[t]{2}{*}{ Suggestion } & B1 & 16 & 3 & .19 & .40 & .000 & 1.000 \\
\hline & $\mathrm{B} 2$ & 16 & 3 & .19 & .75 & & \\
\hline \multirow[t]{2}{*}{ Warn } & B1 & 16 & 2 & .12 & .34 & .473 & .640 \\
\hline & B2 & 16 & 3 & .19 & .75 & & \\
\hline \multicolumn{8}{|c|}{ Closing } \\
\hline \multirow{2}{*}{$\begin{array}{l}\text { Terminal } \\
\text { exchange }\end{array}$} & B1 & 16 & 9 & .56 & .72 & .280 & .781 \\
\hline & B2 & 16 & 8 & .50 & .51 & & \\
\hline
\end{tabular}

In the remaining discourse functions, significant differences were not found, albeit the level of directness between the B1 and B2 group tended to vary, thereby showing more indirect discourse functions in the B2 group than in the B1 group, who seemed to mitigate in some cases the force of their utterances by means of downgraders (Trosborg, 1995). According to Trosborg (1995), downgraders may serve to mitigate the impact of the complaint. This particular aspect, however, was not examined from a quantitative perspective in the present study.

The use of allusion to the offensive act in the complaint may be attributed to the complainers' interest in showing the complainees, in an indirect manner, that an offence has been committed. Specifically, this discourse function could be seen as an indirect way of referring to the offensive grievance without directly accusing or blaming the complainee, although it could involve that the complainee is responsible. In the data of the present study, the B2 group tended to employ this discourse function to show that an offence was 
committed and that the complainee was responsible for the grievance. Nevertheless, no implicit reference to the complainee was made in the utterance, thereby showing an indirect utterance. It is interesting to observe that the B2 level showed higher frequency of use since it could be an indicator of complainer's sociopragmatic sensibility towards the complainee (B1 $f=6$, B2 $f=22$ ). These results appear to be in line with Moskala-Gallaher (2011) who found that more advanced learners seemed to be less direct than lower level learners. Example 5 and Example 6 illustrate the use of this particular discourse function.

Example 5. B1 participants: Use of allusion to the offensive act

\begin{tabular}{|c|c|c|c|}
\hline Line & Turn & Participant & \\
\hline \multicolumn{4}{|c|}{$\begin{array}{l}\text { A: Complainer and B: Complainee } \\
\text { Topic neqotiation }\end{array}$} \\
\hline \multicolumn{4}{|c|}{ Topic negotiation } \\
\hline 1 & 6 & B_\#11 & $\begin{array}{l}\text { and I've heard that one of my } \\
\text { favourite music groups will be } \\
\text { there }\end{array}$ \\
\hline 2 & 7 & A_\#11 & can you repeat please? \\
\hline 3 & 8 & A_\#11 & $\begin{array}{l}\text { I've heard one of my favourite } \\
\text { music groups will be there }\end{array}$ \\
\hline 4 & & B_\#11 & yes <B11:BC_AGREE $<$ yes $>/ /$ BC $>$ \\
\hline 5 & & A_\#11 & and all our friends are invited \\
\hline 6 & & B_\#11 & yes <B11:BC_AGREE $<$ yes $>/ /$ BC $>$ \\
\hline 7 & & A_\#11 & why didn’t you invite me? \\
\hline
\end{tabular}

Example 6. B2 participants: Use of allusion to the offensive act

\begin{tabular}{|c|c|c|c|}
\hline Line & Turn & Participan & \\
\hline \multicolumn{4}{|c|}{ A: Complainer and B: Complainee } \\
\hline 1 & 5 & A_\#26 & $\begin{array}{l}\text { er }<\text { A26:F_PAUSE } \\
<\text { er }>/ / \text { F_PAUSE }>\text { I heard to } \\
\text { Maria and Andrea that you are } \\
\text { organising a party er } \\
<\text { A26:F_PAUSE } \\
<\text { er }>/ / \text { F_PAUSE }>\text { next } \\
<\text { A26:F_PAUSE } \\
<\text { er }>/ / \text { F_PAUSE }>\text { Monday and all } \\
\text { people that I know are invited but } \\
\text { I don't receive some information }\end{array}$ \\
\hline
\end{tabular}


2

3
6

7
B_\#26

A_\#26

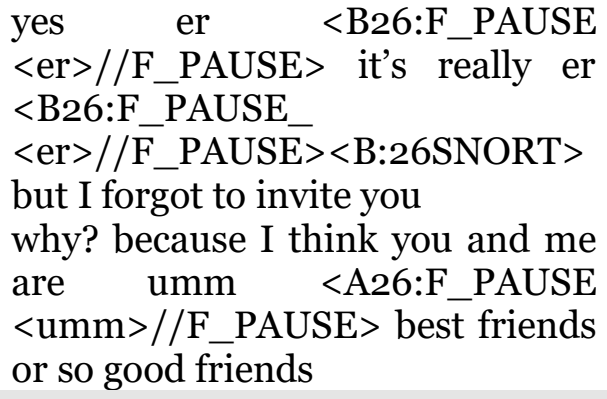

These two examples might serve to illustrate how participants at different levels employed the discourse function of allusion to the offensive act. As observed in the examples, the acknowledgment of a particular problem was expressed. In the case of the B1 participant (Example 5), the complainer started alluding to the offensive and finally she uttered an interrogation in the negative form, which is considered as less polite than positive questions (Brown and Levinson, 1978, 1987). This approach is also supported by Clark and Schunk (1980) who argued that the use of negative questions was rated significantly lower on the politeness scale than their positive counterparts. Hence, although the complainer was initially using a more indirect discourse function, she uttered a negative question, which explicitly involved that the complainee was responsible for that grievance. In the example of the B2 pair (Example 6), the complainer also alluded to the offensive act and immediately the complainee reacted to such utterance admitting that she was right. It is important to note that complainee's reaction is of paramount interest since complainers' utterances were constructed also according to the responses complainees elicited. In the $\mathrm{B} 1$ example, the complainee employed backchannels to show attention, while in the B2 level complainee immediately reacted to the complainer's utterance. The B2 complainer was also interesting in knowing why she was not invited to the party, but instead of uttering a rather threatening discourse function as the $\mathrm{B} 1$ complainer did, she performed a more indirect utterance. Thereby, the level of directness was also observed in these particular examples, showing that the B1 complainer, albeit 
also employing indirect discourse functions, tended be more direct than the B2 complainer.

In addition to this, results also showed that the B2 group outperformed the B1 group in the realisation of dissatisfaction and acceptance in the post-complaint. Concerning dissatisfaction, it might be indicated that this discourse function involves the expression of feelings towards a particular act or behaviour and its use could reveal sociopragmatic knowledge since the complainer might decide to use this discourse function instead of another such as accusation, which is more face threatening (Chen, et al., 2011). The statistical result suggested that B2 performed this specific discourse function more frequently than the B1 group (B1 $f=4, \mathrm{~B} 2 f=17$ ), which, as in the case of allusion to the offensive act, might be associated to participants' sociopragmatic sensibility towards the complainee, thereby indicating that the B2 group appeared to be more aware of the sociopragmatic condition of the situation than the B1 group. Example 7 and Example 8 show the use of dissatisfaction.

Example 7. B1 participants: Use of dissatisfaction

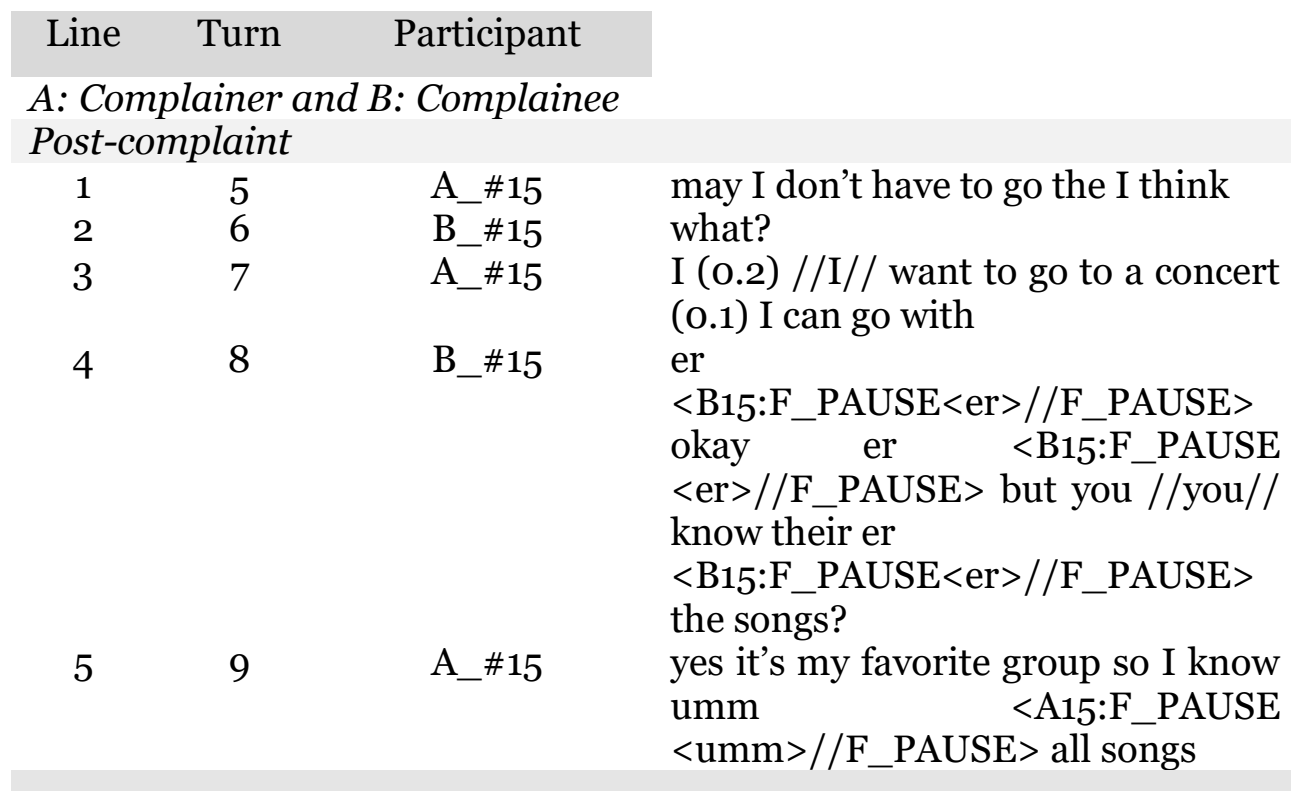


Example 8. B2 participants: Use of dissatisfaction

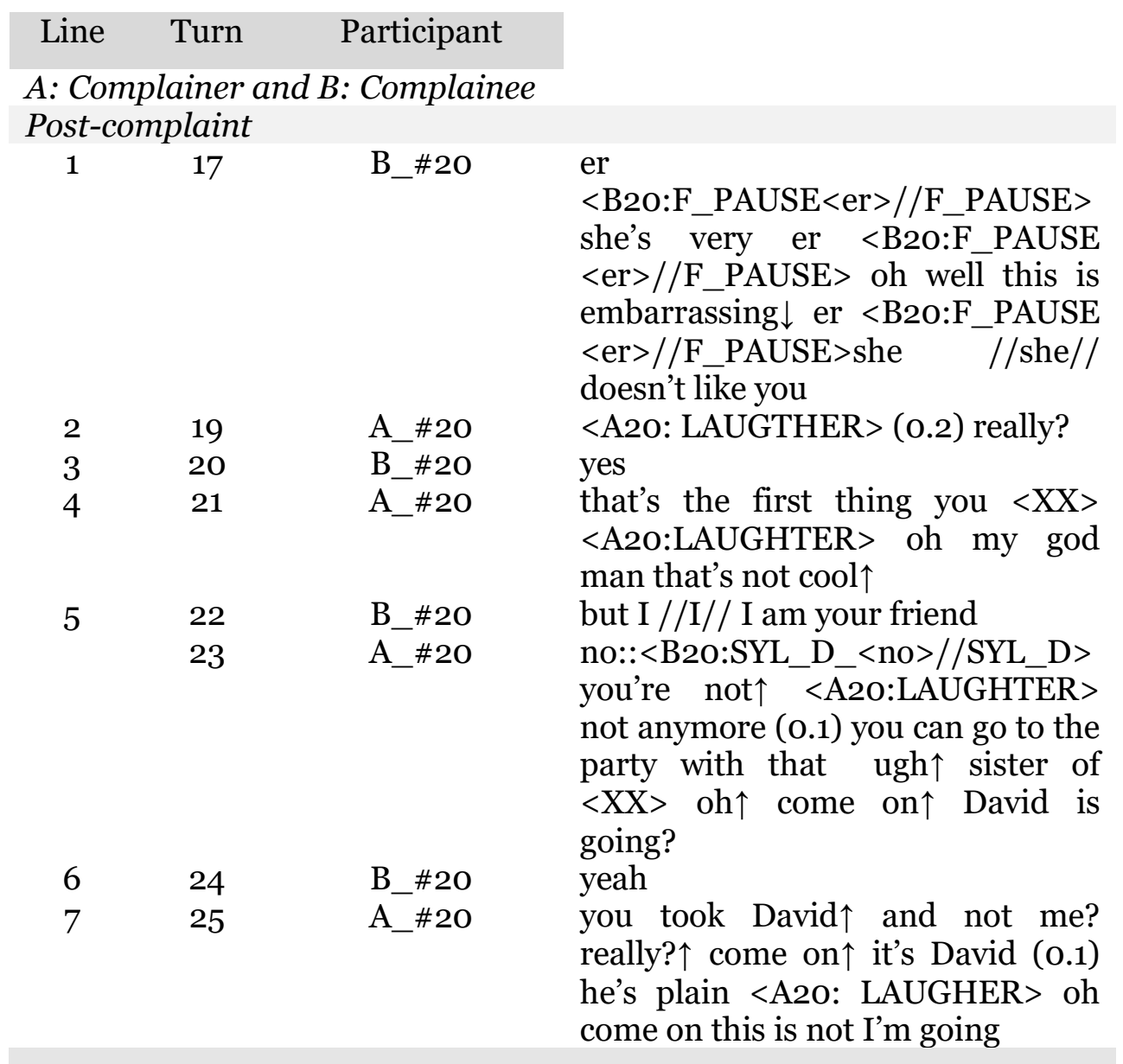

Example 7 and Example 8 evidence the use of the discourse function of dissatisfaction in the two proficiency groups. Example 7 is an extract of the B1 level in which the complainer showed dissatisfaction when, after having revealed interest in going to the party. Example 8 involves two male participants that appeared to have solved the problem, but then, in the post-complaint move, the complainee revealed further information as regards the reasons why the complainer was not invited. Considering the complainee's utterance, the complainer showed his dissatisfaction not only towards the act of not being invited to the party, but also towards the fact that he was disappointed. These two examples serve to illustrate how the complainers performed dissatisfaction in the complaint 
conversation, which was statistically significant in the case of the B2 group.

As regards acceptance, it was shown that the B2 group produced more instances of this particular discourse function (B1 $f=7, \mathrm{~B} 2$ $f=32$ ). Although typically associated to the role of the complainee (Laforest, 2002), the discourse function of acceptance was also observed in the case of the complainer in the pre-complaint move, topic negotiation move and post-complaint move. However, it was found to be statistically significant in the post-complaint move, where the complainer and the complainee might negotiate the repair of the situation. Possibly, in an attempt to reach mutual understanding and repair the situation, complainers performed this particular discourse function in the post-complaint move, which perhaps allowed them to restore harmony. That is, the complainer appeared to accept some of the complainee's requirements in order to avoid damaging the relationship. Example 9 shows the use of acceptance in the post-complaint move.

Example 9. B2 participants: Use of acceptance

\begin{tabular}{|c|c|c|c|}
\hline Line & Turn & Participant & \\
\hline \multicolumn{4}{|c|}{ A: Complainer and B: Complainee } \\
\hline \multicolumn{4}{|c|}{ Post-complaint move } \\
\hline 1 & 9 & B_\#24 & $\begin{array}{l}=\text { the next party I invite } \\
\text { //invite// you }\end{array}$ \\
\hline 2 & 10 & A_\#24 & $\begin{array}{l}\text { yeah maybe but this party } \\
\text { that huge rock event that I } \\
\text { like is going to play }\end{array}$ \\
\hline 3 & 11 & B_\#24 & I don't know (o.1) sorry \\
\hline 4 & 12 & A_\#24 & $\begin{array}{l}\text { all right so keep it in mind I } \\
\text { really love partying }\end{array}$ \\
\hline 5 & 13 & B_\#24 & sorry it's impossible now \\
\hline 6 & 14 & A_\#24 & all right next time don't worry \\
\hline 7 & 15 & B_\#24 & next time I invite you \\
\hline 8 & 16 & A_\#24 & all right we're friends \\
\hline
\end{tabular}

In this example, the complainer assumed that her friend did not finally invite her to the party but in an attempt to repair the situation, 
the complainee provided her friend, the complainer, a solution that is accepted. Indeed, while the complainer could have continued discussing the grievance, she decided to accept and repair it.

It is important to note that the CA approach adopted in the study served to provide a broader picture of the performance of complaint discourse functions. The proposed structure of complaints was expanded in an attempt to show how participants performing the role of complainer expressed discourse functions across the two proficiency groups. The original structure involved: (1) preparation; (2) allusion to the offensive act; (3) dissatisfaction, (4) evaluation; (5) accusation; (6) blame; (7) request; and (8) gratitude. Data showed that other discourse functions could be included, namely those of: (9) acceptance, (10) interrogation (11) justification, (12) refusal, (13) suggestion, (14) empathy, (15) disagreement, (16) warn, (17) joke and (18) not taken it seriously. These discourse functions emerged in the data in the course of the conversation and although they might not be typically associated to the role of the complainer, they seem to be employed not only to approach the complaint itself but also to negotiate and repair the situation. Considering this, it might be suggested that following a CA for the analysis of ILP data, and particularly the speech act of complaints, might provide evidences of how speakers construct talk in and through the interaction (Kasper, 2006b).

Finally, it should be pointed out that the retrospective verbal reports were instrumental in gathering specific information as regards participants' performance. For example, it was found that all the participants would understand that repairing the situation would be ideal, but the act of repairing involves the use of more linguistic elements that might not be properly used by the lower proficiency group, although they may have them at their disposal. The retrospective verbal reports also showed that participants in both proficiency groups indicated that grammar and vocabulary limitations did prevent them, in some occasions, from expressing 
themselves properly. Grammar and vocabulary limitations were mainly noted by the B1 (7/16) group and a participant also indicated that he paid attention to pronunciation as he admitted having problems to pronounce words properly. In the case of the B2 group, grammar and vocabulary limitations were pointed by 4 out of 16 participants. Interestingly, issues of grammar correctness were frequently observed among the B2 group (3/16). More precisely, these participants pointed to the fact that they were focused on whether their utterances were grammatically correct, thereby paying attention to grammar correctness. Sociopragmatic features of the context of the complaint were reported by all the participants since they understood that an offensive act /an offence had been committed.

This section has been devoted to report the results as regards the complainer. In what follows, I focus on the perspective of the complainee.

\subsubsection{Complainee}

As in the case of the complainer, the complaint discourse functions performed by participants performing the role of the complainee were also analysed following the structure of complaint sequences presented in Chapter 2 Section 2.1.2. In reporting the results as regards the perspective of the complainee, it might be noted that their production of discourse functions was to some extend based on what the complainer elicited, as the complainee provided responses to the complainer' production. In this section I present the results of the overall use of the total of 442 discourse functions, and the distribution of the discourse functions in the moves.

The statistical analysis of the total amount of discourse functions elicited by complainees in each particular move showed no 
significant differences when comparing the B1 group and the B2 group (see Table 30 for a summary of the statistical results).

Table 30. Frequency of complainee's discourse functions per moves and proficiency level

\begin{tabular}{lccccccc}
\multicolumn{1}{c}{ Move } & Group & $N$ & $f$ & $M$ & $S D$ & $t$ & $p$ \\
Opening & B1 & 16 & 12 & .75 & .77 & .839 & .658 \\
& B2 & 16 & 10 & .65 & .80 & & \\
\hline Pre- & B1 & 16 & 25 & 1.62 & .61 & .221 & .827 \\
complaint & B2 & 16 & 27 & 1.7 & .94 & & \\
\hline Topic & B1 & 16 & 105 & 6.56 & 5.36 & .417 & .935 \\
negotiation & B2 & 16 & 103 & 6.43 & 2.82 & & \\
\hline Post- & B1 & 16 & 51 & 3.19 & 4.47 & 1.950 & .061 \\
complaint & B2 & 16 & 95 & 5.93 & 3.43 & & \\
\hline Closing & B1 & 16 & 7 & .43 & .512 & .000 & 1.000 \\
& B2 & 16 & 7 & .43 & .51 & & \\
\hline Total & B1 & 16 & 200 & 12.56 & 7.41 & .691 & .273 \\
& B2 & 16 & 242 & 5.42 & 5.4 & 1.116 & .273 \\
\hline
\end{tabular}

$\mathrm{p}<.05^{*}$

Results seemed to suggest that the variable of proficiency did not affect participants' overall realisation of discourse functions as regards the different pre-established moves. Participants' responses to complaints were somehow determined by the complainer, who approached the complainee so as to initiate a complaint communicative event. The complainee, differently to the complainer, provided responses to the complainer, who in a way was in a position of power since the complainee was the responsible for the grievance. Nevertheless, since only one situation was examined, it is complex to examine such behaviour in other contexts.

In receiving a complaint, the complainee could accept, decline it or disregard it (Laforest, 2002). In the simulated task used in this study, all the participants took part in the complaint since any participant decided to reject the complaint explicitly and stop talking. Rather, the complainee tried to provide responses to the complainer and reach mutual understanding if possible. Moreover, it should be noted that although the complainee may provide a response to the complainer in such face-threating situation, the complainee might respect the complainer's turns and once he/she has finalised the turn, 
the complainee may take decisions as regards the type of response. In this sense, politeness appears to be of paramount interest since in order to redress the situation both speakers need to behave politely, especially the complainer, if the purpose is that the complainee "performs some action of repair as a result of the complaint" (Olshtain and Weinbach, 1993: 108). Although it could be suggested that the way the complainer approached the complainee could have affected participants' responses to complaints, the complainee's assessment of the situation might have also influenced the repair of the grievance. That is, the complainer might decide to express his/her displeasure towards a particular action, but it is the complainee who could also decide whether continue talking about the issue or not, as well as whether some action of repair should be taken. Therefore, it is not only the complainer's responsibility, but both. It might be noted that that prior knowledge as regards the structure of a complaint even and the roles performed by participants could have also influenced participants' performance.

Following the structure of responses to complaints a second statistical analysis was conducted to examine complainee's distribution of discourse functions across the moves. In this case, the statistical analysis (see Table 31 for a summary of the statistical results) comparing the two proficiency groups showed that a significant difference was found in the case of the performance of refusal in the topic negotiation move $\left(\mathrm{p}<.05^{*}\right)$, which seemed to reveal that the B1 group produced more refusals than the B2 group in the topic negotiation move. In the post-complaint move, a significant difference was found in the discourse function of suggestions, revealing that the $\mathrm{B} 2$ group produced more suggestions than the B1 group. In the remaining discourse functions significant differences were not found. 
Table 31. Typology and frequency of complainee's discourse functions per moves and proficiency level

\begin{tabular}{|c|c|c|c|c|c|c|c|}
\hline $\begin{array}{l}\text { Discourse } \\
\text { function }\end{array}$ & Group & $N$ & $f$ & $M$ & $S D$ & $t$ & $p$ \\
\hline \multicolumn{8}{|c|}{ Opening } \\
\hline \multirow[t]{2}{*}{ Greeting } & B1 & 16 & 12 & .75 & .77 & .839 & .658 \\
\hline & B2 & 16 & 10 & .62 & .80 & & \\
\hline \multicolumn{8}{|c|}{ Pre-complaint } \\
\hline \multirow[t]{2}{*}{ Justification } & B1 & 16 & 5 & .31 & .49 & 1.275 & .212 \\
\hline & B2 & 16 & 2 & .12 & .34 & & \\
\hline \multirow{2}{*}{ Evaluation } & B1 & 16 & 1 & .06 & .25 & .237 & .559 \\
\hline & B2 & 16 & 2 & .12 & .34 & & \\
\hline \multirow{2}{*}{ Acceptance } & B1 & 16 & 14 & .94 & .25 & 1.000 & .168 \\
\hline & B2 & 16 & 17 & 1.06 & .25 & & \\
\hline \multirow{2}{*}{$\begin{array}{l}\text { Not taken it } \\
\text { seriously }\end{array}$} & B1 & 16 & 1 & .06 & .25 & .346 & .658 \\
\hline & B2 & 16 & 2 & 12 & .50 & & \\
\hline \multirow[t]{2}{*}{ Request } & B1 & 16 & 4 & .19 & .40 & .410 & .681 \\
\hline & B2 & 16 & 4 & .25 & .44 & & \\
\hline \multicolumn{8}{|c|}{ Topic negotiation } \\
\hline \multirow[t]{2}{*}{ Disagreement } & B1 & 16 & 3 & 19 & .54 & .000 & 1.000 \\
\hline & B2 & 16 & 3 & .19 & .40 & & \\
\hline \multirow[t]{2}{*}{ Justification } & $\mathrm{B} 1$ & 16 & 35 & 2.19 & 1.98 & .000 & .212 \\
\hline & B2 & 16 & 35 & 2.19 & 1.10 & & \\
\hline \multirow[t]{2}{*}{ Evaluation } & B1 & 16 & 2 & .12 & .34 & .000 & 1.000 \\
\hline & B2 & 16 & 2 & .12 & .34 & & \\
\hline \multirow[t]{2}{*}{ Request } & B1 & 16 & 9 & .56 & .72 & .000 & 1.000 \\
\hline & B2 & 16 & 9 & .56 & .96 & & \\
\hline \multirow[t]{2}{*}{ Acceptance } & B1 & 16 & 13 & .81 & .75 & .670 & .508 \\
\hline & B2 & 16 & 17 & 1.06 & 1.28 & & \\
\hline \multirow[t]{2}{*}{ Apology } & B1 & 16 & 20 & 1.25 & 1.48 & .605 & .550 \\
\hline & B2 & 16 & 16 & 1.00 & .73 & & \\
\hline \multirow[t]{2}{*}{ Empathy } & B1 & 16 & 8 & .50 & .96 & .518 & .608 \\
\hline & B2 & 16 & 11 & .69 & 1.08 & & \\
\hline \multirow[t]{2}{*}{ Refusal } & B1 & 16 & 9 & .56 & .96 & 2.349 & $.026^{*}$ \\
\hline & B2 & 16 & 1 & .06 & 1.07 & & \\
\hline \multirow[t]{2}{*}{ Suggestion } & B1 & 16 & 2 & .12 & .34 & .389 & .700 \\
\hline & B2 & 16 & 3 & 19 & .54 & & \\
\hline \multirow[t]{2}{*}{ Topic change } & B1 & 16 & 1 & .06 & .25 & .000 & 1.000 \\
\hline & B2 & 16 & 1 & .06 & .25 & & \\
\hline Not taken it & B1 & 16 & 3 & .19 & .40 & .562 & .578 \\
\hline seriously & B2 & 16 & 5 & .31 & .79 & & \\
\hline & & & ost- & nplain & & & \\
\hline Justification & B1 & 16 & 3 & .18 & .40 & 7.99 & .431 \\
\hline & B2 & 16 & 5 & .31 & .41 & & \\
\hline Evaluation & $\overline{\mathrm{B} 1}$ & 16 & 2 & .12 & .34 & .868 & .392 \\
\hline & B2 & 16 & 4 & .31 & .80 & & \\
\hline Request & B1 & 16 & 8 & .50 & .51 & .293 & .772 \\
\hline & B2 & 16 & 9 & .56 & .72 & & \\
\hline Acceptance & B1 & 16 & 9 & .62 & 1.08 & .862 & .061 \\
\hline & B2 & 16 & 17 & 1.30 & 1.08 & & \\
\hline Apology & B1 & 16 & 4 & .25 & .44 & 1.419 & .166 \\
\hline & B2 & 16 & 10 & .62 & .96 & & \\
\hline Empathy & B1 & 16 & 4 & .25 & .44 & .745 & .462 \\
\hline & B2 & 16 & 6 & .37 & .50 & & \\
\hline Refusal & B1 & 16 & 3 & .18 & .40 & .799 & .431 \\
\hline & B2 & 16 & 5 & .31 & .48 & & \\
\hline
\end{tabular}


Chapter 5: Results and discussion

\begin{tabular}{|c|c|c|c|c|c|c|c|}
\hline Suggestion & $\begin{array}{l}\text { B1 } \\
\text { B2 } \\
\end{array}$ & $\begin{array}{l}16 \\
16 \\
\end{array}$ & $\begin{array}{c}3 \\
19 \\
\end{array}$ & $\begin{array}{l}.19 \\
1.37 \\
\end{array}$ & $\begin{array}{r}.40 \\
1.16 \\
\end{array}$ & 3.906 & $.000^{* *}$ \\
\hline Promise & $\begin{array}{l}\text { B1 } \\
\text { B2 }\end{array}$ & $\begin{array}{l}16 \\
16\end{array}$ & $\begin{array}{l}7 \\
8\end{array}$ & $\begin{array}{l}.43 \\
.50\end{array}$ & $\begin{array}{l}.51 \\
.52\end{array}$ & .344 & .733 \\
\hline Joke & $\begin{array}{l}\text { B1 } \\
\text { B2 }\end{array}$ & $\begin{array}{l}16 \\
16 \\
\end{array}$ & $\begin{array}{l}4 \\
4 \\
\end{array}$ & $\begin{array}{l}.25 \\
.25\end{array}$ & $\begin{array}{l}.77 \\
.44 \\
\end{array}$ & .000 & 1.000 \\
\hline Gratitude & $\begin{array}{l}\text { B1 } \\
\text { B2 }\end{array}$ & $\begin{array}{l}16 \\
16 \\
\end{array}$ & $\begin{array}{l}4 \\
6 \\
\end{array}$ & $\begin{array}{l}.18 \\
.31 \\
\end{array}$ & $\begin{array}{l}.40 \\
.48\end{array}$ & .799 & .431 \\
\hline $\begin{array}{l}\text { Not taken it } \\
\text { seriously }\end{array}$ & $\begin{array}{l}\text { B1 } \\
\text { B2 }\end{array}$ & $\begin{array}{l}16 \\
16\end{array}$ & $\begin{array}{l}0 \\
2\end{array}$ & $\begin{array}{l}.00 \\
.12\end{array}$ & $\begin{array}{l}.00 \\
.34\end{array}$ & 1.464 & .154 \\
\hline \multicolumn{8}{|c|}{ Closing } \\
\hline $\begin{array}{l}\text { Terminal } \\
\text { exchange }\end{array}$ & $\begin{array}{l}\mathrm{B} 1 \\
\mathrm{~B} 2\end{array}$ & $\begin{array}{l}16 \\
16\end{array}$ & $\begin{array}{l}7 \\
7\end{array}$ & $\begin{array}{l}.43 \\
.43\end{array}$ & $\begin{array}{l}.51 \\
.51\end{array}$ & .000 & 1.000 \\
\hline
\end{tabular}

As displayed in the table, in the case of the distribution of discourse functions, it seems that participants in the two proficiency groups tended to provide justifications in the topic negotiation move. A significant difference $\mathrm{p}<.05^{*}$ was observed in the case of refusal in the topic negotiation move (B1 group outperformed the B2 group), and in suggestion in the post-complaint move $\mathrm{p}<.001^{* *}$ (B2 group outperformed the B1 group). By means of refusals, the complainee might reject for example the complainer's utterances. By rejecting the proposition uttered by the complainer, the complainee was not, to some extent, contributing to a potential repair or polite discussion. Example 10 shows the use of a refusal in the topic negotiation move elicited by a pair that belonged to the B1 group.

Example 1o. B1 participants: Use of refusal

\begin{tabular}{|c|c|c|c|}
\hline Line & Turn & articipant & \\
\hline \multicolumn{4}{|c|}{ A: Complainer and B: Complainee } \\
\hline \multicolumn{4}{|c|}{ Topic negotiation move } \\
\hline 1 & 5 & A_\#10 & you didn't say me anything \\
\hline 2 & 6 & B_\#10 & $\begin{array}{l}\text { well I think that you don't } \\
\text { mind and I don't tell you but I } \\
\text { think that you are studying }\end{array}$ \\
\hline 3 & 7 & A_\#10 & $\begin{array}{l}\text { but you could say me and I } \\
\text { would say if go or not }\end{array}$ \\
\hline 4 & 8 & B_\#10 & $\begin{array}{l}\text { yes but I invite various little a } \\
\text { few people }\end{array}$ \\
\hline 5 & 9 & A_\#10 & but all our friends come? \\
\hline 6 & 10 & B_\#10 & yes \\
\hline
\end{tabular}




$\begin{array}{llll}7 & 11 & \text { A_\#10 } & \text { me too } \\ 8 & 12 & \text { B_\#10 } & \begin{array}{l}\text { I think that you are studying } \\ \text { and then you don't come }\end{array}\end{array}$

Example 10 shows part of a conversation between two female participants in which the complainer seemed to show her attitude towards what the complainee, for example by uttering "but you could say me and I would say if go or not”. Complainer's opportunity to go to the party depended heavily on the decision of the complainee, who, instead of redressing the grievance, decided to perform an utterance that might imply a decline towards the proposition of the complainer, more precisely, "I think that you are studying and then you don't come". In so doing, the complainee acknowledged, in an indirect manner, that she refused to invite her to go the party.

In the case of the post-complaint move, results indicated that the $\mathrm{B} 2$ group outperformed the B1 group as regards the production of suggestions. Suggestions belong to the category of directive speech acts in which the speaker tries to influence the listener's behaviour (Brown and Levinson, 1978, 1987). Directive speech acts are divided into impositive and non-impositive (Havertake, 1984), where the former involves more FTAs such as requests, pleading, and the latter, includes for example suggestions. The main difference between them is that impositive involves that the speaker obtains the benefit, while in the non-impositive, as in suggestions, the interlocutor obtains the benefit (Rintell, 1979). It should be noted that the potential threat of these speech acts might be minimised by means of modifications devices. The ability to use modifications devices to soften the impact of a FTA involves pragmatic proficiency, which according to Nikula (1996, p 29) refers to "the ability to use language not only correctly as far as grammar and vocabulary are concerned but also appropriately so that language use fits the social context in which it is being used". Example 11 and Example 12 might serve to illustrate the use of suggestions. 
Example 11. B1 participants: Use of suggestion

\begin{tabular}{|c|c|c|c|}
\hline Line & Turn & articipar & \\
\hline \multicolumn{4}{|c|}{ A: Complainer and B: Complainee } \\
\hline \multicolumn{4}{|c|}{ Post-complaint move } \\
\hline 1 & 25 & A_\#32 & $\begin{array}{l}\text { okay I'm sorry another day [we have] } \\
<\text { B32:OVERLAP }<\text { no } / / \text { no } / / \text { sorry } \\
>/ / \text { OVERLAP }>\end{array}$ \\
\hline 2 & 26 & B_\#32 & $\begin{array}{l}{[\text { no } / / \text { no } / / \text { sorry }]<\text { B32:LAUGHTER }>} \\
\text { no sorry }[\text { I'm } \text { so angry }]\end{array}$ \\
\hline 3 & 27 & A_\#32 & $\begin{array}{l}<\text { A32:OVERLAP }<\text { er I }>/ / \text { OVERLAP }> \\
\text { [er }\end{array}$ \\
\hline & & & $\begin{array}{l}\left.<\mathrm{B} 5: \mathrm{F} \text { PAUSE }<\text { er }>/ / \mathrm{F} \_\mathrm{PAUSE}>\mathrm{I}\right] \\
/ / \mathrm{I} / / \text { heard that the group er } \\
<\mathrm{A} 32: \mathrm{F} \text { PAUSE }<\text { er }>/ / \mathrm{F} \text { PAUSE }> \\
\text { will play another concert in another } \\
\text { city the next month we can go } \\
\text { together }\end{array}$ \\
\hline 4 & 28 & B_\#32 & okay you'll pay me the ticket? \\
\hline 5 & 29 & A_\#32 & $\begin{array}{l}\text { yes of course } \\
<\text { B32:LAUGHTER }>\end{array}$ \\
\hline
\end{tabular}

Example 12. B2 participants: Use of suggestion

\begin{tabular}{|c|c|c|c|}
\hline Line & Turn & articipar & \\
\hline \multirow{2}{*}{\multicolumn{4}{|c|}{ A: Complainer and B: Complainee }} \\
\hline \multicolumn{2}{|c|}{ Post-complaint move } & & \\
\hline 1 & 16 & A \#22 & I've got an idea \\
\hline 2 & & B_\#22 & yes $<$ B22:BC_CON $<$ yeas $>/ /$ BC $>$ \\
\hline 3 & & A_\#22 & $\begin{array}{l}\text { er } \\
<\text { A22:F_PAUSE }<\text { er }>/ / F \_P A U S E> \\
\text { in those kinds of places, they put } \\
\text { you a stamp in //in////in// //in// } \\
/ / \text { in// the arm }\end{array}$ \\
\hline 4 & & B_\#22 & yeah $<$ B22:BC_CON $<$ yeah $>/ /$ BC $>$ \\
\hline 5 & & A_\#22 & $\begin{array}{l}\text { er } \\
<\text { A22:F_PAUSE }<\text { er }>/ / F \_P A U S E> \\
\text { we can do this (o.1) you know the } \\
\text { concert is at Ribalta }\end{array}$ \\
\hline 6 & & B \#22 & oh yeah \\
\hline 7 & & A_\#22 & Do you know where where it is? \\
\hline 8 & 17 & B_\#22 & Yes I live near to this \\
\hline 9 & 18 & A_\#22 & $\begin{array}{l}\text { yeah so what we can do is they } \\
\text { would close the //the// umm park } \\
\text { but er there is a fence it's near a } \\
\text { Chinese restaurant you know where } \\
\text { it is? }\end{array}$ \\
\hline 10 & 19 & B_\#22 & I think no \\
\hline 11 & 20 & A_\#22 & $\begin{array}{l}\text { no } \\
<\text { A22:F_PAUSE }<\text { er }>/ / \text { F_PAUSE }>\end{array}$ \\
\hline
\end{tabular}




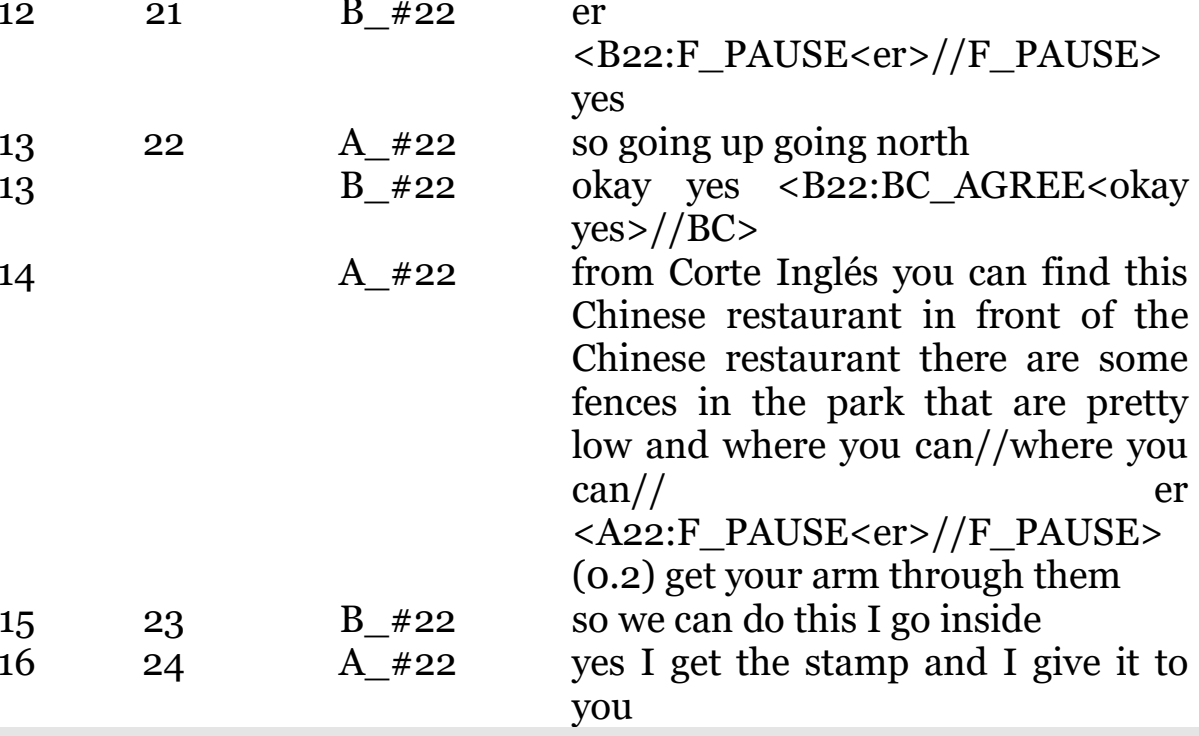

(o.2) you know where Corte Inglés is?

er

$<$ B22:F_PAUSE $<$ er $>/ / F \_P A U S E>$

okay yes <B22:BC_AGREE $<$ okay

Chinese restaurant in front of the

Chinese restaurant there are some

fences in the park that are pretty

low and where you can//where you

$<$ A22:F_PAUSE $<$ er $>/ / F \_P A U S E>$

(o.2) get your arm through them you

In the case of the complainee, it might be suggested that he complainee by means of a suggestion might somehow attempt to influence the complainer's action. These two examples show the use of suggestion in the post-complaint move in the two proficiency groups. In both cases, the complainee elicited a suggestion that might benefit the complainers since they could attend the concert. It might be indicated that the complainees performed the discourse function of suggestion so as to provide some kind of redress that involved that the complainer could obtain a benefit, but at the same time, it seems that this particular action also benefited the repair of the offence. Taking into account this, it would be argued that the benefit of going to the concert is for the complainers, albeit the complainees also obtained some kind of benefit since they tried to repair the situation by means of uttering the discourse function of suggestion.

As in the case of the complainer, the proposed classification of complainee's discourse functions was expanded to include the performance of the data examined. The original structure included (1) acceptance; (2) apology; (3) justification; (4) not taken it seriously; and (5) topic-change. The data revealed that further discourse features could be added, specifically those of: (6) request, 
(7) suggestion, (8) promise, (9) refusal, (10) disagreement, (11) evaluation, (12) empathy, (13) and (14) joke. These discourse functions were found in the data as responses to the complainer. As in the case of the complainer, it should be argued that when examining speech acts from a $\mathrm{CA}$ approach, and particularly responses to complaints, data might reveal different discourse functions that were not pre-established in the suggested structure of responses to complaints.

The retrospective verbal reports provided evidences of the complainee behaviour in the task. Concerning the B1 level, 12 out of 16 participants indicated that they would have behaved in a similar way in a real context although some modifications would have been done. More precisely, of these 12 participants, 8 would have provided further explanations, 2 would have shown regret, and 3 would have been more direct. The remaining participants, 4 out of 16 , indicated that they would have reacted in a different manner, specifically, providing further explanations and showing their real emotions towards the act. Participants who indicated that they would have behaved in a similar manner also indicated that, in a real situation, emotions would have been expressed. In light of these results, it could be argued that due to the lack of real consequences of the task they performed (Roever, 2010) participants were not able to show emotions openly. The lack of real emotions in the simulated complaint situation could have also affected possibly the number of utterances they have performed. Moreover, 7 out of 16 B1 participants admitted having linguistic difficulties to express themselves, which in turn could have also influenced participants' elicitation of utterances, and particularly to provide longer and possibly further elaborated turns, as reported in the retrospective verbal reports.

In the case of the B2 group, 7 out of 16 participants indicated that they would have reacted in a similar manner in a real context, albeit they would have provided longer explanations, and 2 of these 7 
participants also pointed that they would apologise in a real context as they understood the damaged causes. This fact may serve to indicate that they were aware of the sociopragmatic conditions of the complaint. A total of 9 out of 16 participants of the B2 group indicated that they would have behaved in a different manner in a real context, as they did not express themselves as they would due to the lack of real consequences. They reported that they completed the task as expected but that they would have behaved in a different manner. Therefore, the lack of real consequences of the role-play task (Roever, 2010) has appeared to influence participants' performance of further utterances that provide explanations. Linguistic difficulties to express themselves were also noted by 9 out of 16 participants, which in turn could have also affected participants' performance of utterances. It should be also indicated that all the participants in the two proficiency groups acknowledged that a damaged had been caused and that the situation, due to the close relationship of the participants, could be regarded as highly offensive.

Considering the results, it is worth mentioning that the lack of significant differences in the overall use of discourse functions in each move might be primarily related to the dependence on the complainer production and the lack of real life consequences, which prevented complainees to show for example higher emotional involvement. In the case of the distribution of responses to complaints across the different complaint moves, results seemed to indicate that significant differences were observed in the case of refusals in the topic negation move (B1 group) and in suggestions in the post-complaint move (B2 group). Similarly to the previous analysis, the lack of statistical differences in most of the discourse functions might be related mainly to the fact that complainees were focused on providing responses to complainers, rather than initiating turns since the complainer was in a position of relatively more power due to the offence committed by complainees, who attempted to respond to complainers' sequences and repair the situation if 
possible. Regardless these aspects, complainees' assessment of the situation might have also influenced the results.

\subsubsection{Structure of complaints}

Drawing on previous literature I anticipated a possible structure for the communicative act of complaints from an interactive perspective (Chapter 2, Section 2.1.2), that is, taking into account the complainer and the complainee. However, some modifications were done so as to provide a better representation of the data set. In observing participants' pragmatic spoken behaviour from a CA approach, results appeared to demonstrate how speakers, at different proficiency levels, organised their talk in various moves, turns, and discourse functions. Therefore, in light of the results obtained in this study as regards participants' pragmatic behaviour, it might be suggested that the speech act of complaints involves a rather complex communicative act that could be constructed by means of different moves and several discourse functions.

As regards moves, this study demonstrated that there were no statistical differences in the construction of the pre-established moves across proficiency levels (Chapter 5, Section 5.1.1.1), which seems to suggest that all the participants followed a similar structure in the organisation of moves. A necessary condition for a complaint to be identified is the performance of the core move, which, in the present study involves the topic negotiation. Therefore, it might be indicated that the topic negotiation complaint appears to be an obligatory move. In fact, this specific move would be associated to the definition of a complaint, which involves, as pointed out by Trosborg (1995: 311-312), "an illocutionary act in which the speaker (the complainer) expresses his/her disapproval, negative feelings etc. towards the state of affairs described in the proposition (the complainable) and for which he/she holds the hearer (the complainee) responsible, either directly or indirectly". 
The construction of a pre-complaint move and a post-complaint move may depend on the approach taken by the speakers to tackle with the situation. This study has demonstrated that the two proficiency groups tended to construct the pre-complaint move in order to anticipate the forthcoming FTA and the post-complaint move to repair the situation and restore harmony between speakers. Concerning this, it may be argued that speakers' prior knowledge as regards the performance of a complaint might have influenced the results obtained in the present study. By constructing a complaint conversation using various moves, speakers may not only create a further elaborated and complex conversation, but also show pragmatic knowledge and more specifically, sociopragmatic knowledge as regards the performance of the communicative act of complaints. Therefore, drawing on the results obtained in the present study, I would indicate that both the pre-complaint and the postcomplaint are highly recommended moves. Particularly, my approach in considering these two moves as highly recommended is based on the fact that by means of a pre-complaint the complainer may approach the complainee in a less threatening manner and anticipate the forthcoming event, which could lead to pragmatic awareness, and more specifically, to sociopragmatic awareness. By the same token, the construction of a post-complaint move would point to speakers' interest in repairing the situation and restore the harmony, thereby avoiding a situation that may negatively affect their relationship.

In the case of the opening and closing moves, it could be suggested that, regardless they are not exclusively associated to the act of complaining; it is true that they are part of a conversation, and their performance would point to participants' pragmatic awareness as regards the construction of talk. However, these two moves may not be regarded as obligatory, but rather as highly recommended moves in any conversation.

Hence, taking into account the aforementioned aspects, I would point out that the speech act of complaints requires not only the core 
move, that is, the topic negotiation, which, as results have revealed, should be considered as a necessary condition for a complaint to take place, but also the pre-complaint and post-complaint moves in order to construct the complaint communicative act in a further elaborated manner.

In addition to this, the current study also showed that the proposed discourse functions appeared not to account for all the discourse functions that emerged in the data. Therefore, further discourse functions were included to provide a better representation of participants' pragmatic performance. Table 32 displays the structure of the complaint and responses to complaints after the analysis of the data, and it is illustrated with some examples.

Table 32. Structure of the complaints

\begin{tabular}{|c|c|c|}
\hline \multirow{2}{*}{ Moves } & \multicolumn{2}{|c|}{ Discourse functions } \\
\hline & Complainer & Complainee \\
\hline Opening & \multicolumn{2}{|c|}{ Greetings } \\
\hline \multirow{17}{*}{$\begin{array}{l}\text { Complaint } \\
\text { (pre-complaint, } \\
\text { topic negotiation } \\
\text { and post- } \\
\text { complaint) }\end{array}$} & So hey how are you? & Hey! How are you? \\
\hline & Preparation & Acceptance \\
\hline & I wanted to talk to you & Yeah it's true \\
\hline & Allusion to the & Apology \\
\hline & $\begin{array}{l}\text { offensive act } \\
\text { I heard you just er } \\
\text { organized a big big } \\
\text { party... }\end{array}$ & $\begin{array}{l}\text { So I forgot totally sorry } \\
\text { sorry I know }\end{array}$ \\
\hline & Dissatisfaction & Justification \\
\hline & $\begin{array}{l}\text { Yeah but you won't be } \\
\text { able to invite this this } \\
\text { group }\end{array}$ & ...it's my parent's house \\
\hline & Evaluation & Not taken it seriously \\
\hline & I think it's really unfair & $\begin{array}{l}\text { Maybe first buy a new } \\
\text { house }\end{array}$ \\
\hline & Accusation & Topic-change \\
\hline & $\begin{array}{l}\text { What? you didn't say } \\
\text { anything to me }\end{array}$ & $\begin{array}{l}\text { Maybe for the next } \\
\text { party }\end{array}$ \\
\hline & Request & Request \\
\hline & $\begin{array}{l}\text { Can you do something } \\
\text { for me? }\end{array}$ & Can you read it? \\
\hline & Gratitude & Gratitude \\
\hline & Thanks for that & Thank you \\
\hline & Interrogation & Evaluation \\
\hline & $\begin{array}{l}\text { Why didn't you invite } \\
\text { me? }\end{array}$ & I think this can be fun \\
\hline
\end{tabular}




\begin{tabular}{|c|c|c|}
\hline & Joke & Joke \\
\hline & $\begin{array}{l}\text { hehe don't kill me } \\
\text { Empathy }\end{array}$ & $\begin{array}{l}\text { Come on! You can! hehe } \\
\text { Empathy }\end{array}$ \\
\hline & I see what you mean & I understand that \\
\hline & Disagreement & Disagreement \\
\hline & I don't think so & I know but... \\
\hline & Refusal & Refusal \\
\hline & I can't & You must be kidding \\
\hline & Suggestion & Suggestion \\
\hline & What if we ... & What about... \\
\hline & $\begin{array}{l}\text { Not taken it } \\
\text { seriously }\end{array}$ & Promise \\
\hline & Forget the house & I do promise \\
\hline & $\begin{array}{l}\text { Warn } \\
\text { Don't do this again }\end{array}$ & \\
\hline & $\begin{array}{l}\text { Blame } \\
\text { It's your fault }\end{array}$ & \\
\hline & $\begin{array}{l}\text { Acceptance } \\
\text { Ok, you're right }\end{array}$ & \\
\hline & $\begin{array}{l}\text { Justification } \\
\text { The this is that... }\end{array}$ & \\
\hline Closing & $\begin{array}{l}\text { Terminal exchange } \\
\text { Bye! }\end{array}$ & See you! \\
\hline
\end{tabular}

This diversity may lead one to consider that there is not a predictable prototypical set of discourse functions since complaints and responses to complaints might be performed in various ways. The lack of prototypical and predictable discourse functions allows speakers to construct their complaints and responses to complaints drawing on different pragmalinguistic realisations that should be understood within the context of a complaint in order to interpret them as part of a complaint conversation. Finally, it should be indicated that complaints appear to encompass extended sequences rather than fixed adjacency pairs (Drew and Walker, 2009), which also points to the complexity of this specific speech act.

This section has reported on the results as regards the sequence organisation of complaints and responses to complaints. In the following section I focus on the different conversational features that emerged from the corpus. 


\subsubsection{Specific conversational features}

In this section, I report on the quantitative analysis of three discourse features that have a particular relevance in the construction of the interaction: backchannel and overlapping. From the same perspective, I also focus on some paralanguage resources which were identified in the data. In this case, data has been examined taking into account participants' proficiency level and the role participants performed.

\subsubsection{Backchannels}

Backchannels are part of the communicative event and the turntaking system. They are seen as signals of active listener that reveal the understanding and interpretation of the discourse. In a simulated talk; however, it might be argued that participants might not necessarily show the natural backchannel behaviour they would in a natural context. While being aware of the artificiality of the task, a role-play, occurrences of backchannels were found in the data and examined to see whether the variable of proficiency had an effect on their production.

The total number of occurrences (104) was examined without distinguishing typology (see Table 33 for a summary of the statistical results). Results concerning the overall realisation of backchannel in the two groups showed that there was a significant difference $\mathrm{p}<.05^{*}$ between the two proficiency groups regarding the occurrences of backchannel, B2 group outperforming B1 (75\% of the total). Although this result would lead to suggest that the B2 group produced slightly more backchannels than the B1 group, it is complex to ascertain whether the B2 group was aware of the use of backchannel phenomena in conversation. Another variable that could have affected this particular result could be participants' fluency; nevertheless, this variable was not examined in the study. 
Table 33. Frequency of backchannel by participants' role

\begin{tabular}{lccccccc} 
& Group & $N$ & $f$ & $M$ & $S D$ & $t$ & $p$ \\
\hline \multirow{2}{*}{ Backchannel } & B1 & 32 & 26 & .81 & 1.2 & 2.400 & $.019^{*}$ \\
& B2 & 32 & 78 & 2.44 & 3.62 & & \\
Backchannel & B1 & 16 & 16 & 1.00 & 1.54 & .929 & .360 \\
& B2 & 16 & 27 & 1.69 & 2.52 & & \\
Backchannel & B1 & 16 & 10 & .63 & .80 & 2.276 & $.030^{*}$ \\
& B2 & 16 & 51 & 3.19 & 4.43 & & \\
\hline p<.05* & & & & & & & \\
\end{tabular}

When focusing on the use backchannels according to the role played by the participants, results showed that the complainee in the B2 group produced significantly more backchannels than the complainee in the $\mathrm{B} 1$ group $\mathrm{p}<.05^{*}$. By contrast, no statistical differences were found in the case of the complainer. This particular result could be associated to participant's role within the conversation. Although the complainer and the complainee acted as speakers and listeners simultaneously because they were engaged in a conversation, it might be suggested that the complainee appeared to reveal features of active listenership more frequently than the complainer. This idea could be only supported considering that the complainer is the person who addressed the complainee, and the complainee the person who provided responses to such complaint behaviour. In addition, it should be noted that by means of backchannels, listeners may reveal specific signals to the speaker as regards the content, understanding and interpretation of the discourse (Tottie, 1991; Clancy et al., 1996; O’Keeffe and Adolphs, 2008), and it might be even argued that they might reflect emotions (White, 1997; Ward, 2006). In this particular study, it seemed that the B2 complainee showed signals of active listenership more frequently than the $\mathrm{B} 1$ complainee did. As indicated, in the case of the complainer, results seemed to indicate that in both proficiency groups participants tended to employ a similar amount of backchannels in their performance. After examining whether 
proficiency had effects on the total occurrences of backchannel, I proceeded with the analysis of the occurrences of backchannels according to its typology, reviewed in Chapter 1 (Section 1.3.2.2). See Table 34 for a summary of the statistical results. The data of the study showed occurrences of continuer, agreement, assessment, information receipt, and repetition.

Table 34. Backchannel typology by participants' proficiency level

\begin{tabular}{|c|c|c|c|c|c|c|c|}
\hline & Group & $N$ & $f$ & $M$ & $S D$ & $t$ & $p$ \\
\hline \multirow{2}{*}{ Continuer } & B1 & 32 & O & .00 & .00 & 3.144 & $.003^{*}$ \\
\hline & B2 & 32 & 21 & .66 & 1.18 & & \\
\hline \multirow[t]{2}{*}{ Agreement } & B1 & 32 & 20 & .62 & 1.13 & 2.029 & $.047^{*}$ \\
\hline & $\mathrm{B} 2$ & 32 & 52 & 1.62 & 2.55 & & \\
\hline \multirow[t]{2}{*}{ Assessment } & B1 & 32 & 2 & .06 & .24 & 1.438 & .156 \\
\hline & B2 & 32 & $\mathrm{O}$ & .00 & .00 & & \\
\hline \multirow{2}{*}{$\begin{array}{l}\text { Information } \\
\text { received }\end{array}$} & B1 & 32 & 2 & .06 & .35 & 7.25 & .471 \\
\hline & B2 & 32 & 4 & .13 & .33 & & \\
\hline \multirow[t]{2}{*}{ Repetition } & B1 & 32 & 2 & .06 & .24 & .584 & .562 \\
\hline & $\mathrm{B} 2$ & 32 & 1 & .03 & .17 & & \\
\hline
\end{tabular}

Results showed that in comparing participants according to proficiency level group without distinguishing participants' role statistical differences were found in the case of continuer $\left(\mathrm{p}<.05^{*}\right)$, and agreement $\left(\mathrm{p}<.05^{*}\right)$, while no statistical differences were observed in assessment, information receipt, and repetition. Then, these results seemed to suggest that the B2 participants employed statistically significant more backchannels of continuer and agreement than the B1 group. In fact, as observed, results revealed that, in general, the most frequent types of backchannels observed in the data were agreement (69.23\%), and continuer (20.19\%).

On the one hand, considering that continuers are regarded as the most basic form backchannel, which is used to maintain the flow of the conversation (O'Keeffe and Adolphs, 2008), these results seemed to indicate that the $\mathrm{B} 2$ group produced continuer tokens to show the interlocutor the continuation of the conversation. Moreover, by means of continuers, participants also showed perception and the understanding of content (Tottie, 1991; Clancy et 
al., 1996; O'Keeffe and Adolphs, 2008). On the other hand, the backchannel of agreement may be used to support the speaker's conversation and stance (Peters and Wong, 2014) as well as to show understanding (O'Keeffe and Adolphs, 2008). Hence, in light of the results obtained, it may be suggested that the B2 group appeared to support and show understanding towards the interlocutor by means of this particular backchannel more frequently than the B1 group did. These results might be associated to participants' proficiency level as well as to their ability to interact in a spoken conversation, which seemed to allow the $\mathrm{B} 2$ group to produce signals of active listener by means of continuer and agreement more frequently than the B1 group. When each role was analysed separately to compare proficiency effects (see Table 35), results revealed that in the case of the complainer, no statistical differences were found, but the complainee revealed statistical differences $\mathrm{p}<.05^{*}$ for continuer and agreement.

Table 35. Backchannel typology by participants' proficiency level and role

\begin{tabular}{|c|c|c|c|c|c|c|c|}
\hline & Group & $N$ & $f$ & $M$ & $S D$ & $t$ & $p$ \\
\hline \multicolumn{8}{|c|}{ Complainer } \\
\hline \multirow[t]{2}{*}{ Continuer } & B1 & 16 & $\mathrm{O}$ & .00 & .00 & 1.826 & .078 \\
\hline & $\mathrm{B} 2$ & 16 & 8 & .50 & 1.09 & & \\
\hline \multirow[t]{2}{*}{ Agreement } & B1 & 16 & 13 & .81 & 1.47 & .494 & .625 \\
\hline & B2 & 16 & 17 & 1.06 & 1.39 & & \\
\hline \multirow[t]{2}{*}{ Assessment } & $\mathrm{B} 1$ & 16 & 2 & .13 & .34 & 1.464 & .154 \\
\hline & B2 & 16 & $\mathrm{O}$ & .00 & .00 & & \\
\hline \multirow{2}{*}{$\begin{array}{l}\text { Information } \\
\text { receipt }\end{array}$} & B1 & 16 & $\mathrm{O}$ & .00 & .00 & 1.000 & .325 \\
\hline & B2 & 16 & 1 & .06 & .25 & & \\
\hline \multirow[t]{2}{*}{ Repetition } & B1 & 16 & 1 & .06 & .25 & .000 & 1.000 \\
\hline & B2 & 16 & 1 & .06 & .250 & & \\
\hline \multicolumn{8}{|c|}{ Complainee } \\
\hline \multirow[t]{2}{*}{ Continuer } & B1 & 16 & $\mathrm{O}$ & .00 & .00 & 2.546 & $.016^{*}$ \\
\hline & $\mathrm{B} 2$ & 16 & 13 & .81 & 1.23 & & \\
\hline \multirow[t]{2}{*}{ Agreement } & $\mathrm{B} 1$ & 16 & 7 & .43 & .63 & 2.089 & $.045^{*}$ \\
\hline & B2 & 16 & 35 & 2.18 & 3.30 & & \\
\hline \multirow{2}{*}{$\begin{array}{l}\text { Information } \\
\text { receipt }\end{array}$} & B1 & 16 & 2 & .13 & .50 & 30 & .700 \\
\hline & $\mathrm{B} 2$ & 16 & 3 & .19 & .40 & & \\
\hline \multirow[t]{2}{*}{ Repetition } & B1 & 16 & 1 & .06 & .25 & 30 & .325 \\
\hline & B2 & 16 & $\mathrm{O}$ & .00 & .00 & & \\
\hline
\end{tabular}

$\mathrm{p}<.05^{*}$ As shown, these results may suggest that the complainee of the

B2 group showed more frequently signals of active listenership than 
the complainee in the $\mathrm{B} 1$ group in the case of continuer and agreement. The use of the backchannel of continuer might serve to maintain the flow, to show the speaker continuer the talk (Tottie, 1991; Clancy et al., 1996; O'Keeffe and Adolphs, 2008) as well as show support for the speakers' performance (Peters and Wong, 2014).

The most frequent lexical items of continuer backchannel found in both groups were "yeah" and "yes". Then, these backchannel signals may be regarded as invitation for the speaker to continue talking (Ward and Tsukahara, 2000; O'Keeffe and Adolph, 2008). Example 13 shows the use of continuer.

Example 13: B2 level participants: Continuer

\begin{tabular}{|c|c|c|c|}
\hline Line & Turn & articipa & \\
\hline \multicolumn{4}{|c|}{$\begin{array}{l}\text { A: Complainer and B: Complainee } \\
\text { Post-complaint move }\end{array}$} \\
\hline 1 & 33 & $B=10$ & \\
\hline 1 & 33 & D_\#19 & $\begin{array}{l}\text { yean } \\
<\text { B19:SYL_D_<it }>/ / \text { SYL_D }>\text { will be } \\
\text { watching I don't think it would be a } \\
\text { problem }\end{array}$ \\
\hline 2 & 34 & A_\#19 & the point is \\
\hline 3 & & B_\#19 & yeah<A19:BC_CON $<$ yeah $>/ /$ BC $>$ \\
\hline 4 & & A_\#19 & $\begin{array}{l}\text { I think you won't have a lot of space } \\
\text { to }\end{array}$ \\
\hline 5 & 35 & B_\#19 & a lot of space? (...) \\
\hline
\end{tabular}

The above example shows the interaction between two male participants in which they were assessing a particular scenario that might allow them to repair the situation. While the complainee was actively paying attention to the complainer, he performed a backchannel that functioned as a continuer, indicating "please continue" (Ward and Tsukahara, 2000, p. 1183).

The other salient backchannel in the data was agreement (Maynard, 1986) (similarly to convergence tokens in O'Keeffe and Adolph, 2008) in which the speaker shows agreement and support towards the speaker, regardless the speaker does not request for such 
agreement or support in that precise moment. The most frequent lexical items for agreement were "yes", "yeah" and "okay", being the two first typically employed by NSs of (British and American) English (Gass and Houck, 1999). Example 14 illustrates the use of agreement.

Example 14: B1 level participants. Agreement backchannel

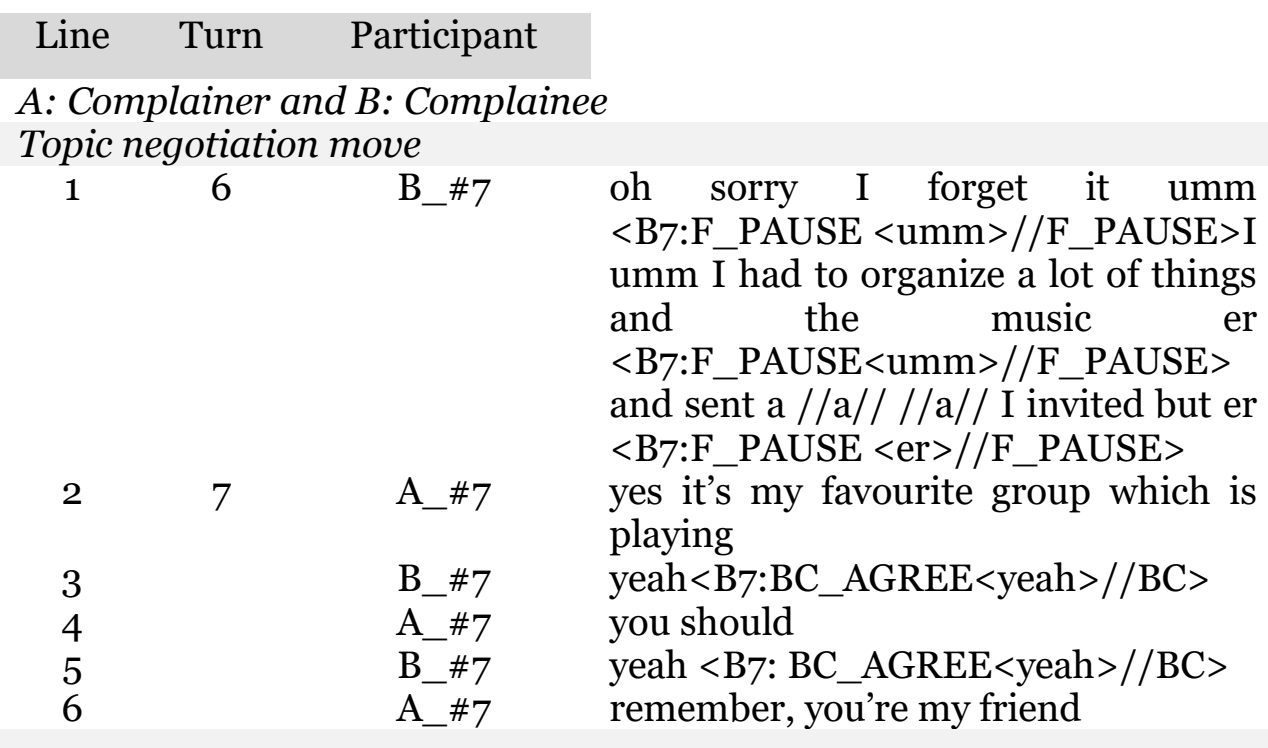

In this particular case, two male participants were involved in the topic negotiation move. More precisely, the complainer and the complainer were discussing the offence that the complainee had committed. As observed, the two agreement tokens were performed by the complainee immediately after the complainer's speech in order to show agreement with the content uttered by the complainer. It should be, however, noted that, in either case, the complainee attempted to obtain the turn in order to elicit a turn, rather, he showed agreement towards the complainer's utterances.

Finally, it should be noted that although participants at different proficiency levels appeared to employ various types of backchannels, particularly continuer and agreement tokens, further research into participants' backchannel behaviour is needed in order to examine whether learners at different proficiency levels are aware of the importance of the backchannel phenomenon. 
After reporting on the results of the backchannel behaviour, in the following section I focus on overlapping, which is another type of simultaneous talk.

\subsubsection{Overlapping}

The same procedure was followed to examine overlapping behaviour. The focus of this analysis was to see the amount of overlapping behaviour according to the proficiency level and the participants' role. In this study, however, I did not explore from a quantitative perspective whether participants managed or not to take the floor by means of overlapping. This specific analysis, albeit of paramount interest, was not carried out here by means of statistical analysis as it was beyond the scope of the study.

The descriptive statistics of overlapping behaviour (see Table 36 for a summary of the statistical results) as regards the comparison of the total number of occurrences (73) showed that there was a significant difference between the groups, $\mathrm{p}<.05^{*}$. As revealed in the statistical analysis, the B2 group produced more occurrences of overlapping in the simulated conversation than the B1 group. Data was also examined according to participants' role and proficiency in an attempt to explore whether there was any difference across them. Specifically, results seemed to indicate that in the case of the complainer, a statistical difference $\mathrm{p}<.05^{*}$ was found between the B1 group and the B2 group, showing that the more advanced group appeared to perform more occurrences of overlapping than the lower proficiency group. In the case of the complainee, results seemed to suggest that there was a significant difference between the two proficiency groups, $\mathrm{p}<.05^{*}$. Particularly, the B2 complainee appeared to have produced more occurrences of overlapping than in the B1 complainee. 
Table 36. Frequency of overlapping

\begin{tabular}{|c|c|c|c|c|c|c|c|}
\hline & Group & $N$ & $f$ & $M$ & $S D$ & $t$ & $p$ \\
\hline \multicolumn{8}{|c|}{ Complainer and complainee } \\
\hline \multirow[t]{2}{*}{ Overlapping } & B1 & 32 & 10 & .31 & .47 & \multirow[t]{2}{*}{3.487} & \multirow[t]{2}{*}{$.001^{*}$} \\
\hline & B2 & 32 & 63 & 1.97 & 2.65 & & \\
\hline \multicolumn{8}{|c|}{ Complainer } \\
\hline \multirow[t]{2}{*}{ Overlapping } & B1 & 16 & 5 & .31 & .48 & \multirow[t]{2}{*}{2.198} & \multirow[t]{2}{*}{$.036^{*}$} \\
\hline & B2 & 16 & 32 & 2.00 & 3.03 & & \\
\hline \multicolumn{8}{|c|}{ Complainee } \\
\hline \multirow[t]{2}{*}{ Overlapping } & B1 & 16 & 5 & .31 & .48 & \multirow[t]{2}{*}{2.774} & \multirow[t]{2}{*}{$.009 *$} \\
\hline & B2 & 16 & 31 & 1.94 & 2.30 & & \\
\hline
\end{tabular}

These results seemed to suggest that the proficiency level appeared to have affected participants' realisation of overlapping in the simulated conversation, showing that more proficient participants produced more overlapping occurrences than lower proficiency participants. Likewise, in splitting data into participants' role and proficiency level, it was observed than in both cases, the B2 complainer and the B2 complainee outperformed the B1 complainer and complainee.

Simultaneous talk might occur between speakers when they construct the conversation over different turns. Overlapping might be seen as signal for stopping talking (Schegloff, 2000) in which the current listener may attempt to elicit a new turn. Brown and Levinson $(1978,1987)$ contend that simultaneous talk such as overlapping may involve a FTA. However, this may vary across different linguistic cultures (Fernández-Amaya, 2013). In fact, Fernández-Amaya (2013) indicates that simultaneous speech between relatives and friends appears to be perceived by speakers as a positive politeness strategy since the interlocutor shows interest for the content elicited by the current speaker. Overlapping is somehow part of everyday conversation and it might serve to some extent to organise participants' contribution to the construction of a conversation. In the case of complaints, the use of overlapping may be associated for example to participants' interest in conveying their turns so as to negotiate the situation and repair it. For language 
learners, especially at lower proficiency levels as the B1 group, performing overlapping might be more challenging than for more advanced learners such as the B2 group. In fact, this study showed that the B2 group appeared to produce more occurrences of overlapping than the B1 group, thereby showing features of authentic talk. Another possible explanation for the results obtained would be fluency, which is not explored in this study.

The following two examples, Example 15 and Example 16, show participants' overlapping.

Example 15: B1 level participants: overlapping

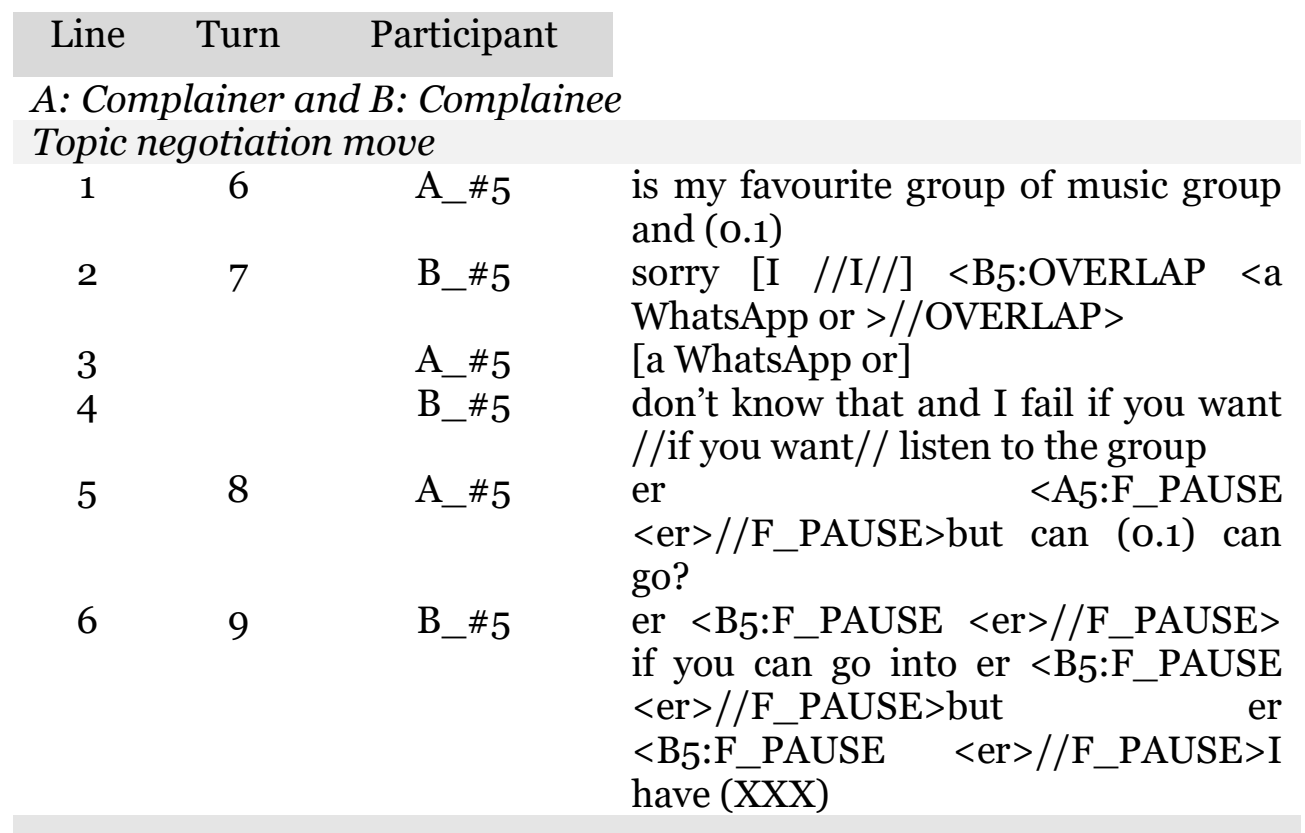

This is an extract taken from the B1 group that shows the conversation of two male participants in the topic negotiation move. As observed, while the complainee attempted to apologise for the grievance (line 2) the complainer overlapped the complainee in line 3, but as shown, he did not take the floor so he had to wait until the complainee finished his turn so as start a new one (line 5). 
Example 16: B2 level participants: overlapping

\begin{tabular}{|c|c|c|c|}
\hline Line & Turn & Participant & \\
\hline \multicolumn{4}{|c|}{ A: Complainer and B: Complainee } \\
\hline \multicolumn{4}{|c|}{ Topic negotiation move } \\
\hline 1 & 7 & A_\#18 & $\begin{array}{l}=\text { why? } \uparrow \text { we're friends } \uparrow \text { [why don't you } \\
\text { invite me?] <B18: OVERLAP <//I } \\
\text { know but }>/ / \text { OVERLAP }>\end{array}$ \\
\hline 2 & 8 & B_\#18 & $\begin{array}{l}\text { [I know but]I //I// thought that you're } \\
\text { not cool //cool// enough [to //to//] } \\
\text { <A18: OVERLAP < what }>/ / \text { OVERLAP }>\end{array}$ \\
\hline 3 & & A_\#18 & [what] \\
\hline 4 & & B_\#18 & $\begin{array}{l}\text { I know a lot of girls are //are coming } \\
\text { and I don't want them to //to// see } \\
\text { them (o.1) I mean I don't want them to } \\
\text { see me with you [and] <A18: OVERLAP }\end{array}$ \\
\hline & & & \\
\hline & 9 & A_\#18 & $\begin{array}{l}\text { [ma::n] (o.1) I thought we were friends } \\
\text { (o.1) and I've just see [the] <B18: } \\
\text { OVERLAP <yeah }>/ / \text { OVERLAP> }\end{array}$ \\
\hline 5 & 10 & B_\#18 & $\begin{array}{l}=[\text { yeah] I know it's your favourite } \\
\text { ba::nd }<\text { B18:SYL_D_<band }>/ / \text { SYL_D }> \\
\text { (o.2) but you have to understand me } \\
\text { [you are not=] <A18: OVERLAP <I } \\
\text { can't understand//OVERLAP }>\end{array}$ \\
\hline 6 & & A_\#18 & [I can't understand] \\
\hline 7 & & B_\#18 & $\begin{array}{l}\text { you're weird [//you're weirdo//] [A18: } \\
\text { OVERLAP < no } \uparrow \text { I'm }>/ / \text { OVERLAP] }\end{array}$ \\
\hline 8 & 11 & A_\#18 & [no $\uparrow$ I'm] not weird= \\
\hline 9 & 12 & B_\#18 & $=$ yes \\
\hline 10 & 13 & A_\#18 & $\begin{array}{l}\text { you have to accept me how I am (o.1) } \\
\text { you're my friend I'm not weird (o.1) I } \\
\text { will not [embarrassing you] <B18: } \\
\text { OVERLAP <ok we have been>// } \\
\text { OVERLAP> }\end{array}$ \\
\hline 11 & 14 & B_\#18 & $\begin{array}{l}\text { [ok we have been] friends like forever } \\
\text { but you have to understand= }\end{array}$ \\
\hline 12 & 15 & A_\#18 & $\begin{array}{l}=\text { that's not how you treat a best friend } \\
\text { man }\end{array}$ \\
\hline
\end{tabular}

This example, taken from the B2 sample, also shows the conversation of two male participants in the topic negotiation move. In this case, the complainer and the complainee overlapped constantly over different turns and in the majority of the cases the speaker who overlapped managed to take the floor. This example serves to reflect 
the intensity of the overlapping behaviour in the topic negotiation move.

These are two representative examples of the data since they showed how two different pairs employed overlapping in the conversations. Although statistical results suggested that the B2 group tended to overlap more frequently that the B1 group, further research into this specific aspect would be required to ascertain whether proficiency as well as other aspects such as fluency could affect participants' production of overlapping.

Having reported on the results as regards overlapping, in the following section I present the results of paralanguage.

\subsubsection{Paralanguage}

The paralanguage resources that emerged from the data were also analysed, particularly, filled pauses (vocalised pauses), classified as vocal segregate by Trager (1958) and laughter (differentiators). It is worth noticing that pause duration between words and utterances and their occurrences were also identified, but they are not included in the present study as their duration was 0.1 or 0.2 in the majority of the cases.

Concerning filled pauses, statistical analyses were run in order to examine whether there were differences as regards the occurrences of filled pauses in each proficiency level and according to participants' role (see Table 37 for a summary of the statistical results).

Table 37. Frequency of filled pauses

\begin{tabular}{|c|c|c|c|c|c|c|c|}
\hline & Group & $N$ & $f$ & $M$ & $S D$ & $t$ & $p$ \\
\hline \multicolumn{8}{|c|}{ Complainer and complainee } \\
\hline Filled & B1 & 32 & 54 & 1.69 & 1.56 & \multirow[t]{2}{*}{5.277} & \multirow[t]{2}{*}{$.000^{* *}$} \\
\hline pauses & B2 & 32 & 133 & 4.16 & 2.11 & & \\
\hline \multicolumn{8}{|c|}{ Complainer } \\
\hline Filled & B1 & 16 & 29 & 1.81 & 2.00 & \multirow[t]{2}{*}{3.266} & \multirow[t]{2}{*}{$.003^{*}$} \\
\hline pauses & B2 & 16 & 67 & 4.19 & 2.10 & & \\
\hline
\end{tabular}




\begin{tabular}{|c|c|c|c|c|c|c|c|}
\hline \multicolumn{8}{|c|}{ Complainee } \\
\hline Filled & $\mathrm{B} 1$ & 16 & 25 & 1.56 & 1.10 & 4.192 & $.000^{* *}$ \\
\hline pauses & $\mathrm{B} 2$ & 16 & 66 & 4.13 & 2.19 & & \\
\hline
\end{tabular}

When comparing the occurrences of filled pauses the two groups together (187), results indicated that a statistical difference was found $\mathrm{p}<.05^{*}$ revealing that the $\mathrm{B} 2$ group produced more filled pauses than the B1 group. Therefore, it seems that proficiency level influenced participants' number of filled pauses, showing greater occurrences in the $\mathrm{B} 2$ group. In exploring data as regards participants' role and proficiency level, results also indicated a statistical difference in the case of the complainer $\left(\mathrm{p}<.05^{*}\right)$ and the complainee $\left(\mathrm{p}<.001^{* *}\right)$, both revealing that B2 group outperformed the B1 group. Hence, results concerning filled pauses seemed to suggest that more advanced proficiency group produced more filled pauses in the conversation, while the lower proficiency group, which also produced filled pauses, accounted for fewer instances. The use of filled pauses along with other paralanguage resources are rarely introduced in the context of instruction and, although they might be seen as part of the communicative competence model (Celce-Murcia, 2007). Filled pauses might have an effect on interlocutors and therefore they should not be ignored due to the communicative meaning they may carry (Saville-Troike, 1985; Local and Kelly, 1986). Example 17 and Example 18 might serve to show the use of filled pauses in each proficiency level.

Example 17: B1 level participants: filled pause

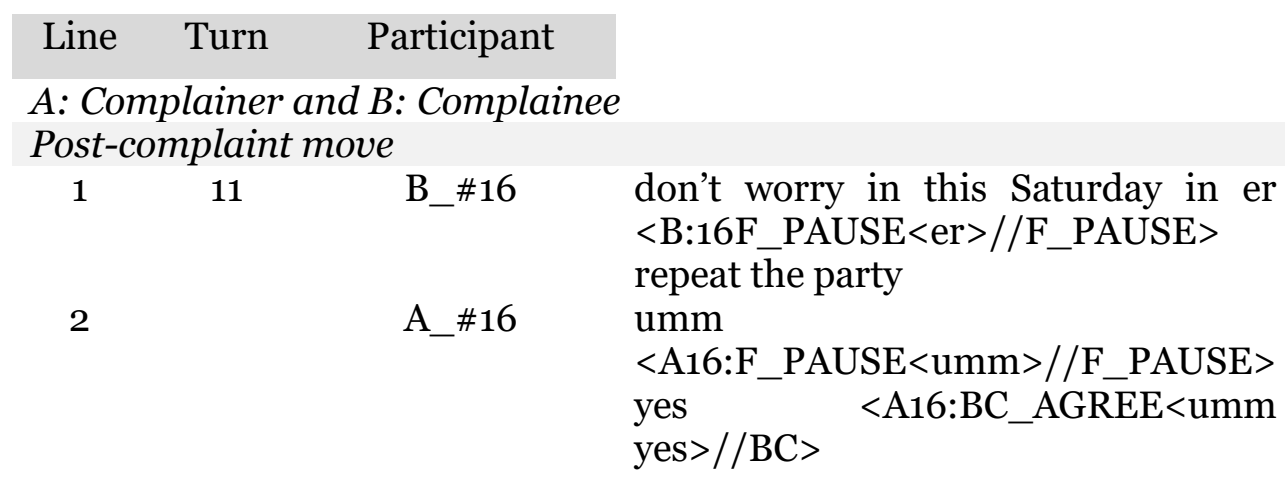


Chapter 5: Results and discussion

\begin{tabular}{|c|c|c|}
\hline 3 & B_\#16 & okay \\
\hline 14 & A_\#16 & 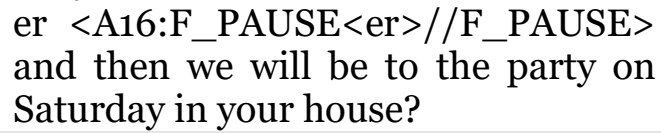 \\
\hline
\end{tabular}

In this particular case, the two participants were involved in the postcomplaint move. It seems that the participants were trying to repair the situation. The occurrence of the filled pause in line 1 might be related to participant's internal process (Goldman-Eisler, 1968) since she seemed to be planning how to complete the turn. It could be, however, argued that the complainee was showing the complainer that the turn had not been completed. Line 2 shows another example of a filled pause. In this case, the filled pause appeared in the initial position accompanying "yes", which, together, formed a backchannel of agreement. The last example observed in this extract is found in line 4. As shown, it is also placed in the initial position of the utterance. This particular filled pause could be regarded as participant's internal process (Goldman-Eisler, 1968) as it seems that the participant elicited it while planning the utterance.

Example 18: B2 level participants: filled pause

\begin{tabular}{|c|c|c|c|}
\hline Line & Turn & Participant & \\
\hline \multirow{2}{*}{\multicolumn{4}{|c|}{$\begin{array}{l}\text { A: Complainer and B: Complainee } \\
\text { Topic negotiation move }\end{array}$}} \\
\hline & & & \\
\hline 1 & 9 & B_\#29 & $\begin{array}{l}\text { yes, it's my favourite group too what } \\
\text { //what// do you want to say to me? }\end{array}$ \\
\hline 2 & 10 & A_\#29 & $\begin{array}{l}\text { er }<\text { A:29 } \\
\text { F_PAUSE }<\text { er }>/ / \text { F_PAUSE }>\text { that I'm } \\
\text { not invited to the party }\end{array}$ \\
\hline 3 & 11 & B_\#29 & $\begin{array}{l}\text { oh I'm sorry but I didn't have your } \\
\text { address so I can't er } \\
<\text { B29:F_PAUSE }<\text { er }>/ / F \_P A U S E> \\
\text { send you the invitation }\end{array}$ \\
\hline 4 & 12 & A_\#16 & but you have my mobile phone \\
\hline
\end{tabular}


The above example shows the interaction between two female participants in the topic negotiation move, where the complainer (line 1) alluded to the offensive act, and then the complainee apologised and justified the grievance. Line 2 shows an example of a filled pause in the initial part of the turn that provided a response to a previous wh-question. This particular filled pause might be attributed to participant's internal processes (Goldman-Eisler, 1968), in the sense that the participant was thinking about the potential response she could utter. The filled pause shown in line 3 can be also regarded a participants' internal process (Goldman-Eisler, 1968). However, differently to the previous example, in this case, it seemed to show participant's search for a verb. In both cases, the filled pauses used may be associated to internal needs in which the participants seemed to have uttered them so as to gain some time while preparing the response (line 2) and searching the appropriate verb (line 3).

In short, results showed that in the case of filled pauses, when comparing the two proficiency groups, proficiency seemed to have influenced the use of these discursive features. Likewise, significant differences as regards performance were found when examining participants' role and proficiency level, in favour of the B2 group. Learners' proficiency and possibly other variables such as fluency could be associated to participants' performance of filled pauses.

Another paralanguage resource identified in the spoken data was laughter, which was also examined according to participants' proficiency level and role. The statistical analysis of the 95 instances of laughter identified in the corpus (see Table 38 for a summary of the statistical results) showed a significant difference $\mathrm{p}<.05^{*}$ across proficiency levels when comparing the two groups, showing that the B1 group produced more occurrences of laughter than the B2 group. 
Chapter 5: Results and discussion

Table 38. Frequency of laughter

\begin{tabular}{|c|c|c|c|c|c|c|c|}
\hline & Group & $N$ & $f$ & $M$ & $S D$ & $t$ & $p$ \\
\hline \multicolumn{8}{|c|}{ Complainer and complainee } \\
\hline \multirow[t]{2}{*}{ Laughter } & B1 & 32 & 72 & 2.25 & 2.314 & \multirow[t]{2}{*}{3.191} & \multirow[t]{2}{*}{$.002^{*}$} \\
\hline & $\mathrm{B} 2$ & 32 & 23 & .72 & 1.420 & & \\
\hline \multicolumn{8}{|c|}{ Complainer } \\
\hline \multirow[t]{2}{*}{ Laughter } & B1 & 16 & 43 & 2.69 & 2.442 & \multirow[t]{2}{*}{2.288} & \multirow[t]{2}{*}{$.029^{*}$} \\
\hline & B2 & 16 & 15 & .94 & 1.843 & & \\
\hline \multicolumn{8}{|c|}{ Complainee } \\
\hline \multirow[t]{2}{*}{ Laughter } & B1 & 16 & 29 & 1.81 & 2.167 & \multirow[t]{2}{*}{2.267} & \multirow[t]{2}{*}{$.031^{*}$} \\
\hline & $\mathrm{B} 2$ & 16 & 8 & .50 & .816 & & \\
\hline
\end{tabular}

Similar results were found when comparing data across proficiency levels and participants' role. As regards the complainer, results demonstrated that the B1 group produced slightly more occurrences of laughter than the B2 group, resulting in a statistical difference between the groups $\mathrm{p}<.05^{*}$. Likewise, in the case of the complainee, results seemed to reveal a statistical difference $\mathrm{p}<.05^{*}$ between the $\mathrm{B} 1$ group and $\mathrm{B} 2$ group, showing that the $\mathrm{B} 1$ group performed more frequently this paralanguage resource.

The performance of this specific paralanguage resource could be related to various aspects. In the case of the B1 group, these results could be associated to participants' attitudes towards the task or the topic of the task, due to nervousness possibly because of confronting a speaking task or a result of the content. Contrarily, in the case of B2, participants appeared to be more relaxed than the B1 group when performing the speaking task and laughter was typically produced when interacting as a result of the content of the utterances, which might be somehow attributed to participants' involvement in the task. Personality traits, of course, could have also affected participants' laughter.

On the other hand, $61.05 \%$ of the occurrences of laughter were performed by the complainers. This particular result could be associated to participants' attitude. In line with this, Edwards (2005) suggests that the complainer may show some stance or attitude towards the particular action committed as well as to the act of 
performing a complaint. The author further indicates that complainers can use displays and formulations of emotional investment, or even ironic stance, when uttering a complaint so as to soften the force of the complaint and its consequences.

The following examples, Example 19 and Example 20, show two fragments in which this paralanguage feature was produced.

Example 19: B1 level participants: Laughter

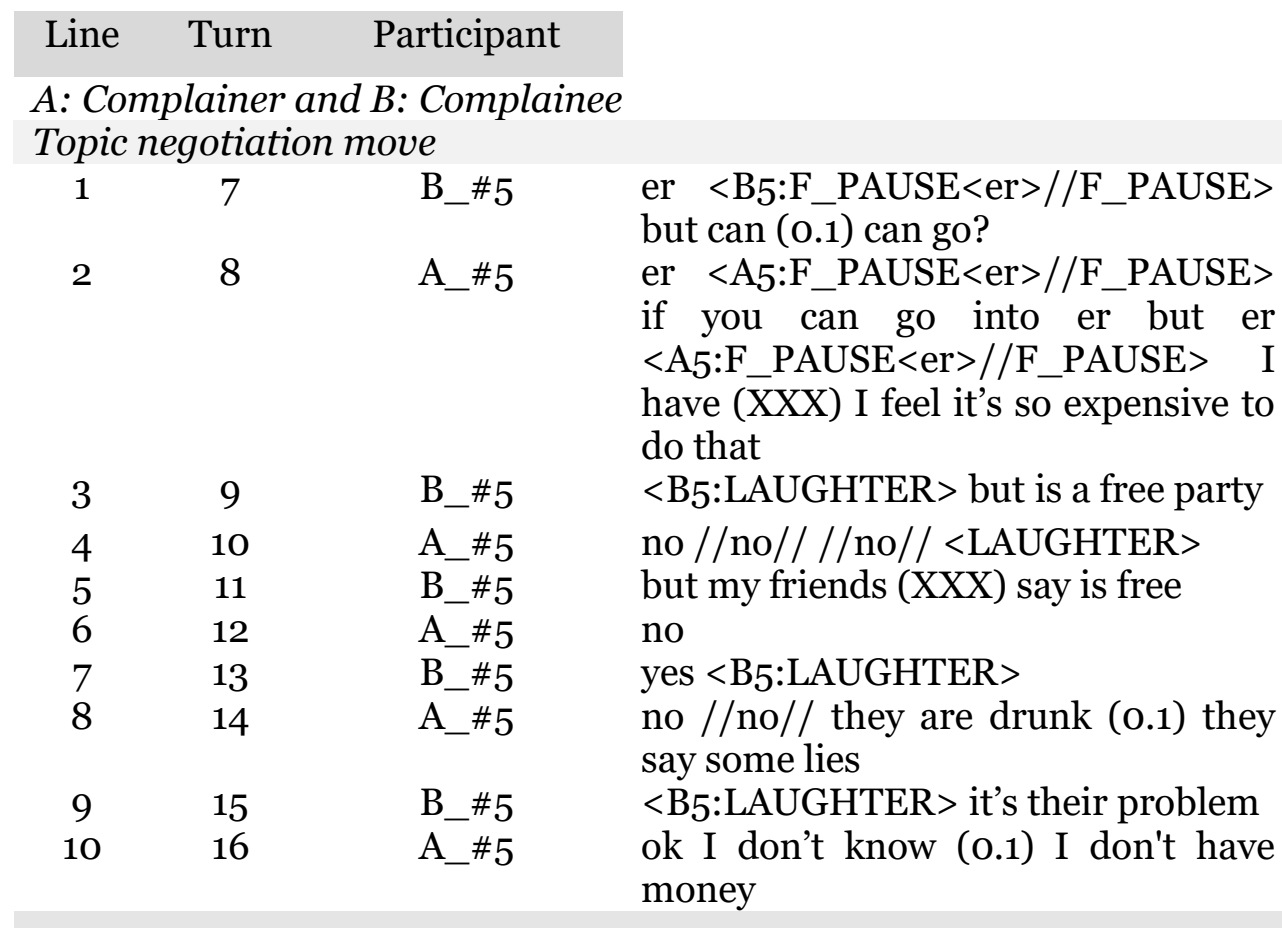

In this case, the two participants were engaged in the core part of the complaint, that is, the topic negotiation move. This particular example shows that both speakers employed laughter constantly during the conversation. Although it could be suggested that they seemed to employ this particular paralanguage resource as a result of the content of the utterances, I would rather consider that laughter was produced as a consequence of other variables, such as their attitude towards the task. As observed, the complainee tried to elicit turns that revealed his intention to go to the party, but in light of the utterances elicited by the complainee, it seemed that he could not 
project properly his approach. By contrast, the complainer seemed not to reveal much concern for the complainee. Furthermore, it could be indicated that he did not show much involvement in the situation.

Example 20: B2 level participants: Laughter

\begin{tabular}{|c|c|c|c|}
\hline Line & Turn & Participant & \\
\hline \multirow{2}{*}{\multicolumn{4}{|c|}{$\begin{array}{l}\text { A: Complainer and B: Complainee } \\
\text { Post-complaint move }\end{array}$}} \\
\hline & & & \\
\hline 1 & 23 & A_\#21 & $\begin{array}{l}\text { so you're planning to organise a } \\
\text { new one yes I will go }\end{array}$ \\
\hline 2 & 24 & B_\#21 & $\begin{array}{l}\text { yes you're invited to the party we'll } \\
\text { have next week (o.1) you will be } \\
\text { there? }\end{array}$ \\
\hline 3 & 25 & A_\#21 & yes of course I will love to so \\
\hline 4 & 26 & B_\#21 & $\begin{array}{l}\text { so the problem solved? } \\
<\text { B21:LAUGHTER }>\end{array}$ \\
\hline 5 & 27 & B_\#21 & yes problem solved really \\
\hline
\end{tabular}

This example shows the interaction between two male participants who are trying to solve the grievance in the post-complaint. Differently to the previous example, in this case, the complainee laughed once he felt that the problem had been solved since he realised that they would restore harmony as they seemed to have reached mutual understanding.

In the case of laughter results showed that significant differences were found between the two proficiency groups in favour of the B1 group. In comparing participants' role and proficiency level, it was found that the B1 group produced slightly more instances of laughter than the B1 group did. Interestingly, the complainer appeared to produce more laughter than the complainee. These results, as indicated above, could be related to other variables such as nervousness or even attitudes towards the task and involvement in the task. Nevertheless, these variables have not been examined in the present study. Finally, concerning the frequency of laughter in the case of the complainer, it could be suggested that the use of laughter 
may be associated to participants' interest in softening the threating nature of the complaint (Edwards, 2005).

This section has addressed the analysis of specific conversational features such as backchannels, overlapping and paralanguage. In the following section I centre on pragmatic appropriateness.

\subsubsection{Pragmatic appropriateness}

The appropriateness of the spoken production was also analysed following the rubric advanced in Chapter 4 Section 4.6.2. In an attempt to examine pragmatic appropriateness in conversation, a rubric based on a 1 to 4 scale involving six different descriptors was used. The descriptors included in the rubric were communication, expressions, turn-taking, backchannel, kinesics and paralanguage. In this section, however, results as regards the four first descriptors is presented since that analysis was conducted taking into account only the audio and transcript data, rather than the video data, which was used to examine the two remaining descriptions (see Section 5.2.2).

Each of the following item communication, expression, turntaking, and backchannel was ranked in 1 to 4 rating scale. The rating was conducted by two researchers (a male and a female) involved in the study, who are teachers of EFL. Differently to Taguchi (e.g. 2006, 2011), NNSs of English were involved in the rating. Although a NSs of English involved in the teaching of EFL would provide valuable results concerning participants' performance, NNSs were considered to be appropriate since most language learners are taught and examined by NNSs of English. In order to ensure internal consistency between the two raters, inter-rater agreement was estimated for each descriptor (see Table 39 for a summary of the statistical results), indicating that there was excellent (alpha coefficient >.9) interreliability between the two raters. 
Chapter 5: Results and discussion

Table 39. Inter-rate agreement

\begin{tabular}{cc}
\hline Descriptor & Cronbach's Alpha \\
Communication & .909 \\
Expressions & .958 \\
Turn-taking & .951 \\
Backchannel & .962 \\
\hline
\end{tabular}

Two types of analysis were conducted to examine appropriateness, on the one hand, the overall appropriateness was calculated without splitting data into participants' role, thereby only into proficiency level groups; and on the other hand, an analysis of appropriateness that involved participants' proficiency level and role was conducted to examine differences not only as regards the proficiency level but also taking into account the role performed.

Concerning the overall analysis of appropriateness according to the proficiency level (see Table 40 for a summary of the statistical results), results indicated that no significant differences were found as regards the descriptors of communication and backchannel, while significant differences were observed in expressions and turn-taking, both $\mathrm{p}<.001^{* *}$.

Table 40. Appropriateness according to proficiency level

\begin{tabular}{lcccccc}
\multicolumn{1}{c}{ Descriptor } & Group & $N$ & $M$ & $S D$ & $t$ & $p$ \\
Communication & B1 & 32 & 3.38 & .55 & 1.417 & .162 \\
& B2 & 32 & 3.56 & .50 & & \\
\hline Expressions & B1 & 32 & 2.22 & .71 & 6.471 & $.000^{* *}$ \\
& B2 & 32 & 3.31 & .64 & & \\
\hline Turn-taking & B1 & 32 & 2.63 & .55 & 6.588 & $.000^{* *}$ \\
& B2 & 32 & 3.50 & .51 & & \\
\hline Backchannel & B1 & 32 & 1.50 & .67 & .661 & .511 \\
& B2 & 32 & 1.63 & .83 & & \\
\hline p<.001** & & & & & &
\end{tabular}

The analysis of appropriateness (see Table 41 for a summary of the statistical results) revealed that in the case of the complainer, no significant differences were observed in communication and backchannel, but the descriptors of expressions and turn-taking revealed significant differences $\mathrm{p}<.001^{* *}$. 
Table 41. Appropriateness according to proficiency level and participants' role

\begin{tabular}{|c|c|c|c|c|c|c|}
\hline Descriptor & Group & $N$ & $M$ & $S D$ & $t$ & $p$ \\
\hline \multicolumn{7}{|c|}{ Complainer } \\
\hline \multirow[t]{2}{*}{ Communication } & B1 & 16 & 3.38 & .619 & 5.066 & .358 \\
\hline & B2 & 16 & 3.56 & .512 & & \\
\hline \multirow[t]{2}{*}{ Expressions } & B1 & 16 & 2.13 & .719 & 5.155 & $.000^{* *}$ \\
\hline & $\mathrm{B} 2$ & 16 & 3.31 & .602 & & \\
\hline \multirow[t]{2}{*}{ Turn-taking } & B1 & 16 & 2.50 & .516 & 5.155 & $.000^{* *}$ \\
\hline & $\mathrm{B} 2$ & 16 & 3.44 & .512 & & \\
\hline \multirow[t]{2}{*}{ Backchannel } & B1 & 16 & 1.50 & .730 & .460 & .649 \\
\hline & $\mathrm{B} 2$ & 16 & 1.63 & .806 & & \\
\hline \multicolumn{7}{|c|}{ Complainee } \\
\hline \multirow[t]{2}{*}{ Communication } & B1 & 16 & $3 \cdot 38$ & .50 & 1.048 & .303 \\
\hline & $\mathrm{B} 2$ & 16 & 3.56 & .51 & & \\
\hline \multirow[t]{2}{*}{ Expressions } & B1 & 16 & 2.31 & .70 & 4.017 & $.000^{* *}$ \\
\hline & $\mathrm{B} 2$ & 16 & 3.31 & .70 & & \\
\hline \multirow[t]{2}{*}{ Turn-taking } & B1 & 16 & 2.75 & .58 & 4.210 & $.000^{* *}$ \\
\hline & $\mathrm{B} 2$ & 16 & 3.56 & .51 & & \\
\hline \multirow[t]{2}{*}{ Backchannel } & B1 & 16 & 1.50 & .63 & .460 & .649 \\
\hline & $\mathrm{B} 2$ & 16 & 1.63 & .88 & & \\
\hline
\end{tabular}

Similar results were found in the case of the complainee, since significant differences $\mathrm{p}<.001^{* *}$ were only observed in the descriptors of expressions and turn-taking. It seems that in all the cases examined, the $\mathrm{B} 2$ group outperformed the B1 in the descriptors of expressions and turn-taking, both when examining the whole proficiency group and when splitting data into participants' role and proficiency group.

Concerning the first analysis, results seemed to suggest that no significant differences were found in the case of communication and backchannels. In the case of communication, it should be noted that participants belonged to two proficiency groups that allowed them to communicate successfully with their interlocutors. It is, however, worth mentioning that, as expected, the B2 group appeared to have more linguistic resources at their disposal than the B1 group. Then, although the B1 group was able to communicate, further communicative errors were observed in the data. Nevertheless, the minor linguistic problems identified did not impede their 
communicative exchange. The second analysis revealed similar results for both roles across proficiency levels.

Surprisingly, both proficiency groups seemed to have been rated similarly in the case of backchannels. As shown in Section 5.1.3.1, results suggested that the $\mathrm{B} 2$ group produced slightly more instances than the B1 group when comparing the total number of occurrences performed by both groups. However, when focusing particularly on each role, results showed that only a significant difference was found in the case of the complainee. It is also important to note that in examining appropriateness, the two raters observed whether the backchannel phenomena were used or not in the conversation, taking into account a scale from commonly used to non-observed (1-4). When focusing particularly on participants' role and proficiency level, results concerning appropriateness also pointed to the lack of significant differences, revealing no significant differences as regards backchannels.

As expected, results concerning appropriateness revealed significant differences in the case of expressions and turn-taking, revealing in both analyses that the B2 group outperformed the B1.

Specifically, the expressions performed by the B2 group in both cases appeared to be more appropriate for the context in the sense that participants, in general, showed further sociopragmatic sensibility towards their interlocutors due to the severity of offence involved in the situation they acted out. Then, they were ranked with higher values than the B1 group, which showed more direct discourse functions. Albeit the level of (in)directness was not statistically examined in this study, participants' choice of paralinguistic features revealed a tendency for the B2 to employ more indirect expressions than the B1 group did. For example, as shown in Section 5.1.2.1, the complainer tended to utter, as statistically shown, slightly more discourse functions of dissatisfaction in the post-complaint than the B1 group, which is an indirect manner of showing that a grievance is committed. Also, in the case of the overall use of discourse functions, 
the B2 appeared to employ more frequently the discourse function of acceptance, possibly to avoid conflict with the complainee in an attempt to restore harmony and repair the situation. In the case of the complainee, results showed that the B2 group employed slightly more discourse functions of the speech act of suggestions than the B1 group (Section 5.1.2.2) in the post-complaint move and from a qualitative perspective it was observed that the $\mathrm{B} 2$ group tended to employ more mitigators while the B1 group did not do it so frequently. In short, participants' choice of pragmalinguistic features appeared to influence the results of the appropriateness.

In the case of turn-taking, results also seemed to indicate that the B2 group produced them in a more successful manner than the B1 did. It is, however, important to note that the raters did not rank any participant of the B1 group with the lowest score since their turntaking performance did not impede communication and any participant was not able to keep the flow of the conversation. Rather, both groups faced, on some occasions, difficulties to perform turns in a natural manner, although this issue was more evident in the B1 group.

Appropriateness in this study, as in Taguchi (2006, 2011) involved the analysis of multiple aspects, which might be attributed to participants' proficiency level. The results of the analysis of appropriateness seemed to be in line with Taguchi $(2006,2011)$ who found that proficiency had an effect on the overall appropriateness of speech act production. Results appeared to indicate that participants' proficiency level seemed to have influenced the overall appropriateness, and particularly the descriptors of expressions and turn-taking. Results as regards turn-taking system could have been also affected the fact that participants at the B1 level appeared to be more focused on the production of the interlocutor in order to provide an utterance than did fit in the context, than on reacting in a more natural manner. This was also observed in the case of 
overlapping as it was found that the B2 level appeared to be show more features of authentic language use.

Having reported on the results concerning the first research question, in the following section I address the results as regards the second research question.

\subsection{RQ2: How does a multimodal approach enrich the analysis of interlanguage complaints across proficiency levels?}

The second research question of this study is concerned with how a multimodal approach might enrich the analysis of interlanguage complaints across proficiency levels. In order to answer the second research question, different analyses were carried out to examine how participants at two different proficiency levels construct talk from a multimodal perspective. Furthermore, an analysis of multimodal appropriateness of conversation was conducted.

\subsubsection{Multimodal pragmatics}

Qualitative research often involves words or language, but may also use pictures or photographs and observations. It includes detailed explanations that give an in-depth picture employed for exploring how and why things have happened. Among the possible systems to qualitatively analyse data in the analysis of language and communication we may include for example discourse analysis or CA.

Since the purpose of this study was not only to examine the verbal performance, but also different features that accompany participants' performance, some methodological decisions were 
taken as regards the compilation of the data. Face-to-face interaction involves not only the verbal messages conveyed in the different turns speakers construct, but also all the extra-linguistic and paralinguistic elements that may accompany and supplement the communicative event. Concerning this, $\mathrm{Li}$ (2014: 219) indicates that differently to "linear progression of verbal utterances, body movements may cooccur with talk in such a simultaneous manner".

Following a multimodal CA approach (Mondada, 2008, 2016; Streeck et al., 2011), I present a qualitative analysis of two role-play data in order to uncover how participants construct, interact and react in a specific scenario. The analysis involved the perspective of the two participants of each pair since the multimodal interaction was the focus, and thus attention is paid to the actions taken by the participants, not only while performing verbal utterances, but also when taking the role of the addressee.

It should be noted that although in this study, a total of 32 videos were collected, as explained in the design of the corpus (see Section 4.3), the qualitative multimodal CA was done on only two of them, involving a pair of each particular proficiency group (B1 and B2). The four participants were selected taking into account the results obtained in the background questionnaire and drawing on the results obtained in the retrospective verbal reports.

Nevertheless, before focusing on the qualitative data of the present study, I present a short summary of the quantitative results of the two proficiency pairs reported in this section. Table 42 displays the quantitative analysis of the multimodal analysis. 
Table 42. Multimodal conversation analysis results

\begin{tabular}{|c|c|c|c|c|c|}
\hline Tier & Total & Complainer & \multicolumn{3}{|c|}{ Complainee } \\
\hline \multicolumn{6}{|c|}{ B1 pair } \\
\hline & & $f$ & $\%$ & $f$ & $\%$ \\
\hline $\begin{array}{l}\text { Discourse } \\
\text { functions }\end{array}$ & 84 & 41 & 48.80 & 43 & 51.20 \\
\hline Backchannel & 5 & 2 & 40 & 3 & 60 \\
\hline Overlap & 5 & 2 & 40 & 3 & 60 \\
\hline Moves & 5 & & & & \\
\hline Gesture & 82 & 27 & 32.93 & 55 & 67.07 \\
\hline Face & 53 & 13 & 24.53 & 40 & 75.47 \\
\hline Gaze & 212 & 95 & 44.82 & 117 & 55.18 \\
\hline Head & 74 & 26 & 35.14 & 48 & 64.86 \\
\hline Paralanguage & 20 & 3 & 15 & 17 & 85 \\
\hline \multicolumn{6}{|c|}{ B2 pair } \\
\hline & & $f$ & $\%$ & $f$ & $\%$ \\
\hline $\begin{array}{l}\text { Discourse } \\
\text { functions }\end{array}$ & 79 & 39 & 49.37 & 40 & 50.63 \\
\hline Backchannel & 19 & 4 & 21.05 & 15 & 78.95 \\
\hline Overlap & 16 & 8 & 50 & 8 & 50 \\
\hline Moves & 4 & & & & \\
\hline Gesture & 109 & 55 & 50.46 & 54 & 49.54 \\
\hline Face & 22 & 10 & $45 \cdot 45$ & 12 & 54.55 \\
\hline Gaze & 175 & 80 & $45 \cdot 71$ & 95 & 54.29 \\
\hline Head & 48 & 20 & 41.67 & 28 & 58.33 \\
\hline Paralanguage & 36 & 16 & 44.44 & 20 & 55.56 \\
\hline
\end{tabular}

As observed in the table, results revealed that participants across the two proficiency levels tended to employ a similar amount of discourse functions ( $\mathrm{B} 1 f=84 ; \mathrm{B} 2 f=79$ ) and moves, albeit the B1 pair interacted in all the pre-established moves (B1 $f=5 ; \mathrm{B} 2 f=4$ ), while the B2 pair did not perform the closing move. Concerning backchannels, results seemed to suggest that the B1 pair produced 6 while the B2 elicited 19. Although both groups produced them, backchannel was mainly observed in the B2 complainee $(f=15)$. Overlapping was found in both groups, but mainly in the B2 group $(f=16)$, probably as a result of their proficiency level.

Concerning the total amount of gestures, results revealed that, although both group performed them in the interaction, the B2 $(f=109)$ produced slightly more gestures than the B1 $(f=82)$. Interestingly, results also showed that the B1 complainee $(f=55)$ employed more gestures than the B1 complainer $(f=27)$. In the case of the B2 pair, both participants seemed to produce a similar amount of gestures, i.e. complainer $(f=55)$ and complainee $(f=54)$. Regarding 
gaze, results revealed that the B1 pair $(f=212)$ performed this particular kinesic resource more frequently than the B2 pair $(f=175)$. In both proficiency groups the participants who performed the role of complainee ( $\mathrm{B} 1 f=117, \mathrm{~B} 2 f=95$ ) tended to exhibit slightly more occurrences than the complainer (B1 $f=95, \mathrm{~B} 2 f=80$ ). This particular result could be attributed to the face threatening nature of the speech act of complaints (Brown and Levinson, 1987).

Facial expressions conveying specific emotional content were mainly observed in the B1 pair $(f=53)$, and more particularly in the participants performing the role of the complainee $(f=40)$. By contrast, in the B2 pair $(f=22)$ results were not as striking since both participants appeared to exhibit a similar amount of occurrences, i.e. the complainer $(f=10)$ and the complainee $(f=12)$. Hence, results seemed to indicate that the complainee in the B1 pair revealed more frequently emotional meaning by means of facial expressions than the remaining participants. This result could be attributed to participant's involvement in the task not only in terms of content but also due to proficiency issues, which may point to the complexity of the task at least for this particular B1 participant.

Results concerning head movement appeared to suggest that the B1 $(f=74)$ employed this particular kinesic resource more frequently than the B2 group did $(f=48)$. In focusing on each specific role, results indicated that the B1 complainee $(f=48)$ performed head movements more frequently not only than the complainer B1 $(f=26)$ but also than the complainer $(f=20)$ and the complainee $(f=28)$ in the B2 pair. Finally, data revealed that in the case of paralanguage, more occurrences were found in the B2 pair $(f=36)$ than in the B1 $(f=20)$. Interestingly, participants performing the role of the complainee appeared to exhibited more occurrences of paralanguage in the conversation, (B1 $f=17, \mathrm{~B} 2 f=20)$.

Moreover, the quantitative results seemed to suggest that the two kinesic resources that were more frequently used when performing complaints and responses to complaints were gaze (B1 
$f=212, \mathrm{~B} 2 f=175)$ and gestures (B1 $f=82, \mathrm{~B} 2 f=109)$ in both proficiency groups. These particular results might indicate that the two pairs employed these two kinesic resources in the conversation not only to co-express their verbal utterances, but also while attending the interlocutors, thereby showing signals of active listenership. Head movement can also contribute to show signals of active listenership as well as backchannels. It is important to pay attention to active listenership signals as they serve to construct the conversation. However, this specific issue has been under-explored in general in the area of pragmatics (Knight and Adolphs, 2008), and particularly in the field of ILP.

In addition to this, it is also important to show from a qualitative perspective the results as regards gesture type and gesture function. Table 43 shows the results obtained in the analysis.

As observed in the table, results seemed to suggest that in both proficiency groups there was a tendency to perform mainly beats (B1 $f=24, \mathrm{~B} 2 f=35$ ), deictics (B1 $f=24, \mathrm{~B} 2 f=34$ ) and adaptors (B1 $f=15$, B2 $f=27$ ). In the case of functions results appeared to reveal that in the B1 pair, the majority of the gestures performed were attributed to the referential function $(f=30)$ followed by the pragmatic function of parsing $(f=21)$. In the case of the B2 pair, results seemed to indicate that the referential function was also widely associated to the gestures participants performed $(f=25)$ as well as to the pragmatic functions of parsing $(f=30)$ and modal $(f=39)$. Moreover, results appeared to suggest that the referential function was mainly attributed to the gestures performed by the complainees in each level proficiency level (B1 $f=22$, B2 $f=14$ ). The pragmatic function of parsing revealed a different result, more precisely, in the case of the B1 pair, this function was more frequently attributed to the complainee $(f=15)$ and in the B2 pair to the complainer $(f=19)$. The modal pragmatic function was mainly observed in both participants, the complainer ( $\mathrm{B} 1 f=7, \mathrm{~B} 2 f=19$ ) and the complainee (B1 $f=6$, B2 $f=20$ ). 
Table 43 • Gesture type and gesture function results

\begin{tabular}{|c|c|c|c|c|c|}
\hline Gesture type & Total & Complainer & \multicolumn{3}{|c|}{ Complainee } \\
\hline \multicolumn{6}{|c|}{ B1 pair } \\
\hline & & $f$ & $\%$ & $f$ & $\%$ \\
\hline Iconic & 6 & 2 & $33 \cdot 33$ & 4 & 66.67 \\
\hline Metaphoric & 9 & 2 & 22.22 & 7 & 77.78 \\
\hline Deictic & 24 & 6 & 25 & 18 & 75 \\
\hline Beat & 24 & 8 & $33 \cdot 33$ & 16 & 66.67 \\
\hline Adaptor & 15 & 7 & 46.67 & 8 & $53 \cdot 33$ \\
\hline Emblem & 4 & 2 & 50 & 2 & 50 \\
\hline Total & 82 & 27 & 32.93 & 55 & 67.07 \\
\hline \multicolumn{6}{|c|}{ B2 pair } \\
\hline & & $f$ & $\%$ & $f$ & $\%$ \\
\hline Iconic & O & O & O & O & $\mathrm{O}$ \\
\hline Metaphoric & 11 & 3 & 27.28 & 8 & 72.72 \\
\hline Deictic & 34 & 19 & 55.88 & 15 & 44.12 \\
\hline Beat & 35 & 21 & 60 & 14 & 40 \\
\hline Adaptor & 27 & 11 & 40.74 & 16 & 59.26 \\
\hline Emblem & 2 & 1 & 50 & 1 & 50 \\
\hline Total & 109 & 55 & 50.46 & 54 & 49.54 \\
\hline Gesture function & Total & \multicolumn{2}{|l|}{ Complainer } & \multicolumn{2}{|c|}{ Complainee } \\
\hline \multicolumn{6}{|c|}{ B1 pair } \\
\hline & & $f$ & $\%$ & $f$ & $\%$ \\
\hline Interpersonal & 4 & 2 & 50 & 2 & 50 \\
\hline Modal & 13 & 7 & 53.85 & 6 & 46.15 \\
\hline Parsing & 21 & 6 & 28.57 & 15 & 71.43 \\
\hline Performative & 14 & 4 & 28.57 & 10 & 71.43 \\
\hline Referential & 30 & 8 & 26.67 & 22 & $73 \cdot 33$ \\
\hline Total & 82 & 27 & 32.93 & 55 & 67.07 \\
\hline \multicolumn{6}{|c|}{ B2 pair } \\
\hline & & $f$ & $\%$ & $f$ & $\%$ \\
\hline Interpersonal & 4 & 2 & 50 & 2 & 50 \\
\hline Modal & 39 & 19 & 48.72 & 20 & 51.28 \\
\hline Parsing & 30 & 19 & 63.33 & 11 & 36.67 \\
\hline Performative & 11 & 4 & 36.36 & 7 & 63.64 \\
\hline Referential & 25 & 11 & 44 & 14 & 56 \\
\hline Total & 109 & 55 & 50.46 & 54 & 49.54 \\
\hline
\end{tabular}

Results from a qualitative perspective, however, need to be enriched by a quantitative perspective in order to better understand participants' performance. Furthermore, personality traits could have also affected participants' performance of gestures and therefore these results should be viewed in context of the study, which involves FL leaners of English. These specific results were presented here to show the total number of frequency of the different modes that were employed in the simulated conversation. Nevertheless, it should be noted that the major focus of this section is to report on the results 
from a qualitative perspective rather than from a quantitative perspective.

In incorporating a multimodal approach for the analysis of complaints and responses to complaints we obtain a full perspective for all the dimensions of the communicative instance, and we may observe how participants, by means of language, paralanguage and bodily motions, unfold and construct their conversation. As I present here, the spoken data and other communicative modes such as gestures, facial expressions, gaze, head movement and paralanguage resources interplayed in the construction of talk. More specifically, these resources appeared accompany and supplement the verbal message.

The multimodal data I discuss in this section involves the interaction of 2 males in each particular proficiency level group. Following the structure of moves, I present the results and discussion of the multimodal analysis from a qualitative perspective. It is important not to lose sight of the fact that data involves FL learners performing a simulated situation and therefore visual information perhaps contains signals of mutual understanding and/or support between the speakers, and even a touch of humour.

In what follows, I present different examples that show the conversation of the two pairs. As I report here, participants used extra-linguistic and paralanguage resources over the course of the conversation. In order to provide an appropriate illustration of the examples, images are embedded just above the transcription so they can be easily identified. In an attempt to avoid an overload of figures containing imagines of the participants' conversation, a selection of representative images is presented. The analysis involved not only the perspective of one participant, but both participants since attention is paid to the actions taken by both participants not only while performing verbal utterances, but also when taking the role of the listener. This study was carried out following a multimodal CA approach (e.g. Mondada, 2011; 2014) of interlanguage complaints. To 
carry out this analysis, the software ELAN, introduced in Chapter 4 Section 4.5.2, involving 36 tiers, was used.

\subsubsection{Opening move}

In this particular section, I report on the opening move of the participants of this study. Example 21 and Example 22 present data as regards each particular pair.

Example 21. Opening move of B1 pair

\section{Line Turn Participant}

A: Complainer and B: Complainee

A moment before the conversation started in which participants were asked about their names

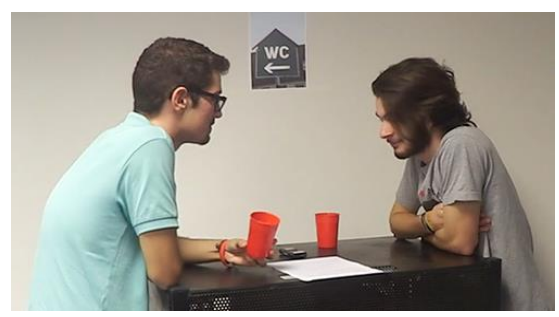

Snapshot 1. B1 Initial position

Opening move

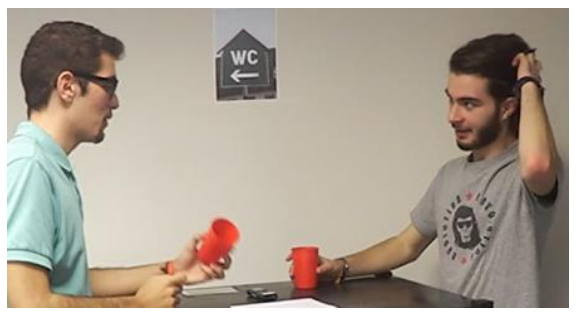

Snapshot 2. B1 Opening

\begin{tabular}{|c|c|c|c|}
\hline 1 & 1 & A_\#6 & hello \\
\hline 2 & 2 & B_\#6 & $\begin{array}{l}\text { hey hi (name of the participant) } \\
\text { how are you? }\end{array}$ \\
\hline 3 & 3 & A_\#6 & I'm ok and you? \\
\hline 4 & 4 & B_\#6 & I'm fine \\
\hline
\end{tabular}

Example 21 involves part of the B1 opening in which the two participants greeted each other. Starting from the initial position in 
which participants were asked about their names (Snapshot 1.), it might be observed that they were just resting their arms on the table, but once they started the conversation (line 1), the complainer immediately performed an adaptor, touching his hair, (Snapshot 2). Although difficult to determine, this adaptor might be associated to participants' emotional state such as nervousness or anxiety. In fact, Gregersen (et al., 2009) found that less proficient participants tended to use adaptive behaviours that could reveal anxiety levels. Nevertheless, it could be also related to personality traits. The complainer's verbal greeting was accompanied with a smile and keeping a fixed gaze direction towards the complainee during the opening move (Snapshot 2 and Snapshot 3). Simultaneously, the complainee, who was holding a glass and even moved it back and forth on some occasions, tended to change gaze direction during the initial turns (line 2 and line 4). Hence, different gaze directions and hand movement changes were observed in the complainee. He kept eye contact with the complainer in the first part of his turn 2 "hey hi", but then he changed gaze direction and looked down to complete the initial turn ("how are you?") (Snapshot 2). After this, the complainee moved his head again and tried to keep contact with the complainer and smiled. This action might be regarded as a signal of turn completion. Then, the complainee changed gaze direction and head position when he performed turn 4 (Snapshot 3). Interestingly, both participants, in a way, changed their bodily position after the first exchanges since they went back to their initial position (Snapshot 3), that is, resting arms on the table. The complainee's gaze direction was interesting since he was changing it quite often within the same turn. More precisely, he was modifying his gaze position while uttering turns, which might be associated to an emotional state, such as anxiety as a result of the perceived complexity of the spoken task, and to proficiency issues. 
Example 22. Opening move of B2 pair

Line Turn Participant

Opening move

A moment before the conversation started in which participants were asked about their names

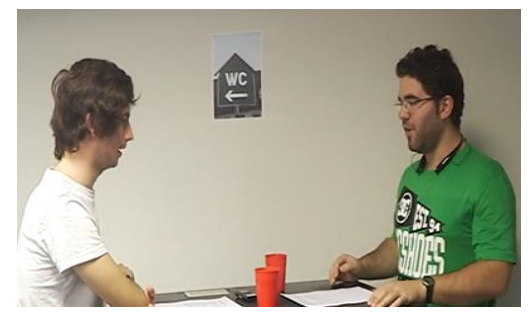

Snapshot 4. B2 Initial position

Opening move

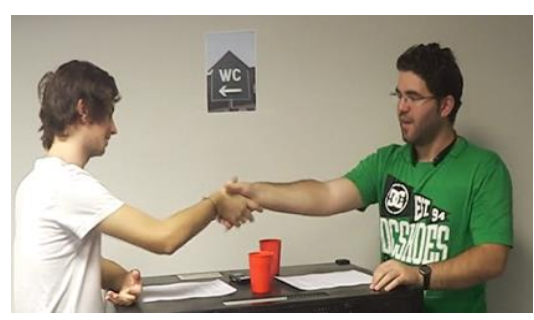

Snapshot 5. B2 Opening

$\begin{array}{llll}1 & 1 & \text { A_\#17 } & \text { so hey how are you? } \\ 2 & 2 & \text { B_\#17 } & \text { how is it going? }\end{array}$

Example 22 shows the opening move of the participants in the B2 group. The initial position of the participants before starting the conversation is shown in Snapshot 4. As can be observed, the complainer rested his hands on the table whereas the complainee rested his arms on it. Once they opened the conversation, the two participants did shake hands while greeting (Snapshot 5). This is indeed a rather ordinary way of performing salutations in many cultures in authentic conversations for example in conversations involving two friends. This particular issue is mentioned here as the cameras can provide this information whereas audio recorder cannot. It seems that the setting, participants' position, as well as the use of cameras, allowed them to perform this type of non-verbal greeting. It could be argued that if the situation had not been video recorded, 
perhaps they would have not employed a non-verbal greeting as they did. Although difficult to appreciate without the video streaming, it was the complainer who started the non-verbal greeting. In this case, face expression revealed that the complainee smiled while the complainer remained more serious, which might be attributed to the context of the situation, a compliant. Nevertheless, both participants kept eye contact in the opening move.

These two particular examples serve to illustrate the opening of the conversation in which participants simply did greet each other. Although these particular examples, apparently, do not provide much insight into participants' proficiency level, it might be, however, suggested that the change in gaze direction of the B1 complainee and the adaptor performed by the $\mathrm{B} 1$ complainer could be attributed to participants' proficiency level and emotional state, showing perhaps nervousness or anxiety. Nevertheless, this is difficult to determine as these two elements can be characteristic of their personality.

\subsubsection{Pre-complaint move}

Moving on to the pre-complaint move, the complainer addressed this issue of the grievance, that is, the particular action that the complainee did and that had a negative effect on the complainer. Since providing a complaint might be rather threating, the complainer is expected to address the complainee in a polite manner so that the situation might be solved and their relationship is not negatively affected (Olshtain and Weinbach, 1993). Example 23 and Example 24 present data as regards each particular pair, the B1 and the $\mathrm{B} 2$ respectively. 
Example 23. Pre-complaint move of B1 pair

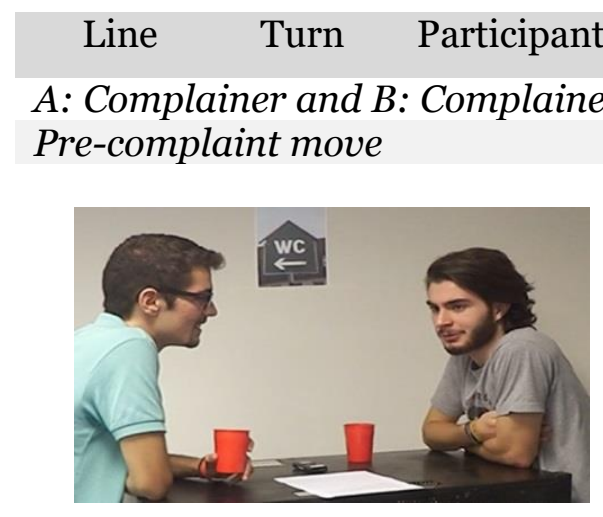

Snapshot 6. B1 Pre-complaint

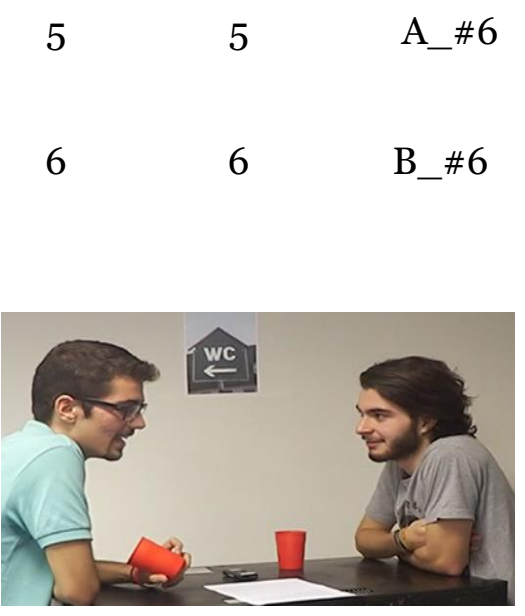

Snapshot 8. B1 Pre-complaint

$\begin{array}{lll}7 & 7 & \text { A_\#6 } \\ 8 & 8 & \text { B_\#6 }\end{array}$

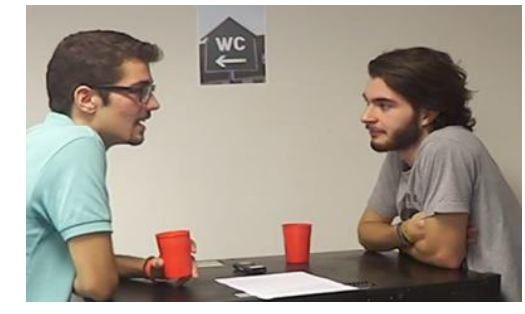

Snapshot 7. B1 Pre-complaint

$$
\begin{aligned}
& \text { er } \\
& <\text { er }>/ / F \_ \text {PAUSE }>\text { what are you } \\
& \text { doing tomorrow? } \\
& \text { er } \\
& <\text { B6:F_PAUSE }<\text { er }>/ / \text { F_PAUSE }>\text { I } \\
& \text { have a party }
\end{aligned}
$$

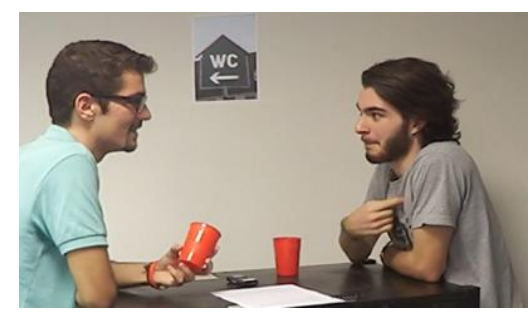

Snapshot 9. B1 Pre-complaint

oh which party?

er <A6:F_PAUSE $<$ er $>/ / F \_P A U S E>I$

have organised a:

$<$ B6:SYL_D $<$ a $>/ /$ SYL_D $>$ party with (o.1) my friends and we invite your friends well our friends but (o.1)

The complainer addressed the complainee in order to know about his plans for the weekend (line 5). Then, he discovered that there was a party and that he was not invited (line 7). The first utterance was coexpressed by different modes, particularly, he looked away and moved his head slowly to one side while performing the first part of the turn in which a filled pause was also uttered in the initial position of the turn, possibly revealing a thinking process (Snapshot 6). Meanwhile, the complainee kept his gaze direction towards the 
complainer while he was performing his turn. However, his bodily position was modified when he had to take the turn. The complainee exhibited a similar behaviour when uttering the first part of turn 6 (line 6). Particularly, he moved his head slowly to one side and changed gaze direction, looked down, moved his hand toward himself, revealing a deictic gesture that might have showed an interpersonal function as it appeared to regulate the turn-taking system, and performed a filled pause in the initial part of the turn (Snapshot 7). Participant's change in gaze direction, head movement and the performance of a filled pause could be attributed to participant's thinking process.

The complainer, in line 7, possibly in an attempt to "pretend" being surprised, raised his eyebrow in the initial part of his turn and then smiled when completing the turn ("which party?") (Snapshot 8). In line 8 , the complainee appeared to exhibit a similar non-verbal response as that shown in line 6 . Specifically, he moved his head slowly to one side, changed gaze direction so as to look down and smiled while uttering a filled pause (Snapshot 8). Moreover, he performed a deictic gesture pointing at himself revealing an interpersonal function that seemed to regulate the turn-taking (Kendon, 2004). The performance of a filled pause in this particular context might be attributed to the participant's thinking process, as in the previous case. This specific bodily position was observed in the initial part of turn 8 "er I have organised a". Then, when completing the turn, the complainee moved his head slowly so that he could also change his gaze direction so as to keep eye contact with the complainer and performed various hand movements. Particularly, he first pointed the complainer and uttered "a party", which might have served him to not only emphasise the event but also to show a referential function. Then, he produced another deictic gesture pointing at himself when he uttered "my friends" in an attempt to show that he referred to his private sphere and revealing a referential function (Snapshot 8). Another deictic gesture was identified in the 
complainee when he performed "your friends", pointing to the complainer (Snapshot 9), possibly revealing a referential function, which appeared to point to a particular element in the speech. This particular gesture, however, could have been influenced by the complainer's deictic gesture (Snapshot 9). Specifically, the complainer pointed at himself to indicate that he was one of the invited friends. The complainer, without producing any sound, moved his lips to utter "me", which was simultaneously accompanied by a deictic gesture. Moreover, while doing so, the complainee kept eye contact with the complainer and smiled. This particular example could reveal the mutual understanding and support that the two participants exhibited while completing the role-play.

Interestingly, both participants employed filled pauses for thinking process, which were performed at the initial part of the turn, possibly to prepare the turn. Moreover, filled pauses were accompanied by a slow head movement and change in gaze direction. Concerning this, Kim (2012) found that less proficient speakers tended to employ more gestures for lexical search. In this concrete move, gestures were not observed to indicate lexical search, but head movement and filled pauses, which appeared to point to lexical search, thinking or planning process (Goldman-Eisler, 1968). The thinking process might be also attributed to a particular proficiency level and ability to take turns in the spoken mode. In fact, in paying attention to the way the turns were organised, it may be observed that participants did not interrupt each other by means of overlapping but waited until the interlocutor completed the turn so as to create a new one. This particular behaviour might be associated to participants' proficiency level in the sense that they remained silent while the other interlocutor was performing the turn. As regards gestures, it might be indicated that the complainer remained mostly with his arms crossed and resting on the table. However, he performed one gesture in order to point at himself "as one of the friends", which could also be regarded as a way of showing mutual 
understanding and support between the participants. By contrast, the complainee employed deictic gestures. For example, he produced one deictic gesture when pointing at himself to signal the turn-taking, thereby somehow orchestrating the floor, as well as to referring to a non-present reference, friends.

Moving on to the B2 pair, participants also performed the precomplaint move in which the complainer addressed the issue of the grievance. Differently to the B1 group, in this case, participants and particularly the complainer, focused on the issue rather than gathering information so as to start the conversation.

Example 24. Pre-complaint move of B2 pair

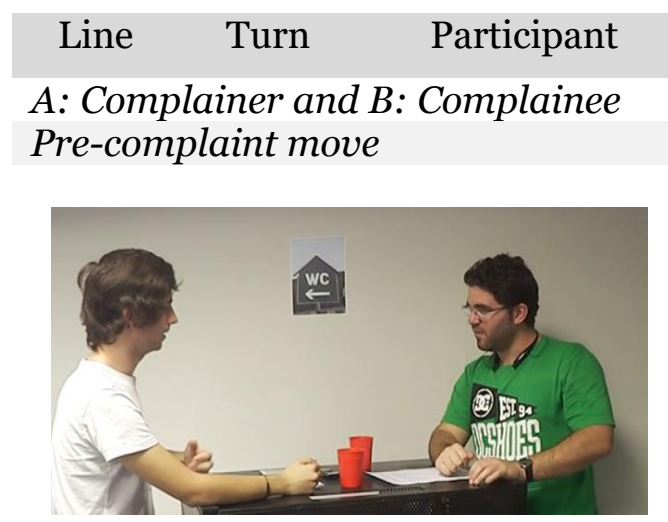

Snapshot 10. B2 Pre-complaint

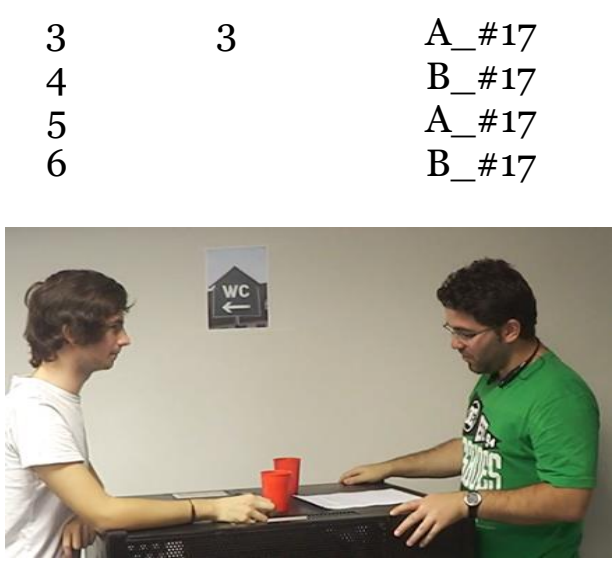

Snapshot 12. B2 Pre-complaint
A_\#17

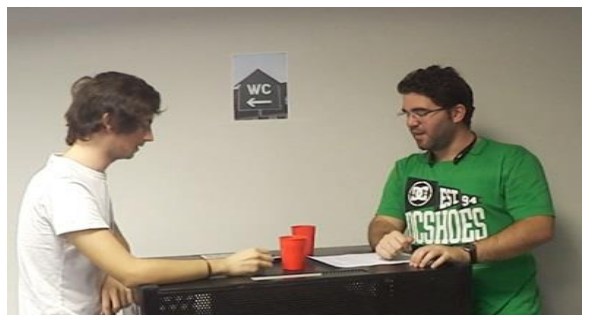

Snapshot 11. B2 Pre-complaint

I wanted to talk to you ok $<$ B17:BC_AGREE $<$ ok $>/ /$ BC $>$ and yeah $<$ B17:BC_CON $<$ yeah $>/ /$ BC $>$

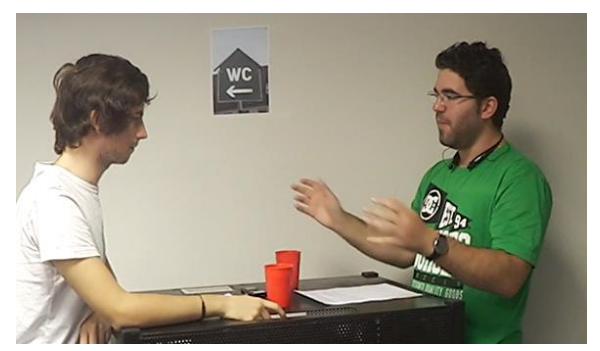

Snapshot 13. B2 Pre-complaint

er $<$ A17:F_PAUSE $<$ er $>/ / F \_P A U S E>$ I heard you just 


er $<$ A17:F_PAUSE
$<$ er $>/ /$ F_PAUSE $>$ organised
organised a big //big// party umm
$<$ A17:F_PAUSE
$<$ umm $>/ /$ F_PAUSE $>$ [a::nd]
$<$ B17:SYL_D_<and $>/ /$ SYL_D $>$
$<$ B17:OVERLAP
yeah $>/ /$ OVERLAP $>$

Once they opened the conversation, the complainer approached the grievance by indicating that there was something to talk about (line 3) by means of a preparation discourse function. In that particular moment, both participants shared eye contact and both remained with signals of a serious face expression, particularly the complainer, who had been negatively affected by the grievance (Snapshot 10). The complainee's change of face expression might have been influenced by the complainer's face expression as well as by his utterance (a preparation discourse function) in line 3 . In this particular moment, in line 4, the complainee performed a backchannel revealing agreement, and when the complainer continued his speech (line 5). The complainee added another backchannel (line 6) (continuer).

The use of backchannels might reveal signal of active listenership. In this particular moment, after performing the first backchannel, the complainee produced a subtle body movement towards the table and performed a head movement, which resulted in a change in gaze direction, and approached his hand towards his body, revealing an adaptor gesture (Snapshot 11). This particular bodily reaction could be related to the forthcoming FTA (Brown and Levinson, 1978, 1987) as well as his attitude towards the situation, thereby suggesting that the gesture could have a modal function. This adaptor might have been produced to develop the interpersonal contact with the complainer. Indeed, this specific adaptor was observed on more occasions during the interaction. Also, the complainer performed a change in his gaze direction since he moved his head down and uttered a backchannel as a response to the complainee's backchannel (Snapshot 11). 
The complainer continued with his speech, and uttered in line 7 "er I heard you just er" and he not only kept his head looking down, but he also changed his bodily position somehow (proxemics) and employed three filled pauses (Snapshot 12). These particular kinesics, proxemics and paralanguage realisations might be associated to a thinking process. Concerning this, it is also important to note that he was about to indicate that his "friend" was responsible for the grievance, and due to the threatening nature of this particular aspect, he might have opted for not keeping eye contact with him. By contrast, the complainee changed his head position by moving it to a position in which he could keep eye contact with the complainer (Snapshot 12).

However, as shown in Snapshot 13, both modified their bodily position. On the one hand, the complainer continued his speech and explicitly referred to the grievance and provided a description of the type of party (line 7, Snapshot 13). In so doing, he performed a metaphorical gesture, which function can be regarded as a referential, i.e. "big party". Particularly, the complainer uttered "organised a big $/ / \mathrm{big} / / \uparrow$ ” and he produced not only the metaphoric gesture but also loudness and repetition along with a face expression revealing anger and addressed his gaze direction towards the complainee. On the other hand, the complainee changed the position of his head so as to modify gaze direction and avoid eye contact with the complainer, who was indeed explicitly pointing him as responsible. Concerning this, it might be suggested that the complainee's reaction might be associated to the complainer's performance of a FTA (Brown and Levinson, 1978, 1987).

In light of this result, it might be argued that the complainer's performance appeared to have an effect on the complainee's, who changed his gaze direction in order to avoid eye contact with the complainer. The complainee's change of gaze direction could be attributed to the FTA elicited by the complainer, which, albeit softened, involved that he was responsible for such grievance. The 
lack of eye contact on some occasions between the two participants would reveal the threatening nature of the situation.

Example 24. Pre-complaint move of B2 pair (continuation)

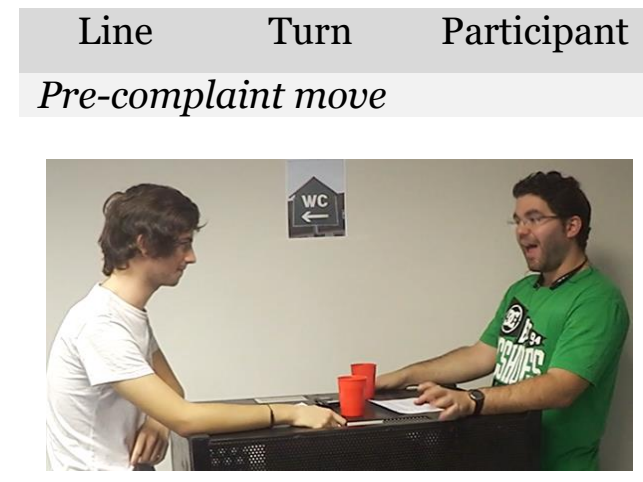

Snapshot 14. B2 Pre-complaint

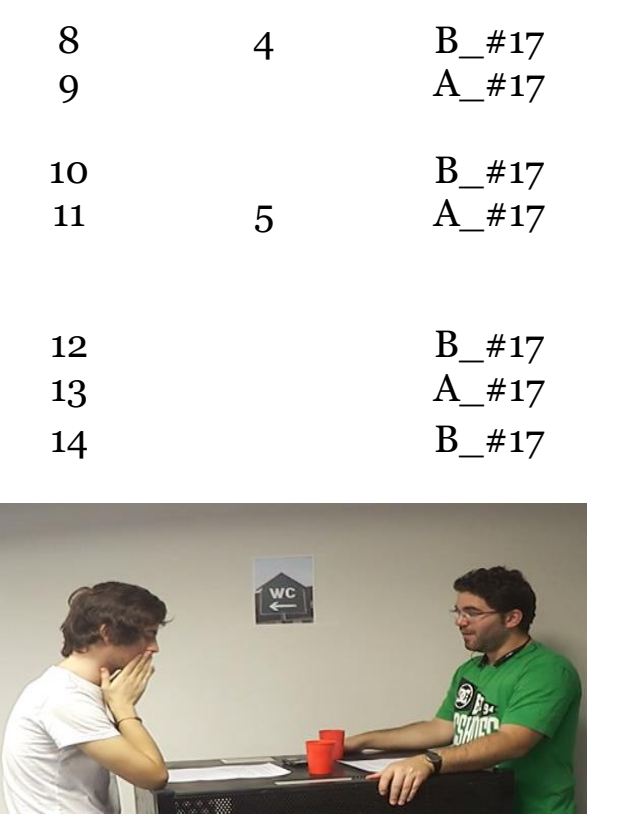

Snapshot 16. B2 Pre-complaint

$\begin{array}{ll}15 & \text { A_\#17 } \\ 16 & \text { A_\#17 } \\ 17 & \text { B_\#17 } \\ 18 & \text { A_\#17 }\end{array}$

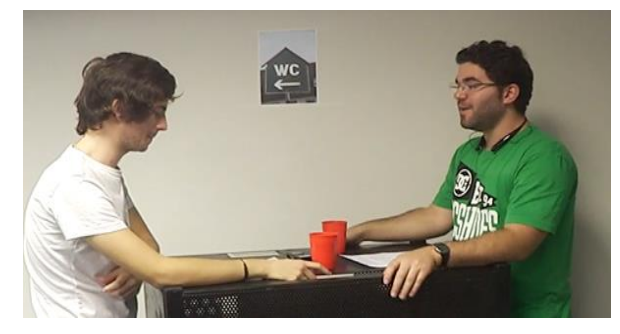

Snapshot 15. B2 Pre-complaint

[oh yeah] that party

er $<$ A17:F_PAUSE $<$ er $>/ / F \_P A U S E>$ yeah $<$ A17:BC_AGREE $<$ yeah $>/ /$ BC $>$ yeah $<$ B17:BC_AGREE $<$ yeah $>/ /$ BC $>$ and I know that er $<$ A17:F_PAUSE $<$ er $>/ / F \_P A U S E>$ one group that $\mathrm{I} \uparrow$ personally love yeah B17:BC_AGREE<yeah $>/ /$ BC $>$ has been invited as well yeah $<$ B17:BC_AGREE $<$ yeah $>/ /$ BC $>$

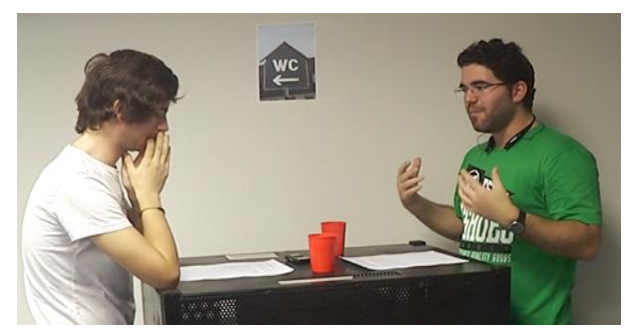

Snapshot 17. B2 Pre-complaint

and you haven't invited me you know (0.1) we've been friends for such a long time umm $<$ B17:BC_AGREE $<$ umm $>/ /$ BC $>$ and you (o.1) haven't invited me why?

In line 11, the complainee moved his head down, which resulted in a change in his gaze direction although he could still keep eye 
contact with the complainer in such position, and performed an adaptor touching his t-shirt, that might be associated to a modal pragmatic function (Snapshot 14). These particular bodily changes might be related to the face threatening situation in which they were involved. In this same sequence, the complainer appeared to produce various changes in his bodily position, as well. Particularly, he modified his gaze direction and head position, and produced a subtle back movement of his body (proxemics) when he referred uttered "and I know that er" (Snapshot 14). This turn was also accompanied by a filled pause, probably revealing a thinking process during the construction of the turn.

Then, in the same turn, line 11, another proxemics feature was identified when the complainer approached his body towards the complainee and performed the following utterance "I $\uparrow$ personally love", which was enriched by means of loudness (Snapshot 15). Concerning this, it might be suggested that he employed this particular movement of body along with the change in tone and his face revealing anger to reinforce his message, which appeared to convey emotional content. In the same turn, the complainee bended his head down a bit more and kept his hand touching his t-shirt, thus performing an adaptor that might be associated to a modal pragmatic function. The complainee might have produced an adaptor so as to maintain the interpersonal contact with the complainer in such particular position. Indeed, this particular adaptor was observed on more occasions during the interaction. The complainee produced a change in his head movement as he appeared to keep on slightly bending his head forward, and then he uttered a backchannel showing agreement (line 13), which was again accompanied by an adaptor by which he moved his hand up and down touching his tshirt (Snapshot 15). Continuing with this turn, the complainer's utterances appeared to evoke a non-verbal response on the complainee, who put his hand on his mouth (line 15) (Snapshot 16). Probably, the complainee performed such action as a consequence of 
the threating situation in which he was involved and he was pointed as responsible, which in turn reflected an emotional state. The complainer further elaborated his turn indicating his position as regards the grievance. This particular message was reinforced by means of a beat gesture that functioned as a parsing pragmatic function that served to accompany his speech (Snapshot 17).

As shown above, participants' interaction appeared to be enriched by means of different modes, not only while taking the floor but also while paying attention to the interlocutor. This particular complaint move revealed examples of changes in gaze direction and head movements of both speakers, but more precisely in the case of the complainee, which might be attributed to the face threatening nature of the communicative act of complaining (Brown and Levinson, 1978, 1987). The complainee also performed some adaptors (Ekman and Friesen, 1969) that could reveal an emotional state derived from the uncomfortable situation. The complainer also employed a beat gesture for example to accompany his speech (Kendon, 2004) as well as changes in loudness so that he could emphasise some specific items within the utterance.

\subsubsection{Topic negotiation move}

An important part of the complaint move is the negotiation of the actual grievance in which speakers express their views on the issue. Example 25 and Example 26 show the topic negotiation move. 
Example 25. Topic negotiation move of B1 pair

\section{Line Turn Participant \\ Topic negotiation move}

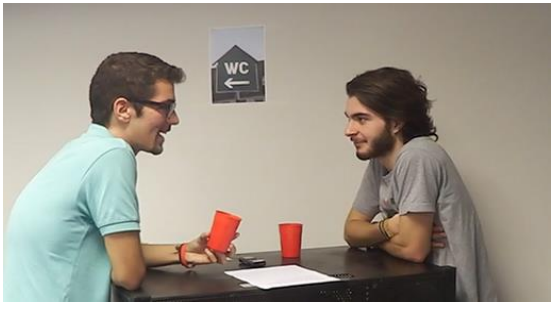

Snapshot 18. B1 Topic Negotiation move

$\begin{array}{ccc}9 & 9 & \text { A_\#6 } \\ 10 & 10 & \text { B_\#6 } \\ 11 & 11 & \text { A_\#6 } \\ 12 & \text { B_\#6 }\end{array}$

Snapshot 20. B1 Topic Negotiation move

$\begin{array}{lll}13 & & \text { A_\#6 } \\ 14 & 12 & \text { B_\#6 } \\ 15 & 13 & \text { A_\#6 } \\ 16 & 14 & \text { B_\#6 }\end{array}$

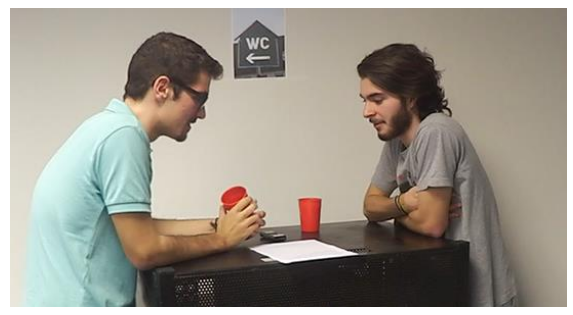

Snapshot 19. B1 Topic Negotiation move

you don't have invite me (o.1) no one said anything to me

I forget it

I was thinking that I will be staying at home all night tomorrow (0.1) there were a party at the same time? yes $<$ B6:BC_AGREE $<$ yes $>/ /$ BC $>$

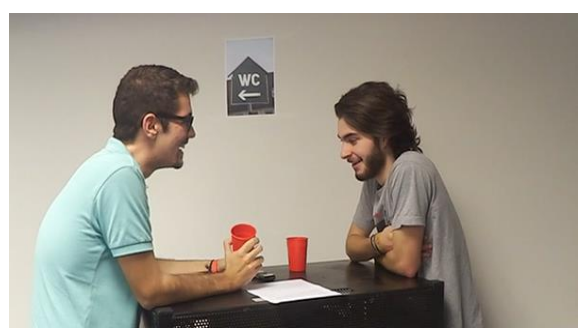

Snapshot 21. B1 Topic Negotiation move

because nobody invited me sorry we forget it (o.1) Ortxata will come <LAUGHTER>

oh I really like Ortxata $<$ LAUGHTER $>$

we know it <LAUGHTER>

The topic negotiation move was also enriched by means of different modes. In this case, the complainer addressed the complainee by explicitly indicating that he had not invited him to the party as well as pointing to their friends, who did not invite him either (line 9).

The complainer remained with his arms crossed and keeping eye contact with the complainee when he uttered "you don't have 
invite me" (Snapshot 18), whereas when he uttered "no one said anything to me", he bended over his head and changed gaze direction. This particular change might be associated to the participant's disillusion towards the grievance as no one had invited him to the party. Meanwhile, the complainee oriented his gaze direction towards the complainer while he was performing his turn. However, once the complainee noticed that the turn was finalised, he moved his head slowly towards the right and changed gaze direction and holding the glass pointing to the complainer (Snapshot 18) and admitted the error. This particular bodily change could be attributed to the participants' proficiency level since he appeared to move his head slowly and change gaze direction in different occasions during the conversation perhaps because he was involved in a thinking process.

Once the complainee performed turn 10, he moved slightly back and smiled, trying to search for mutual understanding with the complainer, who did not react towards such signal. Nevertheless, the complainer modified his non-verbal position when he produced turn 11 (Snapshot 19). More specifically, the complainer bended his head over and changed gaze direction while he was performing the turn, but retuned to a neutral position that allowed him to stare at the complainee. Interestingly, when the complainer was constructing turn 11, he changed gaze direction and moved his head towards the left when he uttered "I will be staying" probably due to the complexity of the tense, which may be complex for a B1 learner, especially in the speaking mode. Then, it seems he was involved in a thinking process.

The complainee moved his body towards the table and grasped the glass with the two hands, and with his head slightly bended over and his gaze direction modified, he looked down instead of at the complainer, admitting the grievance (Snapshot 19). This particular reaction might be explained taking into account the threating nature of the situation. In this case, the complainer was pointing at the 
complainee as the responsible for a particular offence, and the complainee, as observed, produced a kinesic response.

Moving on with the conversation, the complainer, in line 13 insisted again on the fact that he had not been invited to the party (Snapshot 20). In this case, both participants kept eye contact regardless of the fact that the complainer was explicitly addressing the grievance. Concerning this, it might be suggested that the complainee did not change his gaze direction as he was not directly addressed as the only responsible person for the negative action.

In line 14, the complainee took the turn again and he apologised for the grievance and anticipated the group of music that would come (Snapshot 21), and it was the complainer who bended over his head and modified his gaze direction looking down. The complainee, while indicating the name of the music group, he did laugh, which evoked also laugher in the complainee when he uttered "oh I really like Ortxata" (Snapshot 21). The complainee, however, kept looking down during such sequence. This particular non-verbal response elicited by the complainee could be attributed to his attitude towards the situation in which all his friends were invited to a party where a music group he liked was going to play. Therefore, revealing emotions as regards the content of the topic discussed.

Example 25. Topic negotiation of B1 pair (continuation)

Line Turn Participant

Topic negotiation move

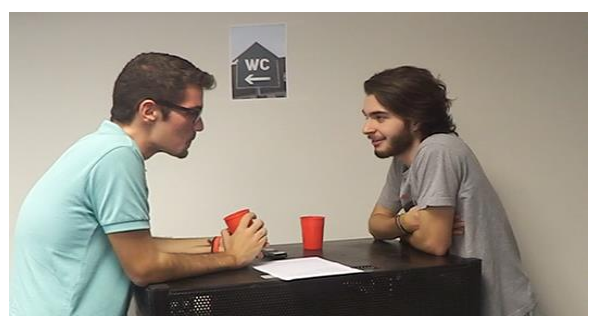

Snapshot 22. B1 Topic Negotiation move

17
15
A_\#6

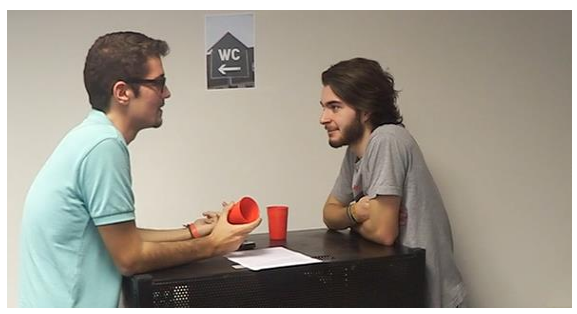

Snapshot 23. B1 Topic Negotiation move

it's my favorite group and nobody thinking me? 


$\begin{array}{lll}18 & 16 & \text { B_\#6 } \\ 19 & 17 & \text { A_\#6 } \\ 20 & & \text { B_\#6 } \\ 21 & & \text { A_\#6 }\end{array}$

sorry I think someone tell you no anybody did it

ok fuck <B6:BC_AGREE $<$ ok fuck $>/ / \mathrm{BC}>$

because I didn't know (o.1) I talk with my friends every day and nobody asked // asked//me to come

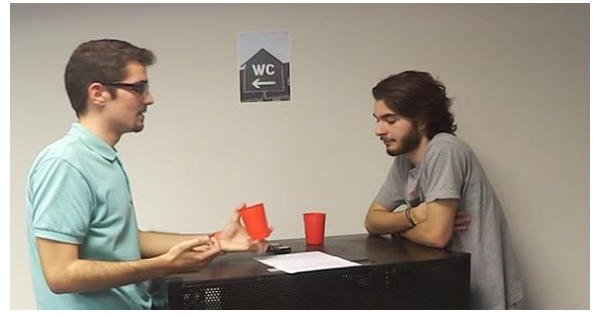

Snapshot 24. B1 Topic Negotiation move

$\begin{array}{ccc}22 & 18 & \text { B_\#6 } \\ 23 & 19 & \text { A_\#6 } \\ 24 & 20 & \text { B_\#6 }\end{array}$

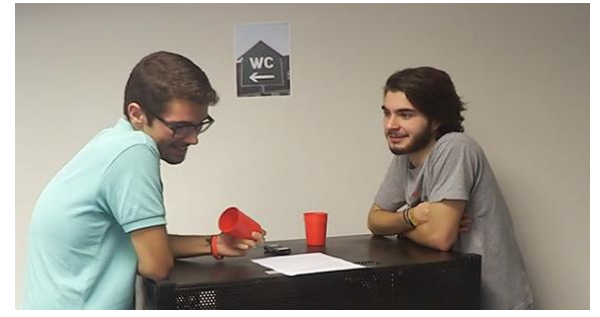

Snapshot 25. B1 Topic Negotiation move

I don't know (0.1) I say they invite all they want or our both friends but I think they tell you no it's your party and it's not your responsibility to invite somebody? yes it's true //it's true// but I don't know (0.1) sorry (0.1) $<$ B6:LAUGHTER $>$ I forget it

The complainee tried to show his feelings in line 17 indicating that that music group was his favourite one. In so doing, he kept eye contact with the complainee showing a neutral face, while the complainee seemed to show a serious face with his head slightly bended over and his gaze direction oriented towards the arms of the complainer (Snapshot 22). The complainee immediately reacted to the utterance elicited by the complainer and apologised for the action (line 18). In so doing, the complainee moved his head slowly up so that he could orient his gaze towards the complainer and open his arms with palms up holding the glass saying "I think someone tell you" (Snapshot 23). This particular movement could have been performed to reveal regret for such grievance. The complainer remained in a fixed position while the complainee was performing that utterance, that is, arms crossed on the table and staring directly at the complainee. More extra-linguistic and paralanguage resources were observed towards the end of the topic negotiation move. 
Particularly, line 22 shows a moment in which they further discussed the responsibility of inviting the complainer to the party. In this particular case, the complainee's turn 18 was accompanied by different moves. The complainee slightly separated his body from the table (proxemics), with his gaze direction towards the complainer and with opened hand up uttered the first part of turn 22, "I don't know", which was finally accompanied by a brief pause (o.1) before continuing with the construction of his turn (Snapshot 24). These specific actions could be somehow attributed to the participants' attitude towards the event in which he was pointed as the main responsible for this situation; while he was trying to show the complainer that more people could have been involved in the grievance. In performing the first part of turn 18 "I don't know", the complainer kept his head slightly bended over and avoided eye contact with the complainee and his gaze direction was also modified so as to look down. This action could be associated to the specific content of the utterance performed by the complainee (line 21).

As they continued interacting, the complainer modified the extra-linguistic behaviour and moved his head up so that he could address his gaze direction towards the complainee. Then, the complainer directly accused the complainee indicating that he was responsible for inviting his friends. This specific utterance involved a change in the complainer's head movement and gaze direction. When he uttered the first part of the turn, "no it's your party" he stared at the complainee, although he also moved his head slightly left and right while performing the turn (Snapshot 25). When the complainer performed the first part of turn 23, the complainee reacted by moving his head towards the right and by changing gaze direction in an attempt to avoid eye contact with the complainer, who instead of ignoring such action, tried to keep eye contact with the complainee (Snapshot 25).

In this particular move, the most prominent extra-linguistic elements were the changes participants produced as regards the 
orientation of gaze direction, which tended to be more frequent when involving uncomfortable moments. As a matter of fact, the topic negotiation move involves the performance of FTAs that might hurt speakers' feelings (Brown and Levinson, 1978, 1987), as observed in this example. Special care should be taken so as to repair the situation since behaving in a non-polite manner could prevent them from solving the problem, or what is worse, damage their relationship. The B2 group also undertook a difficult topic negation move with regard to the exchange of turns that also appeared to influence the participants' kinesic and paralanguage performance.

Example 26. Topic negotiation of B2 pair

Line Turn Participant

Topic negotiation move

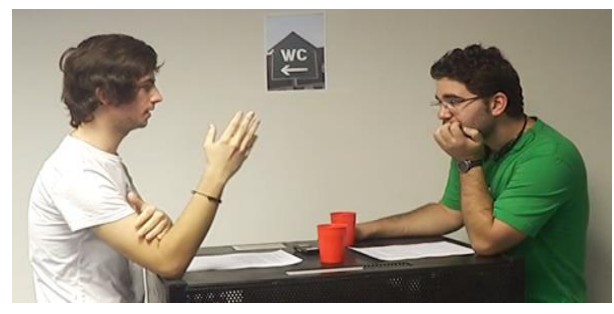

Snapshot 26. B2 Topic Negotiation move
19

6

B_\#17

20 7

A_\#17

A_H17

21

22

23

24

25

26

27

B_\#17

21
22
23
24
25
26

27

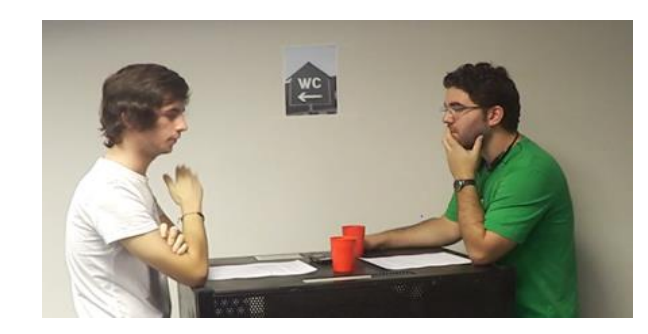

Snapshot 27. B2 Topic Negotiation move

yeah you know it was like it's not like my house (o.1) it's my parents' house and they were like very strict with everyone and they didn't want me to invite like 200 hundred people yes but //but// you invited //you invited// many //many many// people and people you //you// [know for] $=<$ B17:OVERLAP <okay yeah I $>/ /$ OVERLAP $>$

[okay yeah I]

=less time than me= umm $<$ B17:BC_AGREE $<$ umm $>/ /$ BC $>$ and people who are $=$ yeah $<$ B17:BC_AGREE $<$ yeah $>/ /$ BC $>$ $=\mathrm{I}$ thought they were less friends to you than me and, //and// you invited them $=$

yeah umm //umm// 


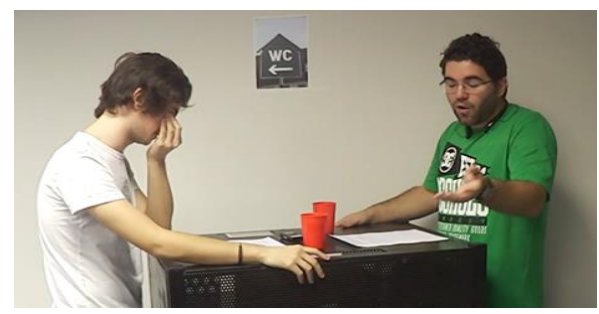

Snapshot 28. B2 $\quad$ Topic Negotiation move

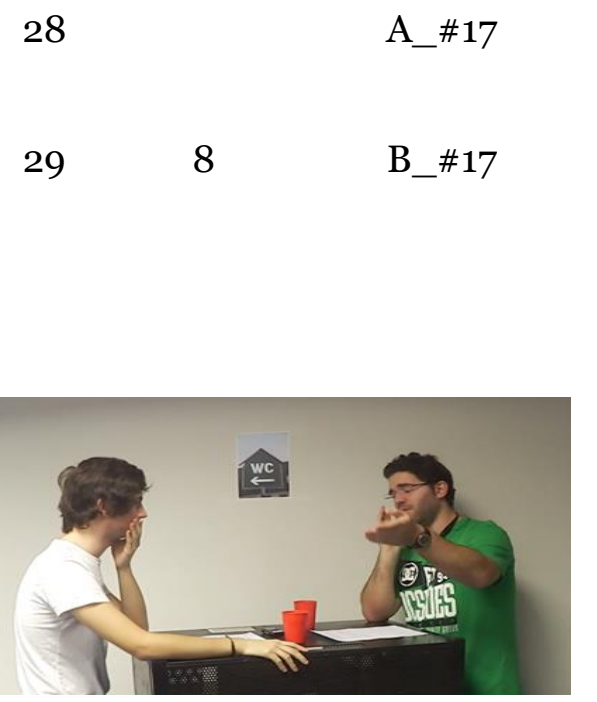

Snapshot 3o. $\quad$ B2 $\quad$ Topic Negotiation move
30
9
A_\#17
31
B_\#17
32
A_\#17
33
34
B_\#17
A_\#17
35
36
$=$ but you know you got me on that that
A17:F_PAUSE $<$ er $>/ / F \_P A U S E>$ WhatsApp group and $=$ yeah $<$ B17:BC_AGREE $<$ yeah $>/ /$ BC $><$ B17: LAUGHTER >
=you know what (0.1) I love that group
yeah $<$ B17:BC_AGREE $<$ yeah $>/ /$ BC $>$ I know that you've created that WhatsApp group for all the people you $=$ yeah $<$ B17:BC_AGREE $<$ yeah $>/ /$ BC $>$ $=$ were inviting you didn't invite me $\uparrow$ either to that group

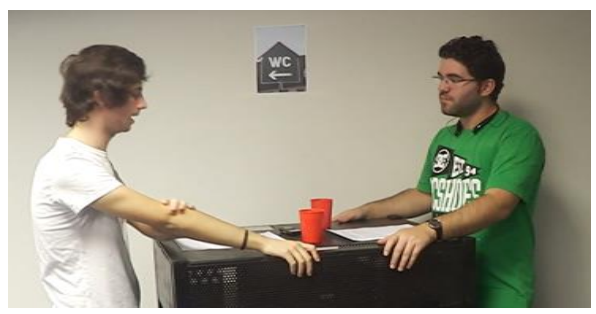

Snapshot 29. B2 Topic Negotiation move

$=$ and I'm here, left [alone] $<$ B17:OVERLAP $\quad<$ yeah I $>/ /$ OVERLAP $>$

[yeah I] just yeah I didn't think about that I don't know maybe I made my //my////my// listing wrong (o.1) I should have chose (0.1) better people that were coming and coming=

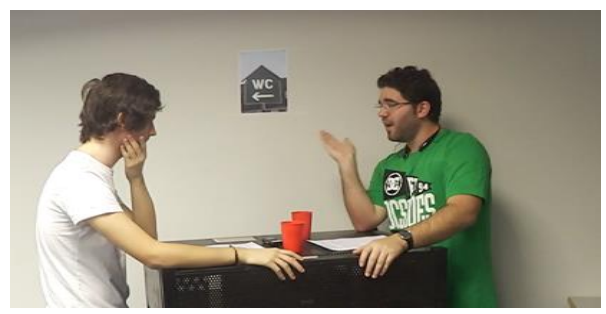

Snapshot 31. B2 Topic Negotiation move

The topic negotiation move was initiated by a turn constructed by the complainee who tried to justify the error. When he took the 
turn, he modified his previous position (Snapshot 26) as he was producing the speech, which was accompanied by various modes. Specifically, the complainee produced an adaptor and two deictic gestures simultaneously. The adaptor gesture involved placing his left hand on his arm, probably revealing a modal function that showed stance towards the situation. Then, two deictic gestures were performed when he was referring to "my house" and "it's my parents" house" (line 18), which could be regarded as containing a referential function. During his speech, he also performed some beat movements to show the flow of the speech. Moreover, as observed in Snapshot 27, he performed a deictic gesture when he uttered "200 hundred people" moving his arm from one side to another, serving as a referential function of the content of the turn. The complainee tried to keep eye contact with the complainer during the first part of his speech, albeit he slowly moved his head to the right and modified his gaze direction when he uttered the phrase "they didn't want me to invite like". His head movement was then back to a neutral position so that he could also share eye contact with the complainer when he finished the turn (line 18).

Meanwhile, the complainer rested his arms on the table while paying attention to the complainee's justification and kept eye contact with him, whenever it was possible. He performed an adaptor gesture by putting his hand on his chin that might have served to show modal function, revealing not only stance towards the content of the utterance elicited by the complainee but also signals of active listenership (Snapshot 26). This particular adaptor was slightly modified when he slightly moved his body back and separated his hand from his mouth. This particular kinesic feature appeared to show an interpersonal function since he started to claim the floor so as to take a new turn (turn 7).

The complainee appeared to reveal his feelings towards the situation by means of a modification of his bodily position. Particularly, by bending his head over and a change in gaze direction 
and putting his left hand over this face (Snapshot 28). Simultaneously, the complainer produced a deictic gesture when he indicated he felt alone since his friend did not invite him to the party (Snapshot 28). This particular gesture may be regarded as modal in the sense that he was indeed referring to a particular attitude towards the situation.

Then, the complainee took the turn again (line 29) and he modified his bodily position so as to claim the floor. Indeed, he overlapped the complainer and managed to take the floor. His change in body position, which involved moving his head slightly up and orienting his gaze direction towards the complainer, could have helped him to take the floor (Snapshot 29). This specific kinesic performance was also accompanied by an adaptor, which appeared to have supported the speaker emotionally when uttering that particular turn. The complainer seemed to yield, in a way, the turn as a result of the complainee's reaction to obtain the floor, and remained with a serious face expression paying attention to his interlocutor (Snapshot 29). His bodily communication was also accompanied by head movements, particularly nodding while focusing on the complainee's speech, revealing again signals of active listenership.

In line 30, the complainer took the floor again and performed two deictic gestures, which appeared to serve as a referential function to represent part of the content of the utterance he elicited as a response to the complainee's turn. Particularly, in line 30, he referred to the "WhatsApp group" (Snapshot 30) and in line 32 to "that group" (Snapshot 31). His face expression was also relevant in both cases since he showed sadness. The complainee, while attending to the complainer's speech, performed an adaptor putting his hand on his mouth and oriented his gaze direction towards the complainer (Snapshot 30). Then, he slightly moved down his hand from his mouth, although he still kept his hand on his face (Snapshot 31). This particular adaptor gesture could reveal participant's attitude towards the situation faced, which involved a rather face threating and 
complex issue, more precisely, a situation in which a friend was offended as he committed a grievance. These particular reactions could be associated to his emotional state as well as to signals of active listenership.

Example 26. Topic negotiation of B2 pair (continuation)

Line Turn Participant

Topic negotiation move

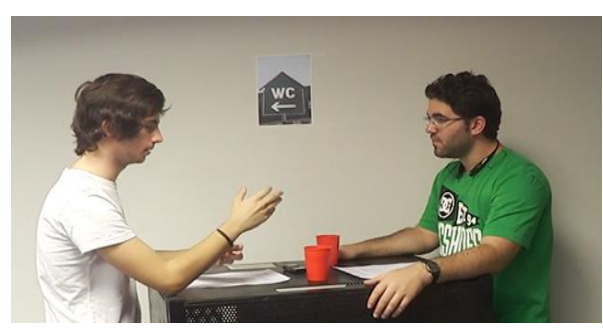

Snapshot 32. B2 Topic Negotiation move

10

$$
\text { B_\#17 }
$$

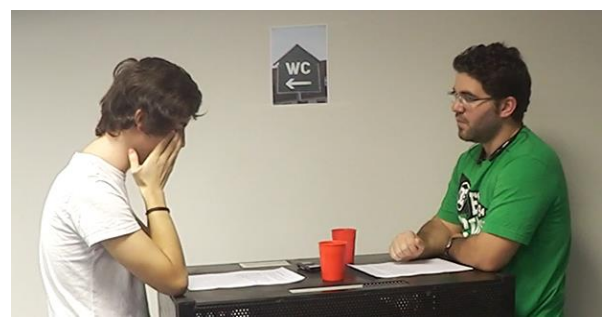

Snapshot 34. B2 Topic Negotiation move

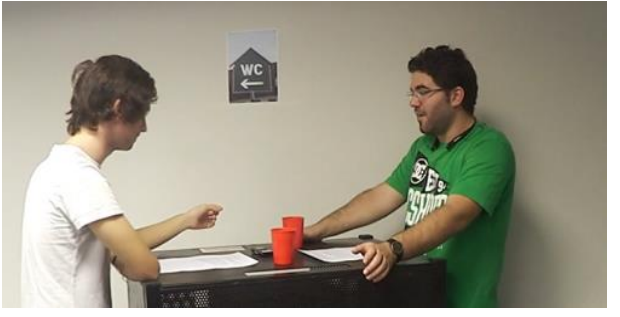

Snapshot $\quad 33 . \quad$ B2 $\quad$ Topic Negotiation move

yeah (0.2) well (0.2) you know on WhatsApp at least we have like this excuse like for the people that I can invite (0.1) it's no more than 50 and that's one of the reasons maybe because I //I// couldn't $\uparrow$ invite more than 50 people because there (o.1) I wasn't $\uparrow$ allowed to //to// //to//add more than 50 people to a group you know [it's] $<$ A17:OVERLAP < SO > / OVERLAP > [so] you invited 50 people and you didn't invite me

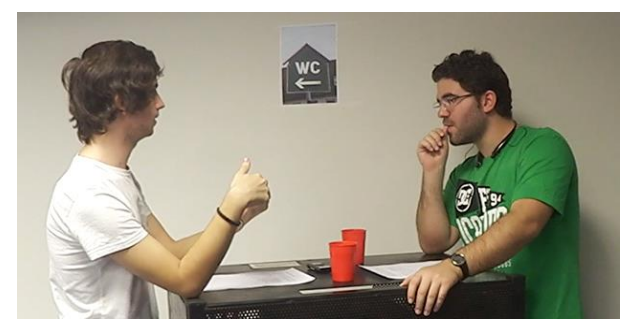

Snapshot

35. B2 Topic Negotiation move

yeah (o.1) maybe I wasn't going to make another group just like party one and party two like the names of the group, I wouldn't //I wouldn't// 


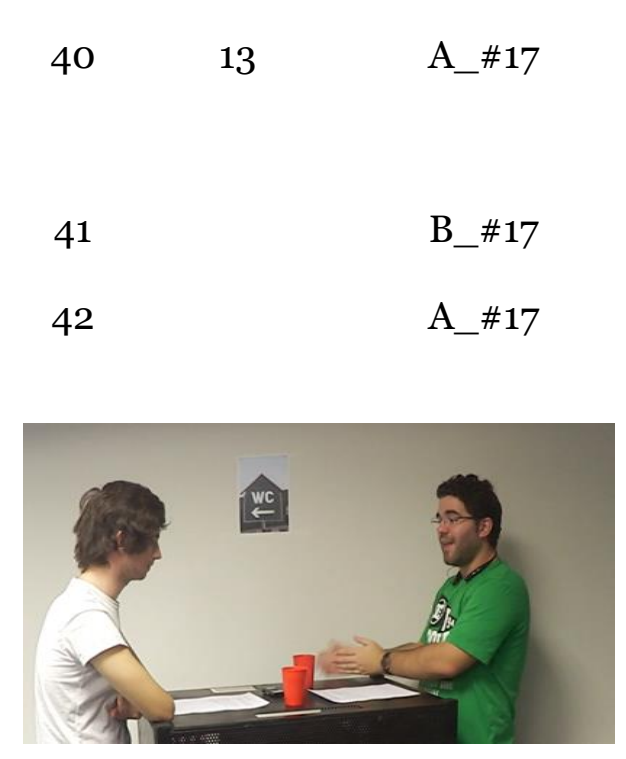

Snapshot 36. B2 Topic Negotiation move

$\begin{array}{ll}43 & \text { B_\#17 } \\ 44 & \text { A_\#17 } \\ 45 & \text { B_\#17 } \\ 46 & \text { A_\#17 }\end{array}$

make another one so I thought (o.1) well that's enough (0.1) that's enough people (0.1) these people and this group and, it's perfect, but I just didn't think about you (o.1) man (0.2) I should have [//I should have// just] < A17:OVERLAP < you know //you know//>//OVERLAP $>$ [you know //you know//] I love that group man (o.1) we've been listening for that group (o.1) $\mathrm{I} \uparrow$ even bought you that CD yeah $<$ B17:BC_AGREE $<$ yeah $>/ /$ BC $>$ you know that group because of $\mathrm{me}=$

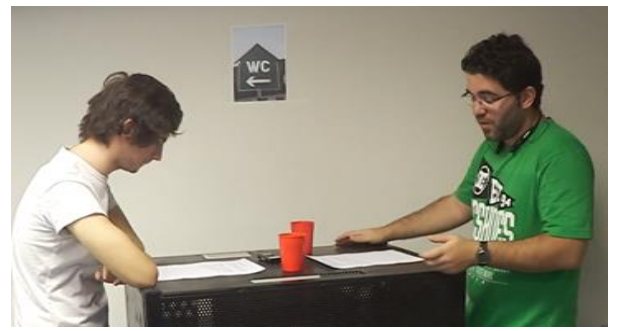

Snapshot $\quad 37 . \quad$ B2 $\quad$ Topic Negotiation move

=yeah $/ /$ yeah $/ /$ I'm sorry= =and now you you //you $/ /$ may //may// need to //to// invite that group and you don't invite me $=$ yeah $<$ B17:BC_AGREE $<$ yeah $>/ /$ BC $>$ =look I don't know what to do with you I (0.2) [you know I] $<$ B17:OVERLAP < well I think //I think//>//OVERLAP $>$

Line 37 shows that the complainee took the turn again so as to justify his fault. In so doing, the complainee expressed his speech by means of various modes that served to enrich the content of the utterances (Snapshot 32). The complainee performed different beat gestures to accompany his speech, which served to indicate the unit of stretch of talk. These particular gestures were then regarded as performing the pragmatic function of parsing. However, the complainee did not only perform a parsing function while performing those gestures, as his gesture repertoire revealed also a modal 
function. Specifically, he tended to emphasise some parts of the speech by slightly moving his arm and hand towards the complainer when he said "5o people" and "to add", and towards his left when he referred to "group" (Snapshot 33). Therefore, it seemed that he produced various gestures within the same unit of talk.

Concerning this, Ferré (2011), drawing on Kendon's (2004) definition of parsing function, argues that a beat gesture might reveal a parsing function when they are produced together with primary and nuclear stress, but interestingly they appear to show a modal function if they reveal emphatic stress, as it observed in this particular example. Moreover, Streeck (2008) posits that gestures may involve various functions simultaneously, revealing therefore a prosodic gesture, which may provide an additional structure that helps recipients in its parsing function.

In addition to this, the complainee modified his head movement during his speech focusing on some occasions on the complainer and sometimes on his hands. The complainee's speech was also enriched by means of paralanguage resources such as loudness. This was observed for example when he performed "I couldn't" and "allowed", probably in an attempt to show the complainer that his justification was based on specific aspects that were external to him, thereby showing the complainer that although he was responsible for such action, other aspects appeared to contribute to the grievance. In a way, it might be argued that he was requesting for forgiveness. This particular assessment might be obtained from the analysis of the visual data, since the audio data could not reveal such subtle information.

Meanwhile, the complainer, at the beginning of the complainee's turn, kept a neutral position resting his arms on the table (Snapshot 32), but little by little modified his bodily position to nod and move slightly back as the content of the complainee's turn was developed (Snapshot 33). Possibly, the bodily position of the complainer could be attributed to his signal of active listenership, 
which was then interrupted when he overlapped the complainee so as to take the floor (line 38). This particular verbal utterance appeared to have an impact of the complainee, who bended slightly over his head (Snapshot 33) and finally put his hands on his face when he started his new turn in line 38 (Snapshot 34).

Little by little, the complainee back to a neutral position, and uttered a new turn (line 39). As in the previous turn, he employed various beat gestures involving the pragmatic function of parsing, but at the same time he performed various gestures within the beat to signal a modal function (Streeck, 2008; Ferré, 2011) particularly when saying: "another group" "that enough" "this group", that involved moving his arms towards the complainer (Snapshot 35). Although he appeared to address his gaze direction towards the complainer, on some occasions, he modified it a bit so that he avoided eye contact with the complainer and looked at his own hands. Towards the end of the turn, he put his hand again on his face. These reactions, and particularly the act of covering his face with his hand, could be associated to the participants' attitude towards the situation as well as his intent to reveal his emotions, for example showing regret, in front of the complainer.

The complainer remained serious and his gaze direction was focused on the complainee (Snapshot 35). However, during the complainee's speech he performed an adaptor, particularly moving his hand towards his chin, revealing not only his stance towards the situation but also an interpersonal function that pointed to his interest in taking the floor again (Snapshot 35). In fact, he managed to take the floor by means of overlapping, as shown in line 40 .

The complainer's speech (turn 13) was also co-expressed by means of various modes. He employed for example different beats, which seemed to have accompanied his speech showing a parsing function. Moreover, he also introduced a deictic gesture that pointed to a specific referent of the content, specifically when he uttered "that group" (Snapshot 36). In the first part of the turn, he kept his gaze 
orientation fixed towards the complainee, but when he performed the last part of his turn, line 46, he slightly bended over his head and modified his gaze orientation, looking down rather than at his interlocutor (Snapshot 37). This particular action could be associated to participants' disillusion towards the complainee's action, thereby showing emotional values.

By the same token, the complainee was first paying attention to the complainer keeping eye contact with him (Snapshot 36), but as the turn went on, he bended over his head, possibly due to the content of the complainer's utterance, which seemed to have an impact on his non-verbal response (Snapshot 37). Moreover, the complainee revealed an adaptor gesture, more precisely; he appeared to touch his t-shirt, as in other occasions, possibly in an attempt to manage his emotions.

As shown in this particular move, speakers undertook a rather conflicting exchange of turns with emotionally-charged utterances that appeared to affect participants' extra-linguistic and paralinguistic realisations. Both participants tended to modify gaze direction as well as head position during the flow of the conversation, but it was the complainee who performed those non-verbal modifications more frequently, probably as a result of the threatening situation and because he felt responsible for the grievance. Beats were also observed in this move, particularly when accompanying long turns, as in the case of the complainee, who provided various turns to justify the grievance. As indicated, the beat gestures performed by the complainee might involve not only a parsing function, but also a modal function (Streeck, 2008; Ferré, 2011). In Adaptors were also identified in this specific move as performed by both participants, although more frequently observed in the case of the complainee, possibly revealing his emotional state as regards the situation. Deictic gestures were also found in this particular move, especially in the case of the complainer, who employed them to 
reinforce the content of the utterances and revealed referential and modal functions.

\subsubsection{Post-complaint move}

The post-complaint move might serve to repair the situation, or at least to try to reach to mutual understanding between the two interlocutors and then restore harmony after the damage caused. Example 27 and Example 28 present the post-complaint move of each particular proficiency group.

Example 27. Post complaint move of B1

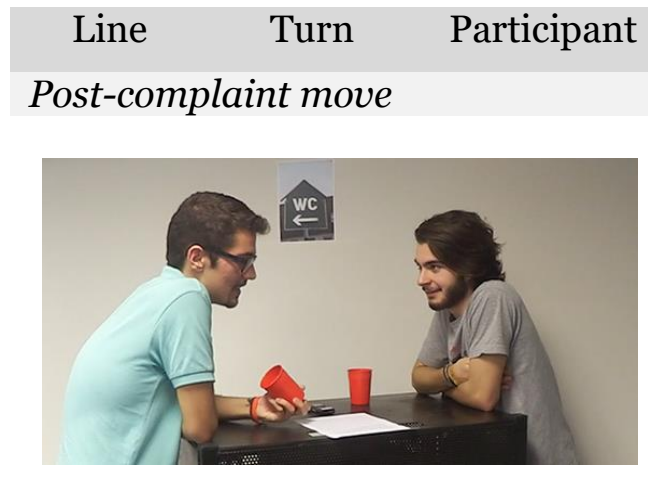

Snapshot move

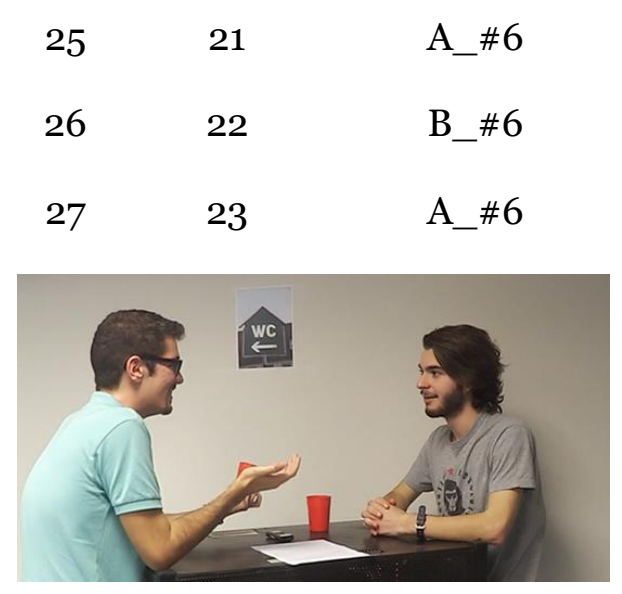

Snapshot 40. Post-complaint move

$\begin{array}{lll}28 & 24 & \text { B_\#6 } \\ 29 & 25 & \text { A_\#6 }\end{array}$

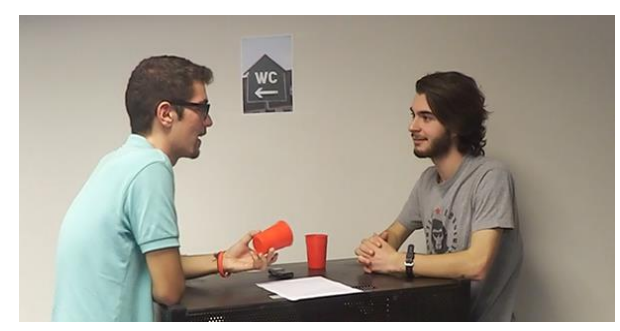

Snapshot 39. Post-complaint move

then, I don't believe that (o.1) can I go now?

er <B6:F_PAUSE $<$ er $>/ /$ F_PAUSE $>$ (o.1) it's so difficult (o.1) I can't why //why// is it so difficult?

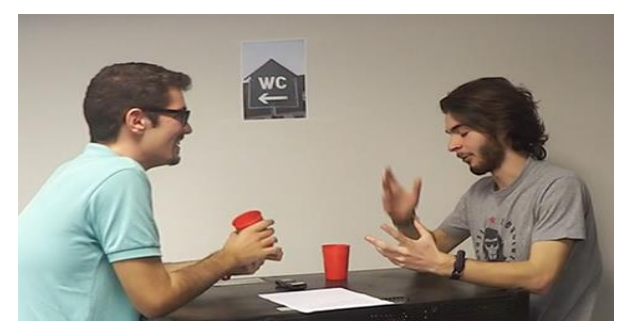

Snapshot 41. Post-complaint move

well I have no space in my home oh man, your house is so big 


\begin{tabular}{|c|c|c|c|}
\hline 30 & 26 & B_\#6 & $\begin{array}{l}\text { yes } \\
<\text { B6:SYL_D }<\text { but }>/ / S Y L \_D>(0.2) \text { I } \\
\text { can try it }\end{array}$ \\
\hline 31 & 27 & A_\#6 & you can try it? \\
\hline 32 & 28 & B_\#6 & $\begin{array}{l}\text { I can try but I can't er } \\
\text { B6:F_PAUSE }<\text { er }>/ / \text { F_PAUSE }>\end{array}$ \\
\hline 33 & 29 & A_\#6 & make sure anything \\
\hline 34 & 30 & B_\#6 & $\begin{array}{l}\text { I can't make sure of anything (0.1) } \\
\text { sorry }\end{array}$ \\
\hline 35 & 31 & A_\#6 & yes, the party is on Saturday? \\
\hline 36 & 32 & B_\#6 & $\begin{array}{l}\text { yes tomorrow } \\
\text { tomorrow// }\end{array}$ \\
\hline
\end{tabular}
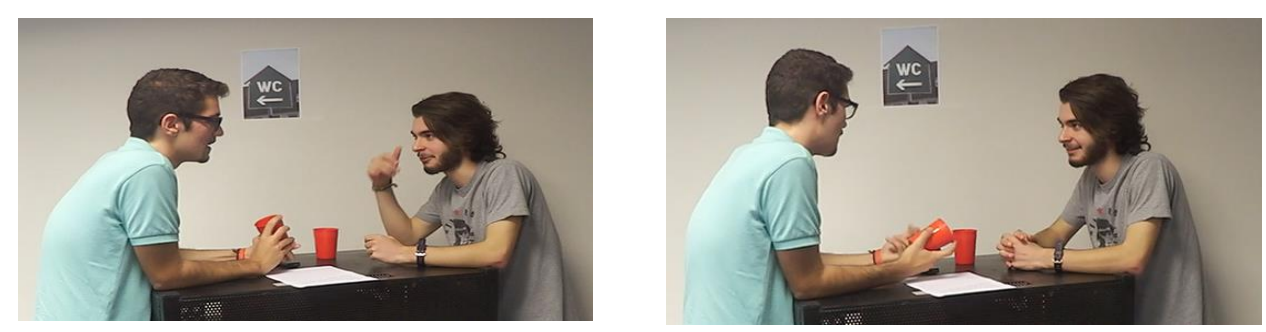

Snapshot 42. Post-complaint move

Snapshot 43. Post-complaint move

\begin{tabular}{|c|c|c|c|}
\hline 37 & 33 & A_\#6 & $\begin{array}{l}\text { tomorrow? okay if I can go to the } \\
\text { party, notice me later }\end{array}$ \\
\hline & & B_\#6 & ok $<$ B6:BC_AGREE $<$ ok $>/ /$ BC $>$ \\
\hline & & A_\#6 & or call me or something \\
\hline 38 & 34 & B_\#6 & $\begin{array}{l}\text { yes I WhatsApp you or call you [or } \\
\text { something] <A6:OVERLAP < } \text { send a } \\
\text { message//>//OVERLAP }>\end{array}$ \\
\hline 39 & & A_\#6 & [send a message] \\
\hline 40 & & B_\#6 & yes don't worry \\
\hline 41 & & A_\#6 & yeah < A6:BC_IR $<$ yeah $>/ /$ BC $>$ \\
\hline 42 & & B_\#6 & I try really \\
\hline 41 & & A_\#6 & ok<A6:BC_AGREE $<$ ok $>/ /$ BC $>$ \\
\hline
\end{tabular}

The post-complaint move was one of the most challenging moves for participants, particularly at B1 level, who appeared to repair the grievance less frequently than the B2 group (see this chapter Section 5.1.1.1). In this case, line 25 shows that the complainer addressed directly the complainee and asked him if he could go to the party (Snapshot 38 ). His verbal message was coexpressed by staring at the complainee directly, probably in an attempt to reveal his interest for the forthcoming party. The complainee, however, did not keep eye contact with the complainer; rather he moved his head slightly and modified his gaze direction 
(Snapshot 38). Then, when the complainee responded, he modified his position a little bit by moving back his body, pointing at the complainer by means of a deictic gesture that might have functioned as a performative action, revealing a refusal in this case. The filled pause performed at the initial part of the turn could be attributed to the thinking process the participant undertook to plan the response (line 26) (Snapshot 39). These actions could have been performed in order to construct his response. While the complainee was performing turn 22, the complainer modified his body position by moving slightly away from the table and resting his arms with the hands together on the table and remained neutral paying attention to the complainee's speech (Snapshot 39), showing signals of active listenership. Once the complainee finished his turn, he introduced a new turn, revealing to some extent his attitude towards the decline performed by the complainee.

The complainee, in attempt to justify the situation, performed an utterance to respond to the complainee's turn (line 28) that was enriched by means of various modes. Particularly, he combined his verbal speech with his arms separated and open palms up as well as with a smile. These combinations of modes were probably performed so as to show the complainee that he could do nothing to change the situation as there was something external that affected that particular scenario and that he was not responsible for such issue (Snapshot 40). Immediately after, the complainer bended his head a bit and performed a deictic gesture so as to acknowledge the referent, that is, the complainee, and he uttered in line 29 the first part of the turn, "oh man" (Snapshot 41), which, in a way, seemed to imply that he did not believe in what the complainee said.

The conversation continued and they appeared to reach mutual agreement in the sense that the complainee showed his intention to ensure that his friend could go the party, but he did not utter for example any promise, which might have served to repair the situation at this particular moment. Then, the complainer, continuing with his 
insistence, in line 37 requested the complainee to contact him by telephone, performing a metaphorical gesture simulating a phone called that pointed to a referential function and keeping eye contact with him (Snapshot 42). The complainee, in line 38, indicated that he would contact him and in so doing he performed a deictic gesture in which the complainer was pointed. This particular gesture could be associated to a performative pragmatic function since the content of the utterance, pragmatically speaking, involved a particular course of action (Snapshot 43). The two participants revealed signals of active listenership during the conversation, which seemed to contribute the construction of the conversation.

Example 27. Post complaint move of B1 pair (continuation)

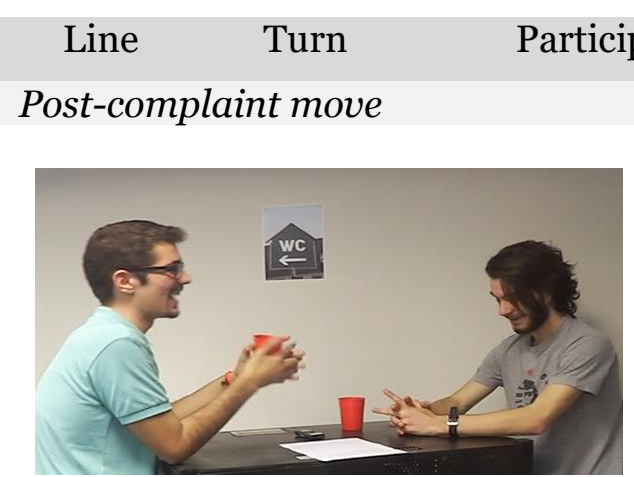

Snapshot 44. Post-complaint move

$\begin{array}{lll}42 & 35 & \text { B_\#6 } \\ & & \\ 43 & & \text { A_\#6 } \\ 44 & & \text { B_\#6 } \\ 45 & 36 & \text { A_\#6 } \\ 46 & 37 & \text { B_\#6 } \\ 45 & 38 & \text { A_\#6 } \\ & & \\ 46 & & \text { B_\#6 } \\ 47 & & \text { A_\#6 } \\ 48 & 39 & \text { B_\#6 } \\ & & \\ 47 & 40 & \text { A_\#6 } \\ 48 & & \text { B_\#6 }\end{array}$

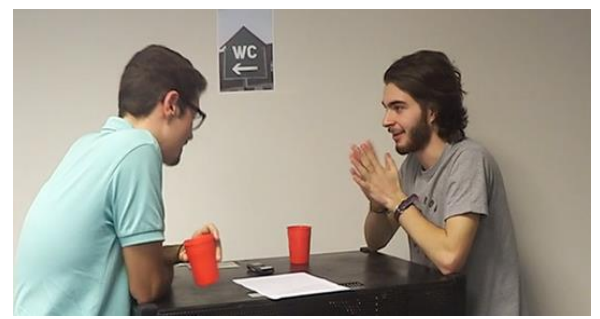

Snapshot 45. Post-complaint move

I'm sorry for what I did but I have so much to do with the party and you know ok $<$ A6:BC_AGREE $<$ ok $>/ /$ BC the exams

try //try//

yes sorry

please it's my favorite group [it's] $<$ B6:OVERLAP $<$ yes//>//OVERLAP> [yes]

Ortxata Song System coming to Castellón tomorrow

$<$ B6:LAUGHTER $>$ there will be a big party a big //big// party I think that a lot of girls will go er $<$ B6:F_PAUSE $<$ er $>/ /$ F_PAUSE $>$ 
49

50

51

52

53

54

55

56

57

58

59

$60 \quad 52$

$61 \quad 53$

$62 \quad 54$

$63 \quad 55$

$64 \quad 56$

65

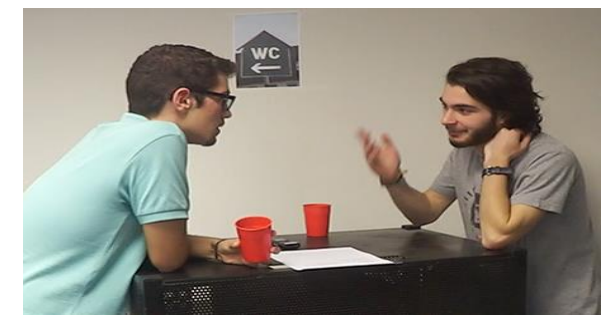

Snapshot 46. Post-complaint move

$\begin{array}{lll}66 & 58 & \text { A_\#6 } \\ 67 & 59 & \text { B_\#6 } \\ 68 & 60 & \text { A_\#6 } \\ 69 & 61 & \text { B_\#6 } \\ 70 & 62 & \text { A_\#6 } \\ 71 & 63 & \text { B_\#6 } \\ 72 & 64 & \text { A_\#6 }\end{array}$

hot girls

[probably]

$<$ probably//>//OVERLAP $>$

[probably]

$<$ B6:LAUGHTER $>$ it's Ortxata

\section{Concert}

I need to go (0.1) it's time to know if I have

maybe for the next party like the film? <B6:LAUGHTER> we will (XXX) our house (0.1) not my house.

do it on your house okay. what did your parents say, how did that?

I don't know they are in Paris

in Paris? oh

when they come

they will need to [buy]

$<$ B6:OVERLAP

$<$ maybe//>//OVERLAP $>$

[maybe] scream a lot $<$ B6:LAUGHTER >

maybe first buy a new house to [make]B6:OVERLAP

$<$ it's//> //OVERLAP>

[it's] (XXX) buy house, burn it and then

party, burn and later

forget the house yes

forget the body and forget everything

maybe (XXX)

okay I need to go another time

to?

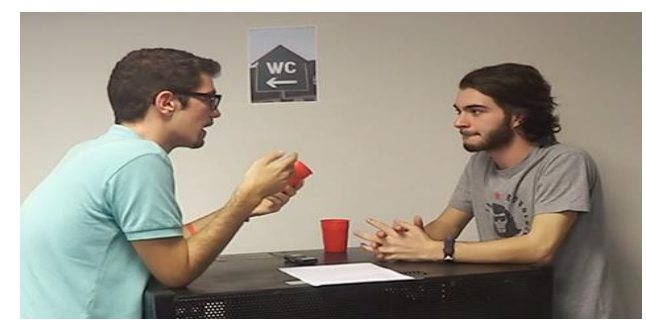

Snapshot 47. Post-complaint move

if you call me later yes //yes// now I'm going to the house (o.1) I'll check the assist

the people

the people who come and (o.1)

the assistance

if you have a slot I will call you

okay so I can go to the party I'm so 


\begin{tabular}{|c|c|c|c|}
\hline & & & thank you for you \\
\hline 73 & 65 & B_\#6 & $\begin{array}{l}\text { sorry I forget that I already (XXX) } \\
\text { everybody complete }\end{array}$ \\
\hline 74 & 66 & A_\#6 & next time we will talk \\
\hline 75 & 67 & B_\#6 & $<$ B6:LAUGHTER > don't kill me \\
\hline 76 & 68 & A_\#6 & $\begin{array}{l}\text { if I organize a party I will call you I } \\
\text { make sure }\end{array}$ \\
\hline 77 & 69 & B_\#6 & thanks //thanks// sorry \\
\hline
\end{tabular}

The complainee, being aware that the situation would be repaired, apologised for the grievance. This particular apology was co-expressed by means of a smile and by raising his arm a bit and joining the palms of his hands together performing a metaphorical gesture that evidenced the act of begging. The pragmatic function of this gesture could be performative function in the sense that he was co-expressing a speech act not only verbally but also by means of a gesture (Snapshot 44). While he was doing so, the complainer kept his head down and therefore he did not look at the complainee. Nevertheless, he was paying attention to such verbal apology, as shown in line 43, where he showed insistence again. This insistence becomes even more evident in line 45 when he requested again an opportunity to go to the party, not only verbally, but also by means of putting the palms of his hands together and raising them a bit so that he could pretend that he was begging as well (Snapshot 45). Therefore, he appeared to perform a metaphoric gesture representing a performative pragmatic function, which was similar to that performed by the complainee in line 42.

They continued the conversation talking about the place where the party would be done and they even made some jokes as regards the house. Then, it was in line 63 when the complainer insisted again and requested the complainee to go to the party. In line 65, the complainer expressed his turn by means of a deictic gesture and adaptor, touching his neck. The deictic gesture could be associated to a referential function, while and the adaptor could be regarded as containing a modal function revealing his attitude and insistence (Snapshot 46). 
While the complainer was performing those linguistic and extra-linguistic elements, the complainee remained with a neutral face and both kept eye contact (Snapshot 46). Immediately, the complainee reacted to the complainer's request by indicating that he would check and in so doing he reinforced the content of the utterance by means of a metaphorical gesture, representing the act of checking, and whose function could be referential. Moreover, while he was doing so, he addressed his gaze direction towards his hands (Snapshot 47). Meanwhile, the complainer rested his arms on the table while paying attention to the complainee, addressed his gaze towards the complainee and remained serious (Snapshot 47).

The B1 group appeared to co-express their verbal utterances by means of various modes, while speaking and paying attention to the interlocutor's talk. Gaze direction changes were observed in some cases, which served for example to avoid eye contact with the interlocutor, especially when facing uncomfortable situations. Metaphorical gestures were also identified during the conversation, particularly to reinforce visually the content of specific elements introduced in the content of the utterances. Concerning proficiency, Kim (2012) found that intermediate proficiency learners appeared to employ more gestures than advanced learners to link the referent to the visual space.

The B2 group was also engaged in the post-complaint move, which is one of the most challenging parts of a complaint. 
Example 28. B2 level participants

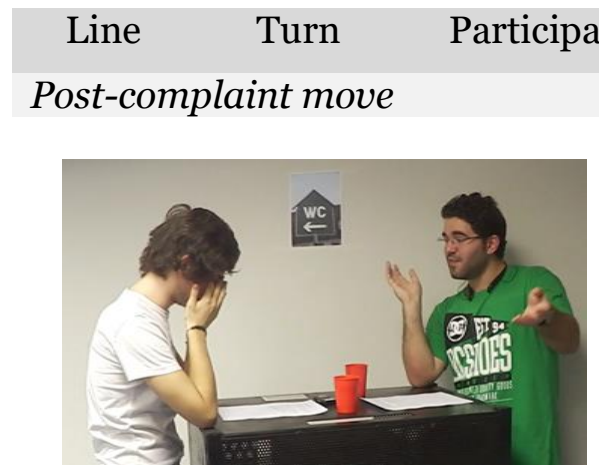

Snapshot 48. Post-complaint move

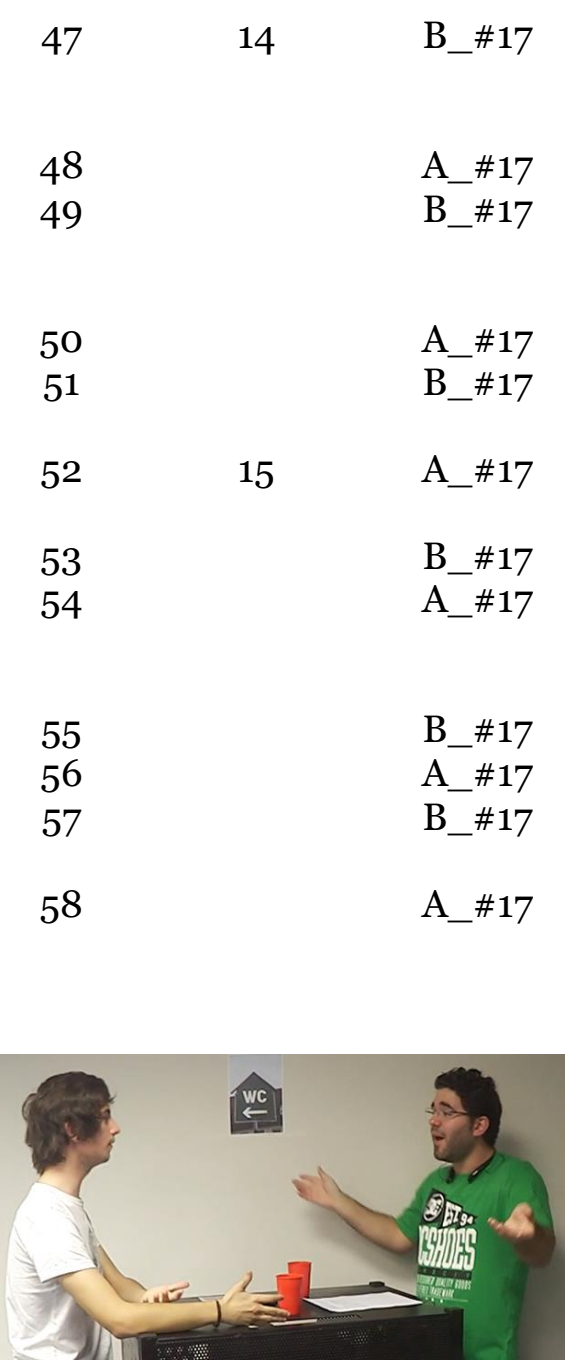

Snapshot 50. Post-complaint move

59
16 B_\#17

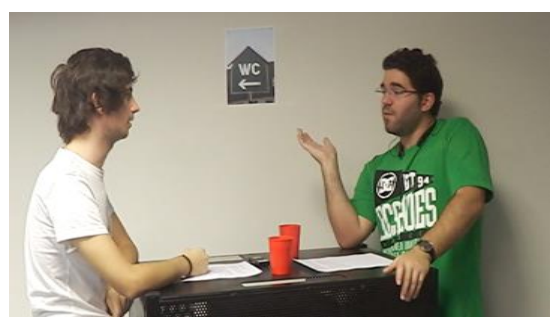

Snapshot 49. Post-complaint move

[well I think //I think//] we can still solve this like [I can] $<B 17$ : OVERLAP _ <how? >//OVERLAP > [how?]

//I can// //I can//[do something] $<$ A17:OVERLAP can't $>$ //OVERLAP $>$ $<\mathrm{I}$ [I can't //I can't//] maybe [I can] <A17:OVERLAP <I don't $>/ /$ OVERLAP $>$

[I don't] trust you anymore you know

$<$ B17:SNORT>

what do I do now [with you $=$ ] $<$ B17:OVERLAP $<$ come on $>$ //OVERLAP $>$

[come on]

man $\uparrow$ we've been friends

well yeah $<$ B17:BC_AGREE $<$ yeah well $>/ / \mathrm{BC}>$

$=$ for so much time [and (xx)] $<$ B17:OVERLAP can $>/ /$ OVERLAP $>$

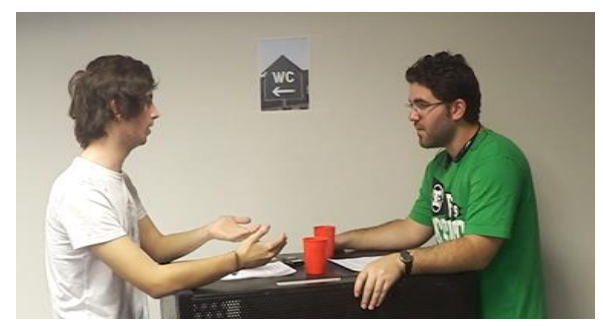

Snapshot 51. Post-complaint move

[we can] still $\uparrow$ solve this we're friends we can still solve this 
Chapter 5: Results and discussion

\begin{tabular}{|c|c|c|c|}
\hline 60 & 17 & A_\#17 & how? \\
\hline 61 & 18 & B_\#17 & $\begin{array}{l}\text { come on (o.1) I can uninvite } \\
\text { someone }\end{array}$ \\
\hline 62 & 19 & A_\#17 & you will uninvite someone \\
\hline 63 & 20 & B_\#17 & yes \\
\hline 64 & 21 & A_\#17 & $\begin{array}{l}\text { I think you will get er } \\
<\text { A17:F_PAUSE }<\text { er }>/ / F_{2} \text { PAUSE }>\end{array}$ \\
\hline 65 & 22 & B_\#17 & $\begin{array}{l}\text { quite pissed off if you do that }= \\
=\text { at least it would be better than } \\
\text { having you pissed off because I } \\
\text { know you for a long //long// time I } \\
\text { don't know }\end{array}$ \\
\hline
\end{tabular}

The co-expression by means of different modes was also evident in the post-complaint of the $\mathrm{B} 2$ group. The participants attempted to repair the situation in this particular move, in which the role of the complainee appeared to acquire a greater relevance.

Line 47 shows the initial turn of the post-complaint in which the complainee obtained the floor by overlapping the complainer. In this particular case, while he was performing his turn, he addressed his gaze direction towards the complainer but little by little, he put his hands on his face, as he tended to do in specific moments during the conversation, which revealed his emotional state towards the situation (Snapshot 48). The complainer finally took the floor (line 52) and performed a particular utterance that was accompanied by different modes (Snapshot 48). Specifically, he addressed his gaze direction towards the complainee with a serious face expression and opened his arms and with the palm of his left hand up and the other arms rested on the table. This particular gesture might be classified as a beat gesture that was employed to accompany the rhythm of his speech. Due to the nature of the content, it might be suggested that it represented a modal pragmatic function.

Immediately after this turn, the complainee reacted by means of a paralanguage element, specifically with a snort, showing a response towards the complainer's utterance (Snapshot 49). The complainer seemed to continue his speech without paying any attention to the complainee's paralanguage response, which could be associated to the threating content of the complainer's utterance as well as to the 
situation he was facing. It should be noted that while the participants were acting as listeners, they revealed signals of active listenership since they appeared to react to the utterances elicited by the current speaker.

At that point, it seemed that the complainee attempted to show not only verbally but also by means of extra-linguistic and paralanguage elements that he felt displeased as a result of the grievance committed. However, on some occasions, it seemed that the complainer did not to focus much on the signals the complainee revealed. Nevertheless, it could be indicated that the complainer might have opted for reacting in such manner to show the complainee his emotional state towards the situation. It is, however, true that they did not take part in a real situation but in a simulated one, and therefore it is not possible to ascertain which their real responses and reactions would involve in a real context.

The conversation continued and the complainee tried to obtain the floor until he finally he managed to take the floor and carried on with his action, which involved repairing the situation (line 59). This particular turn (Snapshot 50) was co-expressed by means of loudness (still) possibly to insist on the idea of repairing the grievance as well as by means of beat gestures that accompany his speech, which appeared to show a pragmatic function of parsing. Moreover, he oriented his gaze direction towards the complainer and kept eye contact with him when producing such turn.

As a response to such utterance, the complainer immediately reacted both verbally and non-verbally by opening his arms and raising them up together with his eye brows raised waiting for an answer that could solve the problem (Snapshot 50). This could be observed as a beat gesture involving a modal pragmatic function since he was showing stance towards the content of the utterance. In line 61, the complainee provided an answer to the complainer's utterance, which was enriched by means of gaze direction oriented towards the complainer, so that they could have eye contact, a serious 
face expression and a beat gesture (Snapshot 50). The pragmatic function of that beat gesture could be attributed to parsing, in which the speaker simply showed the different units of a stretch of his talk. Moreover, he employed a deictic gesture when he uttered "someone", thereby showing a referential function.

As shown in Snapshot 51, the complainee employed a beat gesture in order to co-express his new turn (line 65). This particular gesture was regarded a showing a parsing pragmatic function since it showed the punctuation within the speech. Meanwhile, the complainer appeared to show signals of active listenership in the sense that he placed his arms on the table, revealed a serious face and oriented his gaze direction towards the complainee so that they shared eye contact (Snapshot 51).

Example 28. Post-complaint move of B2 (continuation)

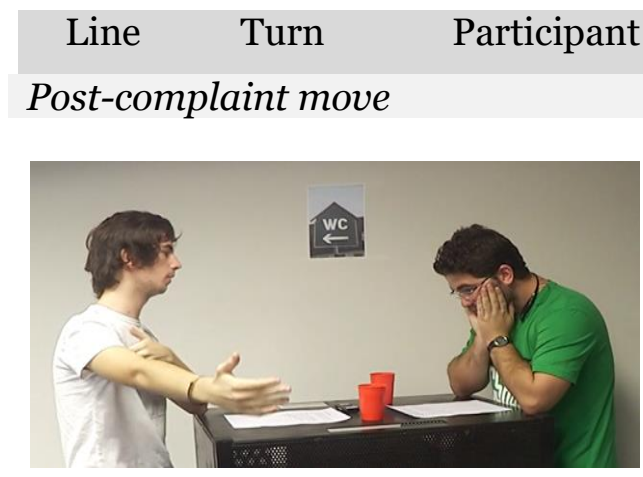

Snapshot move

66 23

67

68

69
52. Post-complaint

\section{ant}

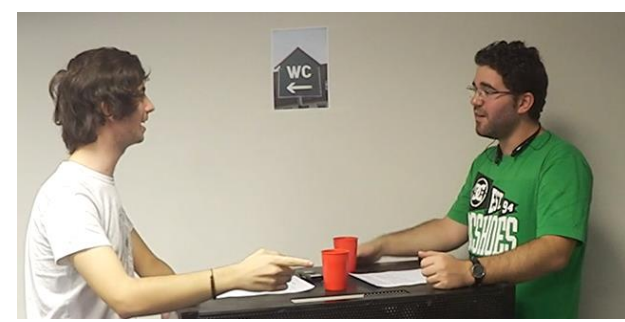

Snapshot 53. Post-complaint move =you know I don't want other people to be //to be// left out because of me but (0.2) $<$ A17:SNORT $>$ you know (0.2) //you know// I'm //I'm// quite angry with you <A17:OVERLAP $<$ look $>$ //OVERLAP $>$ yeah well I can just plan another party [with] $\uparrow<$ A17:OVERLAP $<$ look > //OVERLAP> [look] =less people or more people we can plan a party at some sort of like place $=$ 


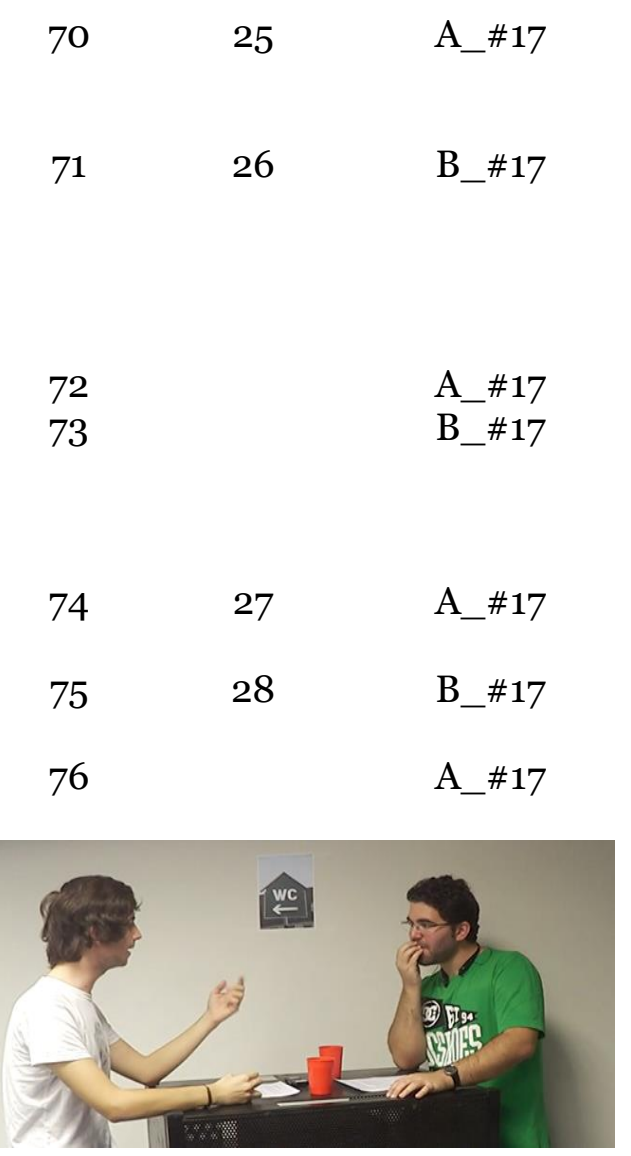

yeah but you won't be able to invite this [group] <B17:OVERLAP $<$ yeah $>$ //OVERLAP $>$

[yeah] $\uparrow$ I will be able to invite you even if I $\uparrow$ if I had to make another group yes $\uparrow$ with you and [me] $<$ A17:OVERLAP < but //but// I $>/ /$ OVERLAP $>$

[but //but// I]

then you are going to come to that party I [can tell you] $<$ B17:OVERLAP <but I $\uparrow$ don't= want $>/ /$ OVERLAP $>$

[but I $\uparrow$ don't want] to listen to another group, I just love this one no $\uparrow$ this group again (0.1) I would pay them = umm <A17:BC_CON $<$ umm $>/ /$ BC $>$

Snapshot move 77
54. Post-complaint B_\#17
81

82

83

84

85

86
A_\#17

B_\#17

29

A_\#17

A_\#17

B_\#17

31

A_\#17

B_\#17

A_\#17

32

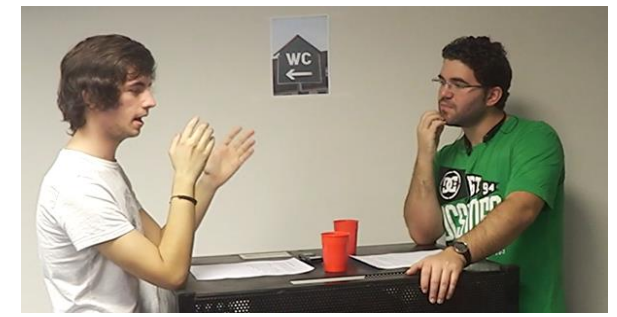

55. Post-complaint move

I would pay them to come, you know what, I'm going to get er $<$ B17:SNORT $>$ come $\uparrow$ on (o.2) this has to work I mean people coming to this party are going to pay a fee like $€ 2.00$ (0.1) for drinks (0.1) I don't care (0.1) and with that money $\uparrow$ we're going to invite the same group, next time and we're going to repeat the party, so you can come, next time (0.1) I've messed up, I know I've messed up a lot, but this can be solved (0.1) I think we can solve this, we're

ok $<$ A17:BC_AGREE $<$ ok $>/ /$ BC $>$

friends $\uparrow$

okay deal? [you promise] $<$ A17:OVERLAP

$<$ deal $>$ //OVERLAP $>$

[deal]

to do that?=

$=$ I promise $/ /$ I promise $/ /$ to do so

okay $<$ A17:BC_AGREE $<$ okay $>/ /$ BC $>$ I do promise yes

$\mathrm{I}::<\mathrm{B} 17: \mathrm{SYL} \_\mathrm{D}<\mathrm{I}>/ / \mathrm{SYL} \_\mathrm{D}>$ trust 
Chapter 5: Results and discussion

$\begin{array}{llll} & & & \text { you, but, don't do this= } \\ 87 & 33 & \text { A_\#17 } & \text { =I won't //I won't// don't worry } \\ 88 & 34 & \text { B_\#17 } & \text { okay? } \\ 89 & 35 & \text { A_\#17 } & \text { okay }\end{array}$

As shown in Snapshot 52, the complainer bended his head slightly over and placed his hand on his face, revealing an adaptor gesture that might point to a modal pragmatic function as he showed his stance towards the situation. This position was adopted when the complainer was finalising turn 23 (line 66), particularly when he revealed his feelings towards the complainee, which were the result of the grievance the complainee had committed.

Line 67 shows the complainee's intent to repair the situation by providing a solution to the grievance (Snapshot 52). This particular utterance was enriched by means of a deictic and an adaptor gesture, a fixed gaze direction towards the complainer as well as by loudness when he uttered "with". The deictic gesture involved a movement of his arm towards his right side to point to "another party" (line 67), which appeared to reveal a referential function. The adaptor gesture, which involved placing his left hand on his chest, was performed in coordination with the deictic gesture, which could be related to a modal pragmatic function in which the complainee showed his stance. Once the deictic gesture was finalised, the adaptor was also finalised.

While he was performing turn 24, the complainer tried to obtain the floor but he did not manage to do it, so the complainee continued his speech. In so doing, he performed a deictic gesture again when referring to "place" (line 69), which could involve a referential function (Snapshot 53). Moreover, as observed in Snapshot 53, his gaze direction was not altered during this particular sequence since it remained oriented towards the complainer, keeping eye contact with him and showing a serious face. Concerning this, it might be indicated that he employed various modes in order to make the complainer understand that there was a possibility to repair the situation and he could do his best to repair it. 
Meanwhile, the complainer modified his position so as to show again attentive listenership towards the complainee by resting his arms on the table, modifying his head position so that he could share eye contact with the complainee, and revealing a serious face. This particular body position involved not only that he was attending the complainee's utterance but also his intention to obtain the floor again in order to provide an answer to the complainee. In fact, he took the turn leaving no gap between the complainee's turn and his own turn so as to decline the complainee's intent of repair (Snapshot 53).

The conversation continued and the participants created various turns that were, on some occasions, interrupted by overlapping. Both participants appeared to be interested in obtaining the floor to express their ideas. The complainee tried to elicit some utterances so as to repair the grievance, while the complainer appeared not to be satisfied with the intent. Nevertheless, the complainee's insistence made the complainer accept the action undertaken by the complainee to repair the situation. It was then in line 75 when the complainee could construct his turn with no interruption from the complainer (Snapshot 55). The complainee, in this case, employed beat gestures during the elaboration of the turn that were also enriched by means of specific movements of his arms that showed emphatic stress. The beat gestures appeared to reveal a parsing function, but in the specific moments in which the complainee emphasised a particular unit of talk by means of specific movements within the same gesture, those were regarded as containing a modal function. Therefore, in this case, the parsing function appeared to reveal an additional function, more specifically, that of modal, which served to show his attitude during the unit of talk. Moreover, in his speech, a filled pause and a snort were elicited, possibly to attribute to the circumstances he was facing and his intention to solve the problem. Moreover, he performed a metaphorical gesture that pointed to a particular reference of the talk. Specifically, he moved his hand making circles when he uttered 
"we're going to repeat the party", thereby reinforcing the verbal message by a metaphorical gesture. Immediately after this gesture, he performed a deictic gesture that pointed to the complainer when he uttered "so you can come to the party". In this particular case, both gestures appeared to show a referential function as they were tightly connected to specific parts of the content of the utterance. Meanwhile, the complainer showed signals of active listenership during the elaboration of the complainee's utterances. Particularly, in this case, the complainer rested his left hand on the table while performing an adaptor gesture in which he placed his hand on his chin and touched it while paying attention to the complainee's speech.

As reported, several modes were combined not only to coexpress the verbal content but also when acting as listeners. Speakers tended to employ various paralanguage resources such loudness so as to reinforce specific parts of the utterances. Moreover, beat gestures, for example, were produced to orchestrate the speech, which, in some cases, involved an emphatic stress. Deictic gestures were also identified in the data, referring for instance to specific referents that were provided in the content of the utterances, as well as a metaphorical gesture to reinforce the message conveyed in the turn. Head movements, changes in gaze direction and adaptors were also observed, particularly in exchanges that involved emotional burden.

\subsubsection{Closing move}

The closing move was only performed by the B1 group. Albeit very short, it is worth providing an example (Example 29). In this particular case, the complainer and the complainee appeared to say goodbye in a friendly manner after having solved the problem. Both interlocutors shared eye contact and smiled at each other while they performed the last verbal exchange (Snapshot 56). 
Example 29. Closing move of B1 pair
Line
Turn
Participant

Closing move

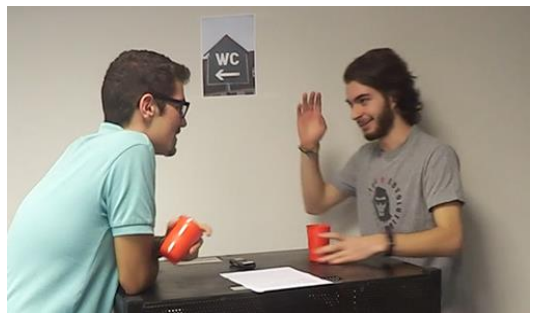

Snapshot 56. B1 Closing move

$\begin{array}{llll}78 & 70 & \text { A_\#6 } & \text { okay see you later } \\ 78 & 71 & \text { B_\#6 } & \text { see you later } \\ 80 & 72 & \text { A_\#6 } & \text { bye }\end{array}$

The complainer raised his arm so as to indicate a salutation form that is typically employed in some cultures, and it could be argued that it involved an emblem by which the complainee accompanied his verbal utterance by means of an emblem. This particular gesture in this context could be understood as containing a performative function that points to the content of the utterance. In the following section I present an overview of the communicative event as well as the analysis of appropriateness.

\subsubsection{Overall communicative event}

The performance of the two pairs discussed above constitutes a selection of the data of the present investigation. The results revealed that, in social interaction, and particularly in spoken data, there were recognisable goal-oriented pursuits that may go beyond words, move and turns exchanges that served to construct the communicative event. By means of a multimodal CA approach, the conversation of each particular pair was deconstructed into its composite extralinguistic and paralinguistic elements. All these elements appeared to contribute to the construction of speakers' action and intention 
during the conversation and provided information as regards the different modes speakers employed to communicate. Furthermore, signals of active listenership were observed in the conversation, which also contributed to the construction of the conversation.

Heritage (1984: 242) indicates that a speaker's contribution to talk is both "context-shaped" and "context-renewing". Specifically, the author points that a speaker's turn is "context-based" in the sense that it can only be properly understood by the participants involved in the communicative event by considering the context within which the turn is performed. Concerning "context-renewing", the author indicates that a turn creates the immediate context of the action. The context in $\mathrm{CA}$ involves all the different sequences of action that emerge in the organisation of the conversation, and in this particular case, the social action revealed the speakers' construction of talk, which was based not only on turns but also on other modes that served to provide further insights into the speakers' communicative action. Moreover, it should be noted that it is not only what the speaker expresses by means of different modes, but also how the communicative action affects the interlocutor, and how the interlocutor, acting as an active listener, reacts and responds while the on-going talk of the speaker is constructed.

My concern here was to present a multimodal analysis of the data following a multimodal $\mathrm{CA}$ approach to depict the construction of talk. As observed in the two pairs analysed, participants constructed the conversation into various turns involving different discourse functions that were embedded within specific moves. There was a clear goal in the task proposed, which involved complaining in a specific situation containing a high level of offence between two participants who were equal and had an intimate relationship (Brown and Levinson, 1978, 1987).

Although the task was based on a simulated situation, and then participants' action may be to some extent predictable in the sense that they were required to complete a conversation that focused on a 
complaint even, the choice of the pragmatic forms of the utterances and the various modes by which the speakers projected their action was not predictable, but constructed over the course of the conversation. The combination of these modes provided them with tools to construct their talk over different turns or 'multimodal turns' so as to reach pragmatic communicative purposes (Kasper, 2006a). Specifically, the four participants appeared to construct their units of talk drawing on different modes, including spoken exchanges, gestures, facial expressions, gaze, head movements, and paralanguage resources.

In face-to-face interaction, and particularly in a situation involving a face threating situation, face expression, gaze and head movement appear to be of paramount interest as they provided evidences of how participants delivered, received and processed not only the verbal message but also the non-verbal information displayed by the speakers. Facial expressions in fact may provide information as regards speakers' emotions (Kappas, Krumhuber, and Küster, 2013) and they might to some extent guide the content of the turns, thereby affecting the choice of the discourse functions. Moreover, it is important to note that attention was not only paid to what the 'speaker' uttered in a particular turn, but also how the 'listener' perceived and reacted towards the message as well as how they showed active listenership signals (Knight, 2011).

Both proficiency pairs constructed the conversation over different turns that were embedded in the proposed moves, with the exception of the B2 pair, which did not perform the closing move. Nevertheless, the opening and the closing move are not an integral part of the communicative event of a complaint, but they may be part of any conversation. The opening in both cases was rather similar, albeit the B1 pair took more turns than the B2 pair in this particular move. The opening move produced by each pair did not provide much information concerning participants' performance, and most importantly, as regards proficiency. 
The pre-complaint, however, was different for each pair. Particularly, the B1 constructed a slightly shorter move compared to the B2 pair, who elaborated a pre-complaint move that involved a further elaborated turn elicited by the complainer as well as the various backchannels performed by the complainee. Although in both proficiency groups the pre-complaint move involved a rather threating situation, the way in which the complainer approached the complainee appeared to be different. The B1 complainer seemed to be more direct than the complainer in the B2 pair, who approached the complainee in a less threating manner. In line with this, Olshtain and Weinbach (1993) indicate that complainers need to employ mitigators so as to address the complainee in order to maintain harmony between speakers. Although it might be argued that their relationship would allow them to interact in such direct manner, the complainer should address the complainee in a more indirect manner, not only in the topic negotiation move, but also in the precomplaint since it is the moment in which the complainer announces a forthcoming FTA. Participants' interaction was not only affected by the verbal message, but also by the different kinesic and paralinguistic resources that accompany the verbal production. In the B1 pair, for example, a particular face expression was identified by the complainer when he was informed of the party. This particular reaction was triggered by the content of the verbal utterance projected by the complainee. In the case of the B2, extra-linguist elements were more evident since they appeared to be more involved in the task than the B1 pair. The sense of involvement in this particular case was observed not only drawing on the discourse functions elicited, but also, and more importantly, taking into account the different modes that were combined in the move. As reported, the B2 complainer approached the complainee by means of a preparation discourse function that was accompanied by various modes that complemented the verbal production. These particular combinations of modes appeared to have an impact on the 
complainee, who modified his gaze direction and performed adaptor gestures as a result of the threating situation, thereby revealing the expression of emotional content. This short move shows how the combination of different modes might support not only the verbal utterance of the speaker, but also the impact that different linguistic and extra-linguistic elements might have on the interlocutor.

As regards the topic negotiation move, both pairs seemed to have created a move in which the complainers addressed the issue of the grievance and indicated that the complainees were responsible for such action. Although in both cases the complainers showed the complainees their attitudes and feelings towards the situation, the B2 complainer managed to elaborate turns that were more emotionally charged than those projected by the B1 complainer, which in a reallife situation would definitely affect participants' construction of talk.

Concerning the perspective of the complainee in this move, it should be noted that the B1 complainee appeared to take some distance from the responsibility by pointing to other people as being responsible for the grievance, too. In so doing, it seems that he did not want to explicitly assume the responsibility of the grievance. By contrast, the B2 complainee assumed the responsibility and elaborated longer and complex turns so as to justify the error. The B1 complainee produced short utterances that were grammatically less complex and less elaborated than those elicited by the B2 complainee. Furthermore, differences as regards lexical richness were also found. The B2 complainer appeared to reveal more varied and richer vocabulary. The lexical richness could be affected by several factors such as the familiarity with the topic or the communicative purpose (Laufer and Nation, 1995) as well as to proficiency level. However, in this case, the topic of the discussion did not involve a complex issue, but rather an everyday situation. In fact, the complexity of the move was based on the construction of utterances that would reflect the nature of the situation, which involved a high level of offence. Thus, the difficulty in the 
construction of the utterances was based on participants' pragmalinguistic choice, which was determined by their sociopragmatic awareness towards the situation and their proficiency level.

In this particular case, speakers were involved in the core of the communicative exchange, which is one of the most challenging moves of the complaint communicative event due to its face threating nature. While, the B1 pair appeared to rely more on face expressions, gaze and head movement during the topic negation move, the B2 pair employed also gestures. The combination of various extra-linguistic features was observed not only while delivering the speech, but also when the interlocutors were paying attention to the speakers. For example, it was observed in the B1 pair that both speakers, in general, but in particular the complainee, tended to modify head position and gaze direction when constructing the turns (Duncan, 1972). These particular modifications in the complainee's bodily position could be attributed to the context of the situation, proficiency issues, as well as to the complainer's content of utterances and kinesic resources, such as a fixed gaze direction when expressing displeasure. In the case of the B2 pair, results suggested that kinesic resources were employed as a support for the verbal production as well as a reaction towards the speakers' performance. Participants tended to employ gestures while delivering their turns but also when acting the role of listeners (e.g. adaptors). Adaptors seemed to reveal emotional content that was triggered a result of the face threating situation, the content of the utterances of the speaker and the kinesic and paralanguage resources that were projected, for example, by means of gaze direction and loudness. Furthermore, it should be noted that the density of the turns participants elicited in each particular proficiency group was different. The $\mathrm{B} 2$ group appeared to produce longer turns, which could have affected the production of for example more gestures that accompany the verbal speech. An example of this could 
be found in Example 26 where the complainee seemed to employ various gestures in his turns.

Moving on to the post-complaint, it should be pointed out that the role of the complainee appeared to become more prominent in the sense that a large part of the communicative power relied on this particular figure, who should carefully choose specific discourse functions that may allow him/her to repair the grievance. However, the B1 pair did not exactly reveal that the complainee made much effort to repair the grievance. It was indeed the complainer's insistence on obtaining a personal benefit which seemed to have affected the content of the turns. In so doing, he managed to guide the talk towards a repair that appeared to benefit more him than the complainee, who seemed not to be much affected by the situation.

Contrarily, it was observed that the B2 complainee insisted on repairing the situation. Concerning this, it might be suggested that taking the responsibility of repairing a situation would involve a much more complex action than simply letting the flow of the conversation reach a repair, as the complainee in the B1 pair did, thereby revealing proficiency issues. Indeed, as shown in the data of the B2 complainer, he did an effort to solve the problem, which resulted in a positive response from the complainer so that the situation was finally repaired. In this particular case, the complainee tried to please the complainer and show repentance. These particular actions, which were projected both verbally and non-verbally, might have helped them to restore harmony and avoid damaging their relationship. The benefit in this case would not be only for the complainee but also for the complainer.

In this particular move, the B1 participants elicited less complex grammar structures and less varied vocabulary than the B2 group, who tended to elicit rather elaborated utterances containing more varied and richer vocabulary as well as more complex grammar structures. It should be noted that although the role of insistence has not been addressed in the present study, it seemed to reveal that the 
B1 complainer did draw on insistence so as to achieve his personal goal, thereby showing more direct pragmatic behaviour, which in fact could be regarded as threatening for the interlocutor (Brown and Levinson, 1978, 1987).

From a multimodal perspective, it may be stated that participants appeared to employ various modes not only when constructing their turns, but also when they performed the role of listeners. The B1 pair seemed to rely more on face expressions, gaze and head movement than on gestures. By means of these three kinesic resources both participants conveyed their communicative purpose as well as showed active listenership towards the speakers. Interestingly, gaze appeared to play a paramount role in the conversation. An example of this could be the force of gaze in the insistence that the complainer projected. Gaze and face expression appeared to have an effect on the complainee, who also reacted nonverbally towards the interplay of modes projected by the complainer. For example, modifications of head position, face expressions and gaze were observed when he was attending his interlocutor. Similarly, when the complainee was delivering his turns, he appeared to modify head position (Kendon, 1967) and gaze (Argyle, et al., 1981). These particular bodily movements could reveal attitudes towards the threatening situation in which he was involved.

The B2 pair appeared to employ a variety of kinesic and paralanguage resources during the post-complaint. All these resources served them not only to project their voices but also to show active listenership. The different kinesic resources speakers used seemed to have had an effect on the interlocutor, particularly in the case of the complainee, who for example, revealed signals of his emotional burden towards the situation by means of for example adaptors or putting hands on his face as a consequence of the content of the utterances and the kinesic and paralanguage resources employed by the complainer. The complainer appeared to have been also emotionally affected by the situation, as he seemed to feel 
displeased with the situation. The emotional values that the two participants projected were observable by means of a multimodal analysis as it provided further insights into what was verbally and non-verbally uttered, revealing that the interaction was constructed by means of different modes. In fact, those modes which were no 'visible' when examining audio data appeared to play a paramount role in the deconstruction of the conversation.

In addition to this, participants' use of paralanguage was also observed during the conversation. Some of the turns elicited involved filled pauses that could be associated to participants' thinking process (Goldman-Eisler, 1968) not only when constructing the turns but also when delivering them. In line with this, it should be noted that gestures play a role in the course of SL/FL development in that they can, to some extent, support SL/FL speaker processing and planning (Gullberg, 1998, 2006). Considering this, Gullberg (2006: 115) indicates that 'it is possible that learners' discourse-related gestures reflect their attempts to reduce the processing load of keeping words, grammar, and the relationships between entities in mind at the same time as planning what to say next”. In this study, however, it was found that head movements and filled pauses appeared to be related to thinking process (Goldman-Eisler, 1968), which, in some cases, could be associated to planning. Furthermore, it might be suggested that the use of kinesic resources could also be applied to other factors such as cognitive factors, language aptitude, affective factors including motivation and anxiety, as well as proficiency, personality traits (e.g. extroversion vs. introversion) and attitudes towards the situation.

In addition to this, appropriateness was also examined taking into account the descriptors of kinesics and paralanguage. The rubric for appropriateness presented in Chapter 4 Section 4.6.2 was employed to conduct the multimodal appropriateness analysis. As reported, the rubric was based on a 1 to 4 rating scale that included two particular descriptors that focused on kinesics and paralanguage. 
The data analysis procedure followed here was the same that was applied to the analysis of appropriateness of the audio and transcripts (Section 5.1.4). Thus, the same EFL teachers were involved in the rating. In an attempt to ensure internal consistency between the two raters, the inter-rater reliability was estimated for each descriptor (see Table 44 for a summary of the statistical results), indicating that there was good inter-reliability (alpha coefficient $>.8$ ) between the two raters in the case of kinesics and paralanguage.

Table 44. Inter-rate agreement of multimodal pragmatic appropriateness

\begin{tabular}{cc} 
Descriptor & Cronbach's Alpha \\
Kinesics & .898 \\
Paralanguage & .875 \\
\hline
\end{tabular}

This particular analysis included the total sampling of the study, that is, the 64 participants. My concern was to examine multimodal appropriateness across proficiency levels. Therefore, I attempted to explore whether the B1 group and the B2 group differed in the overall speech act production by taking into account the two descriptors that were connected to multimodal communication, specifically kinesics and paralanguage. As in the case of the appropriateness of conversation presented in Section 5.1.4, two types of analysis were conducted to examine appropriateness, on the one hand, the overall appropriateness was calculated without splitting data into participants' role, thereby only into proficiency level groups, and on the other hand, an analysis of appropriateness that involved participants' proficiency level and role was also carried out to examine differences as regards the proficiency level and the role performed.

The analysis of multimodal pragmatics appropriateness according to participants' proficiency level (see Table 45 for a summary of the statistical results) revealed no significant differences as regards the descriptors of kinesics and paralanguage. 
Table 45. Statistical results as regards the overall multimodal appropriateness

\begin{tabular}{lcccccc}
\multicolumn{1}{c}{ Descriptor } & Group & $N$ & $M$ & $S D$ & $t$ & $p$ \\
Kinesics & B1 & 32 & 3.50 & .508 & .246 & .806 \\
& B2 & 32 & 3.53 & .507 & & \\
\hline Paralanguage & B1 & 32 & 3.25 & .508 & .479 & .633 \\
& B2 & 32 & 3.31 & .535 & & \\
\hline $\mathrm{p}<.05$ & & & & & &
\end{tabular}

Likewise, the analysis of appropriateness according to the proficiency level and participants' role (see Table 46 for a summary of the statistical results) did not show any significant difference. In all the cases examined, neither group outperformed the other group, so it might be suggested that no difference as regards the rank obtained for each particular descriptor was statistically different. However, it is important to state that both proficiency groups performed kinesics and paralinguistic features in the conversation, thereby enriching and contributing the communitive exchange.

Table 46. Statistical results as regards multimodal appropriateness

\begin{tabular}{lcccccc}
\multicolumn{1}{c}{ Descriptor } & Group & $N$ & $M$ & $S D$ & $t$ & $p$ \\
\multirow{2}{*}{ Kinesics } & B1 & 16 & 3.44 & .512 & .344 & .733 \\
& B2 & 16 & 3.50 & .516 & & .462 \\
\hline Paralanguage & B1 & 16 & 3.25 & .447 & .745 & .500 \\
& B2 & 16 & 3.38 & .500 & & \\
Kinesics & B1 & 16 & 3.56 & .512 & .000 & 1.000 \\
& B2 & 16 & 3.56 & .512 & & \\
\hline Paralanguage & B1 & 16 & 3.25 & .577 & .000 & 1.000 \\
& B2 & 16 & 3.25 & .577 & & \\
\hline p $<.05^{*}$ & & & & & &
\end{tabular}

In reporting the results of appropriateness, I centre my attention on the different elements that did interplay from a multimodal perspective. All the salient elements that were observed in the face-to-face conversation were visual cues such as gestures, face expression, gaze, head movement and paralanguage resources. All these salient elements were of paramount interest for 
understanding how appropriate participants were in their communicative event from a multimodal pragmatic perspective.

In general, the gestures observed were iconic, metaphoric, deictic, beats (McNeill, 1992) adaptors and emblems (Ekman and Friesen, 1969). Iconic gestures contribute to the communication since they were used to reinforce the verbal message by means of gestures that represented the actual idea. Metaphoric gestures were also found in the data to metaphorically picture abstract ideas such as a scale of friendship. Regarding deictic gestures, speakers tended to use them: to point towards them when talking, when referring to particular locations (not present) and people who were not present in the conversation. Beats were observed to contribute to participants' spoken discourse since they seemed to provide some support for the speaker when delivering the speech. These types of gestures, however, did not convey any additional meaning to the content elicited verbally, but help speakers to express their talk and it appeared to show the rhythm of their speech. Examples of beats were observed accompanying the complainee while for example providing justifications. That is, the hand movement seemed to move along with the pulsation of the speech (McNeill, 1992). Adaptors also played a role in the data since participants appeared to perform them in situations in which they revealed for example emotion and feelings. They were for example observed when the situation was repaired as a result of the achievement. Other types of adaptor were for example touching hair, which could be attributed to inhibition. Finally, emblems were also observed in the data. These types of gestures, which are culture-based (Efron, 1941, Kendon, 1983), appeared to be produced to show for example agreement in an attempt to provide support for the interlocutor.

Other important aspects observed when examining appropriateness were face expression, gaze, and head movements, which were in some cases combined with gestures and paralanguage resources. Face expressions were crucial in the communication for 
participants. Face expressions provided information as regards participants' emotions and particularly in contexts involving a complaint. Smile for example was also observed showing for example mutual understanding between the participants, which was not only observed by means of face expressions but also by means of participant's eye contact.

By means of gaze participants also provided valuable information that cannot be captured in audio data. For example, while some participants avoided eye contact in a particular situation in which they were accused of being responsible for the grievance or when they accepted that they were responsible for the offence, others tended to stare at his/her interlocutor during the conversation. Gaze and especially gaze directions (Goodwin, 1981, 1994) were typically combined with head movements. Gaze might not be always continuous in an interaction (Querol-Julián, 2011), and indeed, data revealed that participants changed gaze directions over the course of the conversation. The data also showed examples in which both participants looked at each other when interacting as well as situation in which the 'hearer', in this case the complainee, tended to look more at the complainer than the complainer looked at the complainee (Goodwin, 1981), possibly due to the difficulty to performing a FTA. It might be indicated that gaze was of paramount interest since they employed this particular kinesic resource not only to perform utterances but also while acting as active listeners. Furthermore, changes in gaze direction were also employed for thinking process or planning.

Situations involving participants head movement were identified for example in combination or not with backchannels. As part of the verbal backchannel, head nods appeared to reinforce the meaning of the backchannel (Goodwin, 1980), and as an independent head movement, they served to show active listenership. In fact, several authors have identified head nods as part of the backchannel 
repertoire (e.g. Duncan, 1973; Gass and Houck, 1999; Carter and Adolphs, 2007).

Interestingly, some participants, especially at B1 level, combined, while speaking, face expressions with gaze and gestures for lexical search or for claiming support from the other interlocutor as they were facing linguistic and lexical difficulties. Concerning this, it is important not to lose sight of the type of sample chosen for the present study, that is, FL leaners of English at different proficiency levels. Although the B2 group was more proficient than the B1 group, they were all learners of English and consequently they showed linguistic and lexical difficulties in their face-to-face conversations, which were not only evidenced in the performance of their utterances but also in their gestures, face expressions, gaze, head movements and paralanguage resources (specially filled pauses).

Regarding paralanguage, participants at both proficiency groups produced laughter, filled pauses, short pauses, and in some cases snort. Then, it may be indicated that, in some cases, participants employed various paralanguage resources such as pauses, albeit short (e.g. 0.1, 0.2 seconds), filled pauses, or snort that could be regarded as a response to their interlocutors' utterance, and laughter. Laughter was associated in some cases to issues of nervousness or anxiety due to the situation, especially in the B1 group. Nevertheless, laughter was also used as a result of the communicative exchange, and importantly, this paralanguage resource was not performed in isolation since other kinesic resources such as gaze were embedded simultaneously. Snort was performed by the speaker or by the listener, for example as a response towards what was uttered by the current speaker. As in the case of laughter, snort was also accompanied by kinesic elements such as gaze or head movements. Filled pauses were produced by participants across the two proficiency levels for various reasons. Paralanguage features such as filled pauses revealed information as regards participants' actions taken while performing tasks, which seemed to have an effect not 
only on the verbal production of the utterances but also on the gestures, face expression, gaze and head movement. Hence, it seems that filled pauses along with laughter and snort were not observed in isolation since they were accompanied by kinesic elements and verbal utterances. Paralanguage resources seemed to contribute to the construction and comprehension of the content of the utterances since they were not produced per se, but purposefully as part of the communicative exchange. Concerning this, it might be suggested that paralanguage resources, at least in this study, served to reveal and gather information as regards participants' construction of talk due to the communicative value of paralanguage.

Moreover, signals of support and mutual understanding between participants were also observed. Particularly, I do refer to for example signals of linguistic support in which participants appeared to help each other when facing linguistic and lexical difficulties; signals of emotional support showing appraisal or satisfaction when they completed the task, although signals of disappointment were also observed, perhaps because they were not satisfied with the performance; and other emotional support or mutual understanding as regards the task performed. It should be also noted that in the retrospective verbal reports, participants were also asked to assess their performance, not only their own but also the performance of their interlocutor. Participants' comments as regards this aspect evidenced some of the face expressions observed in the data, pointing for example to the satisfaction as regards their performance. Face expressions also provided evidences of participants' attitudes towards the task as well as to the complexity of speaking an FL, in this case English, due the lack of confidence, which could be associated to proficiency issues.

In addition to this, it is important to indicate that in examining appropriateness drawing only on the audio data and the transcription; raters might not assess the overall communicative exchange. In taking a multimodal perspective, raters can obtain 
further insights as regards participants' performance as it enriches the comprehension of 'appropriateness'. Multimodal data enables us to observe participants' behaviour from a different perspective. Concerning this, it might be suggested that by focusing on the overall communicative event from a multimodal perspective, results as regards the overall appropriateness could differ from an audio-based analysis approach. When observing the full picture of the communicate event, raters could explore in a more detailed manner how the conversation was constructed, taking into account not only the different modes that supported speakers' verbal production but also the modes that were integrated when attending the speakers and how they reacted non-verbally. In the present study, the overall picture of the conversation allowed raters to observe how the interaction was constructed and how they delivered, reacted and showed active listenership during the overall task. Nevertheless, it should be noted that there are so many aspects (e.g. emotions, feelings) that are not always observable or that are not captured or understood by the speaker, and consequently it is sometimes difficult to ascertain the actual meaning of interpersonal communication.

\subsection{Summary}

This chapter has provided the results and discussion of the study conducted. In order to present the results and the discussion of the study in a logical manner, thereby following the research questions proposed for the present study, two main sections have been employed. This study involved the use of various research instruments that served to collect data, which was analysed from a quantitative and qualitative perspective. The use of mixed methods for collecting data facilitated the triangulation of the data. Furthermore, the use of various approaches enriched the results and the discussion. 
In the first section I have attempted to provide an answer to the first research question which focused on the effect of the variable of proficiency on the performance of learners' interlanguage complaints. In order to answer this research question, I have explored different aspects as regards the spoken data. Since I examined not only the perspective of the complainer, as most studies do, but also the perspective of the complainee, some methodological decisions as regards the analysis and the way of presenting results were taken. In light of this necessity, a CA approach for the analysis of interlanguage complaints was adapted as it was considered that this approach could provide a better representation of the data. In so doing, I examined the conversation of the structure by exploring, moves, turns employed, and whether the situation was repaired or not, as well as time and words. This was then followed by an analysis of the sequence organisation of the complaint communicative act, in which I presented the results as regards the pragmatic performance of complainer and the complainee. Furthermore, salient conversational features that emerged from the data were also analysed, more specifically backchannels, overlapping and paralanguage resources. Finally, this first research question involved the analysis of participants' pragmatic appropriateness in conversation.

The second research question focused on how a multimodal approach may enrich the ILP analysis of the speech act of complaints. To do so, two different types of analyses were conducted. On the one hand, a pair of each specific proficiency group was selected in order to conduct the multimodal CA of the interlanguage data. As reported, participants tended to employ different modes to enrich their communicative action by employing extra-linguistic and paralanguage elements when constructing and performing their verbal utterances. Interestingly, extra-linguistic were also observed while participants performed the role of active listener, which pointed to the way they attended the interlocutor. On the other hand, 
I performed an analysis of the appropriateness from a multimodal perspective, thereby focusing on the kinesics and paralanguage resources that served to construct the communicative event.

It is also worth mentioning that the retrospective verbal reports employed in this study were instrumental in revealing information that might not be obtain for example from the role-play task. Retrospective verbal reports provided valuable information as regards participants' performance, which served not only to support the findings of the study but also to point to specific methodologies aspects of the research instrument employed, specifically the lack of real-life consequences.

In short, this chapter has provided the results and discussion as regards the two research questions posed for the present study. As indicated above and previously shown in the chapter, various analyses were conducted so as to provide an answer to each research question. In the following chapter, Chapter 6, I provide a summary of the most relevant findings of the study, along with some limitations that have emerged throughout the study. Moreover, further research considerations for the analysis of ILP, as well as pedagogical implications for the integration of multimodal pragmatics in the FL context are presented in Chapter 6. 
Chapter 6. Conclusion 



\section{Chapter 6. Conclusion}

The objective of the present study was to provide some insights into language learners' performance of interlanguage complaints at different proficiency levels. This study is framed within the field of ILP and multimodal studies, and therefore, it attempts to shed some light into language learners' performance of the communicative act of complaints from a wider perspective, that is, taking into account their pragmatic behaviour as well as the different modes employed to communicate. In Section 6.1, an overview of the major findings of the present study is given. These findings, however, may only be viewed against the limitations of the study, particularly, those which are presented in Section 6.2. Then, in Section 6.3, I focus on further research directions. Finally, in Section 6.4, potential pedagogical implications are highlighted.

\subsection{Summary of findings}

The present study attempted to contribute to the field of ILP and the field of multimodality by focusing particularly on language learners' spoken production of complaint sequences. The specific variable chosen for the purpose of the study was proficiency. Considering this, I attempted to explore whether proficiency had any effects on spoken production.

This study followed a CA approach for the study of interlanguage data, which is not usually followed in the field of ILP. By means of CA analysis, this study focused not only on complaints and responses to complaints, but also on other features such as backchannel and overlapping. Furthermore, taking into account the multimodal nature of spoken data, multimodal CA was conducted. Finally, multimodal pragmatic appropriateness was also examined. Before I go any further, it may be helpful to restate the two research questions guiding the present study: 
Research question 1: Does language proficiency influence language learners' interlanguage complaints?

Research question 2: How does a multimodal approach enrich the analysis of interlanguage complaints across proficiency levels?

\subsubsection{RQ1: Does language proficiency influence language learners' interlanguage complaints?}

In order to answer the first research question, different analyses were conducted to examine the structure of the conversation, the sequence organisation, conversational features, and pragmatic appropriateness.

The analysis of the structure of the conversation involved exploring different issues as regards the composition of the conversation. First, I focus on how participants sequenced the conversation in terms of moves in order analyse the approach taken to construct the conversation. In exploring proficiency effects, results revealed no statistical differences across the two groups. This particular result could be attributed to participants' prior knowledge of the structure of a complaint situation, which might lead to suggest that both groups showed a similar pragmatic knowledge of conversation structure as regards the communicative act of a complaint.

In addition to this, attention was also paid to the amount of turns participants elaborated in order to reach communicative purposes. Results seemed to suggest that no statistical differences were found as regards the participants' role. However, in analysing participants' performance according their proficiency level, a significant difference was found in the post-complaint move, which might reveal that the $\mathrm{B} 2$ group uttered more turns than the B1 group. In this particular move participants can generate as many turns as necessary to repair the situation, or at least, to try to repair it. The use 
of more turns in this move could be attributed to participants' proficiency level as well as to sociopragmatic sensibility towards the situation. It should be mention that in considering that total amount of turns, the B2 group also produced significantly more turns the B1 group.

Participants' repair was also examined as part of the conversation structure. Results appeared to indicate that the B2 group tended to repair significantly more frequently than the B1 group did. This result could be attributed to participants' proficiency level (Moskala-Gallaher, 2011) which allowed them to repair the situation more frequently than the B1 group did. Furthermore, it should be noted that task difficulty (Taguchi, 2007) could have also affected participants' repair. More precisely, repairing a complaint situation could be a more complex action than complaining since further linguistic resources would be required to reach to that end. Moreover, and more importantly, repairing a situation involves the appropriate choice of pragmalinguistic resources that are tightly connected to participants' sociopragmatic awareness and sensibility towards the situation.

Another aspect examined in the structure of conversation was the time used to complete the task. Results showed that no significant differences were found in this particular case, thereby indicating that both proficiency groups employed a similar amount of time to complete the task. In the case of words, this study demonstrated that, in comparing participants' roles, the complainer produced statistically slightly more words than the complainee in the precomplaint, while in the remaining moves no statistical differences were found. This result could be related to the complainer's role in the pre-complaint move, which served to prepare the complainee for a forthcoming complaint. In comparing proficiency levels, results appeared to reveal that proficiency had an effect on the number of words elicited in the post-complaint. Results seemed to suggest that the B2 group used more words than the B1 group, as observed in the case of turns. Taking into account these results, it may be indicated 
that proficiency had an effect on the production of turns and words in the post-complaint move. These results could be attributed to participants' interest in repairing, which in turn may reveal their sociopragmatic sensitivity towards the interlocutor and the situation.

In light of the results obtained as regards the structure of the conversation, it could be suggested that participants' disposal of linguistic resources could have influenced participants' production of turns and words in the post-complaint move. Furthermore, considering that repairing a situation would involve a complex task (Taguchi, 2007), it may be argued that although repairing a complaint situation might be challenging for both proficiency groups, it could be more complex for less proficient participants due to linguistic and lexical limitations. Moreover, another important issue to take into account is participants' sociopragmatic sensibility towards the situation, which could also affect participants' perception of the situation and the action taken to repair.

The other aspect examined to provide an answer to the first research question was the performance of participants. This analysis was conducted so as to analyse the overall use of discourse function in each move and the distribution of the discourse functions in each move.

Results concerning the complainer showed that the B2 group appeared to statistically employ more discourse functions in the postcomplaint move than the B1 group did. This particular result could be attributed to the nature of the move, which involved the repair of the situation and therefore the complexity of the task increased (Taguchi, 2007). In addition to this, participants' perception of the offence could have also influenced the results. A post-complaint move involving a repair requires participants' sociopragmatic knowledge of the situation (Olshtain and Weinbach, 1987). Participants' amount of discourse functions in the post-complaint move could be associated to the perceived level of offence, the social distance between the participants as well as to participants' linguistic knowledge. 
In examining the distribution of discourse functions, results showed that the B2 group produced the discourse function of allusion to the offensive act more often than the B1 group did in the topic negotiation move. This particular discourse function could be used to show in a more indirect manner attitude towards the offence (Chen, et al., 2011). This result is in line with Moskala-Gallaher (2011), who found that more proficient participants tended to be less direct than less proficient participants. This particular result could be attributed not only to participants' disposal of linguistic knowledge to construct the turns but also to participants' attempt to employ indirect discourse functions, thereby revealing sociopragmatic sensibility towards the complainee. Moreover, in the post-complaint, results showed that the B2 group performed significantly more discourse functions of dissatisfaction and acceptance than the B1 group. By means of dissatisfaction participants may show displeasure for a particular action without explicitly referring to the complainee (Chen, et al., 2011). The performance of this specific discourse function could be also related to participants' sociopragmatic sensibility towards the complainee, which in turn might be influenced by the linguistic knowledge required to perform such discourse function. The use of the discourse function of acceptance in the post-complaint move could be associated to participants' interest in reaching mutual understanding in order to repair the situation.

Hence, these findings might point to participants' linguistic knowledge as well as to sociopragmatic awareness and sensibility towards the situation and the complainee, which was observed for example in the choice of discourse functions. In general, the complainer's production seemed to be characterised by participants' performance in the post-complaint move and repair. Results concerning this particular move revealed that more proficient participants employed more turns and words, repaired the situation more frequently, and employed for example specific indirect discourse functions. These particular results could be somehow determined by participants' proficiency level and sociopragmatic 
sensibility towards the situation and the complainee. In line with, it may be suggested that the use of specific indirect discourse functions (i.e. allusion to the offensive act and dissatisfaction) could be related to participants' attempt to repair the situation and avoid any conflict that could affect participants' relationship. Prior knowledge as regards the construction of turns to elaborate a complaint could have also influenced participants' performance.

Moving on to the complainee, results showed that no statistical differences were found across the two proficiency level groups when examining the overall use of discourse functions in each move. This particular result could be associated to participants' role since the complainee appeared to somehow depend on the complainer's performance. Furthermore, it should be noted that although the construction of moves depends on both participants, the complainee could have decided to decline the complaint (Laforest, 2002). Nevertheless, this particular scenario was not found in the data.

In the case of the distribution of the discourse functions in each move, results seemed to reveal that the B1 group elicited significantly more refusals than the $\mathrm{B} 2$ group in the topic negotiation move, possibly to reject the initiating turns of the complainer, which could have negatively affected the potential repair or the polite discussion. By contrast, it was shown that the B2 group produced significantly more suggestions in the post-complaint move than the B1 group. In light of these results, it might be suggested that participants' pragmalinguistic choice could have also affected participants' repair since employing for example suggestions in the post-complaint may to some extent facilitate participants' repair, whereas the use of refusals in the topic negation could negatively affect the negotiation of the complaint and the post-complaint exchange.

In short, results concerning the complainee seemed to point to various aspects, such as participants' prior knowledge as regards the construction of a complaint situation and their dependence on the turns elicited by complainers. Moreover, the complainee's 
performance could have been affected by the assessment of the situation as well as by their disposal of linguistic resources to use specific discourse functions, such as suggestions in the postcomplaint move. Finally, it should be noted that the lack of real-life consequences of the task could have affected participants' performance, revealing for example lack of involvement and emotional burden.

Moving on with a general overview of the results of the complainer and the complainee, it might be pointed that the lack of more differences across the two proficiency groups could be attributed to the fact that only one situation was employed. Perhaps, the use of more scenarios showing a variety of social parameters could provide further evidences as regards the realisation of discourse functions of interlanguage complaints in different contexts.

It is worth mentioning that the data collection instrument could have also influenced participants' elicitation of data. Trench (1994) for example pointed to the limitations of DCTs to obtain examples of specific discourse functions. In the present study, however, a roleplay task was used as it allows exploring features of conversation. It might be, however, argued that the use of natural occurring data could be beneficial to examine further discourse functions. Nevertheless, it should be pointed out that the role-play task designed for the present study was based on an exemplar generation task completed by the participants as well as on a likelihood questionnaire that was used to select the task. This was done purposefully in an attempt to provide participants with opportunities to interact in a situation that could represent an everyday situation that was not only familiar for them (Trosborg, 1995) but also close to their real-life interactions. Notwithstanding, the retrospective verbal reports revealed that the lack of rea-life consequences (Roever, 2010) could have influence to some extent participants' performance.

Trench (1994) also pointed to the limitations of the context where her study was conducted. The present study was conducted in a language laboratory, thereby differently from a natural setting in 
which two close friends may for example meet to have a conversation. This fact was noted by some pairs who pointed to the artificiality of the setting, indicating that a real context would have been more appropriate to interact with a friend. Moreover, the retrospective verbal reports also indicated that some participants were first uncomfortable with the use of cameras, but they appeared to become familiar with them once they had completed the first scenario, which was employed as an ice-breaker.

The structure of complaints and responses to complaints designed for the present study appeared to serve to capture participants' pragmatic behaviour. However, further discourse functions were added in order to provide a better representation of participants' performance. Participants' data was classified according to the different pre-established moves. By means of moves, it was possible to observe how participants organise the different sequences and how they constructed the conversation. Nevertheless, not all moves were required for a complaint to be uttered. While the precomplaint and the post-complaint were regarded as highly recommended moves, the topic negotiation move was found to be necessary. The opening and closing moves were not required either, and in fact, they are not part of a complaint move, but of any conversation. The results obtained as regards the structure of moves and the discourse functions might indicate the complexity of this particular speech act since there is not a prototypal set of discourse functions (Laforest, 2002; Geluykens and Kraft, 2008). Moreover, complaints do not usually contain an adjacency pair structure but extended sequences (Drew and Walker, 2009), which makes the complaint exchange more complex.

In a conversation, typically, speakers follow the turn-taking rules of interaction in which speakers perform turns orderly. However, simultaneous talk may be also observed. In this study, two types of simultaneous talk were identified, overlapping and backchannel. As characterised in Chapter Section 1.3.2.1, overlapping 
involves initiating a turn while the current speaker is performing a turn, while backchannel may serve to show signals of active listenership. Concerning the use of backchannels, results showed that the B2 group appeared to employ significantly more backchannel than the B1 group. In examining each particular role, it was observed that the complainees in the B2 group elicited significantly more backchannel than the $\mathrm{B} 1$ complainees, showing that the $\mathrm{B} 2$ group appeared to show attendance by means of backchannels more frequently. Furthermore, results showed that the B2 group elicited more backchannels involving the categories of continuer and agreement than the B1 group did. In the case of overlapping, proficiency had also an effect on performance since the B2 group appeared to perform them significantly more frequently than the B1 group did. This particular result might be related to participants' involvement in the task and the attention they paid to the turns elaborated by the interlocutor. More specifically, it seemed that the B2 group were more involved in the conversation and therefore in the construction of the on-going talk whereas the B1 group appeared to focus more on how to elaborate the forthcoming turn, which appeared to prevent them from interacting in a more natural manner.

Paralanguage elements were also examined as a response to the first research question. Two different aspects were explored, particularly filled pauses and laughter. Results seemed to indicate that the B2 group produced significantly more filled pauses than the B1 group did. This result could be related to participants' proficiency level and possibly fluency. Laughter was found to be significantly more frequent in the B1 group, possibly as a result of the lack of involvement in the task as well as to anxiety, or perhaps as a result of the content. Furthermore, it was observed to be more frequently used by the complainer, perhaps as an attempt to soften the face threatening nature of the speech act of complaints (Edwards, 2005).

The last aspect examined to respond to the first research question was appropriateness. Results seemed to suggest that the B2 group significantly outperformed the B1 group in the descriptors of 
expressions and turn-taking, which might reveal that participants' proficiency level had a strong impact on the spoken performance as regards these two descriptors. The results further showed that when examining each particular role according to their proficiency level, significant differences were also found in the case of the descriptors of expressions and turn-taking, revealing that the B2 outperformed the B1 group in these two specific descriptors. Hence, it might be suggested that participants' disposal of linguistic resources and knowledge of how to use language in spoken interaction had an impact on appropriateness.

In short, it should be pointed out that proficiency appeared to have affected participants' pragmatic performance in some specific aspects. It was found that more proficient participants tended to employ more turns and more words in the post-complaint move. The post-complaint move involved a rather complex task, particularly, repairing the situation, which was found to be more frequently repaired by the more proficient group. Moreover, in the case of the B2, complainers appeared to employ more indirect discourse functions than the $\mathrm{B} 1$ complainers as well as to elicit more discourse functions in the post-complaint move. The proficiency effect was not so evident for the B2 complainees, although they appeared to perform a particular discourse function (suggestion) in the postcomplaint move more frequently than the B1 group, which might have contributed to the repair of the situation. In general, participants' production was somehow affected by proficiency, which broadly speaking seemed to influence the choice of the discourse functions, the repair the situation, the performance of conversational features, and appropriateness. Nevertheless, further research is needed in order to explore the effect of proficiency on participants' overall pragmatic competence.

It should be also indicated that the integration of $\mathrm{CA}$ for the analysis of ILP data, and more precisely interlanguage complaints, was instrumental in providing information as regards participants' 
construction of conversation. In following this particular approach, data was analysed taking into account all the different verbal elements that were encountered in the interaction such as signals of active listenership. Furthermore, it served to observe how participants oriented and elaborated the conversation over different turns that were generated as a result of the spoken exchange. Therefore, it might be suggested a CA approach may enrich traditional ILP approaches as it reveals information as regards the sequencing of the turns, which is of paramount interest to examine proficiency issues since researchers can obtain a wider representation of the data. Furthermore, the use of a pragmatic rubric to assess participants' appropriateness was instrumental in providing further evidences of participants' pragmatic behaviour in conversation as well as to reveal proficiency issues. Moreover, by means of retrospective verbal reports further data concerning participants' pragmatic performance was obtained, which served not only to triangulate the data gathered but also to comprehend participants' performance.

In addition to this, another way of enriching the ILP analysis is by approaching data from a multimodal perspective. The findings of this particular aspect are presented in the following section.

6.1.2. RQ2: How does a multimodal approach enrich the analysis of interlanguage complaints across proficiency levels?

In order to answer the second research question, a multimodal CA was conducted. To do so, a pair of each particular proficiency level was chosen. Then, by means of a multimodal CA approach, the conversation was examined so as to explore how the different modes that emerged from the data interacted not only while producing speech but also when participants performed the role of active listeners. More precisely, my concern was to deconstruct how the 
different kinesic (face, gaze, head and gestures) and paralanguage resources were used by the four speakers, not only while speaking but also while attending the speaker. Hence, I tried to provide an accurate description of how the conversation was constructed over different modes.

From a quantitative perspective, the multimodal CA approach seemed to suggest that, in general, the four participants seemed to employ different extra-linguistic and paralanguage elements during the conversation, including gestures, face expressions, gaze, head movement, filled pauses, laughter, snort, loudness, and syllable duration. It should be noted that the quantitative analysis seemed to indicate that participants appeared to rely on gaze and gestures more frequently than on other kinesic resources. The qualitative analysis provided further evidences on participants' performance and how they employed various modes to reach communicative purposes. Then, the qualitative analysis seemed to suggest that participants' interaction was characterised by linguistic, extra-linguistic and paralanguage elements.

Interestingly, extra-linguistic elements were observed not only when the speakers were verbally creating the turns but also when they were performing the role of active listeners. Signals of active listenership were of paramount interest as they contributed to the construction of the talk. Paralanguage, due to its communicative value, also contributed to the construction of the conversation. For example, paralanguage, combined with kinesic resources, may serve as a response to a given turn, as it was found in this particular study in the case of snort, which was produced by the B2 complainee as a response to a turn elicited by the B2 complainer. Moreover, paralanguage seemed to have provided insights into the way participants, particularly in the B1 pair, plan the execution of a given turn. Cases in which paralanguage and other modes were integrated simultaneously to plan the execution of a turn were identified. Although further research is needed to support this claim, it seems 
that, at a lower proficiency level, combinations of filled pauses with gaze orientation and head movement may be found for internal processes that could unveil thinking process, for example for planning the execution of a turn. Hence, it could be suggested that the B1 pair, on some occasions, used extra-linguistic elements and paralanguage resources not only to organise and perform their turns, but also to manage proficiency issues. Differently, the B2 participants tended to perform them in a more natural manner in the sense that they were usually attributed to the construction and delivery of the talk.

Moreover, findings seemed to suggest that participants did not remain unaffected by the content of the utterances elicited by the interlocutors since they appeared to react by means of various extralinguistic elements involving gestures, changes in gaze direction as well as face expressions as a result of the on-going talk. This particular aspect was more prominent in the B2 pair, who appeared to react by means of kinesic features more frequently than the B1 group did when performing the role of active listeners. By contrast, the B1 pair, although also employed kinesic resources to construct their talk and to show signals of active listenership, they seemed not to be as noticeable as in the case of the B2 pair. Possible explanations for this particular result would be participants' involvement in the task and proficiency level. By observing participants' extra-linguistic and paralanguage behaviour while talking and while attending the speaker, one may obtain some information as regards participants' involvement in the task. This particular phenomenon could be associated to participants' proficiency level in the sense the B1 group seemed to be more focused on 'what to say' as a response to the turn elicited by the speaker rather than on becoming engaged in the conversation and on following the flow of the conversation as in a natural encounter.

The multimodal analysis performed revealed that the kinesic feature of gaze appeared to play a role in the interaction. A possible explanation for this would be that participants were engaged in a 
rather face threating situation. Nevertheless, this was not the only kinesic feature observed. Results revealed that, although both groups performed gestures, the $\mathrm{B} 2$ produced slightly more gestures than the B1, not only when constructing turns but also when performing the role of active listeners (e.g. adaptors). Results also revealed that head movement was more frequently produced by the B1 pair than the $\mathrm{B} 2$ group did. A possible explanation for this could also be the threatening nature of the situation as well as participants' need for thinking processes since head movement was also found in cases in which filled pauses occur while planning a turn. Gaze was more frequently identified in the B1 pair than in the B2 pair. This particular result could be associated to participants' thinking process or planning as well as to avoid eye contact with the interlocutor as they were engaged in a face threatening situation. As regards paralanguage, the analysis revealed that the B2 pair employed this particular resource more frequently than the B1 pair. Furthermore, it might be indicated that the function they accomplished varied since the examples found in the B2 data were commonly associated to the flow of the conversation whereas in the B1 group, as aforementioned, were frequently related to internal processes for planning the performance of the turns.

It should be remarked that the multimodal $\mathrm{CA}$ approach performed in this section appeared to provide the opportunity to examine ILP data in a more detailed manner. The value of a multimodal CA approach for ILP relies on the fact that researchers can obtain further insights into participants' performance. Particularly, one may obtain information as regards the different actions speakers performed in the conversation, speakers' intentions, how they plan the turns, their reactions towards the interlocutors, the immediate context and the verbal and non-verbal production of the interlocutor, as well as how they show signals of active listenership. Moreover, by means of multimodal analysis, further insights as regards the way of approaching to each other in terms of gesture 
performance, face expressions, gaze direction, and head movement might be gathered, whereas the audio data could not reveal such information. Although difficult to properly identify in the images, the video offered the opportunity to observe participant's emotional state. This valuable source of data, which cannot be observed in audio data, might provide further insights into participants' overall interaction.

Regardless the benefits of multimodal CA and the effort of collecting data by means of video cameras, there are always some aspects that human eyes cannot capture and that is beyond cameras, for example, the inner thoughts and internal processes while performing the task. In an attempt to solve this, retrospective verbal reports were used. Therefore, it seems that by means of a multimodal CA approach and retrospective verbal reports, further aspects of how speakers construct the conversation were observed and it provided further insights as regards participants' pragmatic performance, features of active listenership, emotions, and how they constructed their talk verbally and non-verbally.

Furthermore, in line with the appropriateness aspects explored as a response to the first research question, all the sample of the study was examined in terms of multimodal appropriateness, by focusing on kinesics and paralanguage resources. Results seemed to suggest that no statistical differences were found across proficiency levels. This particular finding might be attributed to participants' appropriate overall use of kinesics and paralanguage resources so as to communicate with the interlocutors as well as to show active listenership. In observing only audio data, as I did in the first analysis of the pragmatic appropriateness, it was not possible to examine the multimodal nature of interaction. Rather, in focusing only on the audio data, a partial analysis of the interaction can be portrayed as it is not possible to demonstrate how different modes are integrated to reach communicative purposes.

Finally, it should be pointed out that further research is required in order to explore not only the contribution of a 
multimodal CA approach for the analysis of ILP data, but also to further investigate whether proficiency may have an effect on participants' paralanguage and kinesic performance. This study has shown the potential of following a multimodal CA approach for the analysis of interlanguage complaints from a wider perspective, which allowed integrating the different modes participants employed in the construction of the conversation not only when speaking but also when acting as active listeners. Furthermore, this particular approach has served to understand in a clearer manner the data participants elicited. This particular approach should be considered in order to provide further insights into participants' pragmatic behaviour.

\subsection{Limitations}

In this section, I address the limitations of the study and it should be indicated that it is against the backdrop of these limitations that the findings of the study should be viewed.

The first limitation concerns the number of participants for each particular proficiency level group. A larger number of participants could have helped to provide further insights into learners' pragmatic performance across proficiency levels from a conversation analytic perspective. It should be noted that previous research has not explored interlanguage complaints from this particular perspective, that is, taking into account the role of the complainer and the complainee. Furthermore, in the field of ILP pragmatics, the multimodal nature of communication has not been addressed.

A second limitation relates to the choice of the participants. Homogeneity was an important precondition and then some sacrifices were made as regards the choice of the participants. A similar amount of participants was required in each proficiency level so, in an attempt to expand the opportunity to collect data from a larger amount of participants, language learners from two university 
degrees were chosen. While participants' choice of university degree might not necessarily have an impact on the results of the study, it is certainly true that their personal choice as regards the university degree may be tightly connected to their professional interests and possibly personality traits. Ideally, they should have belonged to the very same field, but it was not possible due to the number of learners in each group.

A third limitation involves the methodological choice of the production task, the role-play task. Although role-play tasks might be served to gather authentic conversational features, it may not reflect the actual behaviour learners would exhibit in a real situation due to the lack of real-life consequences. Nevertheless, the instrument chosen served to elicit participants' complaint behaviour in English. Perhaps, having more scenarios could have also provided further insights into participants' pragmatic performance as regards the communicative act of complaints. Furthermore, it should be noted that although the construction of the instrument involved an exemplar generation task and a likelihood questionnaire, retrospective verbal reports were not employed to obtain further information as regards participants' choice, which in fact could have provided further information as regards the methodological design of the task. 


\subsection{Directions for further research}

The areas of ILP and multimodality studies are still young fields of inquiry. Nevertheless, both areas have called the attention of several researchers in recent years. However, the number of works studying multimodality from the perspective of SLA is, to the best of my knowledge, limited, whereas there is a growing body of literature devoted to the field of ILP. Furthermore, it should be noted that no studies have been conducted exploring ILP and extra-linguistic and paralanguage resources as a unified construct.

Concerning the analysis of the interlanguage pragmatic data, it should be noted that the present study adopted a CA approach so as to obtain a wider representation of speech act performance in conversation. In so doing, the analysis was conducted taking into account the perspective of the complainer and the complainee, which is rarely done in the area of ILP. Bearing in mind this, the present study attempted to contribute to the area of ILP by exploring simulated spoken data from a CA approach so as to analyse how participants construct talk. Furthermore, it is also important to note that while the variable of language proficiency has been widely examined in the arena of ILP, not much attention has been paid to the effects of proficiency on kinesics. Nevertheless, further research is required in both areas.

My humble contribution is just a preliminary study that attempts to introduce a new perspective for the analysis of ILP data from a CA approach that integrates both, the complainer and the complainee. Particularly, this is a first study that examines FL learners' interlanguage complaints and responses to complaints from a CA approach. Furthermore, I tried to show how a multimodal CA approach can contribute to the analysis of ILP, which may be regarded as a new contribution to the field of ILP since multimodality is not integrated in the field of ILP. 
Giving the findings of the study, and particularly the results obtained in the first part, a major step should be taken on the quantitative data. A larger number of participants involved in more scenarios should be needed to further explore interlanguage complaints and responses to complaints as well as the variable of proficiency. Furthermore, I have highlighted the value of the contribution of a multimodal $\mathrm{CA}$ approach for the analysis of interlanguage complaints and responses to complaints. Further steps should be taken from an interlanguage pragmatic corpus in order to obtain further results as regards multimodal interaction. These efforts would put the research in the position of making generalisations. Moreover, I consider that a relevant suggestion that can be made is to extend the analysis of ILP and multimodality to language and emotions in order to study how the emotional domain interacts with the verbal and non-verbal domains. In addition to this, the role of the active listener in conversation should be further investigated from a multimodal perspective in the ILP context.

Finally, a number of pertinent areas of research relating to the present study should be highlighted. An important aspect to consider is the design of longitudinal research that examines ILP and multimodality as a joint construct so as to explore how learners develop their (multimodal) communicative competence. Furthermore, future research should also address the effect of instruction of multimodal pragmatics, which should be not only observed by means of pre-test and post-test, but also by means of post-delayed tests so as to explore long term effects of instruction. Cross-cultural research should be also conducted as it could also provide further evidences as regards speakers' multimodal pragmatic performance. Multimodal pragmatics should be also examined taking into account not only proficiency, as in the present study, but also other variables such as age, gender, individual motivation, or quantity and quality of input, among others. A detailed analysis of proxemics to observe not only their proxemics behaviour but also its impact on the construction of the conversation and on the 
interlocutors would also reveal more information as regards the communicative event. By the same token, an analysis of prosody and intonation, for example by means of software such as PRAAT, could also provide further evidences of how pragmatic meaning is delivered and constructed in interaction. Also, an in-deep analysis of paralanguage resources would be required so as to examine in detail their impact on speakers' performance.

\subsection{Pedagogical implications}

One of the most prominent aspects to consider is the elaboration of a multimodal communicative competence model that not only tackles the verbal aspects of language, but also the extralinguistic and paralanguage elements of communication. Focusing specifically on pragmatic competence, it might be suggested that this competence could be viewed from a multimodal perspective, thereby involving not only verbal performance but also other resources such as paralanguage and extra-linguistic elements that are employed to communicate. In this sense, I would argue for the use of the term multimodal pragmatic competence, which could involve not only pragmalinguistic and sociopragmatic knowledge but also kinesics, paralanguage, proxemics, haptic knowledge, non-linguistic utterances such as silence and pauses (Celce-Murcia's, 2007 interactional competence) and the visuals used when writing, such as emoticons, capitalization, etc. Indeed, pragmatics is present in interaction, whether spoken or written, and therefore all the different modes that operate at the level of pragmatic performance should be taken into account as they do convey meaning.

The findings of the present study can find pedagogical implications in the area of FL teaching that follows a communicative perspective. On the one hand, the study has shown how speakers at different proficiency levels project their complaints and responses to complaints from a CA perspective. Therefore, one of the most 
important pedagogic implications of this study is the potential of CA for ILP development. By means of CA we might observe how pragmatic meaning emerge from learners' interaction and how they construct talk in a sequential manner. For example, language learners may indicate through their responses in the on-going talk how they perceive and understand the turns elicited by the other interlocutor. Likewise, they project signals of active listenership, which reveals for instance further information as regards learners' understanding and support for the interlocutor.

In following a $\mathrm{CA}$, we may also obtain information as regards learners' proficiency by focusing on how they employ interactional features of conversation, act in the conversation and react towards the interlocutor, show active listenership, as well as how they face linguistic difficulties. Since CA typically focuses on naturally occurring data, an instructional approach that aims to integrate CA in the language classroom might employ authentic data in order to provide more authentic models of language use in real contexts. An awareness-raising approach may provide learners with opportunities for noticing how interaction is constructed in a sequential order and how speakers contribute to this particular construction. Then, in focusing on the different moves of the conversation and the discourse functions in each move, learners may observe how speakers construct conversation. Furthermore, attention should be also paid to the role of the active listener as well as to conversational features of simultaneous talk, such as overlapping and backchannel in order to obtain a wider picture of how the on-going talk is constructed in a natural manner. An analysis of the turn-taking system, the context of the situation and the politeness rules governing the conversation should be also conducted in order to obtain a wider representation of the communicative event. The nature of appropriateness should be also tackled as it may provide learners with further opportunities for focusing on the pragmalinguistic choice and how the sociopragmatic conditions of the context affects pragmatic behaviour. Issues of turntaking as well as backchannel signals and overlapping should be also 
addressed when examining appropriateness. To do so, a rubric based on conversation, as the one used in the present study, could be integrated in the language classroom. Finally, communicative activities based on role-play practice should be provided, together with feedback on performance and on appropriateness. Therefore, it seems that a CA-informed pedagogical approach may provide opportunities to integrate pragmatic competence and interactional competence in the FL context at different proficiency levels.

The present study has also provided evidences of how a multimodal approach can contribute to the understanding of interlanguage pragmatics in conversation. Concerning this, pedagogical implications may be also addressed in order to foster multimodal awareness. Following a multimodal CA approach and employing the ELAN software, learners can be provided with an awareness-raising approach that integrates not only verbal language but also paralanguage and kinesic resources such as the use of filled pauses, loudness, intonation, face expressions, gaze, head movement, gestures, haptics and proxemics. In so doing, learners may notice how conversation is organised in sequences and how speakers construct the on-going talk not only by means of verbal language but also by means of paralanguage and kinesic resources. By the same token, the nature of the active listener as well as conversational features of simultaneous talk such as backchannel and overlapping may be observed not only by focusing on the verbal responses but also by exploring kinesic and paralanguage resources. The ELAN software can be used to integrate authentic conversations or sequences of audio-visual material such as films or sitcoms. An analysis of the kinesic and paralanguage resources that emerge from such data should be conducted in order to better understand how the communicative event is constructed from a multimodal perspective. The analysis can be done following a deductive-inductive approach. The former would involve that the teacher provides the norms or the explanations so that learners can analyse the examples, while the 
latter would refer to learners' exploration of data in which selfdiscovery of kinesics and paralanguage is done by the learner. Furthermore, issues of multimodal appropriateness should be addressed in an attempt to explore how kinesics and paralanguage contribute to the overall appropriateness of the conversation. To do so, a rubric as the one designed for the present study can be exploited in the language classroom. Opportunities for role-play practice as well as feedback on performance and on appropriateness on how kinesics and paralanguage contribute to the construction of meaning in conversation should be provided. Hence, in following a multimodal CA teaching approach, teachers may integrate not only pragmatic competence and interactional competence in the FL context at different proficiency levels, but also kinesics and paralanguage resources.

In short, I argue for a multimodal perspective of pragmatic competence taking into account that communication involves more than words, and therefore all the elements that interact in the construction of the conversation should be integrated as they convey meaning. This is of paramount interest for language learners as they should become aware of the different resources they have at their disposal to communicate. Likewise, in becoming aware of the importance of the different elements that contribute to the construction of conversation, learners might be more competent since they could become better communicators and understand better interlocutors' performance. 



\section{References}

Abercrombie, D. (1968). Paralanguage. British Journal of Disorders of Communication, 3(1), 55-59.

Adams, R.B.Jr., \& Kleck, R.E. (2003). Perceived gaze direction and the processing of facial displays of emotion. Psychological Science, 14(6), 644-647.

Adams, R.B.Jr., \& Kleck, R.E. (2005). Effects of direct and averted gaze on the perception of facially communicated emotion. Emotion, 5(1), 3-11.

Adams, R.B.K.Jr., Nelson, A.J., \& Purring, K. (2013). Eye behaviour. In J. A. Hall \& M.L. Knapp (Eds.), Nonverbal communication. (pp. 229-262). Berlin: Mouton de Gruyter.

Adolphs, S. (2008). Corpus and context: Investigating pragmatic functions in spoken discourse. Amsterdam: John Benjamins Publishing Company.

Agha, A. (2007). Language and social relations. Cambridge: Cambridge University Press.

Alcón, E. (2005). Does instruction work for learning pragmatics in the EFL context? System, 33(3), 417-475.

Alderson, J.C. (2005). Diagnosing foreign language proficiency. London: Continuum.

Al-Gahtani, S., \& Roever, C. (2012). Proficiency and sequential organization of L2 requests. Applied Linguistics, 33(1), 42-65.

Al-Gahtani, S., \& Roever, C. (2013). 'Hi doctor, give me handouts': lowproficiency learners and requests. ELT Journal, 67(4), 413-424.

Antaki, C. (Ed.) (2011). Applied conversation analysis: Intervention and change in institutional talk. Basingstoke, Hampshire: Palgrave Macmillan.

Archer, D., \& Akert, R.M. (1977). Words and everything else: Verbal and nonverbal cues in social interpretation. Journal of Personality and Social Psychology, 35(6), 443-449. 
Argyle, M., \& Kendon, A. (1967). The experimental analysis of social performance. Advances in Experimental Social Psychology, 3, 5598.

Argyle, M., Ingham, R., Alkema, F., \& McCallin, M. (1981). The different functions of gaze. In A. Kendon (Ed.), Nonverbal communication, interaction and gesture (pp. 283-295). The Hague: Mouton.

Arent, (1996).Sociopragmatic decisions regarding complaints by Chinese learners and NSs of American English. Hong Kong Journal of Applied Linguistics, 1(1), 125-147.

Arminen, I., \& Leinonen, M. (2006). Mobile phone call openings: Tailoring answers to personalized summonses. Discourse Studies, 8(3), 339-368.

Austin, J.L. (1962). How to do things with words. Cambridge MA: Harvard University Press.

Austin, J.L. (1969). Speech Acts: An Essay in the philosophy of language. Cambridge MA: Harvard University Press

Bachman, L.F. (1990). Fundamental considerations in language testing. Oxford: Oxford University Press.

Bachman, L.F., \& Cohen, A.D. (1998). Language testing - SLA interfaces: An update. In L.F. Bachman \& A.D. Cohen (Eds.), Interfaces between second language acquisition and language testing research (pp. 1-31). Cambridge: Cambridge University Press.

Bachman, L.F., \& Palmer, A.S. (1996). Language testing in practice: Designing and developing useful language tests. Oxford: Oxford University Press.

Bachman, L.F., \& Palmer, A.S. (2010).Language assessment in practice. Oxford: Oxford University Press.

Baker, C., Emmison, M., \& Firth, A. (2001). Discovering order in opening sequences: Call to a software helpline. In A. McHoul \& M. Rapley (Eds.), How to analyze talk in institutional settings: $A$ casebook of methods (pp. 41-56). London: Continuum. 
Bardovi-Harlig, K. (1999). Exploring the interlanguage of interlanguage pragmatics: A research agenda for acquisitional pragmatics. Language Learning, 49(4), 677-713.

Bardovi-Harlig, K. (2000). Pragmatics and second language acquisition. In R. Kaplan (Ed.), Oxford handbook of applied linguistics (pp. 182-192). Oxford: Oxford University Press.

Bardovi-Harlig, K. (2008). Recognition and production of formulas in L2 pragmatics. In Z. Han (Ed.), Understanding second language process (pp. 205-222). Clevedon: Multilingual Matters.

Bardovi-Harlig, K., \& Bastos, M.T. (2011). Proficiency, length of stay, and intensity of interaction, and the acquisition of conventional expressions in L2 pragmatics. Intercultural Pragmatics, 8(3), 347384 .

Bardovi-Harlig, K., \& Dörnyei, Z. (1998). Do language learners recognize pragmatic violations? Pragmatic versus grammatical awareness in instructed L2 learning. TESOL QUARTERLY, 32(2), 233-259.

Barron, A. (2003). Acquisition in interlanguage pragmatics: Learning how to do things with in a study abroad context. Amsterdam: John Benjamins Publishing Company.

Battersby, S., \& Healey, P.G.T. (2010). Using head movement to detect listener responses during multi-party dialogue. Proceedings of the international conference on language resources and evaluation workshop on multi-modal corpora, (pp. 11-15). Mediterranean Conference Centre, Malta.

Bavelas, J.B., Coates, L., \& Johnson, T. (2002). Listener responses as a collaborative process: The role of gaze. Journal of Communication, 52, 566-580.

Bavelas, J.B., Chovil, N., Coates, L., \& Roe, L. (1995). Gesture specialized for dialogue. Personality and Social Psychology Bulletin, 21(4), 394-405. 
Bavelas, J.B., Chovil, N., Lawrie, D.A., \& Wade, A. (1992). Interactive gestures. Discourse Processes, 15, 469-489.

Bavelas, J.B., Hagen, D., Lane, L., \& Lawrie, D.A. (1989). Interactive gestures and a systems theory of communication. Paper presented at the annual meeting of the International Communication Association, San Francisco.

Bednarek, M. (2011). Approaching the data of pragmatics. In W. Bublitz \& N.R. Norrick (Eds.), Foundations of pragmatics (pp. 537-558). Berlin: Mouton de Gruyter.

Beltrán-Palanques, V. (2013). Exploring research methods in interlanguage pragmatics: A study based on apologies. Saarbrücken: Lambert Academic Publishing.

Beltrán-Palanques, V. (2014). Methodological issues in interlanguage pragmatics: Some food for thought. In G. Alcaraz-Mármol \& M.M. Jiménez-Cervantes Arnao (Eds.), Studies in philosophy. Linguistics, literature and cultural studies in modern languages (pp. 239-253). Newcastle-Upon-Tyne: Cambridge Scholars Publishing.

Beltrán-Palanques, V. (2016a). Synchronous computer-mediated communication in ILP research: A study based on the ESP context. In E. Martín-Monje, I. Elorza \& B. García-Riaza (Eds.), Technology-enhanced language learning for specialized domains: Practical applications and mobility (pp. 73-85). London: Routledge.

Beltrán-Palanques, V. (2016b). Assessing pragmatics: DCTs and retrospective verbal reports. In A. Pareja-Lora, C. Calle-Martínez \& P. Rodríguez-Arancón (Eds.), New perspectives on teaching and working with languages in the digital era (pp. 303-312). Dublin: Research-publishing.net.

Beltrán-Palanques, V. (in press). The distinctive multimodal nature of pragmatic competence: Bridging the gap between modes. In Bonsignori, V. \& B. Crawford Camiciottoli (Eds.), Multimodality 
across communicative settings, discourse domains and genres. Newcastle-Upon-Tyne: Cambridge Scholars Publishing.

Beltrán-Palanques, V., \& Martínez-Flor, A. (2015). Apologies in interlanguage pragmatics: The role of retrospective verbal reports in oral production. In C. Suárez-Gómez \& E. Seoane (Eds.), Englishes today. multiple varieties, multiple perspective (pp. 165190). Newcastle-Upon-Tyne: Cambridge Scholars Publishing.

Benitez-Quiroz, C.F., Wilbur, R.B., \& Martínez, A.M. (2016): The not face: A grammaticalization of facial expressions of emotion. Cognition, 150: 77-84.

Benton, C. (2010). Rapid reactions to direct and averted facial expressions of fear and anger. Visual Cognition, 18, 1298-1319.

Bezemer, J., \& Jewitt, C. (2010). Multimodal analysis: Key issues. In L. Litosseliti (Ed.), Research methods in linguistics (pp. 180-197). London: Continuum.

Bhatia, T. (2009). Bilingualism and second language learning. In J. Mey (Ed.), Concise encyclopedia of pragmatics, (2nd ed) (pp. 49-56). Oxford: Elsevier.

Birdwhistell, R.L. (1952). Introduction to kinesics. Louisville, K.T.: University of Louisville Press.

Birdwhistell, R.L. (1970). Kinesics and context: Essays on body-motion communication. London: Allen Lane.

Blum-Kulka, S. (1987). Indirectness and politeness in requests: Same or different? Journal of Pragmatics, 11, 131-146.

Blum-Kulka, S. (1990). You don't touch lettuce with your fingers: Parental politeness in family discourse. Journal of Pragmatics, 14(2), 259-287.

Blum-Kulka, S., House, J., \& Kasper, G. (1989). Cross-cultural pragmatics: Requests and apologies. Norwood, NJ: Ablex Publishing Corporation.

Bowles, M.A. (2010). The think-aloud controversy in second language research. London: Routledge. 
Boxer, D. (1993). Complaining and commiserating: A speech act view of solidarity in spoken American English. Bern: Peter Lang.

Boxer, D. (1996). Ethnographic interviewing as a research tool in speech act analysis: The case of complaints. In S.M. Gass \& J. Neu (Eds.), Speech acts across cultures. Challenges to communication in a second language (pp. 217-239). Berlin: Mouton de Gruyter.

Boxer, D. (2010). Complaints. How to gripe and establish rapport. In A. Martínez-Flor \& E. Usó-Juan (Eds.), Speech act performance. Theoretical, empirical and methodological issues (pp. 163-178). Amsterdam: John Benjamins Publishing Company.

Brazil, D. (1984). The intonation of sentences read aloud. In D. Gibbon \& H. Richter (Eds.), Intonation, accent and rhythm: Studies in discourse phonology (pp. 46-66). Berlin: Walter de Gruyter.

Brazil, D. (1994). Pronunciation for advanced learners of English. Cambridge: Cambridge University Press.

Brazil, D. (1995). Grammar of speech. Oxford: Oxford University Press.

Brazil, D. (1997). The communicative value of intonation in English. Cambridge: Cambridge University Press.

Brazil, D., Coulhard, M., \& Johns, C. (1980). Discourse intonation and language teaching. London: Longman.

Brown, L. (2011). Korean honorifics and politeness in second language learning. Amsterdam: John Benjamins Publishing Company.

Broth, M., \& Mondada, L. (2013). Walking away: The embodied achievement of activity closings in mobile interaction. Journal of Pragmatics, 47(1), 41-58.

Brown, P., \& Levinson, C.L. (1978). Universals in language usage: Politeness phenomena. In E.N. Goody (Ed.), Questions and politeness: Strategies in social interaction (pp. 56-311) Cambridge: Cambridge University Press.

Brown, P., \& Levinson, C.L. (1987). Politeness: Some universals in language usage. Cambridge: Cambridge University Press. 
Bublitz. W. (2001). Englishche Pragmatik: Eine Einführung [English pragmatics: An introduction]. Berlin: Erich Schmidt Verlag.

Calbris, G. (2011). Elements of meaning in gesture. Amsterdam: John Benjamins Publishing Company.

Calvo, C., \& Geluykens, R. (1995). Politeness strategies and sequential organization in crime fiction telephone conversations. InterfaceJournal of Applied Linguistics, 9(2), 49-66.

Canale, M. (1983). From communicative competence to communicative language pedagogy. In J. Richards \& R. Schmidt (Eds.), Language and communication (pp. 2-27). London: Longman.

Canale, M., \& Swain, M. (1980). Theoretical bases of communicative approaches to second language teaching and testing. Applied Linguistics, 1(1), 1-48.

Carter, R., \& Adolphs, S. (2007). Linking the verbal and visual: New directions for corpus linguistics. In O. Mason \& A. Gerbig (Eds.), Language in context: Papers in honour of Michael Stubbs (pp. 131-147). Tübingen: University of Tübingen Press.

Cauldwell, R.T. (2002). The functional rhythmicality of spontaneous speech: A discourse view of speech rhythms. Apples, 2(1), 1-24.

Celce-Murcia, M. (1995). The elaboration of sociolinguistic competence: Implications for education. In J.E. Alatis, C.A. Straehle, B. Gallenberger \& M. Ronkin (Eds.), Georgetown University round table on languages and linguistics (pp. 699-710). Washington D.C.: Georgetown University.

Celce-Murcia, M. (2007). Rethinking the role of communicative competence in language teaching. In E. Alcón \& M.P. Safont (Eds.), Intercultural language use and language learning (pp. 4157). Dordrecht: Springer.

Celce-Murcia, M., Dörnyei, Z., \& Thurrell, S. (1995). A pedagogical framework for communicative competence: A Pedagogically motivated model with content specifications. Issues in Applied Linguistics, 6(2), 5-35. 
Cenoz, J. (1998). Pauses and communication strategies in second language speech. Reports - Research, 143, 1-11.

Chen, Y., Chen, C.D., \& Chang, M. (2011). American and Chinese complaints: Strategy use from a cross-cultural perspective. Intercultural Pragmatics, 8(2), 253-275.

Cheng, W. (2002). Indirectness in intercultural communication. Conference on pragmatics of interlanguage English. Münster University, Germany.

Cheng, W. (2003). Intercultural conversation. John Benjamins Publishing Company

Cheng, W. (2004). TOOK // did you // from the miniBAR //: What is the practical relevance of a corpus-driven language study to practitioners in Hong Kong's hotel industry? In U. Connor \& T.A. Upton (Eds.), Discourse in the professions: Perspectives from corpus linguistics (pp. 141-166). Amsterdam: John Benjamins Publishing Company.

Cheng, W., \& Warren, M. (2005). //-->well I have a DIFferent // [down arrow] THINking you know //: A corpus-driven study of disagreement in Hong Kong business discourse. In F. BargielaChiappini \& M. Gotti (Eds.) Asian Business Discourse(s) (pp. 241270). Bern: Peter Lang.

Cheng, W., Greaves, C. \& Warren, M. (2008). A corpus-driven study of discourse intonation. Amsterdam: John Benjamins Publishing Company.

Chiras, D.D. (2012). Human body systems: Structure, function, and environment. Burlington, MA: Jones \& Bartlett Learning.

Chomsky, N. (1965). Aspects of the theory of syntax. Cambridge, MA: MIT Press.

Chomsky, N., \& Halle, M. (1968). The sound patterns of English. London: Harper \& Row, Publishers.

Chui, K. (2005). Topicality and gesture in Chinese conversational discourse. Language and Linguistics, 6(4), 635-654. 
Chun, D.M. (2002). Discourse intonation in L2: From theory and research to practice. Amsterdam: John Benjamins Publishing Company.

Clark, H.H., \& Schunk. D.H. (1980). Polite responses to polite requests. Cognition, 8, 111-143.

Clancy, P.M., Thompson, S.A., Suzuki, R., \& Tao, H. (1996). The conversational use of reactive tokens in English, Japanese, and Mandarin. Journal of Pragmatics, 26(3), 355-387.

Cohen, A.D. (1996). Verbal reports as a source of insights into second language learner strategies. Applied Language Learning, 7(1-2), 524.

Cohen, A.D. (2004). Assessing speech acts in a second language. In D. Boxer and A.D. Cohen (Eds.), Studying to inform second language learning (pp. 302-327). Clevedon: Multilingual Matters.

Cohen, A.D. (2010). Strategies for learning and performing speech acts. In N. Ishihara \& A.D. Cohen, Teaching and learning pragmatics. Where language and culture meet (pp. 227-243). London: Longman.

Cohen, A.D., \& Olshtain, E. (1981). Developing a measure of sociolinguistic competence: The case of apology. Language Learning, 31(1), 112-134.

Cohen, A.D., \& Olshtain, E. (1993). The production of speech acts by EFL learners. TESOL Quarterly, 24, 275-301.

Coronel-Molina, S. (1998). Openings and closing in telephone conversations between native Spanish speakers. Working Papers in Educational Linguistics, 14(1), 49-68.

Coulthard, M. \& Brazil, D. (1981). The place of intonation in the description of interaction. In D. Tannen (Ed.), Analyzing discourse: Text and talk (pp. 94-112). Washington DC: Georgetown University Press.

Coulthard, M. \& Montgomery, M., (Eds.). (1981). Studies in discourse analysis. London: Longman. 
Council of Europe, (2001). Common European framework of reference for languages: Learning, teaching, assessment. Retrieved from http://www.coe.int/t/dg4/linguistic/Source/Framework EN.pdf

Coupland, N., Grainger, K., \& Coupland, J. (1988). Politeness in context: Intergenerational issues. Language in Society, 17, 253262.

Crookall, D., \& Saunders, D. (1989). Towards an integration of communication and simulation. In D. Crookall \& D. Saunders (Eds.), Communication and simulation: From two fields to one theme (pp. 3-29). Clevedon: Multilingual Matters.

Crawford, B., (2015). Elaborating explanations during OpenCourseWare humanities lectures: The interplay of verbal and nonverbal strategies. In B. Crawford \& I. Fortanet-Gómez. Multimodal analysis in academic settings. From research to teaching (pp. 144-170). London: Routledge.

Creswell, J.W. (2003). Research design. Qualitative, quantitative, and mixed methods approaches, (2nd ed.). London: SAGE.

Crystal, D. (1985). A dictionary of linguistics and phonetics (2nd ed.). Oxford: Blackwell.

Crystal, D. (1969). Prosodic systems and intonation in English. Cambridge: Cambridge University Press.

Crystal, D. (1975). Paralinguistics. In J. Benthall \& T. Polhemus (Eds.), The body as a medium of expression (pp. 162-174). London: Institute of Contemporary Arts.

Crystal, D., \& Davy, D. (1969). Investigating English style. London: Longman.

Crystal, D., \& Quirk, R. (1964). System of prosodic and paralinguistic features in English. The Hague: Mouton.

Culpeper, J. (2011). Impoliteness: Using language to cause offence. Cambridge: Cambridge University Press. 
Culpeper, J., Bousfield, D., \& Wichmann, A. (2003). Impoliteness revisited: With special reference to dynamic and prosodic features. Journal of Pragmatics, 35, (10-11), 1545-1579.

Cutrone, P. (2013). Assessing pragmatic competence in the Japanese EFL context: Towards the learning of listener responses. Newcastle upon Tyne: Cambridge Scholars Publishing.

D'Amico-Reisner, L. (1985). An ethnolinguistic study of disapproval exchanges. University of Pennsylvania.

Darsley, I., \& Wotton, A. (2000). Complaint sequences with antagonistic argument. Research on Language and Social Interaction, 33(4), 375-406.

Davidson, J.A. (1984). Subsequent versions of invitations, offers, requests, and proposals dealing with potential or actual rejection. In J.M. Atkinson \& J. Heritage (Eds.), Structures of social action: Studies in conversation analysis (pp. 102-128). Cambridge: Cambridge University Press.

DeCapua, A. (1989). An Analysis of pragmatic transfer in the speech act of complaint as produced by native speakers of German and English. Unpublished doctoral dissertation. New York: Teachers College, Columbia University.

Dimberg, U., \& Öhman, A. (1996). Behold the wrath: Psychophysiological responses to facial stimuli. Motivation and Emotion, 20(2), 149-182.

Dittmann, A. (1972). The body movement-speech rhythm relationship as a cue to speech encoding. In A.W. Siegman \& B. Pope (Eds.), Studies in dyadic communication (pp. 135-151). Elmsford: Pergamon.

Dittmann, A., \& Llewellyn, L. (1968). Relationship between vocalizations and head nods as listener responses. Journal of Personality and Social Psychology, 9, 79-84. 
Dörnyei, Z. (2003). Questionnaires in second language research: Construction, administration, and processing. Mahwah, NJ: Lawrence Erlbaum.

Drew, P. (1984). Speakers' reporting in invitation sequences. In J.M. Atkinson \& J. Heritage (Eds.), Structures of social action: Studies in conversation analysis (pp. 129-151). Cambridge: Cambridge University Press.

Drew, P., \& Holt, E. (1988). Complainable matters: The use of idiomatic expressions in making complaints. Social Problems, 35(4), 398417.

Drew, P., \& Walker, T. (2009). Going too far: Complaining, escalating and disaffiliation. Journal of Pragmatics, 41(12), 2400-2414.

Drew, P., \& Couper-Kuhlen, E. (2014). (Eds.). Requesting in social interaction. Amsterdam: John Benjamins Publishing Company.

Duncan, S. (1972). Some signals and rules for taking speaking turns in conversations. Journal of Personality and Social Psychology, 23(2), 283-292.

Duncan, S. (1973). Towards a grammar of dyadic conversation. Semiotica, 9, 29-46.

Duncan, S. (1974). On the structure of speaker-auditor interaction during speaking turns. Language in Society, 2, 161-180.

Duncan, D., \& Niederehe, G. (1974). On signaling that it's your turn to speak. Journal of Experimental Social Psychology, 10(3):234247.

Duncan, D., \& Fiske, D. (1977). Face-to-face interaction: Research, methods and theory. Hillsdale, NJ: Lawrence Erlbaum

Duncan, D., \& Fiske, D. (1985). Interaction structure and strategy. Cambridge: Cambridge University Press.

Edmondson, W. (1981). Spoken discourse: A model for analysis. London: Longman.

Edwards, D. (2005). Moaning, whining and laughing: the subjective side of complaints. Discourse Studies, 7(1), 5-29. 
Eelen, G. (2001). A critique of politeness theories. Manchester: St. Jerome Publishing.

Efron, D. (1941). Gesture and environment. New York: King's Crown.

Efron, D. (1972). Gesture, race and culture a tentative study of the spatio-temporal and "linguistic" aspects of the gestural behavior of eastern Jews and southern Italians in New York City, living under similar as well as different environmental conditions. Berlin: Mouton de Gruyter.

Egbert, M., \& Vöge, M. (2008). Wh-interrogative formats used for questioning and beyond: German warum (why) and wieso (why) and English why. Discourse Studies, 10(1), 17-36.

Ekman, P. (1972). Universals and cultural differences between cultures in expressive movement. In J. Cole (Ed.), Nebraska symposium on motivation (pp. 207-283). Lincoln: University of Nebraska Press.

Ekman, P. (1985). Telling lies: clues to deceit in the marketplace, marriage, and politics. New York: W.W. Norton.

Ekman, P. (2007). Emotions revealed. Recognizing faces and feelings to improve communication and emotional life, (2nd ed.). New York: owl Books.

Ekman, P., \& Friesen, W.V. (1969). The repertoire of nonverbal behavioral categories: Origins, usage, and coding. Semiotica, 1, 4998.

Ekman, P., \& Friesen, W.V. (1975). Unmasking the face: A guide to recognizing emotions from facial clues. Englewood Cliffs, NJ: Prentice Hall.

Ekman, P., \& Friesen, W.V. (1977). Nonverbal behavior. In P.F. Ostwald (Ed.), Communication and social interaction, (pp. 37-54). New York: Grune and Sttratton.

Ekman, P., \& Friesen, W.V. (1978). Facial action coding system: A technique for the measurement of facial movement. Palo Alto, CA: Consulting Psychology Press. 
Ekman, P., \& Friesen, W.V. (1986). A new pan-cultural facial expression of emotion. Motivation and Emotion, 10, 159-168.

Ekman, P., Sorenson, E.R., \& Friesen, W.V. (1969). Pan-cultural elements in facial displays of emotion. Science, 164(3875), 86-88.

Ellis, R. (1985). Understanding second language acquisition. Oxford: Oxford University Press.

Ephratt, M. (2008). The functions of silence. Journal of Pragmatics, 4O(11), 1909-1938.

Erickson, F. (1979). Talking down: Some cultural sources of miscommunication of interracial interviews. In A. Wolfgang (Ed.), Nonverbal behaviour: Applications and cultural implications (pp. 99-126). New York: Academic Press.

Ericsson, K.A., \& Kintsch, W. (1995). Long-term working memory. Psychological Review, 102, 211-245.

Ericsson, K.A., \& Simon, H.A. (1984). Protocol analysis: Verbal reports as data. Cambridge, MA: The MIT Press

Ericsson, K.A., \& Simon, H.A. (1993). Protocol analysis: Verbal reports as data, (Revised Edition). Cambridge, MA: The MIT Press

Eslami, Z., Mirzaei, A., \& Dini, S. (2015). The role of asynchronous computer mediated communication in the instruction and development of EFL learners' pragmatic. System, 48, 99-111.

Esteves, F., Dimberg, U., \& Öhman, A. (1994). Automatically elicited fear: Conditioned skin conductance responses to masked facial expressions. Cognition and Emotion, 8(5), 393-413.

Félix-Brasdefer, F.C. (2007). Pragmatic development in the Spanish as a FL classroom: A cross sectional study of learner request. Intercultural Pragmatics, 4(2), 253-286.

Félix-Brasdefer, J.C. (2008a). Politeness in Mexico and the United States. Amsterdam: John Benjamins Publishing Company.

Félix-Brasdefer, J.C. (2008b). Perceptions of refusals to invitations: Exploring the minds of foreign language learners. Language Awareness, 17(3), 195-211. 
Félix-Brasdefer, J.C. (2010). Data collection methods in speech act performance: DCTs, role plays, and verbal reports. In A. MartínezFlor \& E. Usó-Juan (Eds.), Speech act performance. Theoretical, empirical and methodological issues (pp. 41-56). Amsterdam: John Benjamins Publishing Company.

Fernández-Amaya, L. (2013). Simultaneous speech in American English and Spanish telephone closings. In I. Kecskes \& J. Romero-Trillo (Eds.), Research trends in intercultural pragmatics (pp. 136-180). Berlin: Mouton de Gruyter.

Fetzer, A. (2004). Recontextualizing context: Grammaticality meets appropriateness. Amsterdam: John Benjamins Publishing Company.

French, P., \& J. Local (1983). Turn-competitive incomings. Journal of Pragmatics, $7(1): 17-38$.

Field, T. (1981). Infant gaze aversion and heart rate during face-to-face interactions. Infant Behavior and Development, 4(1), 307-315.

Figueras, N. (2008). El MCER, más allá de la polémica. Evaluación, 7, 26-35.

Firth, A., \& Wagner, J. (2007). Second/foreign language learning as a social accomplishment: Elaborations on a reconceptualized SLA. The Modern Language Journal, 91(1), 800-819.

Fraser, B. (1978). Acquiring social competence in a second language. RELC Journal, 9(2), 1-6.

Fraser, B. (1990). Perspectives on politeness. Journal of Pragmatics, 14(2), 219-236.

Fraser, B., \& Nolen, W. (1981). The association of deference with linguistic form. International Journal of the Sociology of Language, 27, 93-109.

Freedman, N. (1972). The analysis of movement behaviour during clinical interviews. In A.W. Siegman \& B. Pope (Eds.), Studies in dyadic communication (pp. 152-172). Elmsford: Pergamon.

Fries, C. (1952). The structure of English. New York: Harcourt Brace. 
Fukada, A., \& Asato, N. (2004). Universal politeness theory: Application to the use of Japanese honorifics. Journal of Pragmatics, 36(11), 1991-2002.

Garcés, P. (1993). Revisión crítica de algunos de los postulados de la teoría de la cortesía lingüística propugnada por Brown y Levinson. Quarderns de Filologia, Estudis Linguistics, 1, 43-62.

Gardner, R. (1997). The listener and minimal responses in conversation interaction. Prospect, 12(2), 12-32.

Gardner, R. (2001). When listeners talk: Response tokens and listener stance. Amsterdam: John Benjamins Publishing Company.

Garfinkel, H. (1967). Studies in ethnomethodology. Englewood Cliffs: Prentice-Hall.

Garfinkel, H. (2002). Ethnomethodology's program: Working out Durkheim's aphorism. Rowman \& Littlefield Publishers.

Gass, S.M., \& Houck, N. (1999). Interlanguage refusals: A crosscultural study of Japanese-English. Berlin: Mouton de Gruyter.

Gass, S.M., \& Mackey, A. (2000). Stimulated recall methodology in second language research. Mahwah, New Jersey: Lawrence Erlbaum Associates.

Geluykens, R., \& Kraft, B. (2003). Sociocultural variation in native and interlanguage complaints. In K.M. Jaszczolt \& K. Turner (Eds.), Meaning through language contrast (Vol. 2) (pp. 251-261). Amsterdam: John Benjamins Publishing Company.

Geluykens, R., \& Kraft, B. (2008). The use(fulness) of corpus research in cross-cultural pragmatics: Complaining in intercultural service encounters. In Romero-Trillo, J. (Ed.), Pragmatics and corpus linguistics: A mutualistic entente (pp.93-118). Berlin: Mouton de Gruyter.

Geyer, N. (2008). Discourse and politeness. Ambivalent face in Japanese. London: Continuum.

Gibson, J.J. (1977). The theory of affordances. In R.E. Shaw, \& J. Bransford (Eds.), Perceiving, acting and knowing. Toward an 
ecological psychology (pp. 127-143). Hillsdale NJ: Lawrence Erlbaum Associates.

Giddens, D. (1981). An Analysis of the syntax and discourse of oral complaints in Spanish. Unpublished master's thesis. Los Angeles: University of California.

Goffman, E. (1967). Interaction ritual: Essays on face to face behavior. Chicago: Aldine Publishing Company.

Goffman, E. (1971). Relations in public. Micro studies of the public order. Harmondsworth: Penguin.

Golato, A. (2002). German compliment responses. Journal of Pragmatics, 34(5), 547-571.

Golato, A. (2003). Studying compliment responses: A comparison of DCTs and recording naturally occurring talk. Applied Linguistics, 24(1):90-121.

Golato, A. (2005). Compliments and compliment responses: Grammatical Structure and sequential organization. Amsterdam: John Benjamins Publishing Company.

Goldin-Meadow, S. (2003). Hearing gesture: How our hands help us to think. Cambridge: Belknap Press of Harvard University Press.

Goldin-Meadow, S., \& Wagner, S.M. (2005). How our hand help us learn. TRENDS in Cognitive Science, 9(5), 234-241.

Goldman-Eisler, F. (1968). Psycholinguistics: Experiments in spontaneous speech. London: Academic.

González-Lloret, M. (2010). Conversation analysis and speech act performance. In A. Martínez-Flor \& E. Usó-Juan (Eds.), Speech act performance. Theoretical, empirical and methodological issues (pp. 57-73). Amsterdam: John Benjamins Publishing Company.

Goodwin, C. (1979). The interactive construction of a sentence in natural conversation. In G. Psathas (Ed.), Everyday language: Studies in ethnomethodology (pp. 97-121). New York: Irvington. 
Goodwin, C. (1981). Conversational organization. Interaction between speakers and hearers. New York: Academic Press.

Goodwin. C. (1994). Notes on story structure and the organization of participation. In Atkinson, J.M. \& Heritage, J. (Eds.), Structures of social action: studies in conversation analysis (pp. 225-246). Cambridge: Cambridge University Press.

Goodwin, C. (1996). Gesture as a resource for the organization of mutual orientation. Semiotica, 62, 24-49.

Goodwin, C. (2000a). Transparent vision. In E. Ochs, E.A. Schegloff \& S.A. Thompson (Eds.), Interaction and grammar (pp. 370-404). Cambridge: Cambridge University Press.

Goodwin, C. (200ob). Practices of seeing: Visual analysis - an ethnomethodological approach. In T. Van Leeuwen \& C. Jewitt (Eds.), Handbook of visual analysis (pp. 157-182). London: SAGE.

Goodwin, C. (2000c). Action and embodiment within situated human interaction. Journal of Pragmatics, 32, 1489-1522.

Goodwin, C. (2007). Environmentally coupled gestures. In S. Duncan, J. Cassell \& E. Levy (Eds.), Gesture and the dynamic dimension of language (pp. 195-212). Amsterdam: John Benjamins Publishing Company.

Goodwin, C., \& Cekaite, A. (2014). Orchestrating directive trajectories in communicative projects in family interaction. In P. Drew \& E. Couper-Kuhlen (Eds.), Requesting in social interaction (pp. 185214). Amsterdam: John Benjamins Publishing Company.

Goodwin, C., \& Goodwin, M.H. (1987). Concurrent operations on talk: Notes on the interactive organization of assessments. IPRA Papers in Pragmatics, 1(1), 1-54.

Goodwin, C., \& Goodwin, M.H. (1992a). Context, activity and participation. In P. Auer \& A. di Luzo, The contextualization of language (pp. 77-99). Amsterdam: John Benjamins Publishing Company. 
Goodwin, C., \& Goodwin, M.H. (1992b). Assessments and the construction of context. In A. Duranti \& C. Goodwin (Eds.), Rethinking context (pp. 147-190). Cambridge: Cambridge University Press.

Goodwin, M.H. (1980). Processes of mutual monitoring implicated in the production of description sequences. Sociological Inquiry, 5O, 303-317.

Gregersen, T., Olivares-Cuhat, G., \& Storm, J. (2009). An examination of L1 and L2 gesture use: What role does proficiency play? The Modern Language Journal, 93(2), 195-208.

Grice, H.P. (1975). Logic and conversation. In P. Cole \& J.L. Morgan (Eds.), Speech acts [Syntax and semantics 3] (pp. 41-58). New York: Academic Press

Groves, R. (1996). How do we know what we think they think is really what they think? In N. Schwarz \& S. Sudman, Answering questions: Methodology for determining cognitive and communicative processes in survey research (pp. 389-402). San Francisco: Jossey-Bass.

$\mathrm{Gu}$, Y. (1990). Politeness phenomena in modern Chinese. Journal of Pragmatics, 14(2), 237-257.

Gullberg, M. (1998). Gesture as a communication strategy in second language discourse. A study of learners of French and Swedish. Lund: Lund University Press.

Gullberg, M. (2006). Some reasons for studying gestures and second language acquisition (Hommage à Adam Kendon). International Review of Applied Linguistics in Language Teaching, 44(2), 103124.

Gullberg, M. (2010). Methodological reflections on gesture analysis in second language acquisition and bilingualism research. Second Language Research, 26(1), 75-102.

Gullberg, M. (2014). Gestures and second language acquisition. In C. Müller, A. Cienki, E. Fricke, S.H. Ladewig, D. McNeill \& S. 
Tessendor, Body-language-communication: An international handbook on multimodality in human interaction (pp. 18681875). Berlin: Mouton de Gruyter.

Habermas, J. (1970). Towards a theory of communicative competence. Inquiry. An Interdisciplinary Journal of Psychology, 13(1-4), 360-375.

Hadar, U., Steiner, T.J., Grand, E.C. \& Rose, F.C. (1983a). Head movement correlates of juncture and stress at sentence level. Language and Speech, 26, 117-129.

Hadar, U., Steiner, T.J., Grant, E.C., \& Rose, F.C. (1983b). Kinematics of head movements accompanying speech during conversation. Human Movement Science, 2(1-2), 35-46.

Hadar, U., Steiner, T.J., Grand, E.C. \& Rose, F.C. (1984a). The timing of shifts of head postures during conversation. Human Movements Science, 3, 237-245.

Hadar, U., Steiner, T.J., Grand, E.C. \& Rose, F.C. (1984b). The relationship between head movement and speech dysfluencies. Language and Speech, 27, 333-342

Hakulinen, A. (2010). The relevance of context to the performing of a complaint. In D. Barth-Weingarten, E. Reber \& M. Selting (Eds.), Prosody in interaction (pp. 105-108). Amsterdam: John Benjamins Publishing Company .

Halliday, M.A.K. (1978). Language as a social semiotic. London: Arnold.

Halliday, M.A.K. (1985). An introduction to functional grammar. London: Arnold.

Han, Z., \& Tarone, E. (Eds.) (2014). Interlanguage: Forty years later. Amsterdam: John Benjamins Publishing Company.

Harrigan, J.A. (2013). Methodology: Coding and studying nonverbal behavior. In J.A. Hall \& M.L. Knapp, Nonverbal communication (pp. 35-68). Berlin: Mouton de Gruyter. 
Hassall, T. (2008). Pragmatic performance: What are learners thinking?. In E. Alcón \& Martínez-Flor, A. (Eds.), Investigating pragmatics in foreign language learning, teaching and testing (pp. 72-93). Bristol: Multilingual Matters.

Haverkate, H. (1984). Speech acts, speakers and hearers. [Pragmatics and beyond]. Amsterdam: John Benjamins Publishing Company.

Hayashi, M. (2005). Joint turn construction through language and the body: Notes on embodiment in coordinated participants in situated activities. Semiotica, 156(1-4), 21-53.

Hayashi, R. (1988). Simultaneous talk-from the perspective of floor management of English and Japanese speakers. World Englishes, $7(3), 269-288$.

Hayashi, T., \& Hayashi, R. (1991). Back channel or main channel: A cognitive approach based on floor and speech acts. Pragmatics and Language Learning Monograph Series 2, 119-138.

Hayashi, M., Mori, J., \& Takagi, T. (2002). Contingent achievement of co-tellership in a Japanese conversation: An analysis of talk, gaze and gesture. In C. Ford, B. Fox \& S. Thompson (Eds.), The language of turn and sequence (pp. 81-122). Oxford: Oxford University Press.

He, A.W. (1994). Withholding academic advice: Institutional context and discourse practice. Discourse Processes, 18(3), 297-316.

Heath. C. (1986). Body movement and speech in medical interaction. Cambridge: Cambridge University Press.

Heath. C. (1989). Pain talk: The expression of suffering in the medical consultation. Social Psychology Quarterly, 52,113-125.

Heath, C., \& Luff, P. (1996). Convergent activities: Line control and passenger information on the London Underground. In Y. Engeström \& D. Middleton (Eds.), Cognition and communication at work (pp. 96-129). Cambridge: Cambridge University Press.

Heath, C., \& Luff, P. (2000). Technology in action. Cambridge: Cambridge University Press. 
Heath, C., Hindmarsh, J., \& Luff, P. (2010). Video in qualitative research. London: SAGE.

Heinemann, T. (2009). Two answers to inapposite inquiries. In J. Sidnell (Ed.), Conversation analysis: Comparative perspectives (pp. 159-186). Cambridge: Cambridge University Press.

Heritage, J. (1984). A change-of-state token and aspects of its sequential placement. In J.M. Atkinson \& J. Heritage (Eds.), Structures of social interaction: Studies in conversation analysis (pp. 299-345). Cambridge: Cambridge University Press.

Heritage, J. (1997). Conversation analysis and institutional talk: Analysing data. In D. Silverman (Ed.), Qualitative research: Theory, method and practice (pp. 161-182). London: SAGE.

Heritage, J., \& Sefi, S. (1992). Dilemmas of advice: Aspects of the delivery and reception of advice in interactions between health visitors and first-time mothers. In P. Drew \& J. Heritage (Eds.), Talk at work (pp. 359-417). Cambridge: Cambridge University Press.

Hewings, M. (Ed.). (1990). Papers in discourse intonation (Vol. 16) Birmingham: English Language Research.

Hewings, M., \& Cauldwell, R.T. (1997). Forward. In D. Brazil (Ed.), The communicative role of intonation in English, (pp. i-vii). Cambridge: Cambridge University Press.

Hickey, L., \& Vázquez, O. (1994). Politeness as deference: A pragmatic view. Pragmalingüística, 2, 267-286.

House-Edmondson, J. (1986). Cross-cultural pragmatics and foreign language teaching. In K.R. Bausch, F.G. Königs \& R. Kogelheide (Eds.), Probleme und Perspektiven der Sprachlehrforschung (pp. 281-295). Frankfurt am Main: Scriptor.

Hudson, T., Detmer, E. \& Brown, J.D. (1995). Developing prototypic measures of cross-cultural pragmatics. Honolulu: Second Language Teaching and Curriculum Center, University of Hawai'i at Manoa. 
Hutchby, I. (1995). Aspects of recipient design in expert advice-giving on call-in radio. Discourse Process, 19(2), 219-238.

Huth, T. (2006). Negotiating structure and culture: L2 learners' realization of L2 compliment-response sequences in talk-ininteraction. Journal of Pragmatics, 38(12), 2025-2050.

Hymes, D. (1972a). On communicative competence. In J.B. Pride \& J. Holmes (Eds.), Sociolinguistics (pp. 269-293). Harmondsworth: Penguin.

Hymes, D. (1972b). Models of the interaction of language and social life. In J.J. Gumperz \& D. Hymes (Eds.), Directions in sociolinguistics: The ethnography of communication (pp. 35-71). New York: Holt, Rinehart and Winston.

Ide, S. (1989). Formal forms and discernment: Two neglected aspects of universals of linguistic politeness. Multilingua, 8(2-3), 223-248.

Ifantidou, E. (2013). Pragmatic competence and explicit instruction. Journal of Pragmatics, 59, 93-116.

Inoue, J. (1982). A discourse analysis of complaints made by Japanese students. Unpublished master's thesis. Los Angeles: University of California.

Ishihara, N., \& Cohen, A.D. (Eds.) (2010). Teaching and learning pragmatics: Where language and culture meet. London: Longman.

Johar, S. (2015). Emotion, affect and personality in speech. The bias of language and paralanguage. Dordrecht: Springer

Jefferson, G. (1974). Error correction as an interactional resource. Language in Society, 3(2), 181-199.

Jefferson, G. (1978). Sequential aspects of storytelling in conversation. In J. Schenkein (Ed.), Studies in the organization of conversational interaction (pp. 219-248). New York: NY: Academic Press. 
Jefferson, G. (1987). On exposed and embedded correction in conversation. In G. Button \& J.R. Lee (Eds.), Talk and social organization (pp. 86-100). Clevedon: Multilingual Matters.

Jefferson, G. (2004). Glossary of transcript symbols with an introduction. In G.H. Lerner (Ed.), Conversation analysis: Studies from the first generation (13-31). Amsterdam: John Benjamins Publishing Company.

Jefferson, G., \& Schenkein, J. (1978). Some sequential negotiations in conversation: unexpanded and expanded versions of projected action sequences. In J.N. Schenkein (Ed.), Studies in the organization of conversational interaction (pp. 155-172). New York: Academic Press. [reprinted from Sociology 11 (1977): 87103]

Jewitt, C. (2008a). A multimodal take on school English. In M. Solly, M. Conoscenti \& Campagna S. (Eds.), Verbal/visual narrative texts in higher education (pp. 153-177). Bern: Peter Lang

Jewitt, C. (2008b). Technology, literacy and learning: A multimodal approach. London: Routledge.

Jewitt, C. (2013). Multimodal teaching and learning. In C.A. Chapelle (Ed.), The encyclopedia of applied linguistics (pp. 4109-4114). Oxford: Blackwell.

Jewitt, C. (2014a). Introduction. Handbook rationale, scope and structure. In C. Jewitt (Ed.), The Routledge handbook of multimodal analysis (pp.1-14) (2nd ed.). London: Routledge.

Jewitt, C. (2014b). An introduction to multimodality. In C. Jewitt (Ed.) The Routledge handbook of multimodal analysis (pp.15-43) (2nd ed.). London: Routledge.

Jewitt, C., Bezemer, J., \& O’Halloran, K. (2016). Introducing multimodality. London: Routledge.

Johnson, D.M. (1992). Compliments and politeness in peer-review texts. Applied Linguistics, 13(1), 51-71. 
Johnstone, B., \& Marcellino, W.M. (2011). Dell Hymes and the ethnography of communication. In R. Wodak, B. Johnstone \& P. Kerswill (Eds.), The SAGE handbook of sociolinguistics (pp. 5766). London: SAGE.

Jordan, G. (2004). Theory construction in second language acquisition. Amsterdam: John Benjamins Publishing Company.

Judd, E.L. (1999). Some issues in the teaching of pragmatic competence. In E. Hinkel (Ed.), Culture in second language teaching and learning (pp. 152-166). Cambridge: Cambridge University Press.

Kappas, A., Krumhuber, E., \& Küster, D. (2013). Facial behavior. In J.A. Hall \& L. Knapp (Eds.), Nonverbal communication (pp. 131-165). Berlin: Mouton de Gruyter.

Kasper, G. (1990). Linguistic politeness: Current research issues. Journal of Pragmatics, 14(2), 193-218.

Kasper, G. (1994). Politeness. In R.E. Asher (Ed.) \& J.M.Y. Simpson (Coordinating Ed.), The encyclopedia of language and linguistics (Vol. 6) (pp. 3206-3211). Oxford: Pergamon Press.

Kasper, G. (1998). Interlanguage pragmatics. In H. Byrnes (Ed.), Learning foreign and second languages: Perspectives in research and scholarship [Teaching language, literatures, and cultures 1] (pp. 183-208). New York: Modern Language Association.

Kasper, G. (2000). Data collection in pragmatics research. In $\mathrm{H}$. Spencer-Oatey (Ed.), Culturally speaking. Managing rapport through talk across cultures (pp. 316-341). New York: Continuum. Kasper. G. (2001). Classroom research on interlanguage pragmatics. In L.F. Bouton (Ed.), Pragmatics and language learning monograph series (Vol. 10) (pp. 1-25). Urbana, IL: University of Illinois at Urbana-Champaign.

Kasper, G. (2006a). Beyond repair: Conversation analysis as an approach to SLA. AILA Review, 19, 83-99. 
Kasper, G. (2006b). Speech acts in interaction: Towards discursive pragmatics. In K. Bardovi-Harlig, J.C. Félix-Brasdefer \& A.S. Omar, Pragmatics and language learning (Vol. 11) (pp. 281-314). Honolulu HI: University of Hawai'i at Manoa.

Kasper, G. (2006c). When once is not enough: Politeness of multiple requests in oral proficiency interviews. Multilingua, 25(3), 323350 .

Kasper, G. (2009a). L2 pragmatic development. In W.C. Ritchie \& T.K. Bhatia (Eds.), New handbook of second language acquisition (pp. 259-293). Bingley: Emerald.

Kasper, G. (2009b). Politeness. In S. D'hondt, J.O. Östman \& J. Verschueren (Eds.), The pragmatics of interaction (pp. 157-173). Amsterdam: John Benjamins Publishing Company.

Kasper, G., \& Blum-Kulka, S. (1993). Interlanguage pragmatics: An introduction. In G. Kasper and S. Blum-Kulka (Eds.), Interlanguage pragmatics (pp. 3-17). Oxford: Oxford University Press.

Kasper, G., \& Dahl, M. (1991). Research methods in interlanguage pragmatics. Studies in Second Language Acquisition, 13, 215-247.

Kasper, G., \& Roever, C. (2005). Pragmatics in second language learning. In E. Hinkel (Ed.), Handbook of research in second language teaching and learning (pp. 317-334). Mahwah, NJ: Lawrence Erlbaum Associates, Inc.

Kasper, G., \& Rose, K.R. (1999). Pragmatics and SLA. Annual Review of Applied Linguistics, 19, 81-104.

Kasper, G., \& Rose, K. R. (2002). Pragmatic development in a second language. Oxford: Blackwell.

Kasper, G., \& Ross, S.J. (2007). Multiple questions in oral proficiency interviews. Journal of Pragmatics, 39(11), 2045-2070.

Kasper, G., \& Wagner, J. (2014). Conversation analysis in applied linguistics. Annual Review of Applied Linguistics, 34, 171-212. 
Kaulfers, W.V. (1931). Curiosities of colloquial gesture. Hispania, 14, 259-264.

Kelly, S.D., Barr, D.J., Church, R.B., \& Lynch, K. (1999). Offering a hand to pragmatic understanding: The role of speech and gesture in comprehension and memory. Journal of Memory and Language, 40, 577-592.

Keltner, D., \& Kring, A. (1998). Emotion, social function, and psychopathology. Review of General Psychology, 2, 320-342.

Kendon, A. (1967). Some functions of gaze direction in social interaction. Acta Psychologica, 26, 22-63.

Kendon, A. (1970). Movement coordination in social interaction: Some examples described. Acta Psychologica, 32, 100-125.

Kendon, A. (1972). Some relationships between body motion and speech. In A. Siegman \& B. Pope (Eds.), Studies in dyadic communication (pp. 177-210). New York: Pergamon Press.

Kendon, A. (1980). Gesticulation and speech: Two aspects of the process of utterance. In M. Key (Ed.), The relationship of verbal and non-verbal communication (pp. 207-227). The Hague: Mouton.

Kendon, A. (1981). Some functions for the process to frame attunement in face-to-face interaction. In G.P. Ginsberg \& M. von Cranach (Eds.), Discovery strategies in the psychology of action (pp. 229253). London: Academic Press.

Kendon, A. (1983). Gesture and speech: How they interact. In J. M. Wiemann \& R.P. Harrison (Eds.), Nonverbal interaction (pp. 1345). Berverly Hills: SAGE.

Kendon, A. (1985). Some uses of gesture. In D. Tannen \& M. SavilleTroike (Eds.), Perspective on silence (pp. 215-234). Norwood, NJ: Ablex Publishing Corporation.

Kendon, A. (1987). On gesture: its complementary relationship with speech. In A.W. Siegman \& S. Feldstein (Eds.), Nonverbal 
behaviour and the nonverbal communication. (2nd ed.) (pp. 6597). Hillsdale: Lawrence Erlbaum.

Kendon, A. (1988). How gestures can become like words. In F. Poyatos (Ed.), Crosscultural perspectives in nonverbal communication (pp. 131-141). Toronto: Hogrefe.

Kendon, A. (1990a). Conducting interaction: Patterns of behavior in focused encounters. Cambridge: Cambridge University Press.

Kendon, A. (1990b). Some functions in the face kissing round. In A. Kendon (Ed.), Conducting interaction: Patterns of behaviour in focused encounters. Cambridge: Cambridge University Press

Kendon, A. (1995). Gestures as illocutionary and discourse structure markers in southern Italian conversation. Journal of Pragmatics, 23,247-279.

Kendon, A. (1997). Gesture. Annual Review of Anthropology, 26(1), 109-128.

Kendon, A. (2000). Language and gesture: Unity or duality? In D. McNeill (Ed.), Language and gesture (pp. 47-63). Cambridge: Cambridge University Press.

Kendon, A. (2004). Gesture. Visible action as utterance. Cambridge: Cambridge University Press.

Kendon, A. (2007). Some topics in gestures studies. In A. Esposito, M. Bratanic, E. Keller \& M. Marinaro (Eds.), Fundamentals of verbal and nonverbal communication and the biometric issue (pp. 3-19). Amsterdam: IOS Press.

Kendon, A., \& Müller, C. (2001). Introducing GESTURE. Gesture, 1, 1-7.

Kimble, C.E., \& Olszewski, D.A. (1980). Gaze and emotional expression: The effects of message positivity-negativity and emotional intensity. Journal of Research in Personality, 14, 60-69.

Kitao, K. (1990). A study of Japanese and American perceptions of politeness in requests. Doshida Studies in English, 5o, 178-210. 
Kita, S. (1993). Language and thought interface: A study of spontaneous gestures and Japanese mimetics. Unpublished doctoral dissertation. Chicago: University of Chicago.

Kita, S. (2000). How representational gestures help speaking. In D. McNeill (Ed.), Language and gesture (pp. 162-185). Cambridge: Cambridge University Press.

Kita, S. (2009). Cross-cultural variation of speech-accompanying gesture: A review. Language and Cognitive Processes , 145-167.

Kitzinger, C. (2013). Repair. In T. Stivers \& J. Sidnell (Eds.), The handbook of conversation analysis (pp. 229-256). London: WileyBlackwell Ltd.

Klima, E., \& Bellugi, U. (1979). The signs of language. Cambridge, MA: Harvard University Press.

Knight, D. (2011). Multimodality and active listenership. London: Continuum.

Knight, D., \& Adolphs, S. (2008). Multi-modal corpus pragmatics: The case of active listenership. In J. Romero-Trillo (Ed.), Pragmatics and corpus linguistics: A mutualistic entente (pp. 175-190). Berlin: Mouton de Gruyter.

Knox, J.S. (2012). Multimodality and systemic functional analysis. In C.A. Chapelle (Ed.), The encyclopedia of applied linguistics (pp. 4082-4089). Oxford: Blackwell.

Koester, A. (1990). The intonation of agreeing and disagreeing in English and German. In M. Hewings (Ed.), Papers in discourse intonation (pp. 83-101). Birmingham: University of Birmingham: English Language Research.

Koike, D. (1996). Transfer of pragmatic competence and suggestions in Spanish language learning. In S.M. Gass \& J. Neu (Eds.), Speech acts across cultures (pp. 257-281). Berlin: Mouton de Gruyter.

Koike, D., \& Pearson, L. (2005). The effect of instruction and feedback in the development of pragmatic competence. System, 33(3), 481501. 
Kress, G. (1993). Against arbitrariness: The social production of the sing as a foundational issue in critical discourse analysis. Discourse and Society, 4(2), 169-191.

Kress, G. (2009). What's a mode? In Jewitt, C. (Ed.), Handbook of multimodal analysis (pp. 54-66). London: Routledge.

Kress, G., \& Jewitt, C. (2003). Introduction. In C. Jewitt \& G. Kress (Eds.), Multimodal literacy (pp. 1-18). Bern: Peter Lang.

Kress, G., \& Van Leeuwen, T. (2001). Multimodal discourse: The modes and the media of contemporary communication. London: Edward Arnold.

LaBarre, W. (1947). The cultural basis of emotions and gestures. Journal of Personality, 16, 49-68.

Ladewig, S.H., \& Bressem, J. (2013). New insights into the medium hand: Discovering recurrent structures in gestures. Semiotica, 197, 203-231.

Laforest, M. (2002). Scenes of family life: Complaining in everyday conversation. Journal of Pragmatics, 34(10), 1595-1620.

Lakoff, R. (1973). The logic of politeness: Or minding your p's and q's. In C. Corum, T.C. Smith-Stark \& A. Weiser (Eds.), Papers from the Ninth Regional Meeting of the Chicago Linguistics Society (pp. 292-305). Chicago: Chicago Linguistics Society.

Larsen-Freeman, D., \& Long, M.H. (1991). An introduction to second language acquisition. London: Longman.

Laufer, B., \& Nation, P. (1995) Vocabulary size and use: Lexical richness in L2 written production. Applied Linguistics, 16(3), 307-322.

Lavandera, B. (1988). The social pragmatics of politeness forms. In U. Ammon, N. Dittmar \& K. Mattheier, Sociolinguistics (pp. 11961205). Berlin: Walter de Gruyter.

Laver, J. (1976). Language and nonverbal communication. In E.C. Carterette \& M.P. Friedman (Eds.), Handbook of perception (Vol. 7) (pp. 345-361). New York: Academic Press. 
Laver, J. (1980). The phonetic description of voice quality. Cambridge University Press. Cambridge.

Labov, W. (1972). Sociolinguistic patterns. Philadelphia: University of Philadelphia.

Leech, G. (1983). Principles of pragmatics. London: Routledge.

Leppanen, V. (1998). The straightforwardness of advice: Advice-giving in interactions between Swedish district nurses and patients. Research on Language and Social Interaction, 31(2), 209-239.

Lerner, G.H. (1987). Collaborative turn sequences: Sentence construction in social action. Unpublished doctoral. dissertation. Los Angeles: University of California.

Lerner, G.H. (1989). Notes on overlap management in conversation: The case of delayed completion. Western Journal of Speech Communication, 53, 167-177.

Lerner, G.H. (1991). On the syntax of sentences-in-progress. Language in Society, 3o(3), 441-458.

Levinson, S. (1983). Pragmatics. Cambridge: Cambridge University Press.

Li, X. (2014). Multimodality, interaction and turn-taking in Mandarin conversation. Amsterdam: John Benjamins Publishing Company.

Lim, T.S., \& Bowers, J.W. (1991). Face-work: Solidarity, approbation, and tact. Human Communication Research, 17(3), 415-450.

Littlewood, W.T. (1984). Foreign and second language learning: Language acquisition research and its implications for the classroom. Cambridge: Cambridge University Press.

Liu, J. (2006a). Measuring interlanguage pragmatic knowledge of EFL learners. Frankfurt am Main: PeterLang.

Liu, J. (2006b). Assessing EFL learners' interlanguage pragmatic knowledge: Implications for testers and teachers. Reflections on English Language Teaching, 5(1), 1-22.

Local, J., \& Kelly, J. (1980). Projection and 'silence': Notes on phonetic and conversational structure. Human Studies, 9, 185-204. 
LoCastro, V. (2003). An Introduction to pragmatics: Social action for language teachers. Michigan: University of Michigan.

Lyons, J. (1977). Semantics. (Vol. 1.) Cambridge : Cambridge University Press.

Macbeth, D. (2004). The relevance of repair for classroom correction. Language in Society, 33(5), 703-736.

Maclay, H., \& Osgood, C.E. (1959). Hesitation phenomena in spontaneous English speech. Word, 15, 19-44.

Mackey, A., \& Gass, S.M (2005). Second language research: Methodology and design. Mahwah, N.J.: Lawrence Erlbaum.

Maeshiba, N., Yoshinaga, N., Kasper, G., \& Ross, S. (1996). Transfer and proficiency in interlanguage apologizing. In S.M. Gass \& J. Neu (Eds.), Speech acts across cultures (pp. 155-187). Berlin: Mouton de Gruyter.

Malmkjær, K. (2004). The linguistic encyclopedia, (2nd ed.). London: Routledge.

Mao, L.M. (1994). Beyond politeness theory: "Face" revisited and renewed. Journal of Pragmatics, 21(5), 451-486.

Markee, N. (2000). Conversation analysis. Mahwah NJ: LAwrence Erlbaum Associates.

Markee, N., \& Kasper, G. (2004). Classroom talks: An introduction. Modern Language Journal, 88(4), 491-500.

Martínez-Flor, A. (2012). Examining EFL learners' long-term instructional effects when mitigating requests. In M. EconomidouKogetsidis \& H. Woodfield (Eds.), Interlanguage request modification (pp. 243-274). Amsterdam: John Benjamins Publishing Company.

Martínez-Flor, A., \& Beltrán-Palanques, V. (2013). Teaching refusal strategies in the foreign language classroom: a focus on inductivedeductive treatments. Journal of English Studies, 11, 41-67. 
Martínez-Flor, A., \& Beltrán-Palanques, V. (2014). The role of politeness in apology sequences: How to maintain harmony between speakers. ELIA: Estudios de Lingüística Inglesa Aplicada, 43-66.

Martínez-Flor, A., \& Usó-Juan, E. (Eds.) (2010a). Speech act performance. Theoretical, empirical and methodological issues. Amsterdam: John Benjamins Publishing Company.

Martínez-Flor, A., \& Usó-Juan, E. (2010b). Research methodologies in pragmatics: Eliciting refusals to requests. Estudios de Lingüística Inglesa Aplicada, ELIA, 11, 47-87.

Márquez-Reiter, R. (2000). Linguistic politeness in Britain and Uruguay. Amsterdam: John Benjamins Publishing Company.

Márquez-Reiter, R. (2005). Complaint calls to a caregiver service company: The case of desahogo. Intercultural Pragmatics, 2(4), 481-514.

Márquez-Reiter, R. (2013). The dynamics of complaining in a Latin American for profit commercial setting. Journal of Pragmatics, 2(4), 481-514.

Matsumoto, D., \& Willingham, B. (2009). Spontaneous facial expressions of emotion of blind individuals. Language and Cognitive Processes, 24: 239-266.

Matsumoto, Y. (1988). Reexamination of the universality of face: Politeness phenomena in Japanese. Journal of Pragmatics, 12(4), 403-426.

Maynard, S. (1986). On back-channel behaviour in Japanese and English conversation. Linguistics, 24, 1079-1108.

Maynard, S. (1987). Interactional functions of a nonverbal sign: Head movement in Japanese dyadic casual conversation. Journal of Pragmatics, 11, 589-606.

Maynard, S. (1989). Japanese conversation: Self-contextualization through structure and interactional management. Advances in discourse processes, (Vol. 35). Norwood, NJ: Ablex. 
Maynard, S. (1990). Conversation management in contrast: Listener response tokens in Japanese and American English. Journal of Pragmatics, 14, 397-412.

Mazeland, H. (2006). Conversation analysis. In K. Brown (Ed.), Encyclopedia of language and linguistics, (Vol. 3) (2nd ed.) (pp. 153-162). Oxford and Amsterdam. Elsevier.

McClave, E.Z. (2000). Linguistic functions of head movements in the context of speech. Journal of Pragmatics 32(7), 855-878.

McCarthy, M. (2002). Good listenership made plain: British and American non-minimal response tokens in everyday conversation. In R. Reppen, S. M. Fitzmaurice \& D. Biber (Eds.), Using corpora to explore linguistic variation (pp. 49-71). Amsterdam: John Benjamins Publishing Company.

McNeill, D. (1985). So do you think that gestures are not verbal? Psychological Review, 92, 350-371.

McNeill, D. (1992). Hand and mind: What gestures reveal about thought. Chicago \& London: The University of Chicago.

McNeill, D. (2000). Introduction. In D. McNeill (Ed.) Language and gesture (pp. 1-12). Cambridge: Cambridge University Press.

McNeill, D., \& Levy, E.T. (1982). Conceptual representations in language activity and gesture. In R. Jarvella, R. \& Klein, W. (Eds.), Speech, place and action (pp. 271-195). Chichester: Wiley \& Sons.

Mey, J. (2001). Pragmatics: An introduction (2nd Ed). Oxford: Blackwell Publishing.

Mills, S., \& Kádár, D.Z. (2011). Politeness and culture. In D.Z. Kádár \& S. Mills, Politeness in East Asia (pp. 21-44). Cambridge: Cambridge University Press.

Mondada, L. (2008). Using Video for a sequential and multimodal analysis of social interaction: Videotaping institutional telephone calls. Forum Qualitative Sozialforschung / Forum: Qualitative Social Research, 9(3). Retrived from: http://www.qualitativeresearch.net/index.php/fqs/article/view/1161/2566 
Mondada, L. (2014). Requesting immediate action in the surgical operating room. Time, embodies resources and praxeological embeddedness. In P. Drew \& E. Couper-Kuhlen (Eds.), Requesting in Social Interaction (pp. 269-302). Amsterdam: John Benjamins Publishing Company.

Mondada, L. (2016). Multimodal resources and the organization of social interaction. In A. Rocci \& L.d. Saussure (Eds.), Verbal communication (pp. 329-350). Berlin: De Gruyter Mouton.

Monzoni, C. (2008). Introducing direct complaints through questions: The interactional achievement of "pre-sequences"? Discourse Studies, 1O(1), 73-87.

Mori, J. (1999). Negotiating agreement and disagreement in Japanese: Connective expressions and turn construction. Amsterdam: John Benjamins Publishing Company.

Mori, J. (2002). Task design, plan, and development of talk-inInteraction: An analysis of a small group activity in a Japanese language classroom. Applied Linguistics, 23(3), 323-347.

Morris, C. (1938). Foundations of the theory of signs. In O. Neurath, R. Carnap \& C. Morris (Eds.), International encyclopedia of unified science (pp.77-138). Chicago: University of Chicago Press.

Moskala-Gallaher, B. (2011). The speech act of complaint in English and in Russian and its emergence in the pragmatic competence of adult American learners of Russian. Unpublished doctoral dissertation: Pennsylvania: Faculty of Bryn Mawr College.

Murphy, B., \& Neu, J. (1996). My grade's too low: The speech act of complaining. In S.M. Gass \& J. Neu (Eds.), Speech acts across cultures: Challenges to communication in a second language (pp. 191-216). Berlin: Mouton de Gruyter.

Nattinger, J.R., \& DeCarrico, J.S. (1992). Lexical phrases and language teaching. Oxford: Oxford University Press. 
Nesi, H. (2013). ESP and corpus studies. In B. Paltridge \& S. Starfield, The handbook of English for specific purposes (pp. 407-426). Oxford: Wiley-Blackwell.

Newell, S.E., \& Stutman, R. (1989/1990). Negotiating confrontation: The problematic nature of initiation and response. Research on Language and Social Interaction, 23, 139-162.

Nichols, K., \& Champness, B. (1971). Eye gaze and the GSR. Journal of Experimental Social Psychology, 7(6), 623-626.

Niezgoda, K., \& Roever, C. (2001). Pragmatic and grammatical awareness: A function of the learning environment? In R. Kenneth \& G. Kasper, (Eds.), Pragmatics in language teaching (pp. 63-79). Cambridge: Cambridge University Press.

Nikula, T. (1996). Pragmatic force modifiers. A study in interlanguage pragmatics. Jyväskylä: University of Jyväskylä.

Norman. D.A. (1988). The psychology of everyday things. New York: Basic Books. (The paperback version in Norman, 1990).

Norman. D.A. (1990). The design of everyday things. New York: Doubleday.

Norris, S. (2004). Analyzing multimodal interaction: A methodological framework. Routledge: London.

Norris, S. (2011). Identity in (inter)action: Introducing multimodal (inter)action analysis. Berlin: Mouton.

Norris, S., \& Jones, R. (Eds.) (2005). Discourse in action: Introducing mediated discourse analysis. London: Routledge.

Nörth, W. (1990). Handbook of semiotics. Bloomington: Indiana University Press.

Oatley, K., Keltner, D., \& Jenkins, J.M. (2006). Understanding emotions. Blackwell Publishing.

O'Connor, J.D. \& Arnold, G F. 1973. Intonation of colloquial English. Bristol: Longman Group Ltd.

O’Keeffe, A., \& Adolphs, S. (2008). Using a corpus to look at variational pragmatics: Response tokens in British and Irish discourse. In K.P. 
Schneider \& A. Barron, Variational pragmatics (pp. 69-98). Amsterdam: John Benjamins Publishing Company.

O’Keeffe, A., Clancy, B., \& Adolphs, S. (2011). Introducing pragmatics in use. London: Routledge.

O'Driscoll, J. (2007). Brown \& Levinson's face: How it can-and can'thelp us to understand interaction across cultures. Intercultural Pragmatics, 4(4), 463-492.

O’Halloran, K.L. (2005). Mathematical discourse: Language, symbolism and visual images. London: Continuum

O’Halloran, K.L., \& Fei, V. (2014). Systemic functional multimodal discourse analysis. In S. Norris \& C.D. Maier (Eds.), Interactions, images and texts: A reader in multimodality (pp. 137-153). Berlin: Mouton de Gruyter.

Ohbuchi, K., Kameda, M. \& Agerie, N. (1989). Apology as aggression control: Its role in mediating appraisal of and response to harm. Journal of Personality and Social Psychology, 52(2), 219-227.

Okamoto, S. (2010). Politeness in East Asia. In M.A. Locher \& S.L. Graham, Handbooks of pragmatics, (Vol 6) Interpersonal Pragmatics (pp. 71-100). Berlin: Mouton de Gruyter.

Olshtain, E., \& Cohen, A. (1983). Apology: A speech act set. In N. Wolfson \& E. Judd (Eds.), Sociolinguistics and language acquisition (pp. 18-38). Rowley, MA: Newbury House.

Olshtain, E., \& Cohen, A.D. (1991). Teaching speech act behaviour to nonnative speakers. In M. Celce-Murcia (Ed.), Teaching English as a second or foreign language (pp. 154-165). Boston: Heinle \& Heinle.

Olshtain, E., \& Weinbach, L. (1987). Complaints: A study of speech act behavior among native and non-native speakers of Hebrew. In J. Verschueren \& M. Bertuccelli-Papi (Eds.), The pragmatic perspective (pp. 195-208). Amsterdam: John Benjamins.

Olshtain, E., \& Weinbach, L. (1993). Interlanguage features of the speech act of complaining. In G. Kasper \& S. Blum-Kulka (Eds.), 
Interlanguage pragmatics (pp. 108-122). Oxford: Oxford University Press.

Oreström, B. (1983). Turn-taking in English conversation. Lund: Gleerup.

Ostrom, T., \& Gannon, K. (1996). Answering questions: Methodology for determining cognitive and communicative processes in survey research. In N. Schwarz \& S. Sudman (Eds.), Exemplar generation: Assessing how respondents give meaning to rating scales (pp. 293-318). San Francisco: Jossey-Bass.

Oxford, R.L. 2001. Language learning styles and strategies. In M. CelceMurcia (Ed.), Teaching English as a second or foreign language (pp. 539-366), Boston: Heinle \& Heinle.

Patterson, M.L. (2013). Towards a system to nonverbal interaction. In J.A., Hall \& M.L. Knapp, (Eds.), Nonverbal communication. Berlin: Mouton de Gruyter.

Payrató, F. \& Teßendorf, S. (2014). Pragmatic gestures. In C. Müller, A. Cienki, E. Fricke, S.H. Ladewig, D. McNeil \& J. Bressem (Eds.) Body - language - communication. An international handbook of multimodality in human interaction (pp. 1531-1539). Berlin: Mouton Gruyter.

Peters, P., \& Wong, D. (2014). Turn management and backchannels. In K. Aijmer, \& C. Rühlemann (Eds.), Corpus pragmatics: A handbook (pp. 408-429). Cambridge: Cambridge University Press.

Peterwagner, R. (2005). What is the matter with communicative competence?: An analysis to encourage teachers of English to assess the very basis of their teaching. Viena: Lit. Verlag.

Pfau, R., \& Quer, J. (2010). Nonmanuals: Their prosodic and grammatical roles. In D. Brentari (Ed.), Sign languages. (pp. 381402). Cambridge University Press.

Phakiti, A. (2008). Construct validation of Bachman and Palmer's (1996) strategic competence model over time in EFL reading tests. Language Testing, 25(2), 237-272. 
Pickering, L., Hu, G., \& Baker, A. (2012). The pragmatic function of intonation: Cueing agreement and disagreement in spoken English discourse and implication for ELT. In J. Romero-Trillo (Ed.), Pragmatics and prosody in English language teaching (pp. 199218). Dordrecht: Springer.

Piotrowska, M. (1987). An investigation into the sociolinguistic competence of Hong Kong University students with specific reference to making complaints. Unpublished master's thesis dissertation. Pokfulam: The University of Hong Kong.

Pomerantz, A. (1978). Compliment responses: Notes on the cooperation of multiple constraints. In J.N. Schenkein (Ed.), Studies in the organization of conversational interaction (pp. 79-112). New York: Academic Press.

Pomerantz, A. (1984). Agreeing and disagreeing with assessments: Some features of preferred/dispreferred turn shapes. In J. Atkinson \& J. Heritage (Eds.), Structures in social action: Studies in conversation analysis (pp. 57-101). Cambridge: Cambridge University Press.

Pomerantz, A. (1986). Extreme cases formulations: A way of legitimizing claims. Human Studies, 9(2-3), 219-229.

Poyatos, F. (1972). Paralenguaje y kinésica del personaje novelesco: Nueva perspectiva en el análisis de la narración. Revista de Occidente, 113-114, 148-170.

Poyatos, F. (1983). Language and nonverbal systems in the structure of face-to-face interaction. Language \& Communication, 3(2), 129140.

Poyatos, F. (1993). Paralanguage. A linguistic and interdisciplinary approach to interactive speech and sound. Amsterdam: John Benjamins Publishing Company.

Poyatos, F. (2002). Nonverbal communication across disciplines. Paralanguage, kinesics, silence, personal and environmental 
interaction (Vol. 2). Amsterdam: John Benjamins Publishing Company.

Poyatos, F. (2013). Body gestures, manners, and postures in literature. In C. Müller, A. Cienki, E. Fricke, S.H. Ladewig, D. McNeill \& S. Tessendor (Eds.), Body-language-communication: An international handbook on multimodality in human interaction (pp. 287-300). Berlin: Mouton de Gruyter.

Purpura, J. (2004). Assessing grammar. Cambridge: Cambridge University Press.

Querol-Julián, M. (2011). Evaluation in discussion sessions of conference paper presentations. A multimodal approach. Saarbrücken: LAP Lambert Academic Publishing GmbH \& Co.KG.

Querol-Julián, M., \& Fortanet-Gómez, I. (2012). Multimodal evaluation in academic discussion sessions: How do presenters act and react? Journal of English for Specific Purposes, 31(4): 271-283.

Reilly, J.S., McIntire, M., \& Bellugi, U. (1990). The acquisition of conditionals in American Sign Language: Grammaticized facial expressions. Applied Psycholinguistics, 11(4), 369-392

Richards, J.C., \& Schmidt, R. (2013). Longman dictionary of language teaching and applied linguistics. (4th ed.). London: Routledge.

Richards, K., \& Seedhouse, P. (2005). Applying conversation analysis. Basingstoke: Palgrave Macmillan.

Richmond, V. \& McCroskey, J. (2000). Nonverbal behavior in interpersonal relations. (4th ed.). Needham Heights, MA: Allyn \& Bacon.

Rinnert, C. \& Kobayashi, H. (1999). Requestive hints in Japanese and English. Journal of Pragmatics, 31(9), 1173-1201.

Rintel, S., Mulholland, J., \& Pittam, J. (10 de July de 2001). First things first: Internet relay chat openings. Journal of ComputerMediated Communication, 6(3). Retrieved from Wiley Online Library: $\quad$ http://onlinelibrary.wiley.com/doi/10.1111/j.10836101.2001.tbo0125.x/full 
Rintell, E. (1979). Getting your speech act together: The pragmatic ability of second language learners. Working Papers on Bilingualism, 17, 97-106.

Risager, K. (2006). Language and culture. Global flows and local complexity. Bristol: Multilingual Matters.

Roach, P., Stibbard, R., Osborne, J., \& Setter, J. (1998). Transcription of prosodic and paralinguistic features of emotional speech. Journal of the International Phonetic Association, 28(1-2), 83-94.

Robinson, M. (1992). Introspective methodology in interlanguage pragmatics research. In G. Kasper, Pragmatics of Japanese as a native and target language [Second language teaching and curriculum center technical Report No. 3] (pp. 27-82). Honolulu HI: University of Hawai'i Press.

Robinson, J. (2004). The sequential organization of "explicit" apologies in naturally occurring English. Research on Language and Social Interaction, 37(3), 291-330.

Roever, C. (2009). Teaching and testing pragmatics. In M.H. Long \& C.J. Doughty (Eds.), The handbook of language teaching (pp. 560-577). Oxford: Blackwell Publishing Ltd.

Roever, C. (2010). Researching pragmatics. In B. Paltridge \& A. Phakiti, Continuum companion to research methods in applied linguistics (pp. 240-255). London: Continuum.

Roever, C. (2011). Testing of second language pragmatics: past and future. Language Testing, 28(4), 463-481.

Roever, C., \& Al-Gahtani, S. (2015). The development of ESL proficiency and pragmatic performance. ELT Journal, 69(4), 395-404.

Romero-Trillo, J. (Ed.) (2012). Pragmatics and prosody in English language teaching. Dordrecht: Springer.

Romero-Trillo, J. (2014). 'Pragmatic punting' and prosody: Evidence from corpora. In M.A. Gómez, F.J. Ruiz de Mendoza, F. Gonzálvez, \& A. Downing (Eds.), The functional perspective on language and 
discourse: Applications and implications (pp. 209-222). Amsterdam: John Benjamins Publishing Company.

Romero-Trillo, J. (2015). Understanding vagueness: A prosodic analysis of endocentric and exocentric general extenders in English conversation. Journal of Pragmatics, 86, 54-62.

Rose, K. (2005). On the effects of instruction in second language pragmatics. System, 33(3), 358-399.

Rose, K., \& Kasper, G. (2001). Pragmatics in language teaching [Cambridge applied linguistic series]. New York: Cambridge University Press.

Rose, K. \& Ng, K.-f. (2001). Inductive and deductive teaching of compliments and compliment responses. In K. Rose \& G. Kasper (Eds.), Pragmatics in language teaching (pp. 145-170). New York: Cambridge University Press.

Rose, K., \& Ono, R. (1995). Eliciting speech act data in Japanese: The effect of questionnaire type. Language Learning, 45(2), 191-223.

Rosenberg, E.L. (2005). Introduction. The study of spontaneous facial expressions in psychology. In P. Ekman \& E.L. Rosenberg (Eds.), What the face reveals: Basic and applied studies of spontaneous expression using the facial action coding system (FACS), (2nd ed.) (pp. 3-18). Oxford: Oxford University Press.

Rosenfeld, H. (1987). Conversational control functions of nonverbal behavior. In A. Siegman \& S. Feldstein (Eds.), Nonverbal behaviour and communication (pp. 563-601). Hillsdale, NJ: Lawrence Erlbaum Associates.

Rossi, G. (2014). When do people not use language to make requests? In P. Drew \& E. Couper-Kuhlen (Eds.), Requesting in social interaction (pp. 303-334). Amsterdam: John Benjamins Publishing Company.

Royce, T.D. (2007). Multimodal communicative competence in second language contexts. In T.D. Royce and W.L. Bowcher (Eds.), New 
directions in the analysis of multimodal discourse (pp. 361-390). Mahwah, Jew Jersey: Lawrence Erlbaum Associates, Inc.

Ruiz-Madrid, N., \& Fortanet-Gómez, I. (2015). Contrastive multimodal analysis: Conference plenary lectures in English and in Spanish. In B. Crawford \& I. Fortanet-Gómez (Eds.), Multimodal analysis in academic settings. From research to teaching (pp. 39-60). London: Routledge.

Sabaté-Dalmau, M., \& Curell-Gotor, H. (2007). From "Sorry very much" to "I'm ever so sorry:" Acquisitional patterns in L2 apologies by Catalan learners of English. Intercultural Pragmatics, 4(2)287315 .

Sacks, H. (2004). An initial characterization of the organization of turntaking in conversation. In G.H. Lerner (Ed.), Conversation analysis: Studies from the first generation (pp. 35-42). Philadelphia: John Benjamins Publishing Company.

Sacks, H., Schegloff, E.A, \& Jefferson, G. (1974). A simplest systematics for the organisation of turn-taking for conversation. Language Awareness, 50(4), 696-735.

Sacks, H., Schegloff, E.A, \& Jefferson, G. (2002). Home position. Gesture, 2(2): 133-146.

Salamin, H., \& Vinciarelli, A. (2012). Automatic role recognition in multiparty conversations: An approach based on turn organization, prosody, and conditional random fields. IEEE Transactions on Multimedia, 14(2), 338-345.

Sander, D., Grandjean, D., Kaiser, S., Wehrle, T., \& Scherer, K.R. (2007). Interaction effects of perceived gaze direction and dynamic facial expression: Evidence for appraisal theories of emotion. European Journal of Cognitive Psychology, 19(3), 470480 .

Savignon, S. (1983). Communicative competence: Theory and classroom practice. Reading, MA: Addison-Wesley. 
Saville-Troike, M. (1985). The place of silence in an integrated theory of communication. In D. Tannen \& M. Saville-Troike (Eds.), Perspectives on silence (pp. 3-20). Norwood, N.J.: Ablex.

Sbisà, M. (2002). Speech acts in context. Language and Communication, 22, 421-436.

Schachter, J. (1990). Communicative competence revisited. In B. Harley, P. Allen, J. Cummins \& M. Swain (Eds.), The development of second language proficiency (pp. 39-49). Cambridge: Cambridge University Press.

Schaefer, E.J. (1982). An analysis of the discourse and syntax of oral complaints in English. Unpublished master's thesis. Los Angeles: University of California.

Schauer, G.A. (2006). Pragmatic awareness in ESL and EFL contexts: Contrast and development. Language Learning, 56(2), 269-318.

Schauer, G.A. (2009). Interlanguage pragmatic development. The study abroad context. London: Continuum.

Schegloff, E.A. (1968). Sequencing in conversational openings. American Anthropologist, 7o(6), 1075-1095.

Schegloff, E.A. (1972). Notes on a conversational practice: formulating place. In D. Sudnow (Ed.), Studies in social interaction, (pp. 75119). New York: Free Press.

Schegloff, E.A. (1982). Discourse as an interactional achievement: Some uses of 'uh huh' and other things that come between sentences. In D. Tannen (Ed.), Analyzing discourse: Text and talk (Georgetown University Round Table on Language and Linguistics 1981) (pp. 71-93). Washington, DC: Georgetown University Press.

Schegloff, E.A. (1987). Recycled turn beginnings: a precise repair mechanism in conversation's turn taking organization. In G. Button \& J. Lee (Eds.), Talk and social organisation (pp. 70-85). Clevedon: Multilingual Matters. 
Schegloff, E.A. (1992). Repair after next turn: The last structurally provided defense of intersubjectivity in conversation. American Journal of Sociology, 98, 1295-1345.

Schegloff, E.A. (2000). Overlapping talk and the organization of turntaking for conversation. Language in Society, 29(1), 1-63.

Schegloff, E.A. (2002). Reflections on research on telephone conversation: Issues of cross-cultural scope and scholarly exchange, interactional import, and consequences. In K. Luke, \& T. Pavlidou (Eds.), Telephone calls (pp. 249-281). Amsterdam: John Benjamins Publishing Company.

Schegloff, E.A. (2005). On complainability. Social Problems, 52(4), 449-476.

Schegloff, E.A. (2007). Sequence organization in interaction: A primer in conversation analysis (Vol.1). Cambridge: Cambridge University Press.

Schegloff, E.A., \& Sacks, H. (1973). Opening up closings. Semiotica, $8(4), 298-327$.

Schegloff, E. A., Jefferson, G., \& Sacks, H. (1977). The preference for self-correction in the organization of repair in conversation. Language, 53(2), 361-382.

Schegloff, E.A., Koshik, I., Jacoby, S., \& Olsher, D. (2002). Conversation analysis and applied linguistics. Cambridge: Cambridge University Press.

Scollon, R., \& Scollon, S.W. (2003). Discourses in place: Language in the material world. London: Routledge.

Searle, J.R. (1969). Speech acts. Cambridge: Cambridge University Press.

Searle, J.R. (1975). Indirect speech acts. In P. Cole \& J.L. Morgan (Eds.), Speech acts [Syntax and semantics 3] (pp. 59-82). New York: Academic Press.

Searle, J.R. (1976). A classification of illocutionary acts. Language in Society, 5(1), 1-23. 
Searle, J.R., Kiefer, F., \& Bierwisch, M. (1980). Introduction. In J.R. Searle, F. Kiefer \& M. Bierwisch (Eds.), Speech act theory and pragmatics (vii-xii). Dordrecht: Reidel.

Seedhouse, P. (2004). The interactional architecture of the language classroom: A conversational analysis perspective. Malden MA: Blackwell.

Seedhouse, P. (2005). Conversation analysis and language learning. Language Teaching, 38(4), 15-187.

Selinker, L. (1972). Interlanguage. IRAL, 1O, 219-231.

Senft, G. (2014). Understanding pragmatics. London: Routledge.

Shardakova, M. (2005). Intercultural pragmatics in the speech act of American L2 learners of Russian: Apologies offered by Americans in Russian. Intercultural Pragmatics, 2(4), 423-451.

Shözt, S. (2002). Linguistic \& paralinguistic phonetic variation in a speaker recognition \& text-to-speech. Retrieved from http://citeseerx.ist.psu.edu/viewdoc/download?doi=10.1.1.104.14 o1\&rep $=$ rep1\&type $=$ pdf

Sidnell, J. (2009). Participation. In S. D’hondt, J. Östman \& J. Verschueren (Eds.), The pragmatics of interaction (pp. 125-156). Amsterdam: John Benjamins Publishing Company.

Sinclair, J.M., \& Brazil, D. (1982). Teacher talk. Oxford: Oxford University Press.

Sivenkova, M. (2010). Appropriateness in interpersonal communication. In S.K. Tanskanen, M.L. Helasvuo, M. Johansson \& M. Raitaniemi (Eds.), Discourses in interaction (pp. 239-262). Amsterdam: John Benjamins Publishing Company.

So, W.C., Kita, S., \& Goldin-Meadow, S. (2013). When do speakers use gestures to specify who does what to whom? The role of language proficiency and type of gestures in narratives. $J$ Psycholinguistic Research, 42(6), 581-594.

Sperber, D., \& Wilson, D. (1995). Communication and cognition. Cambridge: Cambridge University Press. 
Stenglin, M., \& Iedema, R. (2001). How to analyze visual images: A guide for TESOL Teachers. In A. Burns \& C. Coffin (Eds.), Analysing English in a global context (pp. 194-208). London: Routledge.

Stivers, T. (2013). Sequence organisation. In J. Sidnell \& T. Stivers (Eds.), The handbook of conversation analysis (pp. 191-209). Oxford: Blackwell Publishing Ltd.

Streeck, J. (1993). Gesture as communication I: Its coordination with gaze and speech. Communication Monographs, 6o, 275-299.

Streeck, J. (2006). Gestures: Pragmatic aspects. In E. Goody (Ed.), Encyclopedia of language \& linguistics (2nd ed.) (Vol. 5) (pp. 7176). Oxford: Elsevier.

Streeck, J. (2008). Metaphor and gesture. A view from the microanalysis of interaction. In A. Cienki \& C. Müller (Eds.), Metaphor and gesture (pp. 259-264). Amsterdam: John Benjamins Publishing Company.

Streeck, J. (2009). Forward-gesturing. Discourse Processes, 46,(2-3), 161-179.

Streeck, J., \& Hartge, U. (1992). Previews: Gestures at the transition place. In P. Auer \& A. di Luzio, The Contextualization of Language (pp. 138-158). Amsterdam: John Benjamins Publishing Company.

Streeck, J., Goodwin, C., \& LeBaron, (Eds.) (2011). Embodied interaction: Language and body in the material world. Cambridge: Cambridge University Press.

Strongmana, K.T. \& Champnessa, B.G. (1968). Dominance hierarchies and conflict in eye contact. Acta Psychologica, 28, 376-386.

Swales, J. (1990). Gender analysis: English in academic and research settings. Cambridge: Cambridge University Press.

Tellier, M. (2009). The development of gesture. In K. de Bot \& R. Schrauf (Eds.), Language development over the life-span (pp. 191-216). London: Routledge. 
Taguchi, N. (2002). An application of relevance theory to the analysis of L2 interpretation processes: The comprehension of indirect replies. IRAL, 4O, 151-176.

Taguchi, N. (2006). Analysis of appropriateness in a speech act of request in L2 English. Pragmatics, 16(4), 513-533.

Taguchi, N. (2007). Task difficulty in oral speech act production. Applied Linguistics, 28(1), 113-135.

Taguchi, N. (2009). Pragmatic competence in Japanese as a second language: An introduction. In N. Taguchi (Ed.), Pragmatic competence, (pp. 1-18). Berlin: Mouton de Gruyter.

Taguchi, N. (2010). Longitudinal studies in interlanguage pragmatics. In A. Trosborg (Ed.), Handbook of pragmatics: Pragmatics across languages and cultures, (Vol.7) (pp. 333-361). Berlin: Mouton de Gruyter.

Taguchi, N. (2011). The effect of L2 proficiency and study-abroad experience on pragmatic comprehension. Language Learning, 61, 904-936.

Taguchi, N. (2013). Refusals in L2 English: Proficiency effects on appropriateness and fluency. In O. Marti \& P. Salazar (Eds.), Refusal in instructional context and beyond (pp. 101-119). Amsterdam: Rodopi.

Takahashi, S. (2001). The role of input enhancement in developing pragmatic competence. In K. Rose \& G. Kasper (Eds.), Pragmatics in language teaching. (pp. 171-199). Cambridge: Cambridge University Press.

Taleghani-Nikazm, C. (2002). A conversation analytical study of telephone conversation opening between native and nonnative speakers. Journal of Pragmatics, 34(2), 1807-1832.

Taleghani-Nikazm, C. (2005). Contingent requests: Their sequential organization and turn shape. Research on Language and Social Interaction, 38(2), 159-179. 
Taleghani-Nikazm, C. (2006). Request sequences: The intersection of grammar, interaction and social context. Amsterdam: John Benjamins Publishing Company.

Tanck, S. (2004). Speech act sets of refusal and complaint: A comparison of native and non-native English speakers' production. TESOL Working Papers, 4(2), 1-22.

Tateyama, Y., \& Kasper, G. (2008). Talking with a classroom guest: Opportunities for learning Japanese pragmatics. In E. Alcón \& A. Martínez-Flor (Eds.), Investigating pragmatics in foreign language learning, teaching and testing (pp. 45-71). Bristol: Multilingual Matters.

Tatsuki, D.H., \& Houck, N.R. (Eds.) (2010). Pragmatics: teaching speech acts. Alexandria: TESOL.

ten Have, P. (2007). Doing conversation analysis: A Practical Guide. London: SAGE.

Thomas, J. (1983). Cross-cultural pragmatic failure. Applied Linguistics, 4, 91-112.

Thomas, J. (1995). Meaning in Interaction: An introduction to pragmatics. London: Longman.

Thomason, S. (2001). Language in contact. Edinburg: Edinburg University Press.

Tottie, G. (1991). Conversational style in British and American English. The case of backchannels. In K. Aijmer \& B. Altenberg (Eds.), English corpus linguistics: Studies in honour of Jan Svartvik (pp. 254-335) London: Longman.

Tracy, J., \& Matsumoto, D. (2008). The spontaneous expression of pride and shame. Evidence for biologically innate nonverbal displays. Proceedings of the National Academy of Science (pp. 11655-11660).

Trager, G.L. (1958). Paralanguage: A first approximation. Studies in Linguistics, 13, 1-12. 
Trenchs, M. (1994). Complaining in Catalan, complaining in English: A comparative study of native and EFL speakers. Revista Española de Lingüística Aplicada, 271-288.

Trosborg, A. (1995). Interlanguage pragmatics: Requests, complaints, and apologies. Berlin: Mouton Gruyter.

Turner, K. (1996). The principle principles of pragmatic inference: Politeness. Language Teaching, 29(1), 1-13.

Usó-Juan, E. and Martínez-Flor, A. (2006). Approaches to language learning and teaching: Towards acquiring communicative competence through the four skills. In E. Usó-Juan \& A. MartínezFlor (Eds.), Current trends in the development and teaching of the four language skills (pp. 3-25) Berlin: Mouton de Gruyter.

Vagias, W.M. (2006). Likert-type scale response anchors. Clemson International Institute for Tourism \& Research Development, Department of Parks, Recreation and Tourism Management. Clemson University.

Valstar, M. (2015). Automatic facial expression analysis. In M.K. Mandal \& A. Awasthi (Eds.) Understanding facial expressions in communication. Cross-cultural and multidisciplinary perspectives (pp. 143-172). Dordrecht: Springer.

Vargas, M.F. (1986). Louder than words: An introduction to nonverbal communication. Ames: The Iowa State University Press.

Wannaruk, A. (2008). Pragmatic transfer in Thai EFL refusals. RELC Journal, 39(3), 318-337.

Ward, N. (2006). Non-lexical conversational sounds in American English. Pragmatics and Cognition, 14:113-184.

Ward, N., \& Tsukahara, W. (2000). Prosodic features which cue backchannel responses in English and Japanese. Journal of Pragmatics, 32(8), 1177-1207.

Watson, D. (1978). Categorization, authorization and blame Negotiation in conversation. Sociology, 12(1), 105-113.

Watts, R.J. (2003). Politeness. Cambridge: Cambridge University Press. 
Wesche, M., \& Paribakht, T.S. (1996). Assessing second language vocabulary knowledge: Depth versus breadth. Canadian Modern Language Review, 53(1), 13-40.

Wharton, T. (2011). Pragmatics and nonverbal communication. An exchange. Reply to the review of Kensy Cooperrider. Gesture, 11(3), 383-393.

White, R. (1997). Back channeling, repair, pausing, and private speech. Applied Linguistics, 18(3):314-344

Widjaja, C. (1997). A study of date refusal: Taiwanese females vs. American females. University of Hawai̋ Working Papers in ESL, 15(2), 1-43.

Wittenburg, P., Brugman, H., Russel, A. Klassmann, A., \& Sloetjes, H. (2006). ELAN: A professional framework for multimodality research. Proceedings of fifth international conference on language resources and evaluation (pp. 1556-1559.)

Wooffitt, R. (2005). Conversation analysis and discourse analysis. London: SAGE.

Wootton, A. J. (1981). The management of grantings and rejections by parents in request sequences. Semiotica, 37(1-2), 59-89.

Woodfield, H. (2008). Problematising discourse completion task: Voices from verbal report. Evaluation \& Research in Education, 21(1), 43-69.

Woodfield, H. (2010). What lies beneath?: Verbal report in interlanguage requests in English. Multilingua-Journal of CrossCultural and Interlanguage Communication, 29(1), 1-27.

Woodfield, H. (2012). Pragmatic variation in learner perception: the role of retrospective verbal report in L2 speech act research. In J.C. Félix-Brasdefer \& D. Koike (Eds.), Pragmatic variation in first and second language contexts: Methodological issues (pp. 209-238). Amsterdam: John Benjamins Publishing Company.

Wooffitt, R. (2005). Conversation analysis \& discourse analysis. London: SAGE. 
Wunderlich, D. (1980). Methodological remarks on speech act theory. In J.R. Searle, F. Kiefer \& M. Bierwisch, Speech act theory and pragmatics (pp. 291-312). Dordrecht: Reidel Publishing Company.

$\mathrm{Xu}$, W., Case, R.E., \& Wang, Y. (2009). Pragmatic and grammatical competence, length of residence, and overall L2 proficiency. System, 37(2), 205-216.

Wyner, C., \& Cohen, A.D. (2015). Second language pragmatic ability: individual differences according to environment. Studies in Second Language Learning and Teaching, 5(4), 519-556.

Yamashita, S. (2008). Investigating interlanguage pragmatics ability: What are we testing? In E. Alcón \& A. Martínez-Flor (Eds.), Investigating pragmatics in foreign language learning, teaching and testing (pp. 201-223). Bristol: Multilingual Matters.

Yngve, V. (1970). On getting a word in edgewise. Papers from the Sixth Regional Meeting of the Chicago Linguistic Society, 567-577.

Yule, G. (1996). Pragmatics. Oxford: Oxford University Press.

Zhang, Z. (2015). Disagreements in plenary addresses as multimodal action. In B. Crawford \& I. Fortanet-Gómez (Eds.), Multimodal analysis in academic settings. From research to teaching (pp. 1738). London: Routledge. 
Appendices 



\title{
Appendix A. Consent form
}

\section{DOCUMENTO DE AUTORIZACIÓN}

\section{Complaint Sequences across Proficiency Levels: The Contribution of Pragmatics and Multimodality}

\author{
Información de contacto: $\quad$ Vicent Beltrán Palanques \\ Email: vbeltran@uji.es
}

\section{Objetivo del estudio:}

El objetivo de esta investigación es recopilar dados de estudiantes de inglés como lengua extranjera en el contexto universitario para formar parte del estudio Complaint Sequences across Proficiency Levels: The Contribution of Pragmatics and Multimodality. Para ello se necesita diseñar un corpus de lenguaje hablado mediante la colección de grabaciones en audio y vídeo y transcripciones. La razón principal para la compilación y análisis de los datos es analizar el comportamiento pragmático y multimodal de los estudiantes de inglés como lengua extranjera, diseñar propuestas metodológicas para mejorar la enseñanza de aspectos pragmáticos y multimodales en el aula de inglés y mejorar la formación de docentes y futuros docentes de inglés.

\section{Participación en el estudio}

La participación en el proyecto es voluntaria y no existe ningún tipo de sanción si en algún momento se decide dejar de colaborar en este estudio.

\section{Confidencialidad}

Se mantendrá la confidencialidad de la información en lo que se refiere a información explicita sobre los participantes.

1. Confirmo que he leído y entendido la información

Sí No

2. He tenido la oportunidad de hacer preguntas y éstas se han contestado satisfactoriamente

Sí No

3. Autorizo a ser grabado/a en audio y vídeo

Sí $\quad$ No

4. Estoy de acuerdo en que las grabaciones sean transcritas, pero entiendo que ni mi nombre ni otra información explicita de mi identidad se incluirá en las transcripciones sin haber dado permiso explícito.

Sí No 
5. Entiendo que el total o parte de las grabaciones y transcripciones de la sesión pueden ser utilizados de diversas maneras, así mismo entiendo que puedo hacer explícito si lo deseo (después de la grabación) que estos datos no sean utilizados. De este modo, por la presente autorizo el uso del total o parte de la grabación y transcripción para ser utilizado para fines docentes e investigadores:

- preparación de pruebas o materiales docentes tanto en medios impresos como multimedia

Sí No

- investigación: presentaciones en congresos, publicación de artículos en revistas de investigación, capítulos de libro, monográficos de investigación y tesis doctorales

Sí No

- me gustaría dar autorización específica del material que quiera ser publicado en Internet, así como ser consultado/a cada vez que se vaya a utilizar material nuevo

Sí No

6. Entiendo que mi nombre ni otra información explicita de mi identidad no aparecerá en ningún informe, propuesta pedagógica o investigaciones sin haber dado permiso explícito.

Sí No

7. Estoy de acuerdo en que el investigador se pueda poner en contacto conmigo si necesita alguna ayuda complementaria, como por ejemplo, revisar parte de la grabación si no está clara y presenta problemas para realizar la transcripción, o es necesario otro tipos de información sobre la interacción.

Sí No

Dirección:

Teléfono (personal):

Email:

La firma de este documento indica que entiendo la naturaleza del estudio y que acepto participar en este estudio.

Nombre completo del participante:

Firma del participante

Firma del investigador

Fecha

Fecha 


\section{Appendix B. Background questionnaire}

\section{Section 1 of 7}

\section{"Background Questionnaire"}

Form description

This form is automatically collecting email addresses for Universitat Jaume I users. Change settings

Personal information

Description (optional)

1. Name and surname *

Short-answer text

2. Year of birth *

Short-answer text

3. Gender *

Male

Female

4. Nationality *

Short-answer text

5. If your nationality is not Spanish, for how long have you lived in Spain?

Short-answer text

6. Which is your mother tongue? *

Short-answer text

7. If brought up bilingual/multilingual, please specify other languages.

You're are brought up bilingual/multilingual when you speak two or more languages at home.

Short-answer text 


\section{English language learning experience}

Description (optional)

8. Please tick the formal contexts where you have studied English before coming to the university.

Tick "Never" if you have not studied English before coming to the university.

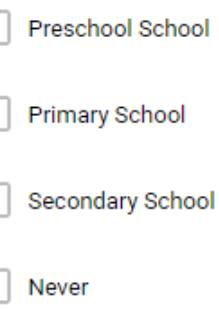

9. At what age did you start learning English in a formal context before coming to the university?

Short-answer text

10. At what age did you start learning English at university? *

11. Please, tick where you have studied English in a non-formal context before * coming to the university.

Tick "None" if you have not studied English in a non-formal context before coming to the university.

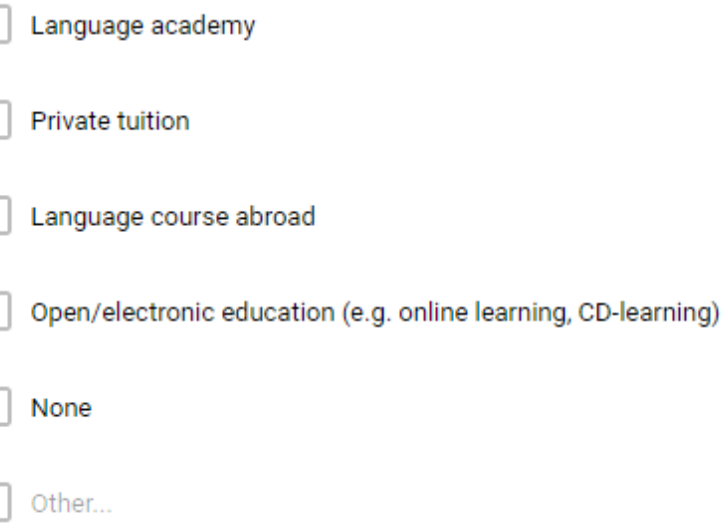


Appendices

12. In the non-formal places you have ticked in the last question, please specify (for all your options) which was your age and how long you were there.

Example: Language academy, 14 years old, 2 years.

Long-answer text

13. Do you study English in any non-formal context at the moment? Please, tick where.

Tick "None" if you do not study English in a non-formal context at the moment.

$\square$ Language academy

Private tuition

Open/electronic education (e.g. online learning, CD-learning)

None

Other.

14. Have you ever studied English at the Escuela Oficial de Idiomas? *

If you answer is "Yes" please complete questions 15, 16 and 17

Yes

No

15. At what age did you start studying English at the Escuela Oficial de Idiomas? 
16. Which is the maximum level you have completed at the Escuela Oficial de Idiomas?
A1
A2
B1
C1
C2

( $B 2$

17. If you are currently completing a particular level at Escuela Oficial de Idiomas, please specify it.
D $\mathrm{A} 1$
- $A 2$
D B1
- $B 2$
- $\mathrm{C} 1$
C2 
Appendices

$:::$

18. Do you have the intention to study English in any of the following contexts in a close future? Please, tick where.

Tick "None" if you have no intention to study English in a close future. If are studying at the moment in one of those contexts, do not tick it

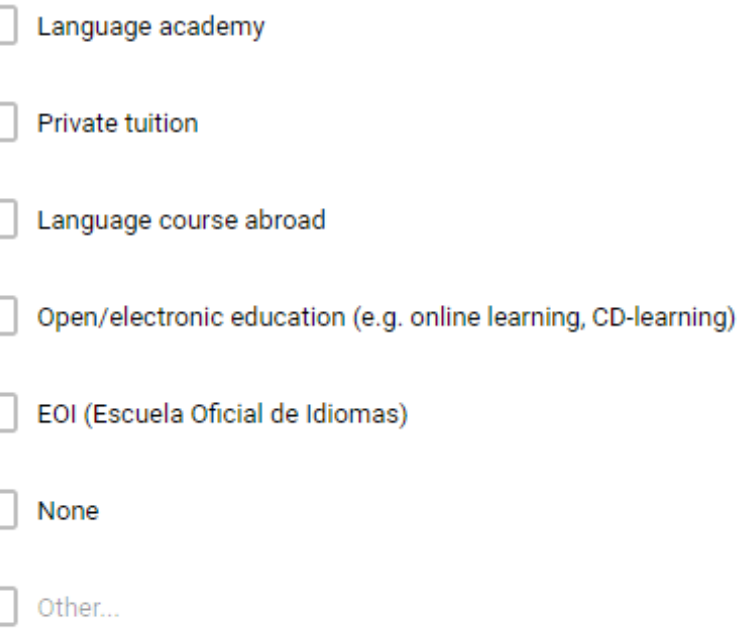

\section{English language qualifications}

Description (optional)

19. Do you have any official certificate of English? *

If your answer is "Yes", please complete questions 21 and 22.

Yes

No 
20. Please specify the institution.

EOI: Escuela Oficial de Idiomas

UCLES: University of Cambridge Local Examinations Syndicate

ACLES: Asociación de Centros de Lenguas en la Enseñanza Superior

$\because \quad \square$ TELC: The European Language Certificates

$\square$ TCL: Trinity College of London

Other...

::

21. And the maximum level you obtained.
$A 1$
A2
B1
B2
C1
C2 
Appendices

Section 4 of 7

\section{Abroad experience in an English speaking country}

Description (optional)

22. Have you ever been to an English speaking country? ${ }^{*}$

If your answer is "Yes", please complete the following questions about your experience.

Yes

No

Place and age

First experience

Short-answer text

For how long (days)

First experience

Short-answer text

Purpose

First experience

Pleasure

Study

Work

Other 
Place and age

Second experience

Short-answer text

For how long (days)

Second experience

Short-answer text

\section{Purpose}

Second experience

Pleasure

Study

Work

Other. 
Appendices

Place and age

Third experience

Short-answer text

For how long (days)

Third experience

Short-answer text

\section{Purpose}

Third experience

Pleasure

Study

Work

Other.

If you have more than 3 experiences abroad, please specify it below Example: London, 18 years old, 3 weeks, study 


\section{English language use}

Description (optional)

23. How often do you do the following for pleasure in English each week?

Row 1. Listen to music in English

Row 2. Listen to the radio in English

Row 3. Listen to podcasts in English

Row 4. Watch TV, videos, sitcoms, films etc

Row 5. Speak in English

Row 6. Read in English

Row 7. Write in English
Column 1. Never

Column 2. A few days (1-2 days)

Column 3. Some days (3-4 days)

Column 4. Several days (5-7 days)

Section 6 of 7

So, now, what do you think about your English language options? If there anything you want to change?

Description (optional) 
Appendices

Section 7 of 7

Thank you for answering this questionnaire!

Description (optional)

Question

Long-answer text 


\section{Appendix C. Retrospective verbal report}

\begin{tabular}{|c|c|c|}
\hline \multicolumn{3}{|c|}{ Complainer } \\
\hline Objetivo & Categoría & Pregunta \\
\hline Relación real & $\begin{array}{l}\text { Relación real entre los } \\
\text { participantes }\end{array}$ & $\begin{array}{l}\text { ¿Qué relación real tienes } \\
\text { con tu interlocutor? }\end{array}$ \\
\hline Relación ficticia & $\begin{array}{l}\text { Relación ficticia entre } \\
\text { los participantes }\end{array}$ & $\begin{array}{l}\text { ¿Qué relación tienes con el } \\
\text { interlocutor? } \\
\text { ¿Crees que eso ha afectado } \\
\text { a la manera de actuar? }\end{array}$ \\
\hline $\begin{array}{l}\text { Conocimiento } \\
\text { pragmático }\end{array}$ & $\begin{array}{l}\text { Pragmalingüística } \\
\text { Sociopragmatica }\end{array}$ & $\begin{array}{l}\text { ¿Crees que te has quejado } \\
\text { de manera adecuada? } \\
\text { ¿Qué aspectos has tenido } \\
\text { en cuenta en el momento } \\
\text { de quejarte? }\end{array}$ \\
\hline $\begin{array}{l}\text { Percepción de la } \\
\text { producción }\end{array}$ & Producción pragmática & $\begin{array}{l}\text { ¿Cómo te has sentido al } \\
\text { interactuar en cada } \\
\text { situación? }\end{array}$ \\
\hline Contexto real & $\begin{array}{l}\text { Producción en una } \\
\text { situación real }\end{array}$ & $\begin{array}{l}\text { ¿Actuarias de manera } \\
\text { simular en una situación } \\
\text { del mismo tipo en la vida } \\
\text { real? }\end{array}$ \\
\hline $\begin{array}{l}\text { Percepción de la } \\
\text { tarea }\end{array}$ & $\begin{array}{l}\text { Evaluación } \\
\text { terea }\end{array}$ & $\begin{array}{l}\text { ¿Cómo te has sentido al } \\
\text { realizar esta tarea? }\end{array}$ \\
\hline & Complainee & \\
\hline Objetivo & Categoría & Pregunta \\
\hline Relación real & $\begin{array}{l}\text { Relación real entre los } \\
\text { participantes }\end{array}$ & $\begin{array}{l}\text { ¿Qué relación real tienes } \\
\text { con tu interlocutor? }\end{array}$ \\
\hline Relación ficticia & $\begin{array}{l}\text { Relación ficticia entre } \\
\text { los participantes }\end{array}$ & $\begin{array}{l}\text { ¿Qué relación tienes con el } \\
\text { interlocutor? } \\
\text { ¿Crees que eso ha afectado } \\
\text { a la manera de actuar? }\end{array}$ \\
\hline $\begin{array}{l}\text { Conocimiento } \\
\text { pragmático }\end{array}$ & $\begin{array}{l}\text { Pragmalingüística } \\
\text { Sociopragmatica }\end{array}$ & $\begin{array}{l}\text { ¿Crees que has respondido } \\
\text { de manera adecuada? } \\
\text { ¿Qué aspectos has tenido } \\
\text { en cuenta al responder? }\end{array}$ \\
\hline $\begin{array}{l}\text { Percepción de la } \\
\text { producción }\end{array}$ & Producción pragmática & $\begin{array}{l}\text { ¿Cómo te has sentido al } \\
\text { interactuar en cada } \\
\text { situación? }\end{array}$ \\
\hline Contexto real & $\begin{array}{l}\text { Producción en una } \\
\text { situación real }\end{array}$ & $\begin{array}{l}\text { ¿Actuarias de manera } \\
\text { simular en una situación } \\
\text { del mismo tipo en la vida } \\
\text { real? }\end{array}$ \\
\hline $\begin{array}{l}\text { Percepción de la } \\
\text { tarea }\end{array}$ & $\begin{array}{l}\text { Evaluación sobre la } \\
\text { terea }\end{array}$ & $\begin{array}{l}\text { ¿Cómo te has sentido al } \\
\text { realizar esta tarea? }\end{array}$ \\
\hline
\end{tabular}




\section{Appendix D. Instruction for the role-play tasks}

Thank you very much for participating in these two role-play tasks.

If there is anything in these situations that you don't understand, please ask me and I will explain it to you.

You will role play each situation with a classmate. Try to respond as you would in a real situation. These situations are taking place in Castellón.

You should first choose the role you want to play (complaining or receiving the complaint) and you will keep this role for both situations. Once you read the instruction, you should decide who starts the conversation.

Start when you feel ready! 


\section{Appendix E. Transcription conventions}

\begin{tabular}{|c|c|}
\hline Complainer & $\mathrm{A}$ \\
\hline Complainee & $\mathrm{B}$ \\
\hline Loudness & $\uparrow$ \\
\hline No break or gap in speech & $=$ \\
\hline Participant's backchannel & $<\mathrm{Ax}: \mathrm{BC} \_\mathrm{x}<\mathrm{x}>/ / \mathrm{BC}>$ \\
\hline Participant's filled pause & $<$ Ax:F_PAUSE $<\mathrm{x}>/ /$ F_PAUSE $>$ \\
\hline Participant's laughter & $<$ Bx:LAUGHTER > \\
\hline Participant's overlap & $<$ Ax:OVERLAP $<x>/ /$ OVERLAP $>$ \\
\hline Participants' snort & $<\mathrm{Ax}: \mathrm{SNORT}>$ \\
\hline Point of overlap onset & {[} \\
\hline Point of overlap ending & ] \\
\hline Repetition & $/ / \mathrm{x} / /$ \\
\hline Shift in rising intonation & , \\
\hline Silence measured in tenth of seconds & $(0.1)$ \\
\hline Syllable duration: prolongation of the & $::$ \\
\hline immediately prior sound & $<\mathrm{Ax}: S Y L \_D<x>/ / S Y L \_D>$ \\
\hline \multirow[t]{5}{*}{ Typology of backchannel } & CON - Continuer \\
\hline & AGREE - Agreement \\
\hline & ASSESS - Assessment \\
\hline & IR - information receipt \\
\hline & REP - repetition \\
\hline Unintelligible to transcriber & $(\mathrm{XXX})$ \\
\hline
\end{tabular}

Adapted from: Jefferson (2004) and MICASE 
